HOHENHEIMER VOLKSWIRTSCHAFTLICHE SCHRIFTEN

Jürgen Kulle

Ökonomie der

Musikindustrie 
Jürgen Kulle

\section{Ökonomie der Musikindustrie}

Die Arbeit behandelt die Musikverwertung mit Hilfe von Tonträgern und Netzen. Nach einem kurzen Abriß der Tonträgergeschichte wird der bestehende Rechtsrahmen im nationalen, europäischen und internationalen Kontext dargestellt. Die Anreize zur Musikproduktion und -verwertung werden herausgearbeitet. Eine industrieökonomische Branchenanalyse der deutschen Tonträgerwirtschaft folgt. Sie zeigt, daß hohe Konzentration und nur geringer Preiswettbewerb herrscht. Hauptsächlicher Aktionsparameter im Wettbewerb ist die Produktkonkurrenz. Abschließend werden die technischen Weiterentwicklungen zur netzgebundenen Online-Verwertung von Musik untersucht, die Eintrittspotentiale marktnaher Unternehmen analysiert und wahrscheinliche Veränderungen bei Marktstruktur, -verhalten und -ergebnissen aufgezeigt.

Jürgen Kulle wurde 1966 in Hannover geboren, studierte von 1987 bis 1993 an den Universitäten Freiburg im Breisgau und Hamburg Volkswirtschaftslehre. Seit 1993 ist er wissenschaftlicher Mitarbeiter an der Universität Hohenheim. Promotion 1998. 
Ökonomie der Musikindustrie 


\section{Hohenheimer \\ Volkswirtschaftliche Schriften}

Herausgegeben von

Prof. Dr. Rolf Caesar, Prof. Dr. Harald Hagemann,

Prof. Dr. Klaus Herdzina, Prof. Dr. Renate Ohr, Prof. Dr. Walter Piesch,

Prof. Dr. Ingo Schmidt, Prof. Dr. Peter Spahn,

Prof. Dr. Gerhard Wagenhals,

Prof. Dr. Helmut Walter

\section{Band 32}

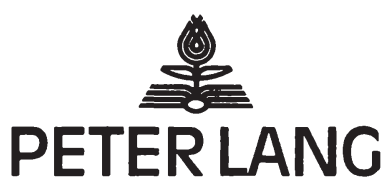

Frankfurt am Main - Berlin - Bern - New York · Paris · Wien 


\section{Jürgen Kulle}

\section{Ökonomie \\ der Musikindustrie}

Eine Analyse

der körperlichen und

unkörperlichen Musikverwertung

mit Hilfe von Tonträgern

und Netzen

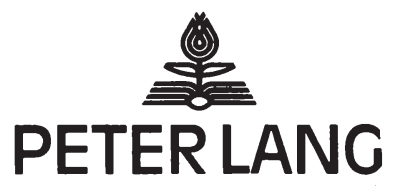

Frankfurt am Main - Berlin - Bern - New York · Paris · Wien 
Die Deutsche Bibliothek - CIP-Einheitsaufnahme

Kulle, Jürgen:

Ökonomie der Musikindustrie : eine Analyse der körperlichen und unkörperlichen Musikverwertung mit Hilfe von Tonträgern und Netzen / Jürgen Kulle. - Frankfurt am Main ; Berlin ; Bern ; New York ; Paris ; Wien : Lang, 1998

(Hohenheimer volkswirtschaftliche Schriften ; Bd. 32)

Zugl.: Hohenheim, Univ., Diss., 1998

ISBN 3-631-34125-3

Open Access: The online version of this publication is published on www.peterlang.com and www.econstor.eu under the international Creative Commons License CC-BY 4.0. Learn more on how you can use and share this work: http://creativecommons.org/ licenses/by/4.0.

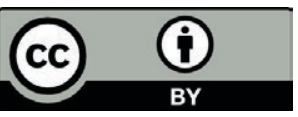

This book is available Open Access thanks to the kind support of ZBW - Leibniz-Informationszentrum Wirtschaft.

Gedruckt mit Unterstützung durch die Deutsche Vereinigung für gewerblichen Rechtsschutz und Urheberrecht e.V.

Gedruckt auf alterungsbeständigem, säurefreiem Papier.

D 100

ISSN 0721-3085

ISBN 3-631-34125-3

ISBN 978-3-631-75477-1 (eBook)

(C) Peter Lang GmbH

Europäischer Verlag der Wissenschaften

Frankfurt am Main 1998

Alle Rechte vorbehalten.

Das Werk einschließlich aller seiner Teile ist urheberrechtlich geschützt. Jede Verwertung außerhalb der engen Grenzen des Urheberrechtsgesetzes ist ohne Zustimmung des Verlages unzulässig und strafbar. Das gilt insbesondere für

Vervielfältigungen, Übersetzungen, Mikroverfilmungen und die Einspeicherung und Verarbeitung in elektronischen Systemen.

Printed in Germany $1234 \quad 67$ 


\section{Vorwort}

Die vorliegende Arbeit wurde von der Wirtschafts- und Sozialwissenschaftlichen Fakultät der Universität Hohenheim im Sommersemester 1998 als Dissertation angenommen.

Die Idee, eine Arbeit über die Musikindustrie zu schreiben, fand anfangs keine breite Zustimmung, doch sie verschaffte genügend intrinsische Energien, das Projekt zu einem erfolgreichen Ende zu bringen. Wenn auch der Verfasser seine musikalische Betätigung letztlich mangels ausreichender Zeit einstellen mußte, so bleibt doch zu hoffen, daß etwas von der Begeisterung spürbar wird, die das Konsumgut Musik hervorzurufen in der Lage ist, und die interessanten Spezifika der Musikindustrie dem Leser zugänglich werden. Obwohl ich mich insbesondere um großen Aktualitätsbezug bemüht habe, ist es nicht ausgeschlossen, daß im Hinblick auf die Dynamik des Untersuchungsgegenstandes einzelne Faktenentwicklungen nicht berücksichtigt werden konnten. Hier wird auf die wöchentliche Fachliteratur verwiesen.

Dank schulde ich einer Reihe von Personen, die nicht unerwähnt bleiben sollen: Zuerst sei meinem Doktorvater Prof. Dr. Ingo Schmidt gedankt für die begleitende Betreuung und für die Bereitschaft, sich auf „unwegsames Terrain“ zu begeben. Herm Prof. Dr. Jörn Kruse, Herm Dr. Björn Frank und den Teilnehmern der Hohenheimer Oberseminare danke ich für wertvolle Kritik, die immer dann weiterhalf, wenn sie konstruktiv vorgebracht wurde. Herm leitenden Regierungsdirektor Schmidt vom Bundeskartellamt danke ich für die Diskussionsbereitschaft und Hilfestellung während meines Forschungsaufenthaltes in Berlin, Herrn Prof. Dr. Klaus Herdzina und Herrn Prof. Dr. Lothar Vollmer habe ich für kritische Anregungen und die Mitwirkung am Promotionsverfahren zu danken.

Meinen Kollegen und Kolleginnen am Institut für Volkswirtschaftslehre der Universität Hohenheim, Dr. Steffen Binder, Silke Dahlke, Annette Fritz, Claudia Hafner, Oliver Letzgus, Dr. Hans Pitlik, Alexander Rieger, Silvia Rottenbiller, Günther Schmid, Dr. André Schmidt, Renate Strobel und Margit Ströbele sei für gute Zusammenarbeit, angenehme Arbeitsatmosphäre und interessante, auch außerfachliche Gespräche gedankt. Frau Christine Tomschi danke ich für die Durchsicht des Manuskripts. Herr Dipl. Kfm. Dirk Ewald von der Tonträgerunternehmung Intercord, Stuttgart, gab aus der Sicht des Praktikers wertvolle Hinweise. Auch dafür bin ich zu Dank verpflichtet.

Die Bezirksgruppe Südwest der Deutschen Vereinigung für gewerblichen Rechtsschutz und Urheberrecht förderte nicht nur die Veröffentlichung dieser Arbeit, sondern erleichterte mit einem Zuschuß auch zwei Forschungsaufenthalte. Hierfur einen recht herzlichen Dank.

Verständnis und Unterstützung auf unterschiedlichen Ebenen erhielt ich durch meine Geschwister und meine Eltern sowie durch Frau Dipl.-Ök. Sandra Strub, die die Arbeit des Geistes unterstützten und dabei auch die Seele begleiteten.

Stuttgart - Hohenheim, im September 1998 
Jürgen Kulle - 978-3-631-75477-1

Downloaded from PubFactory at 01/11/2019 04:31:24AM

via free access 


\section{Inhaltsverzeichnis}

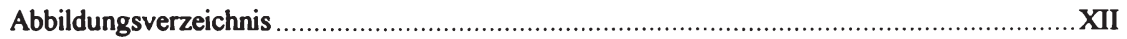

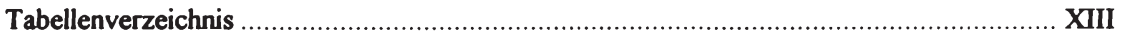

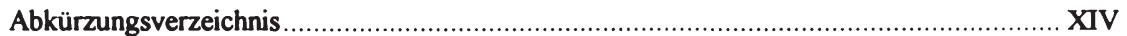

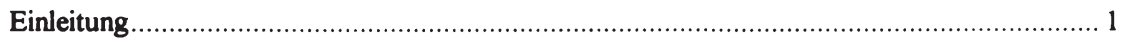

1 Entwicklung der Verwertung von Musik mit Hilfe von Tonträgern ...................... 5

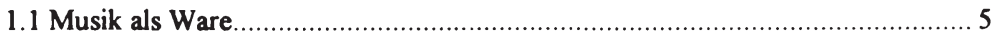

1.1.1 Von der Hausmusik zu Musikdarbietungen........................................... 5

1.1.2 Entstehung des Berufes Musiker .................................................... 6

1.1.3 Verbreitung von Musik durch Konzerte.......................................... 6

1.2 Die technische Entwicklung der Aufzeichnung und Wiedergabe von Musik...... 7

1.2.1 Entstehung von Musikaufzeichnungen.................................... 7

1.2.2 Erfindung von Graphophon, Grammophon und Schellackplatte ....... 9

1.2.3 Mikrophon, Stereophonie und Vinylplatte ............................... 11

1.2.4 Tonband, Abspielgeräte und Musikkassetten ............................. 14

1.2.5 Erfindung der CD und des CD-Spielers .................................. 15

1.2.6 Neuere Entwicklungen .................................................. 17

1.3 Ökonomische Bedeutung der Innovationen

für Musikverwertung mit Tonträgern .................................................... 19

1.3.1 Bedeutung des Innovationsprozesses....................................... 19

1.3.2 Verbreitung der Tonträgersysteme ....................................... 24

1.3.3 Volkswirtschaftliche Bedeutung der Tonträgerindustrie............... 26

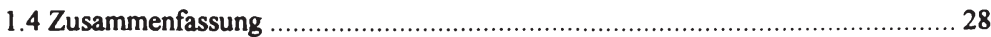

2 Vertragsökonomie (I):

Rechtlicher Rahmen der körperlichen Musikverwertung mit Tonträgern .............. 31

2.1 Urheberrecht, verwandte Schutzrechte und Wahrnehmungsgesetz................ 31

2.1.1 Voraussetzungen für urheberrechtlichen Schutz

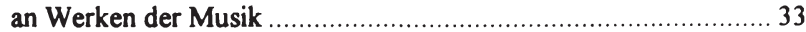

2.1.2 Rechte der Werkinhaber.................................................... 34

2.1.3 Rechte der Tonträgerhersteller .......................................... 38

2.1.4 Rechte der Verwertungsgesellschaften ................................ 40 
2.1.5 Rechtliche und wirtschaftiche Verwertungskette

von Urhebern und Tonträgerherstellern

2.2 Harmonisierung des Urheberrechts in Europa 43

2.2.1 Harmonisierungsbestrebungen in der Europäischen Union ............ 44

2.2.2 Bedeutung von Entscheidungen der Kommission und des EuGH ... 55

2.2.3 Erfolge europäischer Harmonisierungsbestrebungen und die internationale Dimension 60

2.3 Internationale Urheberrechtsabkommen 61

2.3.1 Revidierte Berner Übereinkunft ............................................... 62

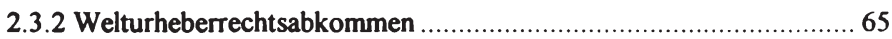

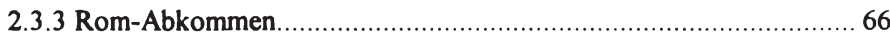

2.3.4 Genfer Übereinkunft zum Schutz von Tonträgerherstellern........... 70

2.3.5 Abkommen über handelsbezogene Aspekte geistigen Eigentums im GATT ................................................. 71

2.3.6 Anwendung des Rechts der Internationalen Urheberabkommen ..... 75

2.4 Zusammenfassung 75

Vertragsökonomie (II):

Ökonomische Analyse der körperlichen Musikverwertung mit Tonträgern 79

3.1 Copyrights für den Tonträgermarkt 80

3.1.1 Verschiedene Rechtsinstitutionen und deren Problematik..............80

3.1.2 Rechtsphilosophische Begründungen für Copyrights...................81

3.1.3 Ökonomische Begründungen für Copyrights ........................... 83

3.2 Positive Analyse der Copyrights für den Tonträgermarkt 87

3.2.1 Copyright als perfekter und kostenloser Ausschluß ohne Zweitmarkt 88

3.2.2 Copyright als Erlaubnisvorbehalt und als Vergütungsanspruch mit einem Zweitmarkt 90

3.2.3 Kosten der Rechtsnormierung, Ausschlußkosten und Rechtsdurchsetzung. 96

3.2.4 Wirkung der Copyrights auf Parameter der Musikverwertung mit Tonträgern

3.3 Copyright bei Betrachtung des internationalen Handels .

3.3.1 Copyright als Strategie zweier Länder

3.3.2 Strategie der Tonträgerunternehmen

bei unterschiedlichem Copyright

3.3.3 Bedingungen für internationales Copyright 
Der deutsche Tonträgermarkt aus industrieökonomischer Sicht

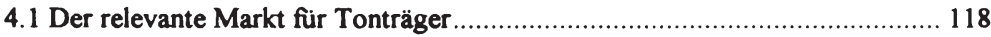

4.1.1 Abgrenzung in sachlicher Hinsicht ......................................... 119

4.1.2 Abgrenzung in räumlicher Hinsicht ...................................... 126

4.1.3 Abgrenzung in zeitlicher Hinsicht ................................. 127

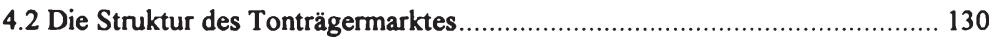

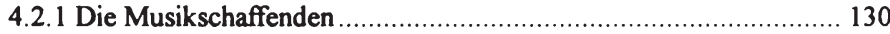

4.2.2 Die Tonträgerhersteller ..................................................... 132

4.2.2.1 Die Majors................................................................. 136

4.2.2.2 Die Independents ............................................ 138

4.2.2.3 Die Konzentrationsentwicklung unter den Tonträgerherstellern ................................ 138

4.2.2.4 Einzelwirtschaftliche Konzentrationsmotive ................ 143

4.2.2.5 Integrationsgrade und Vertragsbeziehungen ................. 144

4.2.2.6 Marktphase und Marktbarrieren ................................. 146

4.2.3 Der Tonträgerhandel ...................................................... 150

4.2.3.1 Handelsformen und Handelsfunktionen ....................... 150

4.2.3.2 Entwicklung der Handelsstruktur und

Konzentrationsentwicklung des Handels .................... 152

4.2.4 Die Nachfrage nach Tonträgern............................................ 154

4.2.4.1 Grundlagen der Tonträgernachfrage ......................... 154

4.2.4.2 Altersstruktur der Tonträgerkäufer und demographische Entwicklung ........................... 156

4.2.4.3 Käuferreichweiten................................................. 158

4.2.5 Zusammenfassung wichtiger Strukturmerkmale ....................... 159

4.3 Das Marktverhalten im Tonträgermarkt ................................................ 159

4.3.1 Vertragsbeziehungen zwischen Musikschaffenden

und Tonträgerherstellern................................................... 160

4.3.2 Das Verhalten der Tonträgerhersteller .................................. 162

4.3.2.1 Vertragsbeziehungen zwischen Majors und Independents................................................ 162

4.3.2.2 Die Produktpolitik der Tonträgerhersteller .................... 166

4.3.2.2.1 Produktpolitik der Majors .......................... 170

4.3.2.2.2 Produktpolitik der Independents................. 171

4.3.2.3 Die Preispolitik der Tonträgerhersteller ....................... 172

4.3.2.3.1 Preispolitik der Majors ............................. 174 
4.3.2.3.2 Preispolitik der Independents..................... 176

4.3.2.4 Strategische Marktbarrieren ..................................... 177

4.3.3 Das Verhalten des Tonträgerhandels ....................................... 181

4.3.3.1 Verhandlungsmacht gegenüber den Tonträgerherstellern 181

4.3.3.2 Betriebsgröße des Tonträgerhandels und Nachfrage ....... 182

4.3.3.3 Sortimentsstruktur und Sortimentspolitik ................... 183

4.3.3.4 Preispolitik gegenüber der Nachfrage und

Preiswettbewerb auf der Handelsstufe ........................ 185

4.3.4 Das Verhalten der Nachfrager nach Tonträgern ....................... 188

4.3.4.1 Kaufintensitäten................................................... 188

4.3.4.2 Kaufverhalten im Hinblick auf

Elastizitäten der Nachfrage ...................................... 190

4.3.4.3 Konsequenzen für die zukünftige Konsumentenstruktur. 195

4.3.5 Zusammenfassung wichtiger Verhaltensmerkmale ................... 196

4.4 Interdependenzen zwischen Marktstruktur, -verhalten und -ergebnissen ........ 198

4.4.1 Marktergebnisse im Tonträgermarkt......................................... 198

4.4.2 Zusammenhänge zwischen Marktstruktur und -ergebnis ............. 212

4.4.3 Zusammenhänge zwischen Marktverhalten und -ergebnis ........... 217

4.5 Zusammenfassung: Industrieökonomischer Ausblick ............................ 221

5 Weiterentwicklungen zur unkörperlichen Musikverwertung …...................... 223

5.1 Neuere technische Entwicklungen der Musikverwertung ........................... 223

5.1.1 Offline-Multimedia-Produkte ........................................... 224

5.1.2 Offline Musikprodukte als Instore-Production .......................... 225

5.1.3 Online Musikverwertung mit Hilfe von Netzen .......................... 227

5.1.3.1 Verteilnetzanwendungen: Multichannel-Dienste und digitales Radio ................................................ 228

5.1.3.2 Vermittlungsnetzanwendungen: Internet und Online-Dienste ............................................... 231

5.1.3.3 Elektronischer Vertrieb von Musik als Teil von Online-Diensten

5.2 Strategien, Unternehmensverhalten und Marktprozesse

für Online-Musikverwertungen ............................................................. 240

5.2.1 Musiker und Tonträgerhersteller als Content-Provider................ 240

5.2.2 Netzinfrastruktur- und Online-Diensteanbieter

als Service-Provider.

5.2.3 Nachfrageakzeptanz, Konsumentenstruktur

und Medienkonkurrenz. 
5.2.4 Auswirkungen des netzgebundenen Vertriebs

auf die Verwertungskette von Musik

5.3 Ökonomische Implikationen, Wettbewerbspotentiale

und Rechtsrahmen bei der Online-Musikverwertung 250

5.3.1 Netzwerkeffekte, Standardisierung und Lock-In-Effekte 250

5.3.2 Auswirkungen auf die Wettbewerbspotentiale der netzgebundenen Musikverwertung

5.3.3 Urheberrechtliche Bestimmungen und Regulierungsansätze für netzgebundene Musikverwertung 262

5.3.3.1 Urheberrechtliche Bestimmungen netzgebundener Musikverwertung 262

5.3.3.2 Regulierungsansätze für eine kompetitive netzgebundene Musikverwertung 268

5.4 Zusammenfassung 271

Schlußbemerkungen 275

Literaturverzeichnis 283 


\section{Abbildungsverzeichnis}

Abb. 1: Ablauf der Musikverwertung ohne Aufzeichnungsmöglichkeiten ........................ 7

Abb. 2: Ablauf der Musikverwertung mit Aufzeichnungsmöglichkeiten............................ 17

Abb. 3: Überblick über die Einzelbefugnisse des Urhebers ............................................ 37

Abb. 4: rechtliche und wirtschaftliche Verwertungskette von Urhebern und Tonträgerherstellern ....................................................................... 43

Abb. 5: Harmonisienungsschritte und -inhalte der Urheberrechtsbestandteile in der EU, die für den Tonträgermarkt relevant sind ............................... 46

Abb. 6: Schutz der Musikurheber nach der Revidierten Berner Übereinkunft

Abb. 7: Schutz der Tonträgerhersteller nach dem Rom-Abkommen ................................69

Abb. 8: Konkurrenzwirtschaftliche Gleichgewichte auf dem Tonträgermarkt bei verschiedenen Preisniveaus ohne Rechtekosten ............................ 101

Abb. 9: Gleichgewicht auf dem Tonträgermarkt bei Rechtekosten ............................... 103

Abb. 10: Rechteerlös und Höhe der Rechtekosten auf dem Tonträgermarkt ..................... 104

Abb. 11: Verschiedene optimale Rechtekostenniveaus bei gegebener Zahl an Veröffentlichungen ................................................ 105

Abb. 12: Marktergebnis bei wettbewerblichem und monopolistischen Tonträgermarkt ...... 107

Abb. 13: Auszahlungsmatrix mit und ohne Copyright im Zwei-Länder-Fall ..................... 110

Abb. 14: Wirkung der Copyrightsetzung im Zwei-Länder-Fall .................................. 110

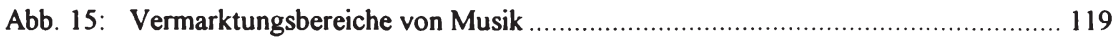

Abb. 16: Marktstufen des Tonträgermarktes................................................................. 122

Abb. 17: Zusammenfassende Darstellung der Übernahmen und der

Konzentrationsentwicklung der Major-Tonträgerhersteller ........................ 141

Abb. 18: Integrationsgrade und Vertragsbeziehungen im Tonträgermarkt ..................... 145

Abb. 19: Tonträgerkäufer und Bevölkerung nach Altersklassen ................................... 157

Abb. 20a: Relativer Anteil der Preiskategorien am Absatz von Musikkassetten .................. 175

Abb. 20b: Relativer Anteil der Preiskategorien am Absatz von Compact Discs.................. 175

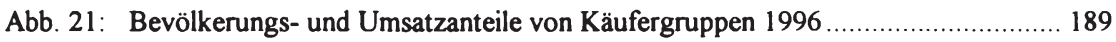

Abb. 22: Preiselastizität der Nachfragereichweite und -intensität .................................... 193

Abb. 23: Technische Möglichkeiten der netzgebundenen Musikverwertung ...................... 228

Abb. 24: Musikvermarktung im Online-Bereich mit physischem Vertrieb ......................... 231

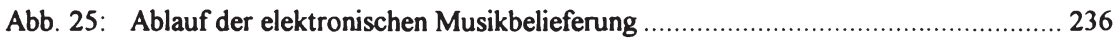

Abb. 26: Organisationsmodell der Online-Musikverwertung …...................................... 238

Abb. 27: Künftiger Tonträgermarkt,

Übergang von körperlicher zu unkörperlicher Musikverwertung .................... 239

Abb. 28: Verwertungskette von Musik mit Tonträgern ................................................. 249

Abb. 29: Verwertungskette der Online-Musikverwertung …........................................ 249 


\section{Tabellenverzeichnis}

Tab. 1: Mengen- und wertmäßige Marktentwicklung des deutschen Tonträgermarkts ............................................................... 133

Tab. 2: Nominales und reales Marktvolumen des deutschen Tonträgermarktes................. 135

Tab. 3: Marktanteile der Tonträgerhersteller am Absatz an den Handel in Deutschland ..... 140

Tab. 4: Anteile der Vertriebswege in Prozent des Umsatzes 1992-1995 ........................... 153

Tab. 5: Entwicklung der altersspezifischen Bevölkerungsstruktur ................................. 158

Tab. 6: Fertigungswerke für Compact Discs in Deutschland 1995 ............................... 179

Tab. 7: Entwicklung der jährlichen Neuveröffentlichungen von Single und

Longplay (nur CD) von 1985-1996 der Mitgliedsfirmen im BPW ................... 199

Tab. 8: Durchschnittliche jährliche Verkaufszahl pro Neuerscheinung ............................ 200

Tab. 9: Zahl, Verweildauer und Neueintritte in die Single-Charts von 1985-1997............ 206

Tab. 10: Entwicklung der Anzahl von Musiktiteln

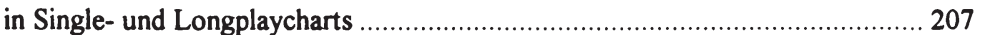

Tab. 11: Goldene Schallplatten, Verteilung auf Musiker und Tonträgerhersteller von 1986-1995 .................................. 209

Tab. 12: Konzentrationsentwicklung von 1985-1997, gemessen mit Chartanteilen

Tab. 13: Einnahmen der Verwertungsgesellschaften und Gesamtmarktvolumen von 1986-1996 


\section{Abkürzungsverzeichnis}

a.a.O........ am angegebenen $\mathrm{Ort}$

Abb.

Abbildung

AB1. Amtsblatt (der EU)

Abs. Absatz

Anm. Anmerkung

Art. Artikel

Aufl. Auflage

BGH. Bundesgerichtshof

BGHZ .......Entscheidungen des Bundesgerichtshofes in Zivilsachen

bzgl.......... bezüglich

bzw........... beziehungsweise

ca. circa

CD ........... Compact Disc

$\mathrm{cm} / \mathrm{s}$......... Zentimeter pro Sekunde

c.p............ ceteris paribus (das übrige wird als konstant angenommen)

DAB ........ Digital Audio Broadcast

DAT ........ Digital Audio Tape

DCC ......... Digital Compact Cassette

ders........... derselbe

dies. ......... dieselbe

d.h............. das heißt

DTK min... Minimum der durchschnittlichen Totalkosten

ebd............ebendieser

ebda. ..........ebenda

EEA ......... Einheitliche Europäische Akte

EG ........... Europäische Gemeinschaft

EGV ........ Vertrag über die Europäische Gemeinschaft

endg..........endgültig

eos ............economies of scale

etc.............et cetera

EU ........... Europäische Union

EUGH....... Europäischer Gerichtshof

e.V........... eingetragener Verein

EWGV ...... Vertrag über die Europäische Wirtschaftsgemeinschaft

f. .............. folgende

ff. .............. fortfolgende

ffrr ............ full frequency range recording

GATT ...... General Agreement on Trade and Tariffs

GbR ......... Gesellschaft bürgerlichen Rechts

gem.......... gemäß 
GEMA ..... Gesellschaft für Musikalische Aufführungs- und Mechanische Vervielfältigungsrechte

ggfs.......... gegebenenfalls

$\mathrm{GmbH}$....... Gesellschaft mit beschränkter Haftung

GRUR/I .... Gewerblicher Rechtsschutz und Urheberrecht - Internationaler Teil

GTÜ ........ Übereinkommen zum Schutz der Hersteller von Tonträgern gegen die unerlaubte Vervielfältigung ihrer Tonträger vom 29.10.1971

GWB ....... Gesetz gegen Wettbewerbsbeschränkungen

GVL ........ Gesellschaft zur Verwertung von Leistungsschutzrechten

Hi-fi .......... High fidelity

Hrsg.......... Herausgeber

IFO ........... Institut für Wirtschaftsforschung (München)

IFPI ......... International Federation of Phonogram and Videogram Producers

IMHV ....... Interessengemeinschaft Musikwissenschaftlicher Herausgeber und Verleger

i.S. ........... Im Sinne

ISDN ........ International Standard Digital Network

i.V.m......... In Verbindung mit

JZ............. Juristenzeitung

Kap........... Kapitel

KOM ........ Mitteilungen der Kommission der Europäischen Union

LDK.......... Langfristige Durchschnittskostenkurve

LGK......... Langfristige Grenzkostenkurve

LP............. Long Playing Record (Langspielplatte)

MC ........... Music Cassette

MD ........... Mini Disc

MGS ......... Mitgliedstaat (der Europäischen Union)

$\mu \mathrm{m}$............. Mikrometer

vm ............ Nannometer

Nr. ........... Nummer

o.a............ oben angegeben

o.g. ........... oben genannt

op. cit........ opus citatum (bereits oben zitiert)

p.m.a........ post mortem auctoris (nach dem Tod des Urhebers)

RA ........... Rom Abkommen (Internationales Abkommen über den Schutz der ausübenden Künstler, der Hersteller von Tonträgern und der Sendeunternehmen vom 26.10.1961)

RBÜ ......... Revidierte Berner Übereinkunft

RCA .......... Radio Corporation of America

S. ............. Seite

SCMS ....... Serial Copy Management System

sog............ sogenannt(e)

TRIPS ....... Trade related Aspects on Intellectual Property Rights 
TV Television

UrhG.........Gesetz über Urheberrecht und verwandte Schutzrechte

Verf. Verfasser

vgl. vergleiche

VLP Video Long Play

WahrnG .... Gesetz über die Wahrnehmung von Urheberrechten und verwandten Schutzrechten

WIPO........World Intellectual Property Rights Organization

WUA ........ Welturheberrechtsabkommen

UKW ........ Ultrakurzwelle

USA.......... United States of America

usw. ........... und so weiter

z.B. .......... zum Beispiel

ZUM.......... Zeitschrift für Urheber- und Medienrecht

ZPÜ ..........Zentralstelle für private Überspielungsrechte

z.Zt........... zur Zeit

$\% \ldots \ldots \ldots \ldots . .$. Prozent 


\section{Einleitung}

Viele Güter des täglichen Bedarfs sind als Verbrauchsgüter von keinem großen Interesse für eine ökonomische Auseinandersetzung. Nicht so verhält es sich mit der Musik, die uns durch Radio und Fernsehen täglich umgibt. Denn nur wenige Verbraucher realisieren, daß der scheinbar freie Zugang zu dieser Musik in Wirklichkeit Teil einer Vermarktungsstrategie der Unternehmen ist, die Musik verkaufen wollen. Noch weniger der potentiellen Konsumenten wundern sich darüber, daß für einen bestimmten Zeitraum immer dieselbe Musik auf diese Weise zugänglich ist, und verstehen, nach welchen Funktionsprinzipien sich der Wechsel der dort angebotenen Musik vollzieht. Die Schaffung von Präferenzen durch das freie Produktangebot selbst gehört zu den Kuriosa der wirtschaftlichen Verwertung von Musik. Damit zählt die Musikindustrie zu den Industriezweigen mit interessanten Spezifika, die zu erforschen Aufgabe dieser Arbeit ist

Die Intensität von Präferenzen äußert sich regelmäßig in der Zahlungsbereitschaft der Konsumenten. Im Hinblick auf Musik sind Knappheiten variabel und der Geschmack der Hörer wechselt schnell und häufig. Werden Nachfrager zu Fans, äußern sie ihre Präferenzen nicht nur mit Geld, sondern auch mit einem intensiven Zeitaufwand für "ihre Musiker", der sich nicht in jedem Fall in wirtschaftliche Erfolge der musikverwertenden Unternehmen umsetzen läßt. Für den Verbraucher ist Musik nicht nur im Alltag gegenwärtig. Musik ist Inhalt von Unterhaltung und Bildung, aber auch Ware und Handelsobjekt auf Märkten und damit Gegenstand ökonomischer Analyse. So betrachteten einzelne Studien die betriebswirtschaftlichen Probleme der Musikverwertung mit Tonträgern, ${ }^{1}$ die Wettbewerbsstrategien der musikverwertenden Unternehmen, ${ }^{2}$ einzelne ökonomische Teilaspekte, ${ }^{3}$ Produktzyklen aus soziologischer ${ }^{4}$ oder Urheberschutzverletzungen aus juristischer Sicht. ${ }^{5}$ Motiv für diese Arbeit ist das Fehlen einer Untersuchung der Funktionsweise der körperlichen Musikverwertung mit Tonträgern sowie der Weiterentwicklung zur unkörperlichen netzgebundenen Verwertung, die unter Berücksichtigung des geltenden Rechtsrahmens die industrieökonomische Situation analysiert und wettbewerbspolitische Probleme aufzeigt. Hierzu leistet die vorliegende Studie einen Beitrag, indem sie nicht nur die Marktstufen der (bisherigen) Musikverwertung analysiert, sondern auch die umwälzenden technologischen Veränderungen bis hin zur Online - Musikverwertung mit einbezieht.

War Musik ursprünglich nur als konzertantes Erlebnis direkt aufführbar, hat seit über hundert Jahren die technische Erfindung der Schallaufzeichnung und Wiedergabe ermöglicht, Musik mit Hilfe eines Trägers zu speichern und zu einer beliebigen Zeit wiederzugeben. Mit der Kon-

Vgl. Steinel, Roland, Zur Lage und Problematik der Musikwirtschaf, München 1992.

Vgl. Schulze, Ralf, Die Musikwirtschaft: Marktstrukturen und Wettbewerbsstrategien der Deutschen Musikindustrie, Hamburg 1996.

3 Für ein Beispiel vgl. Peacock, Alan, The Economic Value of Musical Composition, in: Beitrage zu einer Theorie der Sozialpolitik, Berlin 1973, S. 11-27.

4 Vgl. Peterson, Richard, und David Berger, Cycles in Symbolic Production: The Case of Popular Music, in: American Sociological Review, Vol 40 (1975), S. 158-173; Lopes, Paul, Innovation and Diversity in the Popular Music Industry, in: American Sociological Review, Vol 57 (1992), S. 56-71.

5 Vgl. Bortloff, Nils, Tonträgerpiraterie im Immaterialgüterrecht, Frankfurt a. M. 1995. 
servierung der Musik auf einem Träger wird eine im juristischen Sinn körperliche Verwertung ermöglicht. Die Musik als ein urheberrechtlich schützbares Werk wird mit der Speicherung auf einem Tonträger körperlich verfügbar gemacht. Dies stellt den Anknüpfungspunkt der ökonomischen Auseinandersetzung mit der Musikverwertung dar, an deren Ende die durch die technische Weiterentwicklung ermöglichte unkörperliche Musikverwertung als Inhalt von OnlineDiensten steht, bei der der Konsument die Musik via Netz direkt abfragen kann.

Die Wirtschaftsgeschichte der technischen Entwicklung von Musikaufzeichnung und Wiedergabe mit unterschiedlichen Tonträgersystemen und ihre Bedeutung wird in Kapitel 1 behandelt. Daran anschließend werden in Kapitel 2 die wesentlichen Bestimmungen des Urheberrechts, der verwandten Schutzrechte und des Wahrnehmungsgesetzes aufgezeigt, die für die Marktakteure der körperlichen Musikverwertung, ausübende Künstler, Verwertungsgesellschaften und Tonträgerhersteller, die Spielregeln ihres Handelns am Markt festlegen. Als die wesentlichen Rechtskategorien werden das Vervielfältigungs-, Verbreitungs- und Vermietrecht betrachtet, welche sowohl den Musikurhebern als auch den Tonträgerherstellern zu Steuerung der Musikverwertung als ausschließliches Recht zustehen. In einem weiteren Schritt werden die nationalen Grenzen gesprengt und die Harmonisierungsbestrebungen innerhalb der Europäischen Union dargestellt. Die internationalen Urheberrechtsabkommen trennen die originären Urheberrechte von den verwandten Leistungsschutzrechten. Revidierte Berner Übereinkunft und Welt-urheberrechtsabkommen regeln u. a. den Schutz von Musikurhebern, Romabkommen und Genfer Tonträgerabkommen dienen u. a. dem Schutz der unternehmerischen Leistungen der Tonträgerhersteller. Handelsrechtliche und urheberrechtliche Aspekte verknüpft das Abkommen über Trade related aspects of intellectual property rights, welches zum Ende der Uruguay-Runde des GATT abgeschlossen wurde.

Die Schutzrechte definieren als Copyrights Eigentumsrechte, um eine wirtschaftiche Verwertung von Musik zu ermöglichen. Die ökonomische Analyse der Rechtsinstitutionen folgt in Kapitel 3. Im Mittelpunkt des Interesses steht die Notwendigkeit eines Copyrightschutzes, sein sachlicher Umfang und die Durchsetzungskosten. Dabei wird sowohl die Wirkung eines ausschließlichen Rechts mit Erlaubnisvorbehalt zur Musikverwertung diskutiert als auch die freie Musikverwertung (etwa durch Sendung), die einen Vergütungsanspruch der Rechtsinhaber auslöst. Schließlich wird anhand eines Zwei-Länder-Falles untersucht, welche Ergebnisse entstehen, wenn Copyrightschutz gewährt oder versagt wird. Die theoretischen Ergebnisse werden zum Abschluß dieses Kapitels mit empirischen Befunden zu Schutzniveau - gemessen durch die Mitgliedschaft in Urheberrechts- und verwandten Schutzrechtsabkommen - und Umfang der urheberrechtlichen Schutzrechtsverletzungen konfrontiert.

Mit Hilfe eines weitverbreiteten industrieökonomischen Ansatzes werden in Kapitel 4 die Bestimmungsfaktoren des Tonträgermarktes in der Bundesrepublik Deutschland analysiert. Im Rahmen des sog. Harvard-Ansatzes werden nach der sachlichen, räumlichen und zeitlichen Abgrenzung des relevanten Marktes furr Tonträger die Marktstruktur, in funktionaler Hinsicht getrennt nach Musiker, Tonträgerhersteller, Händler und Nachfrager betrachtet. Als weitere Strukturfaktoren werden Integrationsgrade, Marktbarrieren, Vertragsbeziehungen, Konzentra- 
tionsentwicklungen sowie Alterstruktur der Konsumenten und Käuferreichweiten behandelt. Zum Marktverhalten werden auf der Stufe der Tonträgerhersteller die Aktionsparameter im Wettbewerb, das sind Produktpolitik als Beschaffungswettbewerb, Preispolitik sowie die Setzung strategischer Marktbarrieren durch die Kontrolle der physischen Distribution seitens der Major-Tonträgerhersteller analysiert. Auf der Stufe des Tonträgerhandels werden BetriebsgröBe, Sortimentsstruktur und insbesondere der Preiswettbewerb als wettbewerbsrelevante Aktionsparameter identifiziert. Mit Kaufintensitäten und Käuferreichweiten wird das Konsumentenverhalten charakterisiert. Abschließend werden als Ansatzpunkte für eine Feststellung der Marktergebnisse die Zahl der jährlichen Neuveröffentlichungen, die Plazierung von Musiktiteln in Ranglisten und die Vergabe von Erfolgsauszeichnungen herangezogen sowie Interdependenzen zwischen Marktstruktur, Marktverhalten und Marktergebnissen aufgezeigt.

Die Verwendung des Harvard-Konzeptes als theoretischer Grundlage und Forschungsparadigma der Industrieökonomie geht u. a. auf das von Mason entwickelte MarktstrukturMarktverhalten-Marktergebnis Paradigma zurück, das in den 30er Jahren an der Universität von Harvard zur positiven Analyse von Industriezweigen konzeptioniert wurde. ${ }^{6}$ Mit Bain erfuhr dieser Ansatz seit den 50er Jahren auch eine normative Interpretation im Hinblick auf die Beurteilung der Funktionsfähigkeit des Wettbewerbs. ${ }^{7}$ Der Wettbewerb wird insbesondere dann als funktionsfähig angesehen, wenn der Wettbewerbsprozeß gesellschaftlich erwünschte Marktergebnisse liefert. ${ }^{8}$ Daher ist es Aufgabe der industrieökonomischen Analyse von Branchen und Märkten, Zusammenhänge zwischen Marktstruktur, -verhalten und -ergebnissen aufzuzeigen. Die so gewonnenen Erkenntnisse sollen dann Basis einer ordnungspolitischen Intervention des Staates sein, falls unerwünschte Marktergebnisse auf strukturelle oder verhaltensbedingte Ursachen zurückzuführen sind. ${ }^{9}$ Dieser Forschungsansatz ist in der Folge von Vertretern der österreichischen Schule ${ }^{10}$ und der Chicago School of antitrust analysis ${ }^{11}$ kritisiert worden. Die Auswirkungen der wissenschaftichen Kontroverse über die methodischen Grundlagen der Wettbewerbstheorie und der Funktionsbedingungen des Wettbewerbs haben sich in Deutschland in der Kantzenbach-Hoppmann-Kontroverse manifestiert. ${ }^{12}$ Diese Kontro-

Vgl. u. a. auch Mason, E. S., Economic Concentration and the Monopoly Problem, Cambridge, Mass. 1959. Vgl. Bain, Joe S., und P. David Qualls, Industrial Organization: A Treatise, Greenwich, London 1987, S. $433 \mathrm{ff}$.

8 Vgl. Sosnick, Stephen H., A Critique of Concepts of Workable Competition, in: Quarterly Journal of Economics, Vol. 72 (1958), S. $391 \mathrm{ff}$.

9 Vgl. Audretsch, David B., Divergent views in antitrust economics, in: Antitrust Bulletin, Vol. 33 (1988), S. $135 \mathrm{ff}$.

10 Vgl. Kirzner, Israel M., Wettbewerb und Unternehmertum, Tübingen 1978, S. 3 ff., Kirzner, Israel M., Die Krise aus „osterreichischer" Sicht, in: Die Krise in der Wirtschaftstheorie, hrsg. von Bell, David, und Irving Kristol, Berlin u. a. 1984, S. $148 \mathrm{ff}$. und Hayek, Friedrich August v., Die Verwertung des Wissens in der Gesellschaft, in: Hayek, F. A. v., Individualismus und Wirtschaftiche Ordnung, Erlenbach-Zürich 1952, S. $103 \mathrm{ff}$.

"Vgl. Posner, Richard A., The Chicago School of Antitrust Analysis, in: University of Pennsylvania Law: Review, Vol. 127 (1989), S. 929, Brozen, Yale, The Concentration-Collusion Doctrine, in: Antitrust Law: Journal, Vol. 46 (1977), S. 827 ff., und Demsetz, Harold, Industry Structure, Market Rivalry, and Public Policy, in: Journal of Law and Economics, Vol. 16 (1973), S. $1 \mathrm{ff}$.

12 Zur Kontroverse vgl. Kantzenbach, Erhard, Die Funktionsfähigkeit des Wettbewerbs, 2. Aufl., Göttingen 1967, ders., Das Konzept der optimalen Wettbewerbsintensität, in: Jahrbücher für Nationalökonomie und Statistik, Bd. 181 (1967), S. 193 ff., Hoppmann, Erich, Das Konzept der optimalen Wettbewerbsintensität. 
verse spielt nach wie vor bei der wettbewerbstheoretischen Fundierung staatlicher Eingriffe eine Rolle. Für die vorliegende Dissertation hat die Wahl der Foschungsmethode ZweckmäBigkeitsüberlegungen zu folgen. Da das Erkenntnisinteresse darin besteht, die Funktionsbedingungen der Musikindustrie zu erforschen, kann durchaus auf die Kategorien der Marktstruktur, des Marktverhaltens und ihrer Bedeutung für das Marktergebnis abgestellt werden. Nichtsdestotrotz werden die (methodischen) Grenzen des Harvard Paradigmas nicht verkannt, sondern an gegebener Stelle in Kapitel $4 \mathrm{zu}$ thematisieren sein.

In Kapitel 5 werden die technischen Weiterentwicklungen zur unkörperlichen netzgebundenen Musikverwertung behandelt, die sich in Schritten von offline-Multimedia-Produkten über Multichannel-Dienste, digitalem Radio bis zum elektronischen Vertrieb von Musik als Teil von Online-Diensten vollziehen. Dabei werden die Auswirkungen der unkörperlichen Musikverwertung auf die Verwertungskette betrachtet. Ebenso werden Handlungsoptionen der bisherigen Teilnehmer des Tonträgermarktes analysiert und die Markteintrittsfähigkeit von Unternehmen des marktnahen Bereichs untersucht. Die Weiterentwicklung der technischen Möglichkeiten der Musikverwertung und anderer Urheberrechtsindustrien hat auch eine Weiterentwicklung des rechtlichen Rahmens erfordert. Auf internationaler Ebene wurden auf der Konferenz der World Intellectual Property Rights Organization (WIPO) im Dezember 1996 das Urheberrechtsabkommen World Copyright Treaty (WCT) und das LeistungsschutzRechtsübereinkommen World Performances and Phonogram Treaty (WPPT) beschlossen, an dessen Umsetzung auf europäischer Ebene zur Zeit gearbeitet wird. Bund und Länder als nationale Gesetzgeber haben das Informations- und Kommunikationsdienstegesetz sowie den Mediendienste-Staatsvertrag verabschiedet und zum 1.8.1997 in Kraft gesetzt. In ihnen wird der freie Netzzugang für Online-Dienste und weitere Verwertungsmöglichkeiten ordnungsrechtlich geregelt. Inwiefern sich durch den technischen Fortschritt der Verwertungsmöglichkeiten Veränderungen von Marktstruktur- und Marktverhaltensfaktoren ergeben, wird in einer abschließenden industrieökonomische Analyse betrachtet.

in: Jahrbücher für Nationalökonomie und Statistik, Bd. 179 (1966), S. 286 ff., ders., Wettbewerb als Norm der Wettbewerbspolitik, in: ORDO, Bd. 18 (1967), S. 77 ff., Herdzina, Klaus, Konzept und Voraussetzungen des funktionsfähigen Wettbewerbs, Köln 1970, ders., zur historischen Entwicklung der Wettbewerbstheorie, in: Wettbewerbstheorie, hrsg. Von Herdzina, Klaus, Köln 1975, S. 15 ff., Kaufer, Erich, Konzentration und Fusionskontrolle, Tübingen 1977. Zu einer Übersichtsdarstellung vgl. Tolksdorf, Michael, Stand und Entwicklungstendenzen der Wettbewerbstheorie, in: Wirtschaft und Wettbewerb, 30. Jg. (1980), S. 785 fr. Das SVE-Paradigma wird dennoch in Fallstudien häufig verwendet, so z. B. in Oberender, Peter (hrsg.), Marktstruktur und Wettbewerb in der Bundesrepublik Deutschland, München 1984. 


\section{Kapitel 1: Entwicklung der Verwertung von Musik mit Hilfe von Tonträgern}

Die Untersuchung eines Marktes mit Hilfe mikro- und industrieökonomischer Analysen kann nicht mit dem Status Quo beginnen. Vielmehr steht die historische Entwicklung der Produktionsbedingungen und Vermarktungsmöglichkeiten am Anfang. Durch einen geschichtlichen Abriß können Besonderheiten deutlich werden, die für die Erklärung der weiteren Marktentwicklung herangezogen werden können. Deswegen wird in Abschnitt 1.1 zuerst die Entstehung der Musik als ökonomisches Gut beschrieben, welches dann durch Aufzeichnung und Wiedergabe unabhängig vom Musiker handelbar wird. Die Geschichte der technischen Entwicklung der Aufzeichnungs- und Wiedergabemöglichkeiten ist zugleich die Geschichte des Produktes Tonträger. Sie wird in Abschnitt 1.2 nachvollzogen. Der ökonomischen Bedeutung sowohl der Prozeßinnovationen der Aufzeichnung von Musik als auch der Produktinnovationen der verschiedenen Tonträgerkategorien widmet sich Abschnitt 1.3. Schließlich wird die volkswirtschaftliche Bedeutung der Tonträgerindustrie untersucht.

\subsection{Musik als Ware}

Ökonomisch gesehen entsteht ein Markt immer dann, wenn Bedürfnisse befriedigt werden. Dabei ist es für unseren Untersuchungszweck zweitrangig, ob die betreffenden Bedürfnisse durch die Existenz einer Ware oder eines Gutes erst geweckt werden oder ob die Güter bzw. Waren bereits bestehende Bedürfnisse stillen. Entscheidend ist allein, daß das Angebot eines Wirtschaftssubjektes auf die Nachfrage eines anderen triff. In dieser Arbeit interessiert insbesondere die Ware Musik mit ihrem Gebrauchs- und Tauschwert. ' Dadurch, daß Musik einen Tauschwert bekommen hat, wurde sie überhaupt erst handelbar.

\subsubsection{Von der Hausmusik zu Musikdarbietungen}

Die Anfänge der Musik liegen weiter zurück als ihre ökonomischen Verwendungen. Ursprünglich Ausdruck von Spiritualität oder Religiösität wurde die Musik mehr und mehr zu Unterhaltungszwecken aufgeführt und dadurch professionalisiert. Musiker zogen durch die Lande und boten ihre Dienste bei Hofe an. Die in Urvölkern zu Kultzwecken gepflegte und von Generation zu Generation weitergegebene Fähigkeit des Musizierens, die heute das Äquivalent in der Hausmusik findet, wurde zunehmend durch professionelle Musikdarbietungen verdrängt. Denn erstmalig war es möglich, mit der Aufführung von Musik Geld zu verdienen. Damit entstand der Beruf des Musikers.

1 Für die Erklărung von Gebrauchs- und Tauschwert sei das Beispiel von Wasser und Diamanten angeführt. Wasser hat zwar einen hohen Gebrauchswert (z. B. für die Zubereitung von Getränken und Speisen sowie für viele Produktionsverfahren), ist jedoch relativ billig kăuflich zu erwerben und hat daher einen geringen, in Geldeinheiten ausgedrückten Tauschwert. Dagegen haben Diamanten einen hohen Tauschwert, sind in Geldeinheiten sehr teuer, aber ihr Gebrauchswert ist im Vergleich zum Wasser relativ gering. 


\subsubsection{Entstehung des Berufes Musiker}

Durch die bei Hofe aufkommende Nachfrage nach Musikdarbietungen zu Unterhaltungs- und Repräsentationszwecken suchten die Hofherren, sich ihren eigenen Stamm von Musikern zu halten. Zunächst gab es neben dem reinen Musizieren auch die Aufgabe des Komponierens. Denn anfänglich existierte noch keine Verbreitung von Literatur bzw. Noten; diese wurden nur handschriftlich in Klöstern kopiert. Erst Gutenbergs Erfindung des Druckverfahrens mit beweglichen Lettern um 1450 ermöglichte die kommerzielle Vervielfältigung von Musik in Noten. Daher war es die Arbeit der Hofmusiker, zu festlichen Anlässen Stücke zu komponieren und zur Auffuhrung zu bringen. Es wuchs dabei der Anspruch an die Qualität und den Umfang der Kompositionen. In der Folge wurden mehrere Musiker beteiligt, deren Einsätze in Noten fixiert wurden. Die Musik wurde dadurch wiederholbar und die Leistung der Musiker konnte am Schwierigkeitsgrad der Kompositionen und der Richtigkeit des Spielens gemessen werden. Insofern war es für die Nachfrager im Rahmen ihrer musikalischen Urteilsfahigkeit möglich, die Qualität der Anbieter zu bewerten und Vergleiche zwischen dem Angebot zu ziehen. Die Musiker ihrerseits waren gehalten, sich an der Güte bereits in Noten festgehaltener Stücke zu orientieren und den Wünschen ihrer Nachfrager, der Hofherren, nachzukommen, um nicht in Ungnade zu fallen. So festigte sich das Berufsbild des Musikers und Komponisten, der einerseits die Wünsche seiner Kunden zu erfüllen hatte, andererseits Neues ausprobierte. Im weiteren Verlauf der Entwicklung gab es auch unabhängige Musiker, die zwar bisweilen Aufträge des Adels erfüllten, aber ansonsten von Konzertreisen lebten.

\subsubsection{Die Verbreitung von Musik durch Konzerte}

Für die Verbreitung der Musik war nach dem 15. Jahrhundert von Bedeutung, daß sich die Musik durch Abdruck und Verteilung der Noten, Aufführung der Werke, die gegenseitige Anregung von Schulen und Nationen sowie durch eine Weiterführung der erreichten Techniken weiterentwickelte. Durch Konzertreisen der professionellen Musiker wurde der Markt für die einzelnen Kompositionen erheblich ausgeweitet. Jungk ${ }^{2}$ spricht in diesem Zusammenhang von der Hochentwicklung der abendländischen Musik. Auch die Musiknachfrage dehnte sich nun über die Grenzen einzelner Staaten hinweg aus. Dies führte musikgeschichtlich zur Etablierung bestimmter Stilrichtungen im Abendland (etwa der Barockmusik). Die konzertante Musik blieb aber weiterhin ein jeweils einmaliges „Live-Erlebnis“, welches nur mit anderen Konzerten (und Ensembles), die dasselbe Musikstück aufführten, verglichen werden konnte. Die Arbeitsteilung schritt voran. Wenige Komponisten schrieben Werke für viele Musiker. Die Berufsbilder von Komponist und Musiker fielen zumindest partiell auseinander. Der Bedarf an Komponisten und Musikern entwickelte sich unterschiedlich. Immer noch gab es nur das rein visuelle Festhalten von Musik mit Noten. Die akustische Konservierung gelang erst einige hundert Jahre später. Abbildung 1 faßt den Ablauf der Musikverwertung zu der damaligen Zeit zusammen.

2 Vgl. Jungk, Klaus, Musik im tochnischen Zeitalter: Von der Edison-Walze zur Bildplatte, Berlin 1971, S. 9 f. 


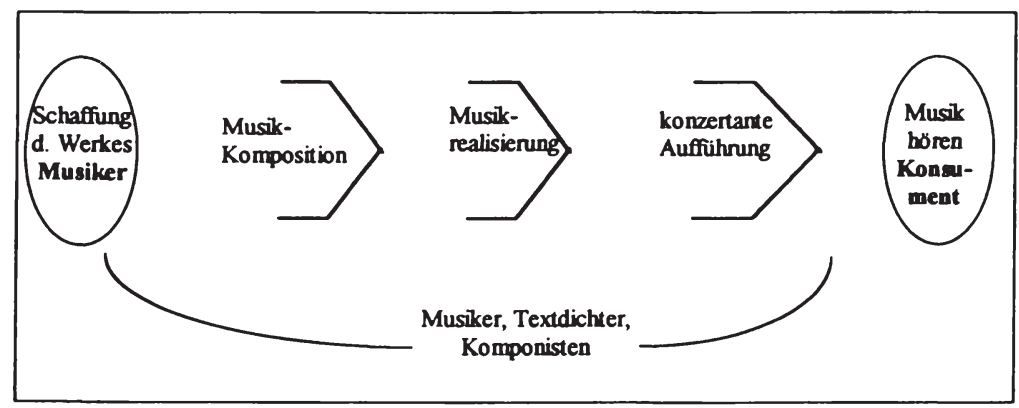

\subsection{Die technische Entwicklung der Aufzeichnung und Wiedergabe von Musik}

Forscher und Wissenschaftler suchten nach Wegen, Musik auch ohne das erneute Musizieren zu wiederholen. Dazu bedarf es einer Aufzeichnung, eines Speichermediums (des Tonträgers) und eines Wiedergabegerätes. Die physikalische Grundlage der Musik, der Schall, mußte zunächst erforscht werden.

\subsubsection{Entstehung von Musikaufzeichnungen}

Bis zu Beginn des 19. Jahrhundert wußte man so gut wie nichts über den Schall, obwohl der ungarische Baron von Kempelen Ende des 18. Jahrhunderts eine Maschine baute, die „sprechen“ konnte. Hierzu wurde mit Hilfe eines Blasebalgs über ein kompliziertes Klappensystem Luft in eine Mechanik von Ventilen, Stiften und Flöten geleitet. ${ }^{3}$ Im Jahre 1830 schaffte es der Göttinger Professor Wilhelm Weber, Schallwellen sichtbar zu machen. Ein auf einer Stimmgabel befestigter Stahlstift schrieb die Schallschwingungen auf einen mit Ruß bestrichenen Papierzylinder ${ }^{4}$ (sog. Phonautograph).

Dem Bonner Physiologen Johannes Müller gelang es 1850, einem präparierten Kehlkopf durch Anblasen und mechanische Steuerung der Muskulatur Melodien zu entlocken. ${ }^{5}$ Am 30. April des Jahres 1877 legte der französische Dichter Charles Cros $^{6}$ der Pariser Akademie der Wissenschaften die Beschreibung eines Parléophones vor, das aus einer Wachswalze bestehen sollte. ${ }^{7}$ Allerdings fand er für seine Idee keine finanzielle Unterstützung, und so war es der

Vgl. Grobe, Günter, Von der Edisonwalze zur Stereoplatte, Berlin 1989, S. 7.

Vgl. Große, Günter, op. cit., S. 8.

Vgl. Jungk, Klaus, op. cit., S. 19.

Vgl. Steinhausen, Hans Werner von, Hundert Jahre Tonträger, in: Streitobjekt Schallplatte, hrsg. von der Deutschen Phono Akademie e. V. Hamburg. Wiesbaden 1978, S. 149 ff.

7 Vgl. Riess, Curt, Knaurs Weltgeschichte der Schallplatte, Zürich 1966, S. 30 f. 
Amerikaner Thomas Alva Edison, der den ersten Phonographen tatsächlich bauen ließ (4.6.12.1877). Ausgehend von Experimenten im Sommer desselben Jahres beauftragte Edison seinen Mitarbeiter John Kruesi, eine mit einer Handkurbel betriebene Spindel mit einem Metallzylinder zu bauen, der mit einer Zinnfolie überzogen war, in welche die Vibrationen der menschlichen Stimme senkrecht eingeschrieben wurden. ${ }^{8}$ Hierzu verwandte Edison eine Membran, an der eine Nadel befestigt war. Die Nadel wiederum ritzte die Schwingungen in den von Hand gedrehten Zylinder. Wollte man nun nach der Klangaufzeichnung die Wiedergabe erreichen, so mußte man nur die Membran gegen eine zur Wiedergabe geeignete tauschen (Vorläufer der Lautsprecher, Anm. des Verf.) und den Zylinder mit derselben Geschwindigkeit wie bei der Aufzeichnung drehen. Die Nadel brachte die Membran zum Schwingen, das Aufgenommene erklang. Edison führte noch im selben Monat seine Erfindung einer breiteren Öffentlichkeit vor und beantragte ein Patent, welches er im Februar 1878 auch erhielt. Die eigens gegründete Edison Speaking Phonograph Company sollte die Erfindung kommerziell nützen. ${ }^{9}$ Edison selbst sah die wirtschaftichen Möglichkeiten seiner Erfindung als sehr weitreichend an. Er veröffentlichte im Juni 1878 im North American Review ein Zehnpunkteprogramm: ${ }^{10}$

1. Aufnahme von Briefen und aller Arten von Diktaten ohne die Hilfe eines Stenographen.

2. Phonographische Bücher, die Blinden den Inhalt eines Buches ohne fremde Hilfe vermitteln.

3. Erteilung von Sprachunterricht.

4. Wiedergabe von Musik.

5. Klingendes Familienarchiv: Eine Sammlung von Aussprüchen und Erinnerungen der Familienmitglieder mit ihren eigenen Stimmen und der letzten Worte der Sterbenden.

6. Musikboxen und Spielzeug.

7. Uhren, die mit deutlicher Stimme mitteilen, wann es Zeit ist, nach Hause zu gehen, das Essen einzunehmen usw.

8. Festhalten verschiedener Sprachen mit richtigem Akzent.

9. Hilfsmittel für den Unterricht: Erklärungen des Lehrers können dem Schüler immer zur Verfügung stehen.

10. Unterstützung des Telefons, damit dieses nicht ein Instrument augenblicklicher Übermittlung bleibt, sondern wichtige und bleibende Mitteilungen furr immer aufbewahren kann.

Obwohl Edison viele Verwertungsmöglichkeiten richtig vorhergesehen hatte, waren die technischen Schwierigkeiten so groß, daß sich kurzfristig nur der sechste Punkt, Musikboxen und Spielzeug, realisieren ließ. Der Phonograph wurde eine Jahrmarktattraktion und fand dort eine starke Verbreitung. Aber schon nach einem guten halben Jahr ließ die Sensationswirkung nach, und es wurden praktisch keine Phonographen mehr verkauft. " Edison entwickelte den Phono-

\footnotetext{
Vgl. Reichardt, Robert, Die Schallplatte als kulturelles und okonomisches Phänomen, Zürich 1962, S. 98.

Vgl. Reichardt, Robert, op. cit., S. 98; Große, Günter, op. cit., S. 15; Haas, Walter, Das Jahrhundert der Schallplatte, Bielefeld 1977, S. 19.

$10 \mathrm{Vgl}$. Haas, Walter, op. cit., S. 20.

" Vgl. Reichardt, Robert, op. cit., S. 98.
} 
graphen nicht weiter, sondern konzentrierte sich auf die Entwicklung der Glühbirne. Daher wurde die technische Verbesserung von anderen Personen vorangetrieben.

\subsubsection{Erfindung von Graphophon, Grammophon und Schellackplatte}

Edisons Speaking Phonograph Company mußte schon bald ihre Tätigkeit einstellen. Insbesondere die starke Verzernung bei der Schallwiedergabe ließ die anvisierte vielseitige Nutzung nicht zu. Die Engländer Chichester Bell und Charles Tainter benutzten 1885 Hartwachs, um die Walze zu beschichten. Dies reduzierte die Verzerrung. Ferner wurde der starre Stift durch einen beweglichen ersetzt und das Problem der gleichen Drehgeschwindigkeit der Walze bei Aufnahme und Wiedergabe durch einen Elektromotor gelöst, der fortan die Walze antrieb. 1886 erlangte die Erfindung, das sogenannte Graphophon, das Patent. Der entscheidende Nachteil des Gerätes war die Abnutzung der Wachswalze, die ein Auswechseln spätestens nach 60 bis 70 Abspielungen erforderte. Bell und Tainter gründeten 1887 die American Graphophone Company, die das Graphophon als Diktiergerät verkaufte. Edison übernahm 1888 die Erfindung, indem er ebenfalls einen Wachszylinder verwandte. Der nun folgende Patentkampf zwischen den Firmen Edisons und Bell/Tainters endete vorläufig damit, daß ein gewisser Jesse Lippincott sich die alleinigen Verkaufsrechte für beide Produkte sicherte und im Juli 1888 die North American Phonograph Company gründete. ${ }^{12}$ Auch Lippincott wollte die Geräte als Diktiergeräte verwenden, und auch er scheiterte. Weiterhin wurden Phonograph und Graphophon als Musikautomaten benutzt, welche nach Einwurf einer Münze Unterhaltungsmusik spielten.

Parallel dazu entwickelte Emil Berliner Grammophon und Schallplatte. Berliner erkannte einen weiteren Nachteil der Walze bzw. des Zylinders als Medium der Schallaufzeichnung und Schallwiedergabe: die Vervielfältigung. Bislang mußte praktisch jede Walze eigens besprochen bzw. bespielt werden. Für die Vermarktung erwies sich das als äußerst hinderlich. ${ }^{13}$ Berliner, aus Hannover nach Amerika ausgewandert, nahm eine Zinkplatte, die er mit einem Gemisch aus Benzin und Wachs übergoB. Das Benzin verdampfte und es blieb eine dünne Wachsschicht übrig, die die Schallschwingungen aufnehmen sollte. Während der Aufnahme übertrug eine Nadel die Schallwellen auf das Wachs. Eine Flüssigkeit spülte die herausgeschnittenen Wachsstreifen gleichzeitig weg. Nach dem Ende des Musikstücks tauchte Berliner die Platte in ein Chromsäurebad, wodurch die Schallinien in das Zink geätzt wurden. ${ }^{14}$ Die Wiedergabequalität war besser als bei den Wachswalzen, und es gab einen geringeren Abnutzungseffekt.

Wichtiger aber war noch die Tatsache, daß von der Zinkplatte Kopien aus Hartgummi hergestellt werden konnten. Dies waren die Schallplatten. Berliner verkaufte von einer Vater UnserPlatte mehrere tausend Exemplare. ${ }^{15}$ Das zugehörige Abspielgerät nannte er Grammophon. Es

12 Vgl. Reichardt, Robert, op.cit., S.98.

13 So mußte fur die Aufstellung von Graphophonen auf der Weltausstellung in Chicago das Stück "After the ball was over" $70 \mathrm{mal}$ aufgenommen werden. Vgl. hierzu Große, Günter, op. cit., S. 19, und Haas, Walter, op. cit., S. 23 f.

14 Vgl. Kuhnke, Klaus, Manfred Miller und Peter Schulze, Geschichte der Pop-Musik, Bd. 1, 2. Aufl., Bremen 1976, S. 164.

is Vgl. Haas, Walter, op. cit., S. 38. 
bestand aus einer Handkurbel mit einer an einem Schalltrichter befestigten Nadel, die auf der sich drehenden Schallplatte ruhte. Die Schallaufzeichnung und -wiedergabe erfolgte in seitlicher „Zickzackbewegung“ anstatt der „Berg- und Talaufzeichnungen“ des Phonographen. Dieses Grammophon wurde ab 1889 in Waltershausen (Thüringen) gebaut, nachdem Berliner sein komplettes Verfahren im November 1887 in Deutschland patentiert bekam. Eine gleichmäßige Umdrehung der Handkurbel mit 70 pro Minute war allerdings Vorraussetzung dafür, daß überhaupt verständliche Musik ertönte. Der Phonograph hingegen war schon mit Elektromotor erhältlich. Des weiteren war die Spieldauer einer Schallplatte auf zunächst nur eine Minute begrenzt, während eine Walze zwei Minuten, ab 1908 sogar vier Minuten Musik reproduzierte. ${ }^{16}$ Aus den o. g. Gründen setzte sich das Grammophon zunächst nicht gegen den Phonographen durch, obwohl Fachleute Berliners Verfahren für technisch ausgereifter hieiten.

Durch einen Besuch bei der Telefongesellschaft Bell Company kam Berliner darauf, ein neues Material für seine Schallplatten zu verwenden. Ein Gemisch aus Schellack, Anteilen von Ruß oder Graphit, Fasern und Gesteinsmehl wurde unter Hitze und Druck leicht formbar und nach Abkühlung sehr hart. ${ }^{17}$ Die Platte aus Schellack war haltbarer als diejenige aus Hartgummi und die Abspielqualität war besser. Schellack blieb bis in die 50er Jahre des 20. Jahrhunderts hinein das Material für Schallplatten. Im Oktober 1895 gründete Emil Berliner die United States Gramophone Company. ${ }^{18}$ Im darauffolgenden Jahr konnte endlich der Wettbewerbsnachteil gegenüber den Phonographen wettgemacht werden, indem in das Grammophon ein von Eldridge Johnson entwickeltes Uhrwerk eingebaut wurde. Das Uhrwerk garantierte die gleichmäßige Umdrehung des Plattentellers für drei Minuten und verursachte kaum Nebengeräusche. $^{19}$

Die Nachfrage nach Grammophonen wuchs jetzt so rasch, daß sie nicht befriedigt werden konnte, obwohl Johnson in riesigen Werkhallen 1000 Stück pro Monat produzierte. Das Grammophon schickte sich an, in den USA dem verbreiteten Phonograph Konkurrenz zu machen. ${ }^{20}$ Die Angebotsseite der Phonographischen Wirtschaft in den USA bestand damals in der Hauptsache aus Columbia, Tochterunternehmen der North American Phonograph Company, der 1896 von Edison gegründeten National Phonograph Company ${ }^{21}$ und der United States Gramophone Company Emil Berliners. Die Columbia erwarb die Auswertungsrechte für die Herstellung von Phonographen und Graphophonen. Die National Phonograph Company Edisons hatte jedoch die Vertretung über die Patente für Phonographen. Der Konkurrenzkampf wurde auch mit Hilfe einer Patentauseinadersetzung vor Gericht geführt. ${ }^{22} \mathrm{Da}$ die damals be-

6 Vgl. GroBe, Günter, op. cit., S. 30.

Vgl. Große, Günter, op. cit., S. 32.

18 Vgl. Reichardt, Robert, op. cit., S. 99.

19 Vgl. Große, Günter, op. cit., S. 33.

20 In Europa waren Grammophone zwar bekannt, aber lăngst nicht so verbreitet wie die Phonographen. Das erste Presswerk fuir Schallplatten in Europa wurde erst im Herbst 1898 in Hannover gegründet.

21 Edison hatte die North American Phonograph Company 1894 bankrott gehen lassen, da sich die Untergliedenung in 30 Tochtergesellschaften in den einzelnen Bundesstaaten als unpraktisch erwies.

22 Vgl. Schulze, Ralf, Die Musikwirtschaft: Marktstrukturen und Wettbewerbsstrategien der deutschen Musikindustrie, Hamburg 1996, S. 373 f. Tatsächlich verbot ein amerikanisches Gericht Johnson die Produktion von Grammophonen für die Berlinergruppe, da das Patent von Bcll- Tainter dadurch verletzt würde 
kannten Unterhaltungskünstler sowohl Wachswalzen für Phonographen als auch Schallplatten für Grammophone bespielten, bestand eine hohe Wettbewerbsintensität. Im Jahr 1901 gründete Johnson die Victor Talking Machines Company, die ein Patent für die Grammophonherstellung besaß. 1902 schließlich endete der Patentkampf zwischen der Columbia und der Victor Talking Machines Company, indem beide ihre Patente vereinigten. ${ }^{23}$ Die Konkurrenz verlagerte sich auf andere Felder. In der Zwischenzeit (1897-1900) hatte Johnson das (Wachs)Matrizenverfahren für die Grammophonaufnahme entwickelt, welches - mit bestimmten Fortentwicklungen - bis zuletzt für die Schallplatten benutzt wurde. ${ }^{24}$

Langfristig setzte sich das Grammophon gegen den Phonographen durch. Die phonographischen Firmen sperrten sich lange gegen das Grammophon, um ihre Gewinne mit dem Phonographen zu maximieren. 1912 schließlich stellte die Columbia, ein Jahr später Edisons National Phonograph Company die Produktion von Phonographen ein. ${ }^{25}$ In den USA waren zu diesem Zeitpunkt noch etwa eine Million Phonographen in Betrieb, weswegen Edison noch bis 1929 Walzen lieferte. ${ }^{26}$ Die Umstellung der Verbraucher auf die Grammophone dauerte auch deswegen eine gewisse Zeit, weil die Geräte gemessen am Durchschnittseinkommen teuer waren.

\subsubsection{Mikrophon, Stereophonie und Vinylplatte}

Die Grammophon- und Schallplattenindustrie expandierte quasi exponentiell. In Europa wurde 1898 die Deutsche Grammophon Gesellschaft und die Gramophone Company in England gegründet; erstere wurde schon 1900 in eine Aktiengesellschaft umgewandelt. Der ehemalige Generalbevollmächtigte Seamans, Prescott, gründete die International Talking Machine $\mathrm{GmbH}^{27}$ und als deren Tochter die italienische Società Italiana Fonotopia. In Hannover stellte die Deutsche Grammophon ca. 25.000 Platten pro Tag her. Die Jahresproduktion im Deutschen Reich stieg, nachdem ein weiteres Presswerk 1907 in Berlin errichtet worden war, 1908 auf 6.200.000 Platten. ${ }^{28}$ Während bislang Tonträger und Abspielgeräte nebenbei verkauft wurden, etablierte sich ab 1909 ein Fachhandel für Grammophon und Schallplatte. ${ }^{29}$ Der erste Weltkrieg brachte starke Einbrüche, die in Europa deutlicher ausfielen als in den USA.

Der bisherige Alleinvertreiber Berliners, Seaman, baute nun selbst Grammophone und schloB ein Abkommen mit der Columbia, welche die Grammophone dann vermarktete. 1901 wurde das Produktionsverbot gegen Johnson wieder aufgehoben und Berliner wieder in die Patentrechte eingesetzt.

23 Vgl. Reichardt, Robert, op. cit., S. 101.

24 Verbessert um die elektromagnetischen Impulse des Mastertapes, eine Matrize aus Metall (Vater genannt) und die für die Pressung mit Chrom verstărkten Sóhne mit einer Lebensdauer von ca. 60.000 Pressungen.

25 1907 stellte die Firma der Brüder Pathé, die von Frankreich aus operierte und ein breites Spektrum an Opern, Operetten und Chansons produziert hatte, die Walzenproduktion ein. (Laut Große, Günter, op. cit., S. 54 erst 1911). Ein von ihnen 1900 entwickeltes Verfahren, mit dem man von einer Aufnahme so viele Zylinder wie gewünscht gießen konnte, kam zu spăt. Bereits 1901 hatten sich ca. 10.000 Tontrăgerhăndler weitweit von der Walze auf die Schallplatte umgestellt. Vgl. Riess, Curt, op. cit., S. 73 f.

$26 \mathrm{Vgl}$. Reichardt, Robert, op. cit., S. 103.

27 Diese Firma brachte 1904 die erste auf zwei Seiten bespielte Platte heraus. Vgl. Kuhnke, Klaus, Manfred Miller und Peter Schulze, op. cit., S. 168

28 Vgl. Schulze, Ralf, op.cit., S. 374

29 Vgl. Riess, Curt, op. cit., S. $137 \mathrm{ff}$ 
Neue technische Impulse kamen zu Beginn der zwanziger Jahre ${ }^{30}$ von den Bell-Laboratorien, der Forschungsabteilung der American Telegraph and Telephone Company. Sie entwickelten Verfahren, um die Aufnahme und Wiedergabe elektro-akustisch zu bewerkstelligen. ${ }^{31}$ Zunächst blieb es aber nur bei der Einführung des Mikrophons zur elektro-akustischen Aufnahme, da die Wiedergabe noch zu teuer und technisch zu wenig ausgereift war. Begleitet wurde die neue Aufnahmetechnik von der Einführung des Radios. Im Oktober $1923 \mathrm{nahm}$ in Berlin in den Räumen der Schallplattengesellschaft Vox der erste Sender seinen Betrieb auf. Auch in Amerika hatten sich Radiogesellschaften gebildet. ${ }^{32}$ Die Unternehmen Victor und Columbia trafen mit der Radio Corporation of America (RCA) und der Western Electric Vereinbarungen und brachten Radio-Grammophon-Kombinationen auf den Markt.

Die alten Aufnahmetrichter verschwanden aus den Aufnahmestudios und wurden durch die Mikrophone ersetzt. Dadurch wurde die Wiedergabe auf der Schallplatte verbessert, besonders in den hohen Frequenzen. Ab Herbst 1925 waren die mit Mikrophon aufgenommenen Platten im Handel. In Deutschland wurden sie durch die neugegründete Electrola, einer Tochter der englischen Gramophone Company, hergestellt und vertrieben. Nach einer großen Ausweitung des Geschäfts sowohl in Europa als auch in den USA führte die Weltwirtschaftskrise zum Einbruch in der gesamten Branche. Waren 1927 in den USA noch 104 Millionen Platten verkauft worden, so betrug der Absatz 1932 nur noch 6 Millionen Stück. Der Grammophonumsatz sank von einer Million 1927 auf 40.000 Stück $1932 .^{33}$

Edison hatte bereits 1926 eine Langspielplatte entwickelt, die sich nicht am Markt durchsetzen konnte. ${ }^{34}$ Auch die nach der Weltwirtschaftskrise fusionierten Unternehmen RCA und Victor entwickelten 1931 eine Langspielplatte mit 14 Minuten Spieldauer auf jeder Seite. Allerdings war das Hardware-Software-Problem bei der Markteinfuhrung hinderlich. Es lag darin, daß gleichzeitig neue Abspielgeräte von den Konsumenten hätten gekauft werden müssen. Deswegen hatte auch RCA-Victor mit dem Projekt keinen Erfolg. Peter Goldmark hatte in den 40er Jahren für die Columbia eine Langspielplatte entwickelt, die 1948 vorgestellt wurde. Das besondere an dieser Platte war die Spieldauer von 23 Minuten pro Seite, die Geschwindigkeit von 33 1/3 Umdrehungen pro Minute, die Mikrorille (224 bis 300 Rillen pro Inch statt der bisherigen 85) und das neuartige Material - Vinyl. ${ }^{35}$ Die Vinylplatte bestand (und besteht bis heute) aus Polyvinylchlorid und Polyvinylacetat. ${ }^{36}$ Einen Füllstoff (wie Gesteinsmehl bei der Schellackplatte) gab es nicht. Damit fallen die Massegeräusche auf ein Minimum. Die Vinylplatte ist ein aus Erdölderivaten hergestelltes Produkt. Sie ist wesentlich bruchsicherer und

$30 \mathrm{Zu}$ dieser Zeit brachte der Jazz neue Impulse musikalischer Art.

31 Auch die Western Electric entwickelte 1924 ein elektrisches Aufnahmeverfahren, welches die Schallwellen im Mikrophon in elektrische Wechselspannungen umsetzt, die in Verstärkerapparaturen verstärkt und nötigenfalls korrigiert werden. Vgl. Elste, Martin, Kleines Tonträgerlexikon: Von der Walze zur Compact Disc, Kassel 1989, S. 18.

32 Vgl. Grobe, Günter, op. cit., S. 72 f., und Reichardt, Robert, op. cit., S. 104 f.

$33 \mathrm{Vgl}$. Reichardt, Robert, op. cit., S. 104.

$34 \mathrm{Vgl}$. Elste, Martin, op. cit., S. 70 f.

35 Vgl. Elste, Martin, op. cit., S. 69.

36 Die genaue Zusammensetzung ist bis heute Betriebsgeheimnis der Presswerke 
damit verschickbar. Ein temporäres Rohstoffproblem bei der Herstellung der Schellackplatte, das dazu geführt hatte, daß im 2. Weltkrieg und in der Zeit danach beim Kauf einer Platte zwei alte abgegeben werden mußten, war beseitigt. Weiterhin trugen die eigens entworfenen Hüllen oder Alben, die fortan jede Vinylplatte umgaben, zur Verdrängung der Schellackplatte bei.

Die Columbia hatte nicht nur die Matrizen für die neue Vinyl-Platte insgeheim vorbereitet, sondern auch mit der Produktion entsprechender Abspielgeräte begonnen. Nach der Vorstellung der Platte bei der RCA-Victor wollte die Columbia wissen, ob die neue Langspielplatte von ihr als Norm akzeptiert wurde. Um das zu erreichen, wäre sie auch bereit gewesen, das Verfahren zur Verfügung zu stellen. ${ }^{37}$ Vermutlich hatten die schlechten Erfahrungen mit dem Konkurrenzkampf zwischen Phonograph und Grammophon die Columbia zu dem Kooperationsangebot bewegt. Auf den Vorschlag einer gemeinsamen technischen Norm ging die RCAVictor nicht ein. Columbia verkaufte so 1,25 Millionen LPs (für long playing record) in einem halben Jahr, RCA-Victor brachte im Gegenzug eine Platte heraus, die 45 Umdrehungen in der Minute brauchte. Der „Krieg der Geschwindigkeiten“ (War of Speeds) brach aus. Er kostete die beteiligten Gesellschaften ca. 7 bis 8 Millionen Dollar. ${ }^{38}$ Im Ergebnis wurden klassische Stücke auf den 33 1/3 LPs und Unterhaltungs- und Tanzmusik auf 45 er Platten (Singles) aufgenommen. Abspielgeräte mit drei Geschwindigkeiten (78, 45 und 33 1/3 Umdrehungen in der Minute) setzten sich durch, ${ }^{39}$ ab 1950 auch in Deutschland.

Eine weitere Erfindung soll diesen Abschnitt beschließen: die Stereophonie. Neben weiteren Verbesserungen der Aufnahmefrequenzbreite [Hi-Fi 1934 und full frequency range recording (ffrr) 1945$]^{40}$ wurde auch die Kanaltrennung bei Aufnahme und Wiedergabe erforscht. 1931 meldete der Ingenieur Alan Blumlein (in Diensten der EMI) in England ein Patent für die Stereoplatte an. Die Erfindung wurde aber nicht kommerziell ausgewertet. ${ }^{41}$ Die Bell Telephone Company brachte 1935 eine Stereoplatte heraus. Seit 1955 machte RCA stereophone Aufnahmen. 1956 entwickelte die Decca ein Verfahren, mit dem die zwei Schallinformationen als „Berg und Tal“ und als Zickzackbewegung der Nadel in einer Rille eingezeichnet werden. 1957 brachte die Firma Westrex eine stereophone Einzeichnungstechnik heraus, die Auslenkungvektoren im Winkel von $45^{\circ}$ zur Plattenfläche vorsieht (sog. 45/45 - Verfahren). 1958 kam der erste Tonkopf zum Abspielen von Stereoplatten auf den Markt. Ein Kommitee der Record Industry Association of America (RIAA) schlug vor, das 45/45 Verfahren zum Standard zu machen. ${ }^{42}$ Als auch die Columbia daraufhin ein eigenes Verfahren zurückzog, wurde ein Konkurrenzkampf vermieden. Die Stereoplatte wurde auf den Markt angeboten, ebenso die entsprechenden Abspielgeräte. Stereozusätze zum Fernsehen wurden angeboten und auch das Radio wurde allmählich bei Musiksendungen auf Zweikanalton umgestellt. Das StereoGeschäft lief sowohl in den USA als auch in Europa nur langsam an, z. B. lieferten die Beatles

37 Vgl. Reichardt, Robert, op. cit., S. 107 f.

38 Vgl. Ludwig, Hans-Werner: Schallplatte/Tonband, in: Kritische Stichwörner zur Medienwissenschaft, hrsg. von Faulstich, Werner, München 1979, S. 295 f.

39 Vgl. Jungk, Klaus, op. cit., S. 59.

40 Vgl. Riess, Curt, op. cit., S. 282, für Hi-Fi, und Elste, Martin, op. cit., S. 49 f., für ffrr.

4 Vgl. Reichardt, Robert, op. cit., S. 110

42 Vgl. Riess, Curh, op. cit., S. 382 ff. 
ihre ersten Aufnahmen in den 60er Jahren noch in Mono ab. Die englische EMI preßte $z$. B. erst ab Juli 1967 alle Neuerscheinungen in Stereo. ${ }^{43}$ Weitere Entwicklungen der Vinylplatte wie die Quadrophonie setzten sich nicht durch. Bis zur Ablösung durch die CD war aber die Vinylplatte als LP und Single der weltweit verbreiteste Tonträger.

\subsubsection{Tonband, Abspielgeräte und Musikkassetten}

Die elektromagnetische Schallaufzeichnung ist ungefähr so alt wie das Grammophon. 1888 veröffentlichte Oberlin Smith in der Zeitschrift „The Electrical World“ den Artikel „Some Possible Forms of Phonograph“. " Er dachte sich Stahldrähte oder mit Stahlstaub durchsetzte Fäden als Tonträger. Der in der Hochfrequenztechnik forschende dänische Ingenieur Poulsen ${ }^{45}$ erhielt im Jahre 1900 für sein Telegraphon den Grand Prix in Paris. Sein Gerät bestand aus einem auf einer Messingwalze aufgewickelten Stahldraht, ${ }^{46}$ der im Rhythmus von Sprache und Musik magnetisiert wurde. Den technischen Durchbruch brachte erst das Tonband, das zunächst aus Papier bestand (1928), welches mit Eisenoxid beschichtet war. Später wurden Acetylzellulose und in der jüngeren Zeit Polyesterfolien verwendet. Bei der Funkausstellung in Berlin 1935 stellte die AEG das Magnetophon und die BASF das Tonband vor. Beide zusammen boten das komplette Tonaufnahmesystem ${ }^{47}$ an. Das Magnetophon-Band hatte eine Spielzeit von ca. 17 Minuten, war also der Schellackplatte bei weitem überlegen. Trotzdem wurde es zunächst nur im Radio benutzt, um unabhängig von der Live-Übertragung zu werden; denn nun gab es die Möglichkeit des Schnitts und damit der Montage von Musik. ${ }^{48}$ Gerade den Nationalsozialisten hat diese Technik zur Zensur jeglicher Radiosendung gedient. Großabnehmer des Magnetophons war die Gestapo, die solche Geräte zum Abhören von Telephongesprächen benützte. ${ }^{49}$ Im Jahre 1941 entwickelten Braunmühl und Weber die Hochfrequenzmagnetisierung. Sie erweiterte den Frequenz- und Dynamikbereich der Tonbandaufnahme. ${ }^{50}$ Dünnere Trägerfolien und die Reduzierung der Bandgeschwindigkeit brachten eine längere Spieldauer, neue Schichtmaterialien für das Band eine Qualitätsverbesserung.

Nach dem 2. Weltkrieg wurde die Technik des magnetischen Tonaufnahmeverfahrens auch für die Schallplattenproduktion benützt. Die deutsche Grammophon Gesellschaft hatte eine Lizenz, und in Amerika wurden ab 1949 alle Aufnahmestudios derart ausgestattet. So konnten

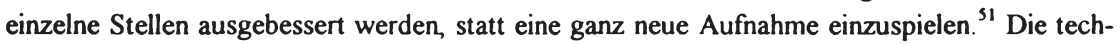
nischen Verbesserungen führten dazu, da $B$ das Tonband mit dem zugehörigen Abspielgerät der

$43 \mathrm{Vgl}$. Elste, Martin, op. cit., S. 118.

44 Vgl. Ludwig, Hans-Werner, op. cit., S. $281 \mathrm{f}$.

$45 \mathrm{Vgl}$. Steinhausen, Hans Werner von, op. cit., S. 153.

46 Vgl. Riess, Curt, op. cit., S. 327 f. Für den Tonfilm wurde dieses Verfahren 2 1/2 Jahre spăter von Curt Stille verwandt. Vgl. Jungk, Klaus, op. cit., S. 71 f.

$47 \mathrm{Vgl}$. Ludwig, Hans-Werner, op. cit., S. $281 \mathrm{f}$.

48 Vgl. Ludwig, Hans-Werner, op. cit., S. 283.

49 Vgl. Reichardt, Robert, op. cit., S. $106 \mathrm{f}$.

so Genauer gesagt werden in diesem Verfahren sowohl hohe als auch nicdrige Frequenzen aufgezeichnet. Vgl. zur ausfuhrlichen Beschreibung des Verfahrens Webers, Johannes, Tonstudiotechnik, 6. Aufl., Poing bei München 1994, S. $377 \mathrm{ff}$.

s1 Vgl. Riess, Curt, op. cit., S. 327. 
Schallplatte mit dem Plattenspieler qualitativ überlegen war. 1951 wurden in den USA mehr als 200.000 Tonbandgeräte (für Aufnahme und Wiedergabe zugleich) und für 2 Millionen Dollar Tonbänder verkauft. ${ }^{32}$ Dennoch blieb das Tonband als eigenständiger Tonträger weit hinter dem Absatz der Schallplatte zurück.

Die nächste Innovation in der Tonträgerindustrie fand statt, als Philips 1963 sein CompactCassetten System (Musikkassette, MC) vorstellte. Die Spurbreite wurde auf 1/8 Zoll, die Dikke des Trägermaterials auf $5 \mu \mathrm{m}$ (Mikrometer) für 60 und 90 minütige Kassetten und auf $3 \mu \mathrm{m}$ für 120 minütige Kassetten verringert. ${ }^{53}$ Die Ablaufgeschwindigkeit dieser Kassette betrug nur noch 4,76 cm/s, weswegen die Abspielgeräte einen extremen Gleichlauf benötigten. Hierin lag der anfängliche Nachteil des Systems. Die klangliche Qualität wurde durch gleichlaufende Geräte und weitere Verbessenungen der Bandmaterialien (Ferro-Chrom und Chromdioxid) an diejenige der Schallplatte angenähert. Das Rauschunterdrückungsverfahren des Amerikaners Dolby (1965) sorgte zusätzlich dafür, ${ }^{54} \mathrm{daB}$ die Musikkassette sich etablierte und die Plattenkonzerne ihr Repertoire sowohl auf Vinylplatten als auch auf MC herausbrachten. Die Vorteile der MC lagen in ihrer kleinen Abmessung, der mobilen Verwendung, der langen Abspielzeit des Bandes und der einfachen Bedienung. Um diese Vorteile jederzeit nutzen zu können, mußten jedoch Abspielgeräte entwickelt werden, die ebenfalls mobil waren. So wurden das Autoradio mit Kassettenabspieler und der Walkman (1979) produziert und verkauft. Die Tonträgerhersteller standen im Innovationswettbewerb um die Etablierung des technischen Systems. Der Philipskonzern gewann, indem er - um die Verbreitung zu beschleunigen - auf alle Tantiemen oder Lizenzgebühren für sein System verzichtete: Die Acht-Spur-Technik konnte durchgesetzt werden (1970).

Die Musikkassette erweiterte das Volumen des Tonträgermarktes. Neue Käufer wurden hinzugewonnen; allerdings entwickelte sich durch das Aufkommen der Leerkassetten eine Substitutionsbeziehung zwischen den Tonträgerkategorien. In der Bundesrepublik wurde bereits 1972 mehr Geld aus dem Verkauf von Tonbandgeräten als aus Plattenspielern erlöst, aber der Umsatzanteil der LP blieb noch bis 1987 über dem der MC. Bei einem Anteil von 10\% aller abgesetzten Tonträger (oder 27,2 Millionen Stück) und einem Umsatzanteil von 5\% für 1997 wird sich die MC langfristig nur als Rand-Tonträgerkategorie in der Tonträgerindustrie halten. ${ }^{55}$

\subsubsection{Erfindung der CD und des CD-Spielers}

Weitere Entwicklungen im Tonträgermarkt lassen erkennen, daß es zunehmend nicht nur um Musik, sondern auch um visuelle Unterhaltung und Vernetzung mit dem Fernsehen und Com-

\footnotetext{
Vgl. Reichardt, Robert, op. cit., S. 107.

Vgl. Ludwig, Hans-Werner, op. cit., S. 283.

Vgl. Steinhausen, Hans Werner von, op. cit., S. 155.

ss Quelle für alle Zahlen dieses Absatzes: Bundesverband der Phonographische Wirtschaf, Jahrbücher 1994 und 1997, Starnberg 1994 und 1997, S. 13, [BPW 1994 und BPW 1997], ders. Phono Press 1998, Hamburg 1998, S. 2 f. und 8 f. [Phono-Press 1998], und Der Markt für CD, MC und LP, hrsg. vom Bundesverband der Phonographischen Wirtschaf, der Deutschen Phono-Akademie und der Deutschen Landesgruppe der IFPI, Hamburg 1995, S. 2 und 5.
} 
puter geht. Zu Beginn der 70er Jahre entwickelt die Firma Teldec eine TED-Bildplatte mit mechanischem Abtastsystem. Nach der Marktreife wird das Produkt 1975 auf dem Markt plaziert, ohne sich langfristig behaupten zu können. Auch die Firmen JVC und RCA entwickelten ähnliche Systeme, CED und VHD genannt, die ebenfalls scheitern. 1981 führen MCA und Philips weltweit das analoge Laservision-System ein, bei dem ein Laserstrahl die Bildplatte abtastet. Ihre Video Long Play (VLP) trat quasi in Konkurrenz zum Videorecorder, der 1970 auf den Markt gekommen war. ${ }^{56}$ Die Bildplatte erzielte bis heute nur in Japan einen Erfolg, wo der Bildplattenspieler zum Zweitgerät wurde.

Der nächste Innovationsschritt war der Übergang zur digitalen Aufzeichnungs- und Wiedergabetechnik. Sony und Philips entwickelten gemeinsam die Compact Disc (CD) und stellten sie 1981 in Salzburg anläßlich der Osterfestspiele vor. Ab 1982 wurde sie für den Markt produziert. ${ }^{57}$ Bei einem Durchmesser von $12 \mathrm{~cm}$ und einem Gewicht von drei Gramm hat sie eine Spieldauer von 75 Minuten. Zwischen der Plastikscheibe und der sie umgebenden Klarlackschicht befindet sich die Datenspur. In $16 \mu \mathrm{m}$ (Mikrometer) auseinanderliegenden Rillen liegen die Pits, die rausch- und knisterfreien Informationen der CD. Ein Laserstrahl mit einer Wellenlänge von ca. $800 \mathrm{vm}$ (Nannometer) tastet die Informationen ab und wandelt sie zurück in Sprache, Musik etc. Im Gegensatz zur Schallplatte wird bei der CD die Information von innen nach außen abgetastet: Zunächst bei 500 Umdrehungen, dann sukzessive abnehmend bis zu 200 Umdrehungen pro Minute, da der Datenfluß und die Informationsdichte konstant gehalten werden müssen. ${ }^{58}$ Während der Aufnahme werden die analogen Töne der Instrumente und Stimmen von einem Computer in digitale Signale umgewandelt, indem 44.000 mal pro Sekunde Tonhöhe und Lautstärke gemessen und codiert werden. ${ }^{59}$

Die CD ist gegenüber mechanischer Abnutzung weitgehend unempfindlich. Ihre Klangqualität ist höher als diejenige der Vinylschallplatte und über einen eigenen Kanal können auf ihr Daten gespeichert werden, die die Bedienerfreundlichkeit erhöhen. So ist eine Programmierung, d. h. das Abspielen vorher ausgewählter Stücke in beliebiger Reihenfolge, ein Zugriff auf eine bestimmte Liednummer und die Anzeige der Spielzeit, Liednummer sowie die Gesamtspielzeit möglich. ${ }^{60}$ Wie die MC ist auch die $\mathrm{CD}$ handlich. Es existieren sowohl kleine tragbare CDSpieler, als auch Geräte für Autos, die in der Bedienung ähnlich einfach wie die Kassettendecks sind. In eine Verstärker-Anlage läßt sich der CD-Spieler problemlos integrieren. In der Bundesrepublik setzte sich die CD nach ihrer Markteinführung 1982 allmählich durch. Wurden 1984 erst 3 Millionen CDs abgesetzt, so waren es 1994 schon 166,2 Millionen. Die absolute Stückzahl wuchs bis 1997 weiter auf 191 Millionen. ${ }^{61}$ Ebenso stieg der Anteil der CD am

s6 Vgl. BPW 1994, op. cit., S. 73.

57 Vgl. Gross, Ulrich, Die digitale Schallplatte: Compact Disc, in: 12. Tonmeistertagung, München 1981, S. $374 \mathrm{f}$.

$58 \mathrm{Vgl}$. Webers, Johannes, op. cit., S. $587 \mathrm{f}$.

59 Für die genaue Erlăuterung der digitalen Aufnahmetechnik vgl. Gross, Ulrich, op. cit., S. 377 f.

60 Vgl. Gross, Ulrich, op. cit., S. 382.

$61 \mathrm{Vgl}$. Phono-Press 1998, op. cit., S. 2 f. 
Wertumsatz aller Tonträgerarten. ${ }^{62}$ Ähnlich wie nach Einführung der MC hatte der Innovationsschub durch die CD auch eine Umsatzweitung zur Folge: 1978 wurden 2,17 Mrd. DM im deutschen Markt umgesetzt, 1994 waren es 4,66 Mrd. DM und 1997 4,91 Mrd. DM. ${ }^{63}$ Dabei hat die CD die Vinyl-LP vollständig verdrängt ${ }^{64}$ und durch ihren höheren Preis einen höheren Umsatz erbracht. ${ }^{65}$ Zum Markterfolg der Tonträgerkategorie $\mathrm{CD}$ hat wesentlich beigetragen, $\mathrm{da} ß$ die anfänglich teuren $\mathrm{CD}$-Spieler schon nach wenigen Jahren billiger wurden. Die Bedeutung der sog. Hardware für den Tonträgermarkt ist evident.

Es haben sich durch die technische Entwicklung von der Walze bis zur CD die Trägerkategorien verändert, aber die Musikverwertung ist demselben Prinzip gefolgt. Denn unabhängig von der Tonträgerkategorie hat sich folgender Ablauf bei der Verwertung von Musik mit Hilfe von Tonträgem etabliert:

\section{Abbildung 2: Ablauf der Musikverwertung mit Aufzeichnungsmöglichkeiten}

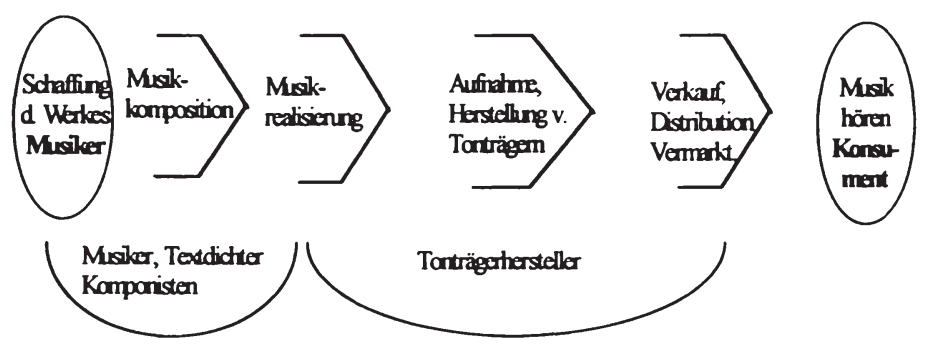

\subsubsection{Neuere Entwicklungen}

Die neueren Entwicklungen werden zum einen durch den Standard der digitalisierten Aufzeichnung und Wiedergabe gesetzt, zum anderen schafft eine immer stärkere Vernetzung durch die neuen Kommunikationstechniken die Möglichkeit neuer Angebote. Japanische Firmen entwickelten 1985 das Digital Audio Tape (DAT), das bei - im Vergleich zur herkömmlichen MC - halber Größe digitale Schallaufzeichnungen ermöglicht. ${ }^{66}$ Die zugehörigen Geräte waren zunächst sehr teuer, weswegen die DAT vor allem im professionellen Bereich Verwendung

621994 betrug der Umsatzwert der CD-Tontrăgerkategorie $81 \%$ und 1997 betrug der Anteil der CD ca. $94 \%$ des Wertumsatzes aller Tonträger. Quelle: Phono-Press 1998, op. cit., S. 2 f.

63 Quelle: Der Markt für CD, MC und LP, op. cit., S. 3; BPW 1994, S. 10; BPW 1997, S. 10, und Phono-Press 1998, S. 1 ff. Die Zahlen gelten nur für die Mitglieder des Bundesverbandes der Phonographischen Industrie, welche ca. $90 \%$ des Marktes kontrollieren. Gesamtmarktschătzungen unter Einbezug der Piraterie stehen unter einem Unsicherheitsvorbehalt.

64 In den Jahren 1995, 1996 und 1997 wurden jeweils noch 400.000 Stück der Vinyl-LPs abgesetzt. Vgl. Phono-Press 1998, op. cit., S. 2 f.

$65 \mathrm{Vgl}$. zur Preispolitik Kap. 1.3.1. und 4.3.2.3.

66 Vgl. Elste, Martin, op. cit., S. 37. 
findet. Die Masse der Konsumenten wurde bisher noch nicht erreicht, wohl auch wegen der Inkompatibilität zu analogen Geräten und Tonträgern. Aus der Bildplatte wird 1988 die Laser Disc mit digitalem Ton (entwickelt von Philips und Polygram). Die zugehörigen Geräte heißen CD Video und sollen die Funktion des Bindeglieds zwischen der Musikanlage und dem Fernseher haben. Auch hiermit wurden die Massen bisher nicht erreicht.

Der französische Konzern Thomson-Brandt entwickelte zwischenzeitlich eine CD-E (löschund wieder bespielbar) und einen CD-Rekorder. Diese Erfindung ging zunächst nicht in Serie. Philips stellt 1990 eine Digital Compact Cassette (DCC) vor ${ }^{67}$ Der DCC-Recorder kann auch analoge Kassetten abspielen. Diese Kategorie hatte keinen Markterfolg. Als nächster Schritt folgte 1992 ebenfalls von Philips die CD-I, die als System zwischen Fernseher und CD-Spieler Bild und Ton verbindet und kompatibel zur DCC ist. Sony entwickelt in demselben Jahr die MiniDisc (MD) in der Größe einer herkömmlichen MC. Sie wird sowohl fertig bespielt als auch bespielbar angeboten, ${ }^{68}$ erzielte aber bis zum Frühjahr 1998 in Deutschland keinen Markterfolg. ${ }^{69}$

Eine Vernetzung über Kabel, Satellit oder terrestrisch ermöglicht die nichtkörperliche Übermittlung von Musik. Durch Datenreduktion oder -kompression ist eine höhere Übertragungsdichte und Übertragungsfülle zu erwarten. Die Entwicklung der unkörperlichen Musikverwertung wird unter dem Begriff "music on demand“ zusammengefasst und in Kapitel 5 thematisiert. ${ }^{70}$ Das bedeutet, daß eine individuelle Lieferung in den Einzelhandel (als CD-Fabrik im Tonträgerladen) oder in das Haus des Konsumenten aus einem elektronischen Katalog ausgewählt und bereitgestellt werden kann. Das Konkurrenzprodukt ist die „MultichannelBelieferung“, bei der dem angeschlossenen Haushalt über dieselbe Technologie ein Musikprogramm mit vielen verschiedenen Musikkanälen geliefert wird. Dafür wird eine monatliche Abonnementgebühr fälig. Der dadurch zu erwartende Substitutionseffekt wird die Nachfrage nach körperlichen, d. h. herkömmlichen Tonträgern schrumpfen lassen. Im Bereich des Hörfunks wird nach Projektphasen an der Einführung eines Digital Audio Broadcast (DAB) gearbeitet, welches das bisherige UKW-Radio ersetzen soll. Hierfür sind aber neue Empfangsgeräte nötig. Daneben ist ein Pay-Audio installiert worden, das Musikprogramme über Kabel oder Satellit in das Hörfunknetz einspeist. Weitere Nutzungen von Musik werden unter den Begriffen Multimedia und netzgebundene Musikverwertung diskutiert und in Kapitel 5 ausführlich behandelt. Es lassen sich drei Elemente definieren, die zu einem Multimediaprodukt gehören: ${ }^{n}$

1. Die Digitaltechnik schafft die Möglichkeit, mehrere Medien (Foto, Graphik, Schrift, Ton, Sprache und Musik) in einen einheitlichen binären Datencode umzuwandeln.

2. Die Integration dieser Medien auf einer gemeinsamen Benutzerplattform (z. B. PC als common interface) wird auf dem Markt für Endgeräte zu Umwälzungen führen.

67 Vgl. Fessler, Hans-Ulrich, DCC: die digitale Compact Cassette, in: Stercoplay, Sept. 1992, S. 9 f.

68 Vgl. Paprotka, Reinhard, Paroli, in: Stereo, Nr. 8 (1992), S. 14 f.

69 Vgl. Phono-Press 1998, op. cit., S. 12.

$70 \mathrm{Vgl}$. Der Markt für CD, MC und LP, op. cit., S. 22.

7 Vgl. Der Markt für CD, MC und LP, op. cit., S. 26. 
3. Der Benutzer der Medien kann interaktiv eingreifen, indem er den Inhalt oder den Programmablauf beeinflußt.

Unterschieden werden kann zwischen On-line und Off-line Anwendungen. Off-line Anwendungen (ohne Netzanbindung) sind heute Realität durch CD-ROM (Read Only Memory) und CD-I (interaktiv). On-line Anwendungen werden durch Internet und Online-Dienste verwirklicht. Kapitel 5 behandelt die Musikprodukte, die mit dieser technischen Weiterentwicklung verbunden sind.

\subsection{Die ökonomische Bedeutung der Innovationen für die Musikverwertung mit Tonträgern}

Nachdem die historische Entwicklung der Tonträgerindustrie kurz skizziert worden ist, sollen nun die ökonomischen Implikationen behandelt werden, die aus den jeweiligen Innovationen resultieren. Dabei wird sowohl auf die Bedeutung des Innovationsprozesses mit den entsprechenden Preisentwicklungen (1.3.1) als auch auf die Verbreitung der Systeme, die Beziehungen der Tonträgerarten untereinander und die Wirkung komplementärer Güter (1.3.2) einzugehen sein. Abschließend soll die volkswirtschaftliche Bedeutung der Tonträgerindustrie und ihr Bezug zur gesamtwirtschafticher Entwicklung untersucht werden (1.3.3).

\subsubsection{Bedeutung des Innovationsprozesses}

Der Beginn der Aufzeichnung und Wiedergabe von Musik im 19. Jahrhundert fällt in die Zeit, in der die Industrialisierung bereits weite Teile Europas und Nordamerikas erfaßt hatte. Die technologischen Entwicklungen in der Musikindustrie, die die wirtschaftliche Verwertung von Musik mit Hilfe der Aufzeichnung und Wiedergabe betreibt, äußerten sich in den in Abschnitt 1.2 beschriebenen Innovationen. Zunächst schlugen sich die objektiv neuen Lösungen des technischen Problems der Aufzeichnung und Wiedergabe von Musik in Prototypen nieder. ${ }^{2}$ Solche Prototypen waren die ersten Phonographen und Grammophone. Mit deren Weiterentwicklung wurde eine ökonomische Nutzung von Phonographen und Grammophonen möglich. In der Geschichte der phonographischen Wirtschaft wechselten sich Prozeß- mit Produktinnovationen $a b .^{73}$ Als Prozeßinnovation können die Neuerungen des Gußverfahrens bei der Walze, die Weiterentwicklung der Preßtechnik im Matrizenverfahren und die Einführung des Mikrophons zur Aufnahme sowie die Stereophonie und Digitaltechnik verstanden werden. Produktinnovationen waren zunächst die Schellackplatte, dann ihre zweiseitige Bespielung, die Vinylplatte, die Langspielplatte, das Tonband, die Musikkassette, die tragbaren Abspielgeräte und schließlich die CD.

Die Kosten von Invention und Innovation werden im Tonträgermarkt erst in der Diffusionsphase von Prozeß- und Produktinnovationen gedeckt. Zur Amortisation bedarf es auch in

${ }^{72}$ Zur Bedeutung von Prototypen für die Innovation vgl. Elßer, Stefan, Innovationswettbewerb: Determinanten und Unternehmensverhalten, Frankfurt u.a. 1993, S. 7 f.

73 Eine Prozeßinnovation ist ein technisch-organisatorisch neues Produktionsverfahren; eine Produktinnovation bringt ein neues Gut (bzw. eine neue Dienstleistung) hervor. Vgl. Elßer. Stefan, op. cit., S. 8. 
dieser Industrie einer schnellen und weiten Verbreitung sowohl der Abspielgeräte als auch der Tonträger selbst. Die industrielle Fertigung von Phonographen und Grammophon ermöglichte die Ausbringung großer Stückzahlen. Mehrere Unternehmen adaptierten die Innovation. Daher ist es nicht verwunderlich, daß die Verbreitung von Phonographen und Grammophonen zügig vonstatten ging. Als eine attraktive Freizeitgestaltung erwies sich das Musikhören nicht nur in den Bürgerhäusem, sondern auch in Gaststätten und Tanzlokalen. Hinzu kam, daß die Schallplatte als Tonträger relativ preiswert zu erhalten war. Vor dem ersten Weltkrieg kostete die Schallplatte in Amerika deutlich weniger als einen Dollar. Dagegen war das Grammophon mit dem Elektroantrieb in der Anschaffung teuer. Wegen der technischen Überlegenheit des Grammophons stellten die neu entstandenen Fachhändler auf die Schellackplatten um. Damit waren die Schallplatten und das Grammophon zum technischen Standard geworden, der etabliert war und eine gewisse Resistenz gegenüber technischen Neuerungen darstellte. Dieser technische Standard verhinderte in der Folge die Innovationen hin zu einer Langspielplatte, ${ }^{74}$ welche dann einen Plattenspieler mit einer anderen Abspielgeschwindigkeit benötigte. Solche Geräte hatten schon damals eine Lebensdauer von zwei und mehr Dekaden. ${ }^{75}$ Schließlich wurden nach dem zweiten Weltkrieg Abspielgeräte auf den Markt gebracht, die drei Geschwindigkeitsoptionen zur Wahl boten: 33 1/3, 45 und 78 Umdrehungen pro Minute. Damit war die Kompatibilität der alten und der zwei neuen Plattentypen gewährleistet. Der einmal angeschaffte Bestand an Schellackplatten konnte weitergenutzt werden.

Bei der Produktion der Walzen konnte auch ein neues Gußverfahren, mit dem ab 1900 von derselben Aufnahme viele Walzen gegossen konnten, nichts an der Überlegenheit des Gramophonns ausrichten. Die Preßtechnik der Schallplattenproduktion konnte dagegen ständig verbessert werden. Die Schallplattenfabriken realisierten economies of scale in der Produktion bis zu einer Ausbringung von ca. 60.000 Stück derselben Tonaufnahme. Danach entstanden sprungfixe Kosten, da eine neue sog. Mutter ${ }^{76}$ als Voraussetzung für die Preßmatrize angefertigt werden mußte. Die sinkenden Stückkosten wurden allerdings nur zum Teil an die Konsumenten weitergegeben. Denn die Tonträgerfirmen entwickelten Marken, sog. Labels für ihre Schallplattenreihen, die einem bestimmten Preisniveau entsprachen. Dies war der Beginn der Preisdifferenzierung im Tonträgermarkt. Daraus folgte aber nicht unbedingt ein ständiger Anstieg der Gewinne. Vielmehr begannen die Musiker und Interpreten, zuerst Caruso, ihre Honorarforderungen zu erhöhen. Dann schlossen sie sich mit den Komponisten und Textdichtern

74 Aus der Etablierung eines technischen Standards erwachsen die Vorteile der increasing retum to adaption (IRTA). Sie entstehen Anbietern als auch Nachfragern dadurch, daß die mit der Etablierung einer Technologie verbundenen Kosten bereits investiert worden sind und nur noch Kosten der Erweiterung des Repertoires getragen werden müssen. Die neue Technologie muß deshalb so große Kosteneinsparungen in der Zukunft versprechen, daß es sich lohnt, die Umstellungskosten zu investieren. Vgl. Arthur, W. B., Competing Technologies, Increasing Returns, and Lock-in by Historical Events, in: Economic Journal, Vol. 99 (1989), S. $116 \mathrm{ff}$.

75 Zur Fortsetzung der Walzenlieferung von Edison bis 1929, obwohl schon scit 1913 keine neuen Stücke auf Walze mehr produziert wurden, vgl. Abschnitt 1.2.2

76 Zur Technik der Schallplattenproduktion mit Vater und Mutter vgl. Abschnitt 1.2.2. Die Mutter ist quasi die Originalvorlage für die „Söhne“, von denen dann die Platten gepreßt werden. 
in Vereinigungen zusammen, um Schutzrechte und Umsatzbeteiligungen geltend zu machen. ${ }^{n}$ Die Produktionskosten für die Tonträgerfirmen wurden teurer. Einen Teil ihrer Gewinne steckten die Tonträgerfirmen in die technische Innovation. So konnten Produktionskosten bei der Musikaufnahme durch die Erfindung des Magnettonbandes gesenkt werden. Auch für das aufkommende Radio erwies sich diese Erfindung als nützlich, denn es wurden Aufnahme und Wiedergabe zeitlich entkoppelt; ebenso konnten Fehler korrigiert werden, ohne daß das ganze Stück noch einmal gespielt werden mußte.

Nach dem zweiten Weltkrieg lief der Verkauf von Schallplatten und Abspielgeräten wieder an. In Europa vollzog sich dies, bedingt durch den Mangel am Rohstoff Schellack, erheblich langsamer als in den USA, wo 1947 schon wieder 400 Millionen Schallplatten und 3,4 Millionen Radio-Grammophon-Kombinationen verkauft wurden. ${ }^{78}$ In der deutschen Schallplattenindustrie wurde erst 1955 wieder das Niveau der Produktion von 1929 (30 Millionen Stück) ${ }^{79}$ erreicht. Begünstigt wurde der Aufschwung durch die anhaltend gute gesamtwirtschaftliche Lage, das Auftreten vieler kleinerer und mittlerer Schallplattenunternehmen auf dem Markt, einer Umschichtung innerhalb der Nachfrage zu jüngeren Käufern und das Auftreten von Discountläden, die Schallplatten zu günstigen Preisen verkauften. ${ }^{80}$ Für 1954 wurde der Wert der Schallplattenproduktion zu Marktpreisen in Deutschland mit 120 Millionen DM angegeben. ${ }^{81}$

Die nächste technische Neuerung etablierte neben der Schallplatte die Musikkassette als weitere Tonträgerkategorie. Musikkassetten waren ab 1965 erhältlich und boten eine Ergänzung der Tonträgernutzung. Das Umsatzvolumen wurde aufgrund dieser Neuerung ausgedehnt, sowohl durch die bespielten als auch unbespielten Kassetten. Kassettenrekorder wurden ab Mitte der 70er Jahre angeboten. Erstmals waren die Wiedergabegeräte tragbar (oder z. B. in einen PKW installierbar) und solche Rekorder waren im Vergleich zu den Plattenspielern preisgünstig. Sie setzten sich daher am Markt sehr schnell durch. Hinzu kam, daß mit Hilfe von Leerkassetten Musik von Radio oder Schallplatten kopierbar wurde. ${ }^{82}$ Dafür brauchte nur der geringere Preis für die Leerkassetten bezahlt zu werden und die Opportunitätskosten der Zeit für das Kopieren aufgewendet werden.

Der Einbruch im Marktvolumen der Tonträgerindustrie gegen Ende der 70er und zu Beginn der 80 er Jahre ${ }^{83}$ betraf nicht nur den deutschen Markt, sondern hatte weltweite Auswirkungen. ${ }^{84}$ Diese erste Umsatzkrise seit dem Ende des Zweiten Weltkriegs wurde durch die Einführung der digitalen Aufzeichnungs- und Wiedergabetechnik mit Hilfe der CD beendet. Diese

77 Als eine der ersten entstand in Frankreich die SACEM, eine Art Vorläufer der späteren Verwertungsgesellschaften. Vgl. hierzu Abschnitt 2.1.4.

78 Vgl. o. V., Record Sales in 1947, in: Fortune Magazine, o. Jg. (1951), S. $97 \mathrm{ff}$

79 Vgl. Zombik, Peter, Die Schallplatte: Kulturträger und Wirtschaftsfaktor, in: Media Perspektiven, o. Jg. (1987), S. 437 [Zombik 1987].

80 Vgl. Reichardt, Robert, op. cit., S. 109.

81 Vgl. Reichardt, Robert, op. cit., S. 109.

82 Vgl. Steinel, Rudolf, Zur Lage und Problematik der Musikwirtschaft, München 1992, S. 87.

83 Vgl. Mahlmann, Carl, Struktur des Deutschen Tontrăgermarktes, in: Handbuch der Musikwirtschaft, hrsg. von Moser, Rolf, und Andreas Scheuermann, 4. Aun., Starnberg 1997, S. 161-184 [Mahlmann 1997].

84 Vgl. Zombik 1987, op. cit., S. 439. 
Tonträgerkategorie führte nicht nur zu starken Umsatzsteigerungen, sondern entwickelte sich mit ca. 94\% Anteil (in 1997) am Gesamtabsatz zu dem meistgekauften Tonträger in Deutschland. Ergänzt wurde die Longplay-CD 1987 um die Maxi-Single mit einer Spielzeit von ca. 15 Minuten.

Die Preisentwicklung läßt sich an den international gültigen Preisklassen Fullprice, Midprice und Budget (Lowprice oder Niceprice) nachvollziehen. ${ }^{85}$ Inzwischen wird diese Einteilung auch in Deutschland verwendet; vor 1990 wurde hier nur zwischen Normalpreis und Niedrigpreis differenziert. ${ }^{86}$ Der deutsche Normalpreis entsprach dem Fullprice und die Kategorie Niedrigpreis umfasste die Klassen Midprice und Lowprice. Nach Mahlmann ${ }^{87}$ gelten folgende Werte als Grenzen zwischen den Preisklassen:

$\begin{array}{lll}\text { Fullprice: } & \text { CD } 30-40 \mathrm{DM} & \text { Vinyl/MC } 25-30 \mathrm{DM} \\ \text { Midprice: } & \text { CD } 20-25 \mathrm{DM} & \text { Vinyl/MC ca. } 15 \mathrm{DM} \\ \text { Lowprice: } & \text { CD ca. } 15 \mathrm{DM} & \text { Vinyl/MC ca. } 10 \mathrm{DM}\end{array}$

Der Absatz von LPs auf Vinyl hat keine große Bedeutung mehr. Bei einem Umsatzanteil unter $1 \%$ sind es vor allem Liebhaber, die Vinyl-LPs nachfragen. ${ }^{88}$ Auch bei den MCs ging die Nachfrage in allen Preisklassen seit 1991 zurück. ${ }^{89}$ Dies ist um so erstaunlicher, als die MC seit dem Ende der 70er Jahre ein Lowprice-Tonträger geworden ist. Die Tonträgerindustrie wollte mit dem niedrigen Preis für Musikkassetten die Substitution durch das Kopieren auf Leerkassetten reduzieren. Daher wurden verstärkt bespielte Kassetten zu einem Preis von 7 - 8 DM angeboten. ${ }^{90}$ Diese Strategie war zunächst erfolgreich. In den $80 \mathrm{er} \mathrm{Jahren} \mathrm{gelang} \mathrm{es,} \mathrm{durch} \mathrm{das}$ Angebot billiger bespielter Kassetten gewerbliches Kopieren auf Leerkassetten zu unterbinden, eine gesetzliche Leerkassetten- und Geräteabgabe im Urheberrecht zu etablieren und das Problem weitgehend auf private Kopieraktivität für den Freundeskreis zu beschränken. Der Nachfragerückgang der MC in den 90er Jahren resultiert aus dem großen Erfolg der CD. Dieser digitale Tonträger konnte - wie in der obigen Tabelle dargelegt - zu einem höheren Preis am Markt etabliert werden. Der Absatz der CD-Longplay-Tonträger ist seit deren Einführung in allen Preisstufen gestiegen. In den letzten Jahren wuchs der Absatz von Fullprice-CDs mit sinkenden, derjenige von Midprice-CDs mit steigenden und derjenige von Lowprice-CDs mit ungefähr konstanten Zuwachsraten. Im Verhältnis von $\mathrm{CD}$ zu MC traten nun zwei Effekte auf. Zum einen wurde die MC von den Nachfragern durch die um ca. 50\% teurere CD substituiert.

$85 \mathrm{Vgl}$. International Federation of Phonographic Industry (IFPI) (Hrsg.), The Recording Industry in Numbers 1994, London 1994.

86 Vgl. Bundesverband der Phonographischen Wirtschaft, Jahrbuch 1995, Starnberg 1995, S. 22. [BPW 1995]

87 Vgl. Mahlmann 1997, op. cit., S. 161-184.

$88 \mathrm{Vgl}$. BPW 1995, op. cit., S. 24. 1994 wurden beim Gesamtabsatz von 190 Millionen Longplay-Tonträgem nur noch ca. 700.000 Vinyl-LPs abgesetzt. In 1995 sank der Absatz auf 400.000 Stück. Bei dieser Stückzahl blieb es bis 1997. Quelle: Phono-Press 1998, op. cit., S. 3.

89 Vgl. Mahlmann 1997, op. cit., S. 90.

$90 \mathrm{Vgl}$. Diederichs, Frank, Budgetlinie und Special Products, in: Handbuch der Musikwirtschaf, hrsg. von Moser, Rolf, und Andreas Scheuermann, 4. Aufl., Starnberg 1997, S. 227-240; und Klose, Werner, und Horst Lietzberg, Budgetlinie, in: Handbuch der Musikwirtschaft, hrsg. von Moser, Rolf, und Andreas Scheuermann, 3. Aufl., Stamberg 1994, S. 128-135. 
Der damit verbundene Wertzuwachs der Tonträgenumsätze insgesamt war für die phonographische Wirtschaft mit Gewinnzuwächsen verbunden. Zum anderen unterliegen die CDs keinen oder nur sehr geringfügigen Abnutzungserscheinungen durch Gebrauch. Daher entstand ein Markt für den gewerblichen Verleih von $\mathrm{CDs}$. $\mathrm{Zu}$ einem vergleichsweise geringen Preis ${ }^{91}$ konnten Konsumenten die gewünschten CDs auswählen, ausleihen und anschließend kopieren. Der Nachfrageausfall, der dadurch entstand, betraf die bespielten MCs. Der Käufer konnte entweder die Original-CD (in digitaler Qualität) erwerben, oder aber er substituierte durch das billigere Ausleihen und private Kopieren. Dabei kann durch die DAT ${ }^{92}$ (Digital Audio Tape) auch die digitale Qualität der Aufnahme erhalten werden. Dieser zweite Effekt war für die Tonträgerindustrie mit erheblichen Verlusten ${ }^{93}$ verbunden. Daher versuchte die phonographische Industrie auf den nationalen deutschen Gesetzgeber und die Kommission der Europäischen Union im Rahmen von Anhörungen einzuwirken, um gesetzliche Änderungen zu erreichen. Nach der Richtlinie über das Vermiet- und Verleihrecht der EU ${ }^{94}$ wurde auch im nationalen Urheberrecht zum 1.7.1995 eine Änderung gültig, die das gewerbliche Verleihen von Tonträgern von der Erlaubnis der Urheber bzw. der Leistungsschutzrechtsinhaber abhängig macht. Das bedeutete das Ende des Marktes für den gewerblichen CD-Verleih; ${ }^{95}$ denn die Erlaubnis wird von den Tonträgerherstellern für nach dem 1.7.1995 hergestellte Tonträger regelmäßig verweigert.

Innerhalb der beschriebenen Preisstufen von Tonträgern haben sich die Umsatzanteile verlagert. Der Anteil des Fullprice-Segments ist in 1994 leicht gesunken und liegt jetzt bei 50,3\% aller abgesetzten Tonträger in Deutschland. Deshalb sinken auch die Gewinnmargen der Tonträgerunternehmungen, ${ }^{\text {\% }}$ die in dieser Preisstufe am größten sind. In den Bereich des FullpriceSegments fallen alle Neuveröffentlichungen. Sie erbringen ca. $70 \%$ des Gesamtumsatzes. Die allgemeine Preisentwicklung von Tonträgern läßt sich mit vier Trends umschreiben: In der ersten Phase von 1970 bis 1978 stiegen die Tonträgerpreise relativ zur allgemeinen Preisentwicklung. ${ }^{97}$ Die vorherrschende Tonträgerkategorie war die Vinyl-LP und ab Mitte der 70er Jahre kam die MC hinzu. Ab 1979 bis ca. 1985 wurden die Tonträger im Vergleich zu anderen Konsumgütern billiger. Die Preise von Vinyl-LP und MC sanken auch absolut. Ab 1985 stiegen die Tonträgerpreise wieder relativ zur allgemeinen Preisentwicklung. Die Einführung und der Markterfolg der teureren CD machten sich bemerkbar. Der letzte Trend seit Beginn der 90er Jahre ist wiederum dadurch gekennzeichnet, daß die Preise des vorherrschenden Tonträgers $\mathrm{CD}$ konstant bleiben und in einigen Bereichen fallen, während die Preisentwicklung des priva-

91 Der Preis schwankte zwischen einer und drei DM pro Kalendertag.

92 Zur DAT vgl. Abschnitt 1.2.6.

93 Genauere Angaben über die Höhe der dadurch entstandenen Verluste sind nicht möglich. Die Schătzungen der phonographischen Industrie erscheinen interessengeleitet und unsicher, zumal keine Angaben über die Vorgehensweise der Schätzungen gemacht werden.

94 Vgl. hierzu ausführlich Abschnitt 2.2.1.

95 Die Bibliotheken gelten nicht als Einrichtungen zu Erwerbszwecken und sind daher von der Erlaubnispflicht befreit.

96 Vgl. Gilbert, Rolf, und Andreas Scheuermann, Künstler-, Produzenten und Bandübernahmeverträge, in: Handbuch der Musikwirtschaf, hrsg. von Moser, Rolf, und Andreas Scheuermann, 4. Aufl., Starnberg 1997, S. 1018-1039.

97 Vgl. Steinel, Rudolf, op. cit., S. 93. 
ten Verbrauchs von 1990 bis 1997 jährliche Wachstumsraten zwischen 1,5 und $4,7 \%$ aufweist. ${ }^{98}$ Die Begründung hierfür liegt darin, daß die $\mathrm{CD}$ als Tonträgerkategorie inzwischen die Ausreifungsphase überwunden hat und damit Preiserosionen nach dem Marktphasenkonzept zu erwarten sind.9

\subsubsection{Verbreitung der Tonträgersysteme}

Voraussetzung für den Absatz jeglicher Tonträger ist die Existenz der entsprechenden Abspielgeräte in den privaten Haushalten. Die Kombination aus Abspielgerät (hardware) und der zugehörigen Tonträgerkategorie (software) wird als Tonträgerystem verstanden. In der Vergangenheit stießen technische Neuerungen nicht sofort auf die entsprechende Nachfrage, da die Verbraucher nicht bereit waren, die anfänglich teuren Abspielgeräte für die neuen Tonträgerkategorien zu kaufen. Dies bremste die Verbreitung der Systeme. Deswegen bestand die Strategie der Tonträgerhersteller im Verbund mit den Geräteherstellem ${ }^{100}$ darin, solche Geräte anzubieten, bei denen die neue neben der alten Technologie nutzbar wird ${ }^{101}$ Mitentscheidend für den Erfolg neuer Tonträger ist also die Markteinführung der Abspielgeräte. Sie wird gemessen durch die Saturation, d. h. der Anteil der Haushalte mit mindestens einem entsprechenden Abspielgerät an den gesamten Haushalten, bzw. die Penetration, d. h. die Anzahl der in hundert Haushalten vorhandenen Audiogeräte. ${ }^{102}$ Von 1984 bis 1996 sank die Saturation beim Plattenspieler von $65 \%$ auf 53\%. Die Penetration beim Plattenspieler sank sie von $90 \%$ auf $63 \%$. Diese Zahlen lassen den Schluß zu, daß der Produktlebenszyklus des Plattenspielers für VinylPlatten jeglicher Abspielgeschwindigkeit zu Ende geht. Schon die stark sinkenden Absatzzahlen der Vinyl-LP deuten in diese Richtung. Die endgültige Einstellung des Verkaufs der VinylLP, von vielen Händlern bereits vollzogen, ist daher nur eine Frage der Zeit; sie kann sich aber wie beim Ende der Produktion von Walzen noch um Jahre hinauszögern.

Bei den Kassettenrekordern ist die Lage anders, die Saturation stieg in demselben Zeitraum von $70 \%$ auf $80 \%$. Trotz sinkender Absatzzahlen der Musikkassetten steigt sowohl der Anteil der Haushalte mit einem Gerät als auch - besonders stark - die Zahl der in hundert Haushalten verfügbaren Geräte insgesamt. Die Penetration stieg je hundert Haushalten beim Kassettenrekorder von 220 auf 300 von 1984 bis 1994 und sank seither wieder auf 280 in 1997. Drei Gründe für diese auf den ersten Blick ungewöhnliche Entwicklung lassen sich anführen. Erstens sind Kassettenrekorder vergleichweise preisgünstig in guter Qualität erhältlich. Geräte niederer Qualität sind schon für unter 100 DM zu kaufen. Damit eignet sich der Kassettenrekorder wie kein anderes Abspielgerät als Zweitgerät neben einer kompletten Musikanlage oder zum Musikhören in anderen Räumen. Zweitens ist der Besitz eines Kassettenrekorders die

98 Vgl. Statistisches Bundesamt, Statistisches Jahrbuch 1997, Stuttgart 1997, und Deutsche Bundesbank, Monatsbericht April 1998, Frankfurt a. M. 1998.

99 Vgl. Heuss, Emst, Allgemeine Markttheorie, Tübingen und Zürich 1965, S. 85 ff.

${ }^{100}$ Zur vertikalen Integration in der Tontrágerindustrie und zu strategischen Vorteilen mit der Industrie der Gerătehersteller vgl. Abschnitt 4.2.2.5 und 4.3.2.4

$101 \mathrm{Vgl}$. die Einführung des Schallplattenspielers mit drei Geschwindigkeiten zum Abspielen alter Schellackplatten, neuer Singles und neuer Langspielplatten nach dem zweiten Weltkrieg.

102 Quelle aller Saturations- und Penetrationsdaten ist BPW 1997, op. cit., S. 46. 
Voraussetzung für das Kopieren der Aufnahmen von anderen Tonträgern auf Leerkassetten. Drittens schließlich sind Kassettenrekorder transportabel und damit vielfältig einsetzbar (im Auto, im Freien, als Walkman etc.). Diese Eigenschaften des Produktes sichern einen langen Lebenszyklus, bis Ersatzgeräte entwickelt und zu ähnlichen Konditionen auf dem Markt erhältlich sind. ${ }^{103}$

Die rasche Verbreitung der CD-Player wird durch obige Zahlen dokumentiert. Die Saturation stieg beim CD-Player von einem Prozent 1984 auf 61\% im Jahr 1996. Drei von fünf Haushalten verfügen 15 Jahre nach der Markteinführung über dieses Gerät. Dazu haben zwei Dinge beigetragen. Zum einen ist die technische Überlegenheit der digitalen Aufzeichnungs- und Wiedergabequalität so gro $B$, daß damit die digitale Technik zum Standard und Paradigma weitergehender Entwicklungen geworden ist. Zum anderen haben die Gerätehersteller aus der Einführung des Kassettenrekorders und der MC gelernt, daß preisgünstig kaufbare Abspielgeräte den Absatz der entsprechenden Tonträger fördern. Hinzu kommt, daß seit jenen Tagen die Verflechtung zwischen Geräte- und Tonträgerindustrie gewachsen ist. Das Preisverhältnis zwischen CD-Playern und CDs beträgt für die untere Qualitätsstufe von CD-Playern nur $1:(6-7)$. Dagegen spielen Zweitgeräte nur eine untergeordnete Rolle. Beim CD-Player stieg die Penetration von ein einem Prozent in 1984 auf 86\% 1996. Statistisch gesehen besitzen ca. ein Viertel der Haushalte einen zweiten CD-Player. Die Begründung hierfür liegt in der Tatsache, $\mathrm{da} ß$ die lösch- und wieder bespielbare CD-E den Marktdurchbruch noch nicht geschafft hat. Hinzu kommt natürlich, daß herkömmliche CD-Player für diese Funktionen nicht geeignet sind, die Verbraucher also neue CD-Player mit den gerade beschriebenen technischen Möglichkeiten kaufen müßten. Solche Geräte sind zwar erhältlich, das Ende des normalen CD-Players ist aber noch nicht vorhersagbar. Eine Verunsicherung des Konsumenten über den weiteren Verlauf der technischen Entwicklung wird erst dann beseitigt sein, wenn die Kombinationsmöglichkeiten digitaler Musikaufzeichnung und Wiedergabe gesichert sind und damit das PreisLeistungsverhältnis transparent ist. Trotz der schnellen technischen Entwicklung der Musikverwertung im On-Line-Bereich (siehe Abschnitt 1.2.6) ist ein Zeitpunkt dafür nicht absehbar.

Der ökonomische Erfolg komplementärer Güter hat positive Rückwirkungen auf den Absatz von Tonträgern. Diese Erkenntnis beeinflußt die Marketingstrategie der Tonträgerfirmen bereits seit langem. ${ }^{104}$ Ein Beispiel ist die gesamte Vermarktung von Filmmusik, die nur denkbar ist, wenn erstens der Film erfolgreich ist und zweitens die Musik einen partiell eigenständigen Charakter hat, so daß sie getrennt verkaufbar ist. Filmmusik hatte 1997 einen Anteil von ca. $1,7 \%$ an den Tonträgerumsätzen in Deutschland. ${ }^{105}$ Weitere komplementäre Güter sind mit Musik unterlegte Fernsehwerbung, mit Musik angereicherte Radio-Comedy-Shows, Musiksender im Fernsehen (M-TV, VIVA etc.), der Besuch von Konzertveranstaltungen usw. Dabei helfen Radio- und Musikfernsehen, den Bekanntheitsgrad von Interpreten und ihrer neuesten

\footnotetext{
${ }^{103}$ Die Abspielgerate für DAT-Kassetten sind vergleichsweise teuer und weit weniger verbreitet.

104 Die erste Anwendung der beschriebenen Strategie ist aus dem Beginn des Tonträgerhandels nach 1910 bekannt. Ein Tonträgerhăndler verschenkte beim Kauf von 20 oder mehr Schallplatten einen einfachen Schallplattenspieler, um die Nachfrage nach Schallplatten weiter anzuregen.

${ }^{105}$ Vgl. BPW 1997, op. cit., S. 13.
} 
Tonträger zu erhöhen. Ebenso steigern Konzerttourneen nach dem Einspielen z. B. einer neuen CD den Absatz derselben. Das Kalkül der Konzerttournee basiert demnach nicht nur auf der Erzielung von Erlösen aus dem Eintrittskartenverkauf, sondern gleichzeitig auf dem Werbeeffekt für den Tonträgerumsatz. Die Rolle dieser eigenständigen Komplementärgüter ist nicht zu unterschätzen. Die Determinanten der Nachfrage nach Tonträgern sind u. a. Medienakzeptanz und Öffentlichkeitspräsenz der Interpreten. Zu ihrer Steigerung haben die Komplementärgüter instrumentalen Charakter.

\subsubsection{Die volkswirtschaftiche Bedeutung der Tonträgerindustrie}

Die Tonträgerindustrie ist im weiteren Sinne zur Freizeitindustrie zu rechnen. Deren Zuwachsraten hängen in erster Linie von der Steigerung des privaten Verbrauchs ab. Der private Verbrauch ist von 1984 bis 1997 nominal von 1001 auf 2084 Mrd. DM gestiegen. Das entsprach einer nominalen Verdopplung und jährlichen realen Zuwächsen zwischen 1,5\% und 4,7 \%. Zugleich stieg das Bruttosozialprodukt nominal von 1763 Mrd. DM im Jahr 1984 auf 3612 Mrd. DM im Jahr 1997. ${ }^{106}$ Hieran hat die deutsche Vereinigung maßgeblichen Anteil. Der Umsatz mit Tonträgern stieg von 2,233 Mrd. DM 1984 auf 5,375 Mrd. DM 1997. ${ }^{107}$ Dabei war 1990 das Jahr mit der höchsten Steigerung der Absatzzahlen mit einer Zuwachsrate von real $14,7 \%$. In diesem Jahr fragten erstmals Konsumenten aus den neuen Bundesländern das Musikrepertoire der westlichen Tonträgerhersteller nach. Der Anteil des Tonträgerumsatzes am BSP stieg demnach von 1,26 Promille 1984 auf 1,48 Promille 1997, derjenige am privaten Verbrauch von 2,23 Promille 1983 auf 2,58 Promille 1997. ${ }^{108}$ Die Bedeutung der Tonträgerindustrie ist - an diesen Zahlen gemessen - volkswirtschaftlich etwas gestiegen.

Betrachtet man die Beschäftigten bei den Tonträgerherstellern und im Groß- und Einzelhandel, dann wird deutlich, daß die Umsatzsteigerung mit derselben Beschäftigtenzahl erwirtschaftet wurde. Waren 1980 ca. 13.000 Beschäftigte bei den Herstellern und 25.000 im Handel angestellt, so waren es 1996 ca. 13.200 bei den Herstellern und 23.000 im Handel. ${ }^{109}$ Für die Zukunft ist zu erwarten, daß bei den Tonträgerherstellern mittel- und langfristig Beschäftigung abgebaut wird. Hierfür verantwortlich sind die neuesten technischen Entwicklungen, die eine Herstellung der Tonträger im Handel nach den individuellen Kundenwünschen ermöglichen. Ferner werden die Marktanteile der unkörperlichen Musikverwertung über Datennetze und Musikfernsehprogramme auf Abruf (Music on demand) als pay per view zunehmen. Diese Angebote werden die entsprechende Nachfrage nach den körperlichen Tonträgern ersetzen und sie zunehmend verdrängen. Davon wird auch die Beschäftigung bei Tonträgerherstellern, Groß- und Einzelhandel nicht unberührt bleiben. Auch hier ist deshalb mittel- und langfristig mit einem Beschäftigungsrückgang zu rechnen. ${ }^{110}$

\footnotetext{
$106 \mathrm{Vgl}$. Statistisches Bundesamt und deutsche Bundesbank, Monatsbericht April 1998, Frankfurt a. M. 1998.

107 Vgl. Phono Press 1998, op. cit., S. 1 ff., und eigene Berechnungen.

108 Quelle: eigene Berechnungen nach Daten des Statistischen Bundesamtes.

$109 \mathrm{Vgl}$. BPW 1997, op. cit., S. 34

$110 \mathrm{Vgl}$. hierzu die in Abschnitt 1.2 .6 beschriebenen technischen Entwicklungen.
} 
Im volkswirtschaftlichen Kontext sind die genannten Entwicklungen in erster Linie abhängig von dem Freizeitverhalten, der Mediennutzung und der Akzeptanz bzgl. der Neuerungen in der Bevölkerung. So äußerten 1993 in einer Befragung des Zentralverbandes der Deutschen Werbewirtschaft $90 \%$ der Bundesbürger, daß ihre liebste Freizeitbeschäftigung das Musikhören sei. ${ }^{111}$ Weiterhin gaben $70 \%$ an, daß sie regelmäßig Radio hörten, $38 \%$ hörten Musik von Tonträgern regelmäßig, $13 \%$ gehen regelmäßig in die Disco und $4 \%$ bzw. $3 \%$ besuchen regelmäßig Oper, Theater, klassische und Rock-, Pop- und Jazzkonzerte. ${ }^{112}$ Dabei kommen die Bundesbürger nach einer 1992 von der Stiftung Lesen angefertigten Studie vom Montag bis Freitag auf durchschnittlich 30 Minuten, am Samstag und Sonntag auf durchschnittlich $46 \mathrm{Mi}$ nuten Hördauer von Tonträgern. ${ }^{113}$ Angesichts der Äußerung, daß Musikhören ihre liebste Freizeitbeschäftigung sei, und der durch die Arbeitszeitverkürzung steigenden Menge an Freizeit, werden unbeschadet der technischen Entwicklungen noch Wachstumspotentiale für die Musikverwertung bestehen. Nach Daten des GfK Panel Services gaben die Bundesbürger in 1992 ca. 20\% ihres Medienbudgets für Tonträger aus gegenüber nur 2\% für Audio - Leerkassetten. $^{114}$

Von besonderer Bedeutung ist die Tatsache, daß Tonträger superiore Güter sind. In jeder Einkommensklasse haben sich die Ausgaben für Tonträger mit der Erhöhung der Durchschnittseinkommen erhöht. ${ }^{115}$ Mit steigenden Gesamtausgaben der Haushalte erhöhten sich auch deren Ausgaben für Tonträger. Stagnierende Reallöhne und Haushaltseinkommen ließen die Nachfrage nach Tonträgern schrumpfen. Besondere Bedeutung verdient in diesem Zusammenhang das Käuferprofil der Tonträgernachfrager. ${ }^{116}$ Ein Anteil von 47,4\% der Bevölkerung der Bundesrepublik Deutschland kauften 1997 überhaupt keine Tonträger. Die sogenannten Intensivkäufer mit einem Nachfragevolumen von individuell mehr als 9 Tonträgern im Jahr sind 5,8\% der Bevölkerung und realisieren etwa $42,7 \%$ der gesamten Nachfrage ${ }^{117}$ Der Großteil der Intensivkäufer stammt aus der Altersgruppe der 14 - 29 jährigen. Dies ist im Zeitablauf in zweierlei Hinsicht ein Risikofaktor. Erstens unterliegen diese Nachfrager kurzfristig den Modetrends des Repertoires, d. h. sie fragen insbesondere Neuproduktionen nach, die dem aktuellen Modetrend der Musikstilrichtung entsprechen. Daher sind Innovationen i. S. von neuen Musikrichtungen und ein reichhaltiges Angebot in der jeweils bevorzugten Musikrichtung eine Voraussetzung für einen erfolgreichen Absatz der Tonträger. Zum zweiten schrumpft langfristig die betroffene Altersgruppe in der Zukunf. Der demographische Altersaufbau in der Bundesrepublik ist in Veränderung begriffen. ${ }^{118}$ Deswegen sinken die absoluten Zahlen der potentiellen Nachfrager dieser Altersgruppe. Die weitere Strategie zur Steigerung sowohl des Marktvolu-

III Vgl. BPW 1994, op. cit., S. 50.

112 Vgl. BPW 1994, op. cit., S. 51.

113 Vgl. BPW 1994, op. cit., S. 52.

114 Vgl. GRK Panel Services, in: BPW 1994, op. cit., S. 49

115 Vgl. Brodbeck, Karl-Heinz, und Marlies Hummel, Musikwirtschaft, Ifo - Studien zu Kultur und Wirtschaft Bd. 5, München 1991, S. 47.

${ }^{116} \mathrm{Vgl}$. hierzu ausführlicher die Grundlagen der Tonträgernachfrage in Abschnitt 4.2.4.

117 Vgl. Phono Press 1998, op. cit., S. 3.

${ }^{118}$ Nach Berechnungen des Ifo-Instituts für Wirtschaftsforschung wird die Zahl der Jugendlichen bis zum Jahr 2000 um 3\% zurückgehen. Vgl. hierzu Leibfritz, W., W. Niehaus und R. Parsche. Der Beitrag des Steuersystems zur Reform der Alterssicherung, Ifo-Studien zur Finanzpolitik Bd. 48, München 1990, Tabelle 1. 
mens als auch der volkswirtschaftlichen Bedeutung der Tonträgerindustrie kann daher nur darin bestehen, die Gruppe der Gelegenheitskäufer zu erweitern und ihre Kaufgewohnheiten für weitere Tonträgerkäufe positiv zu beeinflussen. Des weiteren wird das Repertoire des Angebots verstärkt auch auf andere Altersgruppen auszurichten sein.

Innerhalb der Freizeitindustrie und hier insbesondere der Musikindustrie nimmt die Tonträgerindustrie eine wichtige Rolle ein. Sie ist zwar von der Kontinuität der Umsatzzahlen her eine stabile Industrie, von ihr sind aber weder Beschäftigungsimpulse noch Wachstumseffekte als Spill-overs für benachbarte Industrien zu erwarten. Der weitere Wachstumspfad der Tonträgerindustrie wird ganz entscheidend von der Geschwindigkeit der technischen Innovation und vor allem Diffusion der online nachfragbaren Musikprodukte abhängen. Für die nähere Zukunft ist von einem weiteren Wachstum etwas oberhalb desjenigen des privaten Verbrauchs auszugehen.

\subsection{Zusammenfassung}

Die ökonomische Verwendung von Musik hat durch die Fixierung von Noten und die Verbreitung durch Konzerte nach dem 15. Jahrhundert größere Ausmaße angenommen. Gleichwohl war die Musik ohne Schallaufzeichnungsmöglichkeiten immer eine Dienstleistung, die direkt für die Nachfrage produziert wurde. Aufzeichnungs- und Wiedergabetechniken haben sich seit Edisons Erfindung des Phonographen über Berliners Grammophonen mit Schellackplatten zu Vinyl-Langspielplatten, Musikkassetten und Compakt Disks ständig weiterentwickelt. Dabei erfolgt der Ablauf der Musikverwertung mit Tonträgern durch die Musikkomposition, die Realisierung und erste Festlegung der Musik auf einem Mastertape, die Tonträgerproduktion und den Vertrieb an Handel oder direkt an die Konsumenten. Die beschriebenen Ablaufstufen sind Musikern, Textdichtern, Komponisten, Tonträgerherstellern und Tonträgerhändlern zugeordnet.

Die Tätigkeit des Tonträgerherstellers läßt sich daher beschreiben als Nachfrage nach Musikkomposition und -gestaltung zur Realisierung von Musik und Angebot von bespielten Tonträgern. Abspielgeräte sind die wichtigsten Komplementärgüter. In der Geschichte der Tonträgerindustrie hat sich bei allen Innovationen gezeigt, daß ein Markterfolg neuer Tonträgerarten nur bei ausreichend schneller Marktdurchdringung der entsprechenden Abspielgeräte möglich ist. Daher ist nicht verwunderlich, wenn die Beziehung zu den Geräteherstellern sehr eng ist und viele Unternehmen in diesen Bereich integriert sind. Weitere komplementäre Güter anbietende Unternehmen sind Musiksender (als Fernseh- und Radiosender), Konzertagenturen und die Musikpresse. Verflechtungen mit Tonträgerunternehmen sind vor allem im Medienbereich vorhanden. Die Auswirkungen der Medien auf den Tonträgerabsatz liegen sowohl in einer Steigerung des Bekanntheitsgrades der Tonträgerprodukte als auch in einer möglichen Substitution des Musikkaufs mit Tonträgern durch Musikhören in den Medien.

Nachdem Tonträger bereits zu Anfang dieses Jahrhunderts große Verbreitung erlangt hatten, führten Weltwirtschaftskrise und Weltkrieg zu deutlichen Umsatzrückgängen. Seither ist der 
Absatz von Tonträgern kontinuierlich gestiegen, lediglich eine Rezession gegen Ende der 70er Jahre und zu Beginn der 80er Jahre unterbrach den Wachstumstrend. Im Anschluß daran erfolgte die Etablierung der CD als Tonträgerkategorie, mit der inzwischen annähernd die gesamte körperliche Musikverwertung geschieht. Tonträger sind superiore Güter, deren weiterer Nachfrageverlauf von der Entwicklung des verfugbaren Haushaltseinkommens, des privaten Verbrauchs und der Altersstruktur abhängen.

Die Tonträgerindustrie hat sich aber nicht nur hinsichtlich der verwendeten Technik weiterentwickelt. Auch der Rechtsrahmen, bestehend aus dem Urheberrecht und verwandten Schutzrechten, wurde den Veränderungen angepaßt bzw. ist ständig einem Anpassungsdruck ausgesetzt. Für die auf dem Tonträgermarkt tätigen Akteure bildet der Rechtsrahmen gewissermaBen die „Spielregeln“, innerhalb deren sich ihr Handeln vollzieht. Deshalb werden im folgenden Kapitel das für den Tonträgermarkt relevante nationale, europäische und internationale Urheberrecht dargestellt, um in einem weiteren Schritt die ökonomischen Anreize, die von seinen Regelungen ausgehen, analysieren zu können. 
Jürgen Kulle - 978-3-631-75477-1

Downloaded from PubFactory at 01/11/2019 04:31:24AM

via free access 


\section{Kapitel 2 Vertragsökonomie (I): Rechtlicher Rahmen der körperlichen Musikverwertung mit Tonträgern}

Dieses Kapitel soll den rechtlichen Rahmen veranschaulichen, in dem sich die am Tonträgermarkt beteiligten Wirtschaftssubjekte bewegen. Beginnend mit einer juristischen und ökonomischen Begründung für Urheberrechtsschutz und verwandte Schutzrechte, werden zunächst die für Musik- und Tonträgerherstellung relevanten Bestimmungen des deutschen Urheberrechts und der verwandten Schutzrechte dargestellt (2.1). Erstens wird die Frage behandelt, wann der Werkbegriff für Musikstücke gilt und damit Urheberrechtsschutz eintritt. Zweitens werden die wichtigsten Rechte für den Musikschaffenden erläutert. Drittens wird auf die verwandten Schutzrechte für Tonträgerhersteller eingegangen ( $\S \S 76$ Abs. 2, 77, 85, 86 UrhG) und viertens die Wahrnehmung der Rechte durch die Verwertungsgesellschaften dargestellt ( $\S 1$ bis 18 WahrnG).

Anschließend wird auf die Harmonisierungsbemühungen der Europäischen Union einzugehen sein (2.2). Zunächst soll ein Rechtsvergleich der tonträgerrelevanten Bestimmungen erfolgen. In den Mitgliedsländern der EU bestehen sehr unterschiedliche Abgabenhöhen, die Wettbewerbsverzerrungen herbeiführen können. Dann sollen die im Grünbuch der Kommission enthaltenen Zielsetzungen beschrieben und deren Umsetzung anhand der Richtlinien dargestellt werden. Hier ist insbesondere auf Schutzumfang, -dauer und Abgabenhöhe auch bei den verwandten Schutzrechten einzugehen. Die Beschlußfassung der Kommission und die Rechtsprechung des EuGH werden im Hinblick auf die Gleichheit der Wettbewerbsvoraussetzungen der Marktteilnehmer im einheitlichen Binnenmarkt und im Hinblick auf das Spannungsverhältnis zwischen deutschem WahrnG und den Art. 30 und 36 des EGV analysiert.

Schließlich gilt es, die relevanten Bestimmungen des internationalen Urheberrechts aufzuzeigen (2.3). Es handelt sich hier um die reformierte Berner Übereinkunft in der Pariser Fassung, das Genfer Abkommen zum Schutz der Tonträgerhersteller, das Rom-Abkommen über geistiges Eigentum sowie das Welturheberrechtsabkommen (WUA). Die aktuelle Entwicklung soll nachvollzogen werden anhand des Abkommens über handelsbezogene Aspekte des geistigen Eigentums (TRIPS), welches im Rahmen des GATT ausgehandelt wurde. Die Weiterentwicklung des Rechts für die unkörperliche Musikverwertung erfolgt in Kapitel 5. Eine Zusammenfassung beschließt die Darstellung des rechtlichen Rahmens (2.4)

\subsection{Urheberrecht, verwandte Schutzrechte und Wahrnehmungsgesetz}

Musik ist alleine noch keine Ware, die im marktlichen Prozeß zu Tauschzwecken handelbar ist. Vielmehr entsteht erst durch die Kombination (eines Werkes) der Musik als Immaterialgut mit einem Informationsträger (dem Tonträger) ein Produkt, das am Markt verkauft wird. Umgekehrt wird wegen der Ablösbarkeit des geistigen Gutes Musik von seinem materiellen Träger und der Aufprägung auf einen anderen Träger ohne Identitätsveränderung das geistige Gut 
Musik selbst zum Gegenstand eines Rechtsgeschäfts. ${ }^{1}$ Ein Werk der Musik ist der Inhalt, der gegenüber dem Informationsträger des Werkes eine Selbständigkeit besitzt. Bei Musik ist regelmäßig die Individualität des Urhebers im Werk erkennbar. Die Komposition, Textdichtung und Festlegung der Musik wird als Rechtsbeziehung (sog. droit moral, Begriff des Urheberpersönlichkeitsrechts) anerkannt. ${ }^{2}$ Dem Urheberrecht obliegt demnach die Aufgabe, Urheber hinsichtlich ihrer Persönlichkeitsrechte zu schützen und ihnen die angemessene wirtschaftiche Beteiligung an der Verwertung ihrer Werke und Leistungen zu sichern, wie dies verfassungsrechtlich geboten ist. ${ }^{3}$ In $\S 1$ Urheberrechtsgesetz (UrhG) wird bestimmt, daß die Urheber für ihre Werke Schutz genießen. Damit wird einerseits der personenbezogene Zweck des Gesetzes deutlich, ${ }^{4}$ einem Urheber das subjektive Recht gegenüber jedermann zu gewähren. Andererseits schützt es die Interessen des Urhebers nur in Bezug auf sein Werk als bestimmtes Rechtsobjekt. $^{\text {s }}$ Die juristische Unterscheidung von Urheberinteressen in materielle (vermögensrechtliche) und ideelle (geistige Urheberpersönlichkeitsrechte) wird der Realität nicht gerecht, wenn man unterstellt, daß sowohl die wirtschaftliche Verwertung als auch Ehre und Ansehen für den Urheber eine Rolle spielen. ${ }^{6}$ Daher ist das Urheberrecht als einheitliches Recht anzusehen, wenn es auch in Verwertungsrecht, Urheberpersönlichkeitsrecht und sonstige Rechte gegliedert ist.

Die Hersteller von Tonträgern sind keine Urheber. Ihnen wird jedoch für ihre qualifizierte technische Leistung der Herstellung ein ausschließliches Schutzrecht zugebilligt, ${ }^{7}$ welches sich auf die Vervielfältigung und Verbreitung bezieht. In marktlichen Austauschbeziehungen fungiert der Preis als Instrument des Ausschlusses vom Konsum. Jeder Tonträger (sei es CD, MC, LP oder DAT) hat einen Preis, der vom Endverbraucher bezahlt werden muß (analog zum Kauf anderer privater Güter). Es stellt sich die daher Frage, warum es eines Rechts bedarf, das die handelbare Form von Musik schützt. Es ist jedem Konsumenten nach dem Kauf - sofern entsprechende Geräte verfügbar sind - technisch möglich, den Tonträger mit der Musik darauf zu kopieren und ihn privat im Freundeskreis oder gewerblich weiterzuvertreiben. Der Ausschluß vom Konsum funktioniert also nicht über den Kaufpreis des Tonträgers. Eine prinzipielle Rivalität im Konsum von Tonträgern existiert zwar, sie ist aber für die wirtschaftliche Verwertung nur dann gegeben, wenn tatsächlich Tonträger angeschafft werden. Die Rivalität ist aufgehoben, wenn Tonträger nur kopiert werden. Den Herstellern von Tonträgern, den ausübenden Musikern und Musikverlagen sowie auch den Urhebern selbst entsteht aus dieser Problematik wirtschafticher Schaden in Form von Umsatz- und damit Einkommenseinbußen. Daneben kann es auch zu Rückwirkungen auf den Umfang der auf Tonträgern veröffentlichten

I Vgl. Hubmann, Heinrich, und Manfred Rehbinder, Urheber- und Verlagsrecht, 7. Aufl., München 1991, S. 31. [Hubmann/Rehbinder].

2 Vgl. Hubmann/Rehbinder, op. cit., S. 32, 42 ff. und 146.

3 Vgl. Jörger, Thomas M., Das Plagiat in der Popularmusik, Baden-Baden 1992. S. 5.

4 Dieser Zweck legt eine Rechtsauslegung im Zweifel für den Urheber nahe. Vgl. Fromm, Friedrich Karl, und Wilhelm Nordemann, Urheberrecht: Kommentar, 7. Aufl, Stuttgart u. a. 1988, $§ 1$ Anm. 1. [Fromm/Nordemann].

5 Dies erfordert eine weitgefasste Werkdefinition, wie sie sich in der Anerkennung der sog. kJeinen Münze niederschlăgt. Hierzu vgl. Abschnitt 2.1.1.

6 Die Existenz von Gegenbeispielen berührt die sachlogische Rechtssystematik nicht.

7 Vgl. Fromm/Nordemann, op. cit., $§ \S 85,86$ Anm. 2. 
Musik kommen; d. h., daß weniger produziert wird. Hieran setzen die verwandten Schutzrechte im Urheberrecht an. Für die Umsetzung der ratio legis des Urheberrechts ergibt sich zuerst die Frage nach der Definition des schutzwürdigen Werkes, aus dem dann später die Leistungsschutzrechte abgeleitet werden.

\subsubsection{Voraussetzungen für urheberrechtlichen Schutz an Werken der Musik}

Es existiert kein spezielles Urheberrecht der Musik. Vielmehr sind Werke der Musik gemäß $§ 2$ Abs. $1 \mathrm{Nr}$. 2 Urheberrechtsgesetz (UrhG) als Kunstwerke geschützt. ${ }^{8} \S 2$ beinhaltet eine Aufzählung der Werke, bei denen den Urhebern gemäß der Generalklausel des § 1 UrhG Schutz gewährt wird. Das Werk ist ein unbestimmter Rechtsbegriff. ${ }^{9}$ Werke der Musik sind gemäß $§ 2$ Abs. 2 UrhG dann schützenswert, wenn es sich um eine persönliche geistige Schöpfung handelt. Auf Werke der Musik bezogen, liegt der geistige Gehalt gemäß dem Werkbegriff ${ }^{10}$ in der durch Hören erfaßbaren Tonfolge. Die Musik muß eine Form haben, die der Wahrnehmung durch menschliche Sinne zugänglich ist. ${ }^{11}$ Unter einer geistigen Schöpfung ist aber nicht nur die Kreation von objektiv Neuem zu verstehen, sondern auch die Neukombination bereits bekannter Elemente untereinander oder mit neuen Elementen. Entscheidend ist, daß sich das neue Werk durch Form oder Inhalt von bisherigen Werken unterscheidet. ${ }^{12}$ Es ist herrschende Rechtsmeinung, daß bei einem Musikstück diese Voraussetzung in der Regel gegeben ist. ${ }^{13}$

Der Werkbegriff beinhaltet weiterhin, daß die Schöpfung persönlicher Natur ist, $d . h$. von der Persönlichkeit des Urhebers geprägt sein muß und von Individualität zeugt. Jede musikalische Gedankenäußerung, sei es ein noch so primitiver Schlager, zeugt von der individuellen persönlichen Prägung des Urhebers, wenn festzustellen ist, daß die spezielle Behandlung durch andere möglicherweise anders geschehen wäre. Im Urheberrecht sind daher alle Werke, die diesen Kriterien genügen, durch die sog. Kleine Münze geschützt. ${ }^{14}$ Darunter versteht man Werke von geringem schöpferischem Wert, die aber nach ihrer künstlerischen Gestaltungshöhe gerade noch schutzfähig sind. Solange die Entstehung von Musik vom Willen des Komponisten abhängt, haben auch solche Musikstücke Werkcharakter i. S. des Urheberrechts, die mit technischen Geräten jeder Art entstehen. ${ }^{15}$ Rein durch Maschinen erzeugte (aleatorische) Musik ist keine persönliche Schöpfung und damit kein Werk. Auch der Text eines Musikstückes kann ein eigenständiges Werk sein und ist nicht nur in Verbindung mit der Tonfolge als Werk anzusehen. Voraussetzung für die Schutzwürdigkeit nach $\S 2$ Abs. $1 \mathrm{Nr} .1$ ist aber, daß dem individuellen Geist Ausdruck verliehen wird. ${ }^{16}$ Die Möglichkeit dazu kann im Inhalt, der inneren

\footnotetext{
8 Vgl. Movsessian, Vera, und Fedor Seifert, Einführung in das Urheberrecht der Musik, 3. Aufl., Wilhelmshaven 1995, S. 25.

9 Vgl. Jörger, Thomas M., op. cit., S. 37.

10 Vgl. Schricker, Gerhard, Urheberrecht: Kommentar, München 1987, S. 93.

Vgl. Schricker, Gerhard, op. cit, S. 94.

Vgl. Fromm/Nordemann, op. cit., § 2 Anm. 4.

13 Vgl. Movsessian, V., und F. Seifert, op. cit., S. 28.

$14 \mathrm{Vgl}$. Fromm/Nordemann, op. cit., § 2 Anm. 19.

is Vgl. Fromm/Nordemann, op. cit., $\$ 2$ Anm. 46.

$16 \mathrm{Vgl}$. Hubmann/Rehbinder, op. cit., S. 87.
} 
oder äußeren Form liegen. ${ }^{17}$ Im Zuge der technischen Entwicklung des Elektronik- und Computereinsatzes zur Klangerzeugung und Wiedergabe sowie des Sound-Sampling ${ }^{18}$ erscheint es fraglich, ob eine individuelle Eigenständigkeit i. S. des Werkbegriffs noch operationalisierbar ist bzw. ob Plagiate den urheberrechtlichen Werkbegriff obsolet machen. ${ }^{19}$

\subsubsection{Rechte der Werkinhaber}

Unter Musikurhebern versteht man die Komponisten und Textdichter, ggfs. in einer Person vereint. ${ }^{20}$ Nach $\S 11$ UrhG schützt „das Urheberrecht den Urheber in seinen geistigen und persönlichen Rechten zum Werk und in der Nutzung des Werkes“. Die Rechte des Urhebers unterteilen sich in das Urheberpersönlichkeitsrecht ( $\S 12$ - 14 UrhG) als Immaterialgutschutz, die materiellen Verwertungsrechte ( $\S 15$ - 24 UrhG) und die sonstigen Rechte ( $\S 25$ - 27 UrhG). ${ }^{21}$ Das Urheberpersönlichkeitsrecht hat einen Ausschließlichkeitscharakter. ${ }^{22}$ Es gibt dem Urheber die Befugnis zu entscheiden, ob, wann und in welcher Form sein Werk veröffentlicht werden soll ( $§ 12$ UrhG). Ferner kann er von jedem, der sein Werk mit seiner Erlaubnis an die Öffentlichkeit bringt, verlangen, daß er als Urheber genannt wird, und bestimmen, welche Bezeichnung zu verwenden ist ( $\$ 13$ UrhG). Gegen Entstellung seines Werkes schützt den Urheber $\S 14$ UrhG.

Die materiellen Interessen des Urhebers schützen die Verwertungsrechte, die in die Verwertung in körperlicher ( $§ 15$ Abs. 1) und unkörperlicher ( $(15$ Abs. 2) Art zu unterteilen sind. Zu den körperlichen Verwertungsrechten zählen das Vervielfältigungsrecht (§ 16), das Verbreitungsrecht $(\S 17)$ und das Ausstellungsrecht $(\S 18)$. Eine Vervielfältigung ist die Herstellung einer oder mehrerer Festlegungen, die geeignet sind, das Werk den menschlichen Sinnen auf irgendeine Weise wiederholt unmittelbar oder mittelbar wahrnehmbar zu machen, ${ }^{23} \mathbf{z}$. B. durch Tonträger. Das Vervielfältigungsrecht besteht unabhängig von dem Vervielfältigungsverfahren und der Vervielfältigungsstückzahl. Zur Wahrnehmung des Rechts zur Herstellung von Tonträgern überträgt der Urheber im allgemeinen das Nutzungsrecht zur mechanischen Vervielfältigung an eine Verwertungsgesellschaft, z. B. die GEMA. Für den Tonträgermarkt kontrahiert

17 Musikrelevante Beispiele für den Inhalt sind erfundene Fabeln oder Verse, für die innere Form Strophentext und Refrain und für die ăußere Form die gewăhlte Ausdrucksweise.

18 Hienunter wird die Umsetzung und Speicherung von Schallereignissen in binäre Zahlenwerte mittels Ana$\log / \mathrm{Digital}-W a n d l e r n$ verstanden. Sampler ermöglichen es, joden gespeicherten Klang in verschiedenen Tonlagen abzurufen, zu manipulieren und über Disketten zu archivieren. Vgl. Jörger, Thomas M., op. cit., S. 106.

19 Mehrere Autoren versuchen dem mit einem ganzen Katalog von Anforderungen zu begegnen. Vgl. statt aller Jörger, Thomas M., op. cit., S. 47 ff., der als Anforderungskriterien prüft: Offensichtliches Überwiegen der geistig-ästhetischen Wirkung, erster Eindruck, Erstmaligkeit, Andersartigkeit, Zweckbedingtheit, Verbrauch, Stil, Geschmacksrichtung, Scltenheit, Gestaltungswille etc.

$20 \mathrm{Vgl}$. Fromm/Nordemann, op. cit., § 2 Anm. 1.

21 Vgl. Hummel, Marlies, Die Volkswirtschafliche Bedeutung des Urheberrechts (Gutachten im Auftrag des Bundesministers der Justiz), Schriftenreihe des IFO-Instituts für Wirtschaftsforschnung Nr. 125, Berlin u.a. 1989, S. $31 \mathrm{f}$.

22 Vgl. Eisenmann, Hartmut, GrundriB Gewerblicher Rechtsschutz. und Urheberrecht, 3.Aufl., Heidelberg 1995, S. 27.

$23 \mathrm{Vgl}$. Fromm/Nordemann, op. cit., §16 Anm. 1 
die GEMA wiederum mit dem Tonträgerhersteller. ${ }^{24}$ Das Verbreitungsrecht besteht darin, Original oder Vervielfältigungsstück des Werkes in Verkehr bringen bzw. der Öffentlichkeit anbieten zu dürfen. Nach $\S 17$ Abs. 2 ist den materiellen Interessen des Urhebers Rechnung getragen, wenn das Werk mit seiner Zustimmung veräußert (verkauft, verschenkt oder getauscht) wurde. Das Verbreitungsrecht des Urhebers ist dann erschöpft. ${ }^{25}$ Die Rechtsprechung ist insbesondere bei der Erschöpfung des Verbreitungsrechts von Tonträgern nicht einheitlich, zumal es zeitlich, räumlich oder gegenständlich (d. h. auf Absatzkanäle) beschränkt werden kann. Das Ausstellungsrecht des $\S 18$ hat für die Verwertung von Musik keine Bedeutung.

Von den Regelungen der nichtkörperlichen Verwertung sind für Werke der Musik das Aufführungsrecht ( $(19$ Abs. 2), das Senderecht ( $(20)$, das Recht der Wiedergabe durch Bild- und Tonträger ( $(21)$ und das Recht der Wiedergabe von Funksendungen $(\S 22)$ relevant.

Das Aufführungsrecht gemäß $\S 19$ Abs. 2 bezieht sich auf die konzertante persönliche und öffentliche Darbietung. Hierbei muß es sich nicht um Aufführungen des Urhebers handeln, vielmehr bedeutet persönlich nur die unmittelbare Livedarbietung und nicht die Wiedergabe eines Werkes mittels Tonträgern. In der Praxis wird unterschieden, ob ein Musikwerk Hauptbestandteil oder integrierter Bestandteil einer Aufführung oder Sendung ist oder auf Tonträger aufgenommen wird (sog. großes Recht) oder ob die Musik bloß zur Untermalung bzw. Begleitung der Bühnendarstellung eines Sprachwerkes benutzt wird (sog. kleines Recht) ${ }^{26}$ Während die kleinen Rechte für gewöhnlich von einer Verwertungsgesellschaft (hier GEMA) wahrgenommen werden, ${ }^{27}$ bleibt das große Recht einer individuellen Vergabeentscheidung des Urhebers überlassen. Ebenso zum Aufführungsrecht gehört nach $\S 19$ Abs. 3 die Übertragung durch Bildschirm und/oder Lautsprecher außerhalb des Raumes, in dem die persönliche Darbietung stattfindet. $^{28}$

Ein weiteres unkörperliches Verwertungsrecht ist das Senderecht gemäß $\S 20$. Es bezeichnet das Recht, das Musikwerk durch Hörfunk, Fernsehen oder ähnliche technische Einrichtungen der Öffentlichkeit zugänglich zu machen. Im Zusammenhang mit der Nutzung neuer Übertragungstechniken und Übertragungswege ergeben sich Rechtsfragen bzgl. des Senderechts. Beispielsweise entschied der BGH, daß die Weitersendung von Hörfunk in Abschattungsgebieten mittels Gemeinschaftsantennen mit Kabel-Weitergabe keine neue Werkverwertung darstellt. ${ }^{29}$ Demgegenüber scheint gesichert, daß bei Einspeisung von Programmen in ein Kabelnetz oder Verbreitung über Satellit in jedem Fall das Senderecht gem. $§ 20$ einzuholen ist. ${ }^{30}$ Dies gilt insbesondere für Musiksendungen, die ausschließlich über Kabel bzw. Satellit zu empfangen sind. Das Recht, Werkaufführungen mittels Bild- oder Tonträger öffentlich wahrnehmbar zu

\footnotetext{
24 Vgl. Fromm/Nordemann, op. cit., $\$ 16$ Anm. 3, und die Ausführungen in Abschnitt 2.1.3 und 2.1.4.

Vgl. Eisenmann, Hartmut, op. cit., S. 30.

$26 \mathrm{Vgl}$. Fromm/Nordemann, op. cit., $\$ 19$ Abs. 2 Anm. 3.

27 Zur genaueren Erläuterung des Rechtsrahmens für Verwertungsgesellschaften vgl. Abschnitt 2.1.4.

$28 \mathrm{Vgl}$. Hubmann/Rehbinder, op. cit., S. 139.

29 Vgl. Kabelfernsehen in Abschattungsgebieten, in: Entscheidungen des BGH in Zivilsachen (BGHZ), Bd. 79, S. 350-362.

$30 \mathrm{Vgl}$. Fromm/Nordemann, op. cit., § 20 Anm. 2 - 5
} 
machen ( $(21)$, betrifft sowohl öffentliches Abspielen von Tonträgern in Kaufhäusern, Gaststätten und Tonträgerhandel als auch Musikvideowiedergabe in Kinos und Musikcafes. Im Vergleich zur Erstverwertung der Musik durch Tonträgerverkauf kann das öffentliche Abspielen als ein Zweitverwertungsrecht bezeichnet werden, zu dem der Urheber die Rechte in der Regel den Verwertungsgesellschaften zur Wahrnehmung überläßt. Schließlich umfaßt die nichtkörperliche Verwertung noch das Recht der Wiedergabe von Funksendungen gemäß $\S 22$. Werden Funksendungen aufgezeichnet und öffentlich wiedergegeben, so ist die Erlaubnis des Urhebers, d. h. wie bei $\S 21$ mittels der Einwilligung der Verwertungsgesellschaft nötig. Beispiele sind Musikfilm und Musiksendungen im Radio.

Bearbeitungen von Werken der Musik im Sinne von Änderungen gleich welchen Ranges bedürfen vor der Veröffentlichung oder Verwertung der Einwilligung des Urhebers. Für Musikwerke gilt im Hinblick auf die freie Benutzung die besondere Regelung des $\S 24$ Abs. 2, nach der schon dann keine freie Benutzung i. S. des $\S 24$ Abs. 1 mehr vorliegt, wenn die Melodie des benutzten Werkes in dem neuen Werk erkennbar ist. Dies kann juristisch dahingehend gewertet werden, daß eine freie Benutzung von Werken der Musik ausgeschlossen ist. ${ }^{31}$ Fraglich erscheint die Durchsetzungsmöglichkeit des Verbots freier Musikbenutzung. Die ständig steigende Zahl von Kompositionen läßt den finanziellen Aufwand zur Kontrolle von Urheberrechtsverletzungen stark erhöhen. Die Grenzkosten der Urheberrechtskontrolle dürfen aus Sicht des Rechtsinhabers nicht die Grenzerlöse aus der Rechtsdurchsetzung übersteigen. Das allgemeine Verwertungsrecht wird durch die Aufzählung in $\S 15$ nicht erschöpft. Vielmehr unterliegen auch neu zu erfindende Verwertungsformen und -arten und sämtliche Verwertungsstufen dem Gesamtverwertungsrecht des Urhebers. Insbesondere bei einer Weiterentwicklung des Tonträgermarktes zum Online-Angebot (vgl. Kap. 5) ist die Zustimmung der Urheber erforderlich. Das Urheberrecht endet gem. $\S 64$ Abs. 1 in Verbindung mit $\S 69$ mit Ablauf des siebzigsten Jahres nach dem Tode des Urhebers (post mortem auctoris, p. m. a.). Die folgende Abbildung gibt einen Überblick über die Rechte des Urhebers.

31 So jedenfalls Fromm/Nordemann, op. cit., § 24 Anm. 12 - 17, die berechtigterweise auf die Beschränkung der Freiheit kompositorischen Schaffens im Bereich der ernsten Musik verweisen. Die Schutzfunktion gegenüber Plagiaten im Bereich der Unterhaltungsmusik dürfte sehr gering sein angesichts der Tatsache, daß es nur eine begrenzte Anzahl von Melodien geben kann, der eine jährlich um einige tausend Stück wachsende Zahl an Liedern gegenübersteht. Vgl. Jörger, Thomas M., op. cit., S. 46 und 77, der auf eine Berechnung von Hanser-Strecker aus dem Jahr 1968 verweist, nach der es nur 4050 verschiedene Schlagermelodien geben kann. 


\section{Abb. 3: Überblick über die Einzelbefugnisse des Urhebers}

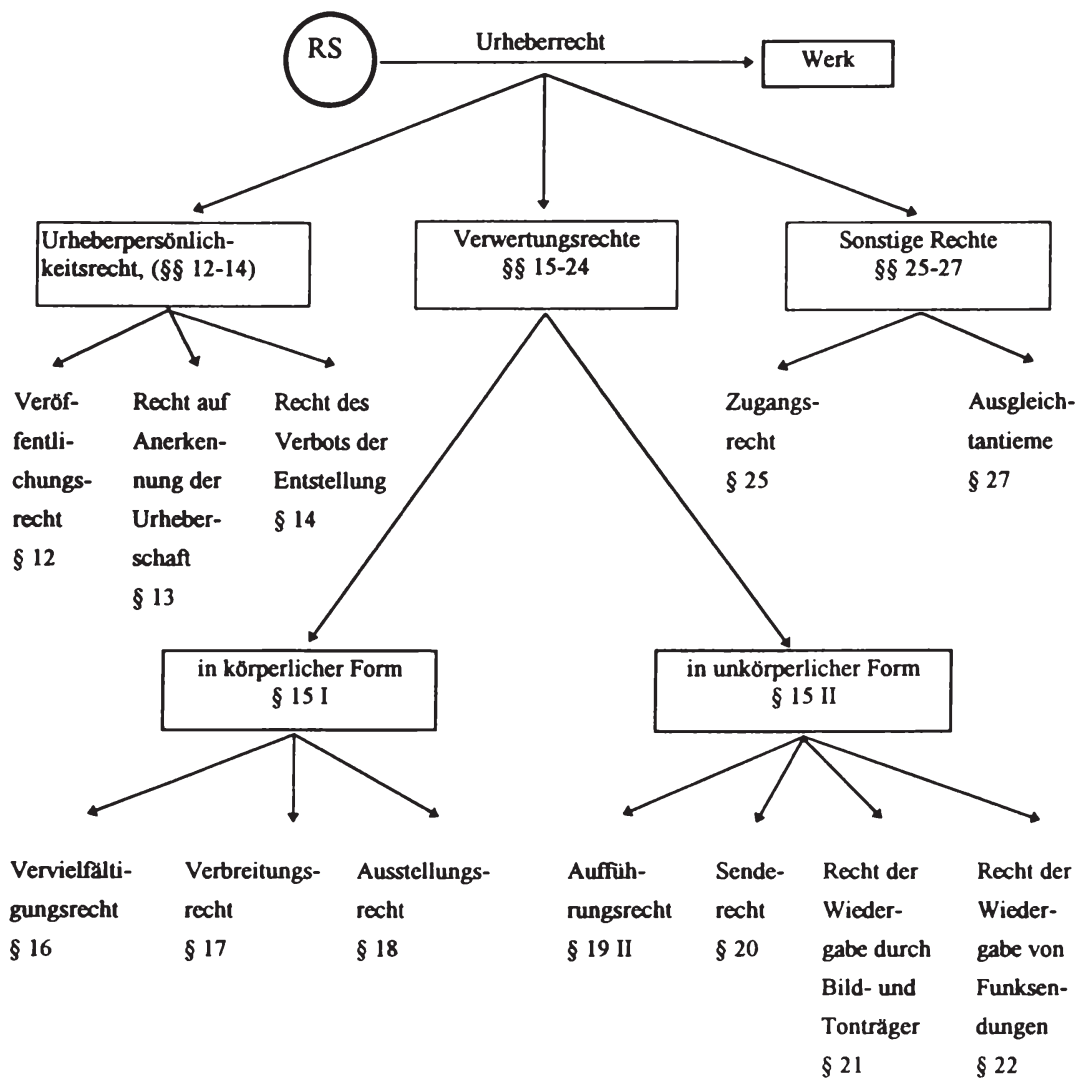

Quelle: In Anlehnung an Eisenmann, Hartmut, op. cit., S. 34. 
Die Hersteller von Tonträgern sind keine Urheber. Ihre Leistung basiert auf der Musikurheberschaft und läßt sich in mehrere Phasen unterteilen. ${ }^{32}$ Zunächst stellt der Tonträgerhersteller die Verbindung zwischen Arrangeur, Dirigent, Musiker und Sänger her, die das Werk furr die Aufzeichnung einspielen sollen. Damit beginnen Kapitaleinsatz und Risiko. Die eigentliche Tonaufnahme im Studio folgt. Sie kann beschrieben werden als eine kreative Team-Anstrengung von Komponist, Dirigent, Musiker, Sänger und Tontechniker, die die werkschöpferische Arbeit mit der möglichen technischen Perfektion verbindet. Bei Werken der Unterhaltungsmusik kommen den technischen Hilfsmitteln zur Verstärkung, Verfremdung und Ergänzung der Instrumente und der menschlichen Stimme besondere Bedeutung $\mathrm{zu}^{33}$ die Anforderung an den Tontechniker steigt. Ist die Tonaufnahme erfolgt, wird sie abgemischt, d. h. ihre Bestandteile werden so miteinander vereinigt, daß der gewünschte synchrone Musikablauf entsteht. Hierbei handelt es sich um eine künstlerische Einflußnahme durch den Tonträgerhersteller bzw. Tontechniker. ${ }^{34}$ Hat man so das sog. Mastertape hergestellt, beginnt die industrielle Fertigung der Vervielfältigungsstücke.

Die Tonträgerhersteller bekommen wegen ihrer qualifizierten technischen Leistung, die auch künstlerische Fertigkeiten verlangt, im Rahmen der sog. verwandten Schutzrechte (Leistungsschutzrechte) den Schutz des Urheberrechtsgesetzes. Dieser bemißt sich nach den $\S \S 85$ und 86 UrhG. $\S 85$ Abs. 1 billigt dem Tonträgerhersteller ein ausschließliches Schutzrecht $\mathrm{zu}, \mathrm{da}$ auf Vervielfältigung und Verbreitung des Tonträgers beschränkt ist. Dabei gilt, $\mathrm{da} \beta$ die erste Festlegung der Musik auf einem Trägermedium das Recht begründet ${ }^{35}$ und nicht die Vervielfältigung bereits produzierter Tonträger. Auch die Neuaufnahme zur qualitativen Verbesserung (etwa von der analogen zur digitalen Wiedergabe) ist keine Herstellung i. S. des $\S 85$ Abs. 1 Satz 3. Rechtsinhaber ist diejenige juristische oder natürliche Person, die die organisatorische Leitung und wirtschaftliche Verantwortung für die erste Festlegung trägt, also der Tonträgerunternehmer und nicht seine Angestellten. Die Erschöpfung des Verbreitungsrechts ist analog zu $\S 17$ Abs. 2 geregelt. Tonträger, die mit Erlaubnis des Rechtsinhabers durch Veräußerung in Verkehr gebracht werden, erschöpfen das Verbreitungsrecht. Nur bei rechtswidrig hergestellten Tonträgern ist eine Erschöpfung ausgeschlossen. ${ }^{36}$ Die Rechtssprechung bzgl. der Weiterverbreitung von Tonträgern außerhalb eines beschränkt eingeräumten Verbreitungs-

32 Vgl. Franz, Eckhard, Der Werkbegriff der Berner Übereinkunft zum Schuty. von Werken der Literatur und Kunst: Zugleich ein Beitrag zum Problem der Werkqualitat von Tonträgern, Baden-Baden 1993, S. 93. Vgl. auch Abschnitt 4.2.2.5.

33 Vgl. Nick, Wolfgang, Musikdiebstahl, Hamburg 1979, S. 15 ff.

34 Vgl. Davies, Gillian, und Hans Hugo von Rauscher auf Weeg, Das Recht der Hersteller von Tonträgern, Baden-Baden 1993, S. 24. Thomas M. Jörger diskutiert daher die Einräumung eines Leistungsschutzrechts für das Ergebnis der Tátigkeit des Tonmeisters. Vgl. Jörger, Thomas M., op. cit., S. $123 \mathrm{fr}$.

35 Der juristische Begriff des Tonträgers bezeichnet die erste Festlegung von musikalischen Informationen, sei es mechanischer, elektromagnetischer oder digitaler Art, die einen Wiederabruf gestattet. Auf den Gebrauchszweck kommt es nicht an. Demgegenüber beschränken wir uns in der industriebkonomischen Analyse auf den handclbaren Tonträger zu Konsumzwecken. Vgl. Stcinel, Roland, Zur Lage und Problematik der Musikwirtschaft, München 1992, S. 104 f.

$36 \mathrm{Vgl}$. Fromm/Nordemann, op. cit., $\$ \S 85 / 86$ Anm. 2. 
rechts ist uneinheitlich. Hier bestehen unterschiedliche Auffassungen zur Erschöpfungslehre und ein Spannungsverhältnis zwischen deutschem und europäischen Recht. ${ }^{37}$ Das Vervielfältigungs- und Verbreitungsrecht besteht am Tonträger, unabhängig davon, ob Werke der Musik i. S. von $\S 2$ Abs. 1 Nr. 2 auf ihm festgehalten sind oder schlicht Geräusche. Nach $\S 86$ steht dem Tonträgerhersteller ein Vergütungsanspruch zu, wenn die Tonträgeraufnahme öffentlich wiedergegeben wird. Dieser Anspruch entsteht aber nur, wenn drei Bedingungen erfüllt sind: Erstens muß die Tonträgeraufnahme von einem ausübenden Künstler bewirkt sein; zweitens muß der Tonträger erschienen sein; ${ }^{38}$ drittens schließlich muß die Aufnahme ein Werk i. S. des $\S 2$ Abs. 1 Nr. 2 sein. Der darauf begründete Vergütungsanspruch richtet sich gegen den ausübenden Künstler. Dieser erhält nach $\S \S 76$ Abs. 2 und 77 eine angemessene Vergütung für die Funksendung bereits auf Tonträgern erschienener Darbietungen bzw. die öffentliche Darbietung durch Tonträger. Wahrgenommen wird der Anspruch sowohl des ausübenden Künstlers als auch des Tonträgerherstellers durch die Verwertungsgesellschaft GVL. ${ }^{39}$ Die Rechte des Tonträgerherstellers enden 50 Jahre nach Erscheinen des Tonträgers bzw. bei Nichtveröffentlichung innerhalb dieser Frist 50 Jahre nach Herstellung. ${ }^{40}$

Einschränkungen erfahren die o. g. Rechte gem. §85 Abs. 3 (wie auch die originären Urheberrechte) durch dreierlei Bestimmungen: Nach $§ 45 \mathrm{ff}$. UrhG sind für Zwecke des Schul- und Unterrichtsgebrauchs, der Berichterstattung in den Medien, für Zwecke der öffentlichen Sicherheit und Rechtspflege und bei der privaten Vervielfältigung Einschränkungen des Urheberrechtes dahingehend erfolgt, daß ein Ausschluß der Nutzung in den o. g. Fällen nicht möglich ist. Dafür stehen dem Tonträgerhersteller Vergütungsansprüche aus $\S 47$ Abs. 2 im Falle von Schulfunkmitschnitten und aus $\S 54$ Abs. 1 in Verbindung mit $\S 54$ Abs. 6 bei Vervielfältigung zum privaten Gebrauch zu. ${ }^{41}$ Die Vergütung wird wegen der Unmöglichkeit, gegenüber jedem privaten Tonträgerkopierenden den Anspruch sowohl der Urheber als auch der Schutzberechtigten zu realisieren, den Leerkassetten- und Geräteherstellern von zur Vervielfältigung geeigneten Geräten auferlegt. ${ }^{42}$ Diese wiederum können die Abgabe über den Gerätepreis auf die Käufer überwälzen. Da die Vergütungsansprüche nach $\S 54$ Abs. 6 nur von einer Verwertungsgesellschaft geltend gemacht werden können, wurde die Zentralstelle für private Überspielungsrechte (ZPÜ) als Inkassostelle der beteiligten Verwertungsgesellschaften geschaffen. ${ }^{43}$ Dies führt zum Recht der Verwertungsgesellschaften.

37 Hat ein Musiker beispielsweise bestimmt, daß seine Musik auf Tontrăgern nur in Deutschland verkauft werden soll, hat er jedoch keine urheberrechtliche Moglichkeit zu verhindern, daß ein Hăndler Ware von dem Tontrăgerhersteller aufkauft und in anderen Mitgliedstaaten der EU veräußert.

38 Vgl. zum Begriff 'Erscheinen' die Erläuterungen zum Synonym 'veröffentlicht' in Abschnitt 2.1.2.

39 Vgl. hierzu ausführlich Abschnitt 2.1.4.

$40 \mathrm{Vgl}$. zur Verlängerung der Schutzdauer Abschnitt 2.2. Im Rahmen der Harmonisierung der Schutzdauer innerhalb der Europäischen Union wurde eine Verlängenung der Rechte auf 50 Jahre beschlossen.

11 Vgl. Movsessian V., und F. Seifert, op. cit., S. $152 \mathrm{ff}$.

$42 \mathrm{Vgl}$. Anlage zum $\S 54$ UrhG, in der die Vergütungssătze aufgeführt sind, und Kreile, Reinhold, Einnahme und Verteilung der gesetzlichen Gerăte- und Leerkassettenvergütung für private Vervielfältigung in Deutschland, in: Gewerblicher Rechtsschutz und Urheberrech/Internationaler Teil (GRUR/), Vol. 94 (1992), S. 24-36.

43 Vgl. Movsessian V., und F. Seifert, op. cit., S. 170 


\subsubsection{Rechte der Verwertungsgesellschaften}

Das dem Urheber zustehende Recht ist grundsätzlich nicht übertragbar. ${ }^{44}$ Allerdings können vom Urheberrecht abgeleitete Nutzungsrechte Dritten zur Verwertung überlassen werden. Die Nutzungsrechte basieren auf den Verwertungsrechte des Urhebers. ${ }^{45}$ Dabei kann der Urheber inhaltliche, zeitliche und räumliche Einschränkungen machen und sowohl einfache (z. B. nur für eine Veranstaltung) als auch ausschließliche Nutzungsrechte vergeben. Nach der sog. Zweckübertragungstheorie ${ }^{46}$ wird ein Nutzungsrecht, sofern vertraglich nichts anderes vereinbart ist, lediglich für einen bestimmten Zweck übertragen. So wird ein Komponist beispielsweise einem Tonträgerhersteller das ausschließliche Recht zur Vervielfältigung und Verbreitung einräumen. Ist im Vertrag die Beschränkung auf die $\S \S 16$ und 17 nicht genannt, ergibt sich aus dem Zweck der Einkommenserzielung des Urhebers in Verbindung mit dem Unternehmensziel des Tonträgerherstellers die Beschränkung auf Vervielfältigung und Verbreitung des Werkes durch Tonträger als Nutzungsrecht. Im Gegensatz zum Urheberrecht ist das Nutzungsrecht mit Zustimmung des Urhebers übertragbar. ${ }^{47}$ Für den Urheber wie für den Tonträgerhersteller ist die direkte Vergabe von Nutzungsrechten an jeden einzelnen Endverwerter unzweckmäßig, teilweise praktisch unmöglich und - wie bereits in 2.1.3 angeführt - teilweise gesetzlich nicht vorgesehen. Durch sog. Wahrnehmungsverträge ${ }^{48}$ (gem. $§ 35$ Abs. 1 Satz 2 UrhG) überläßt der Schutzberechtigte diese Aufgaben anderen.

Verwertungsgesellschaften lassen sich von Urhebern und anderen Schutzberechtigten Rechte treuhänderisch zur Wahrnehmung einräumen. Diese Nutzungsrechte werden dann an die Werkverwerter (Tonträgerfirmen, Veranstalter, Medien, Kinos etc.) gegen eine Gebühr vergeben und überwacht. Nach Abzug der Verwaltungskosten schüttet die Verwertungsgesellschaft die Tantiemen an die Rechteinhaber wieder aus. ${ }^{49}$ Derzeit existieren in Deutschland im Bereich der Musik die Gesellschaft für musikalische Aufführungs- und mechanische Vervielfältigungsrechte (GEMA) in der Rechtsform eines rechtsfähigen wirtschaftichen Vereins kraft Verleihung, die Gesellschaft zur Verwertung von Leistungsschutzrechten (GVL) in der Rechtsform einer $\mathrm{GmbH}$ und die Interessengemeinschaft musikwissenschafticher Herausgeber und Verleger (IMHV) ${ }^{30}$ Die GVL nimmt die Rechte der ausübenden Musiker und der Tonträgerhersteller wahr. Die Inkassostelle ZPÜ in der Rechtsform der GbR ist selbst keine Verwertungsgesellschaft.

Das Recht der Verwertungsgesellschaften ist im Gesetz über die Wahrnehmung von Urheberrechten und verwandten Schutzrechten (WahrnG) von 1965 geregelt. Das Gesetz schafft zwar

$44 \mathrm{Vgl}$. Eisenmann, Hartmut, op. cit., S. 46.

$45 \mathrm{Zu}$ den Verwertungsrechten des Urhebers ( $\S 15-24$ UrhG) vgl. Abschnitt 2.1.2.

$46 \mathrm{Vgl}$. Fromm/Nordemann, op. cit., Anm. 22 vor $\S 31$, Anm. 4 vor $\S 73, \S \S 31$ und 32 Anm. 12-26 und Anm. 28,29 und 34.

$47 \mathrm{Vgl}$. Eisenmann, Hartmut, op. cit., S. 46 ff.

$48 \mathrm{Vgl}$. Fromm/Nordemann, op. cit., Anm. 22 vor $\$ 31$.

$49 \mathrm{Vgl}$. Zeppenfeld, Werner, Tonträger in der Bundesrepublik Deutschland: Anatomie eines medialen Massenmarktes, Bochum 1978, S. 20.

so Die IMHV nimmt im musikalischen Bereich die Leistungsschutzrechte aus den $\S \S 70$ und 71 wahr. 
keine rechtliche Monopolstellung, geht aber von einer solchen faktisch aus. Ökonomisch gerechtfertigt wird die Monopolstellung mit der Ausnutzung von Größenkostenvorteilen (economies of scale). Sie bestehen darin, daß die Verwaltung der Nutzungsrechte mit zunehmender Zahl der verwalteten Musikurheber relativ kostengünstiger wird. Für Weiterverwerter von Musik (TV-Merchandiser, Diskotheken etc.) senkt die Einräumung der Nutzungsrechte durch nur eine Verwertungsgesellschaft die Kosten. Zudem können Verbundvorteile entstehen, wenn Endverwerter mit verschiedenen Verwertungsformen (Filmherstellung, öffentliche Aufführung) alle nötigen Nutzungsrechte von einer Verwertungsgesellschaft erhalten. Transaktionskostenersparnisse ergeben sich sowohl bei der Transaktion zwischen Urhebern und anderen Schutzberechtigten einerseits und der Verwertungsgesellschaft andererseits als auch zwischen der Verwertungsgesellschaft und den Endverwertern. Die faktische Monopolstellung wird durch $\S 102 a$ des Gesetzes gegen Wettbewerbsbeschränkungen (GWB) deutlich, in dem die Verwertungsgesellschaften von den $\S \S 1$ und 15 GWB freigestellt sind. Damit gilt für Verwertungsgesellschaften die Generalklausel über wettbewerbswidrige Verträge und das Verbot von Verträgen über Preisgestaltung oder Geschäftsbedingungen (vertikale Bindungen) nicht. ${ }^{51}$

Im Gegenzug hat der Gesetzgeber den Verwertungsgesellschaften durch Erlaubnispflicht, Zwang zur Wahrnehmung und Abschlußzwang Pflichten auferlegt, die eine Ausnutzung der faktischen Monopolstellung verhindern sollen. Die Erlaubnispflicht gemäß $§ 1$ WahrnG bedeutet, $\mathrm{da} ß$ für die Wahrnehmung von Nutzungsrechten, Einwilligungsrechten und Vergütungsansprüchen auf Rechnung der Urheber bzw. Inhaber der Rechte eine Erlaubnis nötig ist. Diese Erlaubnis zum Geschäftsbetrieb als Verwertungsgesellschaft darf nach $\S 1$ Abs. 4 WahrnG nur einer juristischen Person oder Personengemeinschaft erteilt werden. ${ }^{52}$ Den Berechtigten (das sind Deutsche und Wohnsitzinländer, wenn für letztere anderenfalls keine wirksame Wahrnehmung ihrer Rechte möglich ist) gegenüber besteht ein Wahrnehmungszwang durch die Verwertungsgesellschaft. ${ }^{\$ 3}$ Die Verwertungsgesellschaft ist danach verpflichtet, sämtliche ihr treuhänderisch übertragenen Rechte auch auszuüben ( $\S 6 \mathrm{WahrnG}$ ). Die zwei o. g. Rechte wirken auf der Angebotsseite von Musikverwertungsrechten. Hinsichtlich der Nachfrage nach Musikverwertung besteht ein Abschlußzwang (im ökonomischen Sinn Kontrahierungszwang genannt). Nach $\S 11$ Abs. 1 WahrnG müssen Verwertungsgesellschaften jedermann auf Verlangen zu angemessenen Bedingungen Nutzungsrechte einräumen. Als problematisch erweist sich die Frage, wann eine Vergütung angemessen ist. ${ }^{54}$ Die Aufsichtsbehörde über die Verwertungsgesellschaften ist das Bundespatentamt ( $\S 2$ und 18 Abs. 1 WahrnG). Daneben haben die Verwertungsgesellschaften die Pflicht, ihre Tarife im Bundesanzeiger zu veröffentlichen, mit den Verwertervereinigungen Gesamtverträge zu angemessenen Bedingungen abzuschließen und ihre Einnahmen nach einem aufzustellenden Verteilungsplan auszuschütten. Keine Freistellung

51 Vgl. § 102a GWB i. V. m. § 1 und $\S 15$ GWB.

52 Die Versagung der Erlaubnis ist in $\S 3$ WahrnG geregelt, ein Widernuf der Erlaubnis in $\S 4$ WahrnG.

53 Die EU-Kommission hat den Rechtsanspruch auf Wahrnehmung der Rechte auf alle EU-Bürger ausgedehnt.

S4 Die Angemessenheit der Vergütung ist bisweilen Gegenstand von Gerichtsverfahren. Diese haben aber keine aufschiebende Wirkung für die Nutzung der Musik. 
erfolgt für die Verwertungsgesellschaften von den $\S \S 22$ und 26 Abs. 2 GWB. ${ }^{55}$ Die Kartellbehörde (BKartA) hat nach Feststellung der Marktbeherrschung der Verwertungsgesellschaften gem. $\S 22$ GWB die Aufsicht über den Mißbrauch dieser Stellung. Ebenso beaufsichtigt das BKartA die Einhaltung des Diskriminienungsverbots: Verwertungsgesellschaften dürfen andere Unternehmen weder unmittelbar noch mittelbar ohne sachlich gerechtfertigten Grund unterschiedlich behandeln. Insbesondere die fehlende Ausweichmöglichkeit für Nachfrager nach Leistungen der Verwertungsgesellschaften erhöht die Relevanz dieser Gesetzesvorschrift. ${ }^{56}$ In der Rechtsprechung wird ein Mißbrauch dann angenommen, wenn mit weniger einschneidenden Maßnahmen die Interessen der Urheber und Leistungsschutzberechtigten geschützt werden können, ohne daß dadurch die Kosten der Wahrnehmung erhöht werden. ${ }^{57}$

2.1.5 Rechtliche und wirtschaftliche Verwertungskette von Urhebern und Tonträgerherstellern

Nach der Darstellung der Rechte der Musikurheber, der Tonträgerhersteller und der Rolle der Verwertungsgesellschaften soll nun für das deutsche Urheberrecht zusammenfassend die rechtliche und wirtschaftliche Verwertungskette dargestellt werden. Dabei wird nach Erst-, Zweitund Drittverwertung unterschieden. Erstverwertung von Musik geschieht durch Aufnahme und Verkauf von Tonträgern und die Live-Aufführung. Eine Zweitverwertung besteht durch die Sendung und öffentliche Wiedergabe und die Drittverwertung bezieht sich auf das private Kopieren sowie evtl. Neuauflagen der Musik auf neuen Tonträgern. Die unterschiedlichen Erlöspotentiale für die Musikurheber und die Tonträgerhersteller ergeben sich aus den zwei unterschiedlichen Rechtsinstitutionen des ausschließlichen Rechts der Vervielfältigung, Verbreitung und neuerdings auch der Vermietung, mit dem die Rechtsinhaber die Verwertungswege und die zeitliche Verwertungsabfolge steuern und dementsprechend größere Erlöspotentiale realisieren können (=Erstverwertung). Dem steht die Rechtsinstitution des Vergütungsanspruchs gegenüber, bei dem bei prinzipiell unkontrollierbarer Werknutzung eine Ausgleichszahlung erfolgt. Ein Vergütungsanspruch besteht nur bei Sendung, öffentlicher Wiedergabe durch Tonträger und beim Verleih (=Zweitverwertung).

ss Vgl. Immenga, Ulrich, und Ernst-Joachim Mestmäcker (Hrsg.), Gesetz gegen Wettbewerbsbeschränkungen: Kommentar, 2. Aufl., München 1992, § 102a, Tz. 17-19 [Immenga/Mestmäcker].

s6 $\mathrm{Zu}$ beachten ist, daß die Mißbrauchsaufsicht des Bundeskartellamtes neben der Fachaufsicht des Bundespatentamtes besteht. Letzteres hat kein Vetorecht gegenüber Mißbrauchsverfügungen. Vgl. Immenga/Mestmäcker, op. cit., Tz. 18.

57 Vgl. Ministère Public/Tournier, in: EuGH Slg., 35. Jg. (1989), S. 2521 ff. 


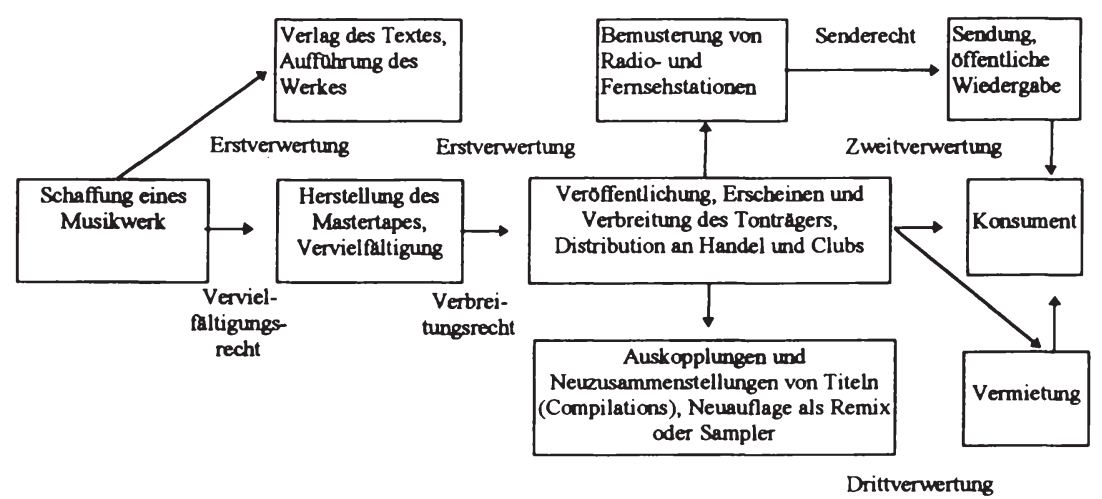

\subsection{Harmonisierung des Urheberrechts in Europa}

Ein europäischer Binnenmarkt ermöglicht es, auf geistigem Eigentum basierende Produkte und Dienstleistungen innerhalb der Europäischen Union frei zu handeln ${ }^{58}$ Angesichts unterschiedlicher Schutzbestimmungen in den einzelnen Mitgliedstaaten hinsichtlich Schutzumfang, Schutzdauer und Schutzvoraussetzungen stellt sich die Frage nach der Notwendigkeit einer Harmonisierung nicht mehr. Ökonomisch gesehen würde ein Fortbestand unterschiedlicher Regelungen einer zweifachen Diskriminierung gleichkommen. Zum einen wird in Ländern mit höherem Schutzniveau die Produktion der auf geistigen Gütern basierenden Produkte (z. B. Tonträgern) verteuert, zum anderen erhalten Urheber und Schutzberechtigte in Ländern mit niedrigerem Schutzniveau weniger Einkommen aus ihren Rechten. Eine Wettbewerbsverzerrung sowohl bei der Schaffung von Musikwerken als auch bei der Produktion der auf ihnen basierenden Produkte ist die Folge. Ein Ausgleich unterschiedlicher Regelungen durch Zoll oder nichttarifare Handelshemmnisse kommt ebensowenig in Frage wie nationale Gesetze, die die Einfuhr dieser Produkte von einer Zahlung der sich aus Rechtsunterschieden ergebenden Differenz abhängig macht. Europäisches Recht steht über dem nationalen Recht. Das Urheberrecht und die verwandten Schutzrechte unterliegen den Art. 30 und 59 EGV (Sicherung des freien Waren- und Dienstleistungsverkehrs) ${ }^{59}$ und den Wettbewerbsvorschriften der Art. 85 und $86 \mathrm{EGV}^{60}$, sowie

s8 Vgl. Art. $30 \mathrm{EGV:} \mathrm{„Mengenmäßige} \mathrm{Einfuhrbeschränkungen} \mathrm{sowie} \mathrm{alle} \mathrm{Maßnahmen} \mathrm{gleicher} \mathrm{Wirkung} \mathrm{sind}$ unbeschadet der nachstehenden Bestimmungen zwischen den Mitgliedstaaten verboten“; und Art. 59 EGV, der den freien Dienstleistungsverkehr regelt.

59 Die zwei genannten Artikel definieren den Schutzbereich, zu dem sowohl urheberrechtlich relevante Dienstleistungen als auch Handel mit urheberrechulich relevanten Produkten gehören.

60 Art. 85 EGV behandelt das Verbot wettbewerbsbehindernder Vereinbarungen oder Beschlüsse. Art 86 EGV den Mißbrauch einer den Markt beherrschenden Stellung. 
dem Art. 6 EGV, nach dem eine Diskriminierung aufgrund der Staatsangehörigkeit nicht erlaubt ist. ${ }^{61}$

Wenn die Notwendigkeit einer Rechtsharmonisierung aus juristischen und ökonomischen Gründen bejaht wird, dann wirt dies die Frage nach der bestmöglichen Umsetzung im Gesetzgebungswege auf. Es ergeben sich drei Möglichkeiten: Ein einheitliches europäisches Urheberrecht als Primärrecht im EGV, ein Sekundärrecht als Verordnung oder die Angleichung der nationalen Rechtssysteme durch Richtlinien. Realität geworden ist die dritte Möglichkeit. 1993 wurde die Richtlinie zur Harmonisierung der Schutzdauer des Urheberrechts und verwandter Schutzrechte erlassen. Die Entwicklung bis zu dieser Richtlinie und danach für den Schutz der Urheber und Tonträgerhersteller wird in Abschnitt 2.2.1 skizziert. Die Rechtsanwendung durch die EU-Kommission und die Bedeutung der Rechtsfortbildung durch das Richterrecht des EuGH wird anhand exemplarisch ausgesuchter Entscheidungen gezeigt (Abschnitt 2.2.2). Ein Ausblick, der die Rolle des europäischen Urheberrechts in den Weltzusammenhang einordnet, beschließt diesen Abschnitt (2.2.3).

\subsubsection{Harmonisierungsbestrebungen in der Europäischen Union}

Zunächst ist zu fragen, worauf die Kompetenz der Europäischen Union zur Rechtsangleichung basiert. Erstens beruht sie auf dem Art. 100a EGV, der nach Inkraftreten der Einheitlichen Europäischen Akte (EEA) Maßnahmen zur Verwirklichung des Binnenmarktes vorsieht. Im Vertrag von Maastricht wurde das Subsidiaritätsprinzip in Art. 3 b Abs. 2 des EGV festgeschrieben. ${ }^{62}$ Dieses besagt, daß die Gemeinschaft in Bereichen, in denen sie nicht die ausschließliche Zuständigkeit hat (hierzu gehört das Gebiet des Urheberrechts), nur tätig werden darf, „wenn die Maßnahmen der Mitgliedstaaten zur Erreichung der Ziele der Gemeinschaft nicht ausreichen und wegen ihres Umfangs und ihrer Wirkungen besser auf Gemeinschaftsebene erreicht werden können“ ${ }^{63}$ Die Zuständigkeit der Gemeinschaft ergibt sich zweitens daraus, $\mathrm{da} ß$ aufgrund unterschiedlicher nationaler Gesetzgebung Wettbewerbsverzerrungen innerhalb der Europäischen Union bestehen ${ }^{64}$ und einige Mitgliedstaaten (MGS) keine gesetzgeberische Initiative zu einer Angleichung des Urheberschutzes unternehmen. Drittens fallen urheberrechtlich relevante Dienstleistungen unter den Art. $62 \mathrm{EGV}^{65}$, der die MGS der EU darauf verpflichtet, nach Inkrafttreten der EEA die tatsächlich erreichte Dienstleistungsfreiheit nicht durch neue Beschränkungen zu behindern.

61 Vgl. Kreile, Reinhold, und Jürgen Becker, Neuordnung des Urheberrechts in der Europäischen Union, in: Gewerblicher Rechtsschutz und Urheberrecht, internationaler Teil (GRUR/), Vol. 96 (1994), S. 902.

62 Vgl. Ulimann, Eike, Die europaische Union und das nationale Wettbewerbs- und Urheberrecht, in: JuristenZeitung (JZ), Jg. 19 (1994), S. 929.

63 Art. 3 b Abs. 2 des EGV.

64 Nach einer anderen Meinung dient die Vereinheitlichung der Verwirklichung des Binnenmarktes. Sie unterlăge dann direkt der Rechtsetzungszuständigkeit der Europäischen Union. Vgl. Ullmann, Eike, supra, S. 929.

65 „Soweit in diesem Vertrag nicht etwas anderes bestimmt ist, unterwerfen dic Mitgliedstaaten die bei seinem Inkraftureten tatsächlich erreichte Freiheit des Dienstleistungsverkehrs keinen neuen Beschränkungen“. 
Nach Art. 235 EGV kann die EU bei der Lösung von Problemen gesetzgeberisch tätig werden, bei denen die Harmonisierung allein nicht ausreicht. Ein solches Problem ist z. B. die Piraterie von Tonträgern. Soll die Tonträgerindustrie in der EU vor Piraterieprodukten geschützt werden, ist die Verhinderung der Einfuhr solcher Produkte in den Binnenmarkt eine denkbare Maßnahme. Dazu ist festzustellen, daß in Ländern mit geringerem Urheberschutz illegale Kopien einen höheren Marktanteil haben als in Ländern mit höherem Schutz. ${ }^{66}$ Eine Ausweitung der Piraterie insbesondere durch Importe in die EU konkurriert mit der legalen Produktion innerhalb der EU. Die Produktionsstätten und mit ihnen die Produktionsfaktoren können in Länder verlagert werden, die einen geringeren Urheberschutz bieten. Die Vermarktung der Tonträger kann dann wegen der höheren Profitabilität in den Ländern mit höherem Schutzniveau erfolgen. Deswegen ist die Harmonisierung des Urheberrechts-Schutzniveaus ein Erfordernis des Binnenmarktes.

Die Kommission der Europäischen Gemeinschaft hat sich bereits 1971 mit dem Urheberrecht und verwandten Schutzrechten sowie dem Wahrnehmungsgesetz befaßt. ${ }^{67}$ Eine im Auftrag der Kommission erstellte rechtsvergleichende Studie über das Urheberrecht in der Europäischen Gemeinschaft erschien $1978{ }^{68}$ In Ihr wurde ein „Drei-Phasen Fahrplan“ zur Harmonisierung vorgeschlagen, ${ }^{69}$ der nach Dringlichkeit für den ungehinderten Verkehr mit sog. Kulturgütern geordnet war. ${ }^{70}$ Es scheint, daß die Kommission sich die Vorschläge der Studie zueigen gemacht hat, denn sie führte am 24.10.1980 eine Anhörung interessierter Kreise zur Harmonisierung der Urheberrechtsschutzfristen durch. ${ }^{71}$ Nach einem weiteren Spezialgutachten ${ }^{72}$ vor dem Beitritt von Spanien und Portugal ${ }^{73}$ veröffentlichte sie das Grünbuch über Urheberrecht und die

66 Innerhalb der Europaischen Union betrăgt der Anteil des Umsatzes mit Piraterieprodukten am Gesamtumsatz in Italien $14 \%$ und in Deutschland 4\%. Außerhalb der Union werden höhere Zahlen erreicht, z. B. $60 \%$ in Saudi-Arabien und $61 \%$ in Polen. Vgl. Bundesverband der Phonographischen Wirtschaft, Jahrbuch 1994 der phonographischen Wirtschaft, Stamberg 1994, S. 44 f. [BPW 1994]

67 In der ersten GEMA-Entscheidung v. 2.6.71, in: ABI. EG Nr. L 134, S. 15-29 [GEMA]. Vgl. hierzu auch Abschnitt 2.2.2.

68 Vgl. Dietz, Adolf, Das Urheberrecht in der Europăischen Gemeinschaf, Baden-Baden 1978

69 Vgl. Dietz, Adolf, op. cit., S. $309 \mathrm{ff}$.

70 In der ersten Phase wurde bzgl. der Schutzfrist von Urhebern eine einheitliche Dauer von 70 Jahren post mortem auctoris (p. m. a.) verlangt. Weiterhin sollten die Vorschriften über die Vervielfaltigung zum persönlichen Gebrauch gekoppelt mit einer Gerăteabgabe bei Ton- und Bildträgergerăten vereinheitlicht werden. Für die unterschiedlichen Rechtsauffassungen zum Verbreitungsrecht und der Erschöpfung des Verbreitungsrechts in den MGS der EU wurde eine gemeinsame Regelung unter Beachtung der Entscheidungen des EuGH gefordert. Im Wahrnehmungsgesetz wurde eine Harmonisierung der nationalen Aufsichtsverfahren angemahnt. In der zweiten Phase sollte die Harmonisierung der Struktur des Urheberrechts in Urheberpersönlichkeitsrecht und Verwertungsrecht, der Regeln über Urheberschaft und der Aufsicht über Verwertungsgesellschaften vollzogen werden. Für die dritte Stufe war die Angleichung der Inhalte und Schranken samtlicher Rechtsteile des Urheberrechts vorgesehen, so daß ein Waren- und Dienstleistungsaustausch ohne Diskriminierung möglich ist.

71 Vgl. Lewinski, Silke von, Der EG-Richtlinienvorschlag zur Harmonisierung der Schutzdauer im Urheberund Leistungsschutzrecht, in: GRUR/, Vol. 94 (1992), S. 724.

$72 \mathrm{Vgl}$. Dietz, Adolf, Das primare Urhebervertragsrecht in der Bundesrepublik Deutschland und in den anderen Mitgliedstaaten der Europăischen Gemeinschaf, München 1984.

73 Zur urheberrechtlichen Situation in den Beitrittsländern Spanien und Portugal wurde ein Gutachten erstellt. Vgl. Dietz, Adolf, Das Urheberrecht in Spanien und Portugal, Baden-Baden 1990. 
technologische Herausforderung, ${ }^{74}$ welches das Harmonisienungsprogramm der Kommission beschreibt. Zu den Zielsetzungen des ersten Grünbuchs gehört der Ausgleich zwischen den wirtschaftichen Interessen der Urheber und Leistungsschutzberechtigten einerseits und dem raschen Zugang der Öffentlichkeit zu Musik- und anderen Kunstwerken als kulturpolitischem Ziel andererseits. ${ }^{75}$ Weiterhin ist die eigentliche Harmonisierung Motivation für das Handeln der Kommission. Signifikante Unterschiede in den einzelstaatlichen Rechtsvorschriften können den Binnenmarkt fragmentieren oder zumindest den Wettbewerb in ihm erheblich verzerren. ${ }^{76}$ Schließlich weist die Kommission darauf hin, daß Investitionen in geistiges Eigentum in der Gemeinschaft auch bei Nutzung außerhalb derselben einen angemessenen Ertrag bringen sollen.

Einen kurzen Überblick über die Harmonisierungsschritte und -inhalte der Urheberrechtsbestandteile, die für den Tonträgermarkt von Bedeutung sind, gibt Abbildung 5:

\section{Abbildung 5: \\ Harmonisierungsschritte und -inhalte der Urheberrechtsbestandteile in der EU, die für den Tonträgermarkt relevant sind}

\begin{tabular}{|ll|}
\hline Grünbuch I (1988) & (a) Piraterie \\
& (b) Privates Kopieren von Tonträgern \\
& (c) Vermiet- und Verleihrecht \\
(d) Schutzdauer und Schutzumfang & (a) Piraterie \\
Arbeitsprogramm (1990) & (b) Privates Kopieren von Tonträgern \\
Richtlinie zum Vermiet- und & (c) Vermiet- und Verleihrecht \\
Verleihrecht (1992) & (d) Schutzdauer und Schutzumfang \\
Richtlinie zur Schutzdauer (1993) & (a), (b), (c), (d), (e) technische Identifi- \\
Grünbuch II (1995) & zierungs- und Schutzsysteme zur \\
& Rechteverwaltung \\
\hline
\end{tabular}

\footnotetext{
74 Vgl. Grünbuch über Urheberrecht und die technologische Herausforderung: Urheberrechtsfragen, die sofortiges Handeln erfordern. Mitteilung der Kommission, KOM (88) 172 endg.

75 Vgl. KOM (88) 172, op. cit., S. 1. Unterziele sind die Stărkung der Unterhaltungs- und Musikindustric, welche wegen ihres überdurchschnittlichen Wachstums für die EU große Bedeutung haben, die Schutzverstärkung wegen der Anfalligkeit für unerlaubte Nachahmung, Vervielfaltigung und Verbreitung und die Förderung des Handels im Binnenmarkt.

76 Vgl. KOM (88) 172, op. cit., S. 4.
} 
In ihrem ersten Grünbuch erachtete die Kommission als die drängendsten Aufgaben ${ }^{77}$ die Piraterie, das private Kopieren von Tonträgern, die Vermiet- und Verleihrechte von Tonträgern, die Schutzdauer und der Schutzumfang. ${ }^{78}$

Die Piraterie bei Tonaufzeichnungen wurde wegen der hohen Einnahmeverluste der phonographischen Industrie schon seit geraumer Zeit thematisiert. ${ }^{79}$ Die Rechtsinhaber hatten sich in Organisationen gegen die Piraterie zusammengeschlossen, bei deren Arbeit die Kommission Unterstützung leistete. ${ }^{80} \mathrm{Da}$ die Piraterie mit der Einführung der digitalen Kassette DAT ${ }^{81}$ ohne Qualitätsverlust und großen Kapitaleinsatz möglich wurde und das „contact process printer" Verfahren es ermöglichte, massenhaft Raubkopien herzustellen, schlug die Kommission ein Lizenzsystem zur Kontrolle oder eine allgemeine Beschränkung des Verkaufs von DATPrintern vor. ${ }^{82}$ Zusätzlich sollten als Maßnahmen die Beschlagnahme illegal hergestellter Ware, die Einführung von Schadensersatzansprüchen und Unterlassungsverfügungen eingesetzt werden. ${ }^{83}$ Eine wirksame Bekämpfung der Piraterie kann letztlich nur mit Unterstützung der Länder gelingen, die als Ursprung von Pirateriewaren bekannt sind.

Die rechtliche Lage bei der Vervielfältigung von Tonträgern für private Zwecke war zum Zeitpunkt des ersten Grünbuches (1988) in der Europäischen Gemeinschaft sehr unterschiedlich. $^{84}$ Die Argumente der betroffenen phonographischen Industrie zu diesem Zeitpunkt trafen trotz ihrer subjektiven Sicht als Interessengruppe zu: Die private Vervielfältigung war gängige Praxis; der Leerkassettenverkauf stieg in Deutschland bis 1991 ständig. ${ }^{85}$ In den industriealisierten Staaten der Europäischen Gemeinschaft verfügten zu diesem Zeitpunkt ca. $70 \%$ der privaten Haushalte über Geräte, die privates Kopieren ermöglichen. Umstritten allerdings war die behauptete Rückwirkung der zunehmenden privaten Vervielfältigung auf den stagnierenden Absatz bespielter Tonträger überhaupt, da dafür nach dem Ende der Umbruchphase von analo-

77 Vgl. KOM (88) 172, op. cit., S. 15 f.

78 Diese Aufgaben wurden weiterverfolgt: Die Piraterie und das private Kopieren im Arbeitsprogramm von 1990 und im zweiten Grünbuch von 1995, das Verbreitungs- und Verleihrecht im Arbeitsprogramm und in der Richtlinie zum Vermieten und Verleihen von 1992, die Beschränkung des Schutzes in der Richtlinie zur Harmonisierung der Schutzdauer des Urheberrechts und bestimmter verwandter Schutzrechte von 1993 und die Beschrănkung des Schutzes von Rechtsinhabern aus der Gemeinschaft in Nichtmitgliedstaaten in den GATT-Verhandlungen.

79 Vgl. Davies, Gillian, und Hans Hugo von Rauscher auf Weeg, op. cit., S. $176 \mathrm{ff}$.

80 Vgl. KOM (88) 172, op. cit., S. 84 f.

81 Zum Digital Audio Tape vgl. Abschnitt 1.2.6.

82 Damit würden neben der Errichtung eines bürokratischen Systems auch administrative Markteintrittsbarrieren für den Markt der Herstellung von Tonträgern geschaffen werden.

83 Vgl. KOM (88) 172, op. cit., S. 88 f.

84 In einigen Lăndern (Belgien, Luxemburg, Griechenland) gab es keine Bestimmungen, die den Vorgang der privaten Vervielfaltigung behandelten. In Großbritannien und Irland galt das private Kopieren als ,fair use“ und eine Vergütung für die Rechtsinhaber wurde abgelehnt. In Italien war das private Kopieren mit Einschrankungen erlaubt. In einigen Staaten war privates Vervielfaltigen gegen eine Vergütung vorgesehen (Deutschland, Spanien, Frankreich und Portugal). Die Vergütung wurde entweder als Geräte- oder Leerkassettenabgabe erhoben oder beides. Dabei besorgte die Einziehung der Vergütung von den entsprechenden Herstellern oder Importeuren und die anschließende Verteilung der Gelder an die Rechtsinhaber in der Regel eine Verwertungsgesellschaft oder eine Inkassostelle derselben. Vgl. Dieselhorst, Jochen. Die Harmonisierung der Leerkassetten- und Geräteabgabe, in: GRUR/, Vol. 96 (1994), S.789 ff.

${ }^{85}$ Vgl. BPW 1994, op. cit., S. 47. 
gen zu digitalen Tonträgern auch andere Gründe anzuführen waren. ${ }^{86}$ Zudem zeigte die weitere Marktentwicklung einen Wiederanstieg der Absatzzahlen der digitalen Tonträger. ${ }^{87}$ Nach der Etablierung der Digitaltechnik bestand aber nach Ansicht der Kommission verstärkt die Gefahr der Ausweitung privaten Kopierens. Erstens liessen sich mit Hilfe des DAT und eines entspechenden Aufnahmegerätes qualitativ perfekte Kopien erstellen, die keiner Abnutzung mehr unterliegen, und zweitens stellte der für digitale im Vergleich zu analogen Tonträgern höhere Kaufpreis einen Anreiz zur Substitution durch privates Vervielfaltigen dar. Die Kommission schlug daher die Einführung eines technischen System des Kopierschutzes vor, das den Rechtsinhabern die Kontrolle über unerlaubte Vervielfältigungen ermöglichte, ohne den legalen Zugang zu Tonaufzeichnungen zu behindern. Die weitere Entwicklung zeigte, daß eine Umgehung aller technischen Lösungen des Kopierschutzes nicht zu verhindern war. Wegen des Übergangs zur digitalen Technik hielt es die Kommission nicht für erforderlich, die in den MGS der EU unterschiedlichen Gebührenverfahren zu harmonisieren. Darüber hinaus seien die bestehenden Abgabensysteme als Instrument zur Kontrolle der künftigen privaten Vervielfältigung ungeeignet. ${ }^{88}$ Die Kommission schlug daher die Erhebung einer Lizenzgebühr an der Quelle, d. h. beim Tonträgerkauf vor. ${ }^{89}$

Zur Verbreitung von Tonaufzeichnungen stellte die Kommission fest, daß digitale Tonträger zunehmend Gegenstand gewerblicher Vermietung wurden. Dadurch sanken c. p. die Einnahmen der Rechtsinhaber, deren Musik auf Tonträgern weniger gekauft wurde. Verleihen und Vermieten sind urheberrechtliche Unterbegriffe der Verbreitung. Die zu beurteilende Rechtslage muß daher an dem Verbreitungsrecht anknüpfen. In den MGS ließ sie sich 1988 in drei Gruppen einteilen: ${ }^{00}$

In der ersten Gruppe von Ländern (Italien und die Niederlanden) gab es keine Möglichkeit, auf die V'ermietung Einfluß zu nehmen, weil die Urheberrechte mit dem ersten Verkauf erschöpft waren. ${ }^{91}$ In einer zweiten Gruppe von Ländern (Deutschland, Dänemark, Portugal und Spanien) galt keine Erschöpfung des Rechts auf Verbreitung. Die Rechtssysteme differierten insoweit, als in Deutschland lediglich eine Vergütungspflicht für die Weiterverbreitung galt und in den anderen Ländern den Rechtsinhabern eine Genehmigung vorbehalten blieb. In der dritten Gruppe von Ländern herrschte Rechtsunsicherheit. Entweder existierte kein Verbreitungsrecht, und Beschränkungen aufgrund von Aufdrucken auf den verkauften Kopien blieben rechtlich umstritten und faktisch bedeutungslos (dies war in Belgien, Luxemburg, Frankreich und Griechenland der Fall); oder die Vermietung veröffentlichter Werke unterlag keinen Einschränkungen (Großbritannien und Irland). Da diese gesetzlichen Regelungen nur für die Urheber

$86 \mathrm{Vgl}$. KOM (88) 172, op. cit., S $113 \mathrm{ff}$.

87 Vgl. BPW 1994, op. cit., S. 12 f., und die Analyse der Marktstrukturentwicklung in Abschnitt 4.2.

$88 \mathrm{Vgl}$. KOM (88) 172, op. cit., S. 133 f.

89 Okonomisch gesehen ist dieser Vorschlag zu verwerfen. Zum einen würde er die Tonträger weiter verteuern und damit einen zusătzlichen Anreiz zum Kopieren auslösen, zum zweiten müßte die Lizenzgebühr unabhăngig von der Absicht verlangt werden, überhaupt Kopien zu erstellen, und zum dritten ist eine Differenzierung nach der Intensităt der Nutzung nicht vorgesehen (z. B. durch die gewerbliche Weitervermietung der bespielten Tontrăger).

$91 \mathrm{Vgl}$. zur Erschöpfungslehre bei der Verbreitung Abschnitt 2.1.2. 
(Komponisten und Textdichter) galten, war nach der rechtlichen Lage der Produzenten der Tonträger zu fragen, die durch die Konstruktion der Übertragung von Nutzungsrechten direkt von den Urheberrechten profitierten. Hier gab es mit Ausnahme von Frankreich und Portugal keine rechtliche Möglichkeit der Kontrolle bzw. Verhinderung späterer Vermietung. Mit der abnutzungsfreien $\mathrm{CD}$ als Tonträgerkategorie entstand ein neuer gewerblicher Mietmarkt. ${ }^{92}$

Deswegen war es nicht verwunderlich, wenn die Kommission ein europaweites Vermietrecht vorschlug. Insbesondere verwies sie dabei auf den Zusammenhang zwischen Vermietung und der Entstehung von Piraterietonträgern. ${ }^{93}$ Daher war die Zielsetzung der Regelung erstens Wettbewerbsverzerrungen zu vermeiden, zweitens die Pirateriegefahr zu reduzieren, drittens die Rentabilität der phonographischen Industrie zu erhöhen und viertens für die Urheber ein entsprechendes Entgelt entstehen zu lassen. Die Regelung sollte Urhebern von auf Tonträgern aufgenommenen Werken, deren Produzenten und die ausübenden Künstler begünstigen. Einzelheiten und praktische Fragen sollten national geregelt werden. Zur Diskussion stellte die Kommission im ersten Grünbuch die Einräumung eines Rechts auf Genehmigung der Vermietung oder das Recht auf angemessene Vergütung ohne einen Erlaubnisvorbehalt.

Diese verschiedenen Rechtsinstitutionen unterscheiden sich in ihrer ökonomischen Konsequenz. Die Verweigerung einer Erlaubnis zur Vermietung sichert den Rechtsinhabern das exklusive Verbreitungsrecht. Dafür kann eben gerade derjenige Teil der Nachfrage nicht befriedigt werden, der nur bereit ist, den entsprechend niedrigeren Mietpreis zu zahlen. Demgegenüber erhalten die Rechtsinhaber bei der Vergütungsregelung auch für den Teil der Nachfrager Geld (wenn auch weniger pro Nachfrager), der nur mieten will. Für die ökonomische Vorteilhaftigkeit einer der beiden Regelungen ist der Grad der Substituierbarkeit von Kauf durch Miete und die Preiselastizität der Nachfrage sowohl der Miete als auch des Kaufs entscheidend. Unter der Annahme der kostenlosen Erhebung der Vergütung und Weiterverteilung auf die Rechtsinhaber sind beide Rechtsinstitutionen ökonomisch gleich zu bewerten, wenn der Grenzertrag des Verkaufs der Summe der Grenzerträge des Vermieters und der Rechtsinhaber entspricht. $^{94}$

Das Arbeitsprogramm von $1990^{95}$ führte die Harmonisierungsbestrebungen fort und zeigte die Internationalisierung der Bemühungen der Kommission. ${ }^{*}$ Die bestehenden nur gemeinschaftsweiten Regelungen reichten nicht aus. Eine gebührenfreie Verwertung von Werken von Urhebern aus der EU in bestimmten Drittländern sollte ebenso verhindert werden wie die Verlagerung der Produktion in Länder mit geringerem Schutz und der Import von unter Verletzung des Urheberrechts hergestellten Erzeugnissen (sog. Piraterieware) in die EU.

92 Vgl. KOM (88) 172, op. cit., S. $161 \mathrm{ff}$.

$93 \mathrm{Vgl}$. KOM (88), op. cit., 172, S. $161 \mathrm{ff}$.

94 Die Fragen der Schutzdauer und des Schutzumfangs werden im Zusammenhang mit der diesbezüglichen Richtlinie behandelt.

95 Vgl. Initiativen zum Grünbuch: Arbeitsprogramm der Kommission auf dem Gebiet des Urheberrechts und der verwandten Schutzrechte. Mitteilung der Kommission, KOM (90) 584 endg.

96 Vgl. KOM (90) 584, op. cit., S. 3 
Zu den im ersten Grünbuch aufgeworfenen Fragen im Hinblick auf private Vervielfältigung erhielt die Kommission Stellungnahmen. ${ }^{97}$ In ihnen sprach sich eine Mehrheit gegen ein Verbot privater Vervielfältigung aus. Im eigenen Interesse waren die Rechtsinhaber jedoch fur eine Vergütungspflicht in allen MGS der EU; die Hersteller von Aufnahmegeräten und Leerkassetten sowie die Verbraucherverbände sprachen sich gegen ein Abgabensystem aus. Wegen der Möglichkeit, mit Hilfe von DAT-Aufnahmegeräten private Kopien in digitaler Qualität herzustellen, wurde ein Konsens über die Einführung des technischen Kopierschutzsystems SCMS (Serial Copy Management System) erzielt. Dieses System erlaubt nur die Anfertigung einer Kopie in digitaler Qualität vom Original, nicht aber das Weiterkopieren von Kopien. Die Kommission kündigte im Arbeitsprogramm weiterhin einen Richtlinienvorschlag für private Vervielfältigungen an. $\mathrm{Zu}$ diesem Richtlinienvorschlag ist es bis heute nicht gekommen. Zwar wurden seit dem ersten Günbuch 1990 in den Niederlanden, ${ }^{98} 1992$ in Italien ${ }^{99}$ und Dänemark $^{100}$ und 1993 in Griechenland ${ }^{101}$ Leerkassettenabgaben eingeführt; Belgien hat eine Abgabe geschaffen ${ }^{102}$ und von den neuen MGS hat Österreich ${ }^{103}$ seit 1981, Finnland seit 1984 eine urheberrechtliche Vergütungsabgabe und Schweden seit 1982 eine Steuer auf Leerkassetten erhoben. Aber Irland, Luxemburg und Großbritannien ${ }^{104}$ widersetzten sich jeder Form der Vergütung für private Vervielfältigungen. Zudem waren die in der EU etablierten Rechtsinstitutionen sehr unterschiedlich ${ }^{105}$ hinsichtlich der belasteten Produkte, der Abgabensätze, ${ }^{106}$ des Zahlungssystems und der Verteilung der Vergütungseinnahmen auf die Rechtsinhaber. Die unterschiedlichen Rechtsinstitutionen in den MGS für privates Kopieren können zu Behinderungen des Handels im freien Binnenmarkt und zu Wettbewerbsverzerrungen führen. Nationale Gegenmaßnahmen greifen wenig, sind mit hohem bürokratischen Aufwand für die Endverkäufer versehen und behindern den freien Handelsverkehr mit Leerkassetten und Aufnahmegeräten. Gerade bei den im Preis niedrigen Leerkassetten ist die Wettbewerbsverzerrung zwischen den Herstellern groß, wenn die Abgaben bis zu der Hälfte des Verkaufspreises betragen. ${ }^{107} \mathrm{Als}$ weiterer Grund für die Harmonisierungsnotwendigkeit ist die Ungleichbehandlung der Rechtsinhaber zu nennen. Bewirken für die Urheber keine oder unterschiedlich hohe Vergütungen für private Vervielfältigung nur einen Unterschied von einem Bruchteil ihrer Gesamteinnahmen, ergeben sich bei Tonträgerherstellern nach Schätzungen der International Federation of Phonographic Industrie (IFPI) Millionenbeträge.

97 Vgl. KOM (90) 584, op. cit., S. 12 f.

$98 \mathrm{Vgl}$. Art. $16 \mathrm{c}-16 \mathrm{~g}$ ndl. UrhG, eingefügt durch Gesetz 305 vom 30.5.1990.

99 Vgl. Art. 4 des Gesetzes Nr. 93 vom 5.2.1992.

$100 \mathrm{Vgl}$. Art. 26a - 26h dăn. UrhG, eingefügt durch Gesetz Nr. 338 vom 12.5.1992.

$101 \mathrm{Vgl}$. Art. 18 des neuen griechischen UrhG, Gesetz Nr. 2121 vom 4.3.1993.

${ }^{102}$ Eingebracht in den belgischen Senat als 145-1 (S.E. 1991-1992) am 7.2.1992 und 1994 verabschiedet.

${ }^{103}$ Die Einführung der nationalen Regelungen stand nicht in Zusammenhang mit Aufnahmeantrăgen zur EU.

104 In Großbritannien konnte die anläßlich der Urheberrechtsreform von 1988 geplante Leerkassetten- und Gerăteabgabe aus Rücksicht auf die Interessen der Geräte- und Kassettenhersteller und der Organisation für Blinde nicht durchgesetzt werden. Blinde benutzen Kassetten und Aufnahmegeräte zur tăglichen Kommunikation und nicht zur privaten Vervielfaltigung.

${ }^{105} \mathrm{Vgl}$. für einen umfassenden Überblick Dieselhorst, Jochen, supra, S. 789-792.

106 Die Abgabensătze für leere Tonträger in den MGS liegen in Prozent des Verkaufspreises pro Abspielstunde bei $0 \%$ in Großbritannien, Irland und Luxemburg; $5 \%$ in Deutschland; $6 \%$ in Griechenland; $7 \%$ in Belgien; $10 \%$ in Italien; $15 \%$ in Spanien; $18 \%$ in Frankreich und $29 \%$ in Dänemark.

$107 \mathrm{Vgl}$. Dieselhorst, Jochen, supra, S. 793. 
Trotz der Ankündigung seitens der EU-Kommission ist kein Richtlinienvorschlag für privates Kopieren veröffentlicht worden, ${ }^{108}$ weil technische Fragen des Anwendungsbereichs, der Anknüpfungsstelle der Abgabenerhebung, der Verteilung des Aufkommens und der Stellung ausländischer Rechtsinhaber geklärt werden müssen. Zudem ist im Entscheidungsprozeß sowohl der Kommission als auch des Rates mit Schwierigkeiten zu rechnen, solange drei MGS private Vervielfältigung als „fair use“ und damit legal ansehen.

Die Kommission hat 1990 einen Richtlinienvorschlag zum Vermieten, Verleihen und damit zusammenhängenden Fragen verwandter Schutzrechte vorgelegt. ${ }^{109}$ Verabschiedet wurde die Richtlinie am 19.11.1992 vom Rat. ${ }^{110}$ Die Umsetzungsfrist in nationales Recht lief bis zum 1.7.1994. Sowohl Vermieten als auch Verleihen stellen urheberrechtliche Nutzungen dar, woraus konsequenterweise gefolgert werden kann, daß die Rechtsinhaber an den Nutzungen wirtschaftlich angemessen beteiligt werden müssen. Verleihen wurde in Art. 1 der Richtlinie definiert als unentgeltliche, nicht gewerbliche zeitweise Überlassung (z. B. durch öffentliche Bibliotheken), Vermieten als entgeltliche zeitweise Überlassung zu Erwerbszwecken des Vermieters. ${ }^{111}$ Die Richtlinie sieht ein ausschließliches Vermietrecht vor. Die Rechtsinhaber (neben Urhebern jetzt auch ausübende Künstler und Tonträgerhersteller) können die Weitervermietung veräußerter Produkte zu gewerblichen Zwecken untersagen oder aber die Erlaubnis von der Zahlung einer Vergütung abhängig machen. ${ }^{112}$ Die Zwischenschaltung einer Verwertungsgesellschaft ist in der Richtlinie den nationalen Gesetzgebern freigestellt. Im deutschen UrhG sind nach $\S 27$ Abs. 3 neue Fassung Vergütungen verwertungsgesellschaftspflichtig. Der Erlaubnisvorbehalt ist im deutschen Urheberrecht eine Neuerung, ${ }^{113}$ da bisher lediglich ein Vergütungsanspruch in $\S 27$ UrhG eingeräumt wurde. ${ }^{114}$ Existieren mehrere Berechtigte, so ist die Zustimmung jedes einzelnen einzuholen. Ebenso wurde bei der Umsetzung der Richtlinie in das deutsche Recht die Erschöpfung des Verbreitungsrechts neu geregelt. Ein Erstverkauf erschöpft das Verbreitungsrecht mit Ausnahme der Vermietung. Hinsichtlich des Verleihrechts sieht die Richtlinie einen angemessenen Vergütungsanspruch vor. Sie beläßt dem nationalen Gesetzgeber Spielräume, ob die Vergütung nur den Urhebern oder auch den Inhabern verwandter Schutzrechte zustehen soll. Im neuen deutschen Urheberrecht haben nach den $\S \S 75$ Abs. 3, 85 Abs. 3 und 94 Abs. 4 auch Tonträgerhersteller, ausübende Künstler und Filmherstel-

108 Vgl. Beseler, Hans Friedrich, Die Harmonisierung des Urheberrechts aus europäischer Sicht, in: Zeitschrift für Urheber- und Medienrecht (ZUM), Jg. 39 (1995), S. 440.

$109 \mathrm{Vgl}$. KOM (90) 586 endg.

${ }^{110} \mathrm{Vgl}$. Richulinie 92/100/EWG des Rates vom 19.11.1992 zum Vermiet- und Verleihrecht sowie zu bestimmten dem Urheberrecht verwandten Schutzrechten im Bereich des geistigen Eigentums, in: ABI. EG L 346, S. $61 \mathrm{fr}$.

"II Vgl. Lewinski, Silke von, Vermieten, Verleihen und verwandte Schutzrechte, in: GRUR/, Vol. 93 (1991), S. 108. [Lewinski 1991].

$112 \mathrm{Vgl}$. Lewinski, Silke von, Die Umsetzung der Richtlinie zum Vermiet- und Verleihrecht, in: ZUM, Jg. 39 (1995), S. 442. [Lewinski 1995]. Ein Beispiel soll das Verhältnis der Berechtigten untereinander veranschaulichen: Hat ein Komponist das Vermietrecht an einen Tontrăgerhersteller übertragen und letzterer gegen Entgelt die Weitervermietung des Tonträgers einem CD-Vermietgeschäft erlaubt, so hat auch der Komponist einen Anspruch auf einen Anteil an dem Entgelt.

113 Vgl. § 17 Abs. 2 UrhG (neue Fassung). Die Verleih- und Vermietrichulinie ist inzwischen im deutschen Urheberrecht umgesetzt worden. Das neue Gesetz wurde am 29.6.95 verkündet und trat am 1.7.95 in Kraft.

$114 \mathrm{Vgl}$. Kreile, Reinhold, und Jürgen Becker, supra, S. 907. 
ler das Recht auf Vergütung. ${ }^{115}$ Die Vergütung muß im Verhältnis zur Gesamtnutzung und in ihrer Aufteilung auf die einzelnen Berechtigten angemessen sein. Dabei ist Bezug zu nehmen auf den Beitrag, den der jeweilige Berechtigte zum verliehenen Gegenstand geleistet hat. ${ }^{116}$ Insgesamt hat die Richtlinie zum Vermiet- und Verleihrecht den Schutz und die Erlöspotentiale für die Berechtigten erhöht.

Der nächste Entwicklungsschritt bestand in dem Richtlinienvorschlag zur Harmonisierung der Schutzdauern des Urheberrechts und verwandter Schutzrechte. Grundsätze für den Vorschlag waren umfassende Harmonisierung der Schutzdauern aller relevanten Schutzrechte, Erhöhung der Schutzfristen gegenüber den in den internationalen Konventionen geltenden Minimalfristen, keine Beeinträchtigung nationaler Rechte, die schon vorher Bestand hatten, und Abstufung der Rechte für Urheber einerseits und für daraus abgeleitete Schutzrechte andererseits.

Der Vorschlag für eine Richtlinie des Rates zur Harmonisierung der Schutzdauer des Urheberrechts und bestimmter verwandter Schutzrechte wurde 1992 veröffentlicht. ${ }^{117}$ Die Richtlinie selbst wurde vom Rat am 29.10.1993 verabschiedet und am 24. November 1993 im Amtsblatt veröffentlicht. ${ }^{118}$ Sie mußte bis zum 01.07 .95 in nationales Recht umgesetzt werden. In ihr wird den Urhebern generell das Schutzrecht für 70 Jahre post mortem auctoris (p. m. a.) zuerkannt. Die ausübenden Künstler und die Tonträgerhersteller erhalten bis 50 Jahre nach Darbietung bzw. Aufzeichnung Rechte. ${ }^{119}$ Sollte die erste öffentliche Wiedergabe vor der Festlegung erfolgen, knüpft daran der Beginn der Schutzfrist an. Damit wird die Schutzdauer für Tonträgerhersteller verdoppelt. ${ }^{120}$ Für Rechtsinhaber aus MGS der EU, in denen bisher kürzere Schutzfristen galten, verlängert sich mit den einheitlichen Schutzfristen der Richtlinie ihr Rechtsschutz. Zusätzlich wird das Recht an schon gemeinfrei gewordenen Werken wiederaufleben, wenn es entsprechend der Richtlinie noch in der Schutzfrist ist. Bei den Leistungsschutzrechten kommt die Verlängerung der Schutzfrist denjenigen zugute, die ein zeitlich unbefristetes Nutzungsrecht erworben haben.

Das zweite Grünbuch der Kommission über Urheberrecht und verwandte Schutzrechte in der Informationsgesellschaft erschien $1995 .{ }^{121}$ In ihm beschäftigte sich die Kommission

\footnotetext{
115 Vgl. Lewinski 1995, supra, S. 447.

$116 \mathrm{Vgl}$. Lewinski 1991, supra, S. 110. Wenn davon ausgegangen wird, daB für den Leihwunsch des Verbrauchers der Beitrag des Urhebers ausschlaggebend ist, dann sollte sein Anteil an der Vergütung höher als der der anderen Berechtigten sein.

$117 \mathrm{Vgl}$. Vorschlag für eine Richtlinie des Rates zur Harmonisienung der Schutzdauer des Urheberrechts und bestimmter verwandter Schutzrechte, KOM (92) 33 endg. - Syn 395, in: ABI. Nr. C 92, Seite 6 ff.

$118 \mathrm{Vgl}$. Richtlinic 93/98 des Rates zur Harmonisierung der Schutzdauer des Urheberrechts und bestimmter verwandter Schutzrechte, in: ABl. EG Nr. L 290, Seite 9 ff.

119 Dies entspricht für ausübende Künstler und Tonträgerhersteller dem Mindestschutz von Art. 14 Abs. 5 des TRIPs-Abkommens. Auf dieses Abkommen wird in Abschnitt 2.3 näher eingegangen.

120 Im Vergleich zur Mehrheit der bisherigen nationalen Bestimmungen der MGS der EU. Vgl. Vogel, Martin, Die Umsetzung der Richtlinie zur Harmonisierung der Schutzdauer des Urheberrechts und bestimmter verwandter Schutzrechte, in: ZUM, Jg. 39 (1995), S. 455.

$121 \mathrm{Vgl}$. KOM (95) 382 endg.
} 
mit den Auswirkungen der neuen technologischen Entwicklungen (Vernetzung und On-LineDienstleistungen in Digitaltechnik) auf das geistige Eigentum und den daraus resultierenden Anpassungsnotwendigkeiten des Rechtssystems. Für die Musikverwertung interessierende Fragen betreffen die Anwendung und Erschöpfung des Verbreitungsrechts, das Vervielfältigungsrecht, das Recht der digitalen Übertragung und die Rechteverwaltung sowie technische Identifizierungs- und Schutzsysteme im Bereich des Urheberrechts der Musik.

Zunächst wurde im Grünbuch festgestellt, daß die neuen Technologien die nationalen Grenzen de facto aufgehoben haben und die Inadäquanz nationalstaatlicher Urheberrechtsbestimmungen zeigen. $^{122}$ Die Anknüpfungspunkte für eine Weiterentwicklung von Urheberpersönlichkeitsund Urheberverwertungsrechten aufgrund der technischen Entwicklung sind unterschiedlich. Die Notwendigkeit für eine Reform des Urheberpersönlichkeitsrechts ergibt sich, wenn durch eine digitale netzgebundene Musikverwertung die übertragene Musik Ausgangspunkt für Veränderungen an ihr wird. Veränderungen bei den Urheberverwertungsrechten können nötig werden, wenn die Ausstattung der privaten Haushalte mit Geräten, die die Nutzung der neuen Technologien erlauben, eine Veränderung der Verwertungsform und -wege bedingt. ${ }^{123}$ Ebenso bedürfen Grundbegriffe des Urheberrechts möglicherweise einer neuen Auslegung. So wird die Originalität als Bedingung für Schutzrechte z. B. durch die Möglichkeit des digitalen Sampling schwer nachzuweisen sein. ${ }^{124}$ Der Begriff der Erstveröffentlichung als Bezugspunkt für den Beginn des Schutzes wird bei der Übertragung von Werken durch Netze durch die Verfügbarmachung zu ersetzen sein. Schließlich ist die Durchsetzung eines Ausschließlichkeitsrechts etwa der Vervielfältigung - angesicht der On-Line Nutzung fraglich. Auch bei der Wahrnehmung der Rechte ergeben sich Konsequenzen aus der zunehmenden unkörperlichen Weiterverbreitung mit unterschiedlichen Verwendungsmöglichkeiten, da die bestehenden Verwertungsgesellschaften nach der Art der Rechtsinhaber bzw. nach Werkkategorien spezialisiert sind.

Das zweite Grünbuch wirf Fragen auf im Hinblick auf die Anwendung und Erschöpfung des Verbreitungsrechts, das Vervielfältigungsrecht, die Rechteverwaltung und die technischen Schutz- und Identifikationssysteme. Beim Recht der digitalen Übertragung und Verbreitung fragte die Kommission nach den wirtschaftichen Folgen, die sich aus der Anwendung der Vermiet- und Verleihrichtlinie ergeben, wenn man diese erweiternd auch auf die elektronische Übertragung Punkt-zu-Punkt anwendet. Das Vermietrecht ist zwar durch die o. g. Richtlinie von der Erschöpfung des Verbreitungsrechts ausgenommen. Die wirtschaftlichen Folgen sind bei einer netzgebundenen Musikverwertung aber eher an die faktischen technischen Möglichkeiten der Zugangskontrolle und Kopiersperren geknüpft als an das formale Ausschlußrecht. Deswegen kann hinsichtlich der Erschöpfung der Rechte beim Vermieten und Verleihen dahingestellt bleiben, ob ein Wettbewerb der Systeme, die die internationale Erschöpfung vorsehen

$122 \mathrm{Vgl}$. KOM (95) 382, op. cit., S. 15.

123 Eine Veränderung der Verwertungsstrategie kann auch dann angezeigt sein, wenn die Saturation bei den multimediafahigen Endgerăten in der Europäischen Union noch hinter derjenigen in den USA zurückbleibt. Vgl. Bericht der Beobachtungsstelle für Informationsmărkte der EU für 1993-94, in: KOM (95) 382, op. cit., S. 23.

$124 \mathrm{Vgl}$. Münker, Reiner, Urheberrechtliche Zustimmungserfordernisse beim Digital Sampling, Frankfurt a.M. 1995, S. 253 ff. 
oder nicht vorsehen, wünschenswert oder kontraproduktiv ist. ${ }^{125}$ Die Fragen der Vervielfältigung zu privaten und gewerblichen Zwecken wurden auch im zweiten Grünbuch von der Kommission lediglich formuliert und keinesfalls abschließend behandelt. Zur Debatte standen weiterhin ein Ausschließlichkeitsrecht an digitalisierten Werken und Dienstleistungen mit oder ohne Ausnahmen oder nur ein Vergütungsanspruch bei prinzipiell zugelassener Vervielfältigung. Die Problematik des Kopierens änderte sich durch die Digitalisierung nur insoweit, als Vervielfältigungen von Werken, die über Netze verbreitet werden, leichter möglich sind als vorher. $\mathrm{Zu}$ den Fragen der Rechteverwaltung schlug die Kommission die Bildung einer zentralen Anlaufstelle ${ }^{126}$ vor, die aus dem Zusammenschluß von Rechtsinhabern und Verwaltern bestehen könnte. Sie verwies in diesem Zusammenhang auf das Beispiel der französischen SESAM, die eine Vereinigung von vier Verwertungsgesellschaften ${ }^{127}$ ist. Eine zentrale Wahrnehmung und Verwaltung der Rechte, die bisher nach Sparten (Musik, Literatur, Film etc.) getrennt organisiert waren, entspricht nach Ansicht der Kommission eher den Erfordernissen zusammenhängender Werkverwertungsformen, optionaler Übertragbarkeit von Werkformen und der Zusammenführung verschiedener Werkarten durch Multimedia-Verwertungen unterschiedlicher Inhalte.

Technische Schutz- und Identifizierungssysteme mit Hilfe elektronischer Kennzeichnung sind nach Meinung der Kommission im Zuge der Digitalisierung möglich und bieten Schutz von über Netze übermittelten Werken und Dienstleistungen. ${ }^{128}$ Für Tonträger wurde ein solcher Code, der International Standard Record Code (ISRC) genannt wird, bereits geschaffen. ${ }^{129}$ Es wird erwartet, daß Identifizierungssysteme die Erhebung und Verteilung der Vergütung für Rechtsinhaber wirksam erleichtern. ${ }^{130}$ Die Kommission will wegen der Wichtigkeit der Schutz- und Identifizierungssysteme diesen Fragen ein eigenes Grünbuch widmen. ${ }^{131}$ Die abschließenden Fragen der Kommission zu diesem Themenbereich lassen erkennen, daß die Realisation technischer Schutzsysteme enorme Schwierigkeiten mit sich bringt. Eine internationale Standardisierung dieser Systeme wäre erforderlich, ist aber noch nicht erfolgt. Die Harmonisierungsbestrebungen der Europäischen Union sind durch das zweite Grünbuch keineswegs vor-

${ }^{125} \mathrm{Vgl.} \mathrm{KOM} \mathrm{(95)} \mathrm{582,} \mathrm{op.} \mathrm{cit.,} \mathrm{S.} 86$ und Richtlinic 92/100/EWG, ABl. EG L 346, S. 61 ff., Artikel 9 Abs. 2. Vermieten und Verleihen sind Unterbegriffe des Verbreitungsrechts. Für die Rechtsinstitution des Verbreitungsrechts gilt mit Ausnahme der Vermietung körperlicher Tonträger der Grundsatz der Erschöpfung, der auch in Art. 6 Abs. 2 des WIPO-WC-Treaty vom 20.12.1996 übernommen wurde. Damit ist der Grundsatz der Erschöpfung im Ergebnis international einheitlich geregelt. Zur Weiterentwicklung des internationalen Urheberrechts, in dem die Verbreitung i. S. eines making available-right an der Verfügbarmachung mit Hilfe von Netzen anknüpft, vgl. Abschnitt 5.3.3.

$126 \mathrm{Vgl}$. KOM (95) 582, op. cit., S. 89.

${ }^{127} \mathrm{Vgl}$. KOM (95) 582, op. cit., S. 76. Die bisherige Arbeitsteilung von Verwertungsgesellschaften bezieht sich einerseits auf verschiedene Werkkategorien (z. B. Literatur, Musik etc.), andererseits auf verschiedene Rechtsinhaber (z. B. Urheber und Tonträgerhersteller).

$128 \mathrm{Vgl}$. KOM (95) 582, op. cit., S. 37.

$129 \mathrm{Vgl}$. KOM (95) 582, op. cit., S. 79.

$130 \mathrm{Vgl}$. das bereits erwăhnte Serial Copyright Management System (SMCS) bei der privaten Vervielfäligung.

${ }^{131} \mathrm{Da}$ ein Bedarf der Informationsindustrie bzgl. Schutz- und Identifizierungssystemen besteht, führ die Kommission ein Projekt mit dem Titel „Copyright in Transmitted Eloctronic Documents“ (CITED) durch, welches die Urheber- und Leistungsschutzrechte an allen in digitaler Form gespeicherten und weitergegebenen Werken und Leistungen gewährleisten soll und Maßnahmen gegen Piraterie erprobt. 
angekommen. Es sind nur Problemkreise zu einer möglichen Weiterentwicklung des Urheberrechts und verwandter Schutzrechte präzisiert worden.

Die Weiterentwicklung der Technik hat die Möglichkeiten für eine unkörperliche netzgebundene Musikverwertung geschaffen. Hierzu ist auch eine Weiterentwicklung des Rechtsrahmens nötig geworden, der zunächst auf internationaler Ebene auf einer Konferenz im Dezember 1996 beschlossen wurde und auf europäischer Ebene mit einer Richtlinie umgesetzt werden soll, zu der im Dezember 1997 ein Richtlinienentwurf vorgelegt wurde. Diese jüngsten Entwicklungen werden in Kapitel 5 behandelt.

\subsubsection{Bedeutung von Entscheidungen der Kommission und des Europäischen Gerichtshofs}

Eine zentrale Rolle spielen im europäischen Harmonisierungsprozess des Urheberrechts und verwandter Schutzrechte die Entscheidungen der EU-Kommission und des Europäischen Gerichtshofs (EuGH). In diesem Abschnitt sollen einige Entscheidungen exemplarisch herausgegriffen und ihre Bedeutung veranschaulicht werden.

Eine der ersten Ermittlungen der Kommission auf dem Gebiet der Wahrnehmung von Urheberrechten war das Auskunftsersuchen wegen wettbewerbsbeschränkender Vertragswirkungen gegenüber der Zentralstelle für private Überspielungsrechte (ZPÜ). ${ }^{132}$ a) Sachverhalt. Die von mehreren Verwertungsgesellschaften gegründete Inkassostelle ZPÜ war beauftragt worden, die Vergütungsansprüche der Rechtsinhaber aus privater Vervielfältigung gemäß der Aufnahmegeräteabgabe nach $\S 54$ UrhG (früher $\S 53 \mathrm{Abs} .5$ ) ${ }^{133}$ einzuziehen und nach Abzug der Verwaltungskosten aufzuteilen. ${ }^{134}$ Die Hersteller und Importeure der Aufnahmegeräte zahlten eine Pauschalsumme für den geschätzten Absatz des jeweils folgenden Jahres an die ZPÜ. Grundlage dafür war der Absatz des vorhergehenden Jahres. Jedoch wurden nicht $100 \%$ des Inlandsabsatzes zugrundegelegt, sondern nur 95\%, da der Exportanteil auf 5\% geschätzt wurde. Diese Berechnungsbasis von $95 \%$ für die Gebühr wurde aber auf jedes Gerät umgelegt, so $\mathrm{da} ß$ die Hersteller und Importeure jedes im Inland abgesetzte Gerät mit der gleichen Belastung versahen. b) Entscheidung. Eine Wettbewerbsbeschränkung wurde von der Kommission dahingehend festgestellt, daß die Rückerstattung der Gebühr von den Herstellern an die Großhändler, die die Geräte exportieren, ebensowenig vorgenommen wurde wie die Rückerstattung seitens der Importeure an exportierende Großhändler. Die Kommission machte die Vertragsgestaltung der ZPÜ mit den Herstellern und Importeuren für deren Verhalten verantwortlich, insbesondere als sich 16 im Zentralverband der elektrotechnischen Industrie (ZVEI) zusammengeschlossene Hersteller nach Tätigwerden der Kommission verpflichteten, die Gebühr bei nachgewiesenen Exporten zurückzuerstatten. Da Art. 85 Abs. 1 EGV neben den bezweckten auch die von einer Vereinbarung bewirkten Wettbewerbsbeschränkungen erfaßt, soweit sie den

\footnotetext{
132 Vgl. ZPÜ v. 01.02.1971, in ABl. EG Nr. L 34, S. 13 ff. [ZPÜ].

133 In der alten Fassung des Urheberrechtsgesetzes wurden lediglich Aufnahmegerăte belastet, erst mit der Urheberrechtsnovelle von 1985 wurden auch Loerkassetten in die private Vervielfäligungsvergütung einbezogen. Die genaue Berechnungsregelung findet sich im Anhang zu $\S 54 \mathrm{~d}$ Abs. 1 UrhG.

$134 \mathrm{Vgl}$. Abschnitt 2.1.4.
} 
Handel zwischen den Mitgliedstaaten zu beeinflussen geeignet sind, hatte die Kommission die wettbewerbsbeschränkenden Vertragswirkungen zu beurteilen. Die ZPÜ widersetzte sich lange Zeit dem Auskunftersuchen, mußte dann aber sowohl ihre Rechtsform und Mitglieder als auch ihre Vertragsgestaltung und -praxis offenlegen und die Rückerstattung mit Hilfe der Hersteller und Importeure gewährleisten. c) Würdigung. Die Anwendung der nationalen Vergütungsregelung auf im Ausland abgesetzte Geräte und leere Tonträger stellte eine Diskriminierung dar. Durch die Entscheidung der Kommission wurde deutlich, daß die Regelung der Vergütung für private Vervielfältigung nicht mittels Inländerbehandlung EU-weit angewendet werden darf, sondern daß die - nicht harmonisierten - nationalen Regelungen auch im europäischen Binnenmarkt bestand haben.

In demselben Jahr beschäftigte sich die Kommission mit der Satzung der größten deutschen Verwertungsgesellschaft und erließ die GEMA-Entscheidung vom 2. Juni 1971. ${ }^{135}$ a) Sachverhalt. Der GEMA wurde ein Mißbrauch ihrer marktbeherrschenden Stellung in mehrfacher Weise vorgeworfen. Die marktbeherrschende Stellung der GEMA ergab sich aus der Tatsache, $\mathrm{da} B$ in der Bundesrepublik im Markt für Musikverwertungsrechte keine Wettbewerber existierten, die GEMA also eine faktische Monopolstellung innehatte. Diese Monopolstellung wurde ihr allerdings nicht hoheitlich verliehen, vielmehr ist in $\S 1$ des WahrnG nur eine Erlaubnispflicht für jegliche Verwertungsgesellschaften geregelt worden. ${ }^{136}$ In der Folge war daher zu prüfen, ob Art. $90 \mathrm{EGV}$ anzuwenden ist, der für bestimmte öffentliche Unternehmen Ausnahmen von Art. 86 EGV regelt. Die verwertungsgesellschaftspflichtigen Ansprüche der Urheber und Leistungsschutzberechtigten könnten prinzipiell auch durch andere Verwertungsgesellschaften, insbesondere durch solche aus anderen MGS der EU geltend gemacht werden. Damit war die GEMA nicht als öffentliches Unternehmen i. S. des Art. 90 Abs. 1 EGV anzusehen. Ferner war die GEMA auch nicht mit Dienstleistungen von allgemeinem wirtschaftlichen Interesse betraut. Vielmehr waren die Verpflichtungen der GEMA, auf religiöse, kulturelle und soziale Belange bei der Tarifgestaltung und der Vorsorgekasse Rücksicht zu nehmen, nur von allgemeinem kulturellem und sozialem Interesse. Daher war auch Art. 90 Abs. 2 nicht anzuwenden. Der Mißbrauch der marktbeherrschenden Stellung der GEMA zeigte sich zum ersten in der Diskriminierung der Angehörigen anderer MGS, die davon abgehalten wurden, Mitglieder der GEMA zu werden. Zum zweiten war die Art mißbräuchlich, in der die GEMA ihre Mitglieder an sich band. Diese Bindung war objektiv nicht gerechtfertigt und erschwerte den Mitgliedern einen Wechsel zu einer anderen Verwertungsgesellschaft unbillig. Drittens verhinderte die GEMA durch ihre Satzung ein Zustandekommen eines einheitlichen Marktes der Dienstleistungen der Musikverleger. Viertens nutzte die GEMA ihre marktbeherrschende Stellung gegenüber den deutschen Schallplattenherstellern mißbräuchlich aus, indem sie die von ihr wahrgenommenen Urheberrechte vertraglich auf ungeschützte Werke ausdehnte. ${ }^{137}$ Weiter nutzte die GEMA ihre Stellung auch dazu aus, die deutschen Importeure von Schallplatten bei der Einfuhr aus anderen MGS zur Zahlung der vollen Lizenzgebühr zu zwingen, obwohl für die betreffenden Schallplatten schon einmal im Herstellerland Lizenzgebühren be-

$135 \mathrm{Vgl}$. GEMA, op. cit., S. 15 ff.

$136 \mathrm{Vgl}$. Abschnitt 2.1.4.

$137 \mathrm{Vgl}$. GEMA, op. cit., S. 22. 
zahlt worden sind. Dies diskriminierte die deutschen Importeure gegenüber den inländischen Herstellern. Schließlich benutzte die GEMA ihre beherrschende Stellung gegenüber den Importeuren von Tonaufnahmegeräten, indem sie von diesen über die ZPÜ eine höhere Gebühr nach $\S 53$ Abs. 5 (heute $\S 54$ ) UrhG verlangte als von den deutschen Herstellern solcher Geräte.

b) Entscheidung. Die Kommission stützte ihre Entscheidung auf Art. 86 EGV und Art. 3 der VO Nr. 17. Hier hat die Kommission das aus dem Auskunftersuchen gegenüber der ZPÜ erlangte Wissen eingesetzt ${ }^{138}$ und verbot der GEMA den weiteren Mißbrauch ihrer marktbeherrschenden Stellung. c) Würdigung. Die GEMA mußte nach dieser Entscheidung ihre Satzung in wesentlichen Punkten ändern. Die Bevorzugung von Musikurhebern aus dem jeweils eigenen Nationalstaat wurde ebenso reduziert wie die Hürden einer Mitgliedschaft in den Verwertungsgesellschaften. Die Entscheidungen der Kommission und des EuGH zu den Verwertungsgesellschaften ${ }^{139}$ hatten Vorfeldwirkung und beeinflußten die Politik der deutschen GEMA mit der Folge, daß sie für ihre Satzungsergänzung ein Negativattest bei der Kommission beantragte. ${ }^{140} \mathrm{Da}$ die Verwertungsgesellschaften keine gesetzliche Monopolstellung innehaben, hat die EU-Kommission keine Möglichkeit zur Deregulierung in diesem Bereich. Sie ist deswegen angesichts der faktischen Monopolstellung auf die Mißbrauchsaufsicht angewiesen und kann gewünschte Strukturveränderungen beispielsweise wegen der durch technische Neuerungen geänderten Nutzung nur anregen.

Die o. a. GEMA-Entscheidung hatte zusätzlich Signalwirkung auch für andere Verwertungsgesellschaften in der EU. So urteilte der EuGH in der Rechtssache BRT $\mathbf{L}^{141} \mathrm{da \beta}$ die belgische Verwertungsgesellschaft SABAM ihre marktbeherrschende Stellung mißbräuchlich ausnutzte, indem sie ihren Mitgliedern Verpflichtungen auferlegte, die zur Erreichung des Gesellschaftszwecks entbehrlich waren, und die Freiheit des Mitgliedes, sein Urheberrecht auszuüben, unbillig beeinträchtigten. 1979 urteilte der EuGH in der Rechtssache über die französische Musikverwertungsgesellschaft SACEM ${ }^{142}$, daß auch dann eine mißbräuchliche Ausnutzung der marktbeherrschenden Stellung i. S. des Art. $86 \mathrm{EGV}$ vorlag, wenn sich diese lediglich auf die Abwicklung von Verträgen bezog, die mit EU-angehörigen Urhebern zur Verwertung ihrer Rechte in Drittländern außerhalb der EU geschlossen wurden.

Der deutschen Gesellschaft zur Verwertung von Leistungsschutzrechten (GVL) wurde von der Kommission in einer Entscheidung vom 29. Oktober 1981 die Diskriminierung ausländi-

${ }^{138} \mathrm{Vgl}$. ZPÜ, op. cit., S. $13 \mathrm{ff}$.

${ }^{139}$ Neben den erläuterten Urteilen des EuGH noch Musik-Vertrieb Membran - GEMA v. 20.01.1981 (verbundene Rechtssachen 55 und 57/80), in: EuGH Slg., Jg. 27 (1981), S. 147-180; SACEM v. 09.04.1987 (Rechtssache 402/85), in: EuGH Slg., Jg. 33 (1987), S. 1747-1771; und Ministère Public - Tournier v. 13.07.1989 (Rechtssache 395/87), in: EuGH Slg., Jg. 35 (1989), S. 2521-2581. Weitere Entscheidungen des EuGH betrafen das Verhalten der Unternehmen Grammophon v. 28.06.1971 (Rechtssache 78/70), in: EuGH Slg., Jg. 17 (1971), S. 487-514; EMI Records und CBS Schallplatten v. 15.06.1976 (Rechtssache 96/75), in: EuGH Slg., Jg. 22 (1976), S. 913-954; EMI Electrola v. 24.01.1989 (Rechtssache 341/87), in: EuGH Slg., Jg. 35 (1989), S. 79-98; sowie Miller International Schallplatten GmbH v. 01.02.1978 (Rechtssache 19/77), in: EuGH Slg., Jg. 24 (1978), S. 131-164.

140 Vgl. GEMA-Satzung v. 04.12.1982, in: ABI. EG Nr. L 94, S. 12 ff.

141 Vgl. BRT I v. 30.01.1974 (Rechtssache 127/73), in: EuGH Slg., Jg. 20 (1974), S. 51-79.

142 Vgl. SACEM v. 25.10.1979 (Rechtssache 22/79), in: EuGH Sig., Jg. 25 (1979). S. 3275-3298. 
scher Künstler vorgeworfen. ${ }^{143}$ a) Sachverhalt. Die GVL war für die Wahrnehmung von Zweitverwertungsrechten ${ }^{144}$ ausübender Künstler und Hersteller von Tonträgern in Deutschland Monopolist. Wie bei der GEMA beruhte diese faktische nicht auf einer rechtlichen begründeten Monopolstellung. Es wurden nicht allgemeine wirtschaftliche Interessen, sondern die Privatinteressen der Künstler und Tonträgerhersteller wahrgenommen. Eine Anwendung des Art. 90 EGV war deshalb auch hier auszuschließen. b) Entscheidung. Die GVL verstieß gegen Art. 86 Abs. 1 in Verbindung mit Art. 7 EGV, wonach jede Diskriminierung aus Gründen der Staatsangehörigkeit verboten ist, indem sie sich weigerte, mit ausländischen Künstlern ohne Wohnsitz in Deutschland Wahrnehmungsverträge abzuschließen. Durch die faktische Monopolstellung der GVL war es den betreffenden Künstlern nicht möglich, auf eine andere Verwertungsgesellschaft auszuweichen. Nach Art. 86 Abs. 2 verhielt sich die GVL diskriminierend, weil sie Wirtschaftspartner aus nicht leistungsbezogenen Gründen unterschiedlich behandelt hat. Daraus folgte eine Wettbewerbsbenachteiligung der ausländischen gegenüber den deutschen Künstlern, ohne daß dafür Rechtfertigungsgründe vorlagen. Eine aufgrund von Wettbewerbsvorschriften gegebene Wahrnehmungsverpflichtung ging von Vergütungsansprüchen ausländischer Künstler aus der Zweitverwertung in Deutschland aus. Dieses galt analog auch für Ansprüche deutscher Künstler in anderen MGS. Durch die Weigerung der GVL, für Ausländer ohne Wohnsitz in Deutschland, aber mit Wohnsitz in der EU die Verwertung ihrer Rechte in Deutschland zu übernehmen, wurde das Zustandekommen eines einheitlichen Marktes für die Wahrnehmung von Leistungsschutzrechten in der EU behindert. c) Würdigung. Die GVL hatte während der Ermittlungen der Kommission durch Änderung des Gesellschafts- und Musterwahrnehmungsvertrags ihre Diskriminierung und Wettbewerbsbenachteiligung ausländischer Künstler mit Wohnsitz in der EU eingestellt. Dadurch wurde ein Schritt zur Herstellung eines einheitlichen Marktes für die Wahrnehmung von Leistungsschutzrechten getan.

Rechtssache EMI Electrola. a) Sachverhalt. Von in Dänemark nicht mehr geschützten Musikwerken wurden Tonträger angefertigt, die in die Bundesrepublik importiert wurden. Der Inhaber der ausschließlichen Vervielfältigungs- und Verbreitungsrechte für Deutschland (der Tonträgerhersteller EMI) klagte vor dem Landgericht Hamburg auf Unterlassung des Vertriebs und auf Schadenersatz. Das LG hat gemäß Art. 177 EGV zur Frage der Vereinbarkeit der Anwendung nationaler Rechtsvorschriften auf dem Gebiet des Urheberechts an Musikwerken um eine Vorabentscheidung des EuGH gebeten. b) Entscheidung. Die Art. 30 und 36 EGV verhindern nicht, daß es einem Tonträgerhersteller in einem MGS gestattet ist, sich auf die ihm zustehenden ausschließlichen Vervielfältigungs- und Verbreitungsrechte von Musikwerken zu berufen, um den Vertrieb von Tonträgern der gleichen Musikwerke im Gebiet dieses Mitgliedstaats verbieten zu lassen, wenn diese Tonträger aus einem anderen Mitgliedstaat eingeführt werden, in dem sie ohne die Zustimmung des Rechtsinhabers rechtmäßig in den Verkehr gebracht worden sind und in dem eine Schutzfrist für die Hersteller dieser Tonträger zwar bestand, aber inzwischen abgelaufen ist. Soweit die unterschiedlichen nationalen Rechtsvorschriften zu Beschränkungen des innergemeinschaftlichen Handels mit Tonträgern führen können,

$143 \mathrm{Vgl}$. GVL v. 29.10.1981, in: ABI. EG Nr. L 370, S. $49 \mathrm{ff}$.

144 Hierzu gehören u. a. Vergütungen aus dem Senderocht und öffentlicher Auffühnung bereits erschienener Tonträger. 
sind diese Beschränkungen auch nach Art. 36 EGV gerechtfertigt, wenn sie auf dem Unterschied zwischen den Regelungen über die Schutzfrist beruhen und diese untrennbar mit dem Bestehen der ausschließlichen Rechte verknüpft sind. c) Würdigung. In der Rechtssache EMI Electrola $^{145}$ wurde durch den EUGH klargestellt, daß es Sache der nationalen Gesetzgeber ist, Voraussetzungen und Modalitäten des Rechtsschutzes für Urheber und sonstige Rechtsinhaber festzulegen. Bestehen Hemmnisse und Wettbewerbsverzernungen im freien Verkehr mit urheberrechtlichen Waren und Dienstleistungen, die auf unterschiedliche Schutzdauern in den MGS zurückzuführen sind, so sind diese nach Art. 36 EGV gerechtfertigt. ${ }^{146}$

Eine gerichtliche Klärung der Anwendung des Diskriminierungsverbots auf das Urheberrecht und verwandte Schutzrechte durch den EuGH wurde durch das Urteil vom 20.10.1993 in der Rechtssache Phil Collins u.a. ${ }^{147}$ bewirkt. a) Sachverhalt. Anlaß zu der Beschäftigung des EuGH mit dem Diskriminierungsverbot war der Vorlagebeschlu $B^{148}$ zweier deutscher Gerich$\mathrm{te}^{149}$ über die Auslegung von Art. 7 EGV (alte Fassung). In Frage stand, ob die LiveDarbietung zweier britischer Künstler, die 1983 in den USA ohne deren Einwilligung durch Dritte aufgezeichnet wurde, in Deutschland vertrieben werden durfte, wie es $\S 125$ UrhG in Deutschland ermöglicht; oder ob dieser Paragraph des deutschen Urheberrechts diskriminierend i. S. des Art. 6 Abs. 1 EGV (alte Fassung: Art. 7 Abs. 1 EWGV) sei, weil nach ihm NichtDeutsche keinen Untersagungsanspruch haben, wenn die Live-Darbietung außerhalb von Deutschland stattfand. b) Entscheidung. Der EuGH stellte zwar heraus, daß es angesichts der Tatsache, daß es kein eigenständiges europäisches Urheberrecht gibt, Sache der MGS sei, die Modalitäten des Urheberrechtsschutzes gesetzlich zu regeln. Allerdings seien die internationalen Abkommen mit der Inländerbehandlung zu beachten. ${ }^{150}$ Ferner sah der EuGH die Aufgabe der Urheberrechte und verwandten Schutzrechte darin, den Schutz der Persönlichkeitsrechte und der wirtschaftlichen Rechte ihrer Inhaber zu gewährleisten. Wegen der Bedeutung der damit verbundenen Ausschließlichkeitsrechte für den Austausch von Gütern und Dienstleistungen sowie der Wettbewerbsverhältnisse in der Gemeinschaft unterliegen Urheber- und verwandte Rechte den Erfordernissen des EGV, insbesondere den Vorschriften der Art. 3, 30, 36, 59 und 66 EGV. Zugleich traf eine Ausnahme nach Art. 36 oder 222 EGV (sog. Bereichsausnahme) nicht zu. ${ }^{151}$ Der EuGH kam daher zu dem Ergebnis, daß durch den $\S 125$ deutsches

145 Vgl. EMI Electrola v. 24.01.1989 (Rechtssache 341/87), in: Entscheidungssammlung des Gerichtshofes [EuGH Slg.], Jg. 35 (1989), S. 79-98.

$146 \mathrm{Vgl}$. KOM (90) 584, op. cit., S. 32.

147 Vgl. Kröger, Detlef, Die Anwendung des Diskriminierungsverbots auf das Urheberrecht und verwandte Schutzrechte, in: Europäische Zeitschriff für Wirtschaftsrecht (EuZW), Jg. 6 (1994), S. 85 - 87.

148 Das Vorlageverfahren basiert auf Art. 177 EGV.

149 Das LG München 1, Phil Collins, in: GRUR/, Vol. 94 (1992), S. 404, und der BGH, Cliff Richard, in: EuZW, Jg. 4 (1992), S. 644.

${ }^{150}$ In dem Verfahren wandte sich der britische Sänger Phil Collins gegen den Vetrieb illegal hergestellter Mitschnitte eines Live-Konzerts in den USA. Obwohl das Heimatland von Collins, das Vereinigte Königreich, dem Rom-Abkommen beigetreten war, nutzte das Collins nichts, da Art. 4 lit. a RA nicht auf die Staatsangehơrigkeit, sondern auf den Darbietungsort abstellt. Die USA sind nicht dem Rom-Abkommen beigetreten, deswegen konnte sich das Unterlassungsbegehren Collins nicht auf internationales Urheberrecht stützen.

1s। Vgl. Mestmäcker, Ernst-Joachim, Der Schutz der ausübenden Künstler und das EWGDiskriminierungsverbot, in: GRUR/I, Vol. 95 (1993), S. 533. 
UrhG Urheber und ausübende Künstler anderer MGS von Rechten ausgeschlossen wurden, die Inländern zuerkannt werden. Dieses stellte einen Verstoß gegen Art. 6 Abs. 1 EGV und das Prinzip der Inländerbehandlung dar. Die völkerrechtlichen Gegenargumente des Territorialitäts- und Reziprozitätsprinzips griffen innerhalb der EU nicht, da ersteres dem Binnenmarkt widerspreche und letzteres im Widerspruch zum grundsätzlichen Gleichbehandlungsgebot in der EU stehe. ${ }^{152}$ c) Würdigung. Die Rechtsfolge dieses Urteils war, daß sich auf Art. 6 Abs. 1 EGV der Anspruch auf Inländerbehandlung gründet. Demzufolge haben ausländische ausübende Künstler ebenso wie die Deutschen das Recht, den Vertrieb unautorisierter Tonträger zu untersagen. ${ }^{153}$ Im Ergebnis wurde eine Schutzlücke im Rom-Abkommen für ausübende Künstler geschlossen.

\subsubsection{Erfolge europäischer Harmonisierungsbestrebungen und die internationale Dimension}

Erklärtes Ziel der Kommission war sowohl die Erhöhung des Schutzniveaus als auch die Harmonisierung der unterschiedlichen nationalstaatlichen Urheberrechte. Dieses Ziel ist als ein Instrument auf dem Weg zu einem einheitlichen europäischen Binnenmarkt ohne Grenzen und Wettbewerbsverzerrungen zu verstehen. Der Handel mit Gütern und Dienstleistungen, die auf urheberrechtlich geschützten Werken basieren wie z. B. die Musikverwertung mit Hilfe von Tonträgern, vollzieht sich in zunehmenden Maße weltweit. Die Harmonisierungsbestrebungen sind daher vor dem Hintergrund der Internationalen Abkommen und ihrer Weiterentwicklung zu bewerten, die in Abschnitt 2.3 betrachtet werden.

Vorrangig forderte die EU-Kommission von den MGS den Beitritt zur Pariser Fassung der Revidierten Berner Übereinkunft (RBÜ) und zum Rom-Abkommen. Inzwischen ist diese Forderung größtenteils erfüllt, denn sämtliche 15 EU-Staaten sind mit Stand zum 1.1.95 der RBÜ beigetreten. Bis heute fehlt ein Beitritt von Portugal und Belgien zum Rom-Abkommen. ${ }^{154}$ Die weiteren Ziele bestanden in der Schaffung einheitlicher Rahmenbedingungen für einen freien Austausch von Gütern und Dienstleistungen und in der Fortentwicklung des Urheberrechts angesichts der Digitaltechnik und der zunehmenden Bedeutung von Informationsnetzen. Die Richtlinien zur Harmonisierung der Schutzdauer und zum Vermiet- und Verleihrecht sind für dieses Ziel geeignet und in nationales Recht umgesetzt worden. Zur Problematik des privaten Kopierens liegt noch kein Richtlinienvorschlag der Kommission vor. Dieses ist zu kritisieren, weil die unterschiedlichen nationalen Bestimmungen auf diesem Gebiet nicht im grenzüberschreitenden Verkehr mit kopierten Gütern angewendet werden dürfen, sofern durch sie der freie Warenaustausch im europäischen Binnenmarkt behindert wird, was praktisch immer der Fall sein wird. Die Bemühungen der Kommission sind geprägt von der politischen Kompromißkultur im Europäischen Rat und zwischen den MGS. Die Vorlagen der Bürokratie werden zurückgestellt, wenn es politisch opportun erscheint. Deshalb ist sehr fraglich, ob die Hand-

\footnotetext{
${ }^{152} \mathrm{Vgl}$. Mestmăcker, Ernst-Joachim, supra, S. 533.

153 Vgl. Braun, Torsten, Das Diskriminierungsverbot des Art. 7 Abs. 1 EWGV und das internationale Urheberund Leistungsschutzrecht, in: Internationale Privatrechtspraxis (IPrax), Jg. 14 (1994), S. 266.

$154 \mathrm{Vgl}$. Schack, Haimo, Urheber- und Urhebervertragsrecht, Tübingen 1997, S. 369, Fn. 88.
} 
lungserfordernisse, die mit der Digitalisierung und der Verbreitung über Datennetze entstanden sind, auch rechtzeitig in europäische Rechtsetzung münden. ${ }^{15 s}$

Die Entscheidungen der EU-Kommission und des EuGH zeugen von dem Willen, keine Diskriminierungen innerhalb des Binnenmarktes zuzulassen. Gleichwohl gelingt über die Inländerbehandlung keine Vereinheitlichung der Urheber- und verwandten Schutzrechte oder eine gleichartige Wahrnehmung über die nationalen Verwertungsgesellschaften.

Das Engagement der Vertreter der EU in den GATT-Verhandlungen für urheberrechtliche Fragen läßt vermuten, daß die Kommission den globalen Zusammenhang der Urheberrechtsproblematik erkannt hat und daher weltweite Lösungen anstrebt. Auf europäischer Ebene bringt die Harmonisierung der Schutzrechte Fortschritte für die betroffenen Industrien (u. a. die Tonträgerindustrie) und die Schutzberechtigten. Gefahren bestehen, wenn die Einflußnahme der Interessenverbände sich nicht an der wirtschaftichen Wohlfahrt und der Implementierung des technischen Fortschrittes orientiert, sondern an den partikulären Interessen der jeweiligen Einflußgruppen. Die Verantwortung für die Rahmensetzung innerhalb der Urheberrechtsindustrien verbleibt bei der EU-Kommission. Die Internationalisierung der Vertragsökonomie aller mit dem Urheberrecht und verwandten Schutzrechten zusammenhängenden Märkte im Rahmen der abgeschlossenen Uruguay-GATT-Runde ist zu begrüßen. Die Kommission der Europäischen Union als Vertreterin eines der größten Handelsblöcke der Welt sollte weiterhin eine aktive Rolle bei der Ausgestaltung und Weiterentwicklung des Rechtsrahmens für Urheberverwertungen spielen.

\subsection{Internationale Urheberrechtsabkommen}

Die internationalen Urheberrechtsabkommen sind zum einen durch das amerikanische zum anderen durch das kontinentaleuropäische Urhebersystem geprägt. Auf dem europäischen Kontinent wird das Urheberrecht traditionell als natürliches Eigentumsrecht des Urhebers auf Grund seiner individuellen schöpferischen Leistung ${ }^{156}$ angesehen, das ihm ein zeitlich befristetes Monopol zur Verwertung seiner Werke garantiert. Die amerikanische Rechtstradition des Copyright stellt hingegen dem Schutz gegen unerlaubte Nachahmung den Vorbehalt des "fair use“ anderer Personen gegen. ${ }^{157}$ Der grundsätzlichen Option zugunsten des Urhebers im europäischen Urheberrecht entspricht die grundsätzliche Option zugunsten des öffentlichen Interesses im amerikanischen Urheberrecht. Im Hinblick auf dieses Interesse instrumentalisiert das amerikanische Urheberrecht den kurzfristigen Gewinnanreiz des Urhebers und Werkverwerters für das langfristige Ziel des Fortschritts der Öffentlichkeit. ${ }^{158}$ Diese Anreizwirkung geht für Werke der Musik jedoch fehl, da Musik keinen Fortschritts-, sondern nur Unterhaltungszwek-

15s Hierzu vgl. den RL-E vom Dezember 1997 zur Umsetzung der Ergebnisse der WIPO-Konferenz von 1996.

$156 \mathrm{Vgl}$. Hubmann/Rehbinder, op. cit., S. $42 \mathrm{ff}$.

157 Vgl. Wagner-Silva Tarouca, Beatrice, Der Urheberschutz der ausübenden Künstler und der Tonträgerproduzenten in den USA, München 1983, S. 6 ff.

158 Vgl. Wagner-Silva Tarouca, Beatrice, op. cit., S. 8, und Prosi, G., Die ókonomische Theorie des Buches, Düsselsorf 1971, S. 18 
ken dient. Die Zweiteilung des internationalen Urheberrechtssystems hat durch den Beitritt der USA zur RBÜ am 1.3.1989 und die damit verbundene Annäherung der amerikanischen an die europäische Rechtskonzeption an Bedeutung verloren. ${ }^{159}$ Daher ist die Gesamtbedeutung der internationalen Urheberrechtsabkommen und angrenzender Schutzrechte stark angestiegen und hat auch neuere Vereinbarungen erst ermöglicht.

Im folgenden sollen als internationale Urheberabkommen die Revidierte Berner Übereinkunf (RBÜ) und das Welturheberrechtsabkommen (WUA) behandelt werden. Internationale Abkommen über die verwandten Schutzrechte sind das Rom-Abkommen (RA) und die Genfer Übereinkunft zum Schutz von Tonträgerherstellern (GTÜ). Beide Rechtsgebiete werden schließlich durch das Abkommen über die Apekte des Handels mit geistigen Gütern (TRIPs im GATT) berührt. Abschließend wird auf die Frage des Verhältnisses der Abkommen zueinander und der Anwendung der internationalen Konventionen eingegangen werden.

\subsubsection{Revidierte Berner Übereinkunft}

Am 9. September 1886 wurde ein multilateraler Vertrag mit dem Namen „Berner Konvention betreffend die Schaffung einer internationalen Union zum internationalen Schutz von Werken der Literatur und Kunst" (RBÜ) unterzeichnet. Anfänglich von 10 Staaten geschlossen, ${ }^{160}$ gehören mit Stand von 1.1.97 125 Staaten ${ }^{161}$ der RBÜ an. Mit der Konvention wurde ein Berner Büro gegründet, welches später organisatorisch mit dem der Pariser Verbandsübereinkunft (PVÜ) zum Vereinigten Internationalen Büro zum Schutze des intellektuellen Eigentums (BIRPI) zusammengefaßt wurde. ${ }^{162}$ Seit 1967 ist an seine Stelle die World Intellectual Property Right Organization (WIPO) getreten. ${ }^{163}$ Nach der Vervollständigung der Berner Urfassung in Paris 1896 folgten bis heute sechs Revisionen: 1908 in Berlin, 1914 in Bern, 1928 in Rom, 1948 in Brüssel, 1967 in Stockholm sowie 1971 in Paris. ${ }^{164}$ Die entscheidende Bedeutung der RBÜ liegt in der Tatsache, daß ihr praktisch alle Industrienationen angehören (alle MGS der EU, die USA, Japan, fast alle übrigen europäischen Staaten, die Volksrepublik China und die Russische Föderation). Zuzätzlich kodifiziert die RBÜ in der neuesten Pariser Fassung einen Katalog von Mindestrechten. ${ }^{165}$

159 Vgl. Drexl, Josef, Entwicklungsmöglichkeiten des Urheberrechts im Rahmen des GATT, München 1990, S. 12.

${ }^{160}$ Diese 10 Staaten waren: Belgien, das Deutsche Reich, Frankreich, Großbritannien, Haiti, Liberia, dic Schweiz, Spanien und Tunesien. Vgl. Nordemann, Wilhelm, Kai Vinck und Paul Hertin, Internationales Urheberrecht und Leistungsschutzrecht der deutschsprachigen Länder unter Berücksichtigung auch der Staaten der Europäischen Gemeinschaft: Kommentar, Düsseldorf 1977, S. 3 f. [Nordemann/Vinck/Hertin 19771

161 Vgl. Katzenberger, Paul, TRIPS und das Urheberrecht, in: GRUR/, Vol. 97 (1995), S. 45I, und Schack, Haimo, op. cit., S. 353.

162 Vgl. Drexl, Josef, op. cit., S. 13

${ }^{163} \mathrm{Vgl}$. Nordemann/Vinck/Hertin 1977, op. cit., S. 4. Die WIPO verwaltet auch das Genfer Tonträgerabkommen und z. T. das Rom-Abkommen.

164 Vgl. Nordemann/Vinck/Hertin 1977, op. cit., S. 4.

165 Vgl. Katzenberger, Paul, supra, S. 454. 
Der materiell-rechtliche Inhalt der RBÜ liegt in den Prinzipien des Verbandes, der Reziprozität, der Inländerbehandlung und den Mindestrechten. Der Rechtsnatur nach ist die RBÜ ein Staatenverband mit einer völkerrechtsfähigen internationalen Organisation (der WIPO) unter Unabhängigkeit des Vertragswerks vom Mitgliederbestand ${ }^{166}$ (Prinzip des Verbandes). Dies bedeutet, daß allein die gemeinsame Mitgliedschaft in der Berner Übereinkunf bei Fehlen einer gemeinsamen Fassung im bilateralen Verhältnis ausreicht, um die Rechte und Pflichten der RBÜ gegenüber den Urhebern aus Vertragsstaaten wirksam werden zu lassen. Der Begriff des Verbandsprinzips kennzeichnet aber nicht den Vorrang des Konventionsrechts vor nationalem Recht. Hingegen verpflichtet sich jeder Verbandsstaat nach dem Prinzip der formellen Gegenseitigkeit (Reziprozität), den Konventionstext anzuwenden. Fälle materieller Reziprozität sind die Ausnahme. Sie kennzeichnen die Abhängigkeit des Schutzes vom Schutzniveau im jeweils anderen Land. ${ }^{167}$ Es gibt fünf Anwendungen dieser inhaltlichen Gegenseitigkeit, von denen für das Urheberrecht der Musik zwei von Belang sind: Der Schutzfristenvergleich nach Art. 7 Abs. 8 RBÜ und die Bestimmung im Zusammenhang mit Retorsionsmaßnahmen nach Art. 6 Abs. 1 RBÜ. Der Schutzfristenvergleich erlaubt Verbandsmitgliedern der RBÜ, zum Nachteil ausländischer geschützter Urheber vom weiter unten zu erläuternden Prinzip der Inländerbehandlung abzuweichen. Dies führt zu einer Diskriminierung der ausländischen Urheber. Angesichts des Zieles der Konvention, eine Verstärkung des internationalen Schutzes zu erreichen, erscheint diese Regelung kontraproduktiv. Sie ist weder mit der Gerechtigkeitsidee zu begründen, nach der ein Werk, welches im Ursprungsland nicht mehr geschützt ist, auch im Ausland weiterhin unter Schutz stehen könne. Noch ist sie praktisch durchsetzbar, da ein Urheber für die Erstveröffentlichung ein Land mit langer Schutzfrist wählen wird. Begründet wird die materielle Gegenseitigkeit mit dem politischen Argument, daß dem ausländischen Urheber Schutz versagt wird, weil auch die eigenen Staatsangehörigen im Ursprungsland des fremden Werks nicht genügend geschützt sind. ${ }^{168}$

Dem Prinzip der materiellen Reziprozität wurde auf europäischer Ebene sowohl durch die Entscheidung des EuGH im Fall Phil Collins als auch durch die Richtlinie zur Harmonisierung der Schutzdauer der Boden entzogen. ${ }^{169}$ Wie weiter unten zu zeigen sein wird, sorgt das TRIPsAbkommen ebenfalls dafür, daß dieses Prinzip an Bedeutung verliert. Die Retorsionsmaßnahme des Art. 6 Abs. 1 RBÜ besagt, daß ein Verbandsland die Möglichkeit hat, den Konventionsschutz gegenüber verbandsfremden Urhebern konventionsgeschützter Werke zu beschränken, sofern der Staat, dem der Urheber angehört, verbandsangehörige Urheber nicht genügend schützt. Der Gebrauch dieser Vorschrift ist an die Notifikation beim Generaldirektor der WIPO gebunden. Bisher ist eine solche Notifikation noch nicht erfolgt. Eventuell hat die Einsicht in die Nutzlosigkeit von Retorsionsmaßnahmen bewirkt, daß die genannte Regelung keine praktische Relevanz erlangt hat. ${ }^{170}$

\footnotetext{
$166 \mathrm{Vgl}$. Drexl, Josef, op. cit., S. 43.

$167 \mathrm{Vgl}$. Drexl, Josef, op. cit., S. $124 \mathrm{ff}$.

$168 \mathrm{Vgl}$. Drexl, Josef, op. cit., S. 136.

169 Zur Entscheidung des EuGH vgl. oben Abschnitt 2.2.2; zur Richulinie vgl. oben Abschnitt 2.2.1.

170 In Kapitel 3 wird gezeigt, daB Retorsion auf dem Gebiet des Urheberrechts keinesfalls paretooptimal aber trotzdem okonomisch vorteilhaft ist. Verschiedentlich ist daher die Abschaffung des Art. 6 Abs. I RBÜ verlangt worden. Vgl. Drexl, Josef, op. cit., S. 151. Dic EU-Kommission hat demgegenüber im zweiten
} 
Das wichtigste Prinzip der RBÜ ist die Inländerbehandlung. ${ }^{171}$ Sie verschafft den Urhebern aus Verbandsländern die gleiche Rechtsstellung, die das Recht des Schutzlandes den inländischen Urhebern gewährt. Dabei schafft die RBÜ kein einheitliches Urheberrecht, sondern geht von der Verschiedenheit der nationalen Urheberrechte aus. Daher werden den Urhebern im Ursprungsland (dem Land der Erstveröffentlichung) keine Rechte aus der Konvention zuteil. Der räumliche Anwendungsbereich der Inländerbehandlung beschränkt sich also auf verbandsangehöriges Ausland. Der sachliche Anwendungsbereich knüpft, wie das deutsche UrhG, an die Definition des Werkbegriffs in Art. 2 Abs. 1 RBÜ an, wobei den Verbandsländern die rechtliche Bestimmung der nötigen Gestaltungshöhe verbleibt. ${ }^{172}$ Der persönliche Anwendungsbereich beschreibt den durch die Inländerbehandlung geschützten Personenkreis. ${ }^{173}$ Konventionsgeschützter Urheber ist neben dem Verbandsurheber auch der Verbandsfremde, der sein Werk erstmalig in einem Verbandsland veröffentlicht. Konventionsgeschützte Werke sind auch diejenigen, die vom verbandsangehörigen Urheber erstmals außerhalb des Verbandes erscheinen. Dem Prinzip der Inländerbehandlung hat auch der EuGH bei den Entscheidungen bzgl. der Verwertungsgesellschaften Rechnung getragen, als er Diskriminierungen durch die GEMA und die GVL unterband. ${ }^{174}$ Rechtsmotivation war allerdings das europäische Kartellrecht, welches nach Art. 86 EWGV die mißbräuchliche Ausnutzung einer marktbeherrschenden Stellung auf dem gemeinsamen Markt verbietet. In der Rechtslogik folgt aus diesem Artikel, daß eine Beschränkung des Wahrnehmungszwangs in nationalen WahrnG auf Inländer zumindest innerhalb der EU nicht zulässig ist.

Schließlich sind die Mindestrechte der RBÜ zu behandeln. Sie bestehen aus dem Urheberpersönlichkeitsrecht, der Mindestschutzdauer von 50 Jahren p. m. a., dem Vervielfältigungsrecht, Aufführungsrecht, Sende- und Vortragsrecht, Bearbeitungsrecht, dem Recht der Festlegung auf Tonträger und dem Recht der Beschlagnahme unbefugt hergestellter Werkstücke. Nach Art. 13 RBÜ haben die nationalen Gesetzgeber der Verbandsländer die Möglichkeit, die Aufnahme von Werken der Musik auf Tonträger von der Zustimmung des Urhebers zu befreien, wenn der Urheber die Festlegung schon einmal gestattet hat. Ein Vergütungsanspruch darf dabei nicht ausgeschlossen werden. ${ }^{175}$ Die staatliche Begrenzung der Wirkung einer entsprechenden Regelung findet in dem Recht ihre Entsprechung, eine außerhalb des Landes erfolgte Aufnahme beschlagnehmen zu lassen. Im deutschen Recht ist diese Regelung entsprechend umgesetzt worden in den $\S \S 15$ Abs. 1, 16, und 21 UrhG und für die Hersteller von Tonträgern in $\S 85$ Abs. 1 UrhG. Durch die Schutzdauerrichtlinie im europäischen Recht hat es die bereits beschriebene Weiterentwicklung gegeben. Die Leistung des Tonträgerherstellers fallt als verwandtes Schutzrecht nicht unter die RBÜ. Sie wirkt aber indirekt über die Anerkennung der Musikurheberrechte auf die Musikverwertung zurück und ermöglicht den Musikurhebern über

Grünbuch eine positive Einstellung zu Gegenmaßnahmen gegenüber Urheberrechtsverletzungen duldenden Staaten zu erkennen gegeben.

171 Vgl. Katzenberger, Paul, supra, S. 454 und 460 f., und Drexl, Josef, op. cit., S. 44 ff., und Hubmann/Rehbinder, op. cit., S. 73 f., und Nordemann/Vinck/Hertin 1977, op. cit., S. 52 ff.

$172 \mathrm{Vgl}$. hierzu die Ausfühnungen in Abschnitt 2.1.1 für das deutsche UrhG.

${ }^{173} \mathrm{Vgl}$. Drexl, Josef, op. cit., S. 63 ff.

$174 \mathrm{Vgl}$. hierzu Abschnitt 2.2.2.

$175 \mathrm{Vgl}$. Drexl, Josef, op. cit., S. 120 
ausschließliche Vervielfältigungsrechte mit Hilfe von Tonträgern die Steuerung der Verwertung ihrer Musik. Die RBÜ ist bis zur Verabschiedung des World Copyright Treaty (WCT) auf der WIPO-Konferenz 1996 die beherrschende multilaterale Übereinkunft im Urheberrecht gewesen.

\section{Abbildung 6: Schutz der Musikurheber nach der RBÜ}

Revidierte Berner Ubereinkunft schützt die Urheber von Musik in allen Verbandsländern nach den Prinzipien

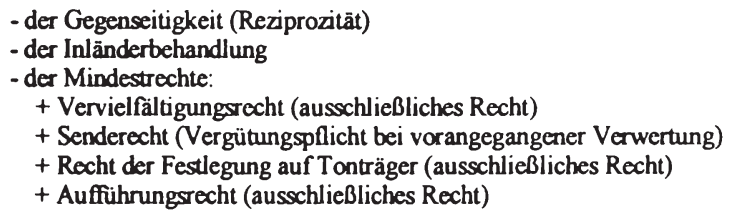

\subsubsection{Welturheberrechtsabkommen}

Das Welturheberrechtsabkommen (WUA) wurde 1952 in Genf geschlossen und 1971 in Paris revidiert. ${ }^{176}$ Mit Stand vom 1.1.97 gehören ihm 95 Mitgliedstaaten an. ${ }^{17}$ Das WUA wurde geschlossen, um die unterschiedlichen urheberrechtlichen Systeme der USA und Europas in ein internationales Schutzabkommen einzubinden. Das WUA ist ein mehrseitiger völkerrechtlicher Vertrag, durch den aber im Gegensatz zur RBÜ kein Staatenverband gebildet wurde. Auch im WUA finden sich die Prinzipien der Inländerbehandlung und die Mindestrechte. Sie garantieren aber nur ein niedrigeres Schutzniveau als es durch die RBÜ erreicht wird. Für die Erlangung des Schutzes des WUA müssen formelle Schutzvoraussetzungen erfüllt sein. ${ }^{178}$ Nach Art. 3 WUA muß das umrandete $C$ als Abkürzung für Copyright in Verbindung mit dem Namen des Inhabers des Urheberrechts und der Jahreszahl der ersten Veröffentlichung auf allen Exemplaren des Werks abgedruckt sein. Für das Verhältnis zwischen RBÜ und WUA gilt, daß verbandseigene Werke der RBÜ in Verbandsländern, die gleichzeitig Vertragsstaaten des WUA sind, nur nach den Vorschriften der RBÜ geschützt sind. Nach dem WUA geschützt werden nicht verbandseigene Werke auch in den Ländern, die der RBÜ angehören.

Die Bedeutung des WUA liegt in der Gewährung eines Minimums an Schutz zwischen Staaten, bei denen völlige Schutzversagung bisher der Fall war. ${ }^{179}$ Seine praktische Bedeutung be-

\footnotetext{
$176 \mathrm{Vgl}$. Nordemann/Vinck/Hertin 1977, op. cit., S. $165 \mathrm{ff}$.

177 Vgl. Katzenberger, Paul, supra, S. 454 f., und o. V., in: GRUR/, Vol. 99 (1997). S. $446-448$

${ }_{178} \mathrm{Vgl}$. Hubmann/Rehbinder, op. cit., S. 77

${ }^{179} \mathrm{Vgl}$. Drexl, Josef, op. cit., S. 209.
} 
schränkt sich nach dem Beitritt der Russischen Föderation, der USA und der VR China zur RBÜ auf die urheberrechtlichen Beziehungen zwischen und zu den 19 Staaten, die nur dem WUA und nicht der RBÜ angehören. ${ }^{180}$

\subsubsection{Rom-Abkommen}

Den Leistungsschutzrechten dient das Internationale Abkommen über den Schutz der ausübenden Künstler, der Hersteller von Tonträgern und der Sendeunternehmen vom 26. Oktober 1961 (sog. Rom-Abkommen, RA). Mit Stand vom 1.1.97 hat dieses bedeutendste internationale Abkommen über verwandte Schutzrechte 52 Mitgliedstaaten. ${ }^{181}$ Ähnlich wie die RBÜ beruht auch das RA auf den Prinzipien der Inländerbehandlung und der Mindestrechte. Die Inländerbehandlung der Tonträgerhersteller ist in Art. 2 Abs. 1 RA geregelt. Sie wird anhand von drei Kriterien definiert: Als objektives Kriterium wird der geschützte Leistungsstand bezeichnet, als subjektives Kriterium der geschützte Rechtsinhaber und als räumliches Kriterium der Schutz in bezug auf die einzelnen Vertragsländer. ${ }^{182}$ „Für die Zwecke dieses Abkommens ist unter Inländerbehandlung die Behandlung zu verstehen, die der vertragsschließende Staat, in dessen Gebiet der Schutz beansprucht wird, auf Grund seiner nationalen Gesetzgebung gewährt: ... den Herstellern von Tonträgern, die seine Staatsangehörigen sind, für die Tonträger, die in seinem Gebiet erstmals festgelegt oder erstmals veröffentlicht werden ..." " ${ }^{183}$ In Art. 5 RA werden die Schutzvoraussetzungen für Tonträgerhersteller geregelt. Danach wird von allen vertragsschließenden Staaten Inländerbehandlung gewährt, wenn eine der folgenden Voraussetzungen gegeben ist: „... a) Der Hersteller von Tonträgern ist Angehöriger eines anderen vertragsschließenden Staates; b) die erste Festlegung des Tons ist in einem anderen vertragschließenden Staat vorgenommen worden; c) der Tonträger ist erstmals in einem anderen vertrayschließenden Staat veröffentlicht. “ ${ }^{184}$

Der objektive Anwendungsbereich ist nach Art. 3 b RA der Tonträger, d. h. ,jede ausschließlich auf den Ton beschränkte Festlegung der Töne einer Darbietung oder andere Töne." Dabei muß der Werkbegriff i. S. von $\S 2$ Abs. 2 UrhG (deutsches Recht) mit der jeweiligen Aufzeichnung der Tonfolge nicht erfüllt sein. Bildtonträger (z. B. Musikvideos) fallen nach Art. 3 b RA generell nicht unter das RA. Der subjektive Anwendungsbereich bezieht sich auf den Tonträgerhersteller; das ist nach Art. 3 c RA, jede natürliche oder juristische Person, die erstmals die Töne einer Darbietung oder andere Töne festlegt“. Spätere Festlegungen gelten als Vervielfältigung ${ }^{185}$ und begründen keinen Rechtsanspruch i. S. des RA. Der Hersteller ist jener, der die organisatorische Verantwortung und das wirtschaftliche Risiko der Tonaufnahme trägt. Das RA definiert aus Rücksicht auf unterschiedliche nationale Gesetze drei alternative Anknüp-

${ }^{180}$ Vgl. Katzenberger, Paul, supra, S. 455.

181 Vgl. Katzenberger, Paul, supra, S. 455, und o. V., in: GRUR/, Vol. 99 (1997), S. 446-448. Die USA sind bis dato nicht Mitglied des RA, weswegen die Wirkung des Schutzes der verwandten Rechte hinter derjenigen der Urheber zurückbleibt. Beigetreten sind jedoch Frankrcich, die Niederlande und die Schweiz.

$182 \mathrm{Vgl}$. Drexl, Josef, op. cit., S. 211.

183 Art. 2 Abs. 1 und Abs. 1 b) RA.

184 Ar. 5 Abs. 1 RA.

${ }^{185} \mathrm{Vgl}$. Nordemann/Vinck/Hertin 1977, op. cit., S. 280, Art. 3 RA, Rn. 9 
fungspunkte für die Schutzgewährung nach der Inländerbehandlung: ${ }^{186}$ Die Staatsangehörigkeit, die erste Festlegung und die erste Veröffentlichung. Die Vertragsstaaten können durch Mitteilung beim Generalsekretär der UNO die Anwendung entweder des Merkmals der Festlegung oder des der Veröffentlichung ausschließen. ${ }^{187}$ Der räumliche Anwendungsbereich bezieht sich nur auf das vertragsschließende Ausland. Es handelt sich bei der Inländerbehandlung um eine fremdenrechtliche Klausel. Die Rechtsfolge ist die günstigste Behandlung des Tonträgerherstellers, die das Recht einem eigenen Staatsangehörigen einräumt. Im deutschen UrhG sind nach $\S 126$ Abs. 1 alle Tonträgerhersteller mit deutscher Staatsangehörigkeit und in $\S 126$ Abs. 2 die ausländischen Tonträgerhersteller für ihre erstmals in Deutschland festgelegten Tonträger geschützt.

Die Mindestrechte des RA für Tonträgerhersteller sind das Vervielfältigungsrecht nach Art. $10 \mathrm{RA}$, die Beschränkung nationalen Formzwangs nach Art. $11 \mathrm{RA}$, der Vergütungsanspruch nach Art. 12 RA sowie die Mindestschutzdauer nach Art. 14 RA. Das Vervielfältigungsrecht räumt dem Tonträgerhersteller das ausschließliche Recht ein, die unmittelbare oder mittelbare Vervielfältigung ihrer Tonträger zu erlauben oder zu verbieten. ${ }^{188}$ Dieser Schutz bezieht sich auch auf eine Aufnahme einer durch Rundfunk und Fernsehen gesendeten Tonträgeraufzeichnung. Das Recht besteht unter dem Vorbehalt der nationalen Anerkennung, die aber von fast allen Vertragsländern gegeben ist. ${ }^{189}$ Der Schutz gegen unerlaubte Vervielfältigung wird in den Fällen nur durch den Inländerbehandlungsgrundsatz gewährt, in denen Tonträger ohne Zustimmung außerhalb von Vertragsländern des RA vervielfältigt und in Vertragsländern verbreitet werden. Hier greift ein ggfs. vorhandenes nationales ausschließliches Verbreitungsrecht, ${ }^{190}$ welches dann Grundlage für die Inländerbehandlung ist.

Die Beschränkung des nationalen Formzwangs sieht vor, daß die im Handel befindlichen Tonträger mit einem umkreisten $\mathrm{p}$ in Verbindung mit der Angabe des Jahres der ersten Veröffentlichung gekennzeichnet sind. Sind in nationalen Gesetzen strengere Formauflagen gefordert, sind sie nur auf nicht durch das RA geschützte Rechtsinhaber anwendbar. Angesichts der Tatsache, daß die USA nicht Vertragsstaat des RA ist, hat dieser Artikel wenig praktische Bedeutung. ${ }^{191}$

Bei der öffentlichen Wiedergabe eines zu Handelszwecken bereits veröffentlichten Tonträgers über Rundfunk, Fernsehen (Sendung) oder auf anderem Weg ist vom Benutzer dem ausübenden Künstler oder dem Tonträgerhersteller oder beiden eine angemessene Vergütung zu zahlen (vgl. Abb. 4). Der Vergütungsanspruch basiert auf der Form der gesetzlichen Lizenz über die

${ }^{186} \mathrm{Vgl}$. Schack, Haimo, op. cit., S. 364.

${ }^{187} \mathrm{Vgl}$. Hubmann/Rehbinder, op. cit., S. 78.

$188 \mathrm{Vgl}$. Drexl, Josef, op. cit., S. 225.

${ }^{189}$ Ein nationales Vervielfältigungsrecht haben die meisten Vertragsstaaten des RA bereits eingeführt. Eine Ausnahme bilden lediglich Costa Rica und Niger. Vgl. Drexl, Josef, op. cit., S. 226.

190 Im deutschen Recht $\S 85$ Abs. 1 UrhG.

191 In den USA gelten Tonträger als urheberschutzfähige Werke, die nur Schutz erlangen, wenn die im amerikanischen Urheberrecht verlangten Formvorschriften erfüllt sind. Vgl. Wagner-Silva Tarouca. Beatrice. op. cit., S. $75 \mathrm{f}$. 
Zweitverwertung. Die Ausgestaltung der Wahrnehmung des Vergütungsanspruches wird den nationalen Gesetzgebern überlassen. Anspruchsinhaber sind ausübende Künstler und Tonträgerhersteller. Der Benutzer soll jedoch die Vergütung nur einmal zahlen. Deswegen sind theoretisch fünf Modelle denkbar. ${ }^{192}$ Erstens ein Zahlungsanspruch nur für die ausübenden Künstler, zweitens nur für die Tonträgerhersteller, drittens ein gemeinsamer Anspruch beider Gruppen gegenüber dem Benutzer, viertens alleiniger Anspruch der ausübenden Künstler gegenüber dem Benutzer und ein Anspruch der Tonträgerhersteller gegenüber den ausübenden Künstlern im Innenverhältnis und füntens schließlich ein alleiniger Anspruch der Tonträgerhersteller gegenüber dem Benutzer und ein Anspruch der ausübenden Künstler gegnüber dem Tonträgerhersteller im Innenverhältnis. Alle rechtlichen Möglichkeiten wurden in verschiedenen Vertragsstaaten in ihrem nationalen Gesetzen gewählt. Ebenso wird die Erhebung und Verteilung der Vergütung teilweise kollektiv über Verwertungsgesellschaften, ${ }^{193}$ teilweise individuell durch die Rechtsinhaber geregelt.

Die Mindestschutzdauer beträgt nach Art. 14 RA zwanzig Jahre ab dem Ende des Jahres der ersten Festlegung für die Tonträgerhersteller. ${ }^{194}$ Das RA folgt nicht dem Grundsatz des Schutzfristenvergleichs, wie er in den bereits beschriebenen Urheberrechtskonventionen vollzogen wird. Man war sich bei der Aushandlung des Vertragstextes der unterschiedlichen Schutzdauern in den beteiligten Staaten durchaus bewußt. Allerdings ging man davon aus, da $\beta$ ein weitgehender Ausgleich für die nach dem Ablauf der Schutzfrist ungünstigere Situation in einem Land durch die dortigen wettbewerbsrechtlichen Vorschriften möglich sein werde. ${ }^{195}$ Dieses ist rechtlich kritisch zu bewerten, da dem wettbewerbsrechtlichen Schutz nur eine subsidiäre Anwendung zukommt. Für Deutschland ist nach herrschender Meinung nicht von einem Wettbewerbsschutz auszugehen, auch nicht nach dem Ende des leistungsrechtlichen Schutzes. $^{\text {!ox }}$

Die sonstigen Regelungen des RA betreffen die diskriminierenden Ausnahmen von der Inländerbehandlung und das allgemeine Mindestschutzprinzip. Art. 16 Abs. 1a (iii) RA erlaubt Vertragsstaaten, die Anwendung des Vergütungsanspruchs nach Art. 12 RA nicht anzuwenden, sofern der Tonträgerhersteller nicht Angehöriger eines Vertragsstaates ist. ${ }^{197}$ Den Vorbehalt materieller Gegenseitigkeit (Reziprozität) bei der Gewährung der Vergütungsansprüche für

$192 \mathrm{Vgl}$. Drexl, Josef, op. cit., S. 229.

193 So im deutschen Gesetz über die Wahrnehmung von Urheber- und Leistungsschutzrochten (WahrnG), vgl. Abschnitt 2.1.4.

$194 \mathrm{Vgl}$. Hubmann/Rehbinder, op. cit., S. 79.

195 Vgl. Nordemann/Vinck/Hertin 1977, op. cit., S. 321, Art 14 RA, Rn. 3.

$196 \mathrm{Vgl}$. Drexl, Josef, op. cit., S. 232, und Schricker, Gerhard, op. cit., Einl., Rn. 39.

197 Diese Vorbehalte bestehen in der Möglichkeit, nach vorheriger Mitteilung an den Generalsekretăr der UNO, Art. 12 RA vollkommen auszuschließen, für bestimmte Benützungen nicht anzuwenden, die Anwendung für Hersteller auszuschließen, die nicht Angehörige eines Vertragsstaates sind, und den Schutz von Angehörigen anderer Vertragsstaaten auf den Umfang und die Dauer des Schutzes zu beschränken, den der andere Vertragsstaat den Angehörigen des Vorbehaltsstaates gewährt. Vgl. Drexl, Josef, op. cit, S. 228 und die Fn. 76 - 79. Zur genaueren Beschreibung der bestimmten Benützungen Nordemann/Vinck/Hertin 1977, op. cit., S. 326, Art. 16 RA, Rn. 3. 
öffentliche Wiedergabe von Tonträgern gemäß Art. 12 RA hat Deutschland eingelegt. ${ }^{198}$ Die Schranken der Inländerbehandlung im RA aufgrund des Zwecks des Maximalschutzprinzips bestehen im Interessenausgleich zwischen Leistungserbringern untereinander und zwischen Leistungserbringern und Urhebern. Für den Interessenausgleich zwischen den nach dem RA geschützten Gruppen ist die Bestimmung des Art. 12 RA entscheidend. Sie beschränkt die Rechte der ausübenden Künstler und Tonträgerhersteller zugunsten der Sendeunternehmen. Sieht ein Vertragsstaat in seinem nationalen Recht nicht nur einen Vergütungsanspruch, sondern ein ausschließliches Recht der Zweitverwertung vor, ist fraglich, ob durch das RA geschützte Personen das günstigere nationale Recht über die Inländerbehandlung in Anspruch nehmen können. ${ }^{199}$ Die Inländerbehandlung als grundlegendes Prinzip wird im RA nur durch die Vorbehalte eingeschränkt, die durch materielle Reziprozität eine Diskriminierung konventionsgeschützter Leistungsschutz-Rechtsinhaber ermöglicht.

\section{Abbildung 7: Schutz der Tonträgerhersteller nach dem RA}

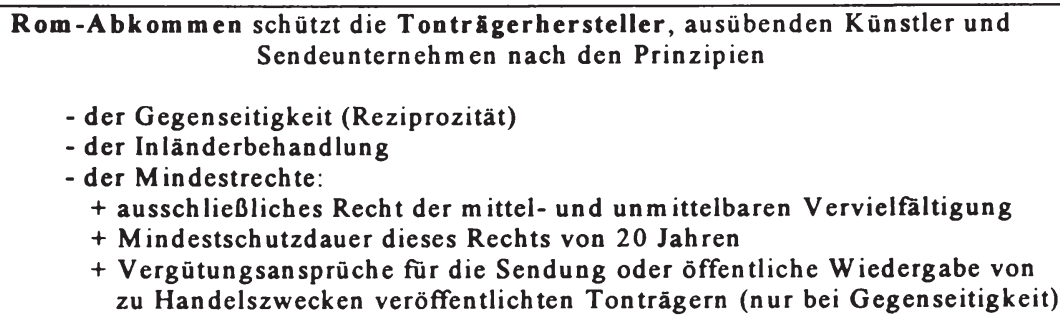

Das RA hat den erhofften globalen Geltungsanspruch bisher nur unzureichend erfullt. Dies liegt einerseits an der vergleichsweise noch immer geringen Zahl der Vertragsstaaten, andererseits daran, daß viele Staaten diese Rechtsmaterie noch nicht innerstaatlich geregelt haben. ${ }^{200}$ Angesichts neuerer technischer Entwicklungen wurde eine Anpassung des Schutzes durch Sonderabkommen mit jeweils konkretem Gegenstand versucht und schließlich im Rahmen der WIPOKonferenz durch den World Performances and Phonograms treaty vom 20.12.96 verwirklicht. Dieses neueste internationale Abkommen zu den verwandten Schutzrechten wird in Kapitel 5 behandelt. Für die körperliche Musikverwertung mit Hilfe von Tonträgern ist das Genfer Tonträgerabkommen das für den Tonträgermarkt relevante Rechtsabkommen.

\footnotetext{
198 Vgl. Schack, Haimo, op. cit., S. 365

199 Vgl. De Sanctis, Valerio, La Convenzione Internazionale per la protezione degli artisti interpreti o esecutori, dei produttori di fonogrammi e degli organismi di radiodiffusione, Rom 1963, S. 141.

${ }^{200} \mathrm{Vgl}$. Drexl, Josef, op. cit., S. $252 \mathrm{f}$.
} 


\subsubsection{Genfer Übereinkunft zum Schutz von Tonträgerherstellern}

Motivation für das Übereinkommen zum Schutz der Hersteller von Tonträgern gegen die unerlaubte Vervielfältigung ihrer Tonträger (GTÜ) vom 29.10.1971 war der weltweite Anstieg der Tonträgerpiraterie Ende der sechziger Jahre. ${ }^{201}$ In Ländern mit gesetzlichem Tonträgerschutz überwiegt das Kopieren der Tonträger auf Leerkassetten, während in Ländern ohne Schutz die nicht genehmigte Produktion von Tonträgern verstärkt anzutreffen ist. ${ }^{202}$ Mit Stand vom 1.1.1997 gehören dem GTÜ 55 Vertragsstaaten einschließlich den USA und der Volksrepublik China an. ${ }^{203}$ Das GTÜ verzichtet auf die vorherige Anerkennung anderer Urheber- und Leistungsschutzrechtsabkommen, um als offenes Abkommen allen Staaten zugänglich zu sein, und den Zweck, einen wirksamen Schutz gegen die Tonträgerpiraterie aufzubauen, möglichst umfassend $\mathrm{zu}$ erfüllen. ${ }^{204}$ Geschützt wird nur vor direkten Verwertungshandlungen, jedoch umfangreicher als im RA durch Schutz sämtlicher Vorstufen der Veröffentlichung über Herstellung, Einfuhr und Vertrieb an den Endverbraucher. ${ }^{205}$ In der Wahl eines geeigneten Rechtsinstrumentariums sind die Vertragsstaaten frei, jedoch haben sie sich an die Zielsetzung der GTÜ zu halten und dürfen - anders als beim RA - keine Vorbehalte geltend machen. Die obligatorische Mindestschutzdauer für veröffentlichte Tonträger beträgt 20 Jahre.

In Art. 1 GTÜ werden zunächst die Begriffe Tonträger, Tonträgerhersteller, Vervielfältigungsstück und Verbreitung an die Öffentlichkeit definiert. Hierbei ergeben sich keine Änderungen zur der im RA benützten Definition. Art. 2 GTÜ bestimmt, daß jeder Vertragsstaat die Hersteller von Tonträgern anderer Vertragsstaaten gegen die Herstellung von Vervielfältigungsstücken ohne Zustimmung des Herstellers schützt, sofern die Vervielfältigung zum Zweck der Verbreitung an die Öffentlichkeit erfolgt. Der Schutz vor unbefugter Vervielfältigung und Verbreitung nach dem GTÜ ist als Schutzpflicht der Vertragsstaaten kein Individualrecht, das Tonträgerhersteller unmittelbar einfordern könnten. Dazu müssen die Vertragsstaaten gemäß Art. 3 GTÜ Bestimmungen des Urheberrechts, des Rechts über unlauteren Wettbewerb oder des Strafrechts erlassen. Die Bestimmungen des Urheberrechts zu diesem Zweck sind für das deutsche Recht in Abschnitt 2.1.3 und auf europäischer Ebene in Abschnitt 2.2.1 ausführlich beschrieben worden. Die Bestimmungen zum unlauteren Wettbewerb setzen an dem unmittelbaren Akt der Piraterie oder der Leistungsentnahme an. ${ }^{206}$ Das Wettbewerbsrecht erscheint aber nur als flankierende Maßnahme, nicht jedoch als alleiniger Schutz i. S. des GTÜ geeignet. Was den strafrechtlichen Schutz angeht, so bedarf die Piraterie, wie sie in Art. 2 GTÜ beschrieben wird, einer Verbotsnorm. Zusätzlich ist ein privater Unterlassungs- und

201 Vgl. Nordemann/Vinck/Hertin 1977, op. cit., S. 343, vor Art. 1 GTÜ, Rn. 1.

202 Vgl. Jehoram, Cohen, Kritische Überlegungen zur wirtschaftichen Bedeutung des Urheberrechts, in: GRUR/I, Vol. 91 (1989), S. 26, und BPW 1997, op. cit., S. 44 f., und für einen systematischen Überblick über Tonträgerpiraterie, Schaefer, Martin, und Manfred Körfer, Tonträgerpiraterie: Ein Leitfaden für die Praxis, Starnberg 1995.

203 Vgl. Katzenberger, Paul, supra, S. 455.

${ }^{204}$ Kritiker behaupten jedoch, daß der im GTÜ gewăhrte Schutz, der allein an der Staatsangehörigkeit des Tontrăgerherstellers anknüpf, sehr schwach ist, und deswegen mehr Vertragsstaaten die GTÜ unterschrieben haben. Vgl. Schack, Haimo, op. cit., S. 365.

${ }^{205} \mathrm{Vgl}$. Nordemann/Vinck/Hertin 1977, op. cit., S. 344, vor Art. I GTÜ, Rn. 4.

206 Vgl. Nordemann/Vinck/Hertin 1977, op. cit., S. 354, Art. 3 GTÜ, Rn. 5. 
Schadensersatzanspruch vorzusehen. Im deutschen Recht ist die durch UrhG verbotene Handlung der Tonträgerpiraterie zu unterlassen, der unerlaubt Handelnde ist nach § 823 BGB schadenersatzpflichtig. Die in Art. 5 GTÜ geforderten Formvorschriften sind mit denjenigen des RA identisch.

Durch den Beitritt der USA und Chinas zum GTÜ ist dessen Bedeutung gewachsen. Die Probleme einer effektiven Beschränkung der Herstellung und des Vertriebs unautorisierter Tonträger liegen in der Schwierigkeit der Identifizierung der illegalen Ware und der Rechtsdurchsetzung. ${ }^{207}$ Die asiatischen Hauptexporteure von Piraterietonträgern sind nicht Mitglied der GTÜ oder widersetzen sich der Forderung nach einer verstärkten Verfolgung der lukrativen Raubkopier- und Schwarzpressindustrie. ${ }^{208}$ Ökonomisch kommt eine mangelhafte Strafverfolgung oder gar eine vollkommene Schutzversagung einer Exportförderung der kostengünstiger herstellbaren, nachgefertigten Tonträger gleich. Im Rahmen des General Agreement on Trade and Tariffs (GATT) entspricht dies einer Ausfuhrsubvention. ${ }^{209}$ Ziel eines wirksameren Schutzes für Tonträgerhersteller war es also, im Rahmen des GATT zu einer Vereinbarung zu kommen, die den Bereich des Handels mit auf geistigem Eigentum basierenden Gütern mit anderen handelspolitischen Fragen verknüpft und so das Interesse der genannten Staaten zur Beseitigung der illegalen Nachahmungsindustrie weckt. Ein solches Abkommen ist im Rahmen des GATT mit dem Trade Related Aspects on Intellectual Property Rights (TRIPs) beschlossen worden

\subsubsection{Abkommen über handelsbezogene Aspekte geistigen Eigentums im GATT}

Nachdem die 1986 begonnene Uruguay-Runde des GATT am 15.12.1993 abgeschlossen und am 15.4.1994 unterzeichnet wurde, ist die neue Welthandelsorganisation (World Trade Organization) WTO zum 1.1.95 gegründet worden. Im Rahmen der Übereinkommen zur WTO wurde das Abkommen über handelsbezogene Aspekte der Rechte des geistigen Eigentums getroffen (Agreement on Trade-Related Aspects of Intellectual Property Rights - TRIPs). ${ }^{210}$ Ziele dieses Abkommens sind die Förderung des wirksamen und angemessenen Schutzes der Rechte des geistigen Eigentums unter Berücksichtigung der Tatsache, daß Maßnahmen und Verfahren zur Durchsetzung dieser Rechte nicht selbst zu Schranken des rechtmäßigen Handels werden. Die bestehenden Unterschiede in den nationalen Rechtsordnungen wirken wie nichttarifäre Handelshemmnisse. Daher heißt es für die Harmonisierung in Art. 1 Abs. $1 \mathrm{~S} .2$ TRIPs: „Die Mitgliedstaaten können in ihr Recht einen umfassenderen Schutz als den im TRIPs geforderten aufnehmen, wenn er nicht den Zielsetzungen des Abkommens zuwiderläuft.“

Die Motivation zu diesem Abkommen liegt in der zunehmenden wirtschaftichen Bedeutung des Handels mit geistigen Gütern, den Defiziten des traditionellen internationalen Schutzes der

${ }^{207}$ Zur Rechtsdurchsetzung vgl. ausfuihrlich Abschnitt 3.2.3.

208 Vgl. Katzenberger, Paul, supra, S. 448 f.

${ }^{209} \mathrm{Vgl}$. Drexl, Josef, op. cit., S. 287.

210 Vgl. BGBI. 1994 II S. 1730 (deutsche Fassung) und o. V., in: GRUR/, Vol. 96 (1994), S. 128 (englische Fassung). 
weiter oben beschriebenen internationalen Abkommen und in der mangelnden Wirksamkeit einseitiger bzw. bilateraler Schutzalternativen. Einer Schätzung zufolge liegt der Anteil der unrechtmäßig hergestellten Tonträger weltweit bei ca. einem Viertel aller Tonträger mit entsprechenden Verlusten der legalen Industrie. ${ }^{211} \mathrm{Da}$ die bisherigen Abkommen lediglich isoliert die Urheber- und verwandten Schutzrechte betreffen, geht von ihnen kein allgemeiner handelspolitischer Anreiz zum Beitritt und zur Weiterentwicklung aus. Der Vorteil des TRIPsAbkommen besteht darin, daß es die Rechte des geistigen Eigentums mit den Vorteilen des internationalen Freihandels verknüpft. Zum Zeitpunkt des Inkraftretens (1.1.95) waren im GATT 125 Staaten Mitglied, ${ }^{212}$ von ihnen waren 30 nicht Mitglied der RBÜ oder des WUA. Nach Art. 2 Abs. 2 TRIPs gelten sowohl die RBÜ als auch das RA fort. Aufgrund der lex posterior-Regel ersetzen bei aufeinanderfolgenden völkerrechtlichen Verträgen, die denselben Gegenstand regeln, die jüngeren die älteren Verträge. Da aber das TRIPs-Abkommen im Vergleich zu den vorhergehenden ein allgemeineres Abkommen ist, gelten dessen Bestimmungen wegen der Regel generalia specialibus non derogant weiter. ${ }^{213}$ Alle Abkommen gelten demnach nebeneinander und sind zu beachten. Die Mitglieder des TRIPs befolgen die Art. 1 bis 21 der RBÜ. Nach Art. 9 Abs. 1 S. 1 TRIPs werden alle Mitgliedstaaten, die die RBÜ nicht unterzeichnet haben, zur Schutzgewährung nach deren Standard verpflichtet. ${ }^{214}$ Eine Schutzgewährung nach dem Rom-Abkommen ist im TRIPs jedoch nicht vorgesehen.

Zusätzlichen Schutz bietet Art.11 TRIPs zum Vermietrecht, welches durch EU-Richtlinie zwar schon in Europa eingeführt wurde, aber in der RBÜ noch nicht berücksichtigt war. ${ }^{215}$ Der Anwendungsbereich des TRIPs betriff alle Urheber, die einem Verbandsland angehören, sowie die nicht einem Verbandsland angehörenden Urheber für ihre Werke, die erstmals in einem Verbandsland veröffentlicht wurden. Was die innerstaatliche Anwendbarkeit von TRIPs angeht, bedarf es nach deutschem Recht nur eines Zustimmungsgesetzes. In der EU sind die Bestimmungen des TRIPs qua Gemeinschaftsrecht unmittelbar anwendbar. ${ }^{216}$

Die materiellen Regeln des TRIPs bestehen aus den Prinzipien der Territorialität, der Inländerbehandlung, Meistbegünstigung und des Mindestschutzes. Das Territorialitäts- und Schutzlandprinzip besagt, daß der Schutz des Landes gewährt wird, in dem die erste Festlegung oder Veröffentlichung des Tonträgers erfolgt ist. Als Mitglied des GATT muß der Staat also die in TRIPs vorgesehenen Rechte gewähren. In Art. 3 TRIPs wird das Prinzip der Inländerbehandlung geregelt, welches ebenso für die RBÜ gilt und dort erklärt wurde. ${ }^{217}$ Die TRIPsInländerbehandlung unterliegt denselben Ausnahmen wie diejenige der RBÜ, welche sich in bezug auf den Schutzfristenvergleich auch auf die in TRIPs weitergehenden Rechte beziehen. Für den Bereich der verwandten Schutzrechte hat die Inländerbehandlung im TRIPs jedoch eine besondere Bedeutung, weil das RA von TRIPs nicht übernommen wird, sondern eigen-

211 Quelle für diese Schătzung: Jehoram, Cohen, supra, S. 23 und 26.

212 Vgl. Katzenberger, Paul, supra, S. 451.

${ }^{213}$ Für eine andere Meinung vgl. Schack, Haimo, op. cit., S. 373.

214 Vgl. Katzenberger, Paul, supra, S. 456.

${ }^{215}$ Zum Vermietrecht innerhalb der EU vgl. Abschnitt 2.2.1.

${ }^{216} \mathrm{Vgl}$. Katzenberger, Paul, supra, S. 459.

217 Vgl. hierzu Abschnitt 2.3.1. 
ständige Rechte normiert werden. ${ }^{218}$ Die Inländerbehandlung gilt demnach in bezug auf ausübende Künstler, Hersteller von Tonträgern und Sendeunternehmen nur für die durch TRIPs selbst gewährten Rechte. Daraus folgt in der Rechtsumsetzung, da $\beta$ die Mitgliedstaaten des TRIPs nicht verpflichtet sind, anderen Angehörigen dieses Abkommens, die aber nicht Mitglieder des RA sind, aufgrund der Inländerbehandlung Rechte zu gewähren, die TRIPs nicht enthält. Angesichts einer Steigerung des Schutzniveaus in TRIPs im Vergleich zum RA dürte die praktische Relevanz dieser Grenze der Inländerbehandlung nicht groß sein.

Die Meistbegünstigung, wie sie in Art. 4 TRIPs normiert wurde, ist eine Neuheit in internationalen Urheberrechtsabkommen und hat ihren Ursprung in den Grundprinzipien des GATT. Das Prinzip der Meistbegünstigung hat zur Folge, daß die TRIPs-Mitgliedstaaten am höchsten Schutzniveau aller bestehenden und zukünftigen Urheber- und verwandten Schutzrechtsabkommen teilhaben, die mindestens ein einzelnes TRIPs-Mitgliedsland abgeschlossen hat bzw. abschließen wird. Andererseits müssen die anderen Mitgliedstaaten im TRIPS den Abkommen mit höherem Schutzniveau nicht beitreten und auch nicht deren Schutz gewähren, sondern nur die im TRIPs garantierten Mindestrechte gewährleisten. Würde das Meistbegünstigungsprinzip ohne Ausnahmen gelten, wären weitere Abkommen auf dem Gebiet des Urheberrechts wegen des induzierten Trittbrettfahrereffekts wohl nicht zu erwarten. ${ }^{219}$ Deswegen sind in Art. 4 TRIPs Ausnahmen von der Meistbegünstigung vorgesehen. Nach Art. 4 S. 2 Buchstabe b) sind solche Vorteile von der Meistbegünstigung ausgenommen, die sich aufgrund von Bestimmungen der RBÜ oder des RA ergeben, die die gewährte Behandlung nicht von der Inländerbehandlung abhängig machen, sondern von der in einem anderen Land gewährten Behandlung. Diese Ausnahme bezieht sich auf alle Regelungen der genannten Konventionen, die materielle Reziprozität vorsehen, wie z. B. den Schutzfristenvergleich. ${ }^{220}$ Eine zweite Ausnahme bezieht sich auf die Leistungsschutzrechte der ausübenden Künstler, Hersteller von Tonträgern und Sendeunternehmen, die nicht im TRIPs geregelt sind, aber in anderen Abkommen gewährt werden. ${ }^{221}$ Schließlich wird von der Meistbegünstigung abgesehen in bezug auf die internationalen Übereinkünfte betreffend den Schutz des geistigen Eigentums, die vor dem Inkraftreten des TRIPs im GATT rechtlich wirksam geworden sind. ${ }^{222}$ In der Rechtsfolge des oben diskutierten Phil Collins-Urteils des EuGH ${ }^{223}$ wirkt der Art. 6 Abs. 1 EGV vorteilhaft zugunsten der Angehörigen anderer EU-Mitgliedstaaten und anderer nicht EU-Mitgliedstaaten, die Mitglied

${ }^{218} \mathrm{Vgl}$. Katzenberger, Paul, supra, S. 460.

219 Okonomisch gesehen ist die Wirkung eines bilateralen Abkommens eines TRIPs-Landes mit irgendeinem anderen Staat diejenige eines offentlichen Gutes. Das vertragschließende Land hat die Aushandlungskosten zu tragen und das höhere Schutzniveau zu gewăhren und zwar gegenüber allen anderen TRIPs-Mitgliedern, ohne daß diese ihrerseits den höheren Schutz gewăhren. Durch das Prinzip der Meistbegünstigung können die anderen TRIPs-Lander nicht vom Nutzen des bilateralen Vertrags ausgeschlossen werden, die Kosten verbleiben aber nur den zwei vertragschließenden Parteien. Daher ist es ökonomisch rational, daß der Abschluß weiterer Verträge unterbleibt, solange der Nutzen nicht internalisiert werden kann, $d$. $\mathbf{b}$. nur bei den vertragsschließenden Parteien verbleibt. So auch Katzenberger, Paul, supra, S. 461, der aber keinen offentlichen Gutscharakter herausarbeitet, sondern nur nach Plausibilität urteilt.

${ }^{220}$ So z. B. die Vorbehaltsregelungen des Art. 16 Abs. la (iii) und (iv) RA, die in Abschnitt 2.3.3 genauer beschrieben wurden.

221 Diese Ausnahme entspricht der Beschränkung der Inlănderbehandlung des Art. 3 Abs. I S. 2 TRIPs.

${ }^{222}$ Vgl. Art. 4 S. 2 Buchstabe d) TRIPs.

${ }^{223}$ Vgl. oben Abschnitt 2.2.2. 
des TRIPs sind. Da nach Art. 4 S. 1 TRIPs in Verbindung mit Art. 6 EGV die innerhalb der EU gewährten Rechte sofort und bedingungslos auch den Angehörigen aller anderen Mitglieder des GATT zu gewähren sind. Dadurch wird das Meistbegünstigungsprinzip in der EU vorrangig und die Bedeutung der Ausnahmen innerhalb der EU wird zweifelhaft.

Wie bereits oben erwähnt, dürfen nach Art. 1 Abs. 1 S. 2 TRIPs die Mitglieder in ihr Recht einen umfassenderen Schutz aufnehmen als er durch dieses Abkommen gewährt wird. Das TRIPs-Abkommen folgt damit wie die anderen internationalen Urheberrechtsabkommen auch dem Prinzip des Mindestschutzes. Abschließend soll auf spezielle Regelungen im TRIPs bzgl. Urheberrechte und verwandte Schutzrechte eingegangen werden. Hierbei handelt es sich um die Vermietrechte, die Mindestschutzdauer und den Schutz von ausübenden Künstlern, Tonträgerherstellern und Sendeunternehmen. Nach Art. 11 TRIPs haben die Urheber von Werken ein ausschließliches Recht, die gewerbliche Vermietung ihrer Werke an die Öffentlichkeit zu gestatten. Dies gilt nach Art. 14 Abs. 4 S. 1, der auf Art. 11 verweist, auch für das Vermietrecht an Tonträgern. Verfügt ein Mitgliedstaat von TRIPs bereits über ein Vergütungssystem für die Tonträgervermietung, so kann es dieses beibehalten, sofern dadurch die ausschließlichen Vervielfältigungsrechte der Rechtsinhaber nicht erheblich beeinträchtigt werden. ${ }^{224}$ Durch die Möglichkeit, bestehende Vergütungssysteme beizubehalten, wird der Zweck des ausschließlichen Vermietrechts in Frage gestellt. Ziel scheint daher zu sein, die Einkommensverluste der Rechtsinhaber zu begrenzen.

Die Mindestschutzdauer nach Art. 12 TRIPs beträgt 50 Jahre. Der Schutz ausübender Künstler, Hersteller von Tonträgern und Sendeunternehmen basiert zwar nicht auf den Bestimmungen des RA, aber Art. 14 Abs. 6 S. 1 TRIPs gestattet es den Mitgliedstaaten, an die in Art. 14 Abs. 1 bis 3 TRIPs zu gewährenden Rechte dieselben Bedingungen, Beschränkungen, Ausnahmen und Vorbehalte anzuwenden, die das RA vorsieht. ${ }^{225}$ Durch die in Art. 14 Abs. 6 S. 2 TRIPs bestimmte Anwendung von Art. 18 RBÜ wird der Schutz von TRIPs auch auf schon veröffentlichte Tonträger ausgedehnt, sofern ihre Schutzfrist nach dem RA nicht schon abgelaufen ist. Die Hersteller von Tonträgern haben nach Art. 14 Abs. 2 TRIPs das Recht, die unmittelbare oder mittelbare Vervielfältigung ihrer Tonträger zu erlauben oder zu verbieten. Nach Art. 14 Abs. 4 S. 1 steht ihnen ebenfalls ein ausschließliches Vermietrecht zu, mindestens aber, bei Existenz eines nationalen Vergütungssystems, eine angemessene Vergütung für die erfolgte Vermietung. Die Mindestschutzdauer für die Rechte der Tonträgerhersteller beträgt 50 Jahre nach Art. 14 Abs. 5 S. 1 TRIPs. Damit wird die durch das RA bestehende Schutzdauer erheblich verlängert.

Das TRIPs erhöht einerseits die Schutzdauer für Tonträgerhersteller und vergrößert zweitens die Wirkung des Urheber- und Leistungsschutzes wegen der größeren Anzahl ihrer Mitgliedstaaten. Drittens aber führt es mit der Meistbegünstigung ein Prinzip in das internationale Urheberrecht ein, welches - wie oben gezeigt - die Schutzwirkung und die Weiterentwicklung des

\footnotetext{
${ }^{224}$ In den USA sind Tonträgerhersteller Urheber, in den Staaten der EU werden sie als Leistungsrechtsinhaber angesehen, für die die verwandten Schutzrechte gelten.

${ }^{225} \mathrm{Vgl}$. Katzenberger, Paul, supra, S. 467.
} 
Schutzumfanges erheblich stören kann. Es bleibt jedoch abzuwarten, ob die wirtschaftlichen Interessen der Urheberindustrien durch die Regierungen der betroffenen Volkswirtschaften im Rahmen der neugegründeten World Trade Organization (WTO) effektiv vertreten werden.

\subsubsection{Anwendung des Rechts der internationalen Urheberabkommen}

Die internationalen Abkommen auf dem Gebiet des Urheberrechts und verwandter Schutzrechte sind stetig weiterentwickelt worden. Dabei ist die Rechtsetzung, ausgehend von der ersten Fassung der Berner Übereinkunft am Ende des 19. Jahrhunderts, ständig hinter der technischen Entwicklung $^{26}$ zurückgeblieben. Insbesondere die weltweite Vernetzung von Computern mit der Möglichkeit der Datenfernübertragung hat das Risiko unkontrollierter Verbreitung geschützter Werke und Leistungen erhöht. Daher ist zu begrüßen, daß mit dem TRIPs-Abkommen im GATT erstmals urheberrechtliche Fragen mit allgemeinen handelspolitischen Fragen verknüpft wurden. Angesichts der weiter steigenden Bedeutung der Urheberrechtsindustrien und der weiteren technischen Entwicklung ist die Aufnahme der internationalen Regeln in die Welthandelsorganisation unabdingbar. Die Fortgeltung der bisherigen Abkommen RBÜ, WUA, RA und GTÜ ergänzt das im TRIPs vereinbarte Schutzniveau für diejenigen Länder, die (noch) nicht Mitglied in der WTO sind. Deren Zahl dürfte im Zeitablauf sinken, da die Vorteile der Handelserleichterungen ${ }^{27}$ für Mitglieder der WTO einen starken Anreiz zum Beitritt ausüben. Fraglich bleibt, ob das durch das TRIPs neu eingeführte Prinzip der Meistbegünstigung einer Fortentwicklung des internationalen Urheberrechts entgegensteht oder ob nicht allgemein über neue nationale Gesetze der Schutz für Urheber und Leistungsrechtsinhaber erhöht wird.

Was die Rechtsdurchsetzung anbelangt, bringt das TRIPs eine Reihe von Neuerungen, die in Art. 41 bis 61 TRIPs enthalten sind. Auf europäischer Ebene zeigt die Rechtsprechung des $\mathrm{EuGH}^{228} \mathrm{daB}$ Rechtsinhaber zur Wahrnehmung ihrer Rechte, teilweise auch gegen die mit ihren Interessen betrauten Verwertungsgesellschaften, vor Gericht diese Rechte durchsetzen können. Für die Harmonisienungsbestrebungen innerhalb der EU sind die Urheberrechte eine weitere Plattform, auf der sowohl EU-Kommission als auch EuGH den Vorrang des europäischen Rechts vor den nationalen Gesetzen demonstrieren können. Auf der Ebene des GATT war bisher stets eine bilaterale Einigung in Streitfragen üblich. Die o. g. Artikel des TRIPs sollen nun die Streitlösung durch die Instanz der WTO-Schiedsstelle fördern. Ob die Bestimmungen im TRIPs dazu beitragen können, die Konflikte bzgl. der Piraterie, des geistigen Diebstahls und der Grauimporte zu entschärfen bzw. beizulegen, wird erst die Zukunft zeigen.

\subsection{Zusammenfassung}

Die Grundlage für einen Rechtsschutz der Tonträgerhersteller ist das Urheberrecht. Komponisten und Textdichter erschaffen Musikstücke, welche nach $\S 2$ Abs. 2 des deutschen UrhG als

\footnotetext{
${ }^{226} \mathrm{Vgl}$. hierzu die Ausfuhrungen zur tochnischen Entwicklung in Abschnitt 1.2.

${ }^{227}$ Drexl sieht einen Zielkonflikt zwischen der prinzipiellen Freiheit des Warenverkehrs und dem Schutz des geistigen Eigentums. Vgl. Drexl, Josef, op. cit., S. 376.

${ }^{228}$ Vgl. hierzu die Erlăuterungen zur Bedeutung der Entscheidungen des EuGH in Abschnitt 2.2.2.
} 
Werke anerkannt werden müssen, um einen Schutz zu erlangen. Bis auf wenige Ausnahmen ist bei Musikstücken wegen der sog. kleinen Münze die Anerkennung als Werk stets gegeben. Die Urheber als Werkinhaber übertragen den Tonträgerherstellern direkt oder über Verwertungsgesellschaften die für die Tonträgerherstellung nötigen Rechte. Es handelt sich um Veröffentlichungs-, Vervielfältigungs- und Verbreitungsrechte nach den $\S \S 12,15$ Abs. 1, 16 und 17 UrhG; ferner um das Recht der Wiedergabe auf Tonträgern nach § 21 UrhG. Die Leistung der Tonträgerhersteller basiert auf derjenigen der Musikurheber. Wegen ihres qualifizierten technischen Anteils an der Musikverwertung genießen die Tonträgerhersteller Schutz nach den verwandten Schutzrechten (sog. Leistungsschutzrechte). Nach $\S 85$ Abs. 1 deutsches UrhG ist dieses Schutzrecht auf Vervielfältigung und Verbreitung beschränkt. Nach $\S 86$ haben Tonträgerhersteller bei öffentlicher Wiedergabe, z. B. in Diskotheken, einen Vergütungsanspruch, der sich aber nur gegen die ausübenden Künstler der Musikaufnahme richtet und über die Verwertungsgesellschaft GVL wahrgenommen wird. Nach mehreren Gesetzesänderungen (zuletzt 1995) haben die Tonträgerhersteller das Recht, die gewerbliche Weitervermietung ihrer Tonträger zu untersagen. Kein Ausschlußrecht haben sie dagegen bei privater Vervielfältigung. Hier steht ihnen nur eine Vergütung nach $\S 54 d$ Abs. 1 UrhG zu, erhoben als Aufnahmegeräteund Leerkassettenabgabe über die Inkassostelle der Verwertungsgesellschaften ZPÜ. Sämtliche genannten Rechte gelten 50 Jahre ab der ersten Festlegung der Musikstücke auf Tonträger bzw. Veröffentlichung der Tonträger.

In der Europäischen Union wurden die Leistungsschutzrechte mit Hilfe von Richtlinien weitgehend harmonisiert. Die Harmonisienung betrifft die Schutzdauer und den Schutzumfang und stellt sicher, daß die für die Bundesrepublik Deutschland bereits oben dargestellten Bestimmungen für Tonträgerhersteller annähernd in allen Mitgliedstaaten gelten. Einzelne Benachteiligungen von Angehörigen anderer Mitgliedstaaten bei der Rechteverwertung durch die immer noch ausschließlich national organisierten Verwertungsgesellschaften wurden durch Gerichtsbeschluß des EuGH (Rechtssache Phil Collins u. a.) abgestellt. Bedeutende Unterschiede bestehen in der Frage privater Vervielfältigungen fort. Hier sind in verschiedenen Mitgliedsländern sowohl unterschiedliche Abgabesysteme und Abgabesätze anzutreffen als auch Mitgliedsländer, die privates Kopieren als "fair use“ ansehen und deswegen keine Abgaben geschaffen haben. Eine Angleichung über eine Richtlinie ist dringend erforderlich, da der EuGH die unterschiedlichen Regelungen für mit dem Binnenmarkt vereinbar hält bzw. die Kompetenz zur Rechtsetzung in dieser Frage der Kommission und den nationalen Regierungen zuweist. Unstrittig ist, daß die unterschiedliche Handhabung zu Wettbewerbsverzerrungen führt, insbesondere da durch eine zunehmende Vernetzung das private Kopieren vereinfacht werden wird.

Unabhängig von der Europäischen Union existieren seit 1961 das Rom-Abkommen und seit 1971 das Genfer Übereinkommen zum Schutz von Tonträgerherstellern. Diese Abkommen haben für die über 50 Teilnehmerstaaten ein Mindestschutzniveau geschaffen, das aber hinter demjenigen der Europäischen Union zurückbleibt. Als weltweite Leistungsschutzrechtsabkommen kranken die o. g. Abkommen an ihrer zu geringen Teilnehmerzahl. Erfolgreicher verspricht das 1994 unterzeichnete Abkommen über handelsbezogene Aspekte der Rechte geistigen Eigentums (TRIPs) im GATT zu werden. Es verknüpft erstmals urheber- und lei- 
stungsschutzrechtliche mit allgemein handelsrechtlichen Fragen. Der Kreis der Mitgliedstaaten der etablierten Handelsorganisation GATT ist zudem wesentlich größer als derjenige des Römischen und Genfer Abkommens. Allerdings bleibt abzuwarten, wieviele Staaten der nach Abschluß der Verhandlungen neugegründeten Welthandelsorganisation WTO (und damit dem TRIPs-Abkommen) beitreten werden. Zur Durchsetzung der beschlossenen Rechte, die dem europäischen Niveau nicht nachstehen, wurde eine Schiedsstelle bei der WTO eingerichtet. Inwieweit sie, ähnlich dem EuGH, die Allgemeinverbindlichkeit der Regeln des Handels mit auf urheberrechtlich geschütztem Eigentum basierenden Produkten sichern kann, kann bezweifelt werden. Der Umfang der Leistungsschutz-Rechtsverletzungen wird in Zukunft von den Ländern, die von und mit Nachahmungen profitierten, abgewogen werden mit den Vorteilen, die ihnen ein Beitritt zur WTO bietet.

Die Herstellung und der Vertrieb von Tonträgern ist nur eine von vielen ökonomischen Verwendungen, die einen Copyrightschutz benötigen. Aufgabe des folgenden Kapitels ist es daher, die Grundlagen der Ökonomie des Copyright darzulegen und für den speziellen Fall des Tonträgermarktes die Anreize des gegebenen rechtlichen Rahmens ökonomisch zu analysieren. 
Jürgen Kulle - 978-3-631-75477-1

Downloaded from PubFactory at 01/11/2019 04:31:24AM

via free access 
Die Produktion und der Handel mit Tonträgern geschieht in einem rechtlichen Rahmen von Urheber- und Leistungsschutzrechten. Das Produkt Tonträger ist die handelbare Festlegung von Musik auf einem Träger, z. B. einer CD oder einer MC. Anbieter im Tonträgermarkt sind die Tonträgerhersteller, die das marktfähige Produkt produzieren. Nicht vollständig integrierte Unternehmen bedienen sich der Leistung anderer. ${ }^{1}$ Nachfrager (im Sinne von Nachfragemittlern) in diesem Markt sind Händler, die als Facheinzelhändler oder als allgemeine Großbetriebsformen des Einzelhandels (Verbrauchermärkte) das Produkt Tonträger an die Konsumenten verkaufen.

Für die Produktion von Tonträgern stellt sich ungeachtet der beschriebenen tatsächlich existierenden Rechtsbestimmungen die Frage nach der ökonomischen Berechtigung für einen Rechtsschutz. Hierzu bieten die Theorie der öffentlichen Güter und die Ökonomie der Copyrights Erklärungsansätze. Im ersten Abschnitt dieses Kapitels (3.1) wird, ausgehend von einer Gutsdiskussion, die Frage beantwortet, ob Tonträger rein private Güter, Mischgüter oder öffentlich ausschließbare Güter sind. Im zweiten Abschnitt (3.2) wird zunächst auf den Analyserahmen im Hinblick auf ausschließliche Rechte, Vergütungsansprüche und ökonomische Effizienz eingegangen. Es wird gezeigt, unter welchen Bedingungen Schutzrechte ökonomisch effizient sind und welche Ergebnisse eine Schutzgestaltung ergibt. Dabei sind neben den Anreizen der Tonträgerhersteller - als Nachfrager von Musikkompositionen und Musikperformance - auch die des Handels und der Endverbraucher - als Nachfrager des Produktes Tonträger - zu berücksichtigen.

Die Internationalisierung des Urheberrechts bedingt eine Betrachtung der Austauschbedingungen für Tonträger zwischen den Staaten mit relevanten Marktumsätzen (3.3). Die Rechteverwertung ersetzt hier den klassischen Außenhandel mit dem körperlichen Produkt Tonträger. Daher sind die Rechte als Vorprodukt der Ansatzpunkt für Außenhandel. Zu klären ist, ob das bestehende Urheberrechtssystem die ökonomisch richtigen Anreize setzt, und welcher räumliche Maßstab angesichts der bestehenden kulturellen Unterschiede für das Urheberrecht bzw. verwandte Schutzrechte geeignet ist. Schließlich werden die theoretischen Ergebnisse mit einer empirischen Untersuchung der bestehenden Rechtssysteme konfrontiert. Eine Zusammenfassung (3.4) der ökonomischen Analyse beschließt dieses Kapitel.

1 Diese anderen Unternehmen sind z. B. selbständige Tonstudios, die das Mastertape erzeugen, Grafikbüros, die die Covergestaltung bewerkstelligen, reine Fertigungsfirmen, die die Vervielfaltigung bzw. das Brennen der Träger in Aufragsarbeit erledigen und schließlich Werbeagenturen, die das Marktangebot der Tonträger medienwirksam begleiten. Zur Fertigungstiefe und zum Integrationsgrad siche die industrieökonomische Analyse der Marktstruktur der Tonträgerhersteller in Abschnitt 4.2.2. 


\subsection{Copyrights für den Tonträgermarkt}

\subsubsection{Verschiedene Rechtsinstitutionen und deren Problematik}

Die effiziente Produktion von Tonträgern wäre theoretisch nicht anders herzuleiten als diejenige anderer privater Güter, ${ }^{2}$ wenn nicht der Inhalt der Tonträger - die Musik - der kaufentscheidende Teil des Produktes wäre. Es wird im folgenden unterschieden zwischen einem Informationsgut (der Musik) und dem Informationsträger (leerer Tonträger). ${ }^{3}$ Die im Handel erhältlichen bespielten Tonträger sind eine Kombination des Informationsgutes mit dem Informationsträger. Der bloße Tonträger als Informationsträger ist ohne Zweifel ein privates Gut, dessen Konsum rivalisiert, und dessen Ausschluß vom Konsum über den Kaufpreis mühelos zu bewerkstelligen ist. Bespielte Tonträger als Kombination des Informationsgutes - der auf Mastertape festgehaltenen Musik - mit dem Informationsträger - dem leeren Tonträger sind keine reinen privaten Güter, da eine Entkoppelung des Informationsgutes vom Informationsträger jederzeit möglich ist. Diese Entkoppelung bietet dem ursprünglichen Konsumenten des bespielten Tonträgers die Möglichkeit, weitere Verwertungen i. S. von Neukombinationen des Informationsgutes mit anderen Informationsträgern vorzunehmen.

Die gebräuchlichste Form der Weiterverwertung ist das Kopieren zu privaten oder gewerblichen Zwecken. ${ }^{4}$ Diese Art der Zweitverwertung kennzeichnet die Schwierigkeit, den Ausschluß technisch zu bewerkstelligen, und den Rechtsinhabern über den Verkauf von autorisierten Tonträgern Einkommen zu sichern. Für die Nachfrager (Konsumenten) ist nur entscheidend, welche Preisdifferenz zwischen einem Tonträgerkauf und den Kosten des Kopierens liegt, und ob die gleiche Qualität reproduzierbar ist oder ggfs. ein Qualitätsverlust durch den Freisunterschied gerechtfertigt wird. Daran mißt sich der Grad der Substituierbarkeit zwischen Originalangebot und Kopie. Der Frage nach dem ökonomischen Sinn und der volkswirtschaftlichen Bedeutung des Ausschlußmechanismus wird an späterer Stelle nachgegangen.

Das ökonomische Problem der Copyrights für den Tonträgermarkt liegt in der Nichtrivaltität im Konsum. Allen Tonträgerkategorien (LP, CD, MC) ist diesselbe Problemstruktur immanent. Ein Ausschluß vom Konsum des Informationsträgers ist über den Kaufpreis möglich, er ist aber durch die Nichtrivalität im Konsum des Informationsgutes Musik möglicherweise ökonomisch nicht effizient. Das Recht an der gehandelten Musik steht den Urheber zu, d. h.

2 Musgrave/Musgrave/Kullmer verwenden als klassisches Beispiel des privaten Gutes Äpfel. Vgl. Musgrave, Richard A., Peggy B. Musgrave und Lore Kullmer, Die offentlichen Finanzen in Theorie und Praxis, Bd. 1, 6.Aufl., Tübingen 1994, S. 69.

3 Die Unterscheidung zwischen einem Informationsgut und dem Informationstrager stammt von Pethig. Vgl. Pethig, Rüdiger, Copyrights and Copyright Costs: A new Price-Theoretic Approach, in: Journal of Institutional and Theoretical Economics (JITE/ZgS), Vol. 144 (1988), S. 462-495.

4 Eine andere Form der Weiterverwertung ist das digitale Sampling, bei dem die auf dem Tonträger befindliche Musik in einen Computer eingespeist wird. Die gespeicherte Musik ist dann in beliebig wăhlbare Teile zerlegbar, die sowohl neu zusammengesetzt werden können, als auch wiederholt, verzernt oder anders verfremdet werden können. 
den Komponisten der Musik. Das Recht wird vornehmlich an die sog. ausübenden Künstler verkauft, d. h. die Interpreten der jeweiligen Musikstücke. ${ }^{5}$ Diese übertragen ein ausschließliches Nutzungsrecht der Verbreitung ${ }^{6}$ auf Tonträger an die Tonträgerhersteller. Die Hersteller von Tonträgern wiederum verwerten die ihnen eingeräumten Rechte entweder weltweit oder in einzelnen Staaten je nach Bekanntheit und einzuschätzendem Erfolg des ausübenden Künstlers. Wenn im Tonträgermarkt die Rechte zum Ausschluß vom Konsum untersucht werden sollen, beziehen sie sich auf das ausschließliche Verbreitungsrecht der Musik mit Hilfe der Tonträger über die verschiedenen Distributionswege an die Konsumenten.

Zunächst seien Copyrights für den Tonträgermarkt als Eigentumsrechte an der auf einem körperlichen Träger - dem Tonträger - transportierten und abrufbaren Musik definiert. Die Ausgestaltung der Rechte kann prinzipiell auf zwei Arten erfolgen. ${ }^{7}$ Entweder wird ein ausschließliches Recht gewährt, welches dem Inhaber ermöglicht, andere von der Nutzung auszuschließen oder es wird ein Vergütungsanspruch eingeräumt, bei dem die Nutzung prinzipiell erlaubt ist, aber dem Rechtsinhaber eine angemessene Vergütung zusteht. ${ }^{8}$

Das Recht zum Ausschluß der Konsumenten ist zugleich die Rechtsinstitution des Copyright. Die Begründungen für Copyrights lassen sich in rechtsphilosophische und ökonomische einteilen. Zunächst werden die rechtsphilosophischen Begründungen betrachtet (3.1.2) und daran anschließend die ökonomischen Begründungen (3.1.3), die zur Rechtfertigung von Copyrights für den Tonträgermarkt dienen.

\subsubsection{Rechtsphilosophische Begründungen für Copyrights}

Ausgehend von John Locke kann das Recht des Urhebers, des Komponisten, Interpreten und des Tonträgerherstellers als Verwerter von Musik auf die Erträge seiner Arbeit als ein natürliches Recht aufgefaßt werden. ${ }^{9}$ Hierbei ist zwischen den Personen zu unterscheiden, die die Musik erschaffen und damit als Begründer des Werks einen stärkeren Schutz nach der Naturrechtsauffassung genießen sollten, und denjenigen, die die Ware Musik wirtschaftlich verwerten. Letztere haben nach der Naturrechtsauffassung keinen besonderen Anspruch auf umfang-

s Werden Musikkompositionen als Auftragsarbeit von den ausübenden Künstlern an die Komponisten gegen Entlohnung vergeben, haben die Komponisten unter bestimmten Voraussetzungen keine Rechte an ihren Kompositionen mehr.

6 Entsprechend der Zweckübertragungstheorie werden Nutzungsrechte nur für einen bestimmten Zweck eingerăumt.

7 Vgl. O'Hare, Michael, Copyright and the Protection of Economic Rights, in: Journal of Cultural Economics, Vol. 6 (1982), S. 33-48. [O'Hare 1982].

8 Beide Rechtsinstitutionen sind in der realen Welt vertreten, wobei das Copyright teilweise auch in die beiden Möglichkeiten aufgeteilt ist. Die Rechtsinstitution des Rechts auf angemessene Vergütung ohne AusschluB von der Nutzung greift z. B. gegenüber Sendeanstalten, die Tonträger ohne Erlaubnis spielen dürfen, dafür aber eine Vergütung an die Urheber, ausübenden Künstler und Tontrăgerhersteller abführen müssen. Vgl. $\S 20$ UrhG. Der Streit darüber, welche Vergütungshöhe angemessen ist, besteht seit der Existenz dieses Rechts.

9 Vgl. Hurt, Robert M., und Robert M. Schuchman, The Economic Rationale of Copyright, in: American Economic Review, Vol. 56 (1966), S. 421-432. [Hurt/Schuchman]. 
reichen Schutz, sondern nur in dem $\mathrm{Maße}$ wie es ihrem wirtschaftlichen Einsatz bzw. ihrer Arbeitsleistung am letztlich gehandelten Produkt entspricht. ${ }^{10}$

Die Leistung der Tonträgerhersteller basiert auf derjenigen der Musikkomponisten und der ausübenden Künstler und ist ohne sie nicht denkbar. In der ökonomischen Konsequenz bedeutet der in der Tradition der Naturrechtsphilosophie stehende Schutzumfang, daß entsprechend der Arbeit an einem Werk der Musik der Schutz gestaltet werden sollte. " Schwierigkeiten bereitet die Bewertung der Arbeit der Musikkomposition. Trotz des Einsatzes von Ressourcen läßt sich die Wertschöpfung der einzelnen Arbeitsschritte, die vor der Marktfähigkeit des Produktes Tonträger liegen, nicht berechnen. Eine Zuordnung des Rechtsumfanges nach dem Wertschöpfungsanteil ist daher unpraktikabel. Sinnvoll ist nur die Unterteilung in Urheber als denjenigen, die durch Melodie und Text eine Musik definieren, und in Leistungsschutzberechtigte, die die Musik hörbar machen und verbreiten.

Die Nutzung der Rechte der Urheber durch die Verwerter ermöglicht ihre Wertmaximierung. Entsprechend der Locke'schen Begründung ist den Verwertern nur ein bloßer Vergütungsanspruch zuzuerkennen, nicht aber das Besitzrecht des Urhebers an der Musik, welches den Ausschluß anderer einschließt. ${ }^{12}$

Als weitere rechtsphilosophische Begründung für einen Copyrightschutz wird das moralische Recht des Urhebers angesehen, da sein Werk Teil seiner Persönlichkeit ist. Dieser Gedanke basiert auf Immanuel Kant und Georg Wilhelm Friedrich Hegel. ${ }^{13}$ Niederschlag gefunden hat er in Kontinentaleuropa im Prinzip des Urheberpersönlichkeitsrechts, des Droit d'auteur. ${ }^{14}$ Ein solches Recht ist als ein Vermögenswert zu verstehen, das nicht durch den Verkauf einer Kopie erschöpft. Daher hat der Käufer auch nicht das Recht, die Kopie in leicht veränderter Form als sein eigenes Werk weiterzuverkaufen. ${ }^{15}$ Die Schwierigkeiten dieser Rechtsbegründung ergeben sich bei der Einräumung der Nutzungsrechte an Weiterverwerter. Auch wenn die Musik als Teil der Persönlichkeit des Komponisten gesehen wird, sind die zu erwartenden Veränderungen durch die ausübenden Künstler (Interpreten) und die Tonträgerhersteller z. B. durch digitales Sampling dem Verwertungsproze $B$ immanent. ${ }^{16}$ Daher ist eine generelle Übertragung der Rechte im kontinentaleuropäischen Urheberrecht nicht vorgesehen. Die bloße Einräumung von Nutzungsrechten bezieht sich nach der Zweckübertragungstheorie nur auf

10 In der Praxis der deutschen Verwertungsgesellschaf GEMA wird interessanterweise implizit mit der Naturrechtsphilosophie argumentiert. Vgl. Kreile, Reinhold, Rede des Vorstands der GEMA, in: GEMA Jahrbuch 1995/96, Baden-Baden 1996, S. 37-46.

"Vgl. Hughes, Justin. The Philosophic of Intellectual Property, in: Georgetown Law Journal, Vol. 77 (1988), S. 287-366.

12 Vgl. Hughes, Justin, supra, S. 365 f.

$13 \mathrm{Vgl}$. Hurt/Schuchman, supra, S. 423 f; Eisenmann, Hartmut, GrundriB Gewerblicher Rechtsschutz und Urheberrecht, 3. Aufl., Heidelberg 1995, S. 27.

14 Vgl. Hubmann, Heinrich, und Manfred Rehbinder, Urheber- und Verlagsrecht, 7. Aufl., München 1991, S. $42 \mathrm{fr}$.

$15 \mathrm{Vgl}$. Hughes, Justin, supra, S. 338

16 Vgl. Münker, Rainer, Urheberrechuliche Zustimmungserfordernisse beim Digital Sampling, Frankfurt a. M. 1995. 
den wirtschaftlichen Verwertungszweck. Für jede Änderung am Werk ist eine Zustimmung des Urhebers erforderlich. Ergibt sich aber die Notwendigkeit zu Änderungen am Werk bei der wirtschaftlichen Verwertung, so folgt daraus, daß nicht nur die Leistung des Urhebers für den Verkaufswert des Tonträgers entscheidend ist. Deshalb scheidet als ausschließliche Begründung für den Rechtsschutz das moralische Recht hegelianischen Ursprungs für die Tonträgerhersteller aus.

Die Gewährleistung des Urheberrechtsschutzes wurde bereits in der von der Generalversammlung der Vereinten Nationen verkündeten Allgemeinen Erklärung der Menschenrechte gefordert. ${ }^{17}$ Die Erwartung eines Ertrags bei der Produktinnovation der Komposition und Verwertung von Musik bei ausschließlichen Rechten wird als Ziel in den entsprechenden Gesetzen ${ }^{18}$ explizit genannt. Für die Prozeßinnovationen neuer Tonträgertechnologien erscheint die persönlichkeitsorientierte Sichtweise zur Begründung des Urheberrechts geeignet, da der Innovationsproze $B$ auf die individuelle Erfindungsleistung zurückführbar ist. Die zeitlich befristete ausschließliche Anwendung einer erfolgreichen Prozeßinnovation zur Amortisierung ist der entscheidende Antrieb zur Erforschung einer solchen. Das zeitlich befristete Monopol verursacht einen Anreiz zur Erforschung neuer Technologien, der auch bei den im Produktionsprozeß vorgelagerten Hardwareherstellern (Geräteindustrie) liegt. ${ }^{19}$ Der Aspekt der Wirkung von Prozeßinnovationen in der Geräteindustrie auf die Musikverwertung soll an dieser Stelle nicht weiter betrachtet werden.

Die Begründung eines Eigentumsrechts an Werken der Musik findet sowohl in der Naturrechtsphilosophie als auch in der moralischen Rechtsauffassung ihre Grenzen in der praktischen Umsetzung. Bestehende internationale Übereinkommen sind - mit unterschiedlichen Schwerpunkten - Mischformen beider Rechtsphilosophien. Da einerseits der Anreiz zur Komposition neuer Musikstücke und -stile gegeben sein soll, andererseits nur die weite Verbreitung bespielter Tonträger ausreichende Einnahmen sowohl für Komponisten, Interpreten als auch für Tonträgerhersteller erbringt, ist nun eine ökonomische Analyse der Notwendigkeit von Copyrights erforderlich.

\subsection{3 Ökonomische Begründungen für Copyrights}

Ein Copyright für Musik auf Tonträgern ist ein zeitlich beschränkt vergebenes Monopol. Es ermöglicht den Rechtsinhabern die alleinige wirtschaftiche Verwertung der festgelegten Musik. Analog zu Patenten, die als traditionelle Unterstützung des Staates Anreize zur Prozeßin-

17 Vgl. Art. 27 Abs. 2 der ErkJărung der Vollversammlung der Vereinten Nationen vom 10.12.1948.

18 So beispielsweise im Copyright Act der USA [17 U.S.A.C Sec. 101-810], der auf Artikel 1 Sektion 8 der amerikanischen Verfassung aufbaut. Vgl. Besen, Stanley M., und Leo J. Raskind, An Introduction to the Law and Economics of Intellectual Property, in: Journal of Economic Perspektives, Vol. 5 (1991), S. 3-27.

19 Nur vertikal rückwărtsintegrierte Tonträgerhersteller bzw. vorwărtsintegrierte Gerätehersteller haben im Zusammenhang mit Prozeßinnovationen strategische Vorteile. Sie bestehen darin, daß sie Inhalte für neue Trăgertechnologien mitliefern können. Für das Gelingen von Markteinführungen neuer Trägertechnologien ist dies eine entscheidende Voraussetzung. 
novation in der Industrie ${ }^{20}$ darstellen, ist das Copyright als Urheberschutz von Individuen gedacht, die Produktinnovationen tätigen. ${ }^{21}$ Die Idee der Alimentation des Urhebers durch die Gesellschaft bei der Nutzung seines Werks wird durch ein Copyright bewirkt, das eine Entlohnung für die Nutzung vorsieht. ${ }^{22}$ Erstens sollte sich das Nutzungsentgelt am tatsächlichen Gebrauch und dem daraus entstehenden Nutzen für die Gesellschaft orientieren und zweitens sollte der Ausschluß in Märkten mit Copyright technisch zu bewerkstelligen sein. ${ }^{23}$ Ein Ausschluß von der Nutzung bzw. eine Erlaubnis zur Nutzung bei Zahlung eines Entgelts - z. B dem Kaufpreis eines bespielten Tonträgers - ist ökonomisch zu rechtfertigen, wenn sich daraus positive Wohlfahrtseffekte für die Gesellschaft ergeben. ${ }^{24}$

Die ökonomische Wohlfahrt ist zu diesem Zweck definiert als Summe von Konsumenten- und Produzentenrente. Konsumentenrente ist der Überschuß der Summe der marginalen Zahlungsbereitschaften der Nachfrage über den Marktpreis, Produzentenrente ist die Summe der Differenzen zwischen dem jeweiligen Preis, zu dem die Anbieter (Tonträgerhersteller) noch anzubieten bereit sind, und dem tatsächlichen Marktpreis. ${ }^{25}$ Ein Copyrightsystem der Musikverwertung durch Tonträger, das den Ausschluß von der Nutzung regelt, ist ökonomisch berechtigt, wenn von ihm Anreize zur Produktion von Musik ausgehen, die anderenfalls nicht komponiert und verwertet werden würde, und die gesellschaftliche Wohlfahrt dadurch größer wird, und der Nutzenzuwachs durch das Copyrightsystem größer ist als die Summe aus administrativen Kosten und Allokationsverzerrungen des Copyrightsystems. ${ }^{26}$

Wird die Weiterverwertung durch Kopieren des Originalangebots verhindert oder von einer Zahlung abhängig gemacht, besteht der positive Wert eines Copyrights für die Anbieter von Musik auf Tonträgern in der Steigerung ihrer Produzentenrente. Der Wert des Copyrights hängt davon $\mathrm{ab}$, ob überhaupt Zweitmärkte für kopierte Tonträger existieren, und ob die Kopiertechnologie eine Qualität ermöglicht, die das kopierte Angebot zum Substitut des Originalangebots macht. ${ }^{27}$ Beide Bedingungen sind für die Tonträgerkategorie CD erfült. Beim digitalen Kopieren entsteht kein Qualitätsverlust, der Wert des Copyrights ist dann höher als bei analogen Kopien, bei denen die Zahlungsbereitschaft geringer ist, weil die Kopien nur unvollkommene Substitute sind. Die Originalanbieter werden in beiden Fällen geschädigt. Sie

$20 \mathrm{Vgl}$. Beier, K.-F., Die Bedeutung des Patentsystems für den technischen, wirtschaftichen und sozialen Fortschritt, in: Gewerblicher Rechtsschutz und Urheberrecht, internationaler Teil (GRUR/I), Vol. 81 (1979), S. $227 \mathrm{ff}$.

21 Vgl. Hurt/Schuchman, supra, S. 421.

$22 \mathrm{Vgl}$. HurtSchuchman, supra, S. $422 \mathrm{f}$.

23 Vgl. O'Hare, Michael, When Is Monopoly Efficient?, in: Journal of Policy Analysis and Management, Vol. 4 (1985), S. 407-418

$24 \mathrm{Vgl}$. HurtSchuchman, supra, S. 425.

25 Vgl. Schumann, Jochen, Grundzüge der mikrobkonomischen Theorie, 6. Aufl., Berlin u.a. 1992, S. 222.

$26 \mathrm{Vgl}$. Hurt/Schuchman, supra, S. 425 ff. Diese Autoren kommen zu dem Ergebnis, daß ein generelles Copyrightsystem kein okonomisch geeignetes Instrument sei. Sie schlagen alternativ als bessere Instrumente Steuerbegünstigungen oder direkte Subventionen für u. a. Komponisten vor.

27 Vgl. O'Hare 1982, supra, S. 33 f. 
argumentieren, daß generell ein Einnahmeausfall durch Kopieren gleich welcher Qualität zu erwarten ist. ${ }^{28}$ Dieser Ausfall läßt sich jedoch schlecht quantifizieren. ${ }^{29}$

Die Kosten des marktfähigen Angebots eines Tonträgers, die in der Komposition, der Festlegung auf Mastertape und dem Einkauf der Verwertungsrechte bestehen, sind in Relation zu Kopien hoch. Die Kosten einer bloßen Kopie dieses Tonträgers sind sowohl für die Originalanbieter als auch für Dritte, die den Tonträger besitzen, niedrig. Wird der Tonträger annähernd zu den Grenzkosten seiner Produktion verkauft, wird der Anreiz gering sein, Kopien anzufertigen. Allerdings wird der Erlös für den Tonträgerhersteller nicht ausreichen, um die Rechte für Komposition und Interpretation sowie die Kosten der Festlegung auf Mastertape $\mathrm{zu}$ decken. ${ }^{30}$ Daraus resultiert der social welfare loss due to underproduction, einer zu geringen Produktion von Musik auf Tonträgern. Bei einem Copyright-Regime, bei dem die Tonträgerhersteller als Rechtsinhaber das Weiterkopieren untersagen können, sind zwei gegenläufige Effekte zu untersuchen. Einerseits wird durch den Rechtsschutz der Erlös des Musikangebots erhöht, andererseits sind die Zugangskosten für die Nachfrager nach bespielten Tonträgern höher und damit c. p. die Nachfrage geringer. Der Effekt der geringeren Nachfrage wird social welfare loss due to underutilization genannt. Die Steigenung der Wohlfahrt ergibt sich nur bei einem positiven Gesamteffekt, wenn die Zunahme der Produzentenrente durch den Schutz vor Kopien die Abnahme der Konsumentenrente durch das teurere Originalangebot überkompensiert.

Das Problem der Nichtrivalität im Konsum des Gutes Musik ist eine ökonomische Rechtfertigung für Copyrightschutz. Obwohl die Nachfrage nach bespielten Tonträgern über den Kaufpreis ausschließbar ist, bleibt der Konsum der darauf gespeicherten Musik nicht-rival und begründet den Charakter eines zwar nicht öffentlichen aber gemischten privaten Gutes. Dabei bedeutet Nichtrivalität hier nicht, daß die Grenzkosten einer weiteren Nutzung gleich null sind. Vielmehr können Tonträger ohne Nutzenverlust kopiert werden, Kopierer sind nicht ausschließbar, aber die Einnahmen der Tonträgerhersteller sind geringer, wenn ein Teil der Nachfrage nur kopiert statt zu kaufen. Dieser Grund für Copyrightschutz von Musik auf Tonträgern ist unabhängig davon, daß Musik über verschiedene Kanäle (Radio, TV etc.) öffentlich zugänglich ist.

Nun wird argumentiert, daß das Wissen um eine bestimmte Musik öffentlich sei. Dieses Wissen, nicht-rival und nicht-ausschließbar, steuere die Nachfrage nach bespielten Tonträgern, wobei letztere private ausschließbare Güter seien. Die auf Tonträgern gespeicherte Musik sei

28 Vgl. Besen, Stanley M., und Sheila Nataraj Kirby, Private Copying, Appropriability, and Optimal Copying Royalities, in: Journal of Law and Economics, Vol. 32 (1989), S. 255-280.

29 Vgl. Davies, Gillian. The Private Copying of Sound and Audio-Visual Recordings: a Study Requested by the Commission of the European Communities 1993, S. 1-75; Fishbein, M., S.E. Middlestradt, und M. Kapp, Home Taping: a Consumer Survey, New York 1982, S. 24 ff.

30 Vgl. Landes, William M., und Richard A. Posner, An Economic Analysis of Copyright Law, in: Journal of Legal Studies, Vol. 18 (1989), S. 325-363 [Landes/Posner]. 
daher ein öffentlich ausschließbares Gut. ${ }^{31}$ Dies impliziert die Anwendbarkeit des ThompsonTheorems auf den Tonträgermarkt. Für Thompson ist ein Copyrightsystem eine gesetzliche Zugangsbarriere. Private Hersteller erhalten Zahlungen für ihr Angebot, die Kunden erwerben dafür die Berechtigung für die jeweilige Nutzung ihres Anteils am Output. ${ }^{32}$ Für bespielte Tonträger ist die Nutzungsberechtigung auf das Abspielen zum privaten Gebrauch beschränkt. Unterstellt man vollständige Markttransparenz, vollkommene Ausschließbarkeit und konvexe Präferenzen der Nachfrage und folgt man den Annahmen ${ }^{33}$ des konkurrenzwirtschaftlichen Angebots öffentlich ausschließbarer Güter (mit dem öffentlichen Teil Musik und dem privaten Teil Tonträger), die mit dem Thompson-Theorem gemacht werden, dann ergibt sich kein Trade-off zwischen dem social welfare loss due to underproduction ohne Copyrightschutz und dem social welfare loss due to underutilization ${ }^{34}$ bei der Gewährung des Rechtsschutzes, sondern ein Überangebot solcher Güter.

Trotz der empirischen Relevanz des Überangebots von Musik auf Tonträgern, ${ }^{35}$ läßt sich der Ansatz der öffentlich ausschließbaren Güter nicht auf den Tonträgermarkt übertragen. ${ }^{36}$ Denn der öffentliche Charakter des Wissens um die Musik, durch die diversen Medien transportiert, ist nicht mit der besitzbaren gespeicherten Musik identisch, die auf dem Tonträger verkauft wird. Wäre das bloße Wissen um ein Gut entscheidend für seinen öffentlichen Charakter, müßten sich die beispielsweise vorhandenen positiven externen Effekte des Wissens um das Gut auf das Gut selbst übertragen. Anderenfalls wäre das öffentliche Wissen, das zum Konsum führt, stets mit dem privaten Charakter des einzelnen Gutes selbst verknüpft. Dann gäbe es nicht viele private Güter, sondern immer nur öffentlich-ausschließbare Güter. Dies ist nicht zutreffend. Die entscheidende Nichtrivalität im Konsum von Musik auf Tonträgern ergibt sich durch die Möglichkeit zur Vervielfältigung und Weiterverbreitung, die erst durch den Tonträgerkauf entsteht. Die Möglichkeit des Zugangs zu Musik über andere Verbreitungskanäle, wie Fernsehen und Radio, hat zwar sowohl komplementären (auch absatzfördernden) als auch

31 Der Begriff offentlich ausschließbarer Güter wurde vor allem vom Thompson verwendet. Vgl. Thompson, Earl A., The Perfectly Competitive Production of Collective Goods, in: The Review of Economics and Statistics, Vol. 50 (1968), S. 1-12 [Thompson 1968].

32 Vgl. Thompson 1968, supra, S. 2.

33 Vgl. Thompson 1968, supra, S. 3 ff.

34 Vgl. Koboldt, Christian, Property Rights und Urheberschutz, in: Ökonomische Analyse der rechtlichen Organisation von Innovationen, hrsg. von Ott, Claus, und Hans-Bernd Schäfer, Tübingen 1994, S. 69-114. Diesen Trade-off sehen die meisten Autoren, die eine okonomische Analyse des Urheberrechts brw. von Copyrights betreiben.

35 Vgl. Conen, Michael, Tonträgermarketing, Wiesbaden 1995, S. 75 ff.

36 Der Aufsatz von Thompson hat eine rege wissenschaftliche Diskussion über die Frage der privaten Bereitstellung offentlicher Güter und die Bedingungen der paretooptimalen Allokation offentlicher Güter ausgelöst. Vgl. Thompson, Earl. A., The perfectly Competitive Production of Collektive Goods, in: The Review of Economics and Statistics, Vol. 51 (1969), S. 479-482; ders., The Private Production of Public Goods: A Comment, in: The Journal of Law and Economics, Vol. 16 (1973), S. 407-412; Demsetz, Harold, The Private Production of Public Goods, ebda., Vol. 13 (1970), S. 293-306 [Demsetz 1970]; ders., Reply to Professor Thompson, ebda., Vol. 16 (1973), S. 413-415; ders., Joint Supply and Price Discrimination, ebda., Vol. 16 (1973), S. 389-405; Oakland, W. H., Public Goods, Perfect Competition and Underproduktion, in: Journal of political Economy, Vol. 82 (1974), S. 927-939; Endres, Alfred, Second Hand Markets and the Private Supply of Excludable Public Goods, in: Public Finance, Vol. 35 (1980), S. 227238. 
substitutiven Charakter, ersetzt aber letztlich nicht den durch Tonträger möglichen Besitz von Musik. Dazu müßte der Musikbesitz in gleicher Qualität bewerkstelligbar sein, wie z. B. durch Empfang von digitalem Radio oder Fernsehen verknüpft mit digitalen Speichermöglichkeiten beim Konsumenten.

Ebenso ist die Annahme der vollständigen Markttransparenz des Thompson-Theorems zu verwerfen. Thompson selbst modifizierte seine Ergebnisse im Hinblick auf ihre Relevanz furr die wirtschaftspolitischen Handlungsweisen, indem er unvollständige Information bzw. Marktintransparenz unterstellte. ${ }^{37}$ Unter diesen Gegebenheiten ist es für die Anbieter nicht möglich, die Nachfrage - Grenzwertschätzung des einzelnen Nutzers - zu bestimmen. Daher wird es bei unvollständiger Information stets einen Anreiz für die Nachfrage geben, die eigene Zahlungsbereitschaft zu verschleiem bzw. mit einem zu geringen Wert zu offenbaren. Ebenso ist es für einen Copyrightgesetzgeber nicht möglich, die Grenzproduktivitäten der Faktoren zu bestimmen, aus denen letztlich öffentlich ausschließbare Güter werden. Der Rechtsschutz würde dann dazu dienen, die Differenz zwischen der Zahlungsbereitschaft der Nachfrage und der tatsächlichen Grenzproduktivität zu schließen. Im Ergebnis bleibt festzuhalten, daß der Ansatz Thompsons nicht dazu führt, die Notwendigkeit von Copyrights für den Tonträgermarkt ökonomisch zu begründen oder abzulehnen. ${ }^{38}$

Die Nichtrivalität des Konsums von Musik erfordert für die körperliche Musikverwertung mit Hilfe von Tonträgern einen Rechtsschutz, der sowohl die Nutzung in anderen Verwendungen als auch diejenige in Zweitmärkten regelt. Abhängig von der konkreten Ausgestaltung des Copyrightsystems besteht der Effekt des Rechtsschutzes in höheren Preisen für Handel und Konsumenten sowie in höheren Erlösen für die Rechtsinhaber. ${ }^{39}$ Daher ist es die Aufgabe des folgenden Abschnitts, die Effekte verschiedener Copyrightregime im Hinblick auf ihre ökonomische Effizienz zu untersuchen. Dabei soll zunächst von der Existenz von Zweitmärkten abstrahiert werden. Später werden diese sowie die Kosten des Ausschlusses mit in die Analyse einbezogen.

\subsection{Positive Analyse der Copyrights für den Tonträgermarkt}

Für die folgende ökonomische Analyse des Rechts sind die Reaktionen der Anbieter und Nachfrager auf bestehende und mögliche Regelungen zu untersuchen. Dabei wird das Copyright als Instrument zur Erreichung größtmöglicher Effizienz auf dem Tonträgermarkt aufge$\mathrm{fa}_{\mathrm{B}} \mathrm{t}^{40}$ und an dieser Zielsetzung gemessen. Ausgegangen wird bei der Wirkungsanalyse der Copyrights auf dem Tonträgermarkt zunächst von einem Ausschlußrecht ohne Zweitmarkt (3.2.1), dann wird das Recht als ein Erlaubnisvorbehalt und als Vergütungsrecht mit der Exi-

37 Vgl. Thompson 1968, supra, S. 11.

38 So auch Demsetz 1970, supra, S. 293-306.

39 Vgl. Landes/Posner, supra, S. 326.

40 Die instrumentalistische Sichtweise des Rechts (law in action) steht im Gegensatz zu der neoklassischen Annahme des Rechts als Datum. Vgl. Posner, Richard A., Economic Analysis of Law, 2. Aufl., Boston 1977. 
stenz eines Zweitmarktes analysiert (3.2.2), schließlich werden die Kosten der Rechtsnormierung, die Ausschlußkosten und die Rechtsdurchsetzung von Urheberrechten (3.2.3) sowie der Zusammenhang zwischen Rechtekosten, Zahl der veröffentlichten Tonträgertitel und Marktform (3.2.4) thematisiert.

\subsubsection{Copyright als perfekter und kostenloser Ausschluß ohne Zweitmarkt}

Zunächst unterstellen wir, daß der Komponist mehrerer Musikstücke und der ausübende Künstler, d. h. der Interpret dieser Musikstücke, ${ }^{41}$ dem Tonträgerhersteller ausschließliche Rechte gewährt. Diese Rechte beziehen sich annahmegemäß auf die Festlegung der ausgewählten Musikstücke auf Mastertape sowie die anschließende Vervielfältigung und Verbreitung mit Tonträgern an die Öffentlichkeit. Weiterhin nehmen wir an, daß kein Außenhandel stattfindet. Dies kann darauf beruhen, daß dem Tonträgerhersteller die Rechte nur für eine Volkswirtschaft eingeräumt wurden, oder darauf, daß in einer zweiten Volkswirtschaft ein anderes Rechtssystem etabliert worden ist, welches den Handel nicht zuläßt bzw. stark diskriminiert. Gegenüber der Nachfrage habe der Tonträgerhersteller folgende Rechte: Die Nachfrager dürfen die gekauften Tonträger nur zum privaten Gebrauch benutzen. Für jede gewerbliche Nutzung ${ }^{42}$ muß eine Erlaubnis des Tonträgerherstellers eingeholt werden. ${ }^{43}$ Für diesen Abschnitt wird davon ausgegangen, daß von den Tonträgerherstellern keine Erlaubnis zur Weiterverwertung erteilt wird. Da der Tonträgerhersteller für eine bestimmte Musik die ausschließlichen Rechte hat, ist er gegenüber dem Handel und den Konsumenten der Monopolist. Seine Preis-Absatz-Funktion hat dann die allg. Form:

$$
p=a-b q
$$

Für den einzelnen Nachfrager stellt a den Prohibitivpreis dar (Schnittpunkt der individuellen Nachfragekurve mit der Ordinate), zu dem er nicht mehr bereit ist, einen Tonträger zu kaufen. ${ }^{4}$ Die Sättigungsmenge a/b (Schnittpunkt der individuellen Nachfragekurve mit der Abzisse) kennzeichnet den Punkt, bei dem der Nachfrager auch für einen Preis von 0 nicht mehr bereit ist, c. p. Tonträger nachzufragen. ${ }^{45}$ Das Angebot an bespielten Tonträgern unterliege der folgenden Kostenfunktion:

41 Beide Tătigkeiten können auch durch ein und dieselbe Person ausgeübt werden.

12 Gewerbliche Nutzungen sind z. B. die entgeltliche Vermietung, das Abspielen der Tonträger in Diskotheken, Radiostationen, Kaufhäusern etc.

43 Das Copyright als Erlaubnisvorbehalt bzw. Vergütungsanspruch bei gewerblicher Nutzung wird in Abschnitt 3.2.2 dargestellt.

44 Die Tonträgerhersteller haben in einer Auftragsstudie an die Gesellschaft für Konsum- und Marktforschung (GfK) 1993 versucht, den Prohibitivpreis für Tontrăger erforschen zu lassen. Offensichtlich ergab die Studie, daß der Prohibitivpreis nicht weit vom Marktpreis für Neuerscheinungen entfernt ist. Die Studie wurde nicht veroffentlicht, sondern blieb Verschlußsache. Vgl. Merx, Stefan, Bis an die Schmerzgrenze, in: Die ZEIT, Nr. 43 vom 21. Okt. 1994, S. 32.

45 Zur Vereinfachung wird davon abgesehen, daß Tontrăger in einer begrenzten Menge zu Werbe- bzw. Promotionzwecken tatsăchlich zum Preis von 0 abgegeben werden. Eine andere Form der Nachfragesättigung erfahren Radiosender und andere Multiplikatoren, denen Tonträger als sog. weiße Ware kostenlos 


$$
K=C+F+k(q)
$$

Hierbei stellen C die Fixkosten für den Rechteeinkauf, F die Fixkosten für die Festlegung bzw. Aufnahme der Musik auf Mastertape und k(q) die variablen Kosten der Produktion der Tontägerexemplare und ihres Vertriebs an Handel und Endverbraucher dar. Die Definition der Rechtekosten $\mathrm{C}$ als Fixkosten impliziert, daß die Tonträgerhersteller dem Musiker für einen Festbetrag die Vervielfäligungs- und Verbreitungsrechte abkaufen. Sie beteiligen ihn damit nicht am Absatzrisiko. Die Durchschnittskosten betragen:

$$
\frac{K}{q}=\frac{(C+F+k(q))}{q}
$$

Die Grenzkosten der Produktion von Tonträgern sind dann:

$$
\partial K / \partial \mathrm{q}=\partial \mathrm{k} / \partial \mathrm{q}
$$

Die Grenzkosten der Tonträgerproduktion bestehen also nur aus den reinen Produktions- und Vertriebskosten des letzten Tonträgerexemplares. Soll die Marktversorgung des Handels und der Konsumenten in einem paretooptimalen Zustand erfolgen, so müßten die Preise den Grenzkosten entsprechen. Weiterhin nehmen wir an, daß Musik nur auf Tonträgern erhältich sei, ${ }^{46}$ die Musiknachfrage demnach nicht mit anderen Gütern konkurriert. Eine Grenzkostenpreissetzung würde für die Tonträgerhersteller dann ein Defizit in Höhe von $\mathrm{F}+\mathrm{C}$ bedeuten. Während die Höhe der Kosten für die Aufnahme des Mastertapes im eigenen Aktionsbereich des Tonträgerherstellers liegt, sind die Rechtekosten abhängig von der Höhe, Dauer und Intensität des Rechtsschutzes sowie der Verhandlungsposition des Rechteinhabers. Können die Kosten des Rechteerwerbs nicht auf den Verkauf der Tonträgerexemplare umgelegt werden (beispielsweise i. S. einer Durchschnittskostenpreissetzung), so wird die Tonträgerproduktion unterbleiben. Die durch die Grenzkostenpreissetzung angestrebte Maximierung der Konsumentenwohlfahrt mißlingt, die Konsumentenrente sinkt auf 0 .

Will man jetzt aus volkswirtschaftlichen Gesichtspunkten eine Durchschnittskostenpreissetzung etablieren, so stellen die Rechtekosten das entscheidende Problem dar. Das Copyright erhöht die Preise für Handel und Konsumenten, aber auch die Erlöse der Tonträgerhersteller. ${ }^{47}$ Welche Rückwirkung gehen vom Copyright auf die Produktion von Musik auf Tonträgern aus? Einerseits sind Urheberrechte als Anreiz zur Komposition von Musik gedacht und

zur Verfügung gestellt werden. Hiermit versuchen die Tontrăgerhersteller, die Marktchancen ihrer Produkte zu testen. Vgl. Conen, Michael, op. cit., S. $76 \mathrm{ff}$.

46 Damit abstrahieren wir von der Medienkonkurrenz und den verschiedenen Zugangskanälen zur Musik (Radio, Fernsehen, Diskotheken etc.). In unserer gedachten Welt bestehen daher weder Komplementarităts- noch Substitutionsbeziehungen zu den anderen Verbreitungskanălen von Musik.

$47 \mathrm{Vgl}$. Landes/Posner, supra, S. 326. 
daher auf 70 Jahre p. m. a. ausgelegt und umfangreich ${ }^{48}$ ausgestattet. Andererseits verteuert der hohe Rechtsschutz den Einkauf des Vervielfältigungs- und Verbreitungsrechtes für die Tonträgerhersteller. ${ }^{49} \mathrm{Da}$ die Zahl der abgesetzten Tonträger ex ante nicht bekannt ist, gibt es keine Kalkulationsgrundlage für die Durchschnittskostenpreissetzung. Vom Absatz vorheriger kann nicht auf denjenigen aktueller Tonträger geschlossen werden. Bei einer Betrachtung der Rechtekosten als Fixkosten liegt das unternehmerische Risiko der Amortisation allein beim Tonträgerhersteller. Dieser setzt den Monopolpreis gemäß dem Cournot'schen Punkt bei $\mathbf{R}^{\prime}=$ $\mathrm{K}^{\prime}$ durch Projektion auf seine Preis-Absatz-Funktion. Der Monopolpreis liegt oberhalb der Durchschnittskosten. Im Vergleich zur Durchschnittskostenpreissetzung sinkt die Konsumentenrente und die Produzentenrente steigt.

Abhängig von der zeitlichen Verteilung der Verkaufszahlen ${ }^{50}$ verringert eine Verkürzung der Urheberrechtsschutzzeit den Wert dieses Rechts und damit die Einkaufskosten der Tonträgerhersteller. Solange diese allerdings Monopolisten sind, werden geringere Kosten nicht über einen geringeren Marktpreis an Konsumenten und Handel weitergegeben.

\subsubsection{Copyright als Erlaubnisvorbehalt und als Vergütungsanspruch mit einem Zweitmarkt}

Das Copyrightsystem des Tonträgermarktes kann auf zwei Arten anders ausgestaltet sein, als dies im letzten Abschnitt angenommen wurde. Erstens können Tonträgerhersteller bei ihrem Ausschlußrecht die gewerbliche Weiterverwertung der Tonträger auf Anfrage und gegen Vergütung erlauben. Zweitens kann das Recht so ausgestaltet sein, daß die Tonträgerhersteller keine Ausschlußmöglichkeit haben, sondern ihnen bei einer urheberrechtlich relevanten Nuizung nur ein Vergütungsanspruch zusteht. Die Rechtsinstitution des Vergütungsanspruchs ohne Erlaubnisvorbehalt ist üblich für privates Kopieren, Senden und Abspielen von Tonträgern in der Öffentlichkeit. Da die Wirkung des Copyrights mit den verschiedenen Rechtsinstitutionen variiert, wird zunächst der Erlaubnisvorbehalt und danach die Vergütung betrachtet.

Eine weitverbreitete Form der Weiterverwertung ist das Kopieren. Wie bereits erläutert, kann ohne Copyrightschutz der einmal angeschaffte bespielte Tonträger auf unbespielte Tonträger kopiert werden. Wenn dabei die gleiche Qualität produziert wird, ist das kopierte Tonträgerexemplar ein annähernd perfektes Substitut des authentischen Tonträgers. Der erheblich

48 Vgl. zum Umfang des Schutzes für Urheber nach deutschem Recht Abschnitt 2.1.2.

49 Das Urheberrecht ist nicht übertragbar. Die genannten Rochte sind daher Nutzungsrechte, die der Musiker als Urheber vergibt. Diese Rechte kann er zeitlich begrenzen. Da aber die Tonträgerhersteller für ihre Tontrăger 50 Jahre das ausschließliche Vervielfältigungs- und Verbreitungsrecht haben, werden sie einer weiteren Begrenzung nicht zustimmen oder für die Zweitverwertung durch andere Tonträgerhersteller Entgelt verlangen. Allerdings können für spătere Musikaufnahmen vom Musiker andere Tontrăgerhersteller gewăhlt werden.

so Werden die höchsten Verkaufszahlen mit Neuerscheinungen erzielt, d. h. im ersten Jahr nach dem Erscheinen des Tonträgers, und verringern sie sich mit zunehmenden Alter kontinuierlich, so bleibt die Wirkung der Verkürzung der Urheberrechtsschutzzeit gering. Das gleiche gilt analog für das Leistungsschutzrecht der Tonträgerhersteller. 
geringere Preis ${ }^{51}$ lenkt die Nachfrage auf die kopierten Tonträger mit der Folge, daß kein Originalangebot mehr zustande kommt oder die Breite des Angebots sinkt (social welfare loss due to underproduction). ${ }^{52}$ Für die Verdrängung des Originalangebots an autorisierten Tonträgern kommen nur solche Kopieraktivitäten in Frage, die gewerblich geschehen. Mit ihnen wird ein nicht autorisiertes Kopienangebot geschaffen, welches einen Zweitmarkt etablieren kann bzw. den ersten Markt substituiert. Für private Kopieraktivitäten gilt dies nicht, da von einem eng begrenzten Kreis von Personen auszugehen ist, die durch private Kopieraktivitäten erfaßt werden können. Gegen eine Ausweitung der privaten Kopieraktivitäten sprechen auch die hohen Transaktionskosten, die der Weiterverbreitung privat kopierter Tonträger im Weg stehen. ${ }^{53}$ Daher wird hier das gewerbliche Kopieren betrachtet.

Zunächst hat der Hersteller von kopierten Tonträgern in die Technologie der Tonträgerherstellung zu investieren. Da nur digitale Qualität dem Originalangebot gleichkommt, ist die CD als umsatzstärkste Longplay-Tonträgerkategorie ${ }^{\text {s4 }}$ der Ansatzpunkt. Die Investition in CDBrennwerkzeuge bedeutet zunächst Fixkosten, die mit denjenigen der Originalanbieter vergleichbar sind. Ebenso sind die variablen Kosten der Produktion der einzelnen $C D$ vergleichbar. Sie liegen bei der Produktion in Deutschland zwischen $1 \mathrm{DM}$ und 1,50 DM. ${ }^{35}$ Daher sind bei einem Endverkaufspreis für Neuerscheinungen zwischen 20 und $35 \mathrm{DM}^{36}$ - neben den Bereichen Marketing und Vertrieb - die Rechtekosten und das Marktrisiko entscheidend. Originalanbieter von Tonträgern haben ein Risiko, das sich vor allem auf den Verkauf von Musik unbekannter Künstler bezieht. Da aber die Anbieter kopierter Ware keine neuen Künstler produzieren müssen, sondern sich auf das Sortiment der erfolgreichen Produktionen beschränken können, reduziert sich für sie das Marktrisiko darauf, den richtigen Zeitpunkt für die Produktion und das Angebot von Kopien zu wählen, sowie eine - möglichst genaue Schätzung des Absatzes zu treffen.

Aus obigen Überlegungen ergibt sich, daß die Aufwendungen für die Rechte einen Kostennachteil für die Originalanbieter darstellen, wenn die Anbieter von kopierter Ware ohne ver-

51 Die reinen Herstellungskosten, z. B. der Tonträgerkategorie CD (einschließlich Hülle und Booklet), betragen ca. 2 DM. Gegenüber dem Abgabepreis des autorisierten Angebots der Tontrăgerindustrie an den Handel von ca. 20-22 DM liegen die reine Herstellungskosten bei nur ca. 10\%. Vgl. Schaefer, Martin, und Manfred Körfer, Tontrăgerpiraterie: Ein Leitfaden für die Praxis, Starnberg 1995, S. 16 ff., und Kreile, Reinhold, und Jürgen Becker, Multimedia und die Praxis der Lizenzienung von Urheberrechten, in: GRUR/, Vol. 98 (1996), S. 677-692, hier S. 681.

52 Vgl. Koboldt, Christian, op. cit., S. 76; Novos, Ian E., und Michael Waldman, The Effects of Increased Copyright Protection: An Analytic Approach, in: Journal of Political Economy, Vol. 92 (1984), S. 236246. [Novos/Waldman 1984].

s3 Von der Wirkung des Nachfrageausfalls aufgrund privater Kopieraktivităt soll an dieser Stelle abstrahiert werden.

54 Die umsatzstărkste Tonträgerkategorie in den Mitgliedsstaaten der EU war 1995 die CD. Dabei variierte der wertmẳige Anteil der CD an allen Longplay-Umsătzen von $57 \%$ in Portugal bis zu $96 \%$ in Belgien und den Niederlanden. Vgl. International Federation of the Phonogram Industry (IFPI), The Recording Industry In Numbers, London 1996, S. 6-31.

ss Nach Angaben von Helmut Fest, des damaligen Vorstandsvorsitzenden der EMI Electrola Deutschland GmbH, auf der Messe Popkomm 1996 am 16.08.1996 in Köln.

\$6 Vg. Merx, Stefan, supra, S. 32. 
gleichbare Kosten und Risiken auf den Markt treten können. Daher ist der Wert des Copyrights für die Tonträgerhersteller hoch. Im folgenden betrachten wir, unter welchen Bedingungen Tonträgerhersteller ein ausschließliches Vervielfältigungs- und Verbreitungsrecht aufgeben werden bzw. ihren Erlaubnisvorbehalt dahingehend nutzen werden, daß sie Herstellern von Kopien gegen Entgelt ihre Tätigkeit erlauben. Ein solches Szenario ist nur unter folgenden Bedingungen denkbar: Die Tonträgerhersteller verfügen in einer Volkswirtschaft über keinen Zugang zur Nachfrage, die Kosten für den Aufbau eines entsprechenden Handels sind zu hoch oder der Markt einer Volkswirtschaft ist nicht attraktiv genug. Unter diesen Bedingungen wäre ein Weiterverkauf der Rechte dann rational, wenn der Erlös des Weiterverkaufs die Kosten der Markterschließung oder den Gewinn im Falle des eigenen Marktengagements übersteigt.

Die Bedienung eines nationalen Tonträgermarktes durch Kopien kann einer Nachfrage nach Originalangeboten zeitlich vorangehen. Hierzu betrachten wir zwei Zeitpunkte. Zuerst existiere ein Markt, in dem sich Nachfrage nach kopierten Tonträgern bildet. Es bestehe kein Copyrightschutz und das Angebot beziehe sich auf Kopien von Originalen aus anderen Märkten. Burke $^{37}$ verweist auf den empirisch feststellbaren Zusammenhang zwischen der wirtschaftichen Entwicklung und dem Umfang des (nicht legalisierten) Kopienangebots. Dann werde im Zuge der Entwicklung der Volkswirtschaft ein Copyrightschutz eingeführt. Zu diesem zweiten Zeitpunkt kann sich schon Nachfrage nach Originalen entwickelt haben. Wenn Tonträger superiore Güter sind, deren Nachfrage mit steigendem Einkommen der Wirtschaftssubjekte überproportional steigt, wird durch die Entwicklung einer Volkswirtschaft die Nachfrage nach Tonträgern steigen. Unter der Annahme, daß der Betrag der Einkommenselastizität der Nachfrage größer als eins ist, sind dann Originaltonträger zu höheren Preisen absetzbar, wenn das Angebot von Kopien unterbleibt. Dann wird es für Tonträgerhersteller nicht vorteilhaft sein, einer Verwertung durch Kopien zuzustimmen. ${ }^{58}$ Zwar kann beim Angebot von Kopien kurzfristig der Verlust an Produzentenrente durch ein Zuwachs an Konsumentenrente kompensiert werden. Langfristig aber überwiegen die negativen Effekte, da ein gleichzeitiges Original- und Kopienangebot wegen der Preisunterschiede nicht möglich, für die Tonträgerhersteller keine Produzentenrente und die Musikurheber kein Einkommen zu erwirtschaften ist und daraus die Einstellung des Originalangebots selbst folgt. Daher werden Tonträgerhersteller ein ausschließliches Vervielfältigungs- und Verbreitungsrecht von Musiktiteln nicht weiterveräußern. ${ }^{59}$ Ohne dieses Recht könnte keine körperliche Verwertung von Musik durch Tonträger bestehen.

57 Vgl. Burke, Andrew E., How Effective Are International Copyright Conventions in the Music Industry?, in: Journal of Cultural Economics, Vol. 20 (1996), S. 51-66. [Burke 1996a].

58 Dies gilt insbesondere im Hinblick auf den kurzen Produkulebenszyklus eines Tontrăgers. Vgl. hierzu Burke, Andrew E., The Dynamics of Product Differentiation in the British Record Industry, in: Journal of Cultural Economics, Vol. 20 (1996), S. 145-164 [Burke 1996b]

59 Nach AbschluB der Erstverwertung eines Tonträgers (die einen unterschiedlich langen Zeitraum umfassen kann), werden Zweitverwertungen in Form von Lizenzienungen an andere Tonträgerhersteller eingeräumt, wenn die Komponisten. Textdichter und ausübenden Künstler dem zustimmen. Aber auch in diesem Fall ist das Entgelt für die Lizenz so bemessen, daß der Tontrăger als low-price-Produkt (15-20 DM) angeboten wird. 
Getrennt davon ist der Vergütungsanspruch zu beurteilen, der nun analysiert wird. Für die rechtliche Institution des Vergütungsanspruchs ohne Ausschlußmöglichkeit ist der Ansatzpunkt der Verbreitung wichtig. Der juristische Begriff der Verbreitung geht grundsätzlich von der Verbreitung körperlicher Vervielfältigungsstücke aus. ${ }^{60}$ Für die Anbieter von Tonträgern steht die unkörperliche Verbreitung etwa über Sender in einer Konkurrenzbeziehung zu ihrem Produkt. Denn zu den wirtschaftlich relevanten Verbreitungshandlungen gehört das Kopieren von Musik über Sender, Netze ${ }^{61}$ etc. Voraussetzung dafür sind neben dem körperlichen Verleih bespielter Tonträger durch entsprechende gewerbliche Vermietgeschäfte die unkörperliche Übertragung durch Medien, vorzugsweise Radiostationen, die auch längere Musikstücke ohne Unterbrechungen übertragen, oder die öffentliche Aufführung in Konzerten. ${ }^{62}$

Die gewerbliche Weitervermietung von Tonträgern unterstützt das private Kopieren. ${ }^{63}$ Für das Ausleihen in einem CD-Verleih ${ }^{64}$ ist das anschließende private Kopieren auf einen leeren Tonträger bei $75 \%$ der Mietnachfrage das Motiv. ${ }^{65}$ Durch das gewerbliche Weitervermieten ist ein Zweitmarkt etabliert worden, in dem die Vermietgeschäfte eine Zweitverwertung der angeschafften Tonträger durch zeitliche Gebrauchsüberlassung gegen Entgelt betreiben. Die Zweitverwertung substituiert die Erstverwertung der Tonträgerhersteller, da die Nachfrage nach bespielten Tonträgern auch durch den Kauf leerer Tonträger, Ausleihen bespielter Tonträger und anschließendes Kopieren der Musik auf den leeren Tonträger befriedigt werden kann. Der Grad der Substituierbarkeit ist annähernd vollkommen, wenn die selbsthergestellte Kopie im Vergleich zum Originalangebot die gleiche Qualität aufweist.

Zwei Rückwirkungen auf das Originalangebot sind die Folge: Zum einen wird die Musik weiter verbreitet als das bei Vorliegen nur des Originalangebots der Fall wäre. Die Nachfrageausweitung liegt an dem geringeren Preis, zu dem die Kopie erstellt bzw. weiterverkauft

60 Vgl. Kreile, Reinhold, und Jürgen Becker, supra, S. 689.

61 Bei der Verbreitung über Medien oder Online über Netze werden nicht die körperlichen Tonträger weiterverbreitet, sondern nur die auf ihnen gespeicherte Musik. Daher fallt die Musikverbreitung mit Hilfe der Medien unter den urheberrechtlichen Begriff der Sendung, die Musikverbreitung mit Hilfe von Konzerten unter den Begriff der offentlichen Wiedergabe. Für beides muß eine Mehrheit von Personen erreicht werden, damit die Musik offentlich zugănglich gemacht worden ist. Daran knüpft ein Vergütungsanspruch an; im Fall der Sendung steht dieser Anspruch den Tonträgerherstellern zu. Zur rechulichen Behandlung der Verbreitung Online über Datennetze vgl. Abschnitt 5.3.3.1.

62 Den unautorisierten Mitschnitt von Live-Konzerten nennt man bootleg. Er kann Ursprung weiterer Kopierhandlungen sein, durch die ein Nachfrageausfall nach bespielten Tontrăgern möglich ist. Vgl. Schaefer, Martin, und Manfred Körfer, op. cit., S. 17 ff.

63 Mahlmann, Carl, Strukturen des deutschen Tonträgermarktes, in: Handbuch der Musikwirtschaft, hrsg. von Moser, Rolf, und Andreas Scheuermann, 4. Aufl., Starnberg 1997, S. 161-184 [Mahlmann 1997].

64 Die gewerbliche Vermietung bespielter Tonträger etablierte sich zwar schon vor der Markteinführung der Tontrăgerkategorie CD, aber durch die Abnutzung, z. B. der analogen Kategorie LP, mußten diese Tonträger nach einigen Vermietungsvorgängen ersetzt werden. Nach Einführung der - bei sachgerechter Bcnutzung - abnutzungsfreien $C D$ entwickelte sich das Vermietgeschaft sehr stark.

65 Vgl. Rochlitz, Burkhard. Vermietung von Tonträgern, in: Handbuch der Musikwirtschaf, hrsg. von Moser, Rolf, und Andreas Scheuermann, 3. Aufl, Stamberg 1994, S. 535-542. [Rochlitz 1994]. Rochlitz. verweist in diesem Zusammenhang auf eine Auftragsstudie, die das Marktforschungsinstitut G \& I. Nürnberg, durchgeführt hat. 
werden kann. ${ }^{66}$ Unter der Annahme einer nicht völlig unelastischen Nachfrage bedingt dies ein Mengenwachstum. Dadurch entsteht ein Zuwachs an Konsumentenrente, der den social welfare loss due to underutilisation verringert. ${ }^{67}$ Zudem kann die Erweiterung des Diffusionskanals durch das Angebot von Kopien auch zu einer zeitlich schnelleren Verbreitung der Musik führen. Der zweite Effekt ist die Verringerung der Zahl der Veröffentlichungen der Tonträgerhersteller. Unter der Annahme, daß eine Verringerung der Nachfrage nach dem höherpreisigen Originalangebot eine Verringerung der Produzentenrente der Tonträgerhersteller bedeutet, werden letztere ihre Produktionen verringern, ${ }^{68}$ was zum social welfare loss due to underproduction führt.

$\mathrm{Zu}$ fragen ist, ob ein Vergütungsanspruch der Tonträgerhersteller zu volkswirtschaftlich günstigeren Ergebnissen führen kann und wenn dies der Fall ist, wie er dann ausgestaltet sein muß. Aus gesamtwirtschaftlicher Sicht sollte der Vergütungsanspruch der Tonträgerhersteller gegenüber den gewerblichen Vermietern ihren Verlust an Produzentenrente verringern. Hierfür ist der Zusammenhang zwischen Mietnachfrage und Originalnachfrage zu untersuchen. Welche Konsumenten mieten welche Tonträger, die sie kaufen würden, wenn im Fall eines Ausschlußrechts der Tonträgerhersteller kein Zweitmarkt existiert? Empirische Untersuchungen $^{69}$ belegen zwar, daß die Intensivkäufer, die jährlich mehr als fünf Tonträger kaufen, den größten Teil der Mietnachfrage ausmachen. Aber welche Tonträger wie oft gemietet werden, ist nicht erfaßt worden. Daher läßt sich der Zusammenhang zum Nachfrageausfall des einzelnen Tonträgerherstellers nicht quantifizieren. ${ }^{70}$ Zum gesamtwirtschaftlichen Effekt des privaten Kopierens aufgrund des gewerblichen Weitervermietens von Tonträgern verweisen die Tonträgerhersteller auf die Entwicklung des Absatzes von Leerkassetten analoger und digitaler Art seit Einführung der Tonträgerkategorie $C D .{ }^{71}$ In der zweiten Hälfte der 80er Jahre war ein ständiger Anstieg des Leerkassettenabsatzes in Deutschland bis zu 151 Mio. Stück in 1991 zu verzeichnen. Seit einigen Jahren sinkt dieser Absatz bis auf 100 Mio. Stück in $1995 .^{72}$ Die Festlegung der Höhe einer optimalen Vergütung scheitert aber auch daran, daß

66 Unbespielte digitale Tontrager sind im Handel etwa zum halben Preis der bespielten Tonträger erhălulich. Die Leihgebühr des Vermietgeschäfts und die Opportunitătskosten der Zeit für das Aufnehmen müssen dann deutlich weniger als den halben Preis bespielter Tontrăger betragen, wenn sich eine Substitution einstellen soll. Davon wird hier ausgegangen.

67 Durch das Copyright der Musiker und das ausschließliche Verbreitungsrecht der Tonträgerhersteller werden - wie oben gezeigt - Musikwerke teurer. Daher wird die Nutzung durch Nachfrage geringer sein als ohne Copyright.

68 Dieser Zusammenhang ist empirisch belegt. Wăhrend zweier Nachfragerückgănge im Zeitraum von 1979 83 und 1992/93 ist die Zahl der Neuveröffentlichungen zurückgegangen. Vgl. BPW 1994 und BPW 1996, S. 15 und 17; Mahlmann 1997, op. cit., S. 164.

69 Vgl. Mahlmann 1997, op. cit., S. 177 ff.; Rochlitz 1994, op. cit., S. 536.

70 Durch die Kennzeichnung auf den Tonträgern ist bekannt, welche Tontrăger von welchem Hersteller stammen. Um die einzelnen Tonträgerhersteller kompensieren zu können, sind genaue Vermietzahlen der einzelnen Tonträger und gleichzeitige Erhcbungen über das Kaufverhalten der Mieter nötig. Da sich die digitalen CDs nicht abnutzen, hat das Vermietgeschäft kein Interesse an einer Erfassung solcher Zahlen.

7 Vgl. Rochlitz 1994, op. cit., S. 536.

$72 \mathrm{Vgl}$. Statistik der Loerkassettenverkaufszahlen, in: BPW 1996, op. cit., S. 45. Eine Erklărung des Rückgangs der Verkaufszahlen ist nicht mit dem Absatz bespielter MCs zu erklären, denn die Verkaufszahlen der MC sanken absolut und in Relation zur CD. 
die Tonträgerfirmen ihre Kalkulation für Neuerscheinungen nicht offenlegen. ${ }^{73}$ Aus Neuerscheinungen besteht jedoch der größte Teil der Produktpalette von Vermietgeschäften. Da weder der Verlust pro Vermietvorgang noch der Nachfrageausfall insgesamt für die Tonträgerhersteller quantifizjert werden können, ist eine gesamtwirtschaftlich befriedigende Lösung einer Vergütungsregelung für Kopiertätigkeit nicht möglich.

Aus einzelwirtschafticher Sicht bedingt der Nachfrageausfall geringere Absatzzahlen des Originalangebots und damit höhere Kosten pro Tonträger. Wenn die Rechtekosten (Aufkauf der Rechte von den Musikern) fix sind, wird die von den Musikern aushandelbare Entlohnung niedriger ausfallen, weil sie sich an der erwarteten Nachfrage orientiert, der sich die Tonträgerhersteller gegenübersehen. Sind die Rechtekosten variabel mit den Tonträgerabsatzzahlen verbunden, existiert dieser Zusammenhang direkt für Musiker und Tonträgerhersteller über den geringeren Absatz. Daher geht das Interesse sowohl der Musiker als auch der Tonträgerhersteller dahin, ausschließliche Rechte zu erhalten, um die gewerbliche Weitervermietung untersagen zu können. ${ }^{74}$ Soll eine Vergütung ohne Ausschlußrecht angesichts der Informationsmängel im Markt eingeführt werden, kann sie entweder den Tonträger selbst als Ausgleich für zu erwartende Kopieraktivitäten oder die Leerkassetten als Trägermedium des Kopierens belasten. Weiterhin können Aufnahmegeräte, die zur technischen Realisierung von Kopien nötig sind, oder die Vermietgeschäfte, die die Vergütung pro Vermietvorgang erheben müßten, Anknüpfungspunkte einer Vergütung sein. ${ }^{75}$

Eine Belastung des Originalprodukts ist zu verwerfen, da sie zur weiteren Preissteigerung führt mit der Konsequenz, daß eine Substitution durch Kopieren wegen des dann noch größeren Preisabstands attraktiver wird. Das Aufkommen der Vergütung würde abhängig von der Nachfrageelastizität wegen der negativen Anreize gering bleiben. Die Belastung der Leerkassetten und Aufnahmegeräte führt dann zu keinerlei Allokationsverzerrungen, wenn Leerkassetten und Aufnahmegeräte ausschließlich zum Kopieren verwendet werden. Andere Nutzungen werden durch die Vergütung diskriminiert. Der beste Ansatzpunkt für die Vergütung ist zweifellos der Vermietvorgang selbst. Mit ihm eröffnet sich der Mieter die Möglichkeit der Kopie. Im Falle tatsächlichen Kopierens wird die Vergütung zur Urheberrechtsgebühr, im Falle des bloßen Mietens stellt sie einen Beitrag dar. Die Höhe der Vergütung darf die Differenz zwischen dem Preis für leere und bespielte Tonträger nicht übersteigen. Damit die administrativen Kosten das Vergütungsaufkommen nicht übersteigen, könnte die Differenz zwischen dem Preis für leere Tonträger und dem durchschnittlichen Low-Preis für $\mathrm{CDs}^{76}$ ein $\mathrm{An}$ -

$73 \mathrm{Vgl}$. Āußerung von Peter Schmitt-Sausen, Leiter der Clearing-Stelle für den Tontrăgermarkt, in: Merx, Stefan, supra, S. 32.

74 Diese Rechtsinstitution ist mit der Umsetzung der EU-Richtlinie zum Vermiet- und Verleihrecht in das deutsche UrhG zum 1.7.1995 etabliert worden. Vgl. Abschnitt 2.2.1.

75 Aus finanzwissenschaftlicher Sicht stellt sowohl die Belastung des Originalangebots von Tonträgern als auch die Belastung von Leerkassetten und Aufnahmegeräten einen Beitrag dar. Hier wird die potentielle Kopieraktivităt belastet. Unter der Annahme, daB alle gemieteten Tontrăger auch kopient werden, ist die Belastung des Vermietvorganges eine Gebühr.

76 Die Anknüpfung an die Tonträgerkategorie $\mathrm{CD}$ erfolgt aufgrund ihrer digitalen Qualität und der Tatsache, daß sie sowohl mengen- als auch wertmåßig den größten Anteil am Gesamtumsatz hat. Vgl. BPW 1996 
haltspunkt für die Höhe der Leihgebühr sein. Wenn die Gebühr im Vermietgeschäft erhoben wird, sind die Kontrollkosten seitens der Gebührenempfänger nicht unerheblich. Das Vermietgeschäft wird aufgrund der Preissteigerung zurückgehen.

Die Verbreitung von Musik durch die Medien Radio und Fernsehen konkurriert mit dem Tonträgerkauf. Die Substitution wird perfekter, wenn auch hier digitale Sendequalität vorliegt und die Musikstücke nicht durch Text- oder Werbebeiträge unterbrochen werden. Dazu muß der Konsument überhaupt in der Lage sein, Kopien in der digitalen Qualität anzufertigen. Die technischen Voraussetzungen dafür sind erfüllt. ${ }^{\pi}$ Sollte sich dieser Verbreitungsweg von Musik etablieren, ist keine Vergütung denkbar, sondern nur ein ausschließliches Recht. Erstens ist die Übertragung auf Ton- bzw. Bildtonträger durch den Konsumenten preislich günstiger, zweitens werden sich Spartenprogramme etablieren, die das entsprechende Programm für den Konsumenten kopiergerecht aufbereiten werden, und drittens werden sich die Sendungen wiederholen, so daß sich die Nachfrager mittels Probehören über die zu kopierende Musik informieren können.

Im Ergebnis bleibt festzustellen: Solange eine konkurrierende Nutzung den Tonträgerkauf nicht substituiert, kann die Rechtsinstitution der Vergütung gewählt werden, wobei die Schwierigkeiten im Hinblick auf Vergütungshöhe und -erhebung berücksichtigt werden müssen. Die Konkurrenznutzung hat oft auch komplementären Charakter, der verkaufsfordernd ist. Wenn allerdings die Nutzung die Herstellung eines konkurrenzfähigen Produkts ermöglicht, so daß die kaufkräftige Nachfrage nach dem Originaltonträger völlig oder teilweise substituiert wird, ist Copyright als ausschließliches Recht zur Vervielfältigung und Verbreitung notwendig.

\subsubsection{Kosten der Rechtsnormienung, Ausschlußkosten und Rechtsdurchsetzung}

Im folgenden Abschnitt werden die Kosten betrachtet, die von den Begünstigten investiert werden, um ausschließliche Rechte oder Vergütungsansprüche zu erhalten. Daran anschlieBend werden die Ausschlußkosten technischer Art diskutiert. Abschließend werden die Kosten zur Rechtsdurchsetzung z. B. anhand von Maßnahmen gegen die Piraterie betrachtet. Die Tonträgerhersteller leisten für die Einführung ausschließlicher Rechte Lobbyarbeit. Dies geschieht mit Hilfe der nationalen Verbände der phonographischen Wirtschaft, der Musikverwertungsgesellschaften und der internationalen Dachverbände für die phonographische Industrie (IFPI) sowie für das geistige Eigentum (WIPO). Zusätzlich werden Gutachten erstellt und Konferenzen abgehalten. Wenn die Lobbyarbeit erfolgreich ist, kommt es zu Urheberrechtsverhandlungen, die in der Verabschiedung und Ratifizierung von internationalen $\mathbf{A b}$ kommen münden. Sind die Schutzlücken weltweit geschlossen, können auch keine Schutzlük-

op. cit., S. 12. Genauere Angaben zur Höhe der Vergütung sind nicht möglich, da die Daten zur Preiskalkulation nicht offentlich sind.

77 Für digitales Radio ist die Pilotprojektphase bereits beendet, digitales Fernsehen wird zur Zeit von einem Anbieter geliefert, der allerdings kein Musikprogramm bietet. 
kenprodukte auf legalem Weg mehr vermarktet werden. ${ }^{78}$ Die Kosten der Rechtsdurchsetzung beziehen sich einerseits auf die Lobbyarbeit, um ausschließliche Gesetze zu erlangen. Andererseits sind für Marktbeobachtung, Kontrolle der Produktion und der Absatzkanäle sowie Beschlagnahmeinitiativen mit Zoll- und anderen Behörden erhebliche Investitionen zu tätigen. Das unautorisierte Angebot bezieht sich auf die Nachfrage nach der Originalware. Je perfekter die Piraterieprodukte den Originalen nachgeahmt sind, um so größer ist die Gefährdung der autorisierten Tonträgerhersteller. Für den Staat liegen die Verluste in der Umsatzund Körperschaftssteuer, die beim Umsatz von unautorisierten Tonträgern nicht abgeführt werden. Daraus ergibt sich auch ein staatliches Interesse an der Bekämpfung von Tonträgerpiraterie.

Mit der Einräumung eines Copyright zur ausschließlichen Vervielfältigung und Verbreitung entstehen aber auch Kosten, um dieses Recht durchzusetzen. Einerseits sind das Investitionen, die die Industrie tätigt, um den Ausschluß überhaupt effektiv bewerkstelligen zu können. Hierunter fallen Kopierschutz-, Identifikations- und Codierungssysteme. Auf der anderen Seite müssen Kosten aufgewendet werden, um die Rechte gegenüber Rechtsverletzungen (sog. Piraterie) durchzusetzen und Rechtsumgehung zu verhindern.

Die Tonträgerindustrie hat in Zusammenarbeit mit der Geräteindustrie 1989 das Serial Copying Management System (SCMS) entwickelt. Es beinhaltet Informationen auf dem bespielten digitalen Tonträger, die von digitalen Abspiel- und Aufzeichnungsgeräten ${ }^{79}$ erkannt werden. Diese Informationen werden beim Kopieren transportiert und ermöglichen in der Regel nur noch die Herstellung einer einmaligen digitalen Kopie. Weitere digitale Kopien sind nicht möglich, jedoch beliebig viele analoge Kopien. Damit soll bei der Erstveröffentlichung von Tonträgern der Zugriff zur gewerblichen Weiterverwertung verhindert werden. ${ }^{80}$ Auch wenn die Geräteindustrie die Kopiersperrkennung inzwischen serienmäßig in die digitalen Aufzeichnungsgeräte einbaut, ${ }^{81}$ läßt sich durch das technische Hindernis nur das private Kopieren begrenzen. Gewerbliche Weiterverwerter können Apparaturen zur Aufhebung der Kopiersperre entwickeln. ${ }^{82}$ Sie können auch eine analoge Erstkopie anfertigen, von der dann ein digitaler

78 Schutzlückenprodukte hatten (inkl. Piraterie) in den Jahren 1992-95 in Deutschland Marktanteile von 2,24\% und Umsatze von 130-220 Mio. DM in Endverbraucherpreisen erreicht. Vgl. BPW 1994, op. cit., S. 9 und 27; BPW 1996, op. cit., S. 9 und 15, hier insb. Fn. 2.

79 Digitale Aufzeichnungsgerăte sind im Markt eingeführt für Digital Compact Cassetten (DCC), Mini-Discs (MD) und Digital Audio Tape (DAT). Vgl. Abschnitt 1.2.6.

80 Vgl. Bortloff, Nils, Der Tonträgerpiraterieschutz im Immaterialgüterrecht, Baden-Baden 1995, S. 218.

81 Das primăre Intersse der Hersteller von leeren digitalen Tonträgern und Aufzeichnungsgeräten (Hardwareherstellern) ist ihre Umsatzsteigenung. Für die Etablierung neuer Systeme ist aber ein verfugbares Musikrepertoire in der jeweiligen Tonträgerkategorie unabdingbar. Ebenso sind einige Hardwarehersteller in die Industrie der Herstellung bespielter Tontrăger integriert. Daher kann zumindest mittelfristig von einer gemeinsamen Interessenlage ausgegangen werden.

82 Diverse Anbieter vertreiben mittlerweile Umbausătze, mit denen die Kopiersperre umgangen werden kann. Vgl. o. V., „Kopierschutz-Knacker“, in: Stereoplay 1993, S. 44-46. 
Zwischenspeicher gefertigt wird. Von diesem sind beliebig viele digitale Kopien möglich. ${ }^{83}$ Daher sind die in das SCMS investierten Ausschlußkosten nicht geeignet, eine Weiterverwertung zu unterbinden, sie erhöhen bloß deren Aufwand geringfugigig. ${ }^{84}$ In den deutschen Markt wurde von den Herstellern bespielter Tonträger 1992 der International Standard Recording Code (ISRC) eingeführt, der jedoch nur zur Identifizierung der urheberrechtlich geschützten Werke dienen soll, um Vergütungsansprüche dokumentieren zu können. Es handelt sich damit lediglich um ein System der Unterstützung von Rechtsansprüchen, nicht jedoch um eine Maßnahme zur Verhinderung der Umgehung des Urheberrechts.

Allen Codierungs- und Identifikationssystemen ist gemein, da $\beta$ sie zunächst Kosten verursachen. Kostensenkungen können in der Rechteverwaltung und in der Vereinfachung der Strafverfolgung entstehen. Diese Kostenreduktionen lassen sich aber nur realisieren, wenn alle Hersteller und Preßwerke die Systeme anwenden. Trotz der starken weltweiten Konkurrenzsituation der über 250 Preßwerke für Tonträger ${ }^{85}$ ist es das Interesse der Auftraggeber und damit mittelfristig auch das Interesse der Preßwerke, Ansatzpunkte für die Verfolgung der Piraterie zu schaffen. Investitionen in die Verbesserung des Ausschlusses der Pirateriewaren vom Markt können das Potential für die legalen Tonträger erhöhen.

Im Ergebnis fallen die Ausschlußkosten auf zwei Ebenen an: Erstens auf der technischen Ebene. Hier wird seitens der Industrie versucht, den Zugriff auf die gespeicherte Musik zu erschweren. Die Entwicklung von Kopiersperre, Codierungs- und Identifikationssystemen stellen für die Industrie Investitionen dar, die Folgeinvestitionen für Umgehung bzw. Nachahmung der Systeme seitens der unautorisierten Anbieter erfordern. Dadurch wird der Preisunterschied zwischen den reinen Herstellungskosten und dem Endverkaufspreis von autorisierten im Giegensatz zu nicht autorisierten Tonträgern nicht geringer. Investitionen in die technische Realisierung sind nicht hinreichend, um den Ausschluß auch tatsächlich zu bewerkstelligen. Daher betrifft die zweite Ebene, auf der Ausschlußkosten anfallen, die Kosten des Rechtssystems bzw. der Einführung ausschließlicher Rechte, die ein unautorisiertes Angebot illegal werden lassen und eine entsprechende Verfolgung ermöglichen.

Um ein bestehendes ausschließliches Vervielfaltigungs- und Verbreitungsrecht durchzusetzen, bedarf es sowohl der Kontrolle der legalen Distributionskanäle, ${ }^{86}$ als auch der illegalen Herstellung und Verbreitung. Letztere verursacht erheblich höhere Kosten und Nachfrageausfäle.

83 Mit der analogen Erstkopie wird die Kopiersperre mit Hilfe des „Back-to-Back-Verfahrens“ umgangen. Die Qualitatsunterschiede der digitalen Folgekopien sind so gering, daß von einem fast perfekten Substitut ausgegangen werden muß

84 So im Ergebnis auch Bortloff, Nils, op. cit., S. 219

85 Vgl. Schaefer, Martin, und Manfred Körfer, op. cit., S. 16 f. Sie verweisen darauf, daB in einigen ostasiatischen Ländern die Preßkapazităt der Werke die Inlandsnachfrage um das zehn- bis zwanzigfache übersteigt.

86 Dies ist die Aufgabe der von der Tontrăgerindustrie geschaffenen und finanzierten Clearingstelle für den Tontrăgermarkt. Mit einem Jahresbudget von ca. 180.000,- DM (Quelle: Merx, Stefan, supra, S. 32) sind deren Aufwendungen gering. Daher wird im folgenden nur die illegale Herstellung und Verbreitung von Tontragern thematisiert. 
Mit dem Begriff der Tonträgerpiraterie wird erstens der unautorisierte Zugriff auf die Leistung des an einem bereits bestehenden Tonträger Berechtigten, zweitens die unautorisierte Vervielfältigung und drittens die unautorisierte Verbreitung der ohne Zustimmung vervielfältigten Tonträger bezeichnet. ${ }^{87}$ Die Piraterieformen sind Bootlegs, ${ }^{88}$ Raubkopien ${ }^{89}$ und Identfälschungen. ${ }^{90}$ Die Kosten der Rechtsdurchsetzung als Form der Ausschlußkosten teilen sich jedoch die Tonträgerhersteller mit staatlichen Stellen.

\subsubsection{Wirkung der Copyrights auf Parameter der Musikverwertung mit Tonträgern}

In diesem Abschnitt soll zuerst die Wirkung der Copyrights als Rechtekosten (und zugleich Rechteerlöse für die Musikurheber) auf die Zahl der veröffentlichten Musiktitel und ihre Preise untersucht werden. Danach wird für ein exogen (z. B. durch den Gesetzgeber) gegebenes Niveau des Copyright die optimale Titelangebotszahl hergeleitet. Dann sei angenommen, da $B$ eine Verwertungsgesellschaft die Interessen der Rechteinhaber vertritt und zuerst einer wettbewerblichen Tonträgerindustrie und schließlich einem monopolistischen Tonträgerhersteller gegenübersteht. Die Ergebnisse der folgenden Modellanalyse lassen Aussagen über Zusammenhänge zwischen Rechtekosten und der Zahl der veröffentlichten Musiktitel auf Tonträgern zu.

Die Tonträgerhersteller fragen Musik von Künstlern nach, um das Produkt Tonträger erstellen zu können. Bei dieser Nachfrage handelt es sich um die Rechte zur Vervielfältigung und Verbreitung der Musik der Rechtsinhaber (Musiker, Textdichter, Komponisten). Betrachten wir die Rechtsinhaber als homogene Gruppe mit der Zielsetzung der Gewinnmaximierung, die durch eine Agentur bzw. Verwertungsgesellschaft vertreten wird. Wir können dann bei gewinnmaximierendem Verhalten die Wirkung der Höhe der Copyrights ${ }^{91}$ im Hinblick auf die Tonträgerpreise und Tonträgertitel (als Zahl der Veröffentlichungen) für eine wettbewerbliche und eine monopolistische Tonträgerindustrie analysieren.

87 Vgl. Bortloff, Nils, op. cit., S. 29. Ebenso gehört die unautorisierte Aufnahme von Klangdarbietungen zum Begriff der Tonträgerpiraterie. Vgl. Schaefer, Martin, und Manfred Körfer, op. cit., S. 14.

* Das englische Wort bootleg bedeutet wörlich Stiefelschaft. Gemeint ist damit das Versteck für Aufnahmegerăte. Die illegal aufgenommene (Live-)Musik wird später zur Herstellung illegaler Tonträger benutzt. Vgl. Schaefer, Martin, Tonträgerpiraterie, in: Handbuch der Musikwirtschaft, hrsg. von Moser, Rolf, und Andreas Scheuermann, 3. Aufl., Starnberg 1994, S. 518; Bortloff, Nils, op. cit., S. 30, hier insb. Fn. 16; Schaefer, Martin, und Manfred Körfer, op. cit., S. 17.

89 Zur Herstellung der Raubkopie wird ein handelsüblicher bespielter Tonträger verwendet. Unterformen dieser Piraterieart sind die klassische Raubkopie, die Raubkopplung und das Raub-Mix. Die Kopieprodukte unterscheiden sich in der Regel außerlich vom autorisierten Angebot.

90 Die Identfalschung ist eine exakte Nachbildung des autorisierten Tontrăgers. Sie verletzt damit nicht nur Urheber- und Leistungsschutz-, sondern auch Markenrechte. Vgl. Schaefer, Martin, und Manfred Körfer, op. cit., S. 28.

91 Hier ist die in einem Copyright-Gesetz zu verankernde Höhe gemeint. 
Auf einem wettbewerblichen Tonträgermarkt sei $\mathrm{n}$ die Zahl der veröffentlichten Tonträgertitel, $\mathrm{p}$ ihr Preis und $\mathrm{f}=\mathrm{f}(\mathrm{n}, \mathrm{p})$ die Nachfrage mit $\frac{\delta f}{\delta p}<0 ; \frac{\delta f}{\delta n}>0$ und $\frac{\delta^{2} f}{\delta n}<0$. Ferner wird angenommen, daß alle Titel mit der Menge $\frac{f}{n}$ verkauft werden. Es seien
F die Fixkosten der Produktion von Tonträgern,
$\mathbf{m}$ die variablen Kosten und
$\mathbf{r}$ der prozentuale Anteil am Erlös pro Tonträger
für die Rechteinhaber (Copyrights).

Unter der Annahme, daß jeder Titel dieselben Fixkosten für die Produktion und dieselben variablen Kosten habe, ergibt sich von jeder verkauften Einheit ein Erlös von: $p(1-r)-\boldsymbol{m}$. Bezogen auf den gesamten Output der Tonträgerhersteller ergibt sich gerade dann kein Verlust, wenn gilt:

$$
\frac{f}{n} \geq \frac{F}{p(1-r)-m}
$$

Die linke Seite der Ungleichung (5) gibt die Zahl der pro Titel (z. B. Beatles-CD) verkauften Tonträger an, die rechte Seite definiert die Verkaufszahl, die nötig ist, um die Gesamtkosten zu decken. Bei gegebenen Rechtekosten $\mathbf{r}$ wird angenommen, daß das Angebot $\mathbf{n}$ an Titeln so reichhaltig ist, ${ }^{92} \mathrm{da}$ es nur durch die begrenzten Verkaufsmöglichkeiten der Tonträgerhersteller zum gegebenen Preis limitiert wird. Letztere Annahme ist vor allem dann plausibel, wenn man ein permanentes Überangebot an Musikern bzw. Musikgruppen unterstellt. Für verschiedene Preisniveaus $p_{4}>p_{3}>p_{2}>p_{1}$ existieren verschiedene Break-Even-Points $B\left(p_{1}\right), B\left(p_{2}\right), B\left(p_{3}\right), B\left(p_{4}\right)$, an denen jeweils die Ungleichung (5) erfült ist. Die BreakEven-Linie gibt für ein gegebenes Preisniveau die zur Kostendeckung nötige Nachfrage (f) für eine jeweilige Zahl von Titelveröffentlichungen ( $n$ ) an.

In Abbildung 8 sind die Schnittpunkte der Nachfrage zu dem jeweiligen Preisniveau $f\left(n, p_{1}\right), f\left(n, p_{2}\right), f\left(n, p_{3}\right), f\left(n, p_{4}\right)$ mit den Break-Even-Linien mit 1, 2, 3 und 4 gekennzeichnet. Das sind die möglichen Gleichgewichtspunkte in einer wettbewerblichen Tonträgerindustrie. Bei einem Preisniveau von z. B. p 1 kann ein Punkt links von 1 kein Gleichgewicht sein, da die verkaufte Stückzahl größer ist als der Break-Even-Point, also $f\left(n, p_{1}\right)>B\left(p_{1}\right)$ gilt. Der Gewinn führt zu Marktzutritten, die Zahl der Titel n steigt, bis die Gewinne 0 sind. Mit zunehmendem Preisniveau von $p_{1}$ bis $p_{3}$ nimmt zuerst die Zahl der veröffentlichten Titel $n$ zu, danach bei weiter steigendem Preisniveau ab.

92 Das bedeutet, daß es immer genügend Musiker gibt, die Musiktitel produzieren. Lediglich die Anforderung der Kostendeckung zusammen mit der beschränkten Nachfrage begrenzen daher die Veroffentlichungspolitik der Tonträgerhersteller. Diese Annahme ist empirisch sehr relevant. 
Abbildung 8 zeigt die Zusammenhänge zwischen der Anzahl der Veröffentlichungen n, den verschiedenen Preisniveaus (mit $p_{4}>p_{3}>p_{2}>p_{1}$ ) und dem zugehörigen Break-Even-Point ( 1 , 2, 3, 4) als Schnittpunkt der Nachfragefunktion und der Break-Even-Linie bei den verschiedenen Preisniveaus: ${ }^{93}$

\section{Abbildung 8: Konkurrenzwirtschaftliche Gleichgewichte auf dem} Tonträgermarkt bei verschiedenen Preisniveaus ohne Rechtekosten

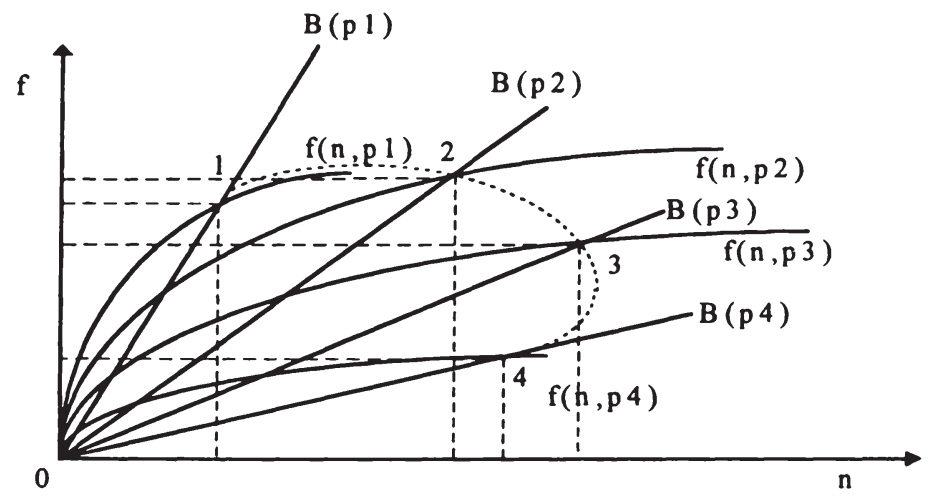

Welcher der vier Schnittpunkte als stabiles Gleichgewicht wahrscheinlich ist, bemißt sich nach den Maxima. Am Punkt 2 erreicht $f$ sein Maximum, dort ist die Nachfrage für die veröffentlichten Musiktitel am größten. Am Punkt 3 erreicht n sein Maximum, dort ist die Zahl der veröffentlichten Musiktitel am größten. Es ist daher wahrscheinlich, daß das stabile Gleichgewicht in dem Bereich zwischen 2 und 3 zu suchen ist. Definieren wir $e_{p}=\frac{\frac{d q}{q}}{\frac{d p}{p}}$ als Preiselastizität der Nachfrage bei konstantem $n$ und $e_{n}=\frac{\frac{d q}{q}}{\frac{d n}{n}}$ als Vielfaltselastizität der Nachfrage bei konstantem p. Die Vielfaltselastizität gibt die relative Verändenung der Nachfrage aufgrund der relativen Veränderung der veröffentlichten Tonträgertitel an. Der Wettbewerb zwischen den Tonträgerherstellern wird zu einem Gleichgewicht zwischen $\mathrm{p}_{2}$ und $\mathrm{p}_{3}$ führen. $\mathrm{Ob}$

93 Baker, Alan J., A Model Of Competition And Monopoly In The Record Industry, in: Journal of Cultural Economics, Vol. 15 (1991), S. 29-54. 
das Gleichgewicht näher an 2 oder an 3 liegt, hängt von den Werten der Preiselastizität der Nachfrage und der Vielfaltselastizität der Musiktitel im Vergleich ab. Denn von einem höheren Preis als $p_{3}$ wird jede weitere Titelveröffentlichung, sei es von Newcomern oder etablierten Firmen die Industrie in Verluste führen, da ein Break-Even-Point nur zu hohen Preisen realisiert werden kann. Diese hohen Preise sind aber nicht konkurrenzfahig, da bereits beim Preisniveau $p_{3}$ mehr Titel den Break-Even-Point erreichen. Daher wird eine Zahl von Titeln wieder vom Markt genommen. Bei einem geringerem Preis als $p_{2}$ werden die Tonträgerhersteller die Zahl an Veröffentlichungen $n$ zu steigern versuchen, solange $p(1-r)>m$. Denn mit einer höheren Veröffentlichungszahl bei einem höheren Preisniveau wird eine höhere Nachfrage erzielt. Dann werden die Tonträger beispielsweise nicht bis zum Ende ihres Produktlebenszyklus verwertet, sondern ständig durch neue Titel ersetzt. Als Folge werden dann sowohl Preis als auch die Veröffentlichungszahl steigen, bis wieder das Gleichgewicht bei $p_{2}$ erreicht wird. Aus Sicht der Konsumenten des Tonträgermarktes ist das Gleichgewicht zwischen $p_{2}$ und $p_{3}$ differenziert zu bewerten. Einerseits steigt die Konsumentenrente mit sinkendem Preis (Tendenz zum Preisniveau $\mathrm{p}_{2}$ ), andererseits sinkt die Vielfalt mit sinkendem Titelangebot, welches bei Präferenz für reichhaltiges Titelangebot wieder einer Tendenz zu Preisniveau $p_{3}$ mit maximalem Titelangebot entspricht.

Um nun den Einfluß der Rechtekosten auf die Zahl der veröffentlichten Musiktitel auf Tonträgern untersuchen zu können, wird zunächst ein gegebener Preis unterstellt. Der verlangte Preis sei $\mathrm{p}_{3}$. Das ist der Preis, an dem die Zahl der Veröffentlichungen n pro Tonträgerhersteller maximal ist. Ferner sei unterstellt, daß alle Hersteller die gleichen Kosten und den gleichen Zugang zu Musikern haben. Werden jetzt die Rechtekosten r erhöht, dann steigen die Erlösanforderungen zur Kostendeckung. In Abbildung 9 hat das eine Abwärtsbewegung auf der Kostendeckungslinie $B\left(p_{i}, r_{i}\right)$ nach links unten zur Folge. Die Gleichgewichte bei Erfuillung der break-even-Bedingung zeigen eine sinkende Zahl von veröffentlichten Musiktiteln $\mathbf{n}$. 


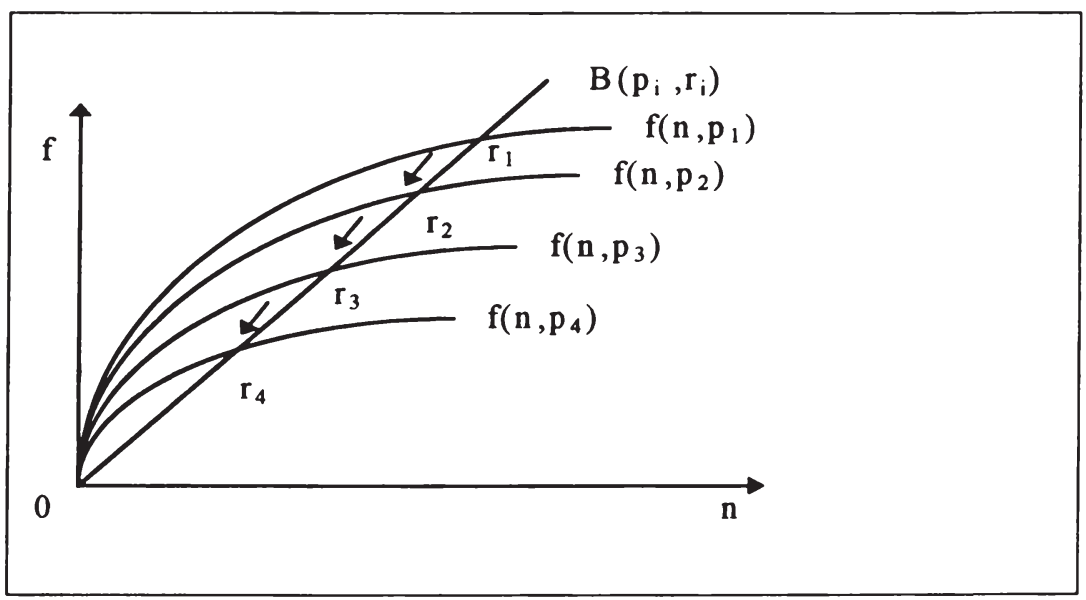

Wegen $\frac{f}{n}=\frac{F}{p(1-r)-m}$ gilt $\frac{d\left(\frac{f}{n}\right)}{d r}=\frac{F\left[\frac{d p}{d r}(1-r)-p\right]}{[p(1-r)-m]^{2}}$ mit $\frac{d p}{d r}=\frac{p}{1-r}$ und $\frac{d\left(\frac{f}{n}\right)}{d r}=0$.

Das bedeutet, daß die Verkaufszahl pro Titel bei Veränderung der Rechtekosten konstant bleibt. Die konstanten Verkaufszahlen pro Tonträgertitel bringen wegen der höheren Preise für die Kostendeckung eine Verringerung der Veröffentlichungen mit sich.

Den Zusammenhang zwischen Rechtekosten und veröffentlichten Tonträgertiteln kann man auch graphisch veranschaulichen. Die Beziehung zwischen $r$ (den Rechtekosten pro Titel) und n (Zahl der Veröffentlichungen) hängt von der Nachfrage der Tonträgerhersteller nach Titeln ab. In der Abbildung 10 sind im ersten Quadranten die Einnahmen pro Titel als abnehmende Funktion von $\mathrm{n}$ dargestellt. D. h., je mehr Titel veröffentlicht werden, desto weniger Erlös pro Titel wird erzielt. Die Funktion $n_{D}(r)$ gilt für die Tonträgerhersteller. Die Tonträger enthalten die Musik der Rechteinhaber (Musiker, Textdichter und Komponisten). Für die Entlohnung der Rechtsinhaber gilt: $A=\frac{r f p}{n}$. Die Entlohnung ist eine abnehmende Funktion der Titelzahl $\mathrm{n}$, in Abbildung 10 im zweiten Quadranten als A(n) gezeichnet. Je höher die Rechtekosten r sind, desto weniger Titel werden produziert. Die produzierten Titel werden zu einem hohem Preis mit hohen Erlösen für die Rechteinhaber verkauft. Sinken die Rechtekosten r, werden mehr Titel produziert, aber der durchschnittliche Rechteerlös sinkt. Das Angebot an Titeln $n_{8}$ hänge von der Entlohnung der Rechtsinhaber ab. Das Angebot $n_{8}(A)$ ist eine wachsende Funktion der Entlohnung. Ab einer bestimmten Entlohnung A wird vom Überangebot der Musiker eine Titelzahl $n$ produziert, die mit abnehmender Entlohnung abnimmt. Da die Ent- 
lohnung der Musiker über die Erlöse aus den Rechten bestritten wird, ${ }^{94}$ ist die Höhe von $r$ für das Gleichgewicht verantwortlich $\left(r_{e}\right)$. Aus einem exogen gegebenen $\left(r_{e}\right)$ ergibt sich eine Zahl von $n_{e}$ Titeln, die veröffentlicht werden. Für sie wird die Entlohnung $A_{e}$ bezahlt.

Abb. 10: Rechteerlös und Höhe der Rechtekosten auf dem Tonträgermarkt

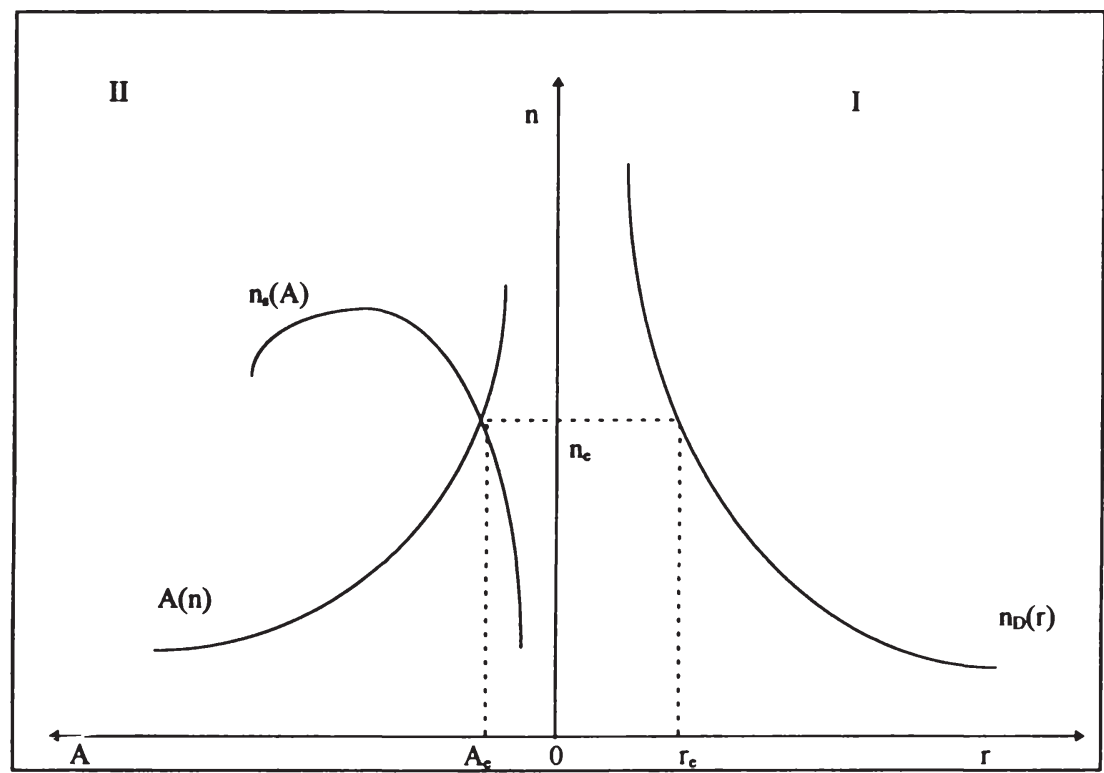

Für die folgende Argumentation wird angenommen, daß eine Verwertungsgesellschaft für die Rechteinhaber deren Erlöse maximiert, z. B. weil ihre Entlohnung mit einem festen Prozentsatz an diejenige der Rechtsinhaber geknüpft ist. Ferner hat die Verwertungsgesellschaft eine Monopolstellung, da sie von allen Musikern mit der Wahrnehmung der Rechte betraut ist. In der ersten Situation steht die monopolistische Verwertungsgesellschaft einer wettbewerblichen Tonträgerindustrie gegenüber und kann das Niveau von $r$ bestimmen. Daher wird untersucht, welches Niveau von $r$ sie wählen sollte und welche Auswirkungen auf den Preis $p$ eines Tonträgers und die $\mathrm{Zahl}$ der veröffentlichten Titel $\mathrm{n}$ zu erwarten sind. Bezüglich dreier gewählter Niveaus von $r$ gilt $r_{1}<r_{2}<r_{3}$. Ferner sei die Rechtekostenelastizität der veröffentlichten Titelzahl definiert als $e_{r}=\frac{d_{r}}{d_{n}} \cdot \frac{n}{r}$. Die Veränderung der Höhe der Rechtekosten $\mathrm{r}$ auf

94 Rechteerlöse sind annahmegemäß die einzigen Erlöse der Musiker aus dem Tontrăgerverkauf. In der Praxis kommen Garantiesummen hinzu, die keine Abschlăge auf den Rechtsanteil pro verkauften Tonträgern sind. 
den Gesamterlös der Rechtsinhaber $\mathrm{R}$ folgt der Gleichung $R=r f p$. R wird maximiert bei der Bedingung erster Ordnung $\frac{d R}{d r}=0$. Es gilt

$$
\frac{d_{R}}{d_{r}}=r\left[f \frac{d_{R}}{d_{r}}\right]+f_{p}=0
$$

Ist der veröffentlichungsmaximierende Preis $\mathrm{p}$ exogen gegeben und das Niveau von $\mathrm{r}$ gesetzt, wird in Abhängigkeit von $\mathbf{n}$ der Rechteerlös $\mathbf{R}$ maximiert. Setzen wir im Rahmen einer $\mathrm{c}$. $\mathrm{p}$. Analyse $\mathrm{n}$ konstant $(\boldsymbol{n}=\bar{n})$, können wir folgende Ergebnisse ableiten: Je geringer die Rechtekosten $r$ und damit aus der break-even-Bedingung folgend auch je geringer $p$, desto höher wird die Nachfrage $f$ sein. Die Rechtekosten haben Auswirkungen auf die Stückzahl der Titel $\mathrm{n}$. Die Mengenanpassung der kompetitiven Tonträgerhersteller wird determiniert durch die break-even-Bedingungen, die in Abbildung 11 den Situationen 1, 2 und 3 entsprechen. Mit einem Preis $p_{1}$ korrespondieren im konkurrenzwirtschaftichen Gleichgewicht die Rechtekosten $r_{1}$, mit dem Preis $p_{2}$ die Rechtekosten $r_{2}$ und mit dem Preis $p_{3}$ die Rechtekosten $r_{3}$. Die Zusammenhänge verdeutlicht die folgende Abbildung 11:

\section{Abbildung 11: Verschiedene optimale Rechtekostenniveaus bei gegebener Zahl von Veröffentlichungen}

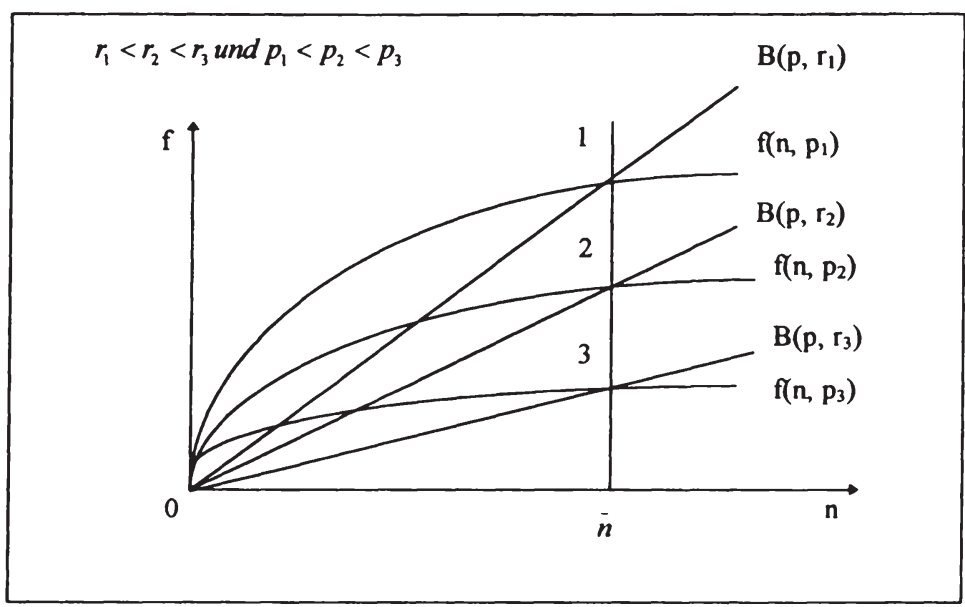

Derjenige Preis, bei dem der Rechteerlös maximiert wird, ist wegen $\bar{n}$ unabhängig von der Zahl der Veröffentlichungen n. Es kann bei geringerem Preisniveau und Rechtekosten eine höhere Stückzahl der $n$ Titel angeboten und nachgefragt werden. 
In der zweiten Situation wird angenommen, daß der monopolistischen Verwertungsgesellschaft, die wieder fur die Rechteinhaber agiert, ein gewinnmaximierender Monopolist als Tonträgerhersteller gegenübersteht. Dessen Preis-Absatz-Funktion sei:

$$
p=f(n, p)[p(1-r)-m]
$$

Der Tonträgermonopolist kann das Problem der Bestimmung der optimalen Zahl der Veröffentlichungen $n$ analog zu Abbildung 10 für ein jeweils von der Verwertungsgesellschaft gegebenes Niveau der Rechtekosten $r$ lösen. Als Monopolist kann er einen gewinnmaximierenden Preis p setzen.

Bei einem Monopson auf der Nachfrageseite der Rechte ist es bei symmetrischer Verhandlungsmacht jedoch unrealistisch davon auszugehen, daß die Verwertungsgesellschaft die Rechtekosten r setzen kann, sofern nicht der Gesetzgeber die Höhe von r festlegt. Bei einer wettbewerblichen Tonträgerindustrie war aber nur davon ausgegangen worden, daß $r$ gesetzt werden kann und nicht $\mathrm{n}$. Nun wird das Niveau von $\mathrm{r}$ gesucht, das im Verhandlungsweg zwischen Tonträgerhersteller und Verwertungsgesellschaft die gesamten Rechteerlöse $\mathbf{R}$ maximiert. Das Ergebnis lautet, daß die Höhe der Rechtekosten $r$ pro Tonträger unabhängig von der Marktform (Monopol oder Wettbewerb) ist, wenn man die Rechteerlöse $\mathbf{R}$ maximieren will. Bei einem optimalen $r^{\bullet}$ maximieren die wettbewerblichen Tonträgerhersteller die Veröffentlichungszahl $n$. Für einen Tonträgermonopolist hat $r^{*}$ dieselbe Höhe, er veröffentlicht jedoch weniger Musiktitel auf Tonträger. Setzt die Verwertungsgesellschaft $r$ und ein Tonträgermonopolist $\mathrm{p}$ und $\mathrm{n}$, dann wird der Verhandlungsspielraum in diesem bilateralen Monopol durch die folgende Abbildung 12 veranschaulicht. Die Ordinate kennzeichnet die Zahl der Tonträgerveröffentlichungen $\mathrm{n}$, die Abszisse die Höhe der Rechtekosten $\mathrm{r} . R_{1}, R_{2}$ und $R_{3}$ seien die Isorechtegewinnkurven der Verwertungsgesellschaft, die den drei gewählten Rechtekostenniveaus $r_{1}, r_{2}$ und $r_{3}$ entsprechen. Die Isorechtegewinnkurven der Verwertungsgesellschaften sind der geometrische Ort aller Kombinationen der Anzahl von Tonträgerveröffentlichungen und der Höhe der Rechtekosten, die für die Verwertungsgesellschaft den gleichen $\mathrm{Ge}$ winn darstellen. Es gilt $R_{1}<R_{2}<R_{3}$. Ferner seien $\Pi_{1}, \Pi_{2}$ und $\Pi_{3}$ die Isogewinnkurven des monopolistischen Tonträgerproduzenten. Sie repräsentieren den geometrischen Ort gleichen Gewinns bei unterschiedlichen Kombinationen von Rechtekosten und veröffentlichter Titelzahl, wobei gilt $\Pi_{1}<\Pi_{2}<\Pi_{3} . A B$ sei die Reaktionsfunktion des Tonträgerherstellers, die angibt, mit welcher Anzahl von Veröffentlichungen $\mathbf{n}$ er auf gegebene Rechtekosten $r$ der Verwertungsgesellschaft reagiert. Hierbei sind die Rechtekosten $r$ maximal bei $B$ und null bei A. In Analogie dazu sei AE die Reaktionsfunktion der Verwertungsgesellschaft bei einer gegebenen Veröffentlichungsrate des Tonträgerproduzenten. Das Marktergebnis bei Wettbewerb unter den Tonträgerherstellern ist repräsentiert durch $\mathrm{E}$ mit $n_{E}$ als Zahl der Veröffentlichungen. Bei einem bilateralen Monopol wird sich das Marktergebnis in Abhängigkeit von der Verhandlungsstärke von Tonträgerhersteller und Verwertungsgesellschaft auf oder innerhalb der Linse MSVT befinden. 
Abb. 12: Marktergebnis bei wettbewerblichem und monopolistischem Tontrăgermarkt ${ }^{\text {9s }}$

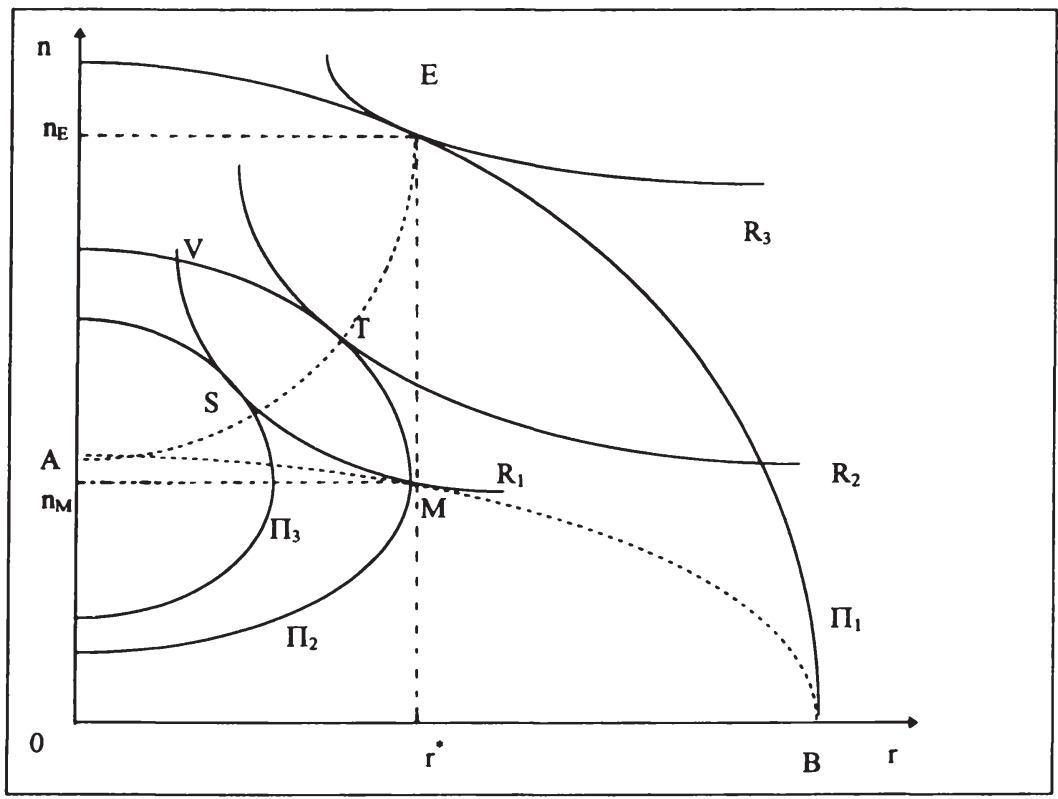

Wenn im Falle des bilateralen Monopols Punkt $M$ realisiert wird, ${ }^{96}$ ergibt sich kein Unterschied in der Höhe der Rechtekosten $r$ bei Wettbewerb unter den Tonträgerherstellern und einem monopolistischen Tonträgerunternehmen. Die Marktform hat dann keine Auswirkungen auf die Höhe der Rechtekosten. Realisiert wird $r^{*}$. Die Höhe der Copyrights wären also in diesem Fall marktformneutral. Jedoch wird beim Marktergebnis von $\mathrm{M}$ nur die geringere Zahl von $n_{M}$ veröffentlicht.

Es sprechen allerdings Gründe dagegen, daß die Lösung $M$ realisiert wird. In einem Regime, in dem die Höhe $r$ der Copyrights nicht exogen vom Gesetzgeber vorgegeben wird, wird $M$ nur dann realisiert werden, wenn man vollständige Information der Verwertungsgesellschaft unterstellt. Jedoch ist realistischerweise davon auszugehen, daß der monopolistische Tonträgerproduzent gegenüber der Verwertungsgesellschaft Informationsvorteile im Hinblick auf seine Kosten und die Nachfrage des Handels und der Konsumenten hat. Ausgehend vom Punkt $M$ sind im Verhandlungsweg Marktergebnisse innerhalb der Linse MSVT wohlfahrts-

95 Quelle: Baker, A. J., supra, S. 47

96 Dieses Ergebnis gilt insbesondere dann, wenn der Verwertungsgesellschaf die Höhe der Rochtekosten exogen durch den Gesetzgeber vorgegeben wird. 
steigernd. Paretoeffizient sind Punkte auf der Reaktionsfunktion der Verwertungsgesellschaft zwischen den Punkten S und T. Hier sind $\mathrm{r}$ und $\mathrm{p}$ geringer wegen der break-even-Bedingung und $\mathrm{n}$ und $\mathrm{f}$ höher wegen des positiven Zusammenhangs zwischen der Nachfrage und der Zahl der veröffentlichten Tonträger.

Die Ergebnisse dieses Abschnitts lassen sich wie folgt zusammenfassen:

1. Kann die Verwertungsgesellschaft in einem wettbewerblichen und monopolistischen Tonträgermarkt dieselben Rechtekosten von den Produzenten verlangen, ist die Zahl der veröffentlichten Titel im wettbewerblichen Tonträgermarkt größer als im monopolistischen $\left(n_{M}<n_{E}\right)$. Die Veröffentlichungszahl $n$ ist ein bedeutender Wettbewerbsparameter im Tonträgermarkt.

2. Geringere Rechtekosten $r$ korrelieren mit einer größeren $Z$ ahl von veröffentlichten Tonträgertiteln $\mathbf{n}$ und einer größeren verkauften Stückzahl (größere Nachfrage f). Wird zwischen monopolistischem Tonträgerhersteller und Verwertungsgesellschaft verhandelt, lassen sich paretoeffiziente Wohlfahrtssteigerungen auf dem Abschnitt ST der Reaktionsfunktion der Verwertungsgesellschaft realisieren.

3. Dieser Zusammenhang gilt für die Musikverwertung mit Tonträgern insbesondere solange die Vielfaltselastizität $e_{n}$ größer ist als die Rechtekostenelastizität $e_{r}$.

An dieser Stelle unberücksichtigt bleiben die Effekte eines gebündelten Rechteerwerbs der Produzenten und Effekte unterschiedlicher Risikoeinstellungen von Tonträgerherstellem im Hinblick auf die break-even-Bedingung von Veröffentlichungen.

Im folgenden Abschnitt soll der Einfluß der Copyrights bei internationaler Produktion und Absatz von Tonträgern sowohl aus der Sicht eines Copyrightgesetzgebers als auch aus derjenigen der Tonträgerproduzenten untersucht werden. 


\subsection{Copyright bei Betrachtung des internationalen Handels}

Nun werden Wirkungen des Copyrights bei Handel in mehreren Volkswirtschaften untersucht. Hierbei werden die verschiedenen alternativen institutionellen Regelungen, Copyrightschutz, kein Copyrightschutz und Copyright mit unterschiedlichem Schutzniveau, als Spielsituationen aufgefaßt, deren Eigenschaften mit Hilfe der Spieltheorie beurteilt werden sollen. Zunächst sind die Gesetzgeber in Abschnitt 3.3.1 die Spieler. Sie können als mögliche Verhaltensweisen ihre Strategien im Hinblick auf Copyrights wählen. Unter bestimmten Annahmen kann die Wirkung der Copyrights auf die Höhe der Konsumenten- und Produzentenrente und die Zahl der angebotenen Tonträger untersucht werden. Ebenso kann die Zielsetzung der Gesetzgeber variiert werden. Danach wird aus Sicht der Tonträgerhersteller argumentiert, die in Abschnitt 3.3.2 als Spieler verstanden werden und die die gesetzlichen Copyrightregelungen als gegeben ansehen. In Abschnitt 3.3.3 wird aufgezeigt, unter welchen Bedingungen es zu einer internationalen Verständigung über ein Copyrightregime kommt. Abschließend wird in Abschnitt 3.3.4 ein Ansatz vorgestellt, mit dem versucht wird, die Effizienz internationaler Urheberrechtsabkommen zu untersuchen.

\subsubsection{Copyright als Strategie zweier Länder}

Gehen wir von Gesetzgebern in zwei unterschiedlichen Ländern aus, die bei zwei möglichen Strategien (Gewährung/keine Gewährung von Copyrightschutz) ohne Kenntnis der Strategiewahl des jeweils anderen Landes ihre eigene Strategie festlegen. Bei diesem nichtkooperativen Spiel interessiert uns die Auswirkungen

a) auf die Produzentenrente der inländischen Tonträgerhersteller,

b) auf die Höhe der Konsumentenrente und

c) auf die Angebotsbreite (veröffentlichte Musiktitelzahl) von bespielten

Tonträgern.

Dem Zahlenbeispiel für den Zwei-Länder-Fall liegen folgende Annahmen zugrunde:

- Völlige Abwesenheit von Copyright führt dazu, daß alle Komponisten, Textdichter und Musiker ihre Produktion einstellen. Dann werden keine autorisierten Tonträger mehr hergestellt.

- Existiert Copyright nur in einem der beiden Länder, ist die Konsumentenrente in dem Land höher, in dem kein Copyright besteht, da hier Tonträger bzw. deren legale Kopien zu geringeren Preisen mehr Nachfrager finden.

- Existiert Copyright nur in einem Land, sind die Einnahmen der Tonträgerhersteller und deren Produzentenrente in dem Land ohne Copyright geringer.

- Existiert Copyright nur im Land A, und Land B führt das Copyright ein, dann steigt die Konsumentenrente im Land A, weil als Rückwirkung des Schutzes in B mehr bespielte Tonträger in A zur Auswahl stehen, wobei von abnehmenden Grenznutzen der Vielfalt ausgegangen wird. Die Konsumentenrente in Land B sinkt, weil zwar die Angebotsvielfalt steigt, die Tonträger dafür aber teurer werden. 
Folgende Auszahlungsmatrix ergibt sich:

Abbildung 13: Auszahlungsmatrix mit und ohne Copyright im Zwei-Länder-Fall

\begin{tabular}{|c||c|c|c|c|}
\hline & $\begin{array}{c}\text { kein Copyright } \\
\text { in A und B }\end{array}$ & $\begin{array}{c}\text { Copyright nur } \\
\text { in A }\end{array}$ & $\begin{array}{c}\text { Copyright nur } \\
\text { in B }\end{array}$ & $\begin{array}{c}\text { Copyright in A } \\
\text { und B }\end{array}$ \\
\hline \hline $\begin{array}{c}\text { Zahl der Tonträger } \\
\text { von Künstlern aus } \\
\text { A und B }\end{array}$ & 0 & 10 & 10 & 20 \\
\hline $\begin{array}{c}\text { Produzentenrente } \\
\text { von Künstlern aus } \\
\text { A }\end{array}$ & 0 & 50 & 50 & 100 \\
\hline $\begin{array}{c}\text { Produzentenrente } \\
\text { von Künstlern aus } \\
\text { B }\end{array}$ & 0 & 50 & 50 & 100 \\
\hline $\begin{array}{c}\text { Konsumentenrente } \\
\text { in A }\end{array}$ & 0 & 200 & 500 & 300 \\
\hline $\begin{array}{c}\text { Konsumentenrente } \\
\text { in B }\end{array}$ & 0 & 500 & 200 & 300 \\
\hline
\end{tabular}

Für den Fall, daß Land A und Land B Copyrightschutz gewähren, beträgt die Summe aus Produzentenrente der Künstler und Konsumentenrente 800. Auf den zwei Märkten besteht ein Angebot von 20 Tonträgern. Die Summe aus Konsumentenrente und Gewinn ist zwar auch in den Fällen 800, in denen jeweils nur Land A oder B Copyrightschutz gewährt. Dafür aber ist die Angebotsbreite mit jeweils nur 10 Tonträgern geringer. Argumentiert man jetzt, $\mathrm{da} ß$ dem Gesetzgeber in jedem Land als Wohlfahrtsmaximierer nur die Summe aus Konsumentenrente und Produzentenrente der Künstler in seinem Land interessiert (z. B. weil er nur an der Maximierung der Renten als Anknüpfungspunkt für die Besteuerung denkt), stellt sich die Frage, ob Copyrightschutz gewährt werden soll oder nicht. Nach obigem Zahlenbeispiel sieht die Matrix wie folgt aus:

Abbildung 14: Wirkung der Copyrightsetzung im Zwei-Länder-Fall

\begin{tabular}{|c|c|c|c|}
\hline & & Land B & \\
\hline & & Kein Copyright & Copyright \\
\hline Land A & Kein Copyright & $0 ; 0$ & $550 ; 250$ \\
\hline & Copyright & $250 ; 550$ & $400 ; 400$ \\
\hline
\end{tabular}


Beide Länder haben die Option, Copyrightschutz zu gewähren oder nicht. Anhand der Auszahlungsmatrix ergibt sich, daß für beide Länder bei jeweils gegebener Strategie ${ }^{97}$ des anderen Landes keine dominante Strategie besteht. Gewährt Land A Schutz, stellt sich Land B besser, wenn es keinen Schutz einräumt und vice versa. Ebenso gibt es kein Nash-Gleichgewicht. ${ }^{98}$ Die Pareto-effiziente Lösung beiderseitigen Copyrightschutzes ergibt sich als Ergebnis des Spiels nur dann, wenn die Länder miteinander in Verhandlung treten und ihre Strategien auf eine Einfuhrung von Copyrights koordinieren. Hierzu ist die dargestellte Spielsituation um die Annahme gegenseitigen Vertrauens bzw. Absprache zu erweitern. Denn selbst bei der Verlängerung des Spiels auf mehrere Perioden ist bei Copyrightschutz des einen Landes für das jeweils andere Land die Schutzversagung die überlegene Strategie. Als weiteren Schritt betrachten wir die Strategie der Tonträgerhersteller bei unterschiedlichen Schutzniveaus in den zwei Ländern.

\subsubsection{Strategie der Tonträgerunternehmen bei unterschiedlichem Copyright}

Die vom Gesetzgeber beabsichtigte Wirkung eines höheren Schutzes liegt in der Erhöhung des Produktionsanreizes für Musikurheber und Tonträgerhersteller und in der Reduzierung der Nutzung ohne Lizenzen. ${ }^{99}$ Besteht allerdings in verschiedenen Ländern ein unterschiedliches Schutzniveau mit unterschiedlichen Urheberrechtskosten, ergibt sich für Tonträgerunternehmen daraus die Möglichkeit zu profitieren. In den Tonträgermärkten besteht ein internationaler Repertoireaustausch. ${ }^{100}$ Der Vertrieb ausländischen Repertoires spielt für den jeweiligen Inlandsmarkt eine große Rolle. Prinzipiell existieren zwei Wege der Verwertung ausländischen Repertoires im Inland: Der Inlandsvertrieb durch Lizenznahme oder durch Parallelimporte aus Märkten, für die Lizenzen vorliegen. ${ }^{101}$ Bei der Lizenznahme erwirbt der inländische Tonträgerhersteller vom ausländischen Rechtsinhaber die ausschließliche Verwertungserlaubnis, die Vervielfältigung, Verbreitung und öffentliche Wiedergabe umfaßt. Auf der Basis dieser Rechte nimmt er dann die Vervielfältigung der Tonträger eigenständig vor. Beim Parallelimport werden die Tonträger selbst eingeführt. Auf sie wurden im Herkunftsland nach den dortigen Regeln Urheberrechtskosten entrichtet. Die Parallelimporte konkurrieren mit den Tonträgern des Lizenznehmers.

Die wirtschaftlichen Gründe, einen Parallelimport durchzuführen, liegen neben evtl. niedrigeren Herstellkosten vor allem in geringeren Urhebergebühren. Für die Tonträgerunternehmen kann es daher rational sein, unterschiedliche Rechtekosten in verschiedenen Ländern durch

97 Die jeweils moglichen Verhaltensweisen eines Spielers nennt man Strategie.

98 Ein Nash-Gleichgewicht besteht immer dann, wenn sich ein Abweichen von einer Strategie bei gegebener Strategie des anderen nicht lohnt. Ein Nash-Gleichgewicht ist bei jeweils gegebener Strategie des anderen ein optimales Strategienpaar.

99 Vgl. zur Wirkung der Erhöhung des Copyrightschutzes Novos/Waldman, supra, S. 236 ff.

${ }^{100}$ Die Sprache als Verwertungshindernis außerhalb des Herkuntslandes spielt insbesondere wegen der Dominanz des Englischen in den Tonträgermärkten keine so große Rolle wie in anderen Urheberrechtsmärkten. Nur ausgeprägt regionales Repertoire unterliegt bei Auslandsverwertung dem cultural discount.

101 Vgl. Reiners, Bernd, Differenzlizenzen und Parallelimporte, in: Handbuch der Musikwirtschaf, hrsg. von Moser, Rolf, und Andreas Scheuermann, 3. Aufl., Starnberg 1994, S. 543-561. [Reiners 1994] 
Parallel-importe auszunutzen. Nach deutschem Urheberrecht ist ein Parallelimport ein Eingriff in das exklusive Verbreitungsrecht des Urhebers nach $\S 17$ Abs. 1 UrhG und das Leistungsschutzrecht des Tonträgerherstellers nach $\S 85$ UrhG. Wenn der Urheber bzw. Tonträgerhersteller einem Mitgliedstaat eines der internationalen Urheberrechtsabkommen angehört, gilt für ihn nach dem Prinzip der Inländerbehandlung die gleiche Rechtsstellung, die sich aus deutschem Recht ergibt. Innerhalb der Europäischen Union wird die Rechtsstellung des Lizenznehmers im Hinblick auf den Parallelimport durch das Prinzip des freien Warenverkehrs nach Art. 30 EGV beschränkt. Die Konsequenz ist eine gemeinschaftsrechtliche Erschöpfung des inländischen Verbreitungsrechts, wenn ein Tonträger in einem EU-Mitgliedstaat in Verkehr gebracht wurde. ${ }^{102}$ Im Ergebnis sind Parallelimporte innerhalb der EU legal.

Ein unterschiedliches Schutzniveau z. B. innerhalb der EU, das sich auf die Höhe der Urheberrechtsentlohnung auswirkt, setzt Anreize, Tonträger aus dem Mitgliedstaat der EU parallel zu importieren, in dem die Urheberrechte die geringsten Kosten verursachen. ${ }^{103}$ Betrachten wir die Strategie zweier Tonträgerunternehmen bei unterschiedlichen Urheberrechtskosten als zweistufiges, sequentielles Spiel. In der ersten Stufe des Spiels veröffentlicht Tonträgerhersteller A einen Tonträger $T_{1}$ im Land $C$ (cheap). Tonträgerhersteller B kauft Exemplare von $T_{1}$ und importiert sie parallel zu einer von A bestehenden Lizenz nach Land $E$ (expensive). Für eine Veröffentlichung von $T_{1}$ im Land $E$ ist $A$ an seinen Preis in $C$ bzw. den Preis von $B$ gebunden, weil B seinen Preis für $T_{1}$ auf der Basis des Preises von A in $C$ kalkulieren wird. Daher wird Tonträgerhersteller A einen zweiten zu veröffentlichenden Tonträger $T_{2}$ in dem Land mit den höchsten Urheberrechtskosten veröffentlichen (in unserem Spiel ist das Land E), wenn A die Verwertungslizenzen aller Länder in der betrachteten Ländergruppe besitzt, um einem Preisvorteil des B durch Parallelimporte zu verhindern. ${ }^{104}$ Wird die vorgelagerte Ebene des Musikurhebers einbezogen, wird dieser von seinem Tonträgerhersteller c. p. verlangen, daß die Veröffentlichung in dem Land erfolgt, in dem die höchsten Urheberrechtserlöse zu erzielen sind. Das Resultat unterschiedlicher Urheberrechtskosten ist c. p. die Erstveröffentlichung von Tonträgern durch die Rechteinhaber in dem Land mit den höchsten Urheberrechtserlösen.

\subsubsection{Bedingungen für internationales Copyright}

In den zwei vorangegangenen Abschnitten war hergeleitet worden, daß es aus gesamtwirtschaftlicher Sicht bzw. aus der Sicht des Copyrightgesetzgebers rational ist, kein Copyright zu gewähren, wenn das andere Land als Handelspartner kein Copyright hat. Aus einzelwirt-

102 Der EuGH hat entschieden, daB Parallelimporte nicht mit dem Hinweis auf nationale Schutzrechte (z. B. ausschlieBliches Verbreitungsrecht) verhindert werden können, wenn die Tontrăger vom Rechtsinhaber selbst oder mit seiner Zustimmung auf dem Markt eines Mitgliedstaates der EU rechtmäBig in Verkehr gebracht worden sind. Es erfolgt keine Anwendung des Art. 36 Abs. 1 EGV für Tonträger mit geschützter Musik.

${ }^{103}$ Unter der Voraussetzung, daB die Tonträger dort mit Zustimmung des Rechteinhabers in Verkehr gebracht worden sind.

104 Hier wird sowohl von Transportkosten als auch anderen Faktoren abstrahicrt. Veroffentlichungszeitpunkt und -ort hängen auch vom Marktvolumen, Marketingstrategien (z. B. Konzerttourneen) etc. ab. 
schaftlicher Sicht sollte die Erstveröffentlichung von Tonträgern in dem Land erfolgen, in dem die Urheberrechtserlöse am größten sind. ${ }^{105}$ Eine nach dem Zahlenbeispiel des Abschnitts 3.3.1 paretoeffiziente Lösung beiderseitigen Copyrightschutzes ist nur durch Absprachen zu erreichen. ${ }^{106}$ Einzelwirtschaftlich entfält dann der Anreiz zu Parallelimporten. Im folgenden werden die Bedingungen für die Realisierung von Absprachen im Hinblick auf einen einheitlichen weltweiten Copyrightschutz untersucht.

Zunächst ist eine Vereinfachung des Zahlenbeispiels hervorzuheben. Hier war bei beiderseitigem Copyrightschutz die Auszahlungssumme der Pay-off-Matrix in beiden Ländern gleich. Unterschiedliche Auszahlungen sind durchaus möglich. D. h., daß verschiedene Staaten aufgrund ihrer Handelsstruktur unterschiedlich von einem Copyrightschutz profitieren. ${ }^{107}$ Das öffentliche Interesse an Mindeststandards im Urheberrechtsschutz ist in den Staaten größer, in denen Urheberrechtsindustrien eine größere Rolle spielen. Andererseits wirkt eine Schutzversagung in Ländern mit untergeordneter Urheberrechtsindustrie wie ein nichttarifäres Handelshemmnis, da eine umfängliche Kopiertätigkeit ohne Urheberentschädigung das Angebot auf den ungeschützten Märkten betriebswirtschaftlich obsolet macht. Anstelle eines Wettbewerbs der Urheberrechtssysteme ${ }^{108}$ können Mindeststandards gesetzt werden, wenn die Interessendifferenzen zwischen den Staaten in urheberrechtlichen Fragen durch andere Handelsinteressen aufgewogen werden. ${ }^{109}$ Mindeststandards bei Copyrights sind diskriminierungsfrei, wenn sie den Zugang zu der geschützten Ware nicht willkürlich, sondern allgemein einheitlich regeln. Dieser Weg ist mit dem TRIPs-Abkommen im GATT/WTO beschritten worden. Die Bedingungen für internationales Copyright liegen in einem Interessenausgleich, der nur auf dem Verhandlungsweg erzielt werden kann.

\subsubsection{Versuch der Beurteilung bestehender Copyrightabkommen}

Für den Ökonomen ist die Fragestellung interessant, ob durch eine Verstärkung des Schutzes in internationalen Copyright-Schutzabkommen die tatsächliche Verbreitung unautorisierter Tonträger zurückgeht. Hierzu wurde in einer empirischen Untersuchung von Burke ${ }^{110}$ versucht, den Zusammenhang zwischen Schutzhöhe und Schutzwirkung zu messen. Für die Schutzwirkung wurde als Kennziffer der Anteil des unautorisierten Tonträgerhandels (sog. Tonträgerpiraterie) am Marktvolumen in einem jeweiligen Nationalstaat gewählt. Für die Schutzhöhe wurde als Maßstab die Mitgliedschaft in den drei Urheberrechtsabkommen Revidierte Berner Übereinkunft, Rom-Abkommen und Genfer Übereinkunft zum Schutz von

\footnotetext{
${ }^{105}$ Wir unterstellten implizit einen positiven Zusammenhang zwischen der Höhe des Copyrightniveaus und den Urheberrechtserlosen.

106 Übertragen auf die Praxis bedeutet das weltweit einheitliche Bestimmungen zu Copyrights.

107 Hierbei wird wieder von der Summe von Konsumenten- und Produzentenrente ausgegangen.

$108 \mathrm{Vgl}$. Mőschel, Wernhard, Neue Medien und Geistiges Eigentum, Papier zum Deutsch-Japanischen Symposium, Tübingen 1996, S. 11.

109 Diesen Weg sind die USA im bilateralen Handelsverhaltnis gegenüber China gegangen, indem sie massive Handelsbeschrănkungen androhten für den Fall, daß China das geistige Eigentum amerikanischer (Audio)Software nicht anerkannte und schützte.

$110 \mathrm{Vgl}$. Burke 1996a, supra, S. 51-66.
} 
Tonträgerherstellern zu zwei Zeitpunkten, 1989 und 1995, angesehen. Die UrsacheWirkungs-Hypothese bestand darin, da $\beta$ mit abnehmendem Piraterieanteil von einer höheren Schutzwirkung ausgegangen wurde. Der Piraterieanteil wurde mit der Mitgliedschaft in Urheberrechtsübereinkommen korreliert, um eine Schutzwirkung mit der Schutzhöhe in Verbindung bringen zu können. Schließlich wurde als Kontrollgröße die Höhe des Bruttoinlandprodukts (BIP) pro Kopf (in US-\$) in den jeweiligen Nationalstaaten gemessen.

Für 53 Staaten wurden Daten ${ }^{111}$ erhoben, die nach dem Piraterieanteil klassiert wurden in Ländergruppen mit unter 10\% Piraterieanteil, Piraterieanteil zwischen $10 \%$ und $30 \%$ und einer höheren Piraterie als $30 \%$ des jeweiligen Marktvolumens. ${ }^{112}$ Ein direkter Zusammenhang zwischen Mitgliedschaft in den drei Urheberabkommen und der Reduzierung einer hohen Piraterie war nicht nachweisbar. Auch bezogen auf die zwei Zeitpunkte 1989 und 1995 ließ sich nicht zeigen, daß mit dem Beitritt zu den Abkommen der Piraterieanteil sank. Es konnte aus den Daten auch nicht geschlossen werden, daß die Abkommen ein effizientes Mittel zur Erreichung niedrigerer Piraterieanteile waren. Die Schaffung eines Urheberrechts bzw. die Mitgliedschaft in Urheberrechtsabkommen garantiert nicht die Rechtsdurchsetzung. Selbst durch letztere ist nicht gesichert, daß keine Tonträgerpiraterie stattfindet. Insoweit ist die Methodik der Untersuchung fragwürdig; zudem wird nicht offengelegt, wie überhaupt der Piraterieanteil ermittelt wurde. Im Hinblick auf die Kontrollgröße BIP pro Kopf kann jedoch vermutet werden, daß die allgemeine wirtschaftliche Entwicklung die Piraterie senkt. Piraterieprodukte im Bereich der Musik (sog. Audio-Piraterie) werden als inferior angesehen und mit wachsendem BIP pro Kopf weniger konsumiert. Daher nimmt in weniger entwickelten Volkswirtschaften Audio-Piraterie einen höheren Marktanteil ein als in weiter entwickelten. Die empirische Untersuchung ist jedoch nicht geeignet, die Wirksamkeit des Copyrightschutzes zu analysieren.

\subsection{Zusammenfassung}

Copyrights sind erstens Urheberschutzrechte für Produktinnovationen (analog zu Patenten) und damit Anreiz zur Produktion neuer Güter. Zweitens sind sie Ausschlußrechte vom Konsum z. B. von Tonträgern für diejenigen Konsumenten, die nicht bereit sind, ein Entgelt zu zahlen. Daneben bestehen drittens rechtsphilosophische Begründungen für Copyrights in dem moralischen Recht des Urhebers auf Schutz seines Werkes und dem natürlichen Recht auf die Erträge seiner Arbeit.

Copyrights sind optimal, wenn es gelingt den Trade-off zwischen dem social welfare loss due to underproduction und dem social welfare loss due to underutilisation zu lösen. Unterproduktion droht bei zu geringem Schutz; zu geringe Nutzung droht bei zu hohem Schutz durch die damit einhergehende Verteuerung der geschützten Produkte für die Konsumenten. Die optimale Höhe der Copyrights hängt ab von der Existenz von Zweitmärkten, den Ausschluß-

\footnotetext{
111 Die Quelle der Pirateriedaten ist: IFPI, The Recording Industry in Numbers '96, London 1996.

112 Vgl. Burke 1996a, supra, S. 58-60.
} 
kosten und den administrativen Kosten des Copyrightsystems. Damit wird deutlich, daß für verschiedene Güter unterschiedlich starker Rechtsschutz gerechtfertigt sein kann. Im Bereich der Tonträger hat der Wert des Copyrights durch Einführung digitaler Speicher- und Wiedergabemedien für die Urheber und Tonträgerhersteller zugenommen.

Unter der Annahme, daß für die Urheber eine rechtserlösmaximierende Verwertungsgesellschaft agiert, lassen sich Tonträgerpreise, Rechtekosten und Zahl der veröffentlichten Tonträgertitel bei wettbewerblichen und monopolistischen Marktformen ableiten. Ergibt sich im Vergleich einer konkurrenzwirtschaftlichen mit einer monopolistischen Tonträgerindustrie die identische Rechtekostenhöhe, werden im Konkurrenzfall mehr Musiktitel auf Tonträger veröffentlicht. Die Copyrights sind unter den Bedingungen des Modells zwar marktformneutral, zwischen Verwertungsgesellschaft und monopolistischem Tonträgerhersteller lassen sich jedoch wohlfahrtssteigernde Verhandlungen durchführen, die im Ergebnis niedrigere Copyrights erbringen. Die Möglichkeit dazu besteht natürlich nur, wenn die Höhe der Copyrights nicht exogen vom Gesetzgeber vorgegeben wird.

Im internationalen Handel spielen die Copyrights als Verwertungsrechte eine entscheidende Rolle. Es wurde gezeigt, daß es für Staaten eine rationale Strategie ist, keinen Copyrightschutz zu gewähren. Existieren verschiedene Copyrightniveaus in mehreren Staaten, die zu unterschiedlichen Rechtekosten führen, ist es für die Tonträgerunternehmen rational, keine teure Lizenz für Staaten mit höherem Copyrightschutz zu erwerben, sondern aus Staaten mit niedrigerem Copyrightschutz billigere Parallelimporte durchzuführen. Daraus folgt für die Musikurheber und Tonträgerhersteller c. p., in denjenigen Länder zuerst zu veröffentlichen, die den höchsten Schutz und damit die höchsten Copyrighterträge gewähren.

Wenn sowohl einzelwirtschaftiche Anreize als auch gesamtwirtschaftliche Strategien gegen Copyright-Abkommen sprechen, stellt sich die Frage, warum solche Abkommen überhaupt getroffen werden. Daher ist eine Übereinstimmung der Staaten notwendig, daß gemeinsame Copyrightgewährung paretoeffizient ist. Dann ist eine Interessengleichheit hinsichtlich Schutzumfang und -dauer erforderlich. Ein weltweiter Rechtsschutz wird theoretisch durch einen einheitlichen Standard erreicht. Verschiedene Staaten haben aber aufgrund ihrer Handelsstruktur unterschiedliche Interessenhöhen im Hinblick auf den Handel mit geistigem Eigentum. Daher liegt die pragmatische Lösung in der Verbindung der Rechtsordnung für geistiges Eigentum mit anderen Teilen einer Welthandelsordnung. Diese Lösung wird mit dem Handelsabkommen über die Aspekte geistigen Eigentums mit der WTO angestrebt.

Vor einer weiteren Stärkung geistiger Eigentumsrechte im Bereich der Musik kann die Frage aufgeworfen werden, wie effizient die bestehenden Abkommen (RBÜ, RA und GTÜ) im Hinblick auf eine Reduzierung der Tonträgerpiraterie wirken, d. h. gegenüber illegaler Produktion und Verbreitung von Tonträgern. Eine Antwort darauf läßt sich aus Gründen der Methodik und der Datenverfügbarkeit nicht geben. Vielmehr steht zu vermuten, daß mit fortschreitender allgemeiner Wirtschaftsentwicklung (gemessen mit Hilfe des Bruttoinlandprodukts pro Kopf) die Piraterie sinkt. 
Nach der Betrachtung der Rechtsgrundlagen für die Verwertung von Musik auf Tonträgern und der ökonomischen Analyse der Copyrightregimes folgt in dem nächsten Kapitel die industrieökonomische Untersuchung des deutschen Tonträgermarktes.

116 


\section{Kapitel 4: Der deutsche Tonträgermarkt aus industrieökonomischer Sicht}

Nachdem im ersten Kapitel die Entwicklung eines eigenständigen Tonträgermarktes, danach im 2. Kapitel dessen rechtlicher Rahmen und im 3. Kapitel seine spezifischen ökonomischen Anreizwirkungen untersucht worden waren, folgt in diesem Kapitel die industrieökonomische Marktanalyse.

Die Analyse von Märkten unter Zuhilfenahme des Struktur-Verhalten-Ergebnis-Paradigmas ist seit ihrer Entwicklung durch Mason, Bain u. a. ${ }^{1}$ vielfach kritisiert worden. ${ }^{2}$ Der Streit in der industrieökonomischen Forschung betrifft vor allem die Frage, welche Zusammenhänge für das Marktgeschehen ursächlich sind bzw. welche Determinanten das Marktergebnis beeinflussen. Die Kritik mündete in einer Weiterentwicklung des Paradigmas, bei dem die Ebenen differenzierter betrachtet und Rückkopplungen zwischen ihnen untersucht wurden. Hieraus folgt, daß nicht mehr von einer strukturalistischen Sichtweise ausgegangen werden kann, bei der die Struktur das Verhalten und beide gemeinsam das Ergebnis determinieren, sondern daß Erkenntnisse über Kausalzusammenhänge nur von einer Synthese, d. h. der Betrachtung der gesamten Struktur-, Verhaltens- und Ergebnisfaktoren und der Wechselwirkungen zwischen ihnen erwartet werden können. Hierbei wird insbesondere das Verhalten der Marktakteure näher untersucht (behavioristische Sichtweise). ${ }^{3} \mathrm{Da}$ im Rahmen dieser Arbeit die Entstehung des Tonträgermarktes, seine rechtlichen Rahmenbedingungen, deren ökonomische Anreize sowie Struktur-, Verhalten- und Ergebniszusammenhänge problematisiert werden, wird die Zweckmäßigkeit des modifizierten SVE-Paradigmas für die Analyse des Tonträgermarktes postuliert.

' Bain, Joe S., Barriers to New Competition, Cambridge, Mass. 1956 [Bain 1956]; ders., Industrial Organisation, 2. Aufl., New York u. a. 1968; ders., Relation of Profit Rate to Industry Concentration: American Manufacturing 1936-1940, in: Quarterly Journal of Economics Vol. 65 (1951), S. 293-324; ders., Economies of Scale, Concentration and the Condition of Entry in Twenty Manufacturing Industries, in: American Economic Review, Vol. 44 (1954), S. 15-19; ders., Changes in Concentration in Manufacturing Industries in the United States 1954-1966: Trends and Relationships to Levels of 1954 Concentration, in: Review of Economics and Statistics, Vol. 52 (1970), S. 411-416.

2 Das Struktur-Verhalten-Ergebnis-Paradigma (SVE) wurde insbesondere von der Osterreichischen Schule kritisiert. Vgl. Hayek, Friedrich A. v., Die Imtümer des Konstruktivismus, Tübingen 1975; ders. Recht, Gesetz und Wirtschaftsfreiheit, in: Freiburger Studien: Gesammelte Aufsätze von F. A. v. Hayek, Tübingen 1969, S. 47 ff., vgl. Kirzner, Israel M., On the Method of Austrian Economics, in: The Foundations of Modern Austrian Economics, hrsg. von Dolan, Edwin G., Kansas City 1976, S. 40 fr. Die Chicago School lehnt im Hinblick auf die contestability einen Zusammenhang zwischen Konzentration und Verhalten ab. Vgl. Brozen, Yale, op. cit., S. 827 ff.; vgl. Bork, Robert H., Antitrust and the Theory of Concentrated Markets, in: Industrial Concentration and the Market System: Legal, Economic, Social and Political Perspectives, hrsg. von Fox, Eleanor M., und James T. Halverson, American Bar Association 1979, S. 81 ff. Beide Schulen betonen den langfristigen Charakter des Marktprozesses. Während die osterreichische Schule eine nomokratische Ordnung bejaht, vertraut die Chicago School stärker auf die Selbstregulierungskräfte des Marktes. Das von der Harvard School favorisierte SVE-Konzept legt staatliche Interventionen nahe, wenn z. B. Marktergebnisse aufgrund von MarktmachtmiBbrauch unerwünscht sind.

3 Auch das weiterentwickelte SVE-Paradigma wird von der Harvard School verwendet. Vertreter sind u. a. Scherer, Frederic, und David Ross, Industrial Market Structure and Economic Performance, 3rd Edition, Boston 1990; Caves, Richard, American Industry: Structure, Conduct, Performance, 6. Aufl., Englewood Cliffs, N. J. 1986, und Phillips, Almarin, Structure, Conduct and Performance - and Performance, Conduct and Structure, in: Industrial Organization and Economic Development, in: Honor of E. S. Mason, hrsg. von Markham, Jesse W., und Gustav F. Papanck, New York u.a. 1970, S. 26-37. 
Für die industrieökonomische Untersuchung dieses Kapitels ergibt sich daraus der im folgenden beschriebene Aufbau:

Zunächst werden der relevante Markt für Tonträger sowie vor- und nachgelagerte Märkte (im Sinne von Marktstufen) abgegrenzt, da hiervon die Verwendbarkeit des Struktur-VerhaltenErgebnis-Konzepts nicht unerheblich abhängt (4.1). Danach werden angebotsseitige Marktstrukturfaktoren herausgearbeitet und der Verlauf der Marktstrukturentwicklung der Tonträgerhersteller seit 1980 für den deutschen Markt skizziert. Eine Beschreibung der Handelsformen und Handelsfunktionen sowie der Konzentrationsentwicklung auf der Handelsstufe folgen. Hinsichtlich der Nachfrage nach Tonträgern werden Altersstruktur und demographische Entwicklung ebenso betrachtet wie die Käuferreichweite (4.2). Im Hinblick auf das Marktverhalten der Tonträgerhersteller wird zwischen Majors und Independents unterschieden. Hierzu betrachten wir insbesondere die Produkt- und Preispolitik sowie die Setzung strategischer Marktbarrieren. Das Verhalten des Tonträgerhandels wird untersucht mit einer Einschätzung der Verhandlungsmacht, der Auswirkung von Betriebsgrößenvorteilen und -nachteilen, der Sortiments- und Preispolitik. Analysekategorien für das Verhalten der Nachfrage sind Kaufintensitäten und Elastizitätswirkungen der Aktionsparameter der vorgelagerten Stufen (4.3). Das Marktergebnis wird nicht in einem eigenen Abschnitt behandelt, sondern anhand der Interdependenzen zwischen Struktur, Verhalten und Ergebnissen (4.4). Eine Zusammenfassung (4.5) beschließt dieses Kapitel.

\subsection{Der relevante Markt für Tonträger}

Die Musikwirtschaft ist ein Teil des Medienbereichs. Zentrale Geschäftsinhalte sind die Produktion, Verwertung, Darbietung und Verteilung von Musik. Innerhalb der Musikwirtschaft ist der Tonträgermarkt ein Teilmarkt, der aus der Speicherung von Musik auf Tonträgern (juristisch Festlegung genannt) sowie der Vervielfältigung und Verbreitung derselben besteht. Verkauft wird die auf dem Träger gespeicherte Musik. Der Tonträger ist die körperliche Verwertungsform ${ }^{4}$ eines ursprünglich immateriellen (d. h. unkörperlichen) Wirtschaftsgutes. Musik wird durch den Tonträger in der gespeicherten Form beliebig wiederholbar und damit als Ware handelbar. ${ }^{5}$ Es wird hierbei nicht verkannt, daß die auf dem Mastertape ${ }^{6}$ gespeicherte Musik für verschiedene Verwertungskanäle, die unterschiedliche Märkte betreffen, das Vorprodukt ist. Hierzu gehört neben der Herstellung von Tonträgern die Sendung in den Medien Rundfunk und Fernsehen, die öffentliche Aufführung (z. B. in Diskotheken) und die Nutzung von Musik im Verbund mit anderen ökonomischen Aktivitäten (Filmmusik, Background-Musik zur Verkaufsförderung, Begleitmusik zu Computerspielen etc.).

4 Bei der Musikverwertung läßt sich die körperliche Form (mittels eines Trăgers) von der unkörperlichen Form (auf Live-Konzerten oder über Netze wie z. B. Internet) unterscheiden. Die neueren technischen Möglichkeiten, Musik in ein Netz einzuspeisen und online über das Netz abzufragen, ermöglichen dic Substitution des offline Gebrauchs, bei dem ein Trăger als Musikspeicher den Besitzer wechseln muß.

5 Dieses gilt für Tonträger im Gegensatz zu anderen Verwertungskanälen von Musik wie z. B. (Live-) Sendung in Medien und öffentlicher Auffuhrung in Konzerten oder Diskotheken.

6 Das Mastertape ist die erste Festlegung bzw. Speicherung der Musik. 
Im Tonträgermarkt wird der mit Musik bespielte Tonträger gehandelt. Die Konsumenten erwerben mit dem Produkt das Recht, den Tonträger jederzeit zu privaten Zwecken im privaten Rahmen abzuspielen. ${ }^{7}$ Die folgende Abbildung 15 zeigt verschiedene Geschäftsinhalte der Musikwirtschaft und ihre Beziehung zum Kernbereich des Tonträgermarktes als vor-, neben- und nachgelagerte oder substitutive und komplementäre Märkte.

\section{Abbildung 15: Vermarktungsbereiche von Musik}

\begin{tabular}{|c|}
\hline nebengelagerte Markte: \\
Merchandiser \\
Film $/$ Video \\
Werbung \\
Sponsoring \\
Hersteller von Musikin- \\
strumenten \\
Musiktheater \\
\end{tabular}

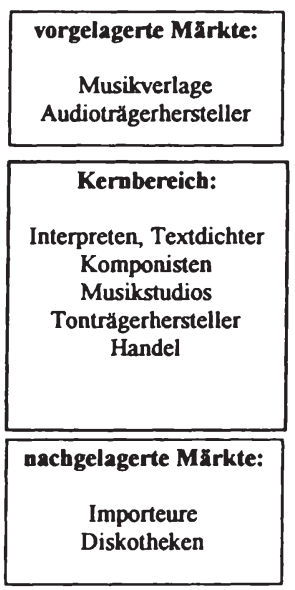

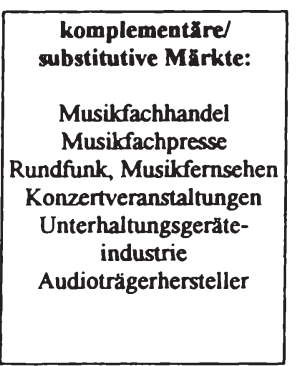

Quelle: Eigene Darstellung in Anlehnung an Schulze, Ralf, Die Musikwirtschaft: Marktstrukturen und Wettbewerbsstrategien der deutschen Musikindustrie, S. 43.

Betrachten wir den Kembereich des Tonträgermarktes, können wir für die weitere Analyse die einzelnen sachlich relevanten Märkte abgrenzen und ihre vertikale Beziehung zueinander charakterisieren (Marktstufenbetrachtung). Danach folgt die räumliche und zeitliche Marktabgrenzung des Tonträgermarktes.

\subsubsection{Abgrenzung in sachlicher Hinsicht}

Aufgabe der Marktabgrenzung in sachlicher Hinsicht ist es, fur die wettbewerbliche Analyse den Produktmarkt so zu definieren, daß die relevante Gruppe von Anbietern und Nachfragern identifiziert wird und von den nicht zur Gruppe gehörenden Anbietern und Nachfragern keine oder nur vernachlässigbare Einflüsse ausgehen. Hierzu wird zunächst auf das gehandelte Produkt hinsichtlich seiner Ausprägungen und relevanten Produkteigenschaften eingegangen. Dabei wird auf das Bedarfsmarktkonzept abgestellt, nach dem ein bestimmter gesellschaftlicher

7 Die Nutzung des Tonträgers zu gewerblichen Zwecken und außerhalb eines privaten Rahmens (z. B. in einer offentlichen Veranstaltung) verstößt gegen das Urheberrecht. Hicrnu vgl. Abschnitt 2.1.3. 
Bedarf nur durch bestimmte, i. d. R. heterogene Güter gedeckt wird. ${ }^{8}$ Danach werden die verschiedenen Marktstufen ausdifferenziert.

Inhalt der Tonträger ist die auf ihm gespeicherte Musik. Die Musik wird dem Konsumenten in verschiedenen Trägerformaten z. B. als Compact Disk (CD) oder Musikkassette (MC) angeboten. Diese Trägerformate bezeichnen wir als Tonträgerkonfigurationen. Sie begründen keine eigenständigen Märkte. Dies ändert sich jedoch, wenn die Inhaltsmenge voneinander abweicht, wie es bei Single- und Longplay-Tonträgerprodukten der Fall ist. Single-Tonträger beinhalten 2-4 Musikstücke, während Longplay-Tonträgerprodukte aus ca. 10-14 Musiktiteln bestehen. Der Inhalt der Single-Tonträger besteht häufig aus Musiktiteln, die in Longplay-Tonträgern ebenfalls enthalten sind. Für Single- und Longplay-Tonträger ist ein gesonderter Markt abzugrenzen. Zwar ist von einer hohen Flexibilität der Herstellung auszugehen, aber analog zu unterschiedlichen Packungsgrößen werden verschiedene Bedürfnisse der Nachfrage befriedigt. Die Märkte stehen sachlich in einer sehr engen komplementären Beziehung, weil die SingleProduktion eine Werbungsfunktion furr die Longplay-Produktion erfüllt. ${ }^{9}$ Bei der Aufzeichnung und Wiedergabe der Musik kann zwischen analoger und digitaler Tonträgerqualität unterschieden werden, wobei erstere durch letztere im Zeitablauf substituiert wird bzw. worden ist. Die Träger an sich sind homogene Massenprodukte, deren Herstellung und Qualitäten standardisiert sind. Die Qualitätsunterschiede begründen keinen eigenständigen Markt für unterschiedliche Qualitäten des Trägermediums, da lediglich dasselbe musikalische Produkt in verschiedenen Verpackungen angeboten wird und sehr hohe Substitutionskonkurrenzen zwischen den einzelnen Tonträgerkonfigurationen bestehen. Ebenso ist die Produktionsflexibilität seitens der Tonträgerhersteller groß.

Im Hinblick auf die unterschiedlichen Musikinhalte wird von Repertoire gesprochen. ${ }^{10}$ Repertoireeinteilungen ergeben sich nach musikwissenschaftlichen Stilelementen. ${ }^{11}$ Sie definieren verschiedene Repertoiresegmente. Dadurch ergibt sich ein hohes $\mathrm{Ma} ß$ an Produktheterogenität. Die erste und neue Veröffentlichung von Musik auf Tonträgern nennt man Erstverwertung. Im Erfolgsfall werden aus den Titeln verschiedener Veröffentlichungen nach bestimmten (z. B. Repertoire-) Kriterien neue Zusammenstellungen als Zweitverwertung angefertigt. Hiervon können im Wege der Lizenzierung Dritt- und weitere Verwertungen folgen, entsprechend der von Tonträgerherstellern getroffenen Nachfrageeinschätzung. Diese Verwertungsfolgen im

8 Vgl. Abbot, Lawrence, Qualität und Wettbewerb, München 1958, S. 96. In der kartellrechtlichen Praxis wird das Bedarfsmarktkonzept regelmäßig angewendet. „The outer boundaries of a product market are determined by the reasonable interchangeability of use or the cross-elasticity of demand between the product itself and substitutes for it (...)." Vgl. Scherer, Frederic M., und David Ross, op. cit., S. 177.

9 Zur zeitlichen Abfolge dieser Produktmärkte vgl. Abschnitt 4.1.3.

$10 \mathrm{Vgl}$. Hill, Leslie F., An Insight into the Finances of the Record Industry, in: The Thrce Banks Review, Nr. 118 (1978), S. 29.

"Diese Stilelemente sind im Bereich klassischer Musik eindeutig, im Bereich zeitgenössischer Musik sind die Grenzen zwischen einzelnen Repertoiresegmenten oftmals flicßend. Vgl. Schulze, Ralf, op. cit., S. 73. 
zeitlichen Ablauf stellen Produktvariationen ${ }^{12}$ dar, die keinen eigenständigen Markt begründen. ${ }^{13}$

Wegen der unterschiedlichen Musikinhalte könnte von Seiten der Konsumenten angenommen werden, daß mit unterschiedlichem Musikrepertoire unterschiedliche Bedürfnisse im Sinne des Bedarfsmarktkonzeptes befriedigt werden. Argumentiert wird, daß sich das Bedürfnis nach leichter musikalischer Unterhaltung eher durch Unterhaltungsmusik (sog. U-Musik) stillen lieBe, während dasjenige nach kultureller Bildung durch ernste Musik (sog. E-Musik) befriedigt werde, worunter vor allem die klassische Musik verstanden wird. ${ }^{14}$ Für die Abgrenzung des relevanten Marktes aus Nachfragersicht ergeben sich jedoch dann keine Änderungen zu der obigen Abgrenzung, wenn beispielsweise klassische Musik zur Entspannung oder leichten Unterhaltung eingesetzt wird. Denn die Konsumentenpräferenzen sind von einem raschen Wechsel im Hinblick auf Interpreten und Repertoiresegmenten gekennzeichnet. ${ }^{15}$ Die mitunter willkürliche Einteilung in U- und E-Musik ist eher damit zu begründen, daß sich angebotsseitig bezüglich der Rechte und der Beschaffung der ausübenden Künstler Unterschiede für die Tonträgerhersteller ergeben. Von daher soll der Unterteilung in U- und E-Musik bei der Betrachtung der Hersteller und ihrer Produktpolitik Aufmerksamkeit geschenkt werden. Das Repertoiresegment Klassik wird bei der Berechnung der Marktanteilsdaten nicht gesondert erfaßt.

Dagegen heterogenisieren die verschiedenen Musikrepertoiresegmente das Produkt Tonträger, weil sich der Nachfragewunsch auf die Musik und den ausübenden Musiker bezieht. Insofern kann aus der Sicht eines verständigen Verbrauchers wegen der Musikeigenschaften nicht von einer hohen bzw. kurzfristigen funktionellen Austauschbarkeit der einzelnen Tonträgerprodukte gesprochen werden. Darauf aufbauend wird argumentiert, daß das Musikangebot bekannter Künstler jeweils einen Elementarmarkt ${ }^{16}$ darstellt, weil die Präferenzen der Konsumenten deren Nachfrage auf den speziellen Künstler festlegt. Diese Sichtweise ist jedoch unzulässig verkürzt. Die Präferenzen bewirken für die Nachfrage zwar eine gewisse Bindung an die Produkte ihrer „Lieblingsmusiker“, doch wird sich der gesamter Tonträgerkonsum nicht nur auf einen Musiker (bzw. Musikgruppe) beziehen. Daher stehen die Tonträger ihres speziellen Musikers in mehr oder minder starker Konkurrenz zu anderen bespielten Tonträgern. Es handelt sich bei Tonträgern um Freizeitkonsumgüter, für die die Nachfrage ein vom Einkommen abhängiges Freizeitbudget auf die in enger Substitutionsbeziehung stehenden Tonträgertitel alloziiert.

12 Vgl. Nieschlag, Robert, Erwin Dichtl und Hans Hörschgen, Marketing, 18. Aufl., Berlin 1997, S. 277. [Nieschlag/Dicht1/Hörschgen]

13 Offenbleiben kann an dieser Stelle, ob mit Tonträgern gemeinsam vertriebene Merchandising-Produkte, die sachlich in keinem Zusammenhang mit dem Tonträger stehen, einen eigenständigen Produktmarkt bilden.

14 Dieser Argumentation hăngt z. B. die zuständige Beschlußabteilung des BKartA an.

is Vgl. zu dieser Einschătzung die EG-Kommission, in: WuW/ E EV 1836 fr. [Thorn EMIVirgin Music], und Kantzenbach, Erhard, Elke Kottmann und Reinald Krüger, Kollektive Marktbeherrschung: Neue Industrieókonomik und Erfahrungen aus der Europäischen Fusionskontrolle, Baden-Baden 1996, S. 67 f. [Kantzenbach/Kottmann/Krüger].

16 Die Sichtweise eines Elementarmarktes als größter vollkommener Teilmarkt eines unvollkommenen Gesamtmarktes geht auf Heinrich von Stackelberg zurück. Vgl. Stackelberg. Heinrich von, Marktform und Gleichgewicht, Wien, Berlin 1934, S. 29 ff. 
Für die Tonträgerhersteller besteht im Hinblick auf die Produktion eine große Umstellungsflexibilität von einem Musiker zu einem anderen. Ebenso bezieht sich das Budget der Tonträgerhersteller für die Vertragsverhandlungen nicht nur auf einen Künstler. Aus der Sicht der Hersteller konkurrieren die Musiker (inklusive Produzenten) um mögliche Vertragsbeziehungen (et vice versa), wobei die Verkaufszahlen der Vergangenheit die Verhandlungsposition determinieren. Lediglich die international vermarktbaren bereits etablierten Musiker bilden wegen ihrer Eigenschaft als Markenartikel eine Ausnahme. Sie haben Präferenzen geschaffen, die eine Bindung der - in einem gewissem Rahmen - preisunelastischen Nachfrage bewirkt. Aber auch das berechtigt nicht zu der Einschätzung, es handele sich um Elementarmärkte, da aus Sicht der Hersteller verschiedene international vermarktbare Musiker produzierbar sind und sich ihre Nachfrage allein schon aus Gründen des Risikos nicht nur auf einen einzelnen Musiker beschränken kann.

Für den Tonträgermarkt ergeben sich drei wesentliche Marktstufen auf dem Weg von der Musikkreation zum Endverbraucher. Abbildung 16 gibt einen Überblick über die Marktstufen des Tonträgermarktes. Die Pfeile kennzeichnen jeweils eine Marktstufe.

\section{Abbildung 16: Marktstufen des Tonträgermarktes}

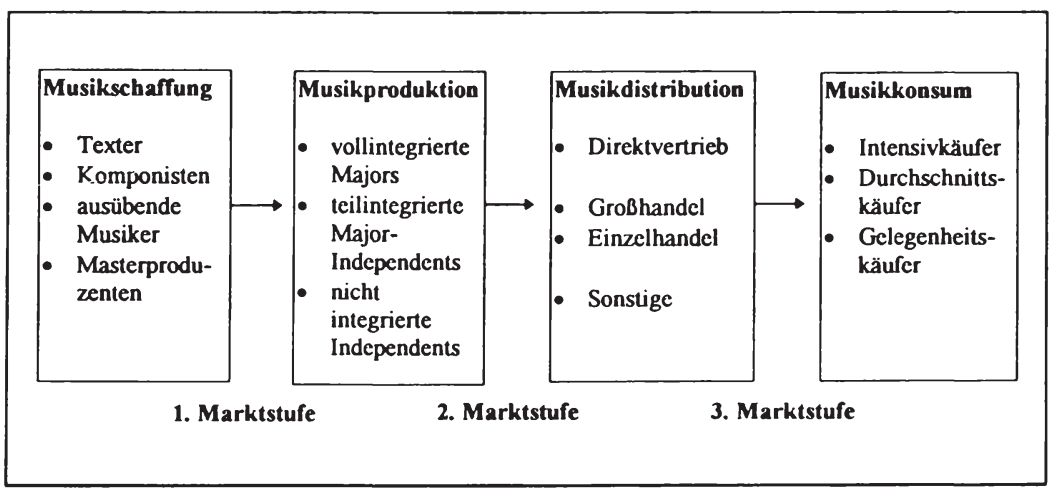

Auf der ersten Marktstufe bieten Komponisten, Textdichter und Musiker ihre Produkte, d. h. Melodien, Texte und Interpretation an. Die Tonträgerproduzenten fragen Musik nach bzw. verpflichten die Musiker vertraglich dazu, ein Angebot zu schaffen. Die Tonträgerhersteller erstellen aus dem Musikangebot das marktfähige Produkt Tonträger.

Auf der zweiten Stufe wird die von den Herstellern auf Tonträgern festgelegte Musik dem Handel angeboten. Der Handel fragt Tonträger nach in Abhängigkeit davon, welche Funktion dieses Produkt innerhalb seines Gesamtsortiments hat. 
Auf der dritten Stufe schließlich werden die Tonträger vom Handel an die Endverbraucher verkauft.

Für die industrieökonomische und wettbewerbspolitische Analyse ist nicht von Belang, daß in einzelnen Fällen weitere Zwischenstufen existieren oder denkbar sind. Beispielsweise kann die physische Herstellung vertraglich ausgelagert sein. Vielmehr gilt es, die Typizität der einzelnen Stufen herauszuarbeiten.

Zur Erstellung eines Musikangebots auf der ersten Marktstufe gehört die eigentliche Produktion von Musik. Deren rechtliche und wirtschaftliche Grundlage ist der Künstlervertrag, den der Musikproduzent mit dem Musiker bzw. Interpreten abschließt. Im urheberrechtlichen Sinne sind Musikinterpreten ausübende Künstler, für die Leistungsschutzrechte bestehen. Wenn der Musiker alle Rechte an der Musik besitzt bzw. sie selbst geschaffen hat, ist er der Urheber. Im Künstlervertrag verpflichten sich Musiker, mit dem Produzenten in einer bestimmten Zeitspanne (i. d. R. 3-5 Jahre) Musikproduktionen durchzuführen. Der Musiker bzw. Interpret überträgt dem Produzenten seine Leistungsschutzrechte zur weltweiten oder räumlich begrenzten Verwertung. ${ }^{17}$

Auf der ersten Marktstufe existieren eine Vielzahl von Musikproduzenten ${ }^{18}$ und eine Vielzahl von Interpreten. Hierfur besteht ein ökonomischer und ein außerökonomischer Grund. Der wesentliche ökonomische Grund ist der durch die Erwartung einer hohen Entlohnung verursachte Anreiz, Musik zu produzieren. Diese hohe Entlohnung ist aber nur für einen geringen, sehr erfolgreichen Teil des Musikangebots realisierbar. Daher kann insbesondere für Musiker bzw. Musikinterpreten davon ausgegangen werden, daß sie in einem sog. winner-take-all market tätig sind. ${ }^{19}$ Winner-take-all Märkte sind dadurch gekennzeichnet, daß die wenigen Erfolgreichen sehr hohe Gewinne erzielen, während der Großteil keine Gewinne oder sogar Verluste realisiert. ${ }^{20}$ Daneben spielen aber auch andere, vorwiegend außerökonomische Motive eine

17 Zur Definition von Leistungsschutzrechten und ihrer Ausgestaltung vgl. Abschnitt 2.1.2 und 2.1.3.

18 Die Tătigkeit des Musikproduzenten kann sowohl eigenstăndig organisiert sein als auch in die Unternehmensfunktionen von Tonträgerherstellem integriert sein, z. B. bei den Majors. Vgl. den Abschnitt 4.2.2.5.

19 Vgl. Frank, Robert H., und Philip J. Cook, The Winner-Take-All Society, New York u. a. 1995, S. 101 ff.

20 Die Kritik daran knüpft an der Existenz und der Bedeutung dieser Märkte an. Im Wettbewerb um den nur für wenige möglichen Erfolg tätigen alle ihre Investitionen noch als potentielle Konkurrenten. Einige wenige werden tatsächlich aktuelle Konkurrenten, von denen wiederum nur wenige Erfolg haben. Hicrin sehen Frank und Cook eine große Verschwendung von Ressourcen, da die nicht erfolgreichen Faktoren keine Ertrăge erwirtschaften. Vgl. Frank, Robert H., und Philip J. Cook, op. cit., S. 105 ff. Empirische Belege dafür, daß der Tontrăgermarkt ein Winner-Take-All-Markt ist, liefern Cox, Felton und Chung. Sie wählen als Indikator für Verkaufserfolg die Vergabe goldener Schallplatten und untersuchen für die USA als weltweit größtem Tontrăgermarkt die Verteilung der Vergabe goldener Schallplatten auf die Musiker im Zeitraum von 1958-1989. Hierzu stellen sie fest, daß dic Zahl der Musiker, die n goldene Schallplatten erhalten, genau $1 / n^{c}$ von denjenigen Musiker ist, die genau eine goldene Schallplatte erhalten. Das bedeutet in der Konsequenz, daß der Markterfolg sehr ungleich verteilt ist und sich große Verkaufserfolge auf wenige Musiker bzw. Musikgnuppen beschränken. Die Beziehung $a_{n}=a_{1} / n^{c}$ mit $a_{n}=Z a h l$ der Musiker, die $n$ goldene Schallplatten erhalten, $a_{1}=$ Zahl der Musiker, die genau eine Schallplatte erhalten, $n=$ Zahl der für einen Musiker vergebenen goldenen Schallplatten und $c=$ Konstante kann verallgemeinertes Gesetz. von Lotka genannt werden. Vgl Cox, Raymond A., James M. Felton und Kee H. Chung. The Concentration of Com- 
Rolle für das Angebot von Musik: Spaß an der Musik, Selbstverwirklichungswünsche etc. Diese in erster Linie außerökonomischen Beweggründe sollen hier nicht analysiert werden.

Wie alle drei Marktstufen so ist auch die erste Marktstufe von einem permanentem Überangebot an (produzierten) Musikstücken gekennzeichnet. Das permanente Überangebot bedeutet für die Tonträgerhersteller bei der Beschaffung zweierlei: Erstens müssen sie aus der Fülle der Musikstücke die ihnen geeignet erscheinenden heraussuchen. Um das Produkt Tonträger erfolgreich beim Handel plazieren zu können, brauchen sie zweitens Musiker, die in dem Sinn bekannt sind, daß sie einen Markenartikel ${ }^{21}$ darstellen. ${ }^{22}$ Daher gilt trotz des Überangebots nur für unbekannte Musiker, daß ihr Preis niedrig ist. Bekannte Musiker sind ökonomisch betrachtet knapp und ihr Preis ist wegen ihrer Qualität als Markenartikel hoch. ${ }^{23}$ Denn einerseits haben diese Musiker Präferenzen bei den Konsumenten geschaffen und andererseits unterliegt ihr Musikangebot dem Präferenztransfer ${ }^{24}$ durch die Nachfrage.

Die zweite Marktstufe kennzeichnet das Austauschverhältnis zwischen Tonträgerindustrie und Handel. Das fertige Produkt wird an die Handelsstufe ausgeliefert, so daß der Handel Absatzmittler ${ }^{25}$ ist. In der prozessualen Betrachtung der Marktstufen können wir entsprechend der Systematik der Betriebswirtschaft klassifizieren zwischen direktem und indirektem Absatz. Beim direkten Absatz handelt es sich um den Direktvertrieb des Herstellers oder dessen AuBendienstes an die Konsumenten. Im Tonträgermarkt existiert direkter Absatz in Form von Direktversand (direct mail). Hier tätige Unternehmen sind Kataloganbieter, Versandhäuser oder Clubs. Dabei können die Unternehmen mit den Tonträgerherstellern verbunden sein (z. B. Bertelsmann-Club) oder eigenständig mit Hilfe von Lizenzen Fremdrepertoire verwerten. Der indirekte Absatz über den Handel ist sowohl einstufig als auch zweistufig organisiert. Beim einsiufigen Absatz gelangen die Tonträger vom Hersteller zum Einzelhandel und von dort zum Konsumenten, während sie beim zweistufigen Absatz vom Hersteller über den Großhandel zum Einzelhandel und dann zum Konsumenten gelangen.

mercial Success in Popular Music: An Analysis of the Distribution of Gold Records, in: Journal of Cultural Economics, Vol. 19 (1995), S. 333-340.

21 Die Markenartikelbindung in Tonträgermarkt bezieht sich auf Musiker, Zusammenstellungen von Musiktiteln oder - bei erfolgreichen Markentransfer - auf andere Konsumgütermarken.

22 Der Markterfolg der Tonträgerhersteller hăngt entscheidend vom Produktangebot bekannter Künstler ab. Vgl. Zombik, Peter, Tonträger im Markt der Zukunft, in: Media Perspektiven o. Jg. (1995), S. 503. [Zombik 1995].

23 Ein Beispiel für hohe Entlohnung bekannter Musiker ist dic Gruppe Rolling Stones.

24 Unter Präferenztransfer ist der Umsetzungsprozeß der Präferenzen von Konsumenten in die Produktionsentscheidung der Anbieter (hier etablierte Musiker) zu verstehen. Dies gilt insbesondere für die Übernahme neuer Repertoirestile. Vgl. Knuse, Jörn, Präferenztransfer und Kontrollwettbewerb in regulierten Unternehmen, in: Jahrbuch für Sozialwissenschaf, Bd. 33 (1982), S. 367-394, hier S. 368.

25 Absatzmittler sind wirtschaftlich und rechtlich selbständige Institutionen im Absatzkanal, die im eigenen Namen und auf eigene Rechnung Güter kaufen und verkaufen. Vgl. Nieschlag/Dichu/Hörschgen, op. cit.,

S. 45-47. 
Die unterschiedlichen Einzelhandelsformen werden folgendermaßen klassifiziert: ${ }^{26}$

- Großbetriebsformen: Warenhauskonzerne, Elektronikkaufhäuser, Megastores.

- Grund- und Mischformen: Verbraucher- und Supermärkte, Filialisten (z. B. Drogerie Müller), Facheinzelhandel, Fachmärkte.

- Sonstige Einkaufsstätten: Foto- und Kaffeegeschäfte, Tankstellen, Kleinpreisgeschäfte, Kinos, Kioske etc.

Die technische Abwicklung des Bezugs der Tonträger durch den Einzelhandel kann sich auf dreierlei Arten abspielen: Erstens die direkte Belieferung durch die Tonträgerherstellerfirmen (z. B. durch Telefonverkauf) oder über deren Außendienstorganisation, zweitens die Belieferung über den Großhändler. ${ }^{27}$ Dritte Form der Handelsbelieferung ist der Import. Die verschiedenen Handelsformen haben unterschiedliche betriebswirtschaftliche Funktionen, die bei der Marktanalyse betrachtet werden.

Die dritte Stufe schließlich umfaßt den eigentlichen Musikkonsum durch Kauf von Tonträgern seitens der Konsumenten im Handel. Der Bedarf des Endnachfragers nach Musik wird dann marktrelevant, wenn er zur Bedürfnisbefriedigung den Besitz von Musik auf einem Träger benötigt. Hierbei spielt die Motivhierarchie eine Rolle. Der latente Besitzwunsch drückt sich nur in einer potentiellen Nachfrage aus, da Musik auch über andere Kanäle, z. B. Radio, Fernsehen, etc. konsumierbar ist. Will der Konsument ohne Fremdstörung (z. B. durch Werbung oder Verkehrsnachrichten) hören, den Zeitpunkt und die Dauer des Musikhörens frei wählen und seine Musikauswahl stimmungsadäquat treffen, so benötigt er Musik auf einem Tonträger. Dieselben Hörmotive liegen dem Musikkonsum zugrunde, der auch mit selbstkopierten Tonträgern zu befriedigen ist, sofern Zugang zu jeweils einem bespielten Tonträger besteht. ${ }^{28} \mathrm{Da}$ her wird er das Originalangebot nur nachfragen, wenn die Kosten für leere Tonträger und das Kopieren (einschließlich der Opportunitätskosten der Zeit) höher sind als der Preis für den Originaltonträger.

Ergänzend zu der bisherigen Betrachtung der Marktstufen ist anzumerken, daß sich durch die neuen technischen Möglichkeiten der unkörperlichen Verwertung (sog. Online-Verwertung über Netze) für die Tonträgerhersteller andere Vertriebsformen ergeben werden, die die Handelsstufen zwischen Herstellern und Konsumenten überflüssig machen könnten, weil keine Musikträger mehr benötigt werden. Da die in Deutschland tätigen Tonträgerhersteller zur Zeit 95\% ihres Umsatzes mit dem Verkauf ihrer Tonträger an Handel, Clubs und Endabnehmer

26 Vgl. BPW 1997, op. cit., S. 32; Schulze, Ralf, op. cit., S. 168, der Grund- und Mischformen unter die Großbetriebsformen subsumiert.

27 Regalgroßhăndler treten als sog. Rack-jobber auch selbst im Einzelhandel auf. Sie mieten Verkaufsraum oder Regalflächen insbesondere in den Verbrauchermärkten und den sonstigen Einkaufsstătten und bieten dort auf eigene Rechnung Tonträger an.

28 Der Tonträger, von dem kopiert wird, braucht kein Exemplar des autorisierten Originalangebots zu sein. Vielmehr können auch Kopien von einer Kopie angefertigt werden. Sofern jeweils digital kopiert wird. ergibt sich kein Qualitátsverlust beim Weiterkopieren. 
erzielen, wird zwar die weitere Entwicklung sowohl technologisch als auch rechtlich zu beobachten sein, jedoch ist für die derzeitige Situation von drei Marktstufen auszugehen. ${ }^{29}$

Die sachliche Marktabgrenzung der Marktstufen des Tonträgermarktes ergibt folgendes Ergebnis: In der ersten Marktstufe bieten Musiker entweder mittels Künstlerverträgen ihre musikalische Dienstleistung oder in Zusammenarbeit mit Masterproduzenten mittels eines Bandübernahmevertrags fertige Masterbänder den Tonträgerherstellern an. Letztere erwerben von den Urhebern (Texter, Komponisten) und Leistungsschutzberechtigten (ausübende Musiker) ausschließliche Nutzungsrechte zur Vervielfätigung und Verbreitung zum Zweck der Festlegung von Musik auf Tonträgern und ihrer anschließenden Vermarktung. In der zweiten Marktstufe bieten die Hersteller ihre Tonträger den verschiedenen Handelsformen bei indirektem Absatz an bzw. wählen den direkten Absatzweg. Der nachfragende Handel wiederum verkauft die Tonträger in der dritten Marktstufe an die Konsumenten.

\subsubsection{Abgrenzung in räumlicher Hinsicht}

Für die verschiedenen Marktstufen sind verschiedene räumliche Märkte relevant. Für die erste Marktstufe ergeben sich zwei Aspekte bei der räumlichen Marktabgrenzung. Im Hinblick auf den Rechtemarkt, auf dem u. a. räumlich getrennte Auswertungen gehandelt werden, können Musiker räumlich getrennte Verwertungen ihres Repertoires an verschiedene Hersteller vergeben, so daß um $\mathrm{Zweitverwertungen} \mathrm{gesondert} \mathrm{verhandelt} \mathrm{werden} \mathrm{muß.} \mathrm{Die} \mathrm{Tonträgerhersteller}$ erhalten die Rechte zur Verwertung der beschafften Musik dann z. B. nur für einzelne Nationalstaaten. Sind Rechte nur beschränkt erhältlich oder im Verhältnis zu den Umsatzchancen zu teuer, beschränkt sich der räumlich relevante Markt aus Sicht der Hersteller auf den Staat (bzw, die Staaten), für den die Rechte bestehen bzw. erworben wurden. Andererseits ist Musik ein Kulturgut, das nicht automatisch weltweit vermarktbar ist, weil kulturelle Unterschiede zwischen Regionen und Staaten existieren. Diese Unterschiede drücken sich etwa in Sprachbarrieren, Harmonien, Rhythmen und Instrumentenauswahl aus. In der wirtschaftswissenschaftichen Diskussion wird dieses Phänomen cultural discount ${ }^{30}$ genannt. Wegen des geringen cultural discount haben englischsprachige Titel an den Musikproduktionen im Bereich der Rock- und Popmusik ein großes Gewicht. Daher ist der Markt für verschiedene Künstler, die bei den Tonträgerherstellern unter Vertrag stehen, räumlich unterschiedlich gro ${ }^{31}{ }^{31}$ je nachdem, ob es sich um international oder nur regional vermarktbare Musiker handelt.

In der zweiten Marktstufe orientiert sich der Handel mit seinen Bestellungen u. a. an den Hitlisten (= Charts), ${ }^{32}$ die die Verkaufserfolge einzelner Tonträgertitel wöchentlich neu angeben

29 Vgl. Mahlmann, Carl, Strukturen des deutschen Tonträgermarktes, in: Handbuch der Musikwirtschaft, hrsg. von Moser, Rolf, und Andreas Scheuermann, 4. Aufl., Starnberg 1997, S. 182 f. [Mahlmann 1997].

30 Vgl. Frank, Björn, Zur Ökonomie der Filmindustrie, Hamburg 1993, S. 106. Vgl. auch Hoskins, Colin, und Rolf Mirus, Reasons for the US dominance in the international trade in television programmes, in: Media, Culture and Society, Vol. 10 (1988), S. 499-515, die die größere Akzeptanz englischsprachiger Filme als wesentliche Ursache der Dominanz der USA im internationalen Filmhandel ansehen.

31

ist auch der Grund zu sehen, daB viele deutsche Musiker nur auf englisch produzieren.

32 Hierbei handelt es sich um die Handelsstrategie der Minimienung des Absatzrisikos und der Maximierung des Tonträgerumschlags. 
und räumlich auf Nationalstaaten ausgerichtet sind. Die Ausrichtung der Sortimentspolitik hat nicht nur Auswirkungen auf die eigene Beschaffungsstrategie der Absatzmittler, die damit eine regionale oder auch nationale Nachfrage nach Tonträgern bedingen kann.

Der engste räumlich relevante Markt ist sicherlich auf der dritten Marktstufe aus Konsumentensicht abzugrenzen, denn hierfür ist die Verfügbarkeit zur Bedarfsdeckung entscheidend. Wenn der Nachfragewunsch nach einer bestimmten Musik z. B. durch das Werbemedium Rundfunk $^{33}$ oder Musikfernsehen (z. B. MTV, VIVA I und II) ${ }^{34}$ geweckt ist, wählt der Konsument die für ihn günstigste Einkaufsmöglichkeit aus. In Ballungsräumen konkurrieren eine Vielzahl von Großbetriebsformen (Warenhauskonzerne, Elektromärkte, Megastores), Facheinzelhandels-, Filialunternehmen und Verbrauchermärkte. In eher ländlichen Gebieten wird die Verfügbarkeit der Tonträgerprodukte ${ }^{35}$ durch Direct Mail (Clubs, Versandhäuser, Kataloganbieter) sichergestellt. ${ }^{36}$

Im Ergebnis kann festgestellt werden, da $\beta$ auf den verschiedenen betrachteten Marktstufen unterschiedlich große räumlich relevante Märkte abgrenzbar sind. Für die folgende Analyse sollen daher nur die Interaktionen der verschiedenen Marktstufen für das Gebiet der Bundesrepublik Deutschland untersucht werden.

\subsubsection{Abgrenzung in zeitlicher Hinsicht}

Voraussetzung für die Marktbeziehung zwischen Tonträgerhersteller und absatzmittelndem Handel sowie zwischen Handel und Konsument ist jeweils die Existenz eines bespielten Tonträgers. Daher ist die sachlich vorgelagerte erste Marktstufe in der Regel auch zeitlich vorgela-

33 Rundfunk hat eine mehrfache Rolle in der Vermittlung von Musikproduktionen. Einerseits werden Musikwünsche unmittelbar („Sie wünschen - wir spielen“) oder mittelbar erfült durch das Aufnehmen von Musiksendungen durch die Hörer, andererseits ist Rundfunk ein Werbemedium für Tontrảgerhersteller, die damit die von ihnen produzierte Musik bekannt machen wollen. Eine Differenzienung nach privatem und offentlich-rechtlichem Radio erübrigt sich $\mathrm{m}$. E., da auch offentlich-rechtliche Rundfunkanstalten über ausschließliche Musikkanăle Programmanbieter von Musik sind

34 Fernsehen war primăr kein Musikmedium. Durch die Entwicklung zum Spartenfernsehen mit ausschließlich musikbezogenen Programmangeboten hat sich das verăndert. Die oben angestellten Überlegungen zum Konkurrenzcharakter einerseits und zum Werbecharakter andererseits sind damit vom Radio auf das Musikspartenfernsehen übertragbar.

35 Mit Stand zum 31.12.1996 schătzt der Bundesverband der Phonographischen Wirtschaft das Gesamtangebot auf ca. 48.000 Tonträger. Quelle: BPW 1997, S. 25. Die Gesamtangebotszahl erfaßt gleichzeitige Veroffentlichungen auf verschiedenen Tonträgerkategorien jeweils gesondert. Die Zahl der Neuerscheinungen lag 1996 bei knapp über 15.000 Stück. Hierbei sind wiederum keine Importe berücksichtigt und gleichzeitige Veröffentlichungen auf verschiedenen Tonträgerkategorien gesondert erfaßt. Daher eignet sich die Statistik des Bundesverbandes der Phonographischen Wirtschaft nicht zur Erfassung der realen Produktinnovationstätigkeit. Das Gesamtangebot wird zusătzlich durch Importe erweitert. Stolberg und Orthmayr berichten von 150.000 vorrätigen Titeln eines Tontrăger-Megastores in Köln. Vgl. Stolberg, Christian, und Wolgang Orthmayr, Vom Schallplattenladen zum Multimediakaufhaus, in: Handbuch der Musikwirtschaf, hrsg. von Moser, Rolf, und Andreas Scheuermann, 4. Auf., Starnberg 1997, S. 245-255.

36 Direct Mail hatte 1996 in Deutschland einen Marktanteil von 16,5\% am Umsatz bespielter Tonträger. Quelle: GFK Panel Services und BPW 1997, op. cit., S. 32. 
gert. Der Rechtemarkt, auf dem u. a. Zweitverwertungen gehandelt werden, ist zeitlich nachgelagert. $^{37}$

Die Werbungsaktivitäten der Tonträgerhersteller in den Medien Rundfunk und Musikfernsehen werden im Hinblick auf die Verkaufsfördenung zeitlich parallel vollzogen. Beobachtbar im Sinne einer Typizität existiert bei allen Tonträgerherstellern eine zeitliche Verwertungskette ${ }^{38}$ der Erst-, Zweit- und Drittverwertung, die wie folgt aussieht: Zunächst erfolgt eine Erprobung der Marktchancen des Musikers anhand von 2-4 Musikstücken als Single, dann wird im Erfolgsfall zeitnah (d. h. innerhalb von max. 2 Monaten) eine Longplay präsentiert zu einem hohen Preis. ${ }^{39}$ Nach einigen Monaten (vom Verkaufserfolg abhängig) wird der Preis gesenkt. ${ }^{40}$ Nach dieser Erstverwertung ist eine Zweit- und Drittverwertung möglich, wozu das Produkt etwas variiert wird, z. B. durch Best of-Tonträger, Neuzusammenstellungen etc. ${ }^{41}$ Zeitlich nachgelagert sind schließlich illegale Aktivitäten wie Raubkopien, Raubmixe, Identfälschungen etc., da für sie das Originalangebot die Vorlage bildet. ${ }^{42}$

Während wir uns im folgenden nicht mit den illegalen Angebotsvarianten befassen wollen, fallen Zweit- und Drittverwertungen in den zwar sachlich gleichen, jedoch zeitlich nachgelagerten Markt. Hingegen läßt sich ein im Sinne eines Produktlebenszyklus zeitlich und im Hinblick auf die Inhaltsmenge auch sachlich getrennter Markt für Tonträger-Single-Produkte abgrenzen. ${ }^{43}$ Aus Angebots- und auch aus Nachfragersicht hat der Single-Markt eine Test-Funktion furr entsprechende Longplay-Produkte. ${ }^{44}$ Auch wegen des zu Longplay-Produkten unterschiedlichen Angebots- und Nachfrageverhaltens ist von einem getrennten Markt auszugehen.

Entscheidend für die zeitliche Erstverwertung von Tonträgern ist, daß es keine Substitutionsmoglichkeiten zu günstigeren Preisen gibt. ${ }^{45}$ Für die zeitlich nachfolgenden Verwertungsschritte bedeutend ist der ursprüngliche Erfolg der Tonträger in der ersten Verwertung, an den bei späteren Verwertungen angeknüpft werden soll. ${ }^{46}$ Schließlich sei noch auf den engen $\mathrm{Zu}-$ sammenhang der zeitlichen Marktabgrenzung zum Produktlebenszyklus eines Tonträgers hin-

37 Zweitverwertungen können in anderen räumlich relevanten Märkten auch zeitlich vorgelagert sein.

38 Nicht alle Tonträgerprodukte werden in diesem zeitlichen Ablauf verwertet. Vielmehr handelt es sich um eine typische Abfolge, bei der jedoch der zeitliche Abstand zwischen den einzelnen Verwertungsstufen unterschiedlich lang ist.

39 Der Werbungscharakter des Single-Tonträgers für den Longplay-Tonträger bedingt eine nahezu gleichzeitige Veroffentlichung.

$40 \mathrm{Zu}$ den Preiskategorien vgl. den Abschnitt 4.3.2.3.

41 Zu den möglichen Formen der Wiederverwertung vgl. den Abschnitt 4.3.1 und 4.3.2.

42 Eine Ausnahme bilden die Parallelimporte, die legal sind, wenn Lizenz- oder Rechtekosten im Herkunftsland abgeführt wurden. Sie sind besonders dann lukrativ, wenn aus Gründen der Verkaufsfordenungen (beispielsweise wegen Konzerttourneen) die Veröffentlichungen des Tonträgerherstellers in verschiedenen Staaten zu verschiedenen Zeitpunkten vorgenommen werden. Dann können Parallelimporte als Erstangebote zeitlich vorgelagert scin.

43 Vgl. Burke, Andrew E., The Dynamics of Product Differentiation in the British Record Industry, in: Journal of Cultural Economics, Vol. 20 (1996), S. 145-164, hier S. 145 und S. 163. [Burke 1996b].

$44 \mathrm{Vgl}$. Schulze, Ralf, op. cit., S. 71.

45 Hierfuir sind sowohl Exklusivităt in der Vertragsbeziehung zwischen Musiker und Tonträgerhersteller entscheidend als auch die Wahl des Veröffentlichungszeitpunktes durch den Hersteller.

$46 \mathrm{Vgl}$. zu spăteren Verwertungen den Abschnitt 4.3.2.2. 
gewiesen, der insbesondere bei bestimmten Repertoiresegmenten (z. B. Weihnachtsproduktionen) wesensimmanent ist. Im Hinblick auf die unterschiedlichen Absatzwege bestehen für die Konsumenten beim Direktvertrieb des Tonträgerhersteller keine Restriktionen, während beim indirekten Absatz über den Handel die Bindung an gesetzliche Ladenöffnungszeiten beachtet werden muß.

Die drei Marktstufen werden in der Untersuchung struktur- und verhaltensrelevanter Faktoren getrennt zu betrachten sein, wobei sich das wettbewerbspolitische Hauptinteresse auf die Beziehung zwischen Herstellern und Händlern bezieht. Neben der dauerhaft hohen Konzentration auf beiden Marktseiten ist die Fokussierung auf diese Marktstufe wegen der hohen Relevanz für das Marktergebnis des Tonträgermarktes insgesamt von Interesse. 


\subsection{Die Struktur des Tonträgermarktes}

In diesem Abschnitt werden Faktoren untersucht, mit denen sich die Struktur des deutschen Tonträgermarktes beschreiben läßt. Hierzu gehören auf der ersten Marktstufe die Musikschaffenden (4.2.1), auf den nachfolgenden Stufen die Tonträgerhersteller, der Tonträgerhandel und die Nachfrage nach Tonträgern. Bei den Tonträgerherstellern (4.2.2) werden die unterschiedlichen internen Unternehmensstrukturen, die Konzentrationsentwicklung unter ihnen im Zeitablauf, einzelwirtschaftiche Konzentrationsmotive, das Ausmaß der vertikalen Integration sowie Marktphase, Marktbarrieren und die Wirkung potentieller Konkurrenz betrachtet. Auf der Stufe des Handels (4.2.3) werden Handelsformen, Handelsfunktionen und die Entwicklung der Handelsstruktur hinsichtlich der absoluten und relativen Konzentration untersucht. Auf der dritten Stufe (4.2.4) werden die Grundlagen der Tonträgernachfrage, die Alterstruktur und die relativen Anteile an der Bevölkerung analysiert. Zusätzlich wird neben der demographischen Entwicklung die Käuferreichweite herangezogen. Eine Zusammenfassung der wichtigsten Strukturbedingungen beschließt diesen Abschnitt.

\subsubsection{Die Musikschaffenden}

Zu der Gruppe der Musikschaffenden gehören die Komponisten, Texter und Interpreten. Komponisten und Texter sind - urheberrechtlich gesehen - die Autoren, Interpreten werden im urheberrechtlichen Kontext ausübende Künstler genannt. ${ }^{47}$ Die Funktionen der Musikschaffenden liegen in der Musikerfindung und ihrer ersten Aufzeichnung. Diese Funktionen können von einer Person oder arbeitsteilig vollzogen werden. Für die Musikverwertung haben sie den Charakter von Vorprodukten. Bereits etablierte Musiker können beispielsweise Auftraggeber von Teilleistungen wie Komponieren und Texten sein. ${ }^{48}$ Der Urheber der Musik im rechtlichen Sinne ist bei Auftragskompositionen regelmäßig der Auftraggeber. Er wird die Übertragung der Rechte zum Gegenstand des Vertrags machen. ${ }^{49}$ Geschieht dies nicht, so sind für die weitere Nutzung gesonderte Rechtsübertragungen (in Form eines Verlagsvertrages) nötig. ${ }^{50}$ Unabhängig von den Marktstufen des Tonträgermarktes ist die Musik der Inhalt aller möglichen Verwertungsformen.

47 Ausübende Künstler sind wie Tonträgerhersteller Leistungsschutzberechtigte, wenn sic lediglich die Musik anderer darbieten. Sie sind Urheber mit weitergehenden Rechten, wenn sie die Musik selbst komponiert und getextet haben oder dieses in Aufragsarbeit durchführen lassen und die Urheberrechte dabei mit erworben haben.

48 Für diese Marktstufe spielt dabei keine Rolle, daß auch etablierte Künstier vertraglich derart gebunden sind, daß sie im Auftrag der Tonträgerhersteller Musik herstellen bzw. herstellen lassen.

49 Die Frage der Rechtsübertragung erübrigt sich in den Fällen, in denen der ausübende Künstler, der das Endprodukt z. B. personifiziert mittels Konzerten am Markt vertritt, identisch ist mit dem Textdichter und Komponisten. Denkbar ist schließlich im Fall der Arbeitsteilung auch, daß Komponisten und Textdichter (evtl. auch in einer Person vereint) ihre Rechte behalten.

so Die Komponisten und Textdichter sind als Rechtsinhaber Autoren, die mit den Tonträgerherstellern einen Verlagsvertrag abschließen. 
Hinsichtlich des Angebots der Musik an die nachfolgende Stufe der Tonträgerhersteller existieren zwei mögliche Vertragsformen: ${ }^{51}$ Künstlerverträge und Bandübernahmeverträge. Hat der Interpret keine Rechte an der Musik und/oder den Texten, wird er mit dem Tonträgerhersteller einen Künstlervertrag abschließen. Hält der Interpret als Musiker alle Urheberrechte an der Musik, und ist er bereit, das Risiko der Erstellung eines Master-Bandes zu tragen, wird er mit der Herstellerstufe einen Bandübernahmevertrag abschließen. ${ }^{52}$ Im Falle des Künstlervertrages sind die Musikschaffenden lediglich dafür verantwortlich, daß Musik, Texte und Musiker für Aufnahmen bereitstehen, die dann auf Kosten und in Verantwortung des Tonträgerherstellers geschehen. Dagegen haben die Musiker bei einer eigenen Fertigung des Masterbandes und Abschluß eines Bandübernahmevertrages noch folgende Funktionen zu übernehmen: Auswahl des Produzenten, d. h. des technischen Betreuers der Aufnahme, Anmietung des Studios, Aufnahme und Abmischung sowie technische Bearbeitung der Aufnahme. ${ }^{33}$

Die Verträge zwischen Musikschaffenden und Tonträgerherstellern regeln die Verteilung der Risiken und der möglichen Erträge zwischen ihnen. Der ökonomische Wert der Gesamtleistung der Musikschaffenden hängt aber nicht allein von der Vertragsform und der darauf basierenden Entlohnung seitens der Tonträgerhersteller ab, sondern neben dem Erfolg des auf dem Markt präsentierten Tonträgers auch von der Institution des Urheberrechts. Das Urheberrecht ${ }^{54}$ ermöglicht durch seinen zeitlichen Rechtsschutz auch Zweit- und Drittverwertungen, die weitere Erträge erbringen können. Desweiteren ist die Höhe der Erträge der Musikschaffenden abhängig von Lizenz- oder Verwertungsgebühren. ${ }^{\text {ss }}$ An bereits bestehenden Aufnahmen können Erträge aus der Nutzung durch Dritte entstehen. Im bestehenden Urheberrecht werden diese durch Verwertungsgesellschaften ${ }^{56}$ erhoben.

Hinsichtlich der Struktur der ersten Marktstufe, in der die Musikschaffenden anbieten, ist zwischen etablierten und neuen Musikern zu unterscheiden, auch wenn wegen der Zahl der Anbieter ein Polypol zu vermuten wäre. Bezüglich der Newcomer läßt sich ein Angebotsüberschuß feststellen. ${ }^{57}$ Etablierung und Erfolg von Musikern ändern sukzessive nicht nur ihre Verhandlungsposition, sondern auch die für sie gültige Marktform von eher polypolistischen zu Strukturen der monopolistischen Konkurrenz. Dabei schaffen sich die Musiker ihren Präferenzraum

SI Vgl. zur Analyse der Vertragsbeziehungen zwischen Musikschaffenden und Tonträgerherstellern Abschnitt 4.3.1.

52 Vgl. Thurow, Norbert, und Peter Zombik, Phonographische Wirtschaft, in: Rauhe, Hermann, und Christine Remmer, Kulturmanagement: Theorie und Praxis einer professionellen Kunst, Berlin u. a. 1994, S. 197210.

s3 Vgl. Thurow, Norbert, und Peter Zombik, op. cit., S. 199.

S4 Wie jedes Schutzrecht bezweckt auch das Urheberrecht letzulich eine Umverteilung ökonomischer Renten von den Konsumenten zu den Produzenten von Musik. Vgl. Macqueen, Hector L., und Alan Peacock, Implementing Performing Rights, in: Joumal of Cultural Economics, Vol. 19 (1995), S. 157-175.

ss Verwertungsgebühren zugunsten des Musikers entstehen z. B. für die Sendung in Radiostationen. Lizenzgebühren entstehen z. B. für eine weitere Verwertung bereits verwerteter Tonträgeraufnahmen

56 Die gröBte deutsche Verwertungsgesellschaft GEMA nahm im Geschäftsjahr 1995 insgesamt für alle Rechtsinhaber (Urheber- und Leistungsschutzberechtigte) knapp 1340 Millionen DM ein. Quelle: GEMAJahrbuch 1996/97, Baden-Baden 1997, S. 49.

57 Vgl. Schmidt, Christoph, Organisation der Majors, in: Handbuch der Musikwirtschaf, hrsg. von Moser, Rolf, und Andreas Scheuermann, 4. Aufl., Starnberg 1997, S. 185-200. 
raum bei den Konsumenten, mit dem sie gegenüber den Tonträgerherstellern an Verhandlungsmacht gewinnen. Den Extremfall stellen sehr erfolgreiche Musiker dar, die sich dann als monopolistische Anbieter des von ihnen etablierten Markenartikels ${ }^{58}$ dem Oligopson ${ }^{59}$ der Major-Tonträgerhersteller gegenübersehen.

\subsubsection{Die Tonträgerhersteller}

Die Tonträgerhersteller lassen sich unterteilen in die Majors und Independents. Unter den Majors versteht man die international tätigen Musikkonzerne Warner Music, Sony Music, Polygram, EMI und Bertelsmann Music Group (BMG). Diese Musikkonzerne sind (oder im Fall von EMI waren) Töchter folgender Muttergesellschaften: Time/Warner (USA), Sony (Japan), Philips (Niederlande), Bertelsmann (Deutschland) und bis zum 17.08.96 (Tag der Entflechtung) Thorn (Großbritannien). Hinzu kommt als kleinerer, aber auch international operierender Musikkonzern MCA (früher Tochter von Matsushita/Japan, heute von Seagram/Kanada). Die Independents (deutsch: Selbständige, Unabhängige) sind kleine Musikunternehmen, die für sich selbst in Anspruch nehmen, musikalisch und/oder kulturell eigenständige Wege zu gehen. Als Mischform zwischen Independents und Majors können Major-Independents klassifiziert werden, die im Gegensatz zu Independents eigene Vertriebsformen aufgebaut haben. ${ }^{60}$

Das Marktvolumen des deutschen Tonträgermarktes läßt sich abbilden durch die mengenmäßige Entwicklung der Tonträgerverkäufe der Mitgliedsfirmen im Bundesverband der Phonographischen Wirtschaft an Handel, Clubs und sonstige Weiterverteiler, die monatlich getrennt nach Tonträgerkategorien erhoben werden. Diese Absatzmengen werden mit den von der Gesellschaft für Konsumforschung (GfK) ermittelten Durchschnittspreisen (Endverkaufspreise inklusive der Umsatzsteuer) der jeweiligen Tonträgerkategorie multipliziert, um das wertmäßige Marktvolumen der Verbandsstatistikteilnehmer zu erfassen. Hinzu kommen die Umsätze der Nicht-Verbandsstatistik-Teilnehmer, zu denen auch einige der Independents zählen, und die Direktimporte des Handels, bereinigt um die Direktexporte. Dann wird das illegale Tonträgerangebot (sog. Tonträgerpiraterie) geschätzt und zum Marktvolumen hinzugefügt. Es gehört wegen der direkten Substitution des autorisierten Angebots zum Markt, läßt aber das Volumen statistisch unsicher erscheinen.

58 Im Tonträgermarkt ist die Etablierung von Marken eine wesentliche Bedingung. Marken können erstens einzelne Musiker oder Musikgruppen sein (z. B. Rolling Stones). Zweitens können durch Zusammenstellungen von Musikrichtungen auf Tontrăgern Marken etabliert werden (z. B. Kuschel-Rock). Drittens ist ein Markentransfer von anderen Produkten auf Tonträger möglich (z. B. Bravo-CD-Zusammenstellungen).

59 Zur Marktform bei den Tonträgerhersteliern vgl. den folgenden Abschnitt 4.2.2.

$60 \mathrm{Vgl}$. Schulze, Ralf, op. cit., S. 141. Diese Zwischenform entstand aus wirtschaftlich erfolgreichen Independents oder aus Kooperationen von Independents untereinander. 
Tab. 1: Mengen- und wertmäßige Marktentwicklung des deutschen Tonträgermarktes

\begin{tabular}{|c|c|c|c|c|c|c|}
\hline Jahr & $\begin{array}{c}\text { Verkaufte } \\
\text { Singles } \\
\text { (in Mio. } \\
\text { Stück) }\end{array}$ & $\begin{array}{c}\text { Verkaufte } \\
\text { Longplay } \\
\text { (in Mio. } \\
\text { Stück) }\end{array}$ & $\begin{array}{c}\text { Summe aus } \\
\text { Single- und } \\
\text { Longplay- } \\
\text { markt }\end{array}$ & $\begin{array}{c}\text { Umsatz zu } \\
\text { laufenden } \\
\text { Preisen (in } \\
\text { Mio. DM) }\end{array}$ & $\begin{array}{c}\text { kumulierter } \\
\text { Marktanteil } \\
\text { der Majors } \\
\text { (in \%) }\end{array}$ & $\begin{array}{c}\text { Gesamt- } \\
\text { markt* } \\
\text { (in Mio. } \\
\text { DM) }\end{array}$ \\
\hline 1980 & 45,0 & 153,0 & 198,0 & 2250 & 91 & 2475 \\
\hline 1981 & 43,3 & 143,2 & 186,5 & 2275 & 91 & 2500 \\
\hline 1982 & 45,1 & 133,1 & 178,2 & 2160 & 90 & 2400 \\
\hline 1983 & 50,8 & 123,4 & 174,2 & 2050 & 90 & 2280 \\
\hline 1984 & 49,6 & 117,4 & 167,0 & 2010 & 90 & 2233 \\
\hline 1985 & 49,6 & 130,2 & 179,8 & 2215 & 89 & 2488 \\
\hline 1986 & 43,4 & 132,7 & 176,1 & 2365 & 87 & 2718 \\
\hline 1987 & 38,5 & 147,3 & 185,8 & 2560 & 86 & 2977 \\
\hline 1988 & 31,6 & 156,7 & 188,3 & 2785 & 85 & 3276 \\
\hline 1989 & 32,3 & 163,3 & 195,6 & 3095 & 84 & 3685 \\
\hline 1990 & 27,2 & 194,7 & 221,9 & 3645 & 83 & 4392 \\
\hline 1991 & 25,4 & 206,4 & 231,8 & 4040 & 83 & 4867 \\
\hline 1992 & 26,6 & 195,1 & 221,7 & 4155 & 81 & 5130 \\
\hline 1993 & 36,8 & 201,5 & 238,3 & 4515 & 80 & 5644 \\
\hline 1994 & 40,3 & 205,1 & 245,4 & 4660 & 81 & 5753 \\
\hline 1995 & 44,1 & 208,7 & 252,8 & 4680 & 80 & 5850 \\
\hline 1996 & 48,1 & 212,1 & 260,2 & 4785 & 82 & 5835 \\
\hline 1997 & 49,4 & 218,6 & 268,0 & 4910 & 82 & 5988 \\
\hline
\end{tabular}

Quellen: Hummel, Marlies, op. cit., S. 52 ff.; BPW 1994, op. cit., S. 8-14; BPW 1996, op. cit., S. 8-11 und BPW 1997, op. cit., S. 8 und 16; Conen, Michael, op. cit., S. 16; Zombik, Peter, 1995, supra, S. 503, Schulze, Ralf, op. cit., S. 64-68 und eigene Berechnungen.

Tabelle 1 zeigt die verkauften Single- und Longplay-Tonträger, die Summe aller verkauften Tonträger der Mitgliedsfirmen des Bundesverbandes der Phonographischen Wirtschaft von 1980 bis 1997, ihren Umsatzwert zu laufenden Preisen, den kumulierten Marktanteil der Verbandsstatistikfirmen und das Gesamtmarktvolumen.

Im betrachteten Zeitraum ist zu beobachten, daß der mengenmäßige Absatz von Tonträgern um ca. $30 \%$ gestiegen ist, der nominale Umsatz der Verbandsstatistikteilnehmer sich mehr als verdoppelt hat und der kumulierte Marktanteil der Majors, aus denen der Bundesverband in der Hauptsache besteht, von $90 \%$ auf $82 \%$ gesunken ist. Die Gesamtmarktzahlen können nur als Näherungsdaten verstanden werden, da die in ihnen enthaltene Tonträgerpiraterie nur geschätzt werden kann. Ungeachtet dessen hat sich der Wert des Gesamtmarktes mehr als verdoppelt. Der deutsche Tonträgermarkt ist von den Umsatzzahlen her im internationalen Vergleich der drittgrößte Markt. Der nominale Weltmarktumsatz aller im internationalen Verband 
(IFPI) organisierten Tonträgerhersteller lag 1981 bei 11,2 Milliarden und 1997 bei 38,6 Milliarden US-Dollar, gemessen in Endverbraucherpreisen inklusive der jeweiligen Umsatzsteuer.

Ein genaueres Bild des deutschen Marktvolumens ergibt sich, wenn der reale, um den Preisindex der Lebenshaltung für Freizeitgüter bereinigte Umsatz betrachtet wird. Dazu wird in Tabelle 2 das Jahr 1985 als Basis genommen. Die deutsche Vereinigung hat nicht nur die Tonträgerumsätze überproportional steigen lassen, sie hat auch statistische Vergleiche unmöglich gemacht. $\mathrm{Da}$ die Tonträgerumsätze in der früheren DDR aus vielen Gründen ${ }^{61}$ nicht mit dem Tonträgermarkt der alten Bundesländer vergleichbar sind, wird die Marktentwicklung hier in Wachstumsraten getrennt für die Zeit bis 1990 und ab 1991 analysiert. Für die Berechnung der Wachstumsraten wird der Preisindex der Lebenshaltung für Freizeitgüter (bis 1990 der alten Länder und ab 1991 für Gesamtdeutschland) herangezogen, da sich Tonträger als Freizeitkonsumgüter klassifizieren lassen. ${ }^{62}$ Gegenübergestellt wird der allgemeine Lebenshaltungspreisindex (bezogen auf alle privaten Haushalt).

${ }^{61}$ Erstens ist das Musikrepertoire der westlichen Mărkte nicht verfügbar gewesen, zweitens ist die Wirkung des technologischen Rückstands im Tontrăgermarkt nicht zu quantifizieren. Drittens herrschten administrierte Preise und viertens politische Einflußnahme auf die Veroffentlichungspolitik. Etwaige weitere Gründe sollen hier nicht thematisiert werden.

${ }^{62}$ Quelle für beide Indices ist: Statistisches Bundesamt, Statistisches Jahrbuch 1997, Stuttgart 1997. 
Tabelle 2: Nominales und reales Marktvolumen des deutschen Tonträgermarktes

\begin{tabular}{|c|c|c|c|c|c|}
\hline Jahr & $\begin{array}{c}\text { nom. } \\
\text { Markt- } \\
\text { volumen in } \\
\text { Mio. DM }\end{array}$ & $\begin{array}{c}\text { real. Markt- } \\
\text { volumen in } \\
\text { Mio. DM* }\end{array}$ & $\begin{array}{c}\text { Preisindex } \\
\text { Lebenshaltung }\end{array}$ & $\begin{array}{c}\text { Preisindex Le- } \\
\text { benshaltung } \\
\text { Güter für Bil- } \\
\text { dung, Unter- } \\
\text { haltung, Freizeit }\end{array}$ & $\begin{array}{c}\text { Jährliche } \\
\text { Wachstumsraten } \\
\text { bezogen auf das } \\
\text { reale Marktvo- } \\
\text { lumen }\end{array}$ \\
\hline 1985 & 2488 & 2488 & 100 & 100 & - \\
\hline 1986 & 2718 & 2694 & 99,8 & 100,9 & $8,3 \%$ \\
\hline 1987 & 2977 & 2930 & 99,9 & 101,6 & $8,8 \%$ \\
\hline 1988 & 3276 & 3190 & 101,0 & 102,7 & $8,9 \%$ \\
\hline 1989 & 3685 & 3550 & 103,9 & 103,8 & $11,3 \%$ \\
\hline 1990 & 4392 & 4139 & 106,7 & 106,1 & $16,6 \%$ \\
\hline $1991+$ & 4867 & 4867 & 100 & 100 & - \\
\hline 1992 & 5130 & 4937 & 105,1 & 103,6 & $1,4 \%$ \\
\hline 1993 & 5644 & 5285 & 109,8 & 106,8 & $7 \%$ \\
\hline 1994 & 5753 & 5283 & 112,8 & 108,9 & $-0,001 \%$ \\
\hline 1995 & 5850 & 5294 & 114,8 & 110,5 & $0,2 \%$ \\
\hline 1996 & 5835 & 5271 & 116,5 & 110,7 & $-0,004 \%$ \\
\hline 1997 & 5988 & 5239 & 118,6 & 114,3 & $-0,006 \%$ \\
\hline
\end{tabular}

* eigene Berechnung auf der Basis des Lebenshaltungsindices für Freizeitgüter des StBA + ab hier erfolgte gesamtdeutsche Statistik mit Umbasierung auf $1991=100$.

Quelle: Statistisches Bundesamt, Statistisches Jahrbuch 1997, Stuttgart 1997 und eigene Berechnungen.

Wird mit der neuen Basis ab dem Jahr 1991 gerechnet, können die vereinigungsbedingten Umsatzsprünge zugunsten einer mehr langfristigen Sichtweise vernachlässigt werden; denn das Wachstum der Jahre 1990 und 1991 ist zum überwiegenden Teil auf die zusätzliche Nachfrage aus den neuen Bundesländern zurückzuführen. ${ }^{63}$ Zeitreihenbetrachtungen, die mit dem Lebenshaltungspreisindex der alten Bundesländer über das Jahr 1990 hinausrechnen, aber die Umsatzzahlen für Gesamtdeutschland verwenden, sind als unseriös zu verwerfen. ${ }^{64}$ Insbesondere wenn man die Durchschnitte der Wachstumsraten getrennt für die zwei Perioden betrachtet und sich damit von den absoluten Zahlen löst, läßt sich erkennen, daß der Tonträgermarkt nach - im Vergleich zum durchschnittlichen realen Wachstum des Bruttoinlandsproduktes derselben Jahre - überproportionalem Wachstum in 1985-1990 (mit durchschnittlich 10,8\%) in der ersten

${ }^{63}$ Ein vereinigungsbedingter Sondereffekt über diese Jahre hinaus ist der Anteil der Tonträgerpiraterie am Marktvolumen, der in den neuen immer noch höher ist als in den alten Bundesländern. Auch der relative Anteil der Tontrăgerkategorien am Gesamtabsatz ist in den neuen Bundesländern anders als in den alten. Dadurch wird die Datenbasis des Zăhlers verbreitert, wahhrend diejenige des Nenners gleichbleibt. Insbesondere wenn die Preissteigerung der alten Bundeslănder von derjenigen der neuen abweicht (was ja tatsăchlich der Fall war), erhalten wir ein unzutreffendes Bild der realen Marktentwicklung. Auch der Bundesverband der Phonographischen Wirtschaft begeht diesen Fehler, wenn er die reale Marktentwicklung mit Hilfe des Preisindex für die Lebenshaltung der alten Bundeslănder (Basis 1985 = 100) beschreibt. 
Hälfte der 90er mit einem durchschnittlichen realen jährlichem Wachstum von $1,4 \%$ in die Stagnation geraten ist. ${ }^{65}$

Um die Umsatzwertentwicklung des Tonträgermarktes volkswirtschaftlich mit anderen Märkten der Freizeitgüterindustrie vergleichen und von daher beurteilen zu können, müßten wir den Preisindex für die Lebenshaltung der Freizeitgüter weiter ausdifferenzieren können. Eine weitere Differenzierung nur für Phonogüter auf der Basis der Lebenshaltungskosten (als Inputkosten der Verbraucher) ist aber nicht möglich, da keine getrennte Ausweisung in der amtlichen Statistik nach Phonogeräten und Tonträgern erfolgt. ${ }^{66}$ Der Teilindex der Lebenshaltungskosten für den Bereich Phono weist eine fallende Tendenz auf, die als Ursache die Preissenkungen der Abspielgeräte hat. ${ }^{67}$ Der durchschnittliche nominale Preis einer CD in der Fullprice-Kategorie ${ }^{68}$ ist nicht preisbereinigt von 1985 bis 1995 um 14,9\% gesunken. ${ }^{69}$ Die Tonträgerpreisentwicklung ist allerdings weder im Hinblick auf die Tonträgerkategorie noch auf die Repertoiresegmente einheitlich. Ebenso scheitert der Versuch, über den Preisindex des Einzelhandels (als Outputgröße des Handels) die Marktentwicklung nur des Tonträgermarktes mit anderen Märkten der Freizeitkonsumgüterindustrie zu vergleichen. Denn der Anteil am Gesamtabsatz von Tonträgern des Facheinzelhandels, dessen Sortiment zum Großteil aus Tonträgern besteht, betrug 1995 nur $37,7 \%{ }^{70}$ und $199638,6 \%{ }^{71}$. Für die anderen Absatzwege werden wiederum keine getrennten Daten des Tonträgerumsatzes in der amtlichen Statistik ausgewiesen. ${ }^{2}$ Daher ist ein Vergleich der relativen Marktentwicklung des Tonträgermarktes mit anderen Freizeitkonsumgütermärkten nicht möglich, da der Preisindex Lebenshaltung Freizeitgüter zu undifferenziert ist. ${ }^{73}$ Obwohl gesicherte statistische Aussagen nicht getroffen werden können, zeigt die Umsatzwertstagnation bei gleichzeitig steigender verkaufter Stückzahl einen Substanzverlust des Marktes.

\subsubsection{Die Majors}

Die größten Anbieter im deutschen Tonträgermarkt sind die fünf Majors, Tochtergesellschaften internationaler Konzerne, bei denen Musik jeweils einen unter mehreren Geschäftsbereichen darstellt. Der Geschäftsbereich Musik ist gegliedert in eine internationale Zentrale und in

65 Das Urteil einer Marktstagnation des Tonträgermarktes stimmt mit demjenigen des BKartA überein. Quellen der Daten: Statistische Jahrbücher 1996 und 1997, Fachserie 15, Ausgaben für den privaten Verbrauch, und Fiebiger, Hilde, Ausgaben für Freizeitgüter in ausgewăhlten privaten Haushalten im früheren Bundesgebiet sowie den neuen Ländern und Berlin-Ost, in: Wirtschaft und Statistik, Wiesbaden Nr. 2 (1993), S. 24-28.

$66 \mathrm{Vgl}$. Statistische Jahrücher 1996 und 1997, jeweils Tabelle 21.6: Aufwendungen ausgewăhlter privater Haushalte für Freizeitgüter, S. 553 und 574.

67 Beispielsweise ist der nominale Preis von CD-Playern von 1986 bis 1995 (nicht preisbereinigt) um 63,9\% gesunken.

68 Internationalen Konventionen folgend wird der Preis von bespielten Tonträgern in den drei Kategorien Full-, Mid- und Lowprice angegeben. Vgl. zu den Preiskategorien den Abschnitt 4.3.2.3.

69 Vgl. BPW 1997, op. cit., S. 48.

70 Vgl. Bundesverband der Phonographischen Wirtschaf, Jahrbuch 1996, Starnberg 1996, S. 30. [BPW 1996].

7 Vgl. BPW 1997, op. cit., S. 32.

72 Von daher ist die Marktabgrenzung auf der Handelsebene statistisch unsicher.

73 Es ist anzunehmen, daB die Preisentwicklung in der Gruppe der Freizeitgüter sehr uneinheitlich ist, da Güter in Markten mit preisunelastischer Nachfrage und elastischerer Nachfrage zusammengefaBt werden. 
für die jeweiligen nationalen Märkte zuständige Ländergesellschaften. Die Aufgaben der Ländergesellschaften liegen in der Schaffung und Vermarktung von nationalen Produkten, der Vermarktung von Produkten der anderen nationalen Schwestergesellschaften, der Zweit- und Drittvermarktung, der Herstellung von Tonträgem, der Distribution an Handel und andere Weiterverkäufer sowie in zusätzlichen Funktionen (Merchandising, Künstlermanagement, Beteiligung an Radiostationen etc.). ${ }^{74}$ Die Majors untergliedern sich nach dem spezifischen $\mathrm{Hu}$ mankapital bzw. Know-how in kleinere Organisationseinheiten. Dabei werden die Funktionen der Musikerselektion und -betreuung sowie teilweise auch die Verkaufsforderung von den dezentralen Einheiten selbst durchgeführt, während die juristischen und kaufmännischen, aber auch Marketing- und Vertriebsfunktionen von den Zentralen wahrgenommen werden. ${ }^{75}$

Jeder Major ist mit mehreren, für verschiedene Repertoiresegmente zuständigen Labeln im Markt. ${ }^{76}$ Ein Tonträger-Label ist rechtlich eine Unter- bzw. Schwesterfirma des Tonträgerherstellers. Label sind nach Musikstilrichtungen organisiert. Es werden in bestimmten Labeln aber auch nur Produkte eines einzigen Musiker veröffentlicht. Das Label fungiert als Markenzeichen für eine bestimmte Musikrichtung bzw. für die Ausrichtung der Produktpolitik.

Kennzeichen der Majors ist ihre vollständige Integration, d. h., daß sie von der Beschaffung der Musikproduktion bis zum Vertrieb sämtliche Unternehmensfunktionen selbst (bzw. mit Hilfe von Tochterunternehmen) durchführen. ${ }^{n}$ Die Majors sind BMG, EMI, Universal (früher MCA) ${ }^{78}$, Sony und Warner. Bis zum Frühjahr 1998 war Polygram weltweit ein Major. Der Philipps-Konzern als Mehrheits-Eigner hat Polygram an die kanadische Seagram-Gruppe verkauft, die mit der Übernahme der MCA von Matsushita erst 1991 in die Musikbranche eingestiegen waren. Daneben bestehen Major-Independents. ${ }^{79}$

Die Beschreibung der Majors wird hier anhand ihrer Firmenbereiche und Label vorgenommen. Zur Bertelsmann Music Group (BMG) gehören die Firmenbereiche BMG Ariola München, BMG Ariola Hamburg, BMG Ariola Miller und verschiedene Label. ${ }^{80}$ Die Bertelsmann-Gruppe ist über das Buchklubgeschäft im Klub- und Direct-Mail-Segment des Tonträgerhandels Marktfuihrer. Zu EMI gehören EMI Germany, EMI Classics, Intercord, Virgin und verschiedene Label. ${ }^{81} \mathrm{Zu}$ Polygram gehörten die Bereiche Metronom, Polydor, Phonogram und Deutsche Grammophon und verschiedene Label, die nun von Universal weitergefuhrt werden. ${ }^{82}$ Zur Sony Music Group gehören Sony Music Entertainment (vormals CBS) und Sony Classical und

\footnotetext{
74 Vgl. Schmidt, Christoph, op. cit., S. $187 \mathrm{ff}$.

75 Vgl. Schmidt, Christoph, op. cit., S. 188.

Vgl. Schulze, Ralf, op. cit., S. 124.

Zum Integrationsgrad vgl. Abschnitt 4.2.2.5.

78 Vgl. Zombik 1995, S. 503 ff.

79 Beispiele für die Mischform der Major-Independents sind Edel, ZYX und Koch.

80 Weitere Label sind beispielsweise Ariola, Arista, Europa, Island, Jupiter RCA.

81 Wichtige Label sind Apple, Blue Note, Capitol, Chrysalis, Harvest, His Masters Voice.

82 Wichtige Label sind A\&M, Decca, Kanussell, Motown, Philips und Philips-Classic.
} 
verschiedene Label. ${ }^{83} \mathrm{Zu}$ Warner Music zählen die Bereiche WEA Music und East West Records (vormals Teldec) und verschiedene Label. ${ }^{84}$

\subsubsection{Die Independents}

Die Independents sind unabhängig von international tätigen Musikkonzernen. Sie sind Bearbeiter von Marktnischen in den traditionellen Labeln (Jazz, Folklore, Weltmusik und experimentelle Musik). Zweitens sind sie Markterprober in den sog. „Underground-Labeln“ für aktuelle Trends und Modeströmungen. Independents als unabhängige Musikproduzenten nehmen zwar zuweilen den Herstellungsservice (z. B. die CD-Fertigung) eines Majors in Anspruch, unterhalten aber ein eigenes Marketing und nutzen rechtlich und wirtschaftich selbständige Unternehmen für die Distribution ihrer Produkte. ${ }^{85}$ Dabei nutzen sie aber nicht zwangsläufig den Vertriebsapparat der Majors (z. B. EfA). Die Existenzdauer von Independents ist oft kurz, weil Verkaufserwartungen nicht erfültt werden, Trends schnell wechseln und die finanziellen Ressourcen klein sind. Daher versuchen Independents, durch Kooperationen untereinander die Finanzierung von Produktionen sicherzustellen, um in Qualität und Preis mit den Majors konkurrieren zu können. ${ }^{86}$

Wichtige Independents in Deutschland sind SPV, Efa, Rough Trade, Edel und ZYX. Die beiden letzteren haben durch ihre erfolgreiche Tätigkeit inzwischen größere Bedeutung erlangt und sind dem Bundesverband der Phonographischen Wirtschaft beigetreten. In jüngerer Zeit sind auch Joint-Ventures zwischen Independents und Majors entstanden. Während dem Major die Flexibilität und teilweise auch die Kreativität der Produktentwicklung fehlt, besitzen die Independents keinen ausreichenden Zugang zu den Absatzkanälen.

\subsubsection{Die Konzentrationsentwicklung unter den Tonträgerherstellern}

Der Konzentrationsprozeß durch Unternehmenszusammenschlüsse von Tonträgerherstellern untereinander war - sowohl weltweit als auch auf dem deutschen Markt - in den 80er und der ersten Hälfte der 90er Jahre der bestimmende Marktstrukturfaktor. ${ }^{87}$

Bertelsmann übernahm 1984 nach der Arista (1979) den amerikanischen Tonträgerhersteller RCA. Die Tonträgeraktivitäten des Bertelsmann-Konzerns wurden dann unter dem Namen Bertelsmann Music Group (BMG) zusammengefaßt. 1989 folgte die Übernahme von Miller International (heute BMG Ariola Miller). Die MCA, heutige Seagram-Tochter Universal, war zunächst mit einem Labelvertrag über BMG im deutschen Markt vertreten. Seit 1992 existiert

83 Wichtige Label sind Columbia, Dance Pool, DefJam, Epic und Sony Classical.

84 Wichtige Label sind Atlantic, Dark Horse, East West, Reprise, Warner und Warner Bros

$85 \mathrm{Vgl}$. Schulze, Ralf, op. cit., S. 133.

86 Vgl. Vormehr, Ulrich, Independents, in: Handbuch der Musikwirtschaft, hrsg. von Moser, Rolf, und Andreas Scheuermann, 4. Auf., Stamberg 1997, S. 201-212.

87 Die Entwicklung eines internationalen Netzes von Tochterfirmen und Lizenznchmern begann bereits in den 70er Jahren durch britische (EMI) und amerikanische (CBS, RCA und Warner) Unternehmen. Vgl. Zombik 1995, S. 504. 
eine eigene deutsche MCA-Tochter, deren Vertrieb weiterhin Bertelsmann durchführt, weswegen die Marktanteile von MCA in Deutschland der BMG zugerechnet wurden, aber 1998 kaufte die Konzernmutter Seagram die Polygramgruppe auf. Damit dürfte der weltweit größte Tonträgeranbieter nun auch im deutschen Markt stark vertreten sein. Die 1971 gegründete Polygramgruppe $^{88}$ (bis zum Frühjahr 1998 Tochter des niederländischen Philips-Konzerns, danach von der kanadischen Seagram-Gruppe übernommen) gründete 1985 für ihre Repertoiregesellschaften Deutsche Grammophon, Phonogram und Metronom die Vertriebsgesellschaft Polygram Musik Vertrieb (PMV). Sie kaufte 1989 Island $^{89}$ und 1990 A\&M auf. 1991 folgte die Übernahme von Decca ${ }^{90}$ und 1994 schließlich der Aufkauf des Label Motown. Polygram war bis zur Übernahme durch Universal Marktführer im Klassik-Bereich. Sony, zuvor u. a. Hersteller von Abspielgeräten, integrierte 1987/88 in den Tonträgermarkt, indem es CBS übernahm und ein eigenes Klassik-Label aufbaute. EMI fusionierte $1980 \mathrm{mit}$ dem britischen Elektronikkonzern Thorn. Für den Tonträgermarkt relevante Aufkäufe von Thorn/EMI waren 1990 Chrysalis, 1992 Virgin und 1994 vom Holtzbrinck-Konzern die deutsche Intercord. Der Warner-Konzern ist seit 1970 im deutschen Markt mit seiner Musiktochter WEA-International tätig. 1988 erfolgte der Aufkauf von Teldec, welches seitdem East West Records heißt.

Die Marktkonzentration im Zeitablauf wird mit Hilfe der Marktanteile dargestellt, definiert als Umsatz der einzelnen Tonträgerhersteller in Relation zum Gesamtmarktvolumen. Durch die Zusammenschlüsse wird der Überblick über die Konzentrationsentwicklung erschwert. Das größte Hindernis im Hinblick auf die Marktkonzentration ist die Geheimhaltungspolitik der Majors. Sie lassen ihre Marktanteile von der GfK Nürnberg monatlich erheben, veröffentlichen die Berichtsbände aber nicht. Auf diese unveröffentlichten Berichtsbände der GfK verweist Conen"1 , der auf der Basis des Absatzes an den Handel die Marktanteile der Tonträgerhersteller für Deutschland am wertmäßigen Marktvolumen von 1985-1990 darstellt:

$88 \mathrm{Vgl}$. Conen, Michael, Tonträgermarketing, Wiesbaden 1995, S. 42 f.

89 Polygram Deutschland konnte den Vertrieb von Island erst 1994 nach Ablauf der Vertiebsvertragsbindung mit BMG übernehmen.

90 Trotz des Unternehmenserwerbs von Decca durch Polygram verblieb der Katalog ( = Sammlung bereits veroffentlichter Tonträgertitel) aus kartellrechulichen Gründen bis Sommer 1994 bei der Teldec (heute East West Records, Tochter von Warner).

91 Vgl. Conen, Michael, op. cit., S. 42. Es steht zu vermuten, daß Conen seine Dissertation, die im Frühjahr 1991 abgeschlossen wurde, erst 1995 veroffentlichte, u. a. weil die von ihm genannten aktuellen Marktanteilsdaten als sensibel gelten. 
Tab. 3: Marktanteile der Tonträgerhersteller am Absatz an den Handel in Deutschland

\begin{tabular}{|l|cccccc|}
\hline \multicolumn{1}{|c}{1985} & 1986 & 1987 & 1988 & 1989 & 1990 \\
\hline BMG & 19,3 & 19,6 & 21,0 & 19,4 & 21,3 & 20,5 \\
\hline Miller int. & 3,5 & 3,5 & 3,3 & 2,5 & bei BMG & bei BMG \\
\hline Bellaphon & 0,6 & 1,2 & 0,7 & 0,6 & 0,7 & 0,6 \\
\hline Sony (CBS) & 11,4 & 11,3 & 10,8 & 11,0 & 10,5 & 10,1 \\
\hline Dino seit'87 & - & - & 1,2 & 0,9 & 1,6 & 1,2 \\
\hline EMI & 12,1 & 11,3 & 12,5 & 13,1 & 12,1 & 13,1 \\
\hline Intercord & 2,8 & 2,9 & 2,2 & 2,4 & 2,3 & 2,7 \\
\hline ITP seit'88 & - & - & - & 1,5 & 0,9 & 0,8 \\
\hline Polygram & 22,4 & 21,9 & 21,2 & 21,7 & 21,3 & 20,7 \\
\hline WEA & 7,9 & 8,9 & 8,9 & 15,0 & 16,7 & 15,1 \\
\hline Teldec & 9,0 & 9,2 & 8,6 & bei WEA & bei WEA & bei WEA \\
\hline Sonstige & 7,8 & 9,3 & 9,7 & 11,8 & 12,5 & 15,1 \\
\hline Summe & 100,0 & 100,0 & 100,0 & 100,0 & 100,0 & 100,0 \\
\hline
\end{tabular}

Quelle: Gesellschaft für Konsumforschung (GKK) Nürnberg, Conen, op. cit., S. 42 und eigene Berechnungen.

Im Tonträgermarkt gelten die aktuellen Marktanteile der Tonträgerhersteller als deren Geschäftsgeheimnis. ${ }^{92}$ Daher ist bei der Betrachtung veröffentlichter Marktanteile immer die Quelle und ihre marktpolitische Motivation mit einzubeziehen. ${ }^{93}$ Marktanteilsangaben beziehen sich häufig nur auf Teilmärkte, die einfach auf den Gesamtmarkt übertragen werden. Unternehmen, die in einzelnen Marktsegmenten stark sind, werden dadurch überbewertet. Marktanteile einzelner Unternehmen, die zu einer Unternehmensgruppe gehören, werden addiert. Hier kommt es zu Mehrfachzählungen, weil Unternehmensgruppen schwer durchschaubar gestaltet sind. Marktanteilsverteilungen, die sich auf einen älteren Zeitpunkt beziehen, sind genauer, da mit zunehmendem Alter der Daten die Gefahr für die Unternehmen sinkt, daß Rückschlüsse auf ihre aktuelle Unternehmenslage gezogen werden können. ${ }^{94}$ Sowohl Zeppenfeld ${ }^{95}$ als auch

92 Das ist die Erklärung von Jürgen Tresp in einem Telefoninterview (GrK, mimco), die gegen die Veröfrentlichung der Marktanteile spricht. Der Grund für die Bestellungspolitik des Handels entsprechend den Marktanteilen der Vergangenheit liegt in der Risikominimierung.

93 Vgl. Schulze, Ralf, op. cit., S. 143.

94 Polygram veröffentlicht bisweilen in seiner externen Rechnungslegung (Jahresabschluß) seinen Marktanteil in Deutschland, ohne daß auf eine Quelle Bezug genommen wird. Laut einer Mitteilung des „MusikDienstes“ (Nr. 916, 1990) waren die Marktanteile im deutschen Tonträgermarkt 1989 wie folgt verteilt: Polygram 21,6\%; BMG 21,1\%; Warner 17,4\%; EMI 12,5\%; CBS (Sony Music) 9,2\%; Intercord 2,4\%; Dino $1 \%$; Bellaphon $0,7 \%$ und andere $14,1 \%$. Für dieses Jahr ergeben sich als Konzentrationswerte $\mathrm{CR}_{3}=$ $60,1 \% ; \mathrm{CR}_{4}=72,6 \%, \mathrm{CR}_{5}=81,8 \%$ und $\mathrm{CR}_{8}=85,9 \%$. Die Zeitschrift Market Research Europe (Heft $11 / 92$, S. 37 unter Bezugnahme auf die Quelle Euromonitor) veröffentlichte die Marktanteile der Majors für 1991 in Frankreich, Deutschland. Italien, Spanien und Großbritannien. In Deutschland hatten die Majors folgende Marktanteile: Polygram 26\%; BMG 20\%; Warner 16\%; Thorn/EMI 14\%; Sony-Music 12\%; Virgin (damals noch selbständig) $4 \%$ und andere $8 \%$.

$95 \mathrm{Vgl}$. Zeppenfeld, Werner, Tonträger in der Bundesrepublik Deutschland: Anatomie eines medialen Massenmarktes, Bochum 1978, S. 82. Zeppenfeld verweist darauf, daß die Veröffentlichungen im Pressedienst 
Schulze $^{96}$ verweisen auf den Pressedienst Rundy. ${ }^{97}$ Die Marktform eines engen Oligopols im deutschen Tonträgermarkt ist trotz der unzureichenden Datenverfügbarkeit zutreffend, da 1992 EMI mit Virgin fusionierte und ab 1994 ebenfalls Intercord zu den Marktanteilen von EMI hinzuzuzzählen sind. Für das Jahr 1995 gibt Schmidt ${ }^{98}$ bei einem CR, von $80 \%$ die Verteilung der Marktanteile auf die fünf Majors in Deutschland wie folgt an: Polygram 22\%, EMI $17 \%$, Bertelsmann Music Group 17\%, Warner 13\% und Sony $11 \%$.

\section{Abbildung 17: Zusammenfassende Darstellung der Übernahmen und der Konzentrationsentwicklung der Majors}

\begin{tabular}{|c|c|c|}
\hline \multicolumn{3}{|c|}{$\begin{array}{l}\text { Bertelsman Music } \\
\text { Groun (BMG) }\end{array}$} \\
\hline \multicolumn{3}{|c|}{ Übernahmen: } \\
\hline \multicolumn{3}{|c|}{$\begin{array}{l}\text { Arista, } 1979 \\
\text { RCA, } 1984 \\
\text { Miller International, } 1989 \\
\text { Vertrieb von MCA, } 1992 \\
\text { Marktanteile: }\end{array}$} \\
\hline 1991 & 1992 & 1995 \\
\hline $20 \%$ & $26 \%$ & $17 \%$ \\
\hline
\end{tabular}
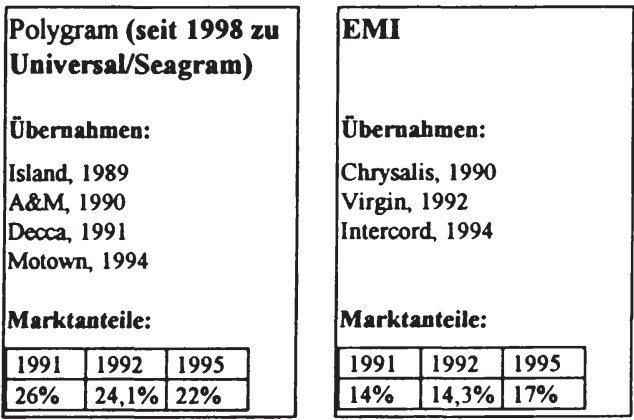

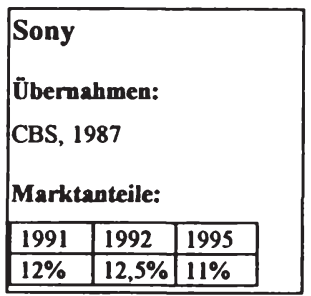

\begin{tabular}{|c|c|c|}
\hline \multirow{2}{*}{\multicolumn{3}{|c|}{$\begin{array}{l}\text { WEA } \\
\text { Übernahmen: } \\
\text { Teldec, } 1988 \\
\text { Marktanteile: }\end{array}$}} \\
\hline & & \\
\hline 1991 & 1992 & 1995 \\
\hline $16 \%$ & $14,5 \%$ & $13 \%$ \\
\hline
\end{tabular}

Einerseits ist der kumulierte Marktanteil der Majors (die im Bundesverband der Phonographischen Wirtschaft organisiert sind) in Deutschland von 1985 bis 1995 von $90 \%$ auf $80 \%$ gesun$\mathrm{ken}^{99}$, andererseits wird das Tonträgerangebot weltweit von sechs Großkonzernen (seit der

Rundy auf ndurchsickernden“ Panel-Ergebnissen der GfK basieren, daher als „Insider-Informationen“ anzusehen sind, und branchenseitig als relativ ausgewogen und zuverlässig gelten.

96 Vgl. Schulze, Ralf, op. cit., S. 144.

97 Der Pressedienst Rundy vom 23.04.1993 weist folgende Marktanteile für 1992 aus: Marktführer in Deutschland ist BMG mit 26\% vor Polygram mit 24,1\%; Warner mit 14,5\%; EMI mit $14,3 \%$ und Sony mit 12,5\%. Daraus ergibt sich ein $\mathrm{CR}_{s}=91,4 \%$. Für das Jahr 1993 ermittelte die GfK nur für das Marktsegment der U-Musik folgende Marktanteile: Polygram 22,2\%; BMG 15\%; Warner 13,8\%; EMI 13,1\%; Sony 9,5\%; Virgin 4,3\% und Intercord 2,5\%.

98 Vgl. Schmidt, Christoph, op. cit., S. 185

99 Quelle: BPW 1994, S. 10, und BPW 1996, S. 10 
Übernahme von Polygram durch Seagram im Mai 1998 nur noch von fünf Majors) dominiert. $^{100}$

Verwendet man zur Erfassung der Gesamtkonzentration den Hirschman-Herfindahl-Index (HHI), bei welchem den größten Unternehmen ein besonderes und den kleineren Unternehmen ein geringeres Gewicht beigemessen wird, so gilt:

$\sum_{i=1}^{n} p_{i}{ }^{2}$, wobei $p_{i}($ für $\mathrm{i}=1 \ldots \mathrm{n})$ mit $\sum_{i=1}^{n} p_{i}=1 \mathrm{bzw} .100 \%$ die relativen Marktanteile darstellt. ${ }^{101}$

Bezogen auf die Marktanteilsdaten von 1992 ergab sich ein HHI von ca. 0,19 oder mit 100 multipliziert und als Prozentzahl ausgedrückt von $19 \%$. Dabei wurde unterstellt, daß sich die restlichen Marktanteile gleichmäßig auf 600 kleine Unternehmen verteilen, was natürlich nur eine Annäherung an die Realität bedeuten kann. Der kritische Konzentrationsgrad des HHI von $10 \%$ ist für den deutschen Tonträgermarkt weit überschritten. ${ }^{102}$

Verschiedene Autoren postulieren u. a. wegen der mangelnden Verfügbarkeit von Marktanteilsdaten eine Übertragbarkeit von den Charts- auf die Marktanteilsverteilungen. ${ }^{103}$ Die Charts (= Hitlisten) geben die Verkaufszahlen der einzelnen Tonträgertitel an. Dazu werden aus Zeitreihenanalysen der Anteile der Tonträger-Hersteller an den jährlichen Charts (getrennt nach Longplay- und Single-Charts) einzelner Märkte die jeweiligen Marktanteile der Jahre abgeleitet. Schulze ${ }^{104}$ folgert eine Bestätigung der Übertragbarkeit der Charts- auf die Marktanteilsdaten daraus, daß seine Untersuchung für das Bezugsjahr 1993 eine annähernde Übereinstimmung ergeben hat. Auch die Studien von Peterson/Berger (1975), Anderson (1980), Rothen-

${ }^{100}$ Vgl. Zombik 1995, S. 505; der von der weltweiten Prägung des Musikgeschäfts durch drei europäische, einem kanadischen, einem amerikanischen und einem japanischen Unternehmen spricht. Schulze schătzt die Weltmarktanteile (als Summe der jeweiligen nationalen Märkte) in 1993 von Warner zwischen 18 und $20 \%$, von Polygram und Sony zwischen 16 und $18 \%$, von EMI und BMG zwischen 14 und $16 \%$. Vgl. Schulze, Ralf, op. cit., S. 144. Schmidt, Christoph, op. cit., S. 185 spricht unter Verweis auf die von den McGraw-Hill Companies herausgegebene Business Week vom 15. Januar 1996 von einem weltweiten (i. S. der Summe der einzelnen nationalen Märkte) $C_{\text {f }}$ für 1995 von 82,5\%, zu dem noch ca. $2 \%$ Marktanteil für den sechsten Major MCA/Geffen hinzuzuzählen sind, der zur kanadischen Seagram-Gruppe gehört.

${ }^{101} \mathrm{Vgl}$. Schmidt, Ingo, Wettbewerbspolitik und Kartellrecht, 5. Auf., Stuttgart 1996, S. 129.

102 Vgl. zum kritischen Konzentrationsgrad eines Marktes nach dem HHI: Scherer. Frederic M., und David Ross, op. cit., S. 72 und S. 277. Auf der Basis der Daten von 1995, die eine geringere Konzentration aufweisen, ergibt sich unter sonst gleichen Annahmen ein HHI von 13,6\%. Die mangelnde Verfügbarkeit der Marktanteilsdaten der kleineren Unternehmen ist beim $\mathrm{HHI}$ unproblematisch, da daraus resultierende $\mathrm{Ab}$ weichungen gering sind.

${ }^{103}$ Vgl. für den Tonträgermarkt der USA: Peterson, Richard A., und David G. Berger, Cycles in Symbolic Production: The Case of Popular Music, in: American Sociological Review, Vol. 40 (1975), S. 158-173; Anderson, B. et al., Hit Record Trends 1940-1977, in: Journal of Communication, o. Jg. (1980), S. 31-43; Rothenbuhler, Eric W., und John W. Dimmick, Popular Music: Concentration and Diversity in the Industry 1974-1980, in: Journal of Communication, o. Jg. (1982), S. 143-149; Burnett, Robert, Concentration and Diversity in the International Phonogram Industrie, Gothenburg (Schweden) 1990; Lopes, Paul D., Innovation and Diversity in the Popular Music Industry, in: American Sociological Review, Vol. 57 (1992), S. 5671. Vgl. für den Tonträgermarkt in Deutschland: Steinel, Roland, Zur Lage und Problematik der Musikwirtschaf, München 1992; Schulze, Ralf, op. cit., S. 296 ff. Fälschlicherweise wird von einer Inzidenz der Charts- für die Marktanteile gesprochen.

${ }^{104} \mathrm{Vgl}$. Schulze, Ralf, op. cit., S. $288 \mathrm{\pi}$. 
buhler/Dimmick (1982) und Lopes (1992) für den US-amerikanischen Tonträgermarkt, von Burnett (1990) für den schwedischen sowie von Steinel (1992) für den deutschen Tonträgermarkt legen diesen Schluß nahe. Da in Deutschland mit Jahresbeginn 1997 ein neues ChartSystem eingeführt wurde, das die Verkaufszahlen noch stärker in der Chartermittlung berücksichtigt ${ }^{105}$, kann der These von der Übertragbarkeit der Charts- auf die Marktanteile zur Ermittlung der Marktanteile gefolgt werden.

\subsubsection{Einzelwirtschaftliche Konzentrationsmotive}

Für die Konzentrationsentwicklung im Tonträgermarkt können verschiedene Gründe aus einzelwirtschaftlicher Sicht angeführt werden. Erstens ist der kürzer werdende Produktlebenszyklus eines Tonträgers zu nennen. Gleichzeitig werden mehr Tonträger veröffentlicht. ${ }^{106}$ Daher wird für die Markteinführung des einzelnen neuen Tonträgers im Markt ein erhöhter Werbeaufwand benötigt, der sich in größerem Kapitalbedarf niederschlägt. Höhere Kosten für die Etablierung ihrer Produkte sind für die Hersteller Konzentrationsmotiv. Ein zweiter Grund liegt in der Internationalisierung des Wettbewerbs. Hierunter ist die Notwendigkeit zu verstehen, einen akquirierten Musiker zeitgleich national und international vermarkten zu müssen. Dabei spielt die Präsenz in den jeweiligen nationalen Märkten mittels der einzelnen Länderabteilungen der multinationalen Tonträgerhersteller eine wichtige Rolle. Kleineren Unternehmen entstehen Nachteile, wenn sie die Leistung der Markteinführung nicht zu adäquaten Konditionen am Markt einkaufen können (siehe Abbildung 18). Ein dritter Konzentrationsgrund liegt in der Verhandlungsstärke der Musiker (vertreten durch ihre Manager) gegenüber den Tonträgerherstellern. Sie hat zu Garantiesummen ${ }^{107}$ geführt, die die Finanzkraft kleinerer Unternehmen, ihre vertrieblichen und werblichen Möglichkeiten übersteigt. Ein Wechsel bereits etablierter Musiker erfolgt regelmäßig nur von einem Major zu einem anderen und nicht von einem Major zu den kleineren Tonträgerherstellern. Der hohe Finanzbedarf zur Akquisition bereits etablierter Musiker ${ }^{108}$ als Folge ihrer Verhandlungsstärke stellt daher ein weiteres einzelwirtschaftliches Konzentrationsmotiv dar. Viertens steigern schnellerer Produktumschlag und Internationalisierung das Ausma $\beta$ der Konkurrenz zwischen den Tonträgerherstellern. Durch eine Konzentrationsstrategie ${ }^{109}$ läßt sich gegenüber der nachgelagerten Markstufe des Handels und den nebengelagerten Medien die Verhandlungsstärke steigern.

${ }^{105} \mathrm{Vgl}$. Zombik, Peter, Die Bedeutung der Charts für die Musikwirtschaft, in: Handbuch der Musikwirtschaft, hrsg. von Moser, Rolf, und Andreas Scheuermann, 4. Aufl., Stamberg 1997, S. 138-146 [Zombik 1997a]; ders., Die offizicllen deutschen Charts, ebda., S. 147-158 [Zombik 1997b].

106 Eine wesentliche Ursache für die steigende Zahl an Veröffentlichungen liegt in der Möglichkeit, mit Hilfe des Computers, d. h. ohne eine spezielle musikalische Ausbildung Musik zu komponieren.

107 Garantiesummen sind Ausschüttungen an Musiker im voraus, die unabhängig vom Verkaufserfolg sind

108 Der anfänglich hohe Finanzbedarf für die Zahlung von Garantiesummen für etablierte Künstler kann eine Markteintrittsbarriere darstellen. Denn für die Investition in Garantiesummen, evtl. verbunden mit länger anhaltenden Anlaufverlusten, müssen Newcomer bei der Finanzienung mit Risikozuschlägen der Kapitalgeber gegenüber den etablierten Tonträgerhersteller rechnen. Vgl. Salop, S.C., Measuring Ease of Entry, in: The Antitrust Bulletin, Vol. 31 (1986), S. $558 \mathrm{f}$.

109 Bei einer Befragung der Tonträgerhersteller selbst wurde dieses Motiv am häufigsten genannt. Die Befragung führte Schulze durch. Vgl. Schulze, Ralf, op. cit., S. 352-365. 


\subsubsection{Integrationsgrade und Vertragsbeziehungen}

Integrationsgrade beschreiben den Umfang der vertikalen Integration der am Markt befindlichen Unternehmen. Aufbauend auf den Marktstufen des Tonträgermarktes (vgl. Abbildung 16) lassen sich verschiedene denkbare Integrationsgrade verschiedener Unternehmenstypen voneinander unterscheiden:

a) Unabhängige Tonträgerhersteller mit Marketing-Funktion, die nur die Herstellung für einen Herstellungspreis pro Einheit und den Vertrieb für eine Vertriebskommission (auf der Basis des Händlerabgabepreises) an Majors geben. Das Absatzrisiko trägt der unabhängige Tonträgerhersteller. Hierzu können auch Importeure gezählt werden mit dem Unterschied, daß ihre Tonträger physisch im Ausland hergestellt wurden.

b) Unabhängige Musikproduzenten, die nur das Masterband herstellen und mit einem MajorTonträgerhersteller oder einem anderen Independent eine Lizenzvereinbarung schließen. Der Major zahlt dann eine Umsatzbeteiligung (auf der Basis des Händlerabgabepreises) und garantiert bestimmte Absatzmengen, die in Tantiemenvorschüssen bezahlt werden. Das Absatzrisiko trägt der Major.

c) TV/Radio-Merchandiser, die von einem Major oder einem Independent Lizenzen für die Verwertung bzw. Nutzungsrechte (meistens bereits erstverwerteter Produkte) einkaufen und lediglich die Vermarktung selbst betreiben. Die anderen Leistungen werden von den Majors durchgeführt. Das Absatzrisiko liegt beim Lizenznehmer, also dem TVMerchandiser.

d) Unabhängige Tonträgerhersteller mit Marketing-Funktion, die die Herstellung der Tonträger von Majors bewerkstelligen lassen und einen unabhängigen Vertrieb nutzen. Die Vertriebskosten sind geringer als bei der Variante a), da der unabhängige Vertreiber höhere Preise pro Tonträger zahlt. Das Absatzsrisiko verbleibt dafür zu einem höheren Anteil bei den Herstellern, da der unabhängige Vertreiber größere Retouren beansprucht.

e) Die vollintegrierten Majors produzieren das gesamte Musikrepertoire selbst, stellen es selbst her, vertreiben und vermarkten es. Daneben üben sie die weiter oben bezeichneten Unternehmensfunktionen für andere, unabhängige Tonträgerhersteller aus.

Die am Markt befindlichen (realen) Tonträgerhersteller lassen sich im wesentlichen in drei verschiedene Integrationsgrade unterteilen (vgl. Abbildung 16, Marktstufen des Tonträgermarktes, Abschnitt 4.1.1):

1. Die vollintegrierten Majors betreiben Musikproduktion, physische Tonträgerherstellung, Distribution und Vermarktung (Promotion) innerhalb ihres Unternehmens. Ferner üben die Majors die Marktfunktion der physischen Herstellung, Promotion und Distribution für kleinere Tonträgerhersteller sowohl im Wege des Bandübernahme- als auch des Lizenzvertrags aus.

2. Kleinere Tonträgerhersteller schließen mit den Musikern Künstlerverträge ab, bewerkstelligen lediglich die Musikproduktion und beauftragen einen Major, die physische Tonträgerherstellung und die Distribution durchzuführen. Dafür bezahlen sie den Majors einen Herstellungspreis pro Tonträger und eine Distributionspauschale, die auf dem Händlerabgabe- 
preis basiert (published price to dealer, ppd). Gegebenenfalls stellen sie die Tonträger auch selbst her. Das Absatzrisiko obliegt bei dieser Form der Zusammenarbeit beim kleineren Tonträgerhersteller.

3. Schließlich existieren Tonträgerhersteller, die mit einem Major einen Lizenzvertrag abgeschlossen haben. Der Major erhält das Mastertape (die fertige Musikproduktion) vom Lizenzgeber und ist sowohl für Herstellung als auch Vertrieb und Vermarktung zuständig. Hier trägt der Major das Absatzrisiko und entlohnt den Lizenzgeber auf der Basis des Händlerabgabepreises pro verkaufter Stückzahl oder anhand einer vorher garantierten Verkaufsmenge. In dieser Kategorie der Lizenzgeber existieren über 200, meist kleine Unternehmen. Sie sind nicht in der Lage, die gesamten genannten Unternehmensfunktionen der Majors auszuüben, da hierfür eine Mindestgröße beim Marktanteil erreicht werden muß. Anderenfalls ist die Unterhaltung eines eigenen Apparates für die Herstellung, Promotion und Distribution unwirtschaftlich.

Abbildung 18: Integrationsgrade und Vertragsbeziehungen im Tonträgermarkt

\section{Vertragstyp/Marktstufe}

Künstlerexklusivvertrag:

Bandübernahmevertrag:

sonstige Lizenzverträge:

Sales/Distributionverträge:

Variante I)

Variante II)

Variante III)
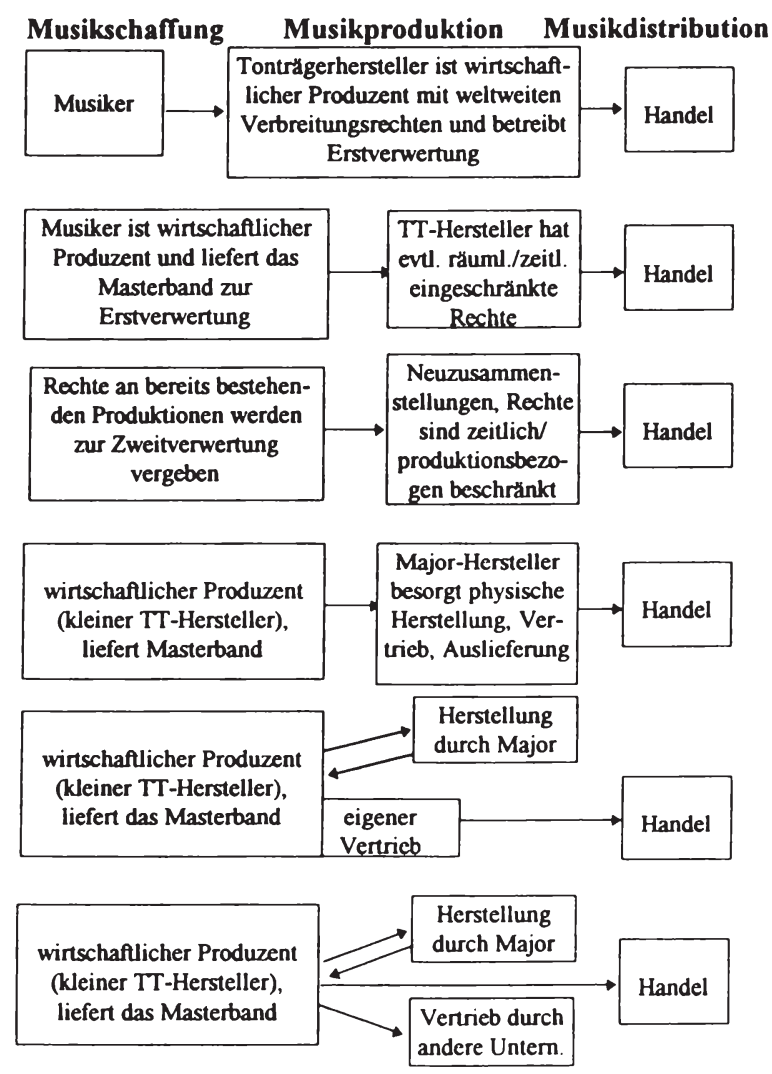
Die physische Herstellung wird zum Teil von den Majors selbst betrieben, zum Teil in Auftragsarbeit vergeben. Die wichtigsten CD-Fertigungswerke in Deutschland sind: ${ }^{110}$ Sonopress Produktionsgesellschaft (Bertelsmann) mit einer Kapazität von $180 \mathrm{Mio}$. Stück/Jahr, TeldecPress (East-West, Tochter von Warner) mit einer Kapazität von 130 Mio. Stück/Jahr, Warner Music Manufacturing Europe GmbH (Warner) mit einer Kapazität von 85 Mio. Stück/Jahr, Polygram Manufacturing \& Polygram Distribution Center GmbH (Polygram) mit einer Kapazität von 140 Mio. Stück/Jahr sowie die unabhängigen Fertigungswerke MPO Audio und Video GmbH mit einer Kapazität von 95 Mio. Stück/Jahr und Compact Discs Albrecht GmbH mit einer Kapazität von 50 Mio. Stück/Jahr.

\subsubsection{Marktphase und Marktbarrieren}

Der Markt für Tonträger in Deutschland befindet sich in einer Stagnationsphase. Die im obigen Abschnitt (4.2.2, Tabellen 1 und 2) dargestellte Entwicklung des Marktvolumens zeigt kein nennenswertes Wachstum seit 1993. Zwar steigen die verkauften Stückzahlen insbesondere in der Kategorie CD-Longplay und CD-Single, aber bei der mit Hilfe des Preisindexes für Freizeitgüter preisbereinigten wertmäßigen Entwicklung zeigen sich insgesamt für den Zeitraum 1991-1996 nur Steigerungen unterhalb der Preisentwicklung für alle Freizeitkonsumgüter. ${ }^{111}$ Diese Stagnationstendenz läßt sich in verstärktem Maße feststellen, wenn die Marktvolumenentwicklung um die im folgenden betrachteten Sondereinflüsse bereinigt wird.

Wie es bei der erfolgreichen Marktdiffusion von Prozeßinnovationen allgemein nachgewiesen werden kann, entstand auch durch die neue Aufnahme-, Herstellungs- und Abspieltechnik im Tonträgerbereich ${ }^{112}$ ein Ersatzbedarf der Konsumenten. Analoge Tonträgerkategorien wurden durch digitale ersetzt. Die Nachfrage der Jahre 1990 und 1991 stieg vereinigungsbedingt an, da Großteile des Musikrepertoires erstmalig für Konsumenten aus den neuen Bundesländern verfügbar waren. Inzwischen sind beide Effekte beendet. Der erfolgreiche Übergang von analogen zu digitalen Tonträgern ging mit der generellen Erhöhung des Preisniveaus ${ }^{113}$ einher, so daß in der Umstellungsphase der Zuwachs des wertmäßigen Marktvolumens denjenigen des Mengenzuwachses überstieg. Digitale Tonträger erzielten 1996 über $90 \%$ des Marktvolumens. ${ }^{114}$ Zwar ist der Preis der vorherrschenden Tonträgerkategorie CD seit 1985 bis 1995 um 14,9\% nominal (von anfänglich $35 \mathrm{DM}$ auf etwas über $30 \mathrm{DM}$ in der Fullprice-Kategorie) gesunken, ${ }^{115}$ doch sind ebenfalls die reinen Herstellungskosten gesunken. Sinkende Verkaufspreise einer Innovation sind nach der erfolgreichen Diffusion zu erwarten.

\footnotetext{
$110 \mathrm{Vgl}$. Schmidt, Christoph, op. cit., S. 193.

"II Vgl. Tabelle 2 in Abschnitt 4.2.2, in der der Preisindex der Lebenshaltung im Hinblick auf Freizeitgüter von 1991 bis 1996 um 10,7\% gestiegen ist, das reale Marktvolumen in demselben Zeitraum aber nur um $8,3 \%$.

112 Die digitale Aufnahme- und Abspieltechnik entstammt der Mikroclektronik und stellt die entscheidende erfolgreiche Prozeßinnovation im Tontrăgermarkt in den 80er Jahren dar. Vgl. Kapitel 1.2.6.

113 Vgl. Mahlmann 1997, op. cit., S. 172.

114 Vgl. BPW 1997, op. cit., S. 12, 16 und 18

115 Vgl. BPW 1997, op. cit., S. 48.
} 
Die Wettbewerbsstruktur und die Wettbewerbsverhältnisse zwischen den Marktteilnehmern, insbesondere der Oligopolgruppe, haben sich durch die Einführung der neuen Technologie nicht wesentlich geändert. Bei ausgereifter Technik und standardisiertem Produktionsverfahren sowohl des Mastertapes als auch der Tonträger beschränken sich Wachstumserwartungen auf die Etablierung neuer Musiktrends, die neben der Verdrängung älterer Titel zusätzliche Nachfrage attrahieren müßten. Dieses entspricht dem generellen Charakter des Marktprozesses im Tonträgermarkt. ${ }^{116}$ Die Stagnation hat von daher keine konjunkturellen, sondern strukturelle Ursachen. Tonträger unterliegen als Freizeitkonsumgüter der Substitutionskonkurrenz mit einer wachsenden Zahl von Produkten, die ähnliche Bedürfnisse der Konsumenten befriedigen (Computerspiele, Videospiele, Videofilme, Musikspartenfernsehen etc.) und einen Kaufkraft${ }^{a b f l u} B^{117}$ auslösen. Die in realen Größen gemessene Umsatzstagnation zeigt, daß die für Tonträger relevante Nachfrage weitgehend erschlossen ist. ${ }^{118}$ Eine Marktanteilssteigerung eines Wettbewerbers in dieser Marktphase geht zu Lasten seiner Konkurrenten. Daher hat die Marktphase des Tonträgermarktes einen wichtigen Einfluß auf den Einsatz von Aktionsparametern im Wettbewerb. Dieser wird sowohl bei der Analyse des Marktverhaltens als auch in der wettbewerbspolitischen Beurteilung berücksichtigt.

Ursachen für strukturelle Markteintrittsbarrieren ${ }^{119}$ in der Definition von Bain ${ }^{120}$ liegen u. a. in Größenkostenvorteilen (economies of scale), absoluten Kostenvorteilen (in der modifizierten

116 Vgl. hierzu den Abschnitt 4.3.2.2.

117 Der Kaufkraftabfluß läßt sich messen, wenn man die Steigerung der Ausgaben für Freizeitprodukte insgesamt in Relation setzt zur Steigerung der Ausgaben für Tonträger. Ein unterproportionales Wachstum zeigt den relativen Kaufkraflabfluß trotz steigender absoluter Absatzstückzahlen. Vgl. Abschnitt 4.3.4.2.

118 Diese Einschătzung der Marktphase wird dadurch bestatigt, daß die Majors 1995 gemeinsam eine sog. Nichtkăuferstudie in Auftrag gegeben haben, in der thematisiert wird, wie neue Nachfrageschichten zu erschließen sind. Vgl. Institut für Psychologie und Sozialforschung (IPS), Nichtkäuferstudie, Kiel 1996.

119 Bain definiert Markteintrittsbarrieren als „(...) the advantages of established sellers in an industry over potential entrant sellers, these advantages being reflected in the extent to which established sellers can persistently raise their prices above a competitive level without attracting new firms to enter the industry." Bain 1956, op. cit., S. 3. Zur Systematik der Markteintrittsbarrieren vgl. Kolbe, Clemens, Eintrittsbarrieren und die Eintrittsfähigkeit potentieller Konkurrenten, Göttingen 1991, S. 51-69.

${ }^{120}$ Bain beschrieb erstmals Markteintrittsbarrieren als Merkmal der Marktstruktur. Seine Sichtweise wurde sowohl weiterentwickelt (so z. B. von Porter, Michael E., Wettbewerbsstrategie: Methoden zur Analyse von Branchen und Konkurrenten, 6. Aufl., Frankfurt 1990, S. 29-42), als auch kritisiert. Caves hält der Definition von Bain entgegen, daß bei herrschender Produktdifferenzierung kein einheitliches Preisniveau bestimmbar sei, folglich auch kein oberhalb des Wettbewerbsniveaus liegendes. Daher steht für Caves die Rendite im Mittelpunkt der Betrachtung. Vgl. Caves, Richard E. und Michael E. Porter, supra, S. 241-261. Für empirische Zwecke eignet sich Caves' Sichtweise nicht, weil Renditeberechnungen nicht mit externen Jahresabschlußunterlagen zu erstellen sind. Entgegen der bisher dargestellten positiv-deskriptiven Sichtweise von Markteintrittsbarrieren lassen Vertreter der Chicago School nur institutionelle Eintrittsbarrieren und absolute Ressourcenmonopole zu. Dieser normativen Sichtweise entspricht die Argumentation Stiglers: „If we define a barrier as a differentially higher cost of new firms, there is no barrier and the firms size is governed by economies of scale and demand conditions." Stigler, George J., The Organization of Industry. Homewood, III. 1968, S. 67. Eine weitere Variante normativer Definitionen für Markteintrittsbarrieren liefert $v$. Weizsäcker. „A barrier to entry is a cost of producing which must be borne by a firm which seeks to enter an industry but is not borne by firms already in the industry and which implies a distortion in the allocation of resources from the social point of view." Weizsäcker, C. C. v., A Welfare Analysis of Barriers to Entry, in: Bell Journal of Economics and Management, Vol. 11 (1980), S. 400. Entscheidend für die Wahl einer Definition ist ihre Zweckmäßigkeit im Hinblick auf den untersuchten Gegenstand. Daher wird hier der weiterentwickelten Bain'schen Sichtweise von Marktbarrieren gefolgt. 
Form eines anfänglich hohen Kapitalbedarfs und des Zugangs zu Beschaffungs- und Absatzkanälen) ${ }^{121}$ und Produktdifferenzierungsvorteilen. Bei der industrieökonomischen Analyse des deutschen Tonträgermarktes sind - aufbauend auf der weiterentwickelten Bain'schen Definition - die Faktoren zu analysieren, die ursächlich sind für die Behinderung des Markteintritts.

Größenkostenvorteile entstehen im Tonträgermarkt aus der Tatsache, daß die Fixkostenbindung durch die Beschaffung, Herstellung des Masters und insbesondere die Vermarktung zunächst nur von einem realisierten Tonträger verursacht wird. Daher existiert eine Fixkostendegression nur bei Verkäufen desselben Tonträgers. Lediglich im Hinblick auf die Beschaffungskosten (vertragliche Verpflichtung des Musikers) entstehen Skaleneffekte, wenn derselbe Musiker weitere Tonträger produziert. Kumulierte Verkaufszahlen verschiedener Tonträger, die die gleichen summierten Umsatzwerte erzielen, bedeuten wegen des höheren Fixkostenanteils geringere Skaleneffekte. Im Hinblick auf die Vermarktung lassen sich Größenkostenvorteile dann erzielen, wenn für verschiedene nationale Märkte dieselbe Werbekampagne genutzt werden kann. Diese Vorteile können jedoch nur die Majors verwirklichen, die in den verschiedenen Märkten agieren. ${ }^{122}$

Weiterhin als Markteintrittsbarriere im Tonträgermarkt relevant sind absolute Kostenvorteile in Gestalt eines anfanglich hohen Kapitalbedarfs ${ }^{123}$ sowie des Zugangs zu den Beschaffungs- und Absatzkanälen. Der hohe Kapitalbedarf für die vertragliche Bindung von Musikern, die Produktion des Masters, die physische Tonträgerherstellung und die Werbung hat nicht nur den Charakter einer Vorfinanzierung. Die Investition in eine Tonträgerveröffentlichung ist im Falle des Scheiterns irreversibel und daher äußerst risikoreich. Der Grad der Irreversibilität wird nur dadurch begrenzt, daß jede Tonträgerveröffentlichung den Bekanntheitsgrad von Musikern erhöht $^{124}$ und weitere Veröffentlichungen auf dieser Bekanntheit aufbauen. Der Zugang zu den Musikern, die diese Bekanntheit bereits erlangt haben, erfordert anfanglich hohen Kapitalbedarf für garantierte Vorauszahlungen. Aus diesen Zusammenhängen resultiert die Tatsache, daß Newcomer (i. S. eines de Novo-Eintritts) zunächst unbekannte Musiker unter Vertrag nehmen und diese zu fordern versuchen.

Produktdifferenzierung als strukturelle Markteintrittsbarriere bezieht sich auf die Bindung der Kunden an die etablierten Unternehmen. Die Kundenbindung bewirkt dann, daß sich die Kreuzpreiselastizität zwischen den Produkten der etablierten Unternehmen und der Newcomer vermindert. ${ }^{125}$ Diese strukturelle Markteintrittsbarriere hat im Tonträgermarkt angesichts der

$121 \mathrm{Vgl}$. Bain 1956, S. 144-166.

$122 \mathrm{Vgl}$. zu diesen Zusammenhăngen Zeppenfeld, op. cit., S. 137.

${ }^{123}$ Die eintrittserschwerende Wirkung des anfanglich hohen Kapitalbedarfs zeigt sich auch im erneuten Markteintritt des Unternehmers Branson, der Virgin 1992 verkauft hatte und nach Ablauf der 5jăhrigen Wettbewerbsverbotsklausel Ende 1997 wieder in den Markt eintritt. Dic Anlaufinvestitionen können nur durch den Gewinn aus seinen anderen Unternehmungen getragen werden. Quelle: Gespräch mit Dirk Ewald, Intecord Tonträger GmbH, und Markus Corallo, V2, am 2.12.97.

124 Der Zusammenhang zwischen dem Bekanntheitsgrad und dem Markterfolg eines Musikers ist zwar stochastisch, aber nicht kausal.

125 Zusátzalich sind bei etablienten Unternehmen die Preiselastizitäten der unternchmensindividuellen Nachfrage unelastischer als bei Newcomern. 
Kürze der Produktlebenszyklen keine Bedeutung. Die Bindung an die Marke ist hier keine Bindung an das Tonträgerunternehmen, sondern an den Musiker. ${ }^{126}$ Sie bewirkt, daß die direkte Preiselastizität gegenüber den Tonträgerveröffentlichungen bekannter Musiker relativ unelastisch ist, unabhängig von dem produzierenden Tonträgerunternehmen. Bei Betrachtung aller genannten strukturellen Markteintrittsbarrieren ist der Eintritt in den Markt der Tonträgerherstellung prinzipiell möglich. Zu differenzieren ist dabei im Hinblick auf den Eintrittserfolg insbesondere nach unterschiedlichen Eintrittsgrößen. ${ }^{127}$

Strukturelle Barrieren wirken im Tonträgermarkt eher als endogene Mobilitätsbarrieren, $d . h$. als Wachstumsbarrieren im Markt. Betrachten wir die Gruppenstruktur innerhalb der Oligopolgruppe der vollintegrierten Majors und der gering integrierten Independents, so lassen sich als Wachstumsbarrieren ${ }^{128}$ im Tonträgermarkt diejenigen Faktoren bezeichnen, die ein Eindringen kleinerer Unternehmen in die Oligopolgruppe der Majors verhindern. Die Barrieren schützen nicht alle Unternehmen im Markt gleich. Insbesondere die Stellung der Majors ist offensichtlich relativ geschützter. ${ }^{129}$ Im Zeitraum von $1980-1996^{130}$ ist es keinem Musikproduzenten oder sonstigem vollintegriertem Anbieter gelungen, in die existierende Oligopolgruppe einzudringen oder die Stellung des Oligopols insgesamt zu gefährden. Zwar existieren kleinere auf Marktnischen spezialisierte Tonträgerhersteller und eine Vielzahl von einstufig organisierten Musikproduzenten, für deren Tätigkeit keine nennenswerten Markteintrittsbarrieren bestehen. Die Aufnahmetechnik ist standardisiert und bekannt, Geräte zur Aufnahme sind weit verbreitet, der Kapitalbedarf zur Erstellung des Mastertapes ist vergleichsweise gering und daher produzieren Musiker sich auch selbst. Im deutschen Markt existieren mehrere Hundert unabhängige Produktionsstudios. ${ }^{131}$ Aber für die kleineren Tonträgerhersteller und die unabhängigen Musikproduzenten liegen die wesentlichen Wachstumsbarrieren im fehlenden Zugang zu Beschaffungs- und Absatzkanälen. ${ }^{132}$

Denn kleinere Tonträgerhersteller sind im Vergleich zu den Majors schlechter in der Lage, ein Vertriebssystem aufzubauen. Dazu bedürtte es einer hinreichend großen und im Zeitablauf annähernd konstanten Zahl von viel verkauften Musiktiteln. Diese könnten nur bei einem den Majors entsprechenden Zugang zu international bekannten Stars garantiert werden. Der $\mathrm{Zu}$ gang zu den Stars wiederum setzt aber die Existenz eines funktionsfähigen Vertriebssystems und internationaler Verwertungsmöglichkeiten voraus. Gleiches gilt für die Verwertung der

${ }^{126}$ Kopplungen sind i. d. R. Joint Ventures und enthalten lizensierte Produkte von vielen Unternehmen, so daB von einer Kundenbindung an Tonträgerfirmen nicht ausgegangen werden kann.

${ }^{127}$ Die Veroffentlichung eines Tonträgertitels unbekannter Musiker erfordent weder hohen anfänglichen Kapitalbedarf für die vertragliche Bindung noch eine hohe Auflage und Werbungskosten, da nicht mit einer groBen Absatzmenge gerechnet werden kann. Insofern kann aber eine einzelne Veröffentlichung betriebswirtschaftlich erfolgreich sein.

128 Zum Begriff der Mobilitătsbarrieren im Markt vgl. Caves, R. E., und M. E. Porter, supra, S. 241-261.

129 Die Existenz einer Gruppe von Oligopolisten und einer Vielzahl sog. fringe firms ist ein typisches Muster der Anbieterstruktur in Konsumgüterindustrien. Vgl. auch Caves, R. E., und M. E. Porter, supra, S. 251.

${ }^{130}$ Eine Erweiterung des Zeitraumes bis 1970 zurück verändert die Ergebnisse nicht. Vgl. hierfür Zeppenfeld, op. cit., S. 43.

131 Vgl. o. V., Branchenhandbuch des Musikmarktes, Starnberg 1997.

132 Daher bedeutet der erfolgreiche Eintritt in die Randgruppe der Independents nicht, daß eine Expansion zu der Oligopolgruppe der Majors möglich ist. 
Musikproduktionen fremder Label. Anfänglicher hoher Kapitalbedarf und mangelnder Zugang zu den Beschaffungs- und Vertriebskanälen sind für den Tonträgermarkt relevante Wachstumsbarrieren vom Independent zum Major. Daher ist nicht nur die bloße Tätigkeit auf allen drei Stufen des Tonträgermarktes, Musikproduktion, physische Herstellung und Distribution mit entsprechendem Marketing, eine notwendige Bedingung für den Marktanteilszuwachs, sondern auch die jeweilige Betriebsgröße und die Präsenz in den wichtigsten nationalen Märkten, in denen die Stars vermarktbar sind. Zusätzlich ergeben sich aus der Produktdifferenzierung im Tonträgermarkt für die Majors wegen ihrer Präsenz in vielen Segmenten Vorteile der Risikostreuung und eines kontinuierlichen Verkaufs.

Gegen das Bestehen von Mobilitätsbarrieren spricht nicht, daß Hardwarehersteller, die die für den Tonträgermarkt relevanten Abspielgeräte herstellen, in den Markt vorwärts integriert haben. ${ }^{133}$ Ebenso ist der Markteintritt der Medienkonglomerate, für die der Tonträgermarkt nachoder nebengelagert ist, kein Argument gegen die Existenz von Mobilitätsbarrieren. ${ }^{134}$ Denn durch den kompletten Aufkauf von vollintegrierten Tonträgerherstellern werden die bestehenden Vorteile der etablierten Unternehmen c. p. übernommen. Das verbleibende Kriterium des Kapitalbedarfs wurde von den aufkaufenden Unternehmen allein dadurch erfüllt, daß sie überhaupt zu der Übernahme in der Lage waren. ${ }^{135}$ Daher ist bei der weiteren Marktstrukturentwicklung von der fortwährenden Existenz der beiden Anbietergruppen, des engen Oligopols der Majors und der Vielzahl kleinerer Independents, und der Stabilität der strukturellen Wettbewerbsbedingungen zwischen ihnen auszugehen.

\subsubsection{Der Tonträgerhandel}

Aus volkswirtschaftlicher Sicht erfült der Handel Distributionsaufgaben. Aus Sicht der Tonträgerhersteller ist der Handel in seinen unterschiedlichen Erscheinungsformen Mittler zur Endnachfrage. In der betriebswirtschaftlichen Literatur zum Marketing wird vom Handel als Absatzmittler gesprochen. ${ }^{136}$ Hier werden zunächst die Handelsformen und die für den Tonträgerhandel relevanten Handelsfunktionen behandelt, bevor mit der Entwicklung der Handelsstruktur die Konzentrationsentwicklung in dieser Marktstufe thematisiert wird.

\subsubsection{Handelsformen und Handelsfunktionen}

Im Handel mit Tonträgern lassen sich zunächst die Erscheinungsformen des Groß- und des Einzelhandels unterscheiden. Die Betriebstypen des Großhandels sind Sortimentsgroßhänd-

\footnotetext{
${ }^{133}$ Hierzu gehören die Übernahmen von EMI durch Thorn 1980, von CBS durch Sony 1988 und von MCA durch Mashushita 1990.

134 Diese marktübergreifenden Integrationen waren z. B. die Übernahme von RCA durch Bertelsmann 1984 und von Teldec durch WEA (1990).

135 Die vollintegrierten Tonträgerhersteller bestehen im deutschen Markt allesamt in der Rechtsform der $\mathrm{GmbH}$. Daher sind keine feindlichen Übernahmen möglich, sondern nur solche auf dem Verhandlungswege, bei denen davon ausgegangen werden muß, daß eine Einigung über den Kaufpreis stattindet.

136 Vgl. z. B. Nieschlag/Dicht/Hörschgen, op. cit., S. $434 \mathrm{fr}$.
} 
ler, ${ }^{137}$ Rackjobber und Automatengrossisten. Die Betriebstypen des Einzelhandels sind Großbetriebsformen (sog. Megastores, Warenhauskonzerne und Elektromärkte), Filialunternehmen, Fachmärkte, Verbrauchermärkte, unabhängige Facheinzelhändler, Direktvermarkter des Einzelhandels und sonstige Einkaufsstätten. Entscheidend für diese Klassifikation ist der Verkauf von Tonträgern an den Endverbraucher durch den Einzelhandel, während der Großhandel an den Einzelhandel verkauft bzw. im Fall von Rackjobbern im Auftrag des Einzelhandels an den Endverbraucher.

Eine weitere Unterscheidung läßt sich nach der Handelsfunktion ${ }^{138}$ in Vollsortimenter und Teilsortimenter treffen. Für die Sortimentspolitik des Handels ist die Funktion des Produktes Tonträger in seinem Gesamtsortiment die relevante Bestimmungsgröße, d. h. der Umsatzanteil, den der Handel mit Tonträgern in Relation zu seinem jeweiligen Gesamtsortiment erzielt. Besteht der Großteil des Gesamtangebots aus Gütern, die in keinem sachlichen, insbesondere komplementären Bezug zu Tonträgern stehen, folgt die Beschaffungspolitik im Hinblick auf die Sortimentsbreite eher konsumentenakquisitorischen Gesichtspunkten. ${ }^{139}$ Sind hingegen Tonträger wesentlicher Teil des Handels, besteht ein höherer Anspruch auf Sortimentsvollständigkeit und Quersubventionierungen aus anderen Sortimentsgruppen sind nicht möglich. Teilsortimenter sind z. B. alle Handelsformen, die Tonträger nach Chart- bzw. Hitlistenplatzierungen von den Herstellern ordern. Ihre Sortimentspolitik beruht im wesentlichen auf der Präferenzschaffung der Tonträgerhersteller. Aus deren Sicht handelt es sich um Hitverteiler, da durch die Platzierung in den diversen Hitlisten große Umschlagshäufigkeiten wahrscheinlich sind. Diese Handelsformen sind daher - bezogen auf die gesamten veröffentlichten Tonträger - Teilsortimenter. Die jeweilige Sortimentsbreite wird zugunsten der größeren Umschlagshäufigkeit ständig den aktuellen Rangplätzen der Charts angepaßt. ${ }^{140}$ In der Praxis fallen darunter sowohl bestimmte Direct Mail-Anbieter (Cluts, Versandhäuser, Kataloganbieter) als auch bestimmte Großbetriebsformen (Warenhauskonzerne und Elektromärkte) sowie bestimmte Filialisten und Fachmärkte (Drogerien und Verbrauchermärkte).

Bestehen seitens der Konsumenten jedoch nur diffuse Präferenzen, z.B. hinsichtlich einer Musikrichtung, kommt dem Tonträgerhandel auch eine präferenzbildende oder zumindestens präferenzkanalisierende Funktion mit Hilfe von Beratung, Service etc. zu. Die zu dieser Gruppe gehörenden Handelsformen sind typischerweise Vollsortimenter. In der Praxis fallen darunter bestimmte Großbetriebsformen (sog. Megastores) und klassischerweise der Facheinzelhandel (das Tonträger-Fachgeschäf). ${ }^{141}$ Daher erfolgt der Absatz der Produkte, die sich nicht bzw. nicht mehr in den Charts befinden, eher durch den Distributionskanal der Vollsortimenter. Ne-

${ }^{137}$ Bezogen auf den Gesamtumsatz des Jahres 1995 zu Endverkaufspreisen wurden $11 \%$ der Umsătze über den SortimentsgroBhandel abgewickelt. Vgl. Mahlmann 1997, op. cit., S. 176.

$138 \mathrm{Vgl}$. grundlegend zu den Handelsfunktionen Oberparleitner, Karl, Funktionen und Risiken des Warenhandels, 2. Aufl., Wien 1955. Weitere Funktionen des Handels, die hier nicht problematisiert werden sollen, bestehen u.a. in der Verteilungs-, Transport-, Finanzienungs-, Lager-, Service- und Selektionsfunktion.

139 Vgl. Mahlmann 1997, S. 176-178.

${ }^{140}$ D. h., daB aus einer bestimmten Chartposition herausfallende Titel (z. B. Platz 50) ausgelistet werden und in bestimmte Positionen aufsteigende Titel geordert werden.

141 Lencher, Uwe, und Bodo Bochnig. Vertriebsstrukturen und Situation des Handels, in: Handbuch der Musikwirtschan, hrsg. von Moser, Rolf, und Andreas Scheuermann, 4. Aufl., Starnberg 1997, S. 241-244. 
ben der Absatzmittlerfunktion haben die Vollsortimenter auch Markterprobungs- und Markterschließungsfunktionen für die Tonträgerhersteller, z. B. durch Erprobung neuer Musikstile und Interpreten. ${ }^{142}$

\subsubsection{Entwicklung der Handelsstruktur und Konzentrationsentwicklung des Handels}

Die Entwicklung der Handelsstruktur kann auf verschiedene Arten untersucht werden: Anhand der Entwicklung der absoluten Zahl der insgesamt bestehenden Tonträgereinkaufsstätten, der Verteilung der verkauften Tonträgerstückzahlen, der Verteilung der Umsätze auf diese Stätten und der Verteilung des bestehenden Sortiments auf die einzelnen Vertriebswege. ${ }^{143}$

Bei der Betrachtung der absoluten Zahl der Verkaufsstätten ist im Tonträgerhandel, parallel zur allgemeinen Situation im Einzelhandel, ${ }^{144}$ ein genereller Rückgang zu beobachten. Lag die Zahl der Verkaufsstellen 1975 bei ca. 15.000 und 1985 bei ca. 9.000 , so hat sie sich bis 1990 (noch bezogen auf die alten Bundesländer) auf ca. 7.000 reduziert und ist bis 1995 (jetzt bezogen auf alte und neue Bundesländer) auf diesem Stand geblieben. ${ }^{145}$ Das entspricht einer Verringerung der Einkaufsstätten für Tonträger auf weniger als die Hälfte innerhalb der vergangenen zwanzig Jahre. In demselben Zeitraum hat sich die Zahl der von den Tonträgerherstellern direkt belieferten Verkaufsstellen von 2.000 auf 1.000 halbiert. ${ }^{146}$

Die Verteilung der verkauften Stückzahlen auf die einzelnen Verkaufsstätten zeichnet dieses Bild nach. ${ }^{147}$ Wurde 1993 noch annähernd jeder vierte Tonträger im Fachhandel gekauf, waren es 1995 nur noch ca. 17\%. Den größten mengenmäßigen Zuwachs konnten in demselben Zeitraum die vorwiegend von Rackjobbern bestückten Verbrauchermärkte verzeichnen, die 1995 ca. 15\% aller Tonträger verkauften. Auch wenn die Umsatzeinbußen des Facheinzelhandels zugunsten der Filialisten, Warenhauskonzerne und der Verbrauchermärkte geringer sind als der Rückgang der verkauften Stückzahlen, ${ }^{148}$ nimmt die Zahl der Tonträgerfachgeschäfte kontinuierlich $\mathrm{ab}$. ${ }^{149}$

${ }^{142}$ Die Markterprobung wird gefördert durch die Kenntnis der Konsumentenpräferenzen. Daher wird unter dem Begriff des Präferenztransfers der Umsetzungprozeß der Präferenzen der Nachfrager in Produktionsentscheidungen der Anbieter des betrachteten Marktes verstanden. Dieser ProzeB ist $\mathrm{m}$. E. durch Interdependenz gekennzeichnet, denn einerseits werden die Präferenzen beim Konsumenten geschaffen, andererseits werden getroffene Kaufentscheidungen als Ausgangspunkt für neue Produkte herangezogen.

${ }^{143}$ Der letzte Punkt wird unter Sortimentspolitik des Handels im Abschnitt 4.3.3.3 untersucht.

${ }^{144} \mathrm{Vgl}$. Schmidt, Ingo, Handelskonzentration, Nachfragemacht und 6. GWB-Novelle, in: Wirtschaft und Wettbewerb, 47. Jg. (1997), S. 101-120 [Schmidt, Ingo, 1997a].

$145 \mathrm{Vgl}$. Mahlmann 1997, S. 176.

146 Vgl. Mahlmann 1997, S. 176.

147 Wegen geringer Datenverfugbarkeit kann hier nur die Entwicklung der vergangenen Jahre nachgezeichnet werden.

${ }^{148}$ Hier liegt eine Divergenz zwischen Mengen- und Wertgerüst vor. Das liegt daran, daß im Facheinzelhandel mehr höherpreisige und in Verbrauchermärkten mehr niedrigpreisige Tonträger verkauft werden. Vgl. Jetzkus, Frank-Werner, Rackjobbing, in: Handbuch der Musikwirtschaft, hrsg. von Moser, Rolf, und Andreas Scheuermann, 4. Aufl., Starnberg 1997, S. 279-287, insbesondere S. 279 f.

$149 \mathrm{Vgl}$. Stolberg. Christian, und Wolfgang Orthmayr, op. cit., S. 247. 
Eine wesentliche Verlagerung der Umsatzanteile der Vertriebswege am Gesamtumsatz zwischen den Betriebsformen des Einzelhandels ist festzustellen, wenn diese stärker ausdifferenziert werden. ${ }^{150}$ In der folgenden Tabelle werden Filialbetriebe, soweit sie zu Warenhäusern, Elektromärkten oder Verbrauchermärkten gehören, diesen zugeordnet:

Tabelle 4: Anteile der Vertiebswege in \% am Umsatz 1992-95

\begin{tabular}{|l|l|l|l|l|}
\hline & 1992 & 1993 & 1994 & 1995 \\
\hline Facheinzelhandel & 25,7 & 26,8 & 24,1 & 20,1 \\
\hline Elektromärkte & 14,1 & 14,6 & 16,3 & 18,3 \\
\hline Warenhauskonzerne & 15,4 & 13,5 & 13,5 & 13,2 \\
\hline Verbrauchermärkte & 9,3 & 9,9 & 11,1 & 11,5 \\
\hline Megastores & 8,9 & 8,6 & 7,7 & 7,6 \\
\hline Mail Order/Versand & 4,9 & 5,9 & 6,7 & 7,2 \\
\hline Club & 6,2 & 6,1 & 5,5 & 5,4 \\
\hline Filialunternehmen & 3,4 & 4,1 & 5,0 & 6,2 \\
\hline Sonderkunden & 5,7 & 4,4 & 4,5 & 4,3 \\
\hline Sonstige & 6,4 & 6,1 & 5,6 & 6,1 \\
\hline
\end{tabular}

Quelle: Mahlmann, 1997, op. cit., S. 176.

Betrachtet man die wertmäßige Marktentwicklung ohne den Sortimentsgroßhandel, lag der Anteil des Facheinzelhandels 1995 noch bei $20 \%$. Mit einem weiteren Rückgang ist zu rechnen. Eine kontinuierliche Steigerung haben sowohl Filialisten als auch Elektromärkte sowie der Versandhandel zu verzeichnen.

Nicht dieser Unterscheidung der Handelsformen und ihrer Anteile am Vertrieb zu entnehmen ist der Konzentrationsprozeß im Tonträgerhandel. Zunächst wird die Handelskonzentration entsprechend der Konzentrationsrate gemessen. Lag der Umsatzanteil der 10 größten Händler $\left(\mathrm{CR}_{10}\right)$ bis 1986 noch unter $40 \%$, so ist er 1990 auf $50 \%$ gestiegen und liegt 1995 bei $60 \%$ des Gesamtumsatzes der Tonträgerhersteller. Danach ist festzustellen, daß dementsprechend auch die relative Konzentration der Absatzmittler - gemessen als Verteilung des Gesamtumsatzes auf die Zahl der Handelsunternehmen - gestiegen ist. Im Jahr 1995 tätigten weniger als 5\% der insgesamt ca. 7.000 Händler $80 \%$ des Umsatzes. ${ }^{151}$ Die Versuche der Tonträgerhersteller, selbst in die Absatzmittlertätigkeit zu integrieren, sind überwiegend gescheitert. ${ }^{152}$ Aus der beschriebenen Konzentrationsentwicklung des Handels kann auf seine steigende Nachfragemacht geschlossen werden. Hierauf wird in Abschnitt 4.3.3.1 eingegangen.

\footnotetext{
${ }^{150}$ Im Gegensatz zu der vom BPW veröffentlichten Statistik.

151 Vgl. Mahlmann 1997, S. 177.

152 Virgin hatte in mehreren deutschen Großstädten Megastores eröffnet. Die letzte Verkaufsstătte von Virgin wurde 1995 geschlossen. Dagegen besteht noch die Verkaufsstätte HMV des Majors EMI.
} 
Die Strukturen der Nachfrage nach Tonträgern lassen sich nicht beschreiben, ohne das Produkt und den Zugang zu ihm zu beschreiben. Daher werden zunächst die Grundlagen für Tonträgerkäufe aus der Theorie des Kaufverhaltens und der Diffusionstheorie behandelt, bevor zur Altersstruktur und zur Käuferreichweite Aussagen getroffen werden.

\subsubsection{Grundlagen der Tonträgernachfrage}

Tonträger sind keine lebensnotwendigen Güter, sondern (Freizeit-)Konsumgüter. Sie befriedigen kulturelle Bedürfnisse, Emotionen, Prestige, Gruppenzugehörigkeit oder sozialen Status. Daher fallen bei der Nachfrage nach Tonträgern die zwei Phasen des Kaufprozesses, Kaufentscheidung und Kaufhandlung, zusammen und man spricht von Impulskäufen. ${ }^{153}$ Impulskäufe wirken bedarfserweiternd und werden häufig erst nachträglich rationalisiert. ${ }^{154}$ Es wird geschätzt, ${ }^{15 s} \mathrm{da}$ über die Hälfte aller Tonträgerkäufe ungeplante Spontan- (impuls)käufe oder Erinnerungsimpulskäufe sind. Weiterhin besteht ein wesentlicher Teil der Nachfrage nach Tonträgern aus Geschenkkäufen. ${ }^{156}$ Der Tonträger-Gesamtumsatz besteht zum wesentlichen Teil aus Umsätzen mit Neuerscheinungen. ${ }^{157}$ Durch die starke Neuheitenorientierung der Nachfrage ist der Diffusionsprozeß der Erklärungsansatz für die Zeitstruktur des Nachfrageverlaufs. Der Diffusionsprozeß beschreibt die Ausbreitung einer Produktinnovation von der Markteinführung bis zum letzten Übernehmer. ${ }^{158}$ Jede Tonträgerneuveröffentlichung ist eine Produktinnovation, zu der jeweils neue Adoptionsprozesse ablaufen, die den individuellen Entscheidungsprozeß zur Übernahme einer Neuheit beschreiben. ${ }^{159}$ Die Übernahmekurve kennzeichnet dann die Gesamtzahl der Übernehmer in Abhängigkeit von der Zeit.

Bezogen auf den Diffusionsprozeß der Tonträgernachfrage lassen sich die Mechanismen der Adoptionsprozesse anhand einer Übernahmeverteilung für Single- und Longplay-Tonträgerkategorien darstellen. Hierzu wurden Tonträgertitel beider Kategorien, die in die Charts (=Hitlisten) gelangten, herangezogen und Diffusionsverlauf und Diffusionszeit in einer Über-

153 Fallen Kaufentscheidung und Kaufhandlung auseinander, spricht man von Suchkăufen. Zwischen geplanten Suchkäufen und vollkommen ungeplanten Impulskäufen bestehen noch die Mischformen der geplanten Impulskăufe, der Erinnerungsimpulskăufe und des ungeplanten Suchkaufes. Vgl. Kroeber-Riel, W., Konsumentenverhalten, 6. Aufl., München 1996, S. 328 ff.

154 Daher haben klassische Informationssysteme, wie z. B. im Buchhandel Kataloge, nur geringe Bedeutung.

$155 \mathrm{Vgl}$. Schulze, Ralf, op. cit., S. 186.

${ }^{156}$ Die Ergebnisse verschiedener Schătzungen variieren um ca. 10-30\%. Vgl. etwa Die Elastizităt der Nachfrage im Tonträgerhandel, unveröff. Manuskript der EMI, Köln 1986, S. 58-60 [Mahlmann 1986].

157 Auf Neuerscheinungen entfallen etwa 65 bis $80 \%$ des Umsatzes. Vgl. Thurow, Norbert, und Peter Zombik, op. cit., S. 202.

158 Nach Rogers, Evereth, Diffusion of Innovations, 4th ed., New York, S. 19 ff. entfallen bei der normalverteilten Übernahmeverteilung von den Übernehmern (=100\%) 2,5\% auf die Innovatoren, $13,5 \%$ auf die frühen Übernehmer, $34 \%$ auf die frühe Mehrheit, 34\% auf die spăte Mehrheit und $16 \%$ auf die Nachzügler.

159 Der AdoptionsprozeB gliedert sich nach Kaas, K. P., Diffusion und Marketing, Stuttgart 1973, S. 14 f., in fünf Phasen: Bewußtheitsphase, Interessephase, Bewertungsphase, Versuchsphase und Übernahmephase. Der Adoptionsprozeß eignet sich zur Beschreibung der einzelwirtschaflichen Entscheidung, wăhrend der Diffusionsprozeß die Marktentwicklung eines Produktes charakterisiert. 
nahmekurve abgebildet. ${ }^{160}$ Daraus ergab sich bei einem Single-Tonträger bei erfolgreicher Markteinführung eine Diffusionszeit von 15-20 Wochen. Bei Longplay-Tonträgern variiert die Diffusionszeit bei erfolgreicher Markteinführung zwischen 6 Monaten und einem Jahr. ${ }^{161}$ Die Absatzkurve von Tonträgern ist kürzer als bei anderen Konsumgütern, der Produktlebenszyklus beträgt nur einige Monate. ${ }^{162}$

Da die auditive Aufnahme die einzige Rezeptionsmöglichkeit für Musik ist und die Nachfrage sich vorwiegend auf bereits rezipierte Musik beschränkt, folgt daraus, daß der Konsument das Produkt kennen muß, wenn er eine Tonträgerkaufentscheidung fällen soll. Die Verkaufsförderung geschieht daher zum Großteil durch die Präsentation der Musik selbst. Untersucht man die Informationsquellen, durch die die Tonträgerkäufer auf neue Produkte aufmerksam werden, z. B. durch Konsumentenbefragung, so kann man diese zu einer Rangfolge der Informationsquellen (d. h. Kriterien der Kaufauswahl) ordnen: ${ }^{163}$

1. Musiksendungen im Radio

2. Freunde/Bekannte

3. Musiksendungen im Fernsehen

4. Konzerte

5. Angebote im Geschäft

6. Plattenkritiken in diversen Pressepublikationen

7. Charts, Hitlisten (veröffentlicht im Fernsehen, Radio und Musikpresse)

8. Zeitschriftenanzeigen

9. Prospektmaterial

10. Diskotheken

11. Beratung im Tonträgergeschäft

12. Handzettel

13. Dekoration im Tonträgergeschäft

Diese Rangfolge zeigt, daß erst das direkte Hören von Musik durch Musiksendungen oder Konzerte oder die persönliche Empfehlung von glaubwürdigen Personen (sog. Multiplikatoren) die Voraussetzung zur Kaufentscheidung durch den Musikkonsumenten schaff. Abgesehen von Geschenkkäufen, bei denen der Beschenkte i. d. R. die Musik kennt, kauft niemand Musik auf Tonträgern, die er oder andere Personen seines Vertrauens nicht vorher selbst gehört haben oder für die durch Rezensionen Vertrauen geschaffen wurde.

Daher bildet der Hörfunk die zentrale Grundlage der Nachfrage nach Musik auf Tonträgern. Es besteht ein wechselseitiges Abhängigkeitsverhältnis zwischen Radioveranstaltern und Tonträ-

\footnotetext{
$160 \mathrm{Vgl.} \mathrm{Mahlmann} \mathrm{1986,} \mathrm{S.} \mathrm{44-49.}$

161 Aus der Form der Übernahmeverteilung ergibt sich bereits ein konkreter Zeitpunkt, an dem über Erfolg oder Mißerfolg einer Markteinführung eines Tonträgertitels entschieden werden kann.

162 Der Produktlebenszyklus eines Tonträgers ist nur durch Charterfolg verlängerbar. Vgl. Thurow; Norber, und Peter Zombik, op. cit., S. 204 f.

$163 \mathrm{Vgl}$. Bezold, N., Marktanalyse Tonträger, unveröffentlichtes Manuskript, Nürnberg 1985, S. $68 \mathrm{ff}$; zitiert nach Conen, Michael, op. cit., S. 60.
} 
gerherstellern; denn die Radioveranstalter benötigen Programminhalte für ihre Sendungen, die größtenteils aus Musik bestehen, und die Tonträgerhersteller brauchen die Radioveranstalter als Zugang zur Öffentlichkeit, um ihre Musiktitel vorzustellen, damit die Tonträgertitel etabliert werden können. ${ }^{164}$ Ziel der Tonträgerhersteller ist ein verstärkter Sendeeinsatz in Radio und Fernsehen für die eigenen Musiktitel und eine positive Berichterstattung über die Musiker. Dabei sind entsprechend den Phasen des Diffusionsprozesses zunächst zum Beginn des Produktlebenszyklus einer Tonträgerneuveröffentlichung vermehrte Sendeeinsätze nötig, die in der Kernphase des Diffusionsprozesses bei Auftreten der Mehrheiten reduziert werden müssen, um eine Sättigung der Konsumenten oder Substitutionsverhalten ${ }^{165}$ zu vermeiden. Die Empfänglichkeit und Erreichbarkeit der Nachfrage durch die verschiedenen Diffusionswege und das daraus resultierende Umsetzen in Konsumentscheidungen sind Erklärungsansätze für die Alterstruktur der Tonträgernachfrage, mit der wir uns im folgenden Abschnitt beschäftigen.

\subsubsection{Altersstruktur der Tonträgerkäufer und demographische Entwicklungen}

Eine Untersuchung der Altersstruktur gegenwärtiger Tonträgerkäufer liefert Erkenntnisse über das zukünftige Potential der Tonträgerkonsumenten, wenn man sie mit der Altersstruktur der gesamten deutschen Bevölkerung vergleicht. Wird unterstellt, daß das altersspezifische Einkaufsverhalten konstant bleibt, kann bei Fortschreibung der Alterspyramide ein langfristig schrumpfendes Konsumentenpotential prognostiziert werden. Der Grund hierfür liegt darin, daß die Altersstruktur der Tonträgerkäufer gegenüber derjenigen der Gesamtbevölkerung differiert. Jüngere Personen tragen überproportional und ältere unterproportional zur Tonträgernachfrage bei. Hierzu betrachten wir für das Jahr 1996 die Alterstruktur der Grundgesamtheit, ${ }^{166}$ die als potentielle Tonträgerkäufer in Frage kommt. ${ }^{167}$ Diese Grundgesamtheit vergleichen wir mit der Altersstruktur der tatsächlichen Tonträgerkonsumenten in 1996.

\footnotetext{
$164 \mathrm{Vgl}$. Thurow, Norber, und Peter Zombik, op. cit., S. 203.

${ }^{165}$ Etwa durch Mitschnitt der Musik auf leere Tonträger.

${ }^{166}$ Die Grundgesamtheit wird definiert als der Teil der Bevölkerung der Bundesrepublik, der am 31.12.96 zehn Jahre oder ălter war und in dessen Haushalt sich ein Abspielgerät für Tontrăger befindet.

167 Von Konsumenten unter 10 Jahren kann abstrahiert werden, da sie keinen direkten Konsum ausüben. Ihr indirekter Konsum (als Beschenkte) wird durch andere Käufergruppen erfaßt.
} 


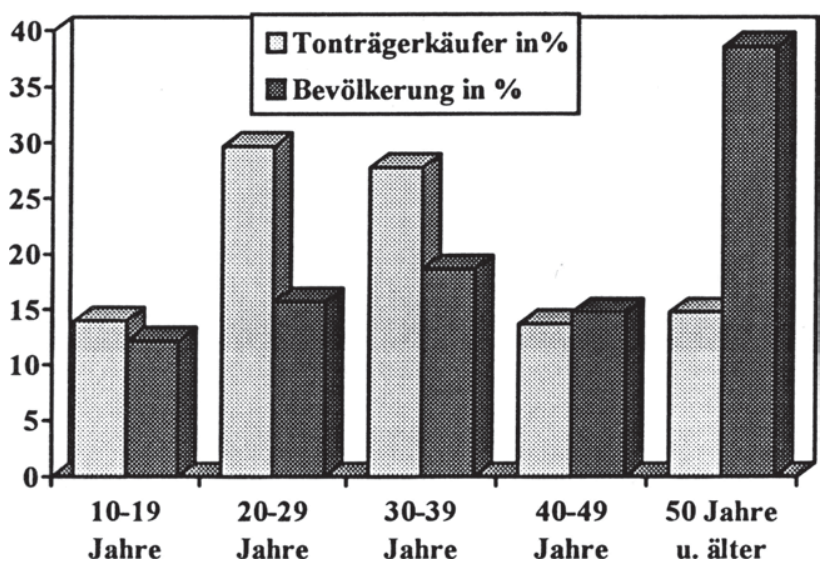

Quelle: BPW 1997, S. 27

Waren am 31.12.1996 ${ }^{168} 38,6 \%$ der Grundgesamtheit 50 Jahre und älter, so lag ihr Anteil an den Tonträgerkäufern im Jahr 1996 bei nur 14,8\%. Die Gruppe der 20 bis 29 jährigen, deren Anteil an der über 9jährigen Bevölkerung zum selben Zeitpunkt 15,7\% betrug, stellten mit 29,7\% die größte Gruppe der Tonträgerkäufer, gefolgt von der Gruppe der 30-39 jährigen, die für $27,8 \%$ der Tonträgerkäufe verantwortlich waren, aber nur einen Anteil von $18,7 \%$ an der Grundgesamtheit hatten. Insgesamt betrug der Anteil der 10 bis 49 jährigen $61,4 \%$ an der über 9 Jahre alten Gesamtbevölkerung, ihr Anteil an Tonträgerkäufen aber 85,2\%. ${ }^{169}$ Die vom Alter her jüngeren und mittleren Teile der Bevölkerung sind überproportional an der Tonträgernachfrage beteiligt. Ihr Anteil an der Gesamtbevölkerung hat sich von 1981 bis 1995 von $58,6 \%$ auf $54,9 \%$ verringert. ${ }^{170}$ Die Personenbasis der Nachfragegruppen mit überproportionalen Tonträgerkäufen sinkt c. p. bei Fortschreiben der gegenwärtigen Alterspyramide. Die Gruppe der 20 39 jährigen, die für $57 \%$ der Tonträgerkäufe verantwortlich sind, stellten beispielsweise 1995 nur 30,8\% der Bevölkerung. Dabei hat sich die Gesamtbevölkerung von 61,7 Mio 1981 (nur alte Bundesländer) auf 81,8 Mio 1995 (alte und neue Bundesländer) erhöht. ${ }^{171}$

\footnotetext{
${ }^{168}$ Neuere Zahlen des statistischen Bundesamtes sind erst im Oktober 1998 erhältlich.

169 Quelle: GrK Panel Services und Statistisches Bundesamt.

170 Statistisches Bundesamt, Fachserie 1, Bevölkerung und Gebict, Jahrgänge 1981 - 1997.

${ }^{171}$ Statistisches Bundesamt, Fachserie 1, Bevölkerung und Gebiet, Jahrgänge 1981 - 1997.
} 
Tabelle 5: Entwicklung der altersspezifischen Bevölkerungsstruktur

Altersgruppen in Prozent

\begin{tabular}{|c|c|c|c|c|}
\hline Jahre & $\begin{array}{l}\text { Gesamt- } \\
\text { bevölkerung * } \\
(=100 \%)\end{array}$ & $\begin{array}{l}10-20 \\
\text { jährig }\end{array}$ & $\begin{array}{l}20-30 \\
\text { jährig }\end{array}$ & $\begin{array}{l}30-40 \\
\text { jährig }\end{array}$ \\
\hline
\end{tabular}

alte Bundes-

länder

$\begin{array}{llllll}1981 & 61712700 & 15,9 & 15,0 & 13,0 & 14,7 \\ 1982 & 61546100 & 15,4 & 15,3 & 13,1 & 14,8 \\ 1983 & 61306700 & 14,7 & 15,8 & 13,1 & 15,1 \\ 1984 & 61049300 & 13,9 & 16,2 & 13,2 & 15,0 \\ 1985 & 61020500 & 13,1 & 16,5 & 13,6 & 14,4 \\ 1986 & 61140500 & 12,4 & 16,9 & 13,9 & 14,1 \\ 1987 & 61238100 & 11,6 & 16,8 & 14,0 & 14,0 \\ 1988 & 61715100 & 11,1 & 17,1 & 14,2 & 13,7 \\ 1989 & 62679000 & 10,6 & 17,2 & 14,5 & 13,3\end{array}$

alte und neue

Bundesländer

$\begin{array}{llllll}1990 & 79753200 & 10,7 & 16,7 & 14,9 & 12,7 \\ 1991 & 80274600 & 10,5 & 16,4 & 15,3 & 12,5 \\ 1992 & 80974600 & 10,5 & 16,0 & 15,6 & 12,4 \\ 1993 & 81338100 & 10,7 & 15,4 & 16,0 & 12,6 \\ 1994 & 81538600 & 10,7 & 14,7 & 16,4 & 12,8 \\ 1995 & 81817500 & 10,9 & 14,0 & 16,8 & 13,2\end{array}$

* Wohnbevölkerung.

Quelle: Statistisches Bundesamt, Fachserie 1, Bevölkerung und Gebiet, verschiedene Jahrgänge.

Die Entwicklung der altersspezifischen Bevölkerungsstruktur zeigt, daß der Anteil der an Tonträgerkäufen überproportional vertretenen Altersgruppen in der Summe sinkt. Dieser Zusammenhang wird bei den Käuferreichweiten im folgenden Abschnitt weiter betrachtet.

\subsubsection{Käuferreichweiten}

Nicht nur im Hinblick auf das Alter der Konsumenten, sondern auch auf die Zahl der Tonträgerkäufer weist der Tonträgermarkt Besonderheiten auf. Hierzu wird die Käuferreichweite als Kriterium herangezogen. Die Käuferreichweite wird definiert als der Teil der tatsächlichen Tonträgerkonsumenten, bezogen auf alle potentiellen Tonträgerkunden in Deutschland. Potentielle Kunden sind alle Personen, die zur im vorangegangenen Abschnitt definierten Grundgesamtheit gehören. Für das Jahr 1995 wurde von einem Potential von 62,5 Mio Personen ausgegangen. ${ }^{172}$ Davon kauften 51,1\% Tonträger, eine Zahl, die in 1996 gleichblieb und deren

${ }^{172}$ Quelle: GfK Panel Services. 
Durchschnittswert der Jahre 1985-1995 bei ca. 52\% lag. ${ }^{173}$ Daraus folgt, daß knapp die Hälfte des Teils der Bevölkerung, der zur Zielgruppe gehört, keine Tonträger kaufen. Die Käuferreichweite ist daher als gering anzusehen. Das Entwicklungspotential zur Erhöhung der Käuferreichweite wird von einer Studie, die von den Major-Tonträgerherstellern in Auftrag gegeben wurde, auf ca. $18 \%$ geschätzt, so daß die potentielle Käuferreichweite bei $70 \%$ gesehen wird. ${ }^{174}$ Die potentielle Käuferreichweite ist definiert als die Summe der aktuellen Konsumenten zuzüglich einer Gruppe von marktnahen Konsumenten, bei denen gewisse Vorbedingungen für den Tonträgerkonsum gegeben sind wie z. B. im Haushalt vorhandene Abspielgeräte, Musikkonsum mittels Radio etc. Als entscheidend für die mittelfristige Erhöhung des Anteils der Käufer wird die Weckung eines Kaufimpulses und seine umgehende Befriedigung angesehen. Die Studie kommt zu dem Ergebnis, daß jeder Konsument, der nicht innerhalb einer kurzen Zeitspanne (ca. 10 Minuten) das gewünschte Tonträgerprodukt findet, vom Kauf absieht. ${ }^{175}$ Die Konsequenzen aus dieser Marktbeobachtung werden bei der Analyse des Marktverhaltens zu untersuchen sein.

\subsubsection{Zusammenfassung wichtiger Strukturmerkmale}

Der deutsche Tonträgermarkt ist - wie weltweit alle wichtigen Tonträgermärkte - von zwei Anbietergruppen geprägt. Zwischen der Oligopolgruppe der Majors und der Randgruppe der Independents bestehen signifikante Mobilitätsbarrieren im Zugang zu international vermarktbaren Musikern und den Absatzkanälen, die für eine hohe Diffusionsgeschwindigkeit angesichts des kurzen Produktlebenszyklus von Tonträgern nötig sind. Hinzu kommen Produktdifferenzierungsvorteile durch die Möglichkeit des Risikoausgleichs und des stetigen Verkaufs in diesem - durch schnelle Präferenzänderungen und neue Segmentierungen gekennzeichneten Markt. Auf der Handelsstufe steht der zunehmenden Konzentration der Umsätze auf wenige Outlets eine Abnahme der absoluten Zahl von Geschäften gegenüber. Grundlegend für den Tonträgerkonsum ist der Bekanntheitsgrad der enthaltenen Musik, weswegen zum Hörfunk ein wechselseitiges Abhängigkeitsverhältnis besteht. In der Bevölkerung nehmen die Nachfragegruppen mit überproportionalen Tonträgerkäufen ab und mit unterproportionalen Tonträgerkäufen zu, während die Käuferreichweiten im betrachteten Zeitraum annähernd konstant blieben.

\subsection{Das Marktverhalten im Tonträgermarkt}

Das Marktverhalten der Marktakteure (Musikschaffende, Tonträgerhersteller, Handel und Nachfrager) kann anhand von Verhaltensparametern untersucht werden. Solche Verhaltensparameter sind in der ersten Marktstufe die Vertragsbeziehungen (4.3.1) zwischen Musikschaffenden und Tonträgerherstellern. Seitens der Tonträgerhersteller (4.3.2) werden sowohl die

\footnotetext{
${ }^{173}$ Vgl. Mahlmann 1997, S. 178.

174 Vgl. Motivation von Nichtkäufern im Tonträgermarkt, Studie durchgeführt von IPS und GrK. Kiel 1996 Diese Studie rechnet mit einem zusătzlichen Potential noch motivierbarer Nichtkäufer von 5,7 bis zu 8,3 Millionen Personen. Sie sieht aber ebenso die Gefahr des Verlustes von ca. 5 Millionen Kăufern. wenn das alterspezifische Kaufverhalten im Tonträgermarkt unverändert bleibt.

175 So auch Schulze. Ralf, op. cit. S. 186
} 
Vertragsbezjehungen zwischen Majors und Independents als auch deren jeweilige Preis- und Produktpolitik thematisiert. Weiterhin wird als Verhaltensparameter das Setzen strategischer Marktbarrieren behandelt. In der zweiten Marktstufe (4.3.3) wird die Verhandlungsmacht des Handels gegenüber den vorgelagerten Tonträgerherstellern, die Betriebsgröße und ihre Wirkung auf die Nachfrage, die Sortimentspolitik sowie die Preispolitik gegenüber der Nachfrage analysiert. In der dritten Marktstufe werden beim Verhalten der Nachfrager (4.3.4) die Kaufintensitäten und das Kaufverhalten im Hinblick auf Nachfrageelastizitäten untersucht, bevor schließlich die Konsequenzen für die zukünttige Konsumentenstruktur gezogen werden.

Die Vertragsbeziehungen im Tonträgermarkt sind geprägt durch die Tatsache, daß die verschiedenen überblicksartig dargestellten Marktstufen (vgl. Abbildung 16) miteinander kontrahieren müssen und daß unterschiedliche Integrationsgrade in den Marktstufen, d. h. zwischen Musikschaffenden, Musikproduzenten und Musikvertreibenden existieren. Daraus ergeben sich folgende unterschiedliche Vertragstypen: Künstlerexklusiv- und Bandübernahmeverträge, Lizenzverträge, Sales-and Distribution-Verträge und Sampling- und Remixverträge. Von diesen Vertragstypen regeln die Künstler- und die Bandübernahmeverträge die Beziehung zwischen den Musikschaffenden und den Tonträgerherstellern, während die übrigen Vertragstypen die Interaktion zwischen den Herstellern selbst regeln.

\subsubsection{Vertragsbeziehungen zwischen Musikschaffenden und Tonträgerherstellern}

Die Vertragsbeziehung zwischen Musikschaffenden und Tonträgerherstellern lassen sich sowohl ihrer juristischen Form als auch ihrer ökonomischen Konsequenz nach typisieren in Künstler- und Bandübernahmeverträge.

In Künstlerverträgen ${ }^{176}$ binden sich die betreffenden Musiker exklusiv über eine gewisse Zeitspanne an die wirtschaftlichen Produzenten, in diesem Fall die Tonträgerhersteller. Das Absatzrisiko liegt bei dieser Art von Verträgen ausschließlich beim Hersteller, der dafür dem Musiker eine geringere Entlohnung pro verkauftem Tonträger zugesteht als beim Bandübernahmevertrag. Im Hinblick auf die Exklusivbindung des Künstlers an den jeweiligen Tonträgerhersteller existieren prinzipiell drei mögliche Formen. Entweder räumt der Musiker dem Hersteller eine Exklusivität an den vertraglich vereinbarten Aufnahmen für den Verwertungszeitraum ein, oder es wird Titelexklusivität vereinbart, d. h., daß der Musiker nach Vertragsablauf dieselben Titel für eine gewisse Zeitspanne (meistens 5 Jahre) nicht nochmals für Dritte aufnehmen darf. Die dritte Form der Exklusivität besteht in einer persönlichen Exklusivbindung. Diese stärkste Form der Bindung bedeutet, daß der gebundene Musiker generell keine Aufnahmen mit Dritten einspielt und bestehende Aufnahmen nicht Dritten zur Verwertung überläßt. Bei Künstlerexklusivverträgen werden die Vervielfältigungs- und Verbreitungrechte entsprechend der zeitlichen Dauer dieser Rechte, das sind 50 Jahre, vom Musiker auf die Tonträgerhersteller übertragen. Die Vertragsdauer variiert je nach der Marktstellung des bzw. der

${ }^{176} \mathrm{Vgl}$. Gilbert, Rolf, und Andreas Scheuermann, Künstler-, Produzenten-, Bandübernahmevertrăge, in: Handbuch der Musikwirtschaf, hrsg. von Moser, Rolf, und Andreas Scheuermann, 4. Aufl., Starnberg 1997, S. 1018-1039. 
Musiker. Etablierte Musiker verhandeln Vertragsspannen von drei bis fünf Jahren, während Newcomer selten über ein Jahr gebunden werden, da der Hersteller das Risiko eines längeren Engagements scheut, sich aber für den Fall des Erfolgs der Newcomer ein einseitiges Optionsrecht vorbehält. Künstlerexklusivverträge beziehen sich im Regelfall auf weltweite Vertriebsrechte.

Im Gegensatz dazu stehen Bandübernahmeverträge, ${ }^{177}$ bei denen alle Kosten und Risiken der Erstellung des Mastertapes der Musiker trägt. Der Musiker selbst ist damit der wirtschaftliche Produzent, weswegen der Tonträgerhersteller eine höhere Vergütung pro verkauftem Tonträger zahlt. Hinsichtlich der Dauer der Vervielfalltigungs- und Verbreitungsrechte, die der Musiker dem Tonträgerhersteller einräumt, sind alle denkbaren Varianten möglich: unbefristete Übertragung, mit Vertragsschluß endende Übertragung und Rechte, die eine bestimmte Zeitspanne über das Vertragsende hinaus gelten. Ebenso ist das Vertragsgebiet Verhandlungsfrage. Hier sind je nach Marktstellung sowohl weltweite als auch territorial eingeschränkte Vertriebsrechte möglich. ${ }^{178}$ Die Vertragsdauer wird für Bandübernahmeverträge analog zu den Künstlerexklusivverträgen geregelt.

Bandübernahme- und Künstlerexklusivverträge regeln die Austauschverhältnisse in der ersten Marktstufe. Die vertragliche Bindung von Musikern ist ökonomisch ein Handel mit Erwartungen. Aus der Sicht der Anbieter gilt, daß etablierte Musiker eher Bandübernahmeverträge bevorzugen, während Newcomer bereit sind, Künstlerexklusivverträge einzugehen. Aus der Sicht der nachfragenden Hersteller gilt, daß für sie Newcomer Investitionen in zukünftige erwartete Erfolge bedeuten, während etablierte Musiker zur Sortimentsabrundung ${ }^{179}$ oder aus Prestigegründen (z. B. nicht-monetärer Nutzen der Entscheidungsträger) verpflichtet werden und, um Wettbewerbern Marktanteile abzunehmen.

Wie aus der Darstellung der Vertragstypen ersichtlich, ist das Marktverhalten bei der Musikbeschaffung in starkem Maße von der Verhandlungsmacht geprägt. Musiker, Komponisten und Textdichter bilden den sog. kreativen Teil innerhalb der Wertschöpfungskette der körperlichen Verwertung von Musik. Die nachfragerelevanten Präferenzen der Konsumenten beziehen sich aber nicht auf den Komponisten, Textdichter oder Musikverleger, sondern regelmäßig auf den Interpreten, unabhängig davon, welchen Anteil er an dem kreativen Produktionsproze $B$ hat. Daher ist die Verhandlungsmacht des Interpreten groß, wenn seine Etablierung im Markt gelungen ist, d. h., daß er den Status eines Markenartikels bekommen hat. Sein Inputfaktor ist aus der Sicht der Marktgegenseite knapp und seine Substituierbarkeit ist beschränkt. Die Ver-

177 Vgl. Gilbert, Rolf, und Andreas Scheuermann, op. cit., S. $1018 \mathrm{fr}$.

${ }^{178}$ Der europäische Binnenmarkt gilt als einheitliches Vertragsgebiet, in dem der freie Verkehr von Waren, Personen, Dienstleistungen und Kapital gewährleistet ist. Vgl. Art. 7a des Maastrichter Vertrages und Emmerich, Volker, Kartellrecht, 7. Aufl., München 1994, S. 500 fr.

179 Das Kontrahierungsargument besagt, daß die Tonträgerhersteller mehrere etablierte Musiker eines Repertoiresegmentes nebeneinander verpflichten. Beispielhaft deutlich wurde dies beim Kontrahierungsverhalten verschiedener Tonträgerhersteller, welches im Rahmen der Fusion von EMI und Intercord vom BKartA untersucht wurde. Dies ist ebenso für die Musiker selbst von Vorteil, da sie neben der fachkundigen Betreuung auch das Know-how für Vertriebs- und Marketingtätigkeit in ihrer Musikrichtung beim jeweiligen Hersteller vorfinden. 
wendung seiner idiosynkratischen ${ }^{180}$ Fähigkeiten für die Aufnahme von Tonträgern lost die Nachfrage aus. ${ }^{181}$ Seine Fähigkeiten als Produktionsfaktor sind nicht beliebig vermehrbar. Aus der Sicht der nachfragenden Tonträgerhersteller ist die Verhandlungsstärke der etablierten Musiker nur begrenzt durch die Gesamtrentabilität der Musikaufnahme bzw. die Einschätzung der zukünftigen Leistungsfähigkeit bei projekt- oder zeitgebundenen Verträgen. ${ }^{182}$ Die Frage, welchen Teil der Erträge sich der Musiker aneignen kann, hängt ex ante von der Informationsverteilung beider Verhandlungsseiten ab. Diese wird sich aufgrund von Erfahrungswissen auf beiden Seiten bilden, so daß davon ausgegangen werden kann, daß etablierte Musiker (bzw. ihre Manager) genaue Vorstellungen über Rentabilitätsgrenzen von Tonträgerherstellern haben, und die Tonträgerhersteller errechnen können, welche Verhandlungssumme über welchen Zeitraum amortisierbar ist.

Demgegenüber ist die standardisierte Dienstleistung von Tontechnikern keine Quelle von Verhandlungsmacht. Auch die Leistung der Komponisten und Textdichter begründet nur geringe Verhandlungsmacht, weswegen sie sich i. d. R. mit pauschalen Abfindungssummen ohne Anspruch auf Urheberrechte begnügen müssen, weil sie wissen, daß die Rentabilität ihres Produktes von der Etablierung des Musikers abhängt.

\subsubsection{Das Verhalten der Tonträgerhersteller}

Verhaltensparameter zwischen den Tonträgerherstellern sind deren Vertragsbeziehungen. Gegenüber den anderen Marktstufen sind Parameter die Produkt- und Preispolitik sowie strategische Verhaltensweisen.

\subsubsection{Vertragsbeziehungen zwischen Majors und Independents}

Die im folgenden zu betrachtenden Verträge regeln Austauschbeziehungen zwischen verschiedenen Unternehmensformen der Tonträgerherstellung, den Majors und den Independents. Ist ein Tonträgerunternehmen Rechtsinhaber einer Musikproduktion und will es diese nicht (z. B. in einem bestimmten geographischen Raum) oder nicht mehr (im Fall von Zweit- oder Drittverwertungen) selbst auswerten, kann es Lizenzen vergeben. Lizenzverträge ${ }^{183}$ werden im Tonträgermarkt produktionsbezogen abgeschlossen. Ihre Laufzeit kann sich sowohl auf eine bestimmte Zeitspanne beziehen als auch auf ein bestimmtes Produktionsvolumen. In beiden Fällen (nur Zeitbezug und nur Produktionsbezug) überwiegen die Nachteile, weswegen als Mischform die Produktion bis zu einem bestimmten Zeitpunkt festgeschrieben wird. Gleichzeitig wird die Veröffentlichungspflicht der Tonträgerhersteller in allen drei Vertragsformen geregelt.

${ }^{180}$ Der Begriff idiosynkratisch beschreibt die individuelle Besonderheit von (Produktions-)Faktoren. Idiosynkratische Faktoren sind solche mit hoher Faktorspezifită, z. B. Humankapitalspezifität.

181 Dabei bezieht sich die Spezifität des Faktors nicht auf die Stimme oder die Interpretation allein, sondern auf den Wiedererkennungseffekt der speziellen Musik, die sich damit einen Präferenzraum geschaffen hat.

182 Für Tonträgerhersteller ergibt sich dann nur die Option, das Angebot so zu gestalten, daß der Musiker annimmt, oder keinen Vertrag abzuschließen.

$183 \mathrm{Vgl}$. Schulze, Ralf, op. cit., S. 125 und $132 \mathrm{f}$. 
Sales- und Distributionverträge ${ }^{184}$ regeln die physische Herstellung, den Vertrieb und/oder die Warenverteilung von Tonträgern. Als Vertragspartner stehen sich der Produzent, der das Master-Band gefertigt hat, aber weitere Unternehmensfunktionen nicht selbst durchfüren will, und der Major bzw. die unabhängige Vertriebsfirma gegenüber, die über Herstellungs- und Vertriebskapazität verfügt und diese mit Fremdrepertoire ausfüllen möchte. Bei dieser Vertragsform erhält der Produzent die Verkaufserlöse abzüglich der Vetriebskommission, der variablen Herstellkosten und der Urheberrechtslizenzen. Der Restbetrag ist i. d. R. höher als bei einem Bandübernahmevertrag. Dafür muß der Produzent die Werbung für seine Produkte auf eigene Rechnung durchführen bzw. durchführen lassen. Für Sales- und Distributionverträge existieren mehrere mögliche Formen:

a) Der Produzent sucht vertraglich einen Herstellungs-, Vertriebs- und Auslieferungspartner.

b) Der Produzent verfuggt über einen eigenen Vertrieb und sucht vertraglich einen Herstellungsund Auslieferungspartner.

c) Der Produzent trennt den Herstellungspartner vom Vertriebspartner und schließt einen reinen Herstellungsvertrag und einen reinen Vertriebsvertrag ab.

In allen Fällen verbleibt das Marktrisiko beim Produzenten. In der Praxis tritt der Fall am häufigsten auf, bei dem der Produzent einen Vertragspartner für die reine Vertriebsarbeit sucht. ${ }^{185}$ Vertragsgegenstand ist die Eigenproduktion des Produzenten oder das von dem Produzenten durch Lizenz erworbene Fremdrepertoire. Der Produzent leitet die Vertriebsrechte an den Vertriebspartner weiter. Dieser ist dann zuständig für:

- Lagerhaltung der Tonträger (inkl. Lagerrisiko),

- Auftragsakquisition,

- Auftragsabwicklung und

- Retourenbehandlung.

Die Vertriebsrechte werden i. d. R. exklusiv vergeben. Ausnahmen bestehen, wenn besondere Absatzwege gewählt werden, wenn die Vertriebsfirma ein Ablehnungsrecht hat oder wenn sie erfolglos ist und der Produzent trotzdem nicht den ganzen Vertrag kündigen möchte. Bei einem reinen Vertriebsvertrag muß der Produzent für die rechtzeitige Anlieferung der Tonträger sorgen. Er trägt dann auch das Risiko des Transports und bleibt Eigentümer der Ware, bis der Handel nach Auslieferung bezahlt hat und das Eigentum an ihn übergeht. Die Disposition (Bestückung des Warenlagers) im Hinblick auf Erstbestückung und Nachbestellungen übernehmen im Regelfall Produzent und Vertriebsfirma in Absprache. Den Veröffentlichungszeitpunkt bestimmt im Regelfall der Produzent, da er für das Marketing zuständig ist. Die Wahl des Veröffentlichungszeitpunktes ist nicht unerheblich, da erstens die absoluten Verkaufszahlen für Charterfolge saisonal unterschiedlich sind, zweitens bestehende Charterfolge desselben

\footnotetext{
184 Vgl. Kornmeier, Udo, „Sales- and Distribution“-Vertuäge, in: Handbuch der Musikwirtschaft. hrsg. von Moser, Rolf, und Andreas Scheuermann, 4. Aufl., Starnberg 1997, S. 1107-1125

$185 \mathrm{Vgl}$. Kornmcier, Udo, op. cit., S. 1109.
} 
Produzenten nicht gefährdet werden sollen ${ }^{186}$ und drittens die Veröffentlichung von Tonträgern mit dem Angebot anderer Produkte (Konzerte etc.) gleichzeitig zu erfolgen hat. Hinsichtlich der Vertragsdauer unterscheidet der Produzent zwischen neuen Vertragspartnern und für ihn bekannten Geschäftspartnern. Um das Risiko zu minimieren, wird die Laufzeit für neue Vertragsbeziehungen auf ein Jahr begrenzt und die Verlängerung mit Hilfe eines Optionsrechtes im Erfolgsfall ${ }^{187}$ wahrgenommen. Ebenso wird ein beiderseitiges Kündigungsrecht im Mißerfolgsfall in den Sales- und Distributionsvertrag eingefuigt. ${ }^{188}$

Sampling- und Remixverträge ${ }^{189}$ regeln den Zugriff Dritter auf bestehende Musikproduktionen. Beide Vorgänge stellen zeitlich nachgelagerte Verwertungen von Originaltonträgern dar, die allerdings nicht auf den Tonträgerverkauf beschränkt sein müssen, worauf wir uns aber im folgenden konzentrieren wollen. Unter Sampling wird verstanden, daß mittels eines mit digitalen Speichermedien (z. B. Festplatte) ausgestatteten Aufnahmecomputers (des sog. Sampler) beliebige akustische Signale digital aufgenommen und gespeichert werden. Diese können auf vielfältige Weise bearbeitet werden und in bestehende Musikaufnahmen integriert oder an sie angepaßt werden. Die Teile der Tonaufnahme können mehr oder minder groß sein bis hin zu Zusammenstellungen neuer Tonträger aus bereits bestehenden. Daran anknüpfend bestehen die Fragen der Verletzung der Rechte Dritter. Mögliche Rechtsverletzungen können die Rechte des Komponisten, Textdichters, ausübenden Künstlers und des Tonträgerherstellers sein. ${ }^{190}$ Daher müssen die betreffenden Rechte von dem Tonträgerhersteller eingeholt werden, der das Sample in Auftrag gibt oder es selbst durchfürt. Die Rechtsübertragung durch den Rechtsinhaber der Originalaufnahme geschieht ausschließlich auf nicht-exklusiver Basis. ${ }^{191}$

Der ökonomische Sinn eines Samples besteht vor allem darin, einen Produkttransfer von einem erfolgreichen Produkt auf das neue, gesampelte Produkt zu erreichen. Daher wird vor allem der Teil gesampelt, der den Konsumenten in Erinnerung bleibt (sog. Hook einer jeden Produktion). Werden entsprechende Beteiligungen am Umsatz verhandelt, dann wird der Lizenzgeber (Originalinhaber) für eine gewisse Zeit (abgestimmt auf die wahrscheinliche Lebensdauer entsprechend dem Produktlebenszyklus) keinem Dritten Rechte an derselben Produktion einräumen, sondern für diese Zeit eine Titelexklusivität gewähren. In der Praxis wird die Höhe der

${ }^{186}$ Die nicht belegbare Behauptung, daß Tontrăgerproduzenten Veröffentlichungen zurückhalten, wenn sich andere Titel ihres Katalogs auf vorderen Chartplătzen befinden, würde eine rationale Unternehmensstrategie darstellen.

187 Der Erfolg wird gemessen mit Hilfe von sog. Erfolgsparametern, z. B. verkaufle Stückzahlen innerhalb einer Zeitperiode.

188 Vertriebsfirmen garantieren i. d. R. Mindestverkaufszahlen und Produzenten garantieren, dab sie sămtliche Vervielfaltigungs- und Vertriebsrechte an der Musikproduktion besitzen und die Urheberrechtsgebühren an die Verwertungsgesellschaft abgeführt haben.

189 Vgl. Zimmermann, Joern H., Sampling- und Remixverträge, in: Handbuch der Musikwirtschaft, hrsg. von Moser, Rolf, und Andreas Scheuermann, 4. Aufl., Starnberg 1997, S. 1085-1106.

190 Jedes Sample stellt im urheberrechtlichen Sinn eine Bearbeitung des geschützten Werkes dar, die vom Originalurheber gem. $\S \S 3,23$ UrhG dem neuen (samplenden) Urheber erlaubt werden muß. Gleichzeitig muß der alte Tonträgerhersteller den neuen gem. $\S 85$ UrhG ein Vervielfältigungs- und Verbreitungsrecht in Form eines Samplingvertrages (generell zeitlich befristet und nicht exklusiv) einräumen, damit überhaupt gesamplet werden darf.

191 Das bedeutet, dab bei Rechtsübertragung die Lizenz endet, wenn der Lizenzgeber nur seinerseits Lizenznehmer ist, und der Original-Inhaber die Rechte nur zeitlich befristet hat. 
Vergütung von der Wichtigkeit des Samples für die neue Produktion, dem zeitlichen Umfang des Samples und dem Umfang der Sample-Rechte abhängig gemacht. Wird eine Umsatzbeteiligung ausgemacht, variiert diese zwischen 1 und 3\% des Händlerabgabepreises (HAP, englisch PPD). Die Vertragsgestaltung lehnt sich an diejenige des Bandübernahmevertrages an.

Remixverträge regeln die neue Abmischung vom Master-Band durch bisher Unbeteiligte. Die sog. Remixer erwerben eigene Rechte an den von ihnen geschaffenen Remixproduktionen. Der Remixer erwirbt wie ein ausübender Künstler Leistungsschutzrechte. ${ }^{192}$ Während der Remixer die einzelnen Teile der bestehenden Musikproduktion verändert, werden sie beim Sample übernommen und im wesentlichen nur neu zusammengesetzt. Gleichwohl wird bei Remixen ebenfalls auch die Sample-Technik angewandt. Die Interessenlage ist beim Remix anders als beim Sample. Der Auftraggeber des Remix ist Inhaber an den im Remix verbleibenden Teilen der Originalaufnahme und muß sicherstellen, $d a ß$ die Rechte an den anderen Teilen des Remix erworben wurden. Der Remixvertrag ähnelt mehr einem (Auftrags-)Produzentenvertrag. Der Auftraggeber findet den Remixer mit einer Pauschalsumme ab, wofür letzterer alle Rechte an dem Remix exklusiv an den Auftraggeber überträgt. ${ }^{193} \mathrm{Im}$ urheberrechtlichen Sinn stellt ein Remix eine Bearbeitung eines geschützten Musikwerkes dar ( $\S 3,23$ UrhG). Als Konsequenz daraus entstehen dem Remixer Vergütungsansprüche in ihrer Eigenschaft als Urheber. Dieses Rechtsproblem wird in der Praxis bisher vernachlässigt und mangels Rechtsdurchsetzung durch die vertragsabhängigen Remixer auch nicht ökonomisch in Form anderer Preise oder Vertragsgestaltung (z. B. mit entsprechender Regelung der Vergütungsansprüche) umgesetzt.

Die Vertragstypologie zeigt, daß die Tonträgerhersteller im Hinblick auf ihre Unternehmensfunktionen sehr ausdifferenziert sind und viele Unternehmensfunktionen als Dienstleistung anderen Tonträgerherstellern angeboten werden. Neben der aufgeführten Typizität lassen sich die Verlagerungen des Risikos als Kriterium für die Verteilungen von Unternehmensfunktionen auf verschiedene Unternehmen anführen. Hier gilt, daß mit der Zunahme der Unternehmensfunktionen, die ein und dasselbe Unternehmen ausführt, diesem auch das Ertragsrisiko zuwächst. Wettbewerblich problematisch zu sehen ist dabei, daß die Majors Dienstleistungen für die Independents erbringen, die sie selbst für ihre Produkte auch erbringen. Ein diskriminierungsfreies Verhalten ist im Hinblick auf die Konkurrenzsituation unwahrscheinlich. Daneben entstehen aus den Dienstleistungen Marktinformationen, die die Major-Tonträgerhersteller in eine Konzentrationsstrategie umsetzen können. Die Kosten der Markterprobung neuer Musiker durch Independents sparen sich die Majors, wenn sie sie erst nach eingetretenem Erfolg aufkaufen. Aufkäufe von Independents durch die Majors könnten dann damit erklärt werden, daß die Entwicklung neuer Musiker in bestimmten Repertoiresegmenten von Independents zu geringe-

192 In der Praxis handelt es sich bei Remixen oft um Neuproduktionen, bei denen Keyboards, Soundeffekte. Rhythmusspuren oder ganze Samples neu eingespielt werden.

193 Bei Originalvorlagen müssen die Rechte beim Auftraggeber liegen, daher ist die Rechtsübertragung kein Problem. Bringt der Remixer eigenes Material ein, gehen die Rechte i. d. R. auf den Auftraggeber über. 
ren Kosten durchgefürt werden als von Majors. Das vertraglich komplementäre Verhältnis existiert daher nur vor dem Hintergrund der weiterhin bestehenden Konkurrenzsituation. ${ }^{194}$

\subsubsection{Produktpolitik der Tonträgerhersteller}

Am Ende des Musikproduktionsprozesses steht das Produkt Tonträger, dessen Inhalt die Musik ist. Der Konsument fragt die Musik nach bzw. ein ganzes Musikprogramm. ${ }^{195}$ Die Tonträger sind daher nur physische Transportmittel ${ }^{196}$ und konkurrieren mit anderen Transportwegen, z. B. Radio und Fernsehen. Diese anderen Transportwege unterliegen den besonderen ökonomischen Bedingungen der Nicht-Rivalität im Konsum. Konsequenz daraus ist, daß die Tonträgerhersteller über $90 \%$ ihres Umsatzes mit der Verbreitung der physischen Träger erzielen, ${ }^{197}$ die Veröffentlichung von Tonträgern daher für sie zentral ist, und demgegenüber die Einnahmen aus den anderen Verbreitungswegen der Musik gering sind. ${ }^{198}$ In diesem Abschnitt werden zunächst die Inhalte der Produktpolitik und ihre Bedeutung für den Wettbewerb dargelegt, danach werden die Produkt- und Prozeßinnovationen im Tonträgermarkt behandelt, bevor in den Unterabschnitten die unternehmensgruppenspezifischen Produktpolitiken betrachtet werden.

Der Inhalt der einzelwirtschaftlichen Produktpolitik besteht darin, Musiktitel auf Tonträgern zu veröffentlichen. ${ }^{199}$ Dabei stellt jeder neuveröffentlichte Tonträger eine Produktinnovation dar. Konsumenten lassen sich im Hinblick auf ihr Nachfrageverhalten gegenüber Produktinnovationen in Adopterkategorien einteilen, mit denen der Diffusionsprozeß im Zeitablauf untersucht werden kann. ${ }^{200}$ Neuveröffentlichungen von Musiktiteln ${ }^{201}$ sind nicht zwangsläufig echte Produktinnovationen ${ }^{202}$ i. S. originärer Musik, die es vorher nicht gab. Daneben treten als QuasiInnovationen Musiktitel, die an bestehende Musik anknüpfen. Hierzu gehören alle (durch Sample und Remix) veränderten Versionen, die als Produkttransfer vom Erfolg der früheren Veröffentlichungen profitieren sollen. Zusätzlich werden als Zweit- und Drittverwertung i. S. einer Pseudo-Innovation Neuzusammenstellungen bereits erschienener Musiktitel veröffentlicht. ${ }^{203}$ Das Produktprogramm eines Tonträgerherstellers nennt man Katalog, bereits verwertete Musiktitel werden dem Back-Katalog zugeordnet. Die Produktpolitik der Tonträgerherstel-

${ }^{194}$ Für die Majors handelt es sich um ein make or buy-Kalkül, wie es in der von Williamson weiterentwickelten Transaktionskostentheorie beschrieben wird. Vgl. Williamson, Oliver E., Markets and Hierarchies: Analysis and Antitrust Implications, New York 1983 (Reprint), S. 82-131.

$195 \mathrm{Vgl}$. Sikorski, Axel, Musikwirtschaft und neue Musik, Frankfurt u. a. 1997, S. 111.

$196 \mathrm{Vgl}$. Zombik, Peter, Einführung in den Tonträgermarkt, in: Zentrum für Kulturforschung (Hrsg.): Kulturstatistik in den 90er Jahren, Berichte zur Kulturstatistik III, Bonn 1991, S. 65-75, hier S. 65 [Zombik 1991].

197 Vgl. Thurow, Norbert, und Peter Zombik, op. cit., S. 197 f.

${ }^{198}$ Einnahmen aus anderen Verbreitungswegen sind beispielsweise GEMA- und GVL-Gebühren.

$199 \mathrm{Vgl}$. Belinfante, Alexander, und Richard L. Johnson, Competition. Pricing and Concentration in the U.S. Recorded Music Industry, in: Journal of Cultural Economics, Vol. 6 (1982), S. 11-24 [Belinfante/Johnson].

$200 \mathrm{Vgl}$. Rogers, Evereth, op. cit., S. 257. Adopterkategorien beschreiben das Nachfrageverhalten gegenüber Produktinnovationen im Zeitablauf. Vgl. Abschnitt 4.3.4.

${ }^{201}$ Der größte Teil (ca. 65 bis $80 \%$ ) des Umsatzes im Tonträgermarkt entfällt auf Neuerscheinungen. Vgl. Thurow, Norbert, und Peter Zombik, op. cit., S. 202.

${ }^{202} \mathrm{Vgl}$. Becker, Jochen, Marketing-Konzeption, 5. Auf., München 1993, S. 130.

${ }^{203} \mathrm{Vgl}$. Hörschgen, Hans, Jürgen Kirsch, Günter Käßer-Pawelka und Jürgen Krenz, Marketing-Strategien: Konzepte zur Strategienbildung im Marketing, 2. Auf., Ludwigsburg, Berlin 1993, S. 124 f. 
steller zeigt sich auch in Streichungen aus dem Katalog der verschiedenen Musikrepertoiresegmente.

Der Wettbewerb auf der Stufe der Tonträgerhersteller findet vor allem durch Produktpolitik statt. ${ }^{204}$ Das bedingt sowohl, daß die Tonträgerhersteller im Wettbewerb um Vertragsabschlüsse etablierter Musiker und um die Rechte zur Verwertung von deren Backkatalog stehen, ${ }^{205}$ als auch, daß sie darin konkurrieren, neue Musiker zu entdecken und zu entwickeln. Ein wesentlicher Charakter der Produktpolitik im Tonträgermarkt ist derjenige des Innovationswettbewerbs mit Hilfe von Neuerscheinungen. Dies resultiert aus der Tatsache, daß der Wert von Musik auf Tonträgern durch einen schnellen ökonomischen Verfall gekennzeichnet ist. ${ }^{206}$ Dabei differeriert die ökonomische von der technischen Lebensdauer. ${ }^{207}$

Produktpolitik mit unterschiedlichen Tonträgerkategorien betriff Single- und LongplayTonträger. Aus Sicht der Tonträgerhersteller läßt sich argumentieren, daß sich durch die Veröffentlichung eines Single-Tonträgers zu geringeren Kosten Informationen über die Nachfrage der Konsumenten erhalten lassen als bei Veröffentlichung eines Albums. ${ }^{208}$ Ein zweites Argument für Singleveröffentlichungen sind Werbungsexternalitäten. ${ }^{209}$ Diese existieren, wenn ein einmal erzielter Bekanntheitsgrad für die Titel einer Single - durch Radio oder andere Medien auf eine spätere Longplay-Veröffentlichung desselben Musikers übertragen werden kann, so $\mathrm{da} ß$ der verkaufsfördernde Effekt bestehen bleibt. ${ }^{210}$ Während das Argument geringerer Informationskosten einen gewissen time-lag zwischen Veröffentlichung der Single und des Albums voraussetzt, bedingt das Argument der Werbungsexternalitäten eine möglichst zeitnahe Umsetzung eines Verkaufserfolgs einer Single in einen Longplay-Tonträger. ${ }^{211}$ Um die Gültigkeit der einen oder der anderen Hypothese überprüfen zu können, wurde für den britischen Markt von 1983-90 die Beziehung zwischen erfolgreicher Produktinnovation auf dem Single Markt und erfolgreicher Platzierung auf dem Alben (=Longplay) Markt (jeweils gemessen in ChartPlatzierungen) desselben Musikers untersucht, wobei in den Alben dieselben Musiktitel wie in

${ }^{204}$ Belinfante/Johnson, supra, S. 12, die von einer Marktanteilsmaximierung der Tonträgerhersteller durch Neurveroffentlichungen ausgehen.

${ }^{205}$ Vgl. Shemel, Sydney und M. William Krasilovsky, This Business of Music, 6th ed., New York 1990, S. 8 f., die auf den ex post-Wettbewerb um den Katalog etablierter Musiker zur Zweitverwertung hinweisen. Daher sehen Wettbewerbsverbotsklauseln in den Verträgen mit den Musikern vor, daß deren Musiktitel nach dem Wechsel zu einem anderen Tonträgerhersteller 5 Jahre lang nicht von den neuen Vertragspartnern verwertet werden dürfen.

$206 \mathrm{Vgl}$. Burke 1996b, supra, S. 145-164.

${ }^{207}$ Die technische Lebensdauer der verschiedenen digitalen Tonträgerkategorien ist unbegrenzt und wird lediglich verkürat durch Abnutzung, Beschädigung oder dergleichen.

208 Vgl. Burke, Andrew E., An Economic Analysis of Enterprise in the Music Industry, Oxford 1994, S. 139 [Burke 1994b].

209 Bei Werbungsexternalităten können mit Hilfe des Dorfman-Steiner-Theorems hohe Ausgaben für Produktdifferenzierung und Werbung erklärt werden. Vgl. Dorfman, R., und P. O. Steiner, Optimal Advertising and Optimal Quality, in: American Economic Review, Vol. 44 (1954), S. 826-836.

${ }^{210} \mathrm{Vgl}$. Leadbeater, T., The Music Market, London 1994, S. 39.

211 Vgl. Burke 1996b, supra. S. 151 
den Singles enthalten waren. ${ }^{212}$ Zur Messung der zeitlichen Dynamik der Beziehung wurden Kreuz-Korrelationen gebildet, die sich vom Zeitpunkt der Singleveröffentlichung auf vor- und nachfolgende Jahre des Alben-Marktes erstreckten. ${ }^{213}$ Hieraus ergab sich, daß der ökonomische Produktlebenszyklus eines Albums höchstens zwei Jahre lang ist. ${ }^{214}$ Wurde umgekehrt untersucht, welche Zahl an Titeln sich in den vierteljährlichen Singlecharts befand, die gleichzeitig oder nur einige Quartale später in die Alben-Charts gelangten, wurde erstens deutlich, $\mathrm{da}$ der ökonomische Produktlebenszyklus von Singles kürzer als drei Quartale ist, ${ }^{215}$ und zweitens, daß die betrachteten Titel hauptsächlich in demselben Quartal beide Charts erreichten. Aus der starken positiven Korrelation zwischen dem Erfolg von Neuveröffentlichungen auf Singles und auf Alben ergibt sich, daß die Singleveröffentlichung in erster Linie Werbungseffekte für den Albenverkauf hat und die Informationskosteneinsparung ein Nebeneffekt ist, wenngleich keine deterministische, sondern eine stochastische Beziehung zwischen dem Erfolg in den Single-Charts und demjenigen in den Alben Charts nachzuweisen ist. ${ }^{216}$ Werbungsexternalitäten erklären damit die Strategie der Tonträgerhersteller, Single und Alben zeitgleich bzw. zeitnah zu veröffentlichen.

Produktpolitik mit unterschiedlichem Repertoire betrifft vor allem die Einteilung in Unterhaltungs- und klassische Musik. Die Kataloge der Anbieter sind in der Unterhaltungsmusik durch die Exklusivbindung der Musiker unterscheidbar. Daraus resultieren Präferenzbindungen der Konsumenten, die die Güter heterogenisieren und zu einer indirekten Konkurrenzbeziehung zwischen den Tonträgerherstellern um das Tonträgerbudget führen. Im Bereich der klassischen Musik sind die wichtigsten Titel (wegen der fehlenden Exklusivbindung $\mathbf{z}$. $\mathbf{T}$. auch mit denselben Musikern) in den Katalogen aller Hersteller vorhanden. Die Tonträger sind damit homogener und die Konkurrenzbeziehungen zwischen den Anbietern direkter. ${ }^{217}$

Neben den Produktinnovationen sollen auch die Prozeßinnovationen im Tonträgermarkt betrachtet werden. Das Verhalten der Tonträgerhersteller und der ihnen vorgelagerten Abspielgerätehersteller (Hardwarehersteller) unterliegt im Innovations-Diffusionsproze B dem Hardware/Software-Problem als einer Form indirekter Netzeffekte. ${ }^{218}$ Wollen die Hardwarehersteller neue Abspielgeräte in den Markt einführen, müssen sie im Verbund mit den Tonträgerher-

212 Die Methodik zur Analyse der Wirkung von Produktinnovation und -differenzienung auf die Nachfrage wird erläutert in: Burke, Andrew E., The Demand for Vinyl L.P.s 1975-1988, in: Journal of Cultural Economics, Vol 18 (1994), S. 41-64. [Burke 1994a]

$213 \mathrm{Vgl}$. Burke 1996b, supra, S. 147. Von den in den Single-Charts vertretenen Titel befanden sich zwischen 29 und 55 Prozent auch in den Alben-Charts desselben Jahres und ein signifikanter Teil in den Alben-Charts des folgenden Jahres, wăhrend im zweiten Jahr danach kein einziger Titel der Single-Charts mehr eine Chartplazierung bei den Alben-Charts erreichte.

214 Das schlieBt aber weder aus, daB das Angebot von Alben nach zwei Jahren nicht mehr aufrecht gehalten wird, noch daß einzelne Alben bereits früher aus den Katalogen gestrichen werden.

215 Dieses Ergebnis deckt sich mit der Ansicht von Branchen-Insidern, daß der Produktlebenszyklus von Singles deutlich kürzer ist als der von Alben. Vgl. Mahlmann 1997, S. 175.

${ }^{216}$ Die Tatsache, daß die Ausübung der Unternehmensfunktionen bis zur Veröffentlichung von Tonträgern entsprechend Zeit benötigt, unterstützt die Gültigkeit dieser Hypothese.

217 Vgl. Conen, Michael, op. cit., S. 45 f.

${ }^{218}$ Zur Definition von indirekten Netzwerkeffekten vgl. Katz, Michael L., und Carl Shapiro, Network Externalities, Competition and Compatibility, in: American Economic Review, Vol. 75 (1985), S. 424-440. 
stellern (sog. Software-Hersteller) die Verfügbarkeit der Softwareinhalte (Musik) garantieren, um durch eine hohe Systemattraktivität einen Derivatnutzen zu erzielen. Hohe Anfangsinvestitionen in eine neue Technologie und die komplementäre Tonträgerkategorie können aus Sicht der Unternehmen langfristig rational sein und stellen dann eine Form der intertemporalen Quersubventionierung ${ }^{219} \mathrm{dar}$, wenn es gelingt, die kritische Masse an Konsumenten zu akquirieren. Mit den zukünftigen Gewinnen können dann die erforderlichen Investitionen finanziert werden. $^{220}$

Bezogen auf den Tonträgermarkt bestehen daher Zusammenhänge zwischen Prozeß- und Produktinovationen. Es existieren unterschiedliche Tonträgerkategorien, für die unter Berücksichtigung der switching costs (Umstellungskosten) eine Produktpolitik betrieben wird. Die Höhe der switching costs ist dabei neben den reinen Anschaffungskosten neuer Abspielgeräte abhängig von der Kompatibilität der Tonträgerkategorien und der komplementären Abspielgeräte zueinander. ${ }^{221}$ Für die Höhe der Diffusionsgeschwindigkeit der technischen Neuerungen sind neben der objektiven Qualitätsverbesserung für die Konsumenten wegen des Übergangs von der analogen zur digitalen Aufzeichnungs- und Wiedergabetechnik indirekte Netzwerkeffekte verantwortlich. Im Tonträgermarkt bestehen indirekte Netzwerkeffekte in der Verfügbarkeit möglichst vieler Musiktitel in der entsprechenden Tonträgerkategorie, da der Konsument bei der Entscheidung für das Abspielgerät einen Nutzen aus einem breiten Produktangebot zieht. Hierunter werden die positiven Auswirkungen der Marktsaturation der CD-Player (Abspielgeräte) auf die Anzahl der angebotenen CDs (der entsprechenden Tonträgerkategorie) verstanden. Die Produktpolitik der Tonträgerhersteller zielte deshalb auf schnelle Marktsaturation mit CD-Playern, um die Konsumenten zum Kauf von CDs zu animieren. Andere Tonträgerkategorien wurden mit zunehmenden Erfolg der $\mathrm{CD}$ zu relativ niedrigpreisigen Tonträgern. $^{222}$

Im folgenden wird die Produktpolitik der Tonträgerhersteller nach den Unternehmenstypen der Majors und der Independents unterschieden. Diese Unternehmenstypen haben verschiedene Produktinnovationsstrategien, daher werden sie im weiteren Verlauf getrennt behandelt.

${ }^{219}$ Vgl. Wiese, Harald, Marktschaffung: Das Startproblem bei Netzeffekt-Gütern, in: Marketing ZFP, 13. Jg. (1991), S. 43-51.

${ }^{220} \mathrm{Vgl}$. Rohlfs, Jeffrey, A Theory of Interdependent Demand for a Communications Service, in: Bell Journal of Economics and Management Science, Vol. 5 (1974), S. 16-37.

${ }^{221}$ Die Markteinführung der $\mathrm{CD}$ wurde durch niedrigpreisige CD-Abspielgerăte von Seiten der Gerätehersteller (die teilweise demselben Konzern wie die Tonträgerhersteller angehören) quersubventioniert. Geräte, die wegen guter Kompatibilităt die Umstellungskosten senken, sind beispielweise sog. Audio-Türme, die alte und neue Abspieltechnik integrieren.

222 Die Produktpolitik der Tontrăgerhersteller ist wegen des gleichzeitigen Angebots unterschiedlicher Qualităten nicht unabhängig vom Musikinhalt. Beispiele für den Zusammenhang zwischen Trägerqualität und Repertoireinhalt sind Kinderproduktionen, die vorwiegend auf analogen Musikkassetten verkauft werden und klassische Musik, die vorwiegend auf CDs veröffentlicht wird. 


\subsection{Produktpolitik der Majors}

Die Produktpolitik der Majors betrifft den überwiegenden Teil aller Repertoiresegmente. Die Zahl der von ihnen veröffentlichten Tonträgertitel ist, bezogen auf die einzelnen Unternehmen der Major-Gruppe, deutlich höher als bei den Independents ${ }^{223}$ und bezieht sich sowohl auf echte Produktinnovationen als auch wegen des großen Backkatalogs auf Quasi- und PseudoProduktinnovationen.

Zur Untersuchung der Produktpolitik der Majors wurden von Burke 224 im britischen Tonträgermarkt Marktanteilsdaten für den Single- und den Albenmarkt der Jahre 1983-93 herangezogen, die von der Britisch Phonographic Industry (BPI) zur Verfügung gestellt wurden. ${ }^{25}$ Im Hinblick auf die Produktpolitik der Majors ergaben sich aus der Studie folgende Ergebnisse: ${ }^{206}$ Bei Major-Tonträgerherstellern sind Musiker unter Vertrag, deren Musiktitel sowohl im Single- als auch im Albenmarkt verkauft werden. Dabei werden temporäre Verluste beim Verkauf von Singles durch die Tonträgerhersteller bewußt in Kauf genommen, da der Werbeeffekt für die Alben-Veröffentlichungen signifikant ist. ${ }^{227}$ Im Zeitraum von 1983-1993 lagen die jeweiligen Major-Marktanteile im Single- nahe bei denjenigen im Alben-Tonträgermarkt bei allen sechs Majors. Aus der Korrelation der Marktanteile ist jedoch keine Kausalität abzuleiten. ${ }^{228}$ Die hohe Korrelation erklärt jedoch das Produktverhalten der annähernd gleichzeitigen Veröffentlichung von Single- und Longplay-Tonträgern bei den Majors.

Im Zusammenhang mit der kurzen ökonomischen Lebenszeit von Tonträgertiteln wurde die Wirkung von Veröffentlichungen auf die Marktanteile der Majors untersucht. Die Neuveröffentlichung von Musiktiteln kann entweder zu Marktanteilsgewinnen auf Kosten der Konkurrenten führen (Wettbewerbseffekt) oder zu einer Nachfrageausweitung des Marktes insgesamt (Wachstumseffekt). Ein Marktwachstumseffekt durch Neuveröffentlichungen basiert dabei auf der Multiplikatorwirkung, daß neue Tonträger neue Nachfrage schaffen, die auch ähnlichen, bereits existierenden Tonträgern zugute kommt. ${ }^{229}$ Generell wurde durch die Veröffentlichungen der Major-Tonträgerhersteller langfristig keine signifikante Marktausweitung erreicht, sondern nur eine Verschiebung der Marktanteile zwischen der Oligopolgruppe der Majors. ${ }^{230}$ Dieses Ergebnis erzielt Burke durch das Schätzen der Nachfragefunktion. Ausnahmen hiervon

${ }^{223} \mathrm{Vgl.} \mathrm{Schulze,} \mathrm{Ralf,} \mathrm{op.} \mathrm{cit.,} \mathrm{S.} \mathrm{293-301.}$

224 Vgl. Burke 1996b, supra, S. 148 ff.

${ }^{225}$ Die originäre Datenquelle sind wöchentliche Musikmagazine.

${ }^{226}$ Die Übertragbarkeit der empirischen Ergebnisse auf den deutschen Tonträgermarkt ergab sich aus der Tatsache, daß es sich um dieselben Majors handelte, das entsprechende Repertoire dieser Jahre vorwiegend international oder sogar britisch war und die jeweiligen deutschen Landesgesellschaften der Majors die hiesige Veröffentlichung lediglich ausführten.

${ }^{227}$ Die Rentabilităt von Singles ist repertoireabhängig. In einigen Repertoiresegmenten sind Singles durchaus rentabel. Vgl. Mahlmann 1997, S. 166.

228 Vielmehr konnte durch ökonometrische Testverfahren (den Gringer-Kausalitătstest und Wald-Test) herausgefunden werden, daß ein gegenwärtiger Marktanteil bei den Alben keine Funktion des vorhergehenden Marktanteils bei den Singles ist und daß ein früherer Marktanteil bei den Alben nur geringen EinfluB auf den gegenwärtigen Marktanteil hat.

${ }^{229} \mathrm{Vgl}$. Burke 1996b, supra, S. 155

${ }^{230} \mathrm{Vgl}$. Burke 1996b, supra. S. 160 
sind Multiplikatoreffekte, in denen Produktinnovationen neue Repertoiresegmente definieren, $^{231}$ die nachfolgende Veröffentlichungen und eine höhere Nachfrage induzieren. ${ }^{232}$

Aus gesamtwirtschaftlicher Sicht kritisch zu sehen ist die überwiegende Wirkung einer Marktanteilsverschiebung durch die Produktinnovationen der Majors. Es ist von daher nicht auszuschließen, daß die Kosten der Produktinnovation bei Betrachtung des Gesamtmarktes bzw. des Marktanteils der Oligopolgruppe der Majors Ressourcenverschwendung sind. ${ }^{233}$

\subsection{Produktpolitik der Independents}

Die Produktpolitik der Independents beschränkt sich im wesentlichen auf das Tonträgerangebot in Nischen, also einzelnen Repertoiresegmenten. Hierbei ist einerseits feststellbar, daß einzelne Independents in einzelnen Repertoiresegmente die größten Anbieter geworden sind (z. B. Koch Records in der Volksmusiksparte). Andererseits werden die Nischen durch eine ständige Marginalisierung immer kleiner, weil alte Repertoiresegmente bestehen bleiben und neue hinzutreten, aber die Nachfrage nicht im gleichen Maße mitwächst. Das führt zu steigender Unübersichtlichkeit des Marktes und einer geringeren Stückzahl verkaufbarer Produkte in den einzelnen Nischen. ${ }^{234}$

Eine empirische Messung der Veröffentlichungspolitik der Independents wurde von Christianen für den niederländischen Markt für die Jahre 1975-1992 durchgeführt. ${ }^{235} \mathrm{Er}$ stellte fest, $\mathrm{da} B$ der Anteil der Neuveröffentlichungen von Independents an den gesamten Neuveröffentlichungen von 1975 unter 10\% auf über 50\% zu Anfang der 90er Jahre zugenommen hatte. ${ }^{236}$ Weiterhin betrachtete Christianen die Verteilung der Veröffentlichungen der Independents über Repertoiresegmente. Die einzelnen Independents bieten Produkte nur in einigen Nischen an, in denen sie dann aber viele Veröffentlichungen tätigen und nischenbezogen hohe Marktanteileerreichen. ${ }^{237}$ Christianen faßt die Produktpolitik von Independents wie folgt zusammen: Die

${ }^{231}$ Ein Beispiel für den deutschen Tontrăgermarkt ist die Adoption des HipHop. Deutsche Texte in diesem Repertoiresegment bewirkten sowohl weitere ăhnliche Veröffentlichungen als auch größere Nachfrage.

${ }^{232}$ Diese Effekte treten aber nur isolient auf und bewirken ein kurzfristiges Abweichen vom generellen Wachstumsverlauf.

233 Ausgenommen von dem Argument der Ressourcenverschwendung sind Backkatalog-Veröffentlichungen, die keine echten Innovationen sind, da die Musik schon veröffentlicht war, aber neu zusammengestellt wird. Für solche Veroffentlichungen fallen weniger Kosten an. Die Hypothese der Ressourcenverschwendung auf der Basis oligopolistisch hoher Preise hat auch in den Einlassungen des BKartA zum Fusionsfall EML/Virgin eine Rolle gespielt. Quelle: Interview mit Karl-Eberhard Schmidt, Mitarbeiter des BKartA, am 10.04.1997.

$234 \mathrm{Vgl}$. Vormehr, Ulrich, op. cit., S. 209.

${ }^{235}$ Vgl. Christianen, Michael, The Dutch music industry, paper presented at the 8th International Congress on Cultural Economics in Witten, 24.-27.8. 1994, Witten, S. 2 ff.

${ }^{236}$ Eine mogliche Erklärung ist, daß die Major-Tonträgerhersteller in dieser Zeit nur ihren bestehenden Repertoire-Katalog auf der neuen Tontrăgerkategorie $C D$ veroffentlicht haben. Die Funktion, neuen Musikern mittels Tonträgern zur Nachfrage zu verhelfen, fiel daher im betrachteten Zeitraum mehr den Independents als den Majors zu. Vgl. Christianen, supra, S. 19.

${ }^{237}$ In der Summe veröffentlichten alle Independents Musik, verteilt über viele Repertoiresegmente mit einem Anteil von über $50 \%$ in 14 von Christianen definierten Repertoiresegmenten. Majors boten zwar in vielen Repertoiresegmenten an, $80 \%$ ihrer Veröffentlichungen stammten aber aus den 5 Repertoiresegmenten Pop. 
Angebotsbreite einzelner Independents (gemessen an der unterschiedlichen Titelzahl) ist gering, während sich in der Summe aller Independents deren Produktpolitik auf sehr viele Repertoiresegmente bezieht. Es werden Repertoiresegmente mit Tonträgerveröffentlichungen bedient, auf denen die Majors nicht anbieten.

Diese Dualität der Produktpolitik entspricht ebenso einer Dualität der Marktstruktur und der Hypothese, daß zwischen Majors und Independents Mobilitätsbarrieren bestehen. Unternehmensgruppenspezifisches Angebotsverhalten ist keine Besonderheit des Tonträgermarktes. Auch in anderen Märkten, beispielsweise im Buchmarkt, existieren ähnlich duale Produktpolitiken.

Abschließend kann versucht werden, die Produktpolitik der Tonträgerhersteller gesamtwirtschaftlich zu bewerten. Unterstellt man normativ, daß eine größere Angebotsbreite erwünschter sei als eine geringere, weil mit einer größeren musikalischen Vielfalt die Konsumentenwünsche besser befriedigt werden, ist ein Kriterium das Ausmaß des Angebots in verschiedenen Repertoiresegmenten. Die Produktinnovation wird dann gemessen an den Neuveröffentlichungen pro Jahrr. ${ }^{238}$ Es läßt sich seit 1990 eine generelle Zunahme sowohl von Tonträgerneuerscheinungen als auch des Gesamtangebots feststellen ${ }^{239}$. Zweiter Indikator für die Vielfalt ist die Entwicklung der Angebotsbreite in verschiedene Repertoiresegmente. Auch hier ist eine Zunahme festzustellen. Z. B. ist Popmusik differenzierter geworden in der Vielfalt: Neue Repertoiresegmente sind dazugekommen und alte haben nicht zu existieren aufgehört. Eine Bewertung der Angebotsvielfalt würde allerdings voraussetzen, daß feststellbar ist, wieviele neue Musiker, neue Musikrichtungen und Debutalben durch die Veröffentlichungspolitik der Tonträgerhersteller in den Markt gelangen. Dabei müßte eine Differenzierung in echte, Quasi- und Pseudo-Produktinnovationen für alle Tonträgerveröffentlichungen möglich sein, um die Funktion der Tonträgerhersteller als einer Art „Gate Keeper" der Musikdiffusion empirisch zu überprüfen. ${ }^{240}$ Dieses ist nicht durchführbar und eine Bewertung der Produktpolitik der Tonträgerhersteller muß daher mangels Datenverfügbarkeit und methodischer Probleme unterbleiben. ${ }^{241}$

\subsubsection{Preispolitik der Tonträgerhersteller}

In dem oligopolistisch strukturierten Markt für Tonträgerhersteller existieren im Hinblick auf die Preispolitik gemeinsame Interessen der Oligopolisten, genauer der Oligopolgruppe der Majors. Ihr kollektives Interesse ist ein - auf Produktgruppen (=Repertoiresegmente) bezogen

Modern Jazz, Orchestrale Musik, englische Vokale Musik und Soundtracks zu Filmen im Zeitraum von 1975-1992.

${ }^{238}$ Die methodischen Probleme einer solchen Bewertung liegen in der unzureichenden Erfassung der Importe, in den Mehrfachveroffentlichungen auf verschiedenen Produktkonfigurationen (=Tonträgerkategorien), die in der offiziellen deutschen Statistik nicht bereinigt werden, und dem nicht operationalisierbaren Problem, tatsăchlich neue Musik zu identifizieren.

239 Vgl. BPW 1997, op. cit., S. 24 f.

${ }^{240}$ Eine Prămissenkritik bezieht sich darauf, daß mehr Vielfalt nicht unbedingt mehr Wohlfahrt bedeutet.

${ }^{241}$ Daher können auch keine gesicherten Aussagen über den Zusammenhang zwischen Konzentration und Innovation getroffen werden. Vgl. im Gegensatz dazu Schulze, Ralf, op. cit., S. 300. 
- einheitliches und hohes Preisniveau. ${ }^{242}$ Die Entwicklung der Marktstruktur hat aber auch gezeigt, daß es auf dem Tonträgermarkt für U-Musik (Pop) weder im Single- noch im Albenbereich ein dominierendes Unternehmen gibt, welches die Preise aufgrund einer dominierenden Marktstellung vorgeben könnte. Daher kann eine kollektive Preispolitik der oligopolistischen Tonträgerhersteller gegenüber dem Handel nur implizit erfolgen, z. B. aus dem gemeinsamen Wissen über Kostenstrukturen, Produktkonfigurationen und Absatzkanäle. Mögliche Form einer solchen Preispolitik ist die barometrische Preisführerschaft. ${ }^{243}$ Relativiert wird die Bedeutung der Preispolitik dadurch, daß der Wettbewerb auf der Ebene der Tonträgerhersteller stärker durch die Aktionsparameter der Produktinnovation und Produktdifferenzierung betrieben wird. Der Preis fungiert eher als Wettbewerbsparameter zwischen den Majors und den Independents als innerhalb der beiden Gruppen von Unternehmen im Markt. ${ }^{244}$ Deutlich wird dies bei einer differenzierten Betrachtung der beiden Unternehmensgruppen.

Zunächst werden im folgenden die unterschiedlichen Preisbestandteile und Preiskategorien erläutert, die unabhängig von der Größe der Tonträgerhersteller sind. Daran anschließend werden im Abschnitt Preispolitik der Majors die Preissetzung unterschiedlicher Tonträgerkategorien behandelt. Schließlich wird die Preispolitik der Independents und ihre Wettbewerbswirkung gegenüber den Majors untersucht.

Der Preis für bespielte Tonträger enthält - unabhängig von der Tonträgerkategorie - folgende Komponenten:

- Der Angebotspreis der Tonträgerhersteller gegenüber den Weiterverkäufern bzw. dem Handel. Er basiert auf einer Preisliste, genannt published price for dealer (ppd, dt: Händlerabgabepreis, HAP), von der unterschiedliche Abschläge für die Händler nach individuellen $\mathrm{Ge}$ sichtspunkten gewährt werden. Im Ergebnis entsteht ein spezifischer Händlerpreis.

- Der Preismarge, die der Weiterverkäufer bzw. Händler aufschlägt, um den Nettoendverkaufspreis zu erhalten.

- Die gesetzliche Umsatzsteuer (Mehrwertsteuer). ${ }^{245}$

${ }^{242}$ In GroBbritannien legte das National Heritage Committee of the House of Commons (NHC) einen Bericht über die Preispolitik der Tonträgerhersteller vor. Vgl. NHC, Bericht vom Mai 1993, London 1993. Daraufhin untersuchte die Monopolies and Merger Commission (MMC) den Tonträgermarkt in Großbritannien und legte 1994 einen Ergebnisbericht vor. Vgl. MMC, The Supply of Recorded Music, London 1994

${ }^{243}$ Die Hypothese einer barometrischen Preisführerschaft der Major-Tonträgerhersteller ist konsistent mit der Feststellung einer preisunelastischen Nachfrage der Konsumenten nach neuen bespielten Tonträgern. Vgl. Belinfante/Johnson, supra, S. 23. Zur Diskussion der Preisfuhrerschaf vgl. Markham, Jesse W., The Nature and Significance of Price-Leadership, in: American Economic Review, Vol. 41 (1951), S. 891-905. Zur Diskussion der barometrischen Preisführerschaft vgl. Bain, Joc S., Price Leaders, Barometers and Kinks, in: Journal of Business, Vol. 33 (1960), S. 193-203.

244 Die unterschiedliche Preispolitik von Independents und Majors basiert z. T. auf den unterschiedlichen Kostenstrukturen dieser Unternehmensgruppen. Demgegenüber sind die Kostensstrukturen der Majors untereinander ăhnlich.

245 Die Deutsche Phonographische Industrie fühlt sich diskriminiert durch den Standardumsatzsteuersatz von 2. Zt. $16 \%$, da andere kulturelle Güter und Verlagserzeugnisse zu einem ermäßigten Satz. besteuert werden. 
Die Preiskategorien im Tonträgermarkt beziehen sich nicht auf Singles, sondern nur auf die Longplay-Produkte (im folgenden Alben). Diese Preiskategorien sind: ${ }^{246}$

Fullprice (Normal- oder Vollpreis),

Midprice (Mediumpreis) und

Lowprice (Niedrig-, Budget- oder Niceprice).

Für die jeweiligen Preiskategorien haben die Listenpreise für die Abgabe an die Händler eher den Charakter von Höchstpreisen ${ }^{247}$ und die Funktion der Definition von Produktkategorien. ${ }^{248}$ Die Preiskategorien sind international gültig und wurden 1990 im deutschen Tonträgermarkt eingeführt. Mit den Preiskategorien lassen sich auch die Preisvariationen im Zeitablauf beschreiben. Der jeweils gegenwärtige Wert des Tonträgers bezieht sich auf den musikalischen Inhalt. Entsprechend der Position des jeweiligen Tonträgers in seinem individuellen Produktlebenszyklus beginnt die Preissetzung von Neuproduktionen zum Vollpreis. Zum Mediumpreis werden ältere Produktionen bzw. Zusammenstellungen von älteren Produktionen abgesetzt. Den Niedrigpreis wählen Tonträgerhersteller für Drittverwertungen, insbesondere auch für den Absatz über nicht-traditionelle Kanäle. Der Niedrigpreis liegt etwa bei $50 \%$ des Vollpreises. Ebenso differieren die Preise für unterschiedliche Tonträgerkategorien.

\subsection{Preispolitik der Majors}

Die Preispolitik der Major-Tonträgerhersteller läßt sich anhand der von ihrem Verband (Bundesverband der Phonographischen Wirtschaft) herausgegebenen Statistiken und veröffentlichten Händlerabgabepreisen untersuchen. Für einen Markt, der durch Heterogenisierung mit Hilfe von Repertoiresegmentierung gekennzeichnet ist, fehlt auf der Händlerabgabestufe bedeutsamer Preiswettbewerb. Deutlicher wird dies, wenn man für die umsatzstärksten Tonträgerkategorien im Longplay-Markt, CD und Musikkassetten, ${ }^{249}$ die Absatzverteilung auf die Preiskategorien untersucht. Der größte Absatzanteil entfällt auf die Fullprice-CD, für die vier von fünf Majors nahezu identische Preise verlangen. ${ }^{250}$

Den relativen Anteil der Preiskategorien in \% am Gesamtabsatz von Tonträgern ${ }^{251}$ der Kategorie Musikkassetten an den Handel zeigt die folgende Abbildung 20a:

\footnotetext{
$246 \mathrm{Vgl}$. Mahlmann 1997, S. 171.

${ }^{247}$ Die Einteilung der Tontrăger in die Preiskategorien geschieht durch die Tonträgerhersteller. Da die Preispolitik des Handels den Endverkaufspreis bestimmt, soll an dieser Stelle auf die Wiedergabe absoluter Preishöhen für die einzelnen Preiskategorien verzichtet werden.

$248 \mathrm{Vgl}$. Belinfante/Johnson, supra, S. 20.

249 Die CD hatte 1996 einen Umsatzanteil von $83 \%$ und die MC von $6 \%$ in Endverbraucherpreisen inkl. Mwst.

${ }^{250}$ Der Beleg für die Tatsache gleichformiger Preissetzung durch die Majors in den Jahren $1992 / 93$ ist ein Unternehmensgeheimnis. Er entstammt verschiedenen Verfahrensakten des BKartA, die der Öffentlichkeit nicht zugänglich sind und deren Verwendung daher in der Verlagsversion dieser Dissertation nicht erlaubt ist. [J.K.].

251 Berücksichtigt sind nur die Verkäufe derjenigen Tontrăgerhersteller an den Handel, die Mitglied im Bundesverband der Phonographischen Wirtschaft sind.
} 
Abbidung 20 a: Relativer Anteil der Preiskategorien am Absatz von Musikkassetten

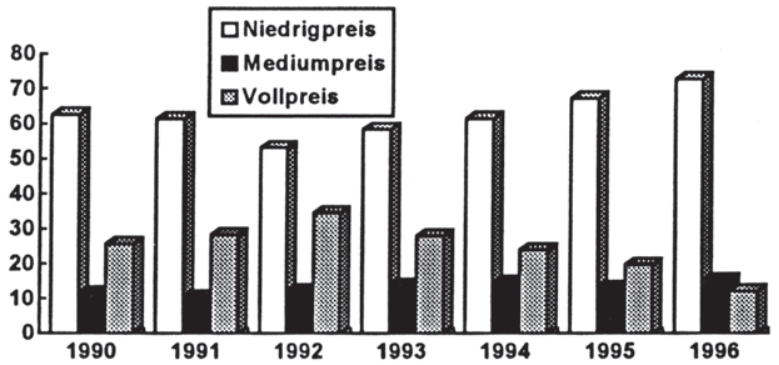

Quelle: BPW 1997, S.22.

Den relativen Anteil der Preiskategorien in \% am Gesamtabsatz von Tonträgern ${ }^{252}$ in der Kategorie Compact Disc an den Handel zeigt folgende Abbildung 20b:

Abbildung 20b: Relativer Anteil der Preiskategorien am Absatz von Compact Discs

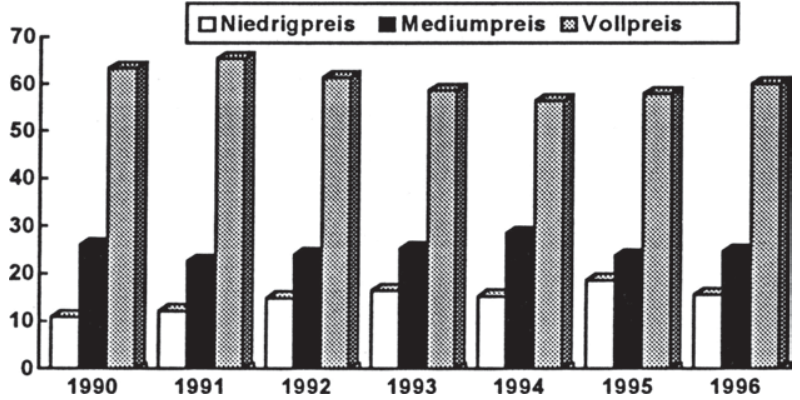

Quelle: BPW 1997, S. 21

Dies bedeutet erstens, daß die Musikkassette vorwiegend eine niedrigpreisige und die $\mathrm{CD}$ eine hochpreisige Tonträgerkategorie ist. Zweitens wird der größte Absatzanteil mit der Tonträgerkategorie CD und innerhalb dieser mit der Vollpreiskategorie getätigt. In der Vollpreiskategorie finden sich in unserer Beispieltabelle Preisvariationen von max. $5 \%$, bei der $C D$ auch nur durch einen Major. Dies zeigt die geringe Bedeutung des Preiswettbewerbs bezüglich des Händlerabgabepreises zwischen den Majors.

${ }^{252}$ Bezugsgrößen siche vorhergehende Fußnote. 
Hat der Preiswettbewerb im Innenverhältnis zwischen den Majors eine untergeordnete Funktion, spielt er bei der Gewinnung neuer Nachfrage und bei der Zweit- und Drittverwertung eine größere Rolle. In der niedrigsten Preiskategorie (Lowprice oder Budget) wird der Tonträger zum Mitnahmeartikel, bei dem die Kaufentscheidung des Konsumenten vor allem durch den Preis spontan geweckt werden soll. Inhalt von Budget-Tonträgern sind Kinderrepertoire, ${ }^{253}$ Backkatalogrepertoire und Spezialprodukte. Backkataloge besitzen in nennenswertem Umfang vor allem die Majors, die damit zweite und dritte Verwertungshandlungen bereits erfolgreich veröffentlichter Musik durchführen. Spezialprodukte sind im Rahmen der Produktpolitik extra für einen Kunden zusammengestellte Tonträger, ${ }^{254}$ die ebenfalls niedrigpreisig weiterverkauft oder verschenkt werden. Der Wettbewerb mit Budget-Tonträgern ist erklärbar im Zusammenspiel der Aktionsparameter Produkt, Preis und Konkurrenz um neue Vertiebswege. Daher ist es das Ziel der Niedrigpreispolitik der Majors, unter einer anderen Marke (Label) neue Zielgruppen zu erschließen und neue Vertriebswege zu etablieren. Dabei ist die erwünschte mittelfristige Wirkung nicht die Substitution der Produkte in anderen Preiskategorien und Vertriebswegen, sondern die Erhöhung der Käuferreichweite. ${ }^{25 s}$

\subsection{Preispolitik der Independents}

Tonträgerhersteller, die nicht zu der Gruppe der Majors gehören, ${ }^{256}$ betreiben eine andere Preis- und Vertriebspolitik. Hierbei gehen sie prinzipiell zwei Wege. Sie versuchen, einen Kostenvorteil zu erlangen, indem sie unbekannte Musiker vertraglich binden und den Kostenvorteil bei der Zusammenarbeit mit Vertriebsfirmen durch Weitergabe niedrigerer Preise an den Konsumenten weitergeben. Neuveröffentlichungen der Independents durch ihre Label finden dann nicht in der Vollpreis-Kategorie, sondern in der mittleren Preiskategorie statt. Der zweite Weg ist es, Produkte anzubieten, die die Majors nicht anbieten können oder wollen. Diese Produkte bestehen z. B. aus Veröffentlichungen noch nicht etablierter Musiker, die von Independents entdeckt und gefördert werden. Für diese Produkte, für die Präferenzen bei den Konsumenten erst noch geweckt werden müssen, bestehen keine direkten Konkurrenzbeziehungen zu den Produkten der Majors; daher können Independents in der Vollpreiskategorie anbieten. Diese Produkte der Independents werden mit zunehmendem Erfolg der Präferenzschaffung in Substitutionskonkurrenz zu denjenigen der Majors treten. Je enger diese Substitutionsbeziehung wird, desto eher gleicht sich die Preispolitik der Independents an diejenige der Majors an.

${ }^{253}$ Das Kinderrepertoire wird dominiert durch ITP, BMG Ariola Miller und Karussell. Unterteilt wird es in die Bereiche Musik und Wort, die vorwiegend als Musikkassette vermarktet werden. Vgl. Diederichs, Frank A., Budgetlinie und Special Products, in: Handbuch der Musikwirtschaft, hrsg. von Moser, Rolf, und Andreas Scheuermann, 4. Aufl, Stamberg 1997, S. 227-240.

${ }^{254}$ Diese speziellen Tonträger wurden ursprünglich zu Werbezwecken für Markenartikler, Verbände, etc. hergestellt. Inzwischen werden Spezialprodukte auch zum Wiederverkauf über traditionelle oder Sondervertriebswege hergestellt.

${ }^{255}$ Kaufen bei unterschiedlicher Preiselastizităt der Nachfrage solche Konsumenten Tontrăger, die ansonsten nicht nachfragen würden, steigt neben der Produzenten- auch die Konsumentenrente und damit die volkswirtschaftliche Wohlfahrt in diesem Markt.

256 In der jüngsten Vergangenheit haben auch Independents die Produkt- und Preispolitik der Majors betrieben (z. B. Koch-Records, ZYX und Edel). Aus der Verhaltenstypologie kann daher keine Gesetzmäßigkeit abgeleitet werden. 
Das gleichformige und gleichgerichtete Preisverhalten bezieht sich dann auf - in den Augen der Konsumenten - gleichwertige Tonträger.

\subsubsection{Strategische Marktbarrieren}

Strategische Markteintrittsbarrieren und marktinterne strategische Wachstumsbarrieren ${ }^{257}$ sind gezielt getroffene Maßnahmen der etablierten Unternehmen, die nicht ihrer kurzfristigen Gewinnmaximierung dienen, sondern die die Behinderung des Marktzutrittes neuer Unternehmen in den Markt ${ }^{258}$ oder des Wachstums von einem Independent zu einem Major im Markt zum Ziel haben. Im Abschnitt 4.2. wurde bereits festgestellt, daß keine nenneswerten Markteintrittsbarrieren, sehr wohl aber Wachsstumsbarrieren im Tonträgermarkt bestehen. Die Rationalität marktinterner strategischer Wachstumsbarrieren resultiert aus der Tatsache, daß die im Tonträgermarkt tätigen Unternehmen - wie oben erläutert - strukturelle Unterschiede aufweisen. Die Unterschiede zwischen Majors und Independents wurden bereits in den Abschnitten Produktpolitik und Preispolitik thematisiert. Sie führen dazu, daß innerhalb der Tonträgerhersteller von unterschiedlichen Anbietergruppen gesprochen werden kann. ${ }^{259}$ Strategische Wachstumsbarrieren sind zu begreifen als Aktionsparameter der Major-Tonträgerhersteller, die gemeinsam eine Oligopolgruppe bilden, gegenüber den Independents als andere Gruppe, die überwiegend am Rand ${ }^{260}$ oder nur in einzelnen Segmenten des Tonträgermarktes anbieten.

Die entscheidende Frage für die Errichtung strategischer Wachstumsbarrieren im Hinblick auf die Unternehmensgröße und den Integrationsgrad besteht darin, ob es Engpaßfaktoren ${ }^{261}$ (sog. bottleneck-Faktoren) gibt, die für ein vollständig integriertes Unternehmen nicht gelten. Diese eröffnen die Möglichkeit zur Überwälzung der Marktmacht einer Stufe auf die nächste und schränken das Wachstum von Independents stark ein. $\mathrm{Zu}$ den wichtigsten strategischen Barrieren im Tonträgermarkt gehören die Kontrolle über Inputfaktoren, das sind international etablierte und vermarktbare Musiker, die Schaffung bzw. Haltung strategischer Überkapazitäten der physischen Herstellung, die Kontrolle über Distributionsfazilitäten ${ }^{262}$ und die permanenten Investitionen in die strategische Produktdifferenzierung. ${ }^{263}$

${ }^{257}$ Vgl. Caves/Porter 1977, supra, S. 241-261.

${ }^{258} \mathrm{Vgl}$. Kolbe, Clemens, Eintrittsbarrieren und die Eintrittsfähigkeit potentieller Konkurrenz, Göttingen 1991, S. 55.

${ }^{259} \mathrm{Vgl}$. Williamson, P. J., Oligopolistic dominance and EC merger policy, in: European Economy, Nr. 57 (1994), S. $157 \mathrm{f}$.

260 Die Betrachtung eines Marktrandes erfolgt in Anlchnung an Caves/Porter, supra, S. 251: „A typical pattern in consumer-good industries is the presence of a small group of producers of a full line of $[\ldots]$ goods and a larger group of producers of unadvertised goods [...]."

${ }^{261} \mathrm{Vgl}$. Kruse, Jörn, Vertikale Integration als Wettbewerbsproblem, in: Wettbewerbspolitik im Spannungsfeld nationaler und internationaler Kartellrechtsordnungen, hrsg. von Kruse, Jörn, Kurt Stockmann und Lothar Vollmer, Baden-Baden 1997, S. 247-270.

${ }^{262} \mathrm{Vgl}$. Vogel, Harold L., Entertainment industry economics, Cambridge u. a. 1986, S. $147 \mathrm{ff}$.

${ }^{263} \mathrm{Vgl}$. Williamson, Oliver E., Selling Expense As A Barrier To Entry, in: Quarterly Journal of Economics, Vol. 77 (1963), S. 112-128 [Williamson, O. E. 1963], und Menge, John A., Style Change As A Market Weapon, in: Quarterly Journal of Economics, Vol. 76 (1962), S. 632-647.

Die Wirksamkeit strategischer Barrieren ist abhängig von der Existenz struktureller (natürlicher) Barrieren Diese zwar notwendige, aber noch nicht hinreichende Wirkungsbedingung wird bei der wettbewerbspolitischen Bewertung dahingehend berücksichtigt, dab die Wettbewerbsbehörde zunächst strukturelle Barrieren 
Die Kontrolle über international vermarktbare Musiker meint nicht deren vertragliche Abhängigkeit von Major-Tonträgerherstellern, sondern die ausschließlich bei den Majors liegende Fähigkeit, diese Musiker vertraglich zu attrahieren. Diese Fähigkeit läßt sich durch die gruppenspezifischen Eigenschaften der Majors erklären. Als Töchter internationaler Konzerne verfügen sie über geeignete Kapitalreserven, um die Vorfinanzierung der Garantiesummen ${ }^{264}$ für diese Musiker zu bewerkstelligen. ${ }^{265}$ Des weiteren verfügen sie über Ländergesellschaften in allen relevanten, d. h. umsatzstarken nationalen Märkten der Welt, die die entsprechenden Marketing- und Distributionsdienstleistungen in diesen Märkten erbringen können. ${ }^{266}$

Im Hinblick auf die physischen Herstellungskapazitäten läßt sich zunächst feststellen, daß keine ökonomischen Begründungen für eine Integration vorliegen. Mögliche Begnündungen lägen in Transaktionskostenersparnissen oder Verbundvorteilen (economies of scope). Die Herstellungskapazitäten der physischen Tonträgerproduktion sind zum großen Teil in den Händen der vollintegrierten Majors. Sollte ein Newcomer nur auf der Stufe der physischen Herstellung eintreten und keine Aufträge von den Majors bekommen, dann würde das Volumen der Aufträge der Independents nicht ausreichen, um eine kostendeckende Auslastung z.B. seiner Preßbzw. Brennkapazität zu erreichen. Die im Jahr 1991 auf den verschiedenen europäischen Märkten bestehenden Kapazitäten, die im Zuge des Fusionsfalles EMI/Virgin aktenkundig wurden, deuten darauf hin, daß erhebliche Überkapazitäten vorliegen. Diese sind insbesondere geeignet, große Nachfrageschwankungen abzudecken. Wie aus den Verfahrensakten der Europäischen Kommission hervorgeht, liegen die Reservekapazitäten ausschließlich bei den Majors. Diese Behauptung kann wiederum nicht öffentlich belegt werden, da die Herstellerangaben im Fusionsfall vertraulich sind und daher nicht zitiert werden dürfen.

Im Jahr 1991 bestand (exemplarisch betrachtet) eine Überkapazität im Volumen von etwa 60\% der Nachfrage auf europäischen Märkten, der eine weitaus geringere Schwankungsbreite der Nachfrage gegenüberstand. Diese Zeitpunktbetrachtung erlaubt zwar keine Aussagen über Veränderungen des Verhältnisses von Nachfrage und Kapazitäten im Zeitablauf, doch ein Vergleich zur Situation 1995 in Deutschland zeigt, daß die Situation auch auf nationaler Ebene ähnlich ist. Im Jahr 1995 stellte sich die Situation im Hinblick auf die Kapazitäten zur physischen Herstellung der Tonträgerkategorie CD in Deutschland wie folgt dar. ${ }^{267}$

untersucht, bevor sie das strategische Wettbewerbsverhalten der Anbieter und dessen wohlfahrtsökonomische Implikationen für das Marktergebnis analysiert. Der Zwei-Stufen Ansatz wird beschrieben von Ordover, J. A., und R. D. Willig, An Economic Definition of Predatory Product Innovation, in: Salop, S. C. (Hrsg.), Strategy, Predation and Antitrust Analysis, Washington, D. C. 1981, S. 45-99.

264 Die Zahlung einer Garantiesumme für international renommierte Musiker ist eine branchenübliche Usance und entspricht der Wahrscheinlichkeit, daß eine Neuveroffentlichung dieser Musiker frühere Erfolge wiederholt. Vgl. Thurow, Norbert, und Peter Zombik, op. cit., S. 206.

${ }^{265}$ Das Argument der anfanglich hohen Kapitalaufwendungen und der zeitlichen Vorfinanzierung bezieht sich sowohl auf den unterschiedlichen Zugang zu Finanzierungsquellen (unternehmensintern bei den Majors, fraglich bei den Independents) als auch auf den Fluß an finanzicllen Mitteln (cash-flow).

266 Vgl. Schmidt, Christoph, op.cit., S. $186 \mathrm{ff}$.

${ }^{267}$ Quelle: Schmidt, Christoph, op. cit., S. 193. Der in der Tabelle nicht aufgeführte Major EMI läßt für die europäischen Märkte in Uden/Niederland fertigen. 
Tabelle 6: Fertigungswerke für Compact Discs in Deutschland (1995):

\begin{tabular}{|l|l|l|}
\hline Fertigungswerk: & Eigentümer & Kapazität in Mio./Jahr \\
\hline Polygram Manufacturing \& D. & Polygram (Major) & 140 \\
\hline Sonopress Produktionsgesell. & Bertelsmann (Major) & 180 \\
\hline Teldec-Press & EastWest (Warner, Major) & 130 \\
\hline $\begin{array}{l}\text { Warner Music Manufactoring } \\
\text { Europe GmbH }\end{array}$ & Warner (Major) & 85 \\
\hline MPO Audio u. Video GmbH & (unabhängig) & 95 \\
\hline $\begin{array}{l}\text { Compact Discs Albrechts } \\
\text { GmbH }\end{array}$ & (unabhängig) & 50 \\
\hline
\end{tabular}

Quelle: Schmidt, Christoph, op. cit., S. 193

Der strategische Vorteil liegt nicht in der Schaffung von Preß- bzw. Brennkapazitäten allein, wie die Existenz unabhängiger Fertigungswerke beweist, sondern in der vertikalen Integration der Majors, die sowohl über entsprechende Kapazitäten verfügen als auch in der Lage sind, diese durch Preß- und Brennauftäge zu füllen bzw. die Kosten der Überkapazitäten zu tragen. Das unzureichende Volumen der von den Independents vergebenen Auftäge zur physischen Herstellung von Tonträgern führt zur einer direkten Abhängigkeit der unabhängigen Fertigungswerke von der vorgelagerten Stufe der Majors, mit deren Herstellkapazitäten sie gerade konkurrieren.

Dabei dienen die ausreichenden Kapazitäten der integrierten Majors dazu, die durchschnittliche Nachfrage nach den eigenen Tonträgerprodukten zu bedienen. Die fehlenden Aufträge zur Kostendeckung werden über den Markt von den nicht integrierten Herstellern akquiriert. Sollten auf der Stufe der physischen Herstellung von Tonträgern Defizite durch das Vorhalten von Überkapazitäten entstehen, ist eine Quersubventionierung aus anderen Marktstufen bei den vollintegrierten Majors denkbar, die den nicht integrierten Unternehmen nicht möglich ist. Ein weiterer strategischer Integrationsvorteil der Überkapazitäten besteht in der höheren Flexibilität. Im Tonträgermarkt sind Nachfrageschwankungen keine Seltenheit, sondern dem Marktprozeß immanent. Während die saisonalen Schwankungen bekannt sind ${ }^{268}$ und daher antizipiert werden können, ist aus Sicht der Hersteller die starke Nachfrage nach einem speziellen Tonträger problematisch. ${ }^{269}$ Die hierbei offenbarten Präferenzen der Konsumenten, ${ }^{270}$ die die Tonträgerhersteller kurzfristig zu erfüllen haben, fordern gerade die Marktstufe der physischen Herstellung. Um Lieferengpässe zu vermeiden und den time-lag zwischen Präferenzoffenbarung und -erfüllung zu minimieren, bieten sich Überkapazitäten oder intensitätsmäßige Anpassungen an, während der zusätzliche Aufbau eigener oder die vertragliche Bindung fremder Kapazitäten zu zeitaufwendig sind

268 Vgl. BPW 1997, op. cit., S. 14.

${ }^{269}$ Ein gutes Beispiel hierfür ist die Elton John CD, welche anläßlich der Trauerfeier für Lady Diana Spencer veröffentlicht wurde. Die Nachfrage nach dieser speziellen $C D$ ließ sich nicht umleiten, obwohl der Inhalt bereits auf mehreren bereits veröffentichten Tonträgern enthalten war und nur leicht zur Trauerfeier modifiziert wurde.

${ }^{270}$ Diese Präferenzen für den speziellen Tonträger sind dann i. d. R. so stark, daß der Konsument nicht auf ein anderes Produkt umgeicitet werden kann und daher bei Nichtlieferung seine Nachfrage ganz. ausfältt 
Die strategische Dimension der Kontrolle über die Distributionsfazilitäten meint nicht nur die kapitalintensive und Fixkosten bindende Unternehmensfunktionen der physischen Herstellung und der logistischen Leistung der Distribution von Tonträgern, sondern schließt insbesondere den Zugang zu den wichtigsten Künstler-Präsentationskanälen Radio, TV und Film mit ein.

Die Investition in die Produktdifferenzierung erweist sich als ein Kernelement des Tonträgermarktes. ${ }^{271}$ Die Repertoiresegmente des Tonträgermarktes betreffen Stilrichtungen der Musik wie z. B. Pop, Rock, Schlager, Dance, Klassik und Jazz, die musikwissenschaftlich abgrenzbar sind. ${ }^{272}$ Die Musikstilrichtungen haben eine unterschiedliche ökonomische Relevanz, ausgedrückt durch ihren Umsatzanteil am Gesamtabsatz. Eine weitere Differenzienung der Repertoiresegmente ist ökonomisch reizvoll in den Musikstilrichtungen, deren Umsatzanteile erheblich sind. ${ }^{273}$ Die Beweggründe der Tonträgerhersteller sind dabei, durch die Etablierung von Trends, neue Musiker und damit neue Tonträgerprodukte im Markt plazieren zu können. ${ }^{274}$ Daher ist die Ausdifferenzierung der Repertoiresegmente ein Aktionsparameter der Tonträgerhersteller. Nur durch die Präsenz in allen Repertoiresegmenten ist es möglich, von kurzfristigen Nachfrageschwankungen und der Mode unterworfenen Präferenzänderungen profitieren zu können. ${ }^{275}$

So hat im Zeitraum von 1992-1996 der Anteil der klassischen Musik am Wert der durch Tonträger verkauften Musik von 9,5\% auf 7,8\% abgenommen und derjenige von Dance-Produkten von $4,2 \%$ auf $13,2 \%$ zugenommen. Dance ist in seinen Ausprägungen Rap, House, Techno, Jungle etc. die Oberkategorie der erfolgreichen Trends der betrachteten Jahre ${ }^{276}$ Für das Argument der strategischen Produktdifferenzierung bedeutet dies, da $\beta$ ein nennenswertes Wachstum des Tonträgermarktes nur durch die Etablierung neuer Produkte bzw. Produktgruppen entsteht. Die Marktdurchdringung der neuen Produkte wiederum setzt organisatorisch und finanziell gesehen erhebliche Aufwendungen furr entsprechendes Marketing voraus. Diese sog. „Style Change Costs“ sind für kleinere Tonträgerhersteller im Vergleich zu den Majors mit höheren Kosten verbunden, ${ }^{277}$ da letztere economies of scale in den absatzfördernden Unternehmensfunktionen realisieren. Independents sind dazu nicht in der Lage ${ }^{278}$ Sie entdecken

${ }^{271}$ In Märkten, in denen die ständige Geschmacksveränderung entsprechend stăndig neue Produkte erfordert, wird das Produkt zur ökonomischen Variablen. Vgl. Chamberlin, Edward H., The Product as an Economic Variable, in: Towards a More General Theory of Value, 2nd printing, New York 1966, S. 105-137.

${ }^{272} \mathrm{Vgl}$. Alpert, Leon, Estimating A Multi-Attribute Model for Different Music Styles, in: Journal of Cultural Economics, Vol. 7 (1983), S. 63-81. Alpert untersucht anhand eines ökonometrischen Modells, ob die unterschiedlichen Konsumentenpräferenzen sich in den Repertoiresegmenten und den Marketingstrategien der Tontrăgerhersteller wiederfinden.

${ }^{273}$ In Märkten, in denen bereits eine starke Produktdifferenzierung besteht, kann weitere Ausdifferenzierung eine profitablere Strategie der etablierten Unternehmen sein als z. B. Limitpricing. Vgl. Schmalensee, Richard, Entry Deterrence in the Ready-to-Eat Breakfast Cereal Industry, in: Bell Journal of Economics,

S. 311-313 und S. 323-324.

${ }^{274}$ Diesen Multiplikatoreffekt der Produktdifferenzierung durch erfolgreiche Setzung eines Musiktrends beschrieb Burke in seiner empirischen Untersuchung. Vgl. Burke 1996b, supra, S. 155.

${ }^{275} \mathrm{Vgl}$. Thurow, Norbert, und Peter Zombik, op. cit., S. 206 f.

${ }^{276} \mathrm{Vgl}$. BPW 1997, S. 13.

277 Vgl. Menge, John A., supra, S. 639 f.

278 Ihre Produktinnovationsrate ermöglicht nicht die Realisierung von scale economies in den genannten Unternehmensbereichen. 
zwar die Musiker, die mit ihrer Musik das Potential für neue Trends ermöglichen, können diese aber nicht alleine vermarkten, da sie hierzu die Hilfe der Majors benötigen, wenn sie sie nicht ganz an sie verlieren. Da Independents Nischenbearbeiter sind, ist es ihnen nur möglich, in einzelnen Segmenten Produktdifferenzierung zu betreiben, nicht jedoch in allen Segmenten, die als Summe den Tonträgermarkt bilden. So kehrt sich der Vorteil der Independents in eine Wachstumsbarriere um, da die Majors alle erfolgreichen Produktdifferenzierungen mitmachen bzw. absorbieren. ${ }^{279}$ Produktdifferenzierung als strategische Barriere setzt daher die Präsenz in den verschiedenen Segmenten des Tonträgermarktes und die Fähigkeit voraus, die Differenzierungsvorteile unternehmensintern zu realisieren. ${ }^{280}$

\subsubsection{Das Verhalten des Tonträgerhandels}

Zuerst wird auf der Grundlage der bereits beschriebenen Konzentrationsentwicklung die Verhandlungsmacht des Handels gegenüber den Tonträgerherstellern thematisiert. Danach wird das Verhalten des Tonträgerhandels hinsichtlich der Kriterien der Betriebsgröße sowie der Sortiments- und der Preispolitik untersucht. Von Interesse sind ferner jeweils die Wirkungen des Handelsverhaltens im Hinblick auf Käuferreichweite und Kaufintensität der Nachfrage sowie die Wirkung von Aktionsparametern gegenüber den Konkurrenten auf der Handelsstufe.

\subsubsection{Verhandlungsmacht gegenüber den Tonträgerherstellern}

Für die Verhandlungsmacht des Handels bzw. einer Handelsorganisation gegenüber den Tonträgerherstellern ist die prozentuale Abnahmemenge am Umsatz der jeweiligen Tonträgerhersteller entscheidend. ${ }^{281}$ Die Auftragsgröße beeinflußt die Verhandlungsmacht gegenüber dem jeweiligen Hersteller und korreliert positiv mit der Verhandlungsposition des Handels. ${ }^{282} \mathrm{Zu}$ sätzlich kann eine goodwill-bedingte Abhängigkeit auftreten, wenn Tonträgerhersteller in einer bestimmten Vertriebsform vertreten sein wollen. ${ }^{283}$ Dieses für Freizeitkonsumgüter - wie Tonträger - relevante Nachfragemachtkriterium bezieht sich besonders auf die Schaffung eines Markenimages. ${ }^{284}$ Im Tonträgermarkt besteht diese Form der Abhängigkeit vor allem bei der

${ }^{279}$ Die Absorption der von Independents getätigten Produktdifferenzierung durch die Majors geschieht dabei durch das direkte Abwerben der Musiker oder ein gleichartiges Produktangebot mit anderen Musikern.

$280 \mathrm{Vgl}$. Williamson, O. E. 1963, supra, S. 113. „(..) selling expense is treated as being the product differentiation barrier. und (...) it is the marketing practices of the firm which permit the firm to realize its advantage."

281 Vgl. Lademann, Rainer, Nachfragemacht von Handelsunternehmen: Analyse der Begriffs-, Erklärungs- und Rechtstatsachenprobleme, Göttingen 1986, S. 80.

$282 \mathrm{Vgl}$. Kirschner, Ulrich, Die Erfassung der Nachfragemacht von Handelsunternchmen: Eine Analyse der okonomischen Beurteilungskriterien und der wettbewerbsrechtlichen Instrumente im Bereich der Verhaltenskontrolle, Frankfurt am Main u. a. 1988, Hohenheimer Volkswirtschaftliche Schriften Bd. 8, S. 124.

283 Zuerst beschrieben wurden goodwill-bedingte Abhängigkeitsverhältnisse von Porter. Vgl. Porter, Michael E., Interbrand Choice, Strategy, and Bilateral Market Power, Cambridge, Mass. und London 1976.

${ }^{284}$ Markenstărkung und Markentransfer als Strategie von Tonträgerherstellern führten z. B. zur Zusammenarbeit mit dem Mineralölunternehmen Aral. Porter hat die goodwill-bedingte Abhängigkeit für Güter des nicht lebensnotwendigen Bedarfs (nonconvenience outlets) durch eine empirische Untersuchung bestätigt. Vgl. Porter, Interbrand Choice, op. cit., S. 222. 
Etablierung von neuen Vertriebswegen, sog. non traditional outlets. ${ }^{285}$ Zusätzlich haben Nachfrageschwankungen Einfluß auf die Verhandlungsstärke des Handels. ${ }^{286}$

Faktoren, die die Verhandlungsmacht der Handelsstufe begrenzen, sind der geringe Unterschied in der Sortimentsflexibilität des Handels und der Produktionsflexibilität der Hersteller. Ebenso haben die für z. B. im Lebensmittelhandel gültigen Thesen im Hinblick auf die Umstellungsflexibilität im Tonträgermarkt keine Geltung. ${ }^{287}$ Zudem bedingt der zeitlich kurze Produktlebenszyklus des einzelnen Tonträgertitels Rahmenverhandlungen, die auf den Verkaufserfahrungen vorangegangener Jahre basieren. Erlangt ein Tonträgertitel eine große Medienaufmerksamkeit und Nachfrage, ist er für den Handel unverzichtbar, die Verhandlungssituation verlagert sich entsprechend. ${ }^{288}$

Bei einer Befragung der Tonträgerhersteller zur Einschätzung der Verhandlungsmacht des Handels wurde diese sowohl von Majors als auch von Independents als hoch angesehen. ${ }^{289}$ Ebenso hoch wurde der daraus resultierende Wettbewerbsdruck eingeschätzt.

\subsubsection{Betriebsgröße des Tonträgerhandels und Nachfrage}

Economies of large scale sind eine wesentliche Begründung für die Zusammenfassung größerer Einheiten im Handel. Zum Sinken der durchschnittlichen Totalkosten bei Lagerhaltung, Transport, Filialisierung, Personal, den sog. realen Effekten, treten die pekuniären economies of scale, die sich auf Finanzierungsvorteile und geringere Einstandspreise erstrecken. ${ }^{290}$ Demgegenüber stehen die Vorteile der kleineren Handelsbetriebe, die in einer größeren Flexibilität der Sortimentsgestaltung, der Motivation des Personals - insbesondere, wenn der Manager Eigentümer ist - und der möglichen Ausrichtung auf - durch Marktsegmente definierte - Nischen bestehen. ${ }^{291}$ Vorteile in der Beschaffung der Großunternehmen können von kleineren Unternehmen durch Einkaufskooperationen ausgeglichen werden. ${ }^{292}$

Für die Nachfrage nach Tonträgern besteht bei größeren Handelsformen eine Anziehungskraft, die aus der Größe resultiert. Wesentlicher Grund ist die Konsumentenvermutung der Vorteilhaftigkeit. Bewirkt sie nur eine Umverteilung zwischen Käufern der Region, erhöht sich die Käuferreichweite nicht. Bewirkt sie eine längere Aufenthaltsdauer im Handelsgeschäft mit vermehrter Geldausgabe, steigert sich die Kaufintensität. Den Vorteilen der Größe steht allerdings als Nachteil die sog. Schwellenangst gegenüber, die wegen der Erschwerung persönlicher

285 Das gilt nur, wenn mit dem neuen Vertriebsweg ein Markentransfer erreicht werden kann.

${ }^{236}$ Bei einer geringen Nachfrage steigt $c$. p. die Verhandlungsmacht et vice versa.

$287 \mathrm{Vgl}$. Schmidt, Ingo, 1997a, S. 109.

${ }^{258}$ Das Unverzichtbarkeitskonzept kann dann angewandt werden. Die Konsumenten werden den entsprechenden Titel im Handel einfordern. (sog. pull-Effekt, vgl. Nieschlag/Dicht/Hörschgen, op. cit., S. 535.)

289 Die Befragung wurde 1990/91 von Schulze durchgeführt. Vgl. Schulze, Ralf, op. cit., S. 354 u. S. 173 f.

$290 \mathrm{Vgl}$. Koutsoyiannis, A., Modern Microeconomics, 2. Aufl., London 1981 (Reprint), S. 126-137.

291 Vgl. De Alessi, Louis, Property Rights, Transaction Costs, and X-Efficiency: An Essay in Economic Theory, in: American Economic Review, Vol. 73 (1983), S. 64-81.

292 Zur kartellrechtlichen Problematik der Einkaufskooperationen vgl. Selex-Tania, in: WuW/E BKartA $2191 \mathrm{ff}$. und OLG $3737 \mathrm{ff}$. 
Kommunikation zur Abnahme von Käuferreichweiten und Kaufintensitäten führt. Eine optimale Betriebsgröße des Tonträgerhandels liegt daher für die Käuferreichweite unterhalb derjenigen für die Kaufintensität. Eine eindeutige Überlegenheit kleinerer oder größerer Betriebsformen des Handels kann angesichts der ambivalenten Wirkung auf die Nachfrage nicht nachgewiesen werden.

\subsubsection{Sortimentsstruktur und Sortimentspolitik}

Zentraler Entscheidungsparameter eines Handelsbetriebs ist seine Sortimentsstruktur und Sortimentspolitik. Für den Handel mit Tonträgern ist festzustellen, daß Handelsbetriebe mit unterschiedlicher Sortimentsstruktur Tonträger vertreiben. Nimmt man als Bezugsgröße den Anteil, den der Handel mit Tonträgern am gesamten Umsatz einnimmt, kann untergliedert werden in folgende Sortimentsstruktur:

- Tonträger spielen eine geringe Bedeutung in einem nicht durch Musik geprägten Sortiment (Warenhauskonzerne, Verbrauchermärkte),

- Tonträger erbringen etwa gleichwertige Umsatzanteile in Kombination mit Unterhaltungselektronik oder Musikalien (Elektromärkte),

- aus Tonträgern besteht der Großteil des Handels (Megastores, Facheinzelhandel).

Die Sortimentsstruktur hat Auswirkungen auf die Sortimentspolitik der Handelsbetriebe nach deren einzelwirtschaftlichem Kalkül. Im Hinblick auf den Handel mit Tonträgern lassen sich die unterschiedlichen Sortimentspolitiken erfassen mit dem Kriterium der Sortimentsbreite. Allgemein beschreibt die Sortimentsbreite das Angebot zusätzlicher Kaufmöglichkeiten verschiedener Waren. Bezogen auf den Tonträgermarkt bedeutet die Sortimentsbreite die Anzahl der in der Warengattung Tonträger geführten Tonträgerkategorien und der gefürten Musiktitel. ${ }^{293}$ Letztere wiederum können zu verschiedenen Sortimentsarten ${ }^{294}$ zusammengefaßt werden, aus denen sich die Sortimentsbreite zusammensetzt. Die unterschiedlichen Sortimentsbreiten ${ }^{295}$ lassen sich folgendermaßen untergliedern: ${ }^{29}$

- Vollsortimenter

- Teilsortimenter

- Klassik-Spezialist

- Pop-Spezialist (Trendsetter)

- Hitverteiler

${ }^{293}$ Neben der Sortimentsbreitc, die die Warengattung, die Warenart und die Artikel (Tontrăger, Tontrăgerkategorie, Titel eines Interpreten) betriff, wird in der Handelsbetricbslehre mit der Sortimentstiefe das Angebot alternativer Kaufmöglichkeiten der ăhnlichen Sorte charakterisiert. Die Sortimentstiefe im Tonträgermarkt besteht nur aus alternativen Angeboten bzw. Aufnahmen der jeweils gleichen Musiktitel. Für die Analyse der Sortimentspolitik beschrănken wir uns daher auf die Sortimentsbreite.

${ }^{294}$ Die Sortimentsarten im Tontrăgermarkt kennzeichnen das jeweilige Repertoiresegment wie z. B. Spezialsortiment (Jazz, Klassik, Kinderrepertoire, Volksmusik etc.), Basissortiment, aktuelle Hitliste der Charts oder als Impuls-Sortiment medienbeworbene Tonträger.

${ }^{295} \mathrm{Zu}$ beachtende Faktoren bei der Entscheidung über die Sortimentsbreite sind u. a.: Bedarf der Konsumenten im Einzugsgebiet, Bedarfsweckung, Sortiment und Preise der Konkurrenz.

${ }^{296}$ Die Untergliederung stammt von den Tonträgerherstellern. Vgl. Mahlmann 1986. S. 93 
Eine einzelwirtschaftiche Sortimentsoptimierung knüpft an ein Sortimentsgleichgewicht an, das durch die Leistungsfähigkeit, gemessen am Umsatzbeitrag eines jeden Artikels, operationalisiert wird. Übertragen auf den Tonträgermarkt wird die Leistungsfahigkeit gemessen nach den wöchentlichen Verkäufen einer Tonträgerkategorie. Das führt zur Popularitätskurve, mit der die Leistungsfähigkeit, gemessen nach Umsatzwert, dargestellt wird. Beispielsweise hat die Popularitätskurve von einem Hitlistensortiment einen steil sinkenden Verlauf, mit ihr wird ausgedrückt, daß z. B. der erste Platz der Hitliste $100 \mathrm{mal}$ in einer Woche verkauft wird, der 10. Platz etwa $40 \mathrm{mal}$ und der 50 Platz etwa $10 \mathrm{mal}^{297}$ Anhand der Popularitätskurve lassen sich Schätzungen über Verkaufsverläufe der verschiedenen Sortimentsarten anstellen.

Im folgenden untersuchen wir die Auswirkungen der Sortimentspolitik des Handels auf die Nachfrage. Die Sortimentsbreite kann zu groß sein (Übersortiment) mit der Folge von Retouren, deren Risiko sich der Einzelhandel entsprechend spezieller Retourenregelungen mit den Großhändlern oder Herstellern teilt. Die Sortimentsbreite kann zu klein sein (Untersortiment). Artikel werden nachgefragt, die nicht vorhanden sind, mit der Folge, daß der Kaufwunsch sich im Kauf anderer Produkte äußert. Der Tonträgermarkt erleidet dann einen Opportunitätsverlust. ${ }^{298}$ Die konkreten Auswirkungen der Sortimentsbreite auf die Nachfrage lassen sich nicht quantifizieren. Es ist jedoch davon auszugehen, daß mit zunehmender Sortimentsbreite die Kaufintensität zunimmt, jedoch mit abnehmenden Grenzraten. Demgegenüber nimmt die Käuferreichweite mit zunehmender Sortimentsbreite erst zu und dann wieder ab, da das Angebot für Extensivkäufer nicht mehr handhabbar ist.

Zusätzlicher Aktionsparameter der Sortimentspolitik ist die Sortimentsdynamik. Die Dynamik des Sortiments als Entscheidungsproblem des Handels bezieht sich auf die Aufnahme neuer und die Eliminierung alter Titel. Die Aufnahme neuer Titel ist entscheidend für die Diffusion. Der Lebenszyklus eines Titels wird zum Kriterium der Sortimentsauswahl. Denn Händler mit einem Sortiment neuer Titel sind gezwungen, die Intensivkäufer als Multiplikatoren anzusprechen und die Diffusion der neuen Musiktitel zu unterstützen. ${ }^{299}$ Ist die Markteinführung erfolgreich und der Musiktitel in die Hitliste gelangt, partizipieren Händler mit reinem Hitlistenrepertoire am Erfolg der Markteinführung durch andere ohne eigenes Risiko. Auf der Handelsstufe sind die Auswirkungen der Dynamik des Sortiments in externen Effekten zu sehen. Wir sprechen hier von den externen Effekten der Induzierung von Nachfrageverbundenheit etwa durch Mitläufereffekte. Der Händler mit einem Vollsortiment schafft Nachfrage, die nicht ihm, sondern anderen Händlern zugute kommt. Im Hinblick auf die Eliminierung alter Titel aus dem Sortiment vollzieht der Handel die Produktinnovationspolitik der Tonträgerhersteller nach, die impliziert, daß für neue Titel Platz geschaffen werden muß ${ }^{300}$ Ein einzelwirtschaftlicher Ver-

$297 \mathrm{Vgl}$. Mahlmann 1986, S. 95 f. Dieses Beispiel wurde konstruiert auf der Basis von Verkaufszahlen, die reprăsentativ für einen Tonträgerhändler in einem regionalen Absatzgebict sind.

298 Vgl. Mahlmann 1986, S. 96.

299 Aus Sicht der Tontrăgerhersteller erfülen sie damit bei der Markteinführung von neuen Musiktiteln eine wichtige Funktion.

${ }^{300}$ Die eigenstăndige Handelsfunktion besteht darin, das Ende des Produktlebenszyklus eines Titels zu erkennen und den Herstellem anzuzeigen, wann sie die betreffenden Titel aus dem Katalog streichen können. Erkennt der Handel nicht, daß die Gruppe der Nachzügler als Konsumenten auftritt und damit der Produktlebenszyklus zuende geht, entstehen durch Retouren Verluste. 
lust, der aus der falschen Antizipierung der Länge von Produktlebenszyklen einzelner Tonträgertitel resultiert, ist in der Summe gesamtwirtschaftich als eine Verschwendung von Ressourcen zu kritisieren, deren Ursache in der Verkürzung der Produktlebenszyklen liegt. ${ }^{301}$

\subsubsection{Preispolitik gegenüber der Nachfrage und Preiswettbewerb auf der Handelsstufe}

Die Preispolitik des Handels gegenüber der Nachfrage wird anhand der verschiedenen Prinzipien der Nachfrageorientierung, der Konkurrenzorientierung, der Kostenorientierung und der Preisdifferenzierung charakterisiert. Die nur nachfrageorientierte Preispolitik setzt eine Marktintransparenz aufgrund zeitlicher, räumlicher, sachlicher oder persönlicher Präferenzen und damit eine weitgehend monopolistische Position voraus. Sie ermöglicht die Preissetzung innerhalb von Preisakzeptanzgrenzen, die seitens der Nachfrage nach unten infolge der Vermutung von Qualitätsmängeln und nach oben durch die mangelnde Zahlungsbereitschaft bestimmt sind. Innerhalb der Akzeptanzgrenzen existieren nochmals unterschiedliche Bereiche, ${ }^{302}$ in denen die Nachfrage jeweils elastischer reagiert. Oberhalb und unterhalb dieser Bereiche reagiert die Nachfrage nur wenig. Daher kann der Handelsbetrieb hier eine nur nachfrageorientierte Preispolitik betreiben.

Durch eine Konkurrenzsituation auf dem z. B. regionalen Markt des Tonträgerhandels kann sich der einzelne Händler nicht mehr ausschließlich an seiner Nachfrage orientieren, er muß auch die Wettbewerbssituation berücksichtigen. Im Gegensatz zum Verhältnis der Tonträgerhersteller untereinander herrscht auf der Handelsstufe reger Preiswettbewerb. ${ }^{303}$ Großbetriebsformen des Einzelhandels benötigen ein entsprechend großes Nachfragepotential, das i. d. R. das lokale Potential übersteigt. Daher werden diese Einzelhandelsformen versuchen, ihr Einzugsgebiet mit einem Verdrängungswettbewerb, den sie mit Hilfe aggressiver Preispolitik führen, auszudehnen. Auf den Preisvorteil reagieren insbesondere die preiselastischeren Intensivkäufer, die dann bei den kleinen und mittleren Handelsformen mit ungünstigeren Kostensituationen als Absatzpotential ausfallen. Für die kleineren Handelsformen führt das zu einer schlechteren Wettbewerbssituation bis hin zum Ausscheiden aus dem Markt. In der Folge halten sich Konsumenten (vor allem Gelegenheitskäufer) mit einem Vermeidungsverhalten (sog. Schwellenangst) gegenüber Großbetrieben mit dem Kauf zurück. Die Käuferreichweite nimmt ab mit dem Rückgang der kleineren und mittleren Betriebsgrößen. ${ }^{304}$

${ }^{301}$ Der Zusammenhang zwischen Wohlfahrtseffekten, Konsumgüterwerbung. Produktlebenszyklen und Konzentration wird u. a. untersucht von Moritz, Carl Heinz, Marktpolitische Probleme der Konsumgüterwerbung, Berlin 1977, S. $30 \mathrm{ff}$.

${ }^{302}$ Solche Preisbereiche sind z. B. furr Tonträger 20 oder 30 DM.

${ }^{303} \mathrm{Vgl}$. Belinfante/Johnson, supra, S. 12.

${ }^{304}$ Daraus folgern die Tonträgerhersteller, daß ihre Absatzpolitik dafür sorgen muß, daß ein flächendeckendes Netz von kleineren und mittleren Handelsbetrieben erhalten bleibt. In einem Gesprăch mit Vertretern der Industrie erfuhr der Verfasser, dab die Industrie dazu folgende Instrumente einsetzt: Konzeptionelle Beratung des Verbandes von kleineren und mittleren Tonträgerhändlern, großzügigere Retourenregelungen. Werbungskostenzuschüsse. Markteintrittshilfen für Handelsneugründungen durch Konditionengestaltung. und gemeinsame Entwicklung von Verkaufsstrategien. 
Die Formen des Preiswettbewerbs bestehen darin, daß es entweder mehr als einen Preisführer gibt oder um die Preisführerschaft gekämpft wird. Das Zusammenspiel von erwarteter und tatsächlicher Nachfrage führt zu Preissenkungen eines Händlers, der das Preisniveau seiner Konkurrenten signifikant unterbietet, um seinen Umsatz und damit Marktanteil zu Lasten seiner Konkurrenten zu erhöhen. Die Konkurrenten wiederum reagieren ebenfalls mit Preisreduktionen, um ihren ursprünglichen Marktanteil zurückzuerlangen. Diese Aktions-Reaktionskette endet i. d. R. mit einer zumindest ähnlichen Marktanteilsverteilung der Handelsunternehmen bei einem insgesamt niedrigeren Preisniveau. ${ }^{305}$ Diese Form des Preiswettbewerbs ermöglicht den Konsumenten eine größere Nachfrage und c. p. die Realisierung einer höheren Konsumentenrente, während die Konkurrenz unter den Händler deren Produzentenrente sinken läßt. Es ergeben sich aber insgesamt positive Wohlfahrtseffekte, da eine insgesamt höhere Marktversorgung die Summe aus Konsumenten- und Produzentenrente steigen läßt.

Hat der Preiswettbewerb auf der Händlerebene die Funktion, Konkurrenten aus dem Markt zu verdrängen, ergeben sich andere Wohlfahrtseffekte. Einzelwirtschaftlich betrachtet wird ein Preiswettbewerb mit Verdrängungsabsicht durch einen Händler ausgelöst, der eine bessere Kosten- und Liquiditätslage als seine Konkurrenten aufweist und im Gegensatz zu ihnen über Möglichkeiten des kalkulatorischen Ausgleichs verfügt. ${ }^{306}$ Durch Verdrängung gefährdet sind Einzelhandelsbetriebe mit tiefem Sortiment, schlechteren Einkaufskonditionen und geringen Möglichkeiten des kalkulatorischen Ausgleichs. ${ }^{307}$ Gelegentlich wird dieser Verdrängungswettbewerb auch durch Verkäufe unter Einstandspreis geführt, wobei die systematische Verdrängungsabsicht i. d. R. nicht nachgewiesen werden kann ${ }^{308}$ Aus einzelwirtschafticher Sicht sind Nachteile der Preissetzung unter Einstandskosten in der Zerstörung des Qualitätsimages der Tonträgerhersteller und damit der Zerstörung des Referenzpreises für die umkämpften Artikel zu sehen, der durch die Nachfrager auch auf andere Artikel übertragen wird, und schließlich in der Reduktion der Geschenkartikelfunktion von Tonträgern, wenn diese zu billig werden. ${ }^{309}$

Einzelwirtschaftichen Nachteilen steht eine gesamtwirtschaftlich ambivalente Wirkung gegenüber. Ein gesamtwirtschaftlicher Vorteil besteht in der Phase des Preiskampfes in der höheren Konsumentenversorgung zu niedrigeren Preisen. Gesamtwirtschaftliche Nachteile entstehen erst, wenn die Verdrängung erfolgreich ist, damit für die Nachfrager höhere Transport- und Wegekosten entstehen, langfristig die Angebotsvielfalt von Tonträgern abnimmt und die übriggebliebenen Unternehmen ihre Preise erhöhen können. ${ }^{310}$ Die Verdrängungsfolge des Preis-

${ }^{305}$ Die Ergebnisse des Preiswettbewerbs werden vom jeweiligen Modellrahmen determiniert. Für den Wettbewerb unter Handelsunternehmen, deren Sortimentsbreite hinsichtlich der Tonträger nicht kongruent ist, ist von heterogenen Oligopolen auszugehen. Vgl. hierzu Gutenberg, Erich, Grundlagen der Betriebswirtschaftslehre, Band 2, 17. Aufl., Berlin u. a. 1984, S. 290-319.

306 Diese Möglichkeiten ergeben sich z. B. für Großbetriebsformen des Einzelhandels durch günstigere Einstandkosten und Rationalisienungsmöglichkeiten und für Filialisten durch Vorteile des zentralen Einkaufs.

307 Zusătzlich zu den Preisreduktionen haben diese Handelsbetriebe mit Umsatzrückgängen bei nachfrageverbundenen Artikeln und Substituten zu rechnen.

$308 \mathrm{Vgl}$. Hitlisten-Platten, in: WuW/E BGH $2977 \mathrm{ff}$.

${ }^{309}$ Die Geschenkartikelfunktion wird dadurch reduziert, daß niedrige Preise auch vom Beschenkten wahrgenommen werden. Vgl. Abschnitt 4.3.4.2.

${ }^{310}$ Der Individualschutz kleinerer und mittlerer Unternehmen vor relativer Marktmacht durch Großbetriebsformen des Einzelhandels wird in der Folge des BGH-Urteils zu den Hitlisten-Platten von einigen Autoren 
wettbewerbs läßt sich nicht unterbinden mit dem Verweis auf unbillige Behinderung der Konkurrenten durch Kampfpreisstrategien i. S. des $\S 26$ Abs. 4 GWB. ${ }^{311}$ Denn der BGH hat unbillige Behinderung nur dann angenommen, wenn einzelne Wettbewerber gezielt vom Markt verdrängt werden sollen oder die Voraussetzungen für wirksamen Wettbewerb insgesamt nachhaltig beeinträchtigt werden. ${ }^{312}$

Die kostenorientierte Preisbildung hat im Tonträgerhandel zwei Funktionen. Die Einstandskosten für Tonträger, neben Personal und Miete die wichtigste Kostenart, haben insbesondere für den Verdrängungswettbewerb die Funktion, den Preis nach unten zu begrenzen. Eine weitere Senkung des Preisniveaus läßt sich nur realisieren durch die Verringerung der Beschaffungskosten, Reduzierung der Handelsleistung oder Rationalisierung. Lediglich mitbestimmende Funktion hat eine Kostenorientierung bei der kompensatorischen Preisbildung (Mischkalkulation). Werden im Tonträgermarkt diejenigen Produkte zu Ausgleichsnehmern, ${ }^{313}$ deren Nachfrage am höchsten ist, können die Kompensationsartikel mit einer geringeren Preiselastizität der Nachfrage nicht aus der Sortimentsgruppe der Tonträger, sondern nur aus anderen Sortimentsgruppen kommen. ${ }^{314}$ Der Effekt dieser Preissetzung ist eine Besserstellung der Konsumenten, deren Versorgung annähernd zu Kostenpreisen möglich ist, und eine Schlechterstellung derjenigen Handelsbetriebe, deren Sortiment im wesentlichen aus Tonträgern besteht.

Schließlich sind die Wirkungen einer Preisdifferenzierung zu analysieren. Wie in Abschnitt 4.3.2.3 hergeleitet, definieren im Tonträgermarkt Preisklassen der Hersteller gegenüber dem Handel Produktgruppen bzw. -kategorien. Daher ist es ökonomisch rational, daß die Hersteller die Übernahme ihrer Preissetzung gegenüber dem Endverbraucher erwarten. Dabei ist jedoch die marktbeobachtende Funktion des Handels Voraussetzung dafür, daß neben der Preisdifferenzierung von verschiedenen Produktgruppen eine zeitliche Differenzierung stattfinden soll. Wie bereits im Abschnitt Produktpolitik der Tonträgerhersteller hergeleitet, stellt jede Veröffentlichung eines neuen Tonträgers eine Produktinnovation dar, die der Markteinführung bedarf. Soll die Diffusion eines speziellen Tonträgertitels durch niedrige Preise unterstützt werden, damit z. B. Intensivkäufer als Multiplikatoren die Diffusion beschleunigen, muß der Fachhändler die Preise wieder erhöhen, bevor im Phasenverlauf der Diffusion die Mehrheiten als Käufer auftreten. Anderenfalls ist die akquisitorische Wirkung der ursprünglichen Preissenkung nicht mehr gegeben. Diese Preispolitik ist für den Tonträgerfachhändler rational, wenn er Ge-

kritisch als nicht ausreichend angesehen. Vgl. stellvertretend Schmidt, Ingo, Hauptprobleme der 6. Kartellnovelle, in: Wirtschaftsdienst, 77. Jg. (1997), S. 637-646, hier S. 643. [Schmidt, Ingo, 1997b]

$311 \mathrm{Vgl}$. Schmidt, Ingo, 1997a, S. $115 \mathrm{f}$. Vgl. auch Schmidt, Ingo, und Jürgen Wuttke, Leistungswettbewerb und unbillige Behinderung i. S. des $\S 26$ Abs. 4 GWB, in: Betriebs-Berater, 53. Jg. (1998), S. 753-758.

${ }^{312} \mathrm{Vgl}$. Hitlisten-Platten, in: WuW/E BGH 2977 ff. Der BGH führt aus, daß die Machtmacht geeignet sein müsse „durch Behinderung kleiner oder mittlerer Wettbewerber die strukturellen Voraussetzungen für wirksamen Wettbewerb ... nachhaltig zu beeinträchtigen." Selbst bei systematischem Vorgehen müssen noch Aussagen über den Umfang und die Marktbedeutung der Maßnahme des Untereinstandspreises getroffen werden können, die begründen, daß gerade durch sie die dargelegte Gefahr für den Wettbewerb entsteht.

313 Ausgleichnehmer sind Produkte, die niedrigpreisig angeboten werden (z. B. als Sonderangebot $z$. T. unter Einstandspreis). Im Tonträgerhandel ist vorwiegend aktuelles Hitrepertoire (Chartitel) Ausgleichsnehmer.

314 Werden Backkatalog-Tonträger als Hochpreisartikel angeboten, wird wegen der Nachfrageverbundenheit innerhalb der Sortimentsgruppe Tonträger keine Kompensationswirkung erreicht 
winneinbußen vermeiden will. Für Händler, die Mischkalkulation betreiben, wird jetzt der Bezug des Tonträgers und der Weiterverkauf als Ausgleichsnehmer (sog. Lockvogel) interessant. Eine Preiserhöhung durch die Fachhändler bedeutet für sie einen signifikanten Wettbewerbsnachteil, während in Verbrauchermärkten und Warenhäusern die Mischkalkulation eine Kompensation durch andere Sortimentsteile ermöglicht. Für informierte Konsumenten bedeutet die zeitliche Preisdifferenzierung einen Vorteil, der nur in dem Fall an die restlichen Konsumenten weitergegeben wird, in dem das Produkt als Ausgleichsnehmer fungiert. Der Handel gibt in diesem Fall die Ergebnisse seiner Nachfragemacht an die Konsumenten weiter, die den Vorteil dann erzielen, wenn sie keine Kompensationsartikel kaufen.

\subsubsection{Das Verhalten der Nachfrager nach Tonträgern}

Das Konsumentenverhalten der Nachfrager nach Tonträgern wird mit Hilfe der Kriterien der Kaufintensität und der Nachfrageelastizitäten im Hinblick auf Aktionsparameter der Tonträgerhersteller und des Handels untersucht. Abschließend werden die Konsequenzen für die zukünftige Konsumentenstruktur von Tonträgern abgeleitet.

\subsubsection{Kaufintensitäten}

Die Kaufintensität wird definiert als Häufigkeit, mit der die Konsumenten pro Jahr Tonträger kaufen. Sie kann auf den Wert (zu Endverkaufspreisen) oder die Stückzahl bezogen werden. ${ }^{315}$ Für eine kontinuierliche Marktbeobachtung des Konsumentenverhaltens wurde die Kaufintensität (in Stückzahlen) in drei Gruppen klassifiziert:

- Intensivkäufer, die 10 oder mehr Tonträger pro Jahr kaufen,

- Durchschnittskäufer, die zwischen vier und neun Tonträgern pro Jahr kaufen, und

- Extensivkäufer, deren Tonträgerkonsum sich auf ein bis drei Tonträger beschränkt.

Die klassifizierten Käufergruppen können in Relation gesetzt werden zu einer Grundgesamtheit, die alle potentiellen Tonträgerkonsumenten umfaßt (potentielle Käuferreichweite). Hierzu gehört der Teil der Bevölkerung der Bundesrepublik, der 10 Jahre oder älter ist, und in einem Haushalt lebt, in dem mindestens ein Abspielgerät für Tonträger existiert. ${ }^{316}$

Die Intensivkäufer umfaßten 1996 von der Personenzahl her nur 5,7\% der betrachteten Grundgesamtheit. ${ }^{317}$ Sie trugen in demselben Jahr zu 42,9\% der Gesamtnachfrage bei. Die Gruppe der Intensivkäufer sank von 1993 bis 1996 sowohl von der Personenzahl her (von $7,9 \%$ auf $5,7 \%$ der betrachteten Grundgesamtheit) als auch von ihrem Anteil am Gesamtumsatz von Tonträgern (von $56,8 \%$ auf $42,9 \%$ ).

315 Bezogen auf den Wert lag die Kaufintensităt 1995 nominal bei 160,30 DM. Der Mittelwert der Jahre 198595 lag bei 138 DM. Die Kaufintensităt in Stück schwankte von 1985 bis 1995 zwischen 9,4 und 7,2 Stück. Ein eindeutiger Trend war nicht festzustellen. Vgl. Mahlmann 1997, S. 178.

${ }^{316}$ Für 1996 beträgt diese Grundgesamtheit 62,5 Millionen potentieller Konsumenten. Vgl. IPS (1996), S. 10.

${ }^{317} \mathrm{Vgl}$. BPW 1997, op. cit., S. $29 \mathrm{ff}$. 
Durchschnittskäufer stellten 1996 13,0\% der Grundgesamtheit und waren für $31,4 \%$ des Umsatzes in demselben Jahr verantwortlich. Der relative Anteil der Durchschnittskäufer an der betrachteten Grundgesamtheit blieb im Zeitraum seit 1993 annähernd konstant. Ihr relativer Anteil am Gesamtumsatz stieg von ca. einem Viertel auf knapp ein Drittel des Umsatzes.

Der restliche Nachfrageteil wird den Extensivkäufern zugerechnet. Ihr Umsatzanteil von $25,7 \%$ im Jahr 1996 verteilt sich auf eine Personengruppe von 32,4\% der Grundgesamtheit. Hinsichtlich dieser Käufergruppe ist festzustellen, daß sie in den Jahren seit 1993 sowohl von der Personenzahl her (Wachstum ihres Anteils am gesamten Konsumentenpotential von 25,9\% auf $32,4 \%$ ) als auch von der durch sie bewirkten Umsatzgröße (Steigerung von $16,5 \%$ auf $25,7 \%$ ) ständig gestiegen ist. Die folgende Abbildung 21 zeigt die Verteilung der Kaufintensität auf die potentielle Käuferreichweite:

\section{Abbildung 21: Bevölkerungs- und Umsatzanteile von Käufergruppen 1996}

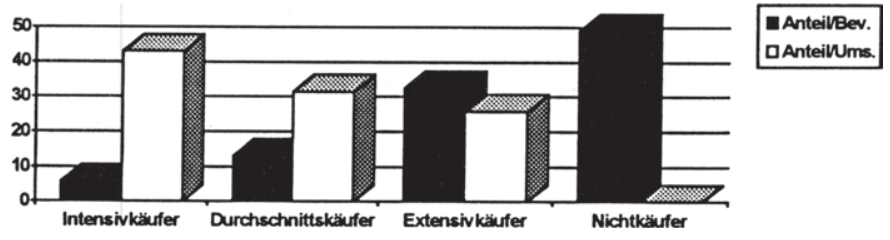

Quelle: IPS, BPW 1997, S. 29-31.

Die Entwicklung der letzten Jahre hat eine von Brancheninsidern aufgestellte Regel widerlegt, nach der 10\% der Bevölkerung zwei Drittel der Nachfrage und weitere $40 \%$ das restliche Nachfragedrittel tragen. ${ }^{318}$ Es kann zwar weiterhin festgestellt werden, daß die Käuferreichweite nicht nennenswert über $50 \%$ liegt und damit knapp die Hälfte der potentiellen Konsumenten bisher überhaupt nicht für den Tonträgerkauf motiviert worden sind, innerhalb der Käufergruppen ist es aber zu bedeutenden Verschiebungen gekommen. Die Extensivkäufer sind die am stärksten gewachsene Konsumentengruppe, deren Anteil sich sowohl durch Verschiebungen vom Intensiv- über den Durchschnittskäufer und von diesem zu Extensivkäufern erhöht hat, zu der aber auch bisherige Nichtkäufer hinzugetreten sind. Die Gruppe der Intensivkäufer sinkt seit Jahren kontinuierlich. Daher ist zu beobachten, daß die Konzentration der Käuferseite - gemessen am Umsatzanteil - abgenommen hat

${ }^{318}$ Mahlmann 1986, S. 69. 


\subsubsection{Kaufverhalten im Hinblick auf Elastizitäten der Nachfrage}

Elastizitäten der Nachfrage lassen sich als Ausdruck des Kaufverhaltens der Konsumenten interpretieren. Die relative Veränderung der nachgefragten Menge an Tonträgern (gemessen in Käuferreichweite und Kaufintensität) wird dabei als Wirkung und damit abhängige Variable aufgefaßt. Die unabhängige Variable, die als ursächlich begriffen wird, gliedert sich in die folgenden Aktionsparameter: Motivations- und Kommunikationsfahigkeit, Preise für Tonträger, Sortimentsbreite und Standorte des Handels.

Motivationen sind Beweggründe für das Handeln. Ihnen liegen Motive zugrunde, von denen für die Kaufhandlung eines Tonträgers angenommen werden kann, daß sie sekundäre oder soziale Motive darstellen. ${ }^{319}$ Aus Motivationen, die sich mit Gegenstandsbeurteilungen verbinden, entstehen Einstellungen. Positive Einstellungen im Hinblick auf Güter signalisieren Kaufbereitschaft bzw. können zur Kaufabsicht werden. ${ }^{320}$ Der Motivationsprozeß ist gekennzeichnet durch die Übertragung von Kaufmotivation auf den Konsumenten. Für den Motivationsprozeß ist ein vorausgehender Kommunikationsproze $B$ notwendig, insbesondere die persönliche Kommunikation. ${ }^{321}$ Persönliche Kommunikation wird im Tonträgermarkt in erster Linie betrieben durch Meinungsführer, die Informationen aus Massenmedien übernehmen und sie als Kommunikationsagenten in die soziale Umwelt der Konsumenten tragen. Meinungsführer wirken dann in einem mehrstufigen Kommunikationsproze $B^{322}$ als Multiplikatoren, weil sie Informationen an ein Vielfaches potentieller Verbraucher weitertragen und den DiffusionsprozeB von Produktinnovationen (d. h. jeder Tonträgerveröffentlichung) beschleunigen. ${ }^{323}$

Die persönliche Kommunikation wird ergänzt durch den persönlichen Verkauf im Handel. Die Kommunikationsaufgaben des Handels im Diffusionsprozeß liegen in der Motivation der Einführung neuer Musiktitel und der Unterstützung bei der Etablierung neuer Musiker im Markt. Hierzu bedarf es eines eigenständigen Einsatzes aller Aktionsparameter des Handels. Die Motivation für einen Kauf ist um so höher, je mehr Harmonisierung zwischen Verkaufspersonal und Kundenstruktur besteht. Dies setzt eine Motivation des Verkaufspersonals voraus. ${ }^{324}$

Zusammengefaßt hat eine bestehende Motivations- und Kommunikationsfähigkeit positive Auswirkungen auf Käuferreichweite und Kaufintensität und damit auf die Gesamtmarktnachfrage. Je schneller über mehrstufige Kommunikationsprozesse (Massenmedien, Multiplikatoren

${ }^{319}$ Soziale oder sekundäre Motive sind gelernt und aus Grundbedürfnissen abgeleitet. Vgl. Nieschlag/Dicht/Hörschgen 1997, op. cit., S. 166. Ein gutes Beispiel für ein sekundäres Motiv ist Selbstverwirklichung.

${ }^{320} \mathrm{Vgl}$. Kroeber-Riel, W., op. cit., S. 170.

321 Vgl. Kaas, K. P., op. cit., S. 52.

${ }^{322}$ Ein Beispiel für einen zweistufigen KommunikationsprozeB ist die Informationsverbreitung über Massenmedien, die nur einige Konsumenten erreicht und die in einer zweiten Stufen durch die Multiplikatoren, die die Information (meistens gefilter und bewertet) weitergeben, zusätzliche Konsumenten erreicht.

${ }^{323} \mathrm{Vgl} \mathrm{Kaas}$, op. cit., S. 117.

${ }^{324}$ Die Motivierung des Personals wird vor allem erzeugt durch Erwartung und Anreiz, z. B. Mitbeteiligung des Personals am MarktprozeB. Vgl. Heckhausen, H., Motivation und Handeln. 2. Auf., Berlin u. a. 1989 , S. $172 \mathrm{ff}$. 
und Handel) die Konsumenten erreicht werden können, um so größer ist die Käuferreichweite, die für den jeweiligen Tonträger erreicht werden kann. ${ }^{325}$ Für die Gesamtmarktnachfrage gilt, $\mathrm{da} ß$ die Käuferreichweite und noch stärker die Kaufintensität mit dem Motivationspotential zunehmen, das den Konsumenten in seiner Einkaufsstätte erreicht.

Die Preiselastizität der Nachfrage nach Tonträgern wird gemessen durch das Kaufverhalten der Konsumenten gegenüber dem Handel als Anbieter. ${ }^{326}$ Das Preisverhalten der Konsumenten wird bestimmt durch Preiswahrnehmung, Preiskenntnis, Urteil über Preisgünstigkeit und das Urteil über die Günstigkeit des Einkaufs. ${ }^{327}$ Die Preiswahrnehmung orientiert sich an Preisschwellen und an Referenzpreisen. ${ }^{328}$ Im Tonträgermarkt werden deshalb gebrochene Preise verwendet, die eher einer niedrigeren Preisschwelle zugeordnet werden, und Preiskategorien als Referenzpreise für Produktgruppen eingesetzt. Die Preiskenntnis der Konsumenten hängt neben dem Informationsverhalten von der Kaufintensität ab. Intensivkäufer haben eine genauere Preiskenntnis als Extensivkäufer. Diese Preiskenntnis bezieht sich sowohl auf den Preis eines speziellen Tonträgers als auch auf die Preise ganzer Repertoiresegmente. Schließlich wird die Preiskenntnis übertragen auf die Einkaufsstätte und damit verhaltensbestimmend.

Das Urteil über die Preiswürdigkeit eines Tonträgers hängt vom musikalischen Inhalt und der Tonträgerkategorie $a b$. Tonträgerkategorien $(C D, M C)$ sind in sich qualitativ homogen und gegeneinander im wesentlichen hinsichtlich des Merkmals analog-digital qualitativ unterscheidbar. Digitale Tonträger sind qualitativ hochwertiger als analoge. Entscheidender ist die Wertigkeit des musikalischen Inhalts. Für die Nutzeneinschätzung der Konsumenten spielt die subjektive Neuheit ${ }^{329}$ der Musik (in Pop-Repertoiresegmenten), ihre Platzierung in Ranglisten (Charts, Hitlisten) und der Bekanntheitsgrad der ausübenden Musiker (in Klassik- und Volksmusik-Repertoiresegmenten) eine wichtige Rolle. Ebenso hat der Preis von Tonträgern eine soziale Teilqualität, ${ }^{330}$ die insbesondere Geschenkkäufe beeinflußt ${ }^{331}$ Der Maßstab für das Preiswürdigkeitsurteil der Nachfrager ist - abhängig von seinem Kenntnisstand - der Referenzpreis, d. h. die Preiskategorie, zu der der musikalische Inhalt üblicherweise gehört. Um diesen Referenzpreis besteht ein Akzeptanzbereich, außerhalb dessen das Angebot als nicht preiswürdig gilt. ${ }^{332}$ Das Urteil über die Günstigkeit des Einkaufs bezieht andere Aspekte als den

${ }^{325}$ Diese Zusammenhănge sind gerade auch wegen des zeitlich kurzen Produktlebenszyklus einer Tonträgerveröffentlichung von Bedeutung.

${ }^{326} \mathrm{Vgl}$. Schumann, Jochen, Grundzüge der mikroökonomischen Theorie, 6. Aufl., Berlin u. a. 1992, S. 79.

${ }^{327} \mathrm{Vgl}$. Müller-Hagedorn, L., Handelsmarketing, 2. Aufl., Stuttgart u. a. 1993, S. 193.

${ }^{328}$ Ein Referenzpreis ist die historisch entstandene Preishöhe für ein genau definiertes Gut und stellt eine Orientierung für den Konsumenten dar. Im Tonträgermarkt sind das die Preishöhen für Preisklassen.

329 Die subjektive Neuheit beschreibt lediglich das Empfinden des Konsumenten. In der Tat sind Musiktitel im Pop-Repertoiresegment oft nur leicht verănderte Versionen bereits veröffentlichter Tontrăger.

330 Soziale Teilqualität charakterisiert den Demonstrationszweck des Konsums, der sich in einem hohen Preis ausdrückt. Thorstein Veblen hat diesen Effekt als erster beschrieben. Der Effekt tritt auf, wenn der Konsum höherpreisiger Güter nach außen sichtbar ist und einen sozialen Status wirksam suggeriert. Vgl. Veblen, Thorstein, The Theory of the leisure class: an economic study of institutions, London 1924.

331 Geschenkkäufe demonstrieren Achtung, Zuneigung, Geschmack des Schenkenden. Die Preiselastizität der Nachfrage nach Geschenkkäufen ist als unelastisch einzustufen.

$332 \mathrm{Vgl}$. Müller-Hagedorn, op. cit., S. $270 \mathrm{f}$. 
Preis mit ein und läßt im Ergebnis einen unelastischeren Verlauf der Nachfrage innerhalb eines engen Preisspielraumes zu, ohne daß die Nachfrage abwandert. ${ }^{333}$

Zusammengefaßt betrachtet hängt eine Kaufentscheidung der Konsumenten neben einer preisinduzierten Nachfragemengenänderung auch von der Qualitätsvermutung - insbesondere bei Geschenkkäufen - ab. Zudem kann der Preis von Tonträgern nicht unabhängig vom Nutzungsverhalten der Konsumenten gesehen werden. Daher wird in Abbildung 22 die Veränderung der Nachfrageintensität I und der Nachfragereichweite $R$ in Abhängigkeit von Preisveränderungen dargestellt. Unterstellt man Nutzenmaximierung der Nachfrage ${ }^{334}$ und ordnet man Tonträger den Freizeitkonsumgütern zu, so bestehen Substitutionsbeziehungen zu anderen Gütern mit ähnlichem Nutzungscharakter. Entsprechend der abnehmenden Grenzrate der Substitution ist das Verhältnis der Austauschbarkeit von Tonträgern mit anderen Freizeitgütern beschränkt. ${ }^{335}$ Steigt der Preis für Tonträger, wird die Zahl der Käufe abnehmen. In geringeren Maß sinkt die Reichweite R, die u. a. stärker auf Geschenkkäufen von Extensivkäufern basiert. In stärkerem $\mathrm{Ma} ß$ wird die Intensität I durch die Intensivkäufer reduziert wegen der Substitution mit anderen Freizeitkonsumgütern. Denn in der Folge von Preiserhöhungen für Tonträger sinkt das relative Preisniveau der anderen Freizeitkonsumgüter. Sinkt dagegen der Preis für Tonträger, werden sie in Relation zum Freizeitetat der Konsumenten c. p. billiger. Mögliche Auswirkungen sind eine Erhöhung der Nutzungsintensität und der Nutzungsreichweite, in Abbildung 22 dargestellt durch den Anstieg der Nachfrageintensität I und der Nachfragereichweite R. Dabei führen Preissenkungen zu einer stärkeren Steigerung der Intensität I, begründet im stärkeren Konsum der Jugendlichen und der anderen Intensivkäufer. Dagegen werden die Preissenkungen die Reichweite $\mathbf{R}$ nicht wesentlich erhöhen, weil der Zunahme von spontanen Mitnahmekäufen die Abnahme von Geschenkkäufen gegenübersteht. Die Erhöhung der Käuferreichweite durch Preissenkungen erscheint nur erfolgreich, wenn gleichzeitig neue Vertriebskonzepte die Nichtkäufer ansprechen und die Verbreitung der Abspielgeräte erhöhen. Zwischen den auf Preissenkungen und -steigerungen reagiblen Bereichen existiert ein Bereich der Preisindifferenz auf dem gesamten Tonträgermarkt. In Abbildung 22 ist er als unelastischer Bereich gekennzeichnet. In ihm sind gleichermaßen Nachfrageintensität und Nachfragereichweite unempfindlich für Preisvariationen.

${ }^{333}$ Zur theoretischen Fundierung der Preisspielraume bei heterogenen Marktsituationen vgl. Gutenberg, Erich, op. cit., S. 245-256.

${ }^{334}$ Nutzenmaximierung der nachfragenden Haushalte ist eine grundlegende Verhaltensannahme der Mikroökonomie. Vgl. beispielsweise Denzau, Arthur, Microeconomic Analysis, Boston 1992, S. 15.

${ }^{335} \mathrm{Vgl}$. Schumann, op. cit., S. 50. 
Nachfragereichweite (R)

Nachfrageintensität (I)

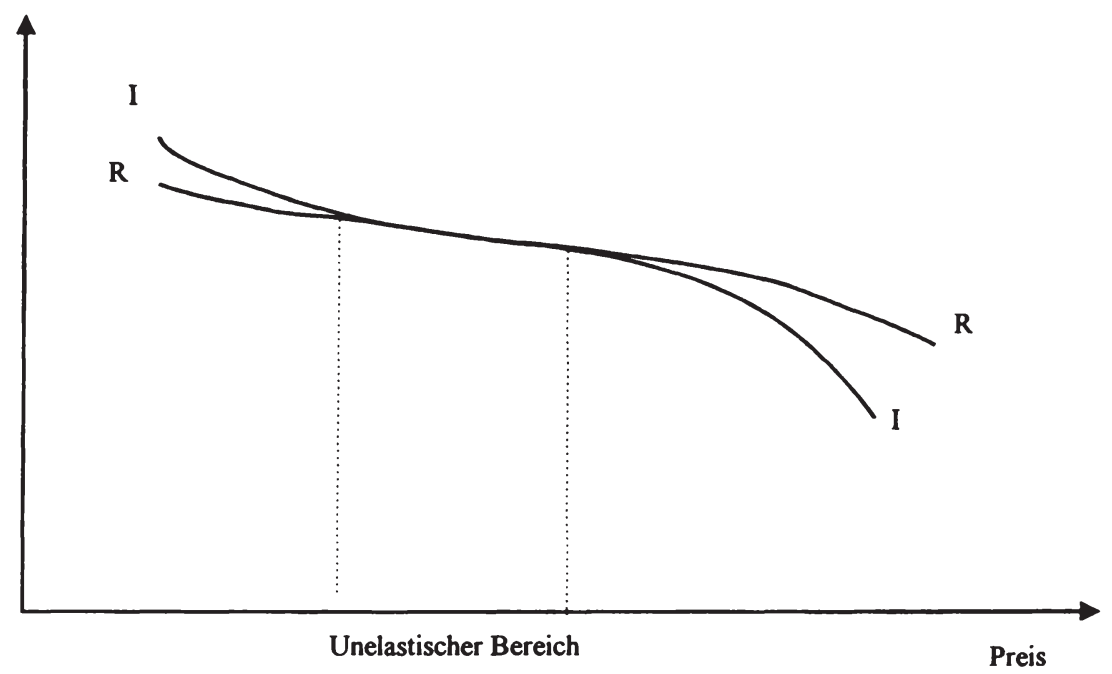

Quelle: Eigene Darstellung in Anlehnung an Mahlmann, 1986, op. cit., S. 138.

Als nächstes wird die Reaktion der Nachfrage auf die Sortimentsbreite untersucht. ${ }^{336}$ Sortimentsbreite beschreibt das Angebot der zusätzlichen (additiven) Kaufmöglichkeiten. Im Tonträgermarkt ist unter Sortimentsbreite die Anzahl der Tonträgerkategorien (=Warenarten) und die Anzahl unterschiedlicher Titel (=Anzahl der Artikel) zu verstehen. ${ }^{337}$ Die Sortimentsbreite kann aus der Sicht der Konsumenten zu groß (Übersortiment) ${ }^{338}$ oder zu klein (Untersortiment) sein. Im Falle des Untersortiments werden Artikel nachgefragt, die nicht vorhanden sind mit der Folge, daß kein Kauf zustande kommt oder andere Produkte gekauft werden. Der Tonträgermarkt erleidet einen Opportunitätsverlust. Mit zunehmender Sortimentsbreite wird zunächst eine Zunahme sowohl von Käuferreichweite als auch Kaufintensität er-

${ }^{336}$ Sortimentsbreite und -tiefe sind die quantitativen Aspekte der Sortimentsgestaltung des Handels. Hier interessieren nur ihre Auswirkungen auf die Nachfrage.

${ }^{337}$ Beispiele für Sortimentsarten im Tonträgermarkt sind: Basissortiment (găngiger Katalog), TrendSortiment, Test-Sortiment (Singles), Spezial-Sortiment (Klassik, Jazz, Kinderrepertoire, Importe etc.), Sonderangebotssortiment und Impuls-Sortiment (aus der Radio- und TV-Werbung).

338 Aus der Sicht des Handels kann ein Anreiz zur Übersortimentienung bestehen, wenn das Absatzrisiko durch Retourenregelungen bei den Tonträgerherstellern verbleibt. 
zielt, ab einer optimalen Sortimentsbreite wird eine Abnahme der Käuferreichweite und nur eine unterproportionale Zunahme der Kaufintensität folgen.

Die Wirkung zusätzlicher Sortimentsbreite auf zusätzliche Kaufintensität und zusätzliche Käuferreichweite ist positiv, wobei der inkrementelle Effekt stärker bei der Kaufintensität auftritt. Die stärkere Wirkung der Sortimentsbreite auf die Kaufintensität resultiert aus den Ausstrahlungseffekten, die das bisherige Sortiment auf die zusätzlichen Sortimentsteile hat. Ursache hierfür ist eine Nachfrageverbundenheit, die insbesondere bei impulsiv gekauften Gütern - wie es Tonträger sind - wirksam ist. Bei weiter zunehmender Sortimentsbreite wird ihre Wirkung auf die Nachfrager ambivalent. Die Käuferreichweite nimmt ab, da der Konsument aufgrund der zu großen Angebotsvielfalt nicht mehr zu Impulskäufen neigt. Die Kaufintensität steigt mit weiter steigender Sortimentsbreite zwar geringfügig weiter, jedoch sind die Kosten der Verfügbarkeit mit dem zusätzlich entstehenden Auswahlnutzen der Intensivkäufer abzuwägen.

Abschließend wird auf die Nachfrageelastizität des Standortes eingegangen. Die erste Fragestellung ist, welche Standortbedingungen auf die Nachfrage einwirken. Hierzu werden die einzelnen mikroökonomischen Variablen der Standorttheorie, ${ }^{339}$ die den Handel betreffen, im Hinblick auf die Kontakthäufigkeit zum potentiellen Konsumenten angeführt. Es sind dies die verkehrstechnische Erreichbarkeit, der Bedarf und die Kaufkraft (verfügbares Einkommen) im Einzugsbereich, die räumliche Entfernung zu den potentiellen Konsumenten, die Attraktivität des Standortes und die Entfernung zu konkurrierenden Tonträgereinkaufsstätten. ${ }^{340}$ Nehmen wir die verkehrstechnische Erreichbarkeit und die Kaufkraft als exogen gegeben an, können wir für die Erklärung der Kontaktwahrscheinlichkeit und -häufigkeit der potentiellen Nachfrage die Entfernung, die Attrakttivität und die Konkurrenzsituation heranziehen.

Unterstellt man aufgrund des hohen Anteils von Impuls- und Erinnerungsimpulskäufen ${ }^{341}$ jedoch, daß die Hemmschwelle gegenüber dem Kauf von Tonträgern gering ist und daß sich ferner gleichgerichtet zur Kontaktwahrscheinlichkeit auch die Kaufwahrscheinlichkeit entwikkelt, so kann abgeleitet werden, daß gerade Fußgängerzonen, Einkaufszentren und andere Orte mit hoher Personenfrequenz für den Tonträgerhandel wichtige Standorte darstellen. Im Hinblick auf die Nachfrage kann abgeleitet werden, daß die geringe Entfernung zu jeweiligen Zentren (d. h. flächendeckende Versorgung) für die Käuferreichweite die erklärende Variable ist. Dies gilt insbesondere, wenn man die Attraktivität der Tonträgereinkaufsstandorte durch die Geschäftslage beschreibt. ${ }^{342}$ Die höchste Attraktivität hat eine Geschäftslage im Zentrum

$339 \mathrm{Vgl}$. Todt, Horst, Wettbewerb durch Standortwahl in der Fläche, in: Beiträge zur Standortforschung, hrsg. v. Behnke, Horst u. a., Berlin 1994, S. 75-92.

$340 \mathrm{Vgl}$. Todt, Horst, op. cit., S. 84, sowie die Aussagen des Reilly'schen Gravitationsgesetzes des Einzelhandels.

31) Die zum Anteil von geplanten und ungeplanten Tontrăgerkáufen kursierenden Schătzungen gehen von ca. $20 \%$ geplanten und $\mathbf{8 0 \%}$ ungeplanten Kăufen aus. Vgl. Schulze, Ralf, op. cit., S. 186, und Mahlmann 1986, S. 37 ff. Dabei unterscheidet Schulze nach Planungsaufwand, indem er von geplant zu ungeplant in Suchkauf, geplanter Suchkauf, Erinnerungsimpulskauf, ungeplanter Suchkauf und reiner Impulskauf unterteilt.

$342 \mathrm{Vgl}$. für einen theoretischen Ansatz zur Erklärung unterschiedlicher Fluktuation von Handelsbetrieben in Städten: Behnke, Horst, Ein ErkJărungsansatz für unterschiedliche Veränderungen in der Standortstruktur 
von Orten; sie nimmt sukzessive von innen nach außen ab. ${ }^{343}$ Einkaufszentren in Randlagen bilden Subzentren, in denen Großbetriebsformen des Einzelhandels ihren Standortnachteil durch Größenkostenvorteile, die sie zum Teil an die Nachfrage weitergeben, zu kompensieren versuchen. Für die Nachfrage entsteht dadurch ein verringerter Anreiz zu Impulskäufen, da eine explizite Entscheidung gegeben sein muß, den Standort in der Randlage überhaupt aufzusuchen. Folge ist ein Trade-off im Kaufverhalten der Konsumenten. Er besteht darin, daß die geringere Attraktivität von Randlagen für die kaufintensive Nachfrage durch geringere Preise ausgeglichen wird, aber die Käuferreichweite sinkt, weil die Entfernung zwischen Tonträgereinkaufsstätte und potentiellen Konsumenten durch die Verlagerung von zentralen zu Randlagen steigt. $^{344}$

Bezieht man schließlich die Auswirkungen der Konkurrenzsituation im Tonträgerhandel auf die Nachfrage mit ein, führt die Verlagerung der kaufintensiven Nachfrage auf die Randlagen c. p. zu deren Ausfall in den Zentren. Scheiden deswegen Händler in zentralen Lagen aus, reduziert sich die Kontaktwahrscheinlichkeit und damit die Kaufwahrscheinlichkeit potentieller Kunden. Die Ergebnisse der Standortelastizität der Nachfrage zeigen eine höhere Reagibilität der Käuferreichweite und eine geringere Reagibilität der Kaufintensität im Hinblick auf die Entfernung der Konsumenten zu den Tonträgereinkaufsstellen.

\subsubsection{Konsequenzen für die zuküntige Konsumentenstruktur}

Für die weitere Analyse verbinden wir die Kriterien der Alterstruktur, der Käuferreichweite, der Kaufintensität und der Elastizitätswirkungen der Aktionsparameter des Handels miteinander, um die Konsequenzen für die zukünftige Konsumentenstruktur ableiten zu können.

Die Kaufintensität ist, bezogen auf das Alter, sehr ungleich verteilt. ${ }^{345}$ Für den Tonträgermarkt erwachsen daraus Risiken. Verändert sich das alterspezifische Kaufverhalten nicht, ${ }^{346}$ geht mit der Veränderung der Altersstruktur eine Reduktion der Konsumentenbasis und damit c. p. eine geringere Nachfrage nach Tonträgern einher.

Eine Marktausweitung hängt entweder von der Ausweitung der Käuferreichweite oder der Befriedigung der speziellen Wünsche der Intensivkäufer ab. Für die Ausweitung der Käuferreichweiten ist ein Instrument das Angebot von altersspezifischem Repertoire, da die Al-

von Geschafien innerhalb verschiedener Stădte bei gleichen Veränderungen in den Rahmenbedingungen. in: Beiträge zur Standortforschung, hrsg. von Behnke, Horst, u. a., Berlin 1994, S. 59-73.

$343 \mathrm{Vgl}$. die Aussagen zur flächendeckenden Versorgung in Abschnitt 4.3.3.4.

${ }^{344}$ Insbesondere für ăltere Konsumenten steigen unter der Annahme eingeschränkter Mobilităt die Kosten durch die Handelskonzentration auf wenigere Standorte stärker als für jüngere. Vgl. Schmidt, Ingo 1997a, S. 107.

$345 \mathrm{Zu}$ demselben Ergebnis kommt die Nichtkäuferstudie im Auftrag der Majors. Der Anteil der Nichtkäufer steigt mit zunehmendem Alter. Vgl. IPS, op. cit., S. 22

346 Wie bereits oben gezeigt, kaufen jüngere Personen mehr und ältere weniger Tonträger 
tersstruktur der Tonträgerkäufer stark nach Repertoiregruppen differiert. ${ }^{347}$ Eine Steigerung des Konsumentennutzens ließe sich erreichen, wenn die Präferenzen der älteren Nachfrager nicht nur in Produktionsentscheidungen umgesetzt, sondern die Produkte auch zielgruppengerecht vertrieben werden würden. Ein weiteres Instrument zur Erhöhung der Käuferreichweite ist die größere Verfügbarkeit von Tonträgern. Wie die Standortanalyse gezeigt hat, ist dafür eine größere Präsenz von Tonträgersortimentsteilen nötig, um Tonträgern einen ubiquitären Charakter zu verleihen. Eine Veränderung der Konsumentenstruktur ergibt sich dann, wenn zusätzliche Nachfrage älterer Personen durch die Kombination der Herstellung von altersspezifischen Tonträgerprodukten und deren Angebot an alterspezifischen Einkaufsstellen ${ }^{348}$ mobilisiert werden kann.

Die Erhöhung der Kaufintensität mit Hilfe einer Absatzsteigerung in der Gruppe der Intensivkäufer hingegen ist stärker von erfolgreichen Innovationen bzw. dem Setzen neuer Trends abhängig. ${ }^{349}$ Die Elastizitätsanalyse des vorangegangenen Abschnitts hat gezeigt, daß für eine Steigerung der Kaufintensität die Erhöhung der Kommunikations- und Motivationsfähigkeit unter Nutzung der Multiplikatorwirkung nötig ist. Die Elastizität der Sortimentsbreite in Verbindung mit derjenigen des Standorts verdeutlicht, daß Intensivkäufer mobilere Konsumenten sind, für die nicht die zentrale Lage der Tonträgereinkaufsstätte entscheidend ist, sondern die Existenz eines Vollsortiments. Dieses ermöglicht eine weitere Erhöhung der Kaufintensität durch die auf Nachfrageverbundenheit beruhenden Ausstrahlungseffekte des Sortiments. Für die Steigerung der Kaufintensität ist daher eher der Präferenztransfer, d. h. die Übertragung der Konsumentenwünsche (vor allem diejenigen der Gruppe der Intensivkäufer) auf die Produktionsentscheidungen der Tonträgerhersteller von Bedeutung.

Eine Erhöhung der Kaufintensität stellt damit zumindest einen partiellen Trade-off zur Erhöhung der Käuferreichweite dar. Denn die Rückwirkung der Handelskonzentration auf die Verbraucher ist, daß mit der Konzentration eine Aggregation der Nachfrage auf wenige Tonträgereinkaufsstätten einhergeht, die die Verfügbarkeit von Tonträgern und damit die Käuferreichweite mittelfristig reduziert. Dagegen verursacht der Preiswettbewerb, der von den Großbetriebsformen des Einzelhandels ausgeht, einen Anreiz zur Erhöhung der Kaufintensität.

\subsubsection{Zusammenfassung wichtiger Verhaltensmerkmale}

Künstlerexklusiv- und Bandübernahmeverträge regeln die Austauschverhältnisse zwischen Musikern und Tonträgerherstellern. Während die Verträge für unbekannte Musiker eher Versorgungscharakter haben, wird die Verhandlungsmacht etablierter Musiker nur begrenzt durch

\footnotetext{
${ }^{347}$ Repertoiresegmente, in denen die ălteren Konsumenten größere Anteile am Gesamtkonsum haben, sind Klassik, Schlager und Volksmusik. Ein Ausbau dieser Segmente ist für die Attrahierung ălterer Konsumenten von Bedeutung.

${ }^{348}$ Ein Beispiel für altersspezifische Einkaufsstätten, die in jüngster Zeit Tontrăger in ihr Sortiment aufgenomen haben, sind die Tschibo-Filialen.

${ }^{349}$ Die Bedeutung der Intensivkäufer hat von 1993 bis 1996 von $56,8 \%$ auf $42,7 \%$ des Tonträgenumsatzes kontinuierlich abgenommen. Während der prozentuale Anteil der Durchschnittskäufer etwa konstant geblieben ist, hat sich der Anteil der Extensivkäufer von 1993 bis 1996 von 16,5\% auf 31,4\% erhöht.
} 
die Gesamtrentabilität ihrer Tonträgeraufnahmen bzw. die Zahlungsbereitschaft der Tonträgerhersteller. Der bedeutendste Aktionsparameter im Wettbewerb unter den Herstellern - sowohl im Binnenverhältnis der Majors als auch im Intergruppenwettbewerb zwischen den Anbietergruppen Majors und Independents - ist die Produktpolitik durch Veröffentlichung von Tonträgertiteln, die den Charakter eines Innovationswettbewerbs aufweist. Angesichts kurzer Produktlebenszyklen und schneller Präferenzänderung der Nachfrage handelt es sich bei den veröffentlichten Musiktiteln neben echten Produktinnovationen (Erstverwertung) auch um QuasiInnovationen durch Bearbeitung bereits erfolgreich veröffentlichter Musik und PseudoInnovationen durch Neuzusammenstellungen von Musiktiteln (Zweitverwertung) oder durch Neuauflage mit verändertem Äußeren (Drittverwertung). Strategische Vorteile der oligopolistischen Majorgruppe liegen sowohl in dem Vorteil der Risikostreuung durch Produktdifferenzierung mit Hilfe eines Angebots in vielen Repertoiresegmenten als auch im umfangreichen Katalog von Musiktiteln zur Zweit- und Drittverwertung. Die Anbietergruppe der Independents ist demgegenüber auf die Entdeckung und Förderung neuer Musiker und auf einzelne Repertoiresegmente spezialisiert. Weitere Aktionsparameter im Wettbewerb spielen im Tonträgermarkt nur eine untergeordnete Rolle. Insbesondere die Preispolitik der Oligopolgruppe ist weitgehend einheitlich und die etablierten Preiskategorien haben die Funktion, Produktgruppen zu definieren. Strategische intergruppenspezifische Wachstumsbarrieren zwischen Majors und Independents liegen u. a. im Zugang zu den Medien, mit denen für die Bekanntheit der Musiker und der Musik gesorgt wird, und der Fähigkeit der Majors, flexibel und schnell auf Nachfrageschwankungen durch das Vorhalten eigener physischer Herstellungs- und Distributionskapazitäten reagieren zu können.

Auf der Ebene des Tonträgerhandels ist der Wettbewerb stark preisorientiert. Dies ist ein Ausdruck der Handelskonzentration und der unterschiedlichen Bedeutung von Tonträgern im Sortiment der verschiedenen Handelsformen. Die Nachfrage nach Tonträgern ist ebenfalls stark konzentriert. Allerdings ist der Umsatzanteil der Gruppe der Intensivkäufer rückläufig und derjenige anderer Käufergruppen zunehmend. Das Kaufverhalten der verschiedenen Käufergruppen reagiert unterschiedlich auf die betrachteten Einflußgrößen. Während Intensivkäufer elastischer auf ein großes Sortiment und niedrige Preise reagieren, sind Extensivkäufer reagibler hinsichtlich des Einkaufsortes. Daher hat die räumliche Verfügbarkeit i. S. eines flächendeckenden Händlernetzes großen Einfluß auf die Käuferreichweite und die zukünftige Konsumentenstruktur. 
Nach der Abgrenzung des relevanten Tonträgermarktes und der Darstellung der Marktstruktur- und Marktverhaltensfaktoren sollen in diesem Abschnitt die Marktergebniskriterien entwickelt sowie Interdependenzen zwischen Struktur, Verhalten und Ergebnis aufgezeigt werden. In 4.4.1 werden die Ansatzpunkte für das Marktergebnis im Tonträgermarkt behandelt, 4.4.2 beinhaltet die Ansätze zur Feststellung von Zusammenhängen zwischen Struktur und Ergebnis, in 4.4.3 werden die Zusammenhänge zwischen Verhalten und Ergebnis auf den einzelnen Marktstufen betrachtet. Abgeschlossen wird das vierte Kapitel mit einem industrieökonomischen Ausblick (4.5).

\subsubsection{Marktergebnisse im Tonträgermarkt}

In industrieökonomischen Studien werden als Kriterien für die Beschreibung von Marktergebnissen zumeist der Gewinn und der Umsatz der im Markt agierenden Unternehmen sowie die Entwicklung der Endverbraucherpreise herangezogen. Im Tonträgermarkt sind die für eine Beurteilung der Umsätze und Gewinne nötigen Daten der einzelnen Unternehmen nicht erhältlich. Dies liegt u. a. daran, daß die in der Rechtsform der $\mathrm{GmbH}$ organisierten Tonträgerhersteller Töchter multinationaler Konzerne sind, in deren Konzernbilanzen die für den Tonträgermarkt relevanten Daten aufgehen. Die Umsatzentwicklung für den gesamten Tonträgermarkt wurde bereits oben (in Abschnitt 4.2) ebenso wie die Entwicklung der Preise auf der Ebene der Endverbraucher dargestellt. Es konnte festgestellt werden, daß in den letzten Jahren in realen Größen Umsatzstagnationen zu verzeichnen waren. Die nominalen Preise für die CD als überwiegend abgesetzte Tonträgerkategorie in der Vollpreisklasse, mit der ca. $70 \%$ des Umsatzes getätigt wird, sind von 35 DM (1984) auf inzwischen 27 DM (1997) gesunken. Die Preisentwicklung sagt als Durchschnittswert für eine Marktergebniskategorie wenig aus, weil sie - wie in Abschnitt 4.3 bereits dargelegt - ein hauptsächlicher Aktionsparameter des Wettbewerbs auf der Handelsebene ist.

Daher müssen zur Darstellung und Beurteilung des Marktergebnisses andere Größen herangezogen werden. Als Ersatzgrößen kommen die Anzahl der jährlichen Neuveröffentlichungen zur Bestimmung der Angebotsbreite in Frage. Weiterhin können die Ranglisten (sog. Charts) für den Single- und den Longplay-Markt herangezogen werden. Schließlich kann angeknüpft werden an die Vergabe von Erfolgsauszeichnungen für absolute Verkaufszahlen einer Tonträgerproduktion (z. B. goldene Schallplatten). Die Erfassung aller jährlich neuveröffentlichten Tonträgertitel in Deutschland wirft Probleme auf. Im Gegensatz zum Buchmarkt, in dem in einem Gesamtkatalog die Neuveröffentlichungen erfaßt sind, sind im Tonträgermarkt alle bestehenden Gesamtverzeichnisse veraltet. Jährlich erscheint für die Mitgliedsfirmen im Bundesverband der Phonographischen Wirtschaft, das sind die Majors und einige größere Independents, eine Statistik von Neuveröffentlichungen, ${ }^{348}$ in der keine Importe und keine Neuveröffentlichungen von Nicht-Verbandsmitgliedsfirmen enthalten sind. Die kumulierten Marktanteile der Mitgliedsfirmen entsprechen im betrachteten Zeitraum achtzig Prozent (oder mehr) des

${ }^{348}$ Vgl. BPW 1994, S. 28; BPW 1996, S. 24, und BPW 1997, S. 24. 
Gesamtmarktes. Unterstellt man vereinfachend eine proportionale Verteilung von Veröffentlichungszahlen und Marktanteilen, könnte man auf die Zahl der jährlichen Gesamtmarktveröffentlichungen hochrechnen. Diese Zahl kann nur als Schätzung interpretiert werden, da erstens viele Veröffentlichungen sowohl in der Kategorie $\mathrm{CD}$ als auch $\mathrm{MC}$ getätigt und daher doppelt gezählt werden, und zweitens nicht erfaßt wird, welche der Musiktitel zugleich als Single und als Longplay erscheinen. Von daher kann aus der Neuveröffentlichungsstatistik nicht geschlossen werden, wieviele verschiedene Musiktitel neu erschienen sind. Um Doppelzählungen zu vermeiden, trennen wir - der Marktabgrenzung folgend - die Single- von den Longplayveröffentlichungen und benutzen bei letzteren nur die Veröffentlichungen in der Kategorie CD. Die CD hat sich seit 1987 zur Standard-Tonträgerkategorie sowohl auf dem Single- als auch dem Longplaymarkt entwickelt, ${ }^{349}$ was den sprunghaften Anstieg der Veröffentlichungen bei den Longplays von 1986 bis 1987 erklärt.

Tabelle 7: Entwicklung der jährlichen Neuveröffentlichungen von Single und Longplay (nur CD) von 1985-1996 der Mitgliedsfirmen im BPW

\begin{tabular}{|l|l|l|l|l|l|l|l|l|l|l|l|l|}
\hline Jahr & 1985 & 1986 & 1987 & 1988 & 1989 & 1990 & 1991 & 1992 & 1993 & 1994 & 1995 & 1996 \\
\hline $\begin{array}{l}\text { Single- } \\
\text { Tonträger }\end{array}$ & 2937 & 2860 & 3055 & 3665 & 5177 & 5314 & 4961 & 4329 & 3460 & 3460 & 3698 & 4162 \\
\hline $\begin{array}{l}\text { Longplay- } \\
\text { Tonträger* }\end{array}$ & 1715 & 1895 & 4105 & 4755 & 5528 & 6151 & 8108 & 6548 & 7225 & 8876 & 9907 & 8898 \\
\hline
\end{tabular}

* enthalten sind nur Veröffentlichungen der Tonträgerkategorie CD

Quelle: BPW 1994, S. 28, BPW 1996, S. 24 und BPW 1997, S. 24.

Neuerscheinungen auf anderen Tonträgerkategorien sind im wesentlichen als Doppelveröffentlichungen zu betrachten. Mangels Alternativen wird trotz der angeführten methodischen Probleme auf die Statistik des BPW zurückgegriffen, um die Angebotsbreite der Jahre 1985-1996 abzubilden. Die Wahl des Untersuchungszeitraumes 1985-1996 erfolgt vor dem Hintergrund, $\mathrm{da} ß$ die reale Marktentwicklung und die Entwicklung der Marktanteile ebenfalls (soweit verfügbar) für diesem Zeitraum analysiert wurden.

Die Zahl der jährlichen Neuerscheinungen ist gestiegen, wenn man den gesamten Zeitraum betrachtet. Im Single-Markt sind 1990 die meisten Singles erschienen. Die Zahl der jährlichen Longplay-Veröffentlichungen zeigt für den Longplay-Markt deutlich die Art der Marktentwicklung. War zunächst nach der Markteinführung der Tonträgerkategorie CD die Zahl der Neuerscheinungen auf diesem Trägermedium gering, ist seit 1987 festzustellen, daß sich die $\mathrm{CD}$ als Standard durchgesetzt hat. Gerade deswegen läßt sich die Veröffentlichungspolitik anhand der CD abbilden. 1987 wurden etwas mehr als 4.000 Titel auf CD veröffentlicht. Einer Verdopplung der jährlichen Neuerscheinungen auf über 8.000 veröffentlichter Titel bis 1991 folgte eine Reduktion und schließlich wieder eine Zunahme auf etwas weniger als $9.000 \mathrm{Neu}$ -

${ }^{349}$ Im Longplay-Markt repräsentierte die CD 1996 über 93\% des Umsatzwertvolumens und im Single-Markt wurden 1996 über $98 \%$ der Umsatzmenge mit der Tonträgerkategorie CD getätigt. Vgl. BPW 1997, S. 12 und 18. 
erscheinungen pro Jahr. Wie bereits festgestellt, ist der Charakter des Wettbewerbs im Tonträgermarkt durch die Produktpolitik der Tonträgerhersteller und damit durch ihr Veröffentlichungsverhalten gekennzeichnet. ${ }^{350}$ Der Zuwachs des Marktvolumens beträgt ein Bruchteil desjenigen der jährlichen Neuerscheinungen. Daraus resultiert die Tatsache, daß die Zahl der Verkäufe pro Veröffentlichung statistisch gesehen stark gesunken ist. Dieser vor allem für Longplay-Tonträger evidente Zusammenhang ist in Tabelle 8 dargestellt.

Tabelle 8: Durchschnittliche jährliche Verkaufszahl pro Neuerscheinung

\begin{tabular}{|l|l|l|l|l|l|l|l|l|l|l|l|l|}
\hline Jahr & 1985 & 1986 & 1987 & 1988 & 1989 & 1990 & 1991 & 1992 & 1993 & 1994 & 1995 & 1996 \\
\hline $\begin{array}{l}\text { Single- } \\
\text { Tonträger }\end{array}$ & $\begin{array}{l}1688 \\
8\end{array}$ & $\begin{array}{l}1517 \\
5\end{array}$ & $\begin{array}{l}1260 \\
2\end{array}$ & 8622 & 6239 & 5119 & 5120 & 6145 & $\begin{array}{l}1063 \\
6\end{array}$ & $\begin{array}{l}1164 \\
7\end{array}$ & $\begin{array}{l}1192 \\
5\end{array}$ & $\begin{array}{l}1155 \\
7\end{array}$ \\
\hline $\begin{array}{l}\text { Longplay- } \\
\text { Tonträger }\end{array}$ & $\begin{array}{l}7591 \\
8\end{array}$ & $\begin{array}{l}7002 \\
6\end{array}$ & $\begin{array}{l}3588 \\
3\end{array}$ & $\begin{array}{l}3295 \\
5\end{array}$ & $\begin{array}{l}2954 \\
1\end{array}$ & $\begin{array}{l}3165 \\
3\end{array}$ & $\begin{array}{l}2545 \\
6\end{array}$ & $\begin{array}{l}2979 \\
5\end{array}$ & $\begin{array}{l}2788 \\
9\end{array}$ & $\begin{array}{l}2310 \\
7\end{array}$ & $\begin{array}{l}2106 \\
6\end{array}$ & $\begin{array}{l}2383 \\
7\end{array}$ \\
\hline
\end{tabular}

Quelle: eigene Berechnungen nach Daten des BPW.

Wurden Mitte der 80er Jahre noch durchschnittlich fünfzehntausend Singles und siebzigtausend Longplays pro Neuveröffentlichung abgesetzt, sank diese Zahl bis auf funftausend Singles zu Beginn der 90er Jahre, um sich dann bei über elftausend Mitte der 90er Jahre zu stabilisieren. Bei den Longplays ist die durchschnittliche Verkaufszahl pro Veröffentlichung beständig gesunken, um sich Mitte der 90er Jahre bei ca. dreiundzwanzigtausend zu stabilisieren.

Das Marktergebnis der größeren Angebotsbreite hat zwei Effekte. Einerseits ist der Konsument in der Lage, aus einer größeren Vielfalt zu wählen. Unterstellt man einen positiven $\mathrm{Zu}$ sammenhang zwischen der Steigerung des Angebots im Zeitverlauf und der Konsumentenwohlfahrt, ist die größere Angebotsbreite als wohlfahrtssteigernd zu bewerten. Andererseits benötigen die einzelnen Tonträgerhersteller mehr Ressourcen, um ihr jeweiliges Angebot aus der Menge der veröffentlichten Titel herauszuheben. ${ }^{351}$ Dies stellt höhere Anforderungen an die Unternehmen, weil in dem stagnierenden Markt ein größerer Anteil der erwirtschafteten Erträge auf die Verkaufsförderung verwendet werden muß. Dies kann zu höheren Kosten der Tonträgerhersteller führen, um ihre Produkte zu exponieren, durch die wegen der steigenden Zahl an Veröffentlichungen verstärkte Wettbewerbsintensität aber auch zu Kostendisziplin zwingen.

Ein möglicher indirekter Effekt des Wettbewerbs ist der Einfluß des Kostendrucks auf die Art der Neuerscheinungen. Rationale Folge ist sowohl eine größere Anzahl von Backkatalogverwertungen als auch eine Neuverwertung von bestehendem Material, an dem die Tonträgerhersteller Rechte haben. Aus der in Kapitel 1 dargestellten technischen Entwicklung ${ }^{352}$ bei der Aufnahme von Musik resultiert das Samplen und Remixen des Back-Katalogs, das zwei positi-

$350 \mathrm{Vgl}$. Alexander, P.J., Entry Barriers, Release Behavior, and Multiproduct Firms in the Music Recording Industry, in: Review of Industrial Organization, Vol. 9 (1994), S. 85-98. [Alexander, Peter J., 1994]

$351 \mathrm{Vgl}$. Black, M., und D. Greer, Concentration and Non-Price Competition in the Recording Industry, in: Review of Industrial Organization, Vol. 3 (1987), S. 13-37.

352 Die technische Entwicklung hat zur digitalen Aufnahme und Wiedergabe von Musik gefuhrt. Damit sind alle Verănderungen an Musikstücken mit Hilfe von Computern durchführbar. 
ve Effekte auf der einzelwirtschaftlichen Ebene der Tonträgerhersteller hervorbringt. Einerseits kann der Hook, das ist der Teil eines Musikstücks, der die Wiedererkennung durch die Konsumenten garantiert, von bereits bestehenden Stücken übernommen werden. Die Nachfrage nach dem neubearbeiteten Titel kann dann auf der früheren Nachfrage aufbauen. Zweitens ist diese Art von Musikproduktion kostensparend, sofern die Rechte an den bestehenden Musiktiteln bei dem neubearbeitendem Unternehmen liegen. ${ }^{333}$

In Relation zu anderen Märkten hat der technische Fortschritt auch zu negativen Folgen für das Marktergebnis des Tonträgermarktes geführt. Sie werden unter dem Begriff Baumol's Cost Disease diskutiert. ${ }^{354}$ Eine Wirkung des technischen Fortschritts ist sein arbeitssparender Effekt, der zu veränderten Faktorintensitäten zwischen Arbeit und Kapital führt. Kapital als der relativ billigere Faktor wird vermehrt eingesetzt und verdrängt den relativ teureren Faktor Arbeit.

„...the relativ lag in the price of the progressive component, together with the fixed proportion in which they are employed, means that the progressive input must constitute an ever declining share of the overall budget of the enterprise, while the stagnant input must for the same reason constitute an ever increasing share of that budget. "3sss

Industrien, in denen das Einsatzverhältnis zwischen Arbeit und Kapital nicht (bzw. nicht so stark) zugunsten des billigeren Faktors verändert werden kann - weil beispielsweise von den Konsumenten erwartet wird, daß Musikaufführungen und Musikproduktion durch Menschen durchgeführt werden und vorwiegend die Musiker die Bindung der Tonträgerkonsumenten an die Produkte der Tonträgerhersteller bewirken - haben mit einem Kosten- und Produktivitätsnachteil zu kalkulieren, der im Zeitablauf relativ zu anderen Industrien wächst. Dieser Zusammenhang wird dadurch verstärkt, daß sich die Lohnentwicklung in Kulturindustrien an derjenigen anderer Industrien orientiert bei einer gleichzeitig nur unterproportionalen Steigerung der Arbeitsproduktivität. ${ }^{356}$ Im Tonträgermarkt sind die Möglichkeiten begrenzt, technologischen Fortschritt zur Steigerung der Arbeitsproduktivität einzusetzen. Eine unter mehreren Auswirkungen ist der verstärkte Einsatz von Technik bei der Komposition und Produktion von Musik. ${ }^{357}$ Dabei kann einerseits der ökonomische Einfluß von neuen Produktionstechniken auf Musikinhalte diskutiert, ${ }^{358}$ andererseits die Wirkung der Cost Disease auf das Angebotsverhal-

${ }^{353} \mathrm{Vgl}$. Zimmermann, Joern H., op. cit., S. 1085-1106 und Abschnitt 4.3.2.1.

354 Vgl. Baumol, William J., und William G. Bowen, Performing Arts: The Economic Dilemma, 2. Aufl., New York 1978 [Baumol/Bowen].

${ }^{35 s}$ Baumol/Bowen, op. cit., S. 115.

356 Vgl. Késenne, Stefan, Can A Basic Income Cure Baumol's Disease, in: Journal of Cultural Economics, Vol. 18 (1994), S. 93-100.

${ }^{357}$ Vgl. Colonna, Carl M., Patricia M. Kearns und John E. Anderson, Electronically Produced Music and its Economic Effects on the Performing Musician and Music Industry, in: Journal of Cultural Economics, Vol. 17 (1993), S. 69-75.

${ }^{358} \mathrm{Vgl}$. hierzu beispielsweise Deboer, L.. Is Rock 'n 'Roll a Symptom of Baumol's Disease, in: Journal of Cultural Economics, Vol. 9 (1985), S. 48-59. Die Diskussion über den Einfluß des technischen Fortschritts auf Musikinhalte ist nicht Gegenstand der vorliegenden Arbeit. 
ten von Musikern untersucht werden ${ }^{359}$; drittens können die Einflußmöglichkeiten des Staates auf die Nachfrage dargestellt und beurteilt werden. ${ }^{360}$ Die letzte Frage betrifft den Zusammenhang zwischen Konsumentensouveränität, Befriedigung der Präferenzen der Konsumenten und der Ressourcenallokation durch die Unternehmen. ${ }^{361}$ Bei der wettbewerbspolitischen Analyse des Tonträgermarktes kann letztlich nicht wohlfahrtstheoretisch entschieden werden, welche Zahl an veröffentlichten Musiktiteln den Präferenzen der Konsumenten entspricht. Es kann lediglich anhand der meßbaren und zugänglichen Marktergebniskriterien festgestellt werden, wieviele Titel nach der abgegrenzten Statistik veröffentlicht werden, wieviele davon in Ranglisten bestimmte Plätze für wie lange belegen und wieviele der Titel mit Verkaufsauszeichnungen (goldenen Schallplatten) versehen werden.

Als zweiter Ansatzpunkt für die Darstellung des Marktergebnisses werden die sog. Charts verwendet, die eine Rangordnung der auf Tonträgern bespielten Musiktitel darstellen, getrennt nach Single- und Longplay-Markt. In Deutschland werden als Kriterium zur wöchentlichen Rangfolgebildung von 100 Titeln für den Longplay-Markt ausschließlich die Verkäufe an Endverbraucher herangezogen, ${ }^{362}$ während für den Single-Markt die ersten fünfzig Titel nach Verkaufszahlen und die Plazierung 51 bis 100 nach Verkaufszahlen sowie Hörfunkeinsätzen (sog. Airplay) gebildet werden. ${ }^{363}$ Bei der Ermittlung der wöchentlichen Rangtabellen wurden die Verkäufe bis 1996 mit Hilfe von Fragebögen erfaßt. Seit der entsprechenden Verbreitung des

359 Vgl. Peacock, Alan, The Cost Disease: Analytical and Policy Aspects, in: Special Supplement to the Journal of Cultural Economics 1985, S. 51-58; und Frey, Bruno S., The Economics of Music Festivals, in: Journal of Cultural Economics, Vol. 18 (1994), S. 29-39.

${ }^{360} \mathrm{Vgl}$. die Aussagen des Linder Theorems. Mit ihm wird argumentiert, daß mit steigenden Lohnen weniger Kultur bzw. Output von Kulturindustrien konsumiert wird. Hierzu wird angenommen, daB Konsum von Kultur und kulturelle Aktivităten generell zeitintensiver sind als andere Konsumaktivităten. Wenn die Reallohne steigen und damit der relative Preis der Zeit steigt, wird die Zeit relativ teurer im Vergleich zu einem beliebigen anderen Marktgüterbündel. Da die Möglichkeit beschränkt ist, die Nachfrage nach dem Güterbündel durch Zeit für kulturelle Aktivitäten zu substituieren, werden letztere c. p. teurer und die Nachfrage nach kulturellen Aktivităten sinkt. Dieses sog. Linder-Theorem wurde modifiziert von Baumol auf Kulturindustrien angewandt. Vgl. Linder, S., The Harried Leisure Class, New York 1970, und Baumol, W., Income and Substitution Effects of the Linder Theorem, in: Quarterly Journal of Economics, Vol. 87 (1973), S. 629-633.

361 So argumentiert beispielsweise Scitovsky: „That raises the question whether policy and what kind of policy could speed and facilitate matters by inducing the public to change its expenditure pattern in ways that would reduce resource costs without reducing consumer satisfaction. (...) yet it ought to be possible to save material resources while detracting neither from the consumer's satisfaction nor from his sovereignty." Scitovsky, Tibor, Can Changing Consumer's Tastes Save Resources?, in: Journal of Cultural Economics, Vol. 1 (1977), S. 1-12, hier S. 2.

${ }^{362}$ Vor dem 1.1.97 wurden die Rangfolgen mit Hilfe von Fragebögen erstellt, die an die Tonträgerfachhăndler verschickt wurden. Daher war das Chartsystem neben der Auswahl der Outlets abhängig davon, daß und wie sich die Händler beteiligten. Die Kritik an dem bis 31.12.1996 gültigen System der Chartermittlung betraf u. a. methodische Probleme wie Flatter- und Beharrungseffekte, die trotz einer Aktualisienung und Bereinigung stăndige Fehlerquellen blieben.

${ }^{363}$ Die Einbeziehung nutzungsrelevanter Daten beschränkt sich auf den Hörfunkeinsatz und geschieht vor dem Hintergrund, daß die statistische Absicherung der Rangplătze 51 bis 100 zusătzlicher Datenquellen bedarf. Vgl. Zombik, Peter, 1997b, op. cit., S. 151. Die Gewichtungsverteilung zwischen Verkăufen und Hörfunkeinsătzen wurde mehrfach geăndert. Z. Zt. steigt der Anteil von $1 \%$ Hörfunkeinsatz und $99 \%$ Verkaufsmenge bei Rang 51 bis zu 50\% Hörfunkeinsatz und 50\% Verkaufsmenge bei Rang 100. Die Einbeziehung von Hörfunkeinsätzen ermöglicht die Beeinflussung der Rangfolgebildung durch die Tonträgerhersteller mit Hilfe der Beeinflussung der für die Programmgestaltung zustăndigen Entscheidungstrăger. 
Panels PhonoNet ${ }^{364}$ werden die damit gewonnenen Daten verwendet. Sie erfassen die Mehrzahl der Verkäufe des Handels an die Endverbraucher. Die Coverage, d. h. die Abdeckung der gesamten Verkäufe durch diejenigen, die über PhonoNet erfaßt werden, liegt bei ca. $52 \%$ mit Stand vom Januar 1998. ${ }^{365}$ Seit Jahresbeginn 1997 werden für die Ermittlung der LongplayCharts und der ersten 50 Plätze der Single-Charts nur noch die über das PhonoNet transportierten Verkaufsdaten berücksichtigt. Auch wenn dadurch die Beeinflussungsmöglichkeiten und Erfolgschancen wettbewerbswidriger Praktiken sinken, ${ }^{366}$ bleiben aus einer Gesamtmarktbetrachtung weitere Kritikpunkte an der Verwendung der Charts als Marktergebnisfaktoren bestehen, auf die vor ihrer Verwendung hingewiesen werden soll.

Der erste Kritikpunkt betrifft die Auswahl der Händler, die Daten für die Chartermittlung melden. Wurde früher eine mehr oder minder subjektive Auswahl von Fachhändlern ${ }^{367}$ getroffen, werden heute alle Outlets berücksichtigt, die PhonoNet beigetreten sind. Dadurch ist der Anteil der nicht erfaßten Vertriebswege gesunken. PhonoNet und das Chartsystem verursachen Kosten. ${ }^{368}$ Daher werden die Händler und andere Vertragspartner im Rahmen ihres Marginalkalküls den zusätzlichen Erfassungsaufwand in Relation zu ihrem individuellen Nutzen, z. B. den Kostenspareffekt des mit PhonoNet verbundenen Warenwirtschaftssystems, setzen. Damit werden nicht per se weitere Anschlüsse an das PhonoNet induziert. Nur bei einer vollständigen Erfassung aller Outlets und aller Verkäufe wären die Rangtabellen das korrekte Abbild des Marktergebnisses.

Der zweite Kritikpunkt bezieht sich auf die Mindestpreise, die erforderlich sind, damit die Verkäufe einer Tonträgerveröffentlichung bei der Chartermittlung überhaupt berücksichtigt werden. Die Nichterfassung von Budgetprodukten ${ }^{369}$ schließt alle Vertriebswege aus, die Tonträger als preisgünstige Mitnahmeartikel anbieten und damit auf reine Impulskäufe abstellen. Die

${ }^{364}$ PhonoNet ist ein 1991 gegründetes Dienstleistungsunternehmen des BPW, welches mittels elektronischer Kommunikation Bestellungen des Handels bei den Herstellern und Verkăufe des Handels an die Konsumenten erfaßt. Ausschließlich dieses Instrument wird seit Januar 1997 zur Chartermittlung der LongplayCharts benutzt. Vgl. BPW 1997, S. 35.

${ }^{365}$ Diese Information erhielt der Verfasser in einem Gespräch mit einem Brancheninsider (Dirk Ewald, Intercord Tonträger $\mathrm{GmbH}$ ) am 16. Januar 1998.

${ }^{366}$ Ein Beispiel für solche Praktiken ist Payola. Hierunter wird die Bestochung von Redakteuren in Medien verstanden, die über den musikalischen Inhalt von Sendungen entscheiden. Gegen Vergabe von Geld oder geldwertgleichen Vorteilen soll die Medienpräsenz der Musiktitel eines Tonträgerherstellers gesichert werden. In den USA hat es diesbezüglich Kartellverfahren gegeben, in denen Payola verboten worden ist. Vgl. Coase, Ronald, Payola in radio and television broadcasting, in: Journal of Law and Economics, Vol. 22 (1979), S. 269-328.

367 Vgl. Zombik, Peter, 1997b, op. cit., S. 148 f. Zum Fachhandel gezâhlt wurden die Fachabteilungen der Warenhăuser und der Tontrăgereinzelhandel, in dem das Tontrăgersortiment überwiegt. Nicht dazu gezăhlt wurden Rackjobber und der sog. Automatenhandel.

3681998 betragen die einmaligen Kosten für die Aufnahme in das System PhonoNet 40.000,- DM für Unternehmen mit Umsatzerlossen unterhalb von 5 Mio. und 80.000,- DM für Unternehmen mit Umsatzerlösen oberhalb von 5 Mio. Quelle: Gesprăch mit einem Brancheninsider (Dirk Ewald, Intercord Tonträger $\mathrm{GmbH}$ ) am 16. Januar 1998. Diese Kosten können als Markteintrittsbarriere auf der Industrie- und Handelsstufe interpretiert werden. Demgegenüber steigt aber der Nutzen der PhonoNet-Teilnehmer mit der Zahl der Teilnehmer.

369 Budgetprodukte erbrachten 1996 bei der CD über $15 \%$ und bei der MC über $70 \%$ des mengenmäBigen Umsatzes. Vgl. BPW 1997, S. 21 f. 
einzelwirtschaftliche Rationalität, die u. a. einen bestimmten Stückgewinn für den Aufwand der Chartermittlung verlangt, widerspricht dem Anspruch, mit einer Rangliste auf der Basis von Verkaufszahlen Gesamtmarktergebnisse publizieren zu wollen. ${ }^{370} \mathrm{DaB}$ dieser Anspruch nicht hinter der Chartermittlung zu stehen scheint, beweisen die für verschiedene Produkte vorgenommenen Ausdifferenzierungen in Preisen und Vertriebswegen und mehrfachen Anpassungen der Mindestpreise im Zeitablauf. ${ }^{371}$

Der dritte Kritikpunkt schließlich bezieht sich auf den Umfang, d. h. musikalischen Inhalt, auf den sich Charts als Rangtabellen jeweils beziehen. Eine Repertoiredifferenzierung und damit eine jeweils getrennte Darstellung von Rangtabellen für einzelne Musikrichtungen beinhaltet die methodische Schwierigkeit, daß verschiedene Musikrichtungen typische Charakteristika aufweisen, Übergänge zwischen ihnen jedoch fließend sind. Je enger ein Repertoiresegment abgegrenzt wird, desto leichter ist es, in die betreffenden Charts zu gelangen, desto geringer ist aber auch die Aussagekraft dieser Rangtabellen. ${ }^{372}$ Daher kann sich die Aussage einer Chartplazierung nur darauf beziehen, wieviele Exemplare eines Tonträgers in dem definierten Zeitraum von jeweils einer Woche im Vergleich zu anderen Tonträgern desselben Chartrepertoires und desselben Zeitraumes verkauft worden sind. Die Feststellung der Positionierung am Markt dient vor allem den Rückschlüssen über Verkaufspotentiale durch die Hersteller. ${ }^{373}$ Demgegenüber wird behauptet, daß die qualitative Aussage eines ersten Platzes für einen Musiktitel immer dieselbe ist. ${ }^{374}$ Werden die Rangplätze zu absoluten Verkaufszahlen in Beziehung gesetzt, kann diese Behauptung nicht gehalten werden. ${ }^{375}$ Deswegen werden weiter unten als dritte Ergebnisgröße Auszeichnungen für absolute Verkaufszahlen herangezogen.

Die offiziellen deutschen Charts haben als wichtigste Rangtabellen Leitfunktionen i. S. der Programmgestaltung von Radiostationen, der Auswahl und Steuerung des Marketing- und Vertriebsinstrumentariums der Tonträgerhersteller, der Dispositionsentscheidung des Handels $^{376}$ sowie einer Information und Beeinflussung von Konsumenten. Entscheidend für die

${ }^{370}$ An diesem Punkt wird deutlich, daß es keine Kongruenz zwischen dem Erkenntnisinteresse über das Marktergebnis und den Partialinteressen der an der Chart-Ermittlung interessierten Gruppen gibt. Vgl. im Gegensatz dazu Zombik, Peter, 1997a, S. 146.

${ }^{371}$ Der Verweis auf internationale Standards liefert daher keine Rechtfertigung für das Vorgehen, sondern zeigt lediglich, daß auch in anderen nationalen Märkten Ranglisten nach überwiegend einzelwirtschaftlichen Gesichtspunkten erstellt werden.

${ }^{372}$ Vgl. Zombik, Peter, 1997a, S. 140 f. Ranglisten spielen auch in anderen Märkten eine wichtige Rolle. Von der Fachpresse und Radiostationen werden auch selbsterstellte, meistens nicht repräsentative Ranglisten zur Kundenbindung eingesetzt.

${ }^{373}$ Vgl. Wicke, Peter, Die Charts im Musikgeschäfh, in: Musik und Unterricht, o. Jg. (1996), S. 9-14.

${ }^{374}$ So z. B. Schulze, Ralf, op. cit., S. 289.

${ }^{375}$ Wicke führt als Beispiel aus der Mitte der 80er an, daß sich ein Musiktitel in den US-amerikanischen Charts schon nach 8.000 Verkäufen in einer Woche auf Platz 1 befand, während der - im Untersuchungszeitraum dieser Arbeit - erfolgreichste Titel auf Platz 1 innerhalb einer Woche 6 Mio. mal verkauft wurde. Vgl. Wicke, Peter, supra, S. 10, und Wicke, Peter, Bigger Than Life: Rock und Pop in den USA, Leipzig 1991, S. 75.

${ }^{376}$ Die auf Chartplazierungen ausgerichtete Sortimentspolitik des Handels und die Kanalisierung der Verkaufsförderung auf Chart-Titel wirken im Ergebnis als Verstärker, da die Präsenz im Handel und das Schaffen von Öffentlichkeit für den Großteil von Verkäufen verantwortlich ist. Vgl. zur Kritik an den Charts als sich selbst erfüllende Verkaufsprophezeiung Zombik, Peter 1997a, S. 139. Vgl. Schulze, Ralf, op. cit., S, 232 f. zum von ihm sog. Chart-Dilemma. 
ökonomische Wirkung von Charts ist ihre Beachtung durch die Öffentlichkeit und letztlich ihre Berücksichtigung bei der Kaufentscheidung des einzelnen Konsumenten. Charts induzieren einen Mitläufereffekt, der sich mit Hilfe der sozialen Interaktionen zwischen den Konsumenten erklären läßt. Dadurch werden die Präferenzen einzelner Konsumenten vom Konsumverhalten anderer beeinflußt. ${ }^{37}$ Im Tonträgermarkt ist der Mitläufereffekt signifikant in peer groups, die aus Konsumenten ähnlichen Alters und ähnlichen Konsumverhaltens bestehen und die in häufigen Sozialkontakten untereinander stehen. Weiterhin werden Mitläufereffekte über das Programmverhalten von Radiostationen transportiert, die u. a. meinungsbildend auf Konsumentengruppen wirken. ${ }^{378}$ Dabei knüpft die Programmgestaltung wiederum an den Charts an und vermittelt als positive Rückkopplung Informationen über Verkaufserfolge, die sie selbst damit noch verstärkt. Durch diesen Rückkopplungsmechanismus wird u. a. eine Marktdynamik mit kurzen Produktlebenszyklen und dem schnellen Erreichen des maximalen Umsatzes der einzelnen Tonträgertitel bewirkt. ${ }^{379}$

Um die Erfolgsverteilung der Musikproduktion auf Single-Tonträgern anhand der Charts von 1985-1997 zu messen, werden in Tabelle 9 Zusammenstellungen der Daten zu den SingleCharts vorgenommen. Hierbei wird in Spalte zwei die Zahl der Musiktitel angegeben, die es im Laufe eines Jahres zeitweilig geschafft haben, in die ersten zehn Rangplätze zu gelangen. Spalte drei enthält die Zahl der verschiedenen Musiker pro Jahr, die diese Titel gesungen haben. In Spalte vier wird die durchschnittliche Verweildauer der Titel in den Top Ten aufgeführt. Die Zahl der verschiedenen Musiktitel pro Jahr, die zeitweilig den ersten Ranglistenplatz belegten, wird in Spalte fün dargestellt, deren durchschnittliche Verweildauer auf dem ersten Platz in Spalte sechs. Die letzte Spalte schließlich kennzeichnet den prozentualen Anteil der neuen Musiktitel in den Charts, bezogen auf die jährlich zur Verfügung stehenden Chartplätze.

\footnotetext{
377 Vgl. Cowan, Robin, William Cowan, und Peter Swann, A model of demand with interactions among consumers, in: International Journal of Industrial Organization, Vol. 15 (1997), S. 711-732.

378 Dabei kann der Effekt sowohl dadurch zustande kommen, daß die Radiosendungen nur aus dem Abspielen der Rangtabellen bestehen, als auch dadurch, daß sich die Hörer als potentielle Konsumenten an den Praferenzen der Musikredakteure orientieren. Vgl. Granovetter, M., Threshold models of collective behavior, in: American Journal of Sociology, Vol. 83 (1978), S. 1420-1443.

$379 \mathrm{Vgl}$. Steinel, Roland, op. cit., S. 243-246. Steinel weist auf die methodischen Schwierigkeiten hin, die bestehen, wenn mit den Charts die Produktlebenszyklen von Longplay- und Single-Tonträgern gemessen werden.
} 
Tabelle 9: Zahl, Verweildauer und Neueintritte in die Single-Charts von 1985-1997

\begin{tabular}{|c|c|c|c|c|c|c|}
\hline Jahr & $\begin{array}{c}\text { Top Ten } \\
\text { Hits }\end{array}$ & $\begin{array}{c}\text { Musiker } \\
\text { mit Top } \\
\text { Ten Hits }\end{array}$ & $\begin{array}{c}\varnothing \text { Verweildauer } \\
\text { in den Top Ten } \\
\text { (in Wochen) }\end{array}$ & $\begin{array}{c}\text { Nr. 1- } \\
\text { Hits } \\
\text { pro Jahr }\end{array}$ & $\begin{array}{c}\text { Verweildauer } \\
\text { auf Platz 1 } \\
\text { (in Wochen) }\end{array}$ & $\begin{array}{c}\text { Neueintritte zu } \\
\text { Chartplätzen** } \\
\text { pro Jahr }^{\text {380 }}\end{array}$ \\
\hline 1985 & 87 & 73 & 5,3 & 13 & 3,9 & 8,8 \\
\hline 1986 & 92 & 77 & 5,0 & 13 & 3,9 & 8,5 \\
\hline 1987 & 90 & 78 & 5,1 & 13 & 3,8 & 8,3 \\
\hline 1988 & 89 & 70 & 5,2 & 13 & 4,0 & 8,6 \\
\hline 1989 & 76 & 63 & 6,1 & 9 & 5,7 & 9,3 \\
\hline 1990 & 73 & 57 & 6,3 & 7 & 7,3 & $6,5 *$ \\
\hline 1991 & 67 & 62 & 6,8 & 8 & 6,4 & 7,4 \\
\hline 1992 & 63 & 52 & 7,2 & 7 & 7,3 & 8,2 \\
\hline 1993 & 61 & 48 & 7,6 & 9 & 5,7 & 8,7 \\
\hline 1994 & 71 & 61 & 7,2 & 11 & 4,6 & 7,8 \\
\hline 1995 & 75 & 56 & 6,7 & 13 & 4,1 & 8,2 \\
\hline 1996 & 81 & 64 & 6,4 & 14 & 5,1 & 8,3 \\
\hline 1997 & 82 & 69 & 6,3 & 10 & 4,1 & 9,1 \\
\hline
\end{tabular}

Quelle: Musikmarkt div. Jg., eigene Berechnungen. * Die Chartlisten wurden 1989 von 75 auf 100 Plătze verlängert. **Von 1985-1998 gab es 3900, 1989 waren 4400 und seit 1990 pro Jahr 5200 Chartplătze zu belegen.

Es kann festgestellt werden, daß die Zahl der Top Ten Hits und der Top Ten Musiker bis 1993 gesunken ist und danach wieder ansteigt, das Verhältnis zwischen beiden Größen jedoch annähernd konstant geblieben ist. Mit der abnehmenden Zahl an Top Ten Hits ist deren durchschnittliche Verweildauer in den Top Ten gestiegen, mit dem Wiederanstieg der Top Ten Hits sinkt die Verweildauer jedoch wieder. Ebenso ist die Zahl der Nr. 1 Hits bis 1992 gesunken und danach wieder angestiegen. Die Verweildauer verhält sich hierzu ebenfalls invers, seit 1994 aber nicht mehr so eindeutig wie in den Jahren zuvor. Erklärbar ist letzteres mit einer zeitlichen Ungleichverteilung der Nr. 1 Hits: Während einige Titel lange an der Spitze bleiben, sind die restlichen Nr. 1 Hits jeweils nur kurze Zeit bzw. eine Woche an dieser Position. Über den gesamten Zeitraum betrachtet ist die Erfolgsverteilung, bezogen auf das Erreichen der Top Ten durch die Musiker relativ konstant geblieben. ${ }^{381}$ Dies gilt insbesondere vor dem Hintergrund, daß die Zahl der Neuerscheinungen im betrachteten Zeitraum von unter 3.000 bis zu über 5.000 Titel jährlich geschwankt hat.

380 Die Tabelle 9 liest sich am Beispiel der ersten Zeile wie folgt: 87 Titel haben es im Laufe des Jahres 1985 geschaff, zeitweilig in die Top Ten zu gelangen. Diese 87 Titel wurden von 73 Musikern (bzw. Musikgruppen) gesungen. In demselben Jahr belegten 13 Titel zeitweilig den ersten Platz der Charts. Nur 8,8\% der Chartplätze wurden 1985 von neuen Musiktiteln belegt. Neu bedeutet in diesem Zusammenhang, daB die Titel im betreffenden Jahr erstmalig in die Charts gelangten.

381 Der Quotient aus der Zahl jăhrlicher Top Ten Hits und der Musiker mit diesen Hits liegt zwischen 1,08 und 1,34. Der häufigste Wert $(1,2)$ ist in fün von 13 Jahren gegeben. 
In der letzten Spalte der Tabelle 9 wird die Relation der Neueintritte zu den Chartplätzen pro Jahr betrachtet, wobei der Prozentsatz der neuen Musiktitel an der Gesamtzahl möglicher Chartplätze mit ca. $8 \%$ trotz steigender Zahl der Chartplätze relativ konstant geblieben ist. Instrumentalisiert man die Single-Charts als Indikator für die Produktinnovationen im Tonträgermarkt, ${ }^{382}$ kann man von den in Tabelle 9 enthaltenen absoluten Veröffentlichungszahlen diejenigen Single-Titel betrachten, die überhaupt in die Rangtabelle gelangen. Über den gesamten betrachteten Zeitraum erreichten deutlich weniger als $20 \%$ der Neuerscheinungen Chartplätze, in einigen Jahren sogar weniger als $10 \%{ }^{383}$ Um den Erfolg der Innovationen zu messen, werden die jährlich neu in der Rangliste plazierten Titel auf die für Singles verfügbaren Chartplätze bezogen. Die Relation der Neueintritte zu Chartplätzen pro Jahr lag von 1985 bis 1988 relativ konstant zwischen $8,3 \%$ und 8,8\%. Im Jahr 1989 wurden die Single-Charts von 75 auf 100 Plätze verlängert, was in 1989 selbst zu der für den gesamten Zeitraum höchsten Quote von 9,3\% Neueintritten und im Folgejahr 1990 zu der niedrigsten Einstiegsquote von 6,5\% führte. Seither steigt die Relation der Neueintritte zu Chartplätzen wieder an und variiert zwischen 7,4\% (1991) und 9,1\% (1997). Daraus läßt sich schließen, daß das Chartdesign mittelfristig keinen Einfluß auf die prozentualen Neueintritte hatte. Der Erfolg von Produktinnovationen mit Singles im Tonträgermarkt ist im Zeitablauf annähernd konstant geblieben. Von der großen Zahl veröffentlichter Singles erreichte nur ein kleiner Teil den Erfolg des Charteintritts.

Tabelle 10 zeigt von 1990 an - dem Jahr, ab dem in Single- und Longplaycharts 100 Plätze erfaßt werden - die absolute Zahl von Musiktiteln, die sich jeweils in den Charts befanden:

\section{Tabelle 10: Entwicklung der Anzahl von Musiktiteln in Single- und Longplay-Charts}

\begin{tabular}{|l|l|l|l|l|l|l|l|l|}
\hline Jahr & 1990 & 1991 & 1992 & 1993 & 1994 & 1995 & 1996 & 1997 \\
\hline Singles & 433 & 485 & 555 & 550 & 504 & 525 & 520 & 636 \\
\hline Longplays & 390 & 389 & 464 & 552 & 597 & 602 & 626 & 816 \\
\hline
\end{tabular}

Quelle: Musikmarkt, div. Jg., BPW 1997, S. 63.

Absolut und bezogen auf die mögliche Gesamtzahl von Titeln, die in den Charts sein können (= 5200), ist die Zahl der Titel von 1990-1997 gestiegen. Erklärbar ist die größere Titelzahl in den Charts nur durch eine geringere Verweildauer in den Charts insgesamt. Die Tabellen 9 und 10 differieren insoweit, als Tabelle 10 die Gesamtzahl der Titel im jeweiligen Jahr angibt, mehrere Titel aber über den Jahreswechsel in den Charts bleiben. Diese Entwicklung ist der Tabelle 9 nicht zu entnehmen. Hier konnte eine absolute Abnahme der Top Ten Hits von 1985-1993 festgestellt werden, die mit einer immer längeren Verweildauer in diesen Chartpositionen einherging. Seither nahm die Zahl der Top Ten Hits bis 1997 wieder zu und die durchschnittliche Verweildauer entsprechend ab. Die Zahl der Nr. 1-Hits war im Jahr 1997 geringer als 1985

382 Wir hatten bereits weiter oben hergeleitet, daß Singles für Longplay-Veröffentlichungen Werbecharakter wegen bestehender Werbungsexternalitäten haben und daher meistens zeillich kurz vor den Longplays veroffentlicht werden.

${ }^{383}$ Der Anteil der jährlichen Neuerscheinungen, die in die Chartplätze gelangen, an der Gesamtzahl der Neuveröffentlichungen wird fehlinterpretier, wenn man ihn als Break-Even-Quote ansieht. Hierzu bedarf es der Kenntnis des jeweiligen einzelwirtschaflichen Kostenkalküls, das nicht bekannt ist. 
und deren Verweildauer auf Platz 1 länger. Allerdings ist beim Nr. 1-Hit kein eindeutiger Trend auszumachen. Die Verweildauer der Musiktitel auf den vorderen 10 Rangplätzen ${ }^{384}$ ist bis 1993 - ausgehend von einer längeren Verweildauer in der Periode 1985-1988 - stark gesunken, um bis 1997 wieder anzusteigen, ohne jedoch das Ausgangsniveau zu erreichen. Die Fluktuation der Musiktitel in den hinteren Chartplätzen ist demgegenüber größer als diejenige in den vorderen Plätzen und überkompensiert das Verharren der erfolgreichen Titel in den Top Ten. Dadurch wird insgesamt die absolute Zunahme der Musiktitel bei gleichbleibender Chartplatzzahl bewirkt. Interessanterweise stehen sich der Effekt der längeren Verweildauer in den vorderen Chartplätzen und der stärkeren Fluktuation in den hinteren Chartplätzen gegenüber. Dies unterstützt die Hypothese, daß der Markterfolg weniger bei gleichzeitig starker Konkurrenz einer Vielzahl veröffentlichter Musiktitel charakteristisch für den Tonträgermarkt ist. ${ }^{385}$ Auf der Basis dieser Daten wird deutlich, daß der Unternehmenserfolg der Tonträgerhersteller von der vertraglichen Bindung der wenigen erfolgreichen Musiker abhängt.

Als weitere Marktergebnisgröße soll die absolute Zahl jährlicher Auszeichnungen, ihre Verteilung auf Musiker bzw. Musikgruppen und der Anteil ausgezeichneter Musiker herangezogen werden, die neu, d. h. erstmals ausgezeichnet worden sind. Für Musiker sind Auszeichnungen ein Indikator hoher Entlohnung, ${ }^{386}$ und auch bei den Tonträgerherstellern liegen regelmäßig hohe Stückgewinne vor, wenn ein Musiktitel auszeichnungsfahige Absatzzahlen erreicht. Die Veröffentlichung sehr erfolgreicher Musiktitel, von denen jeweils hohe Stückzahlen verkauft werden, impliziert economies of scale bei den Tonträgerherstellern. Modelltheoretisch kann daher unter bestimmten Annahmen ein optimaler Grad an Produktdifferenzienung, d. h. Katalogbreite eines Tonträgerherstellers hergeleitet werden. ${ }^{387}$ Die Produktstrategie der Tonträgerhersteller erfolgt in der Praxis als Balance der vertraglichen Bindung neuer, unbekannter, kontinuierlich verkaufender Musiker sowie Stars, ${ }^{388}$ theoretisch läßt sie sich beschreiben als Portefeuille unterschiedlich riskanter Investitionen. ${ }^{389}$

Auszeichnungen als Indikator für Marktergebnisse sind keine Rangziffern, weil sie mit absoluten Verkaufszahlen verbunden sind. Sie sind ein genauerer Maßstab für Erfolg und Verteilung des Erfolgs von Tonträgerunternehmen als Chartplazierungen, da sie die klassierten Umsatzzahlen ausgezeichneter Titel mit den veröffentlichenden Unternehmen angeben. Ebenso werden damit Titel und Umsätze von Tonträgerunternehmen erfaßt, die nicht in dem relativ kurzen Zeitraum von einer Woche so große Absatzmengen erreichen, daß sie in die Charts gelangen. Die Untersuchung der Vergabe von goldenen und platinen Schallplatten hat auch den Vorteil,

${ }^{384}$ Eine zusătzliche Attraktivităt der ersten Rangplätze besteht darin, dab Tonträgerhersteller bei Vertragsverhandlungen mit Musikern darauf verweisen können, bereits entsprechende Charterfolge erzielt zu haben.

${ }^{385} \mathrm{Vgl}$. die Ausführungen zum Winner-Take-all-Market i. S. von Frank und Cook im Abschnitt 4.1.1.

${ }^{386}$ Rosen fand heraus, dab die absoluten Entlohnungsunterschiede zwischen Musikern wesentlich von ihrer Rangstellung abhăngt. Vgl. Rosen, Sherwin, The Economics of Superstars, in: American Economic Review, Vol. 71 (1981), S. 845-858.

${ }^{387}$ Vgl. Dixit, Avinash K., und Joseph E. Stiglitz, Monopolistic Competition and Optimum Product Diversity, in: American Economic Review, Vol. 67 (1977), S. 297-308.

${ }^{388} \mathrm{Vgl}$. Hill, Leslie, supra, S. 35.

${ }^{389}$ Musikproduktionen sind statistisch gesehen riskante Investitionen. Vgl. zum Portefeuille der Tontrăgerveröffentlichungen Steinel, Roland, op. cit., S. 173-186. 
$\mathrm{da} ß$ sie nicht so stark auf bestimmte Musikrepertoiresegmente fokussiert ist. In Deutschland werden für mindestens 250.000 Stück verkaufter Tonträger desselben Musiktitels pro Jahr goldene Schallplatten und für 500.000 Stück platine Schallplatten verliehen. ${ }^{390}$ Tabelle $11 \mathrm{er}$ faßt die goldenen Schallplatten, die für Single-Tonträger im Zeitraum 1986-1995 vergeben worden sind:

Tab. 11: Goldene Schallplatten, Verteilung auf Musiker und TT-Hersteller v. 1986-1995

\begin{tabular}{|l|l|l|l|l|l|l|l|l|l|l|}
\hline Jahr & 1986 & 1987 & 1988 & 1989 & 1990 & 1991 & 1992 & 1993 & 1994 & 1995 \\
\hline $\begin{array}{l}\text { Zahl ausgezeich- } \\
\text { neter Singles* }\end{array}$ & 3 & 9 & 18 & 19 & 17 & 13 & 20 & 47 & 64 & 73 \\
\hline $\begin{array}{l}\text { Zahl ausgezeich- } \\
\text { neter Musiker** }\end{array}$ & 2 & 8 & 17 & 13 & 13 & 9 & 16 & 28 & 40 & 44 \\
\hline $\begin{array}{l}\text { Zahl ausgezeich- } \\
\text { neter Hersteller + }\end{array}$ & 2 & 5 & 4 & 5 & 6 & 5 & 8 & 9 & 10 & 10 \\
\hline
\end{tabular}

* Platine Auszeichnungen wurden als doppelte Gold-Auszeichnungen gewertet. Zugeordnet dem Jahr, in dem die Verkaufsstückzahl zur Auszeichnung erreicht wurde. ** Berücksichtigt sind Musiker, die im Betrachtungszeitraum erstmalig ausgezeichnet wurden. + Die Label wurden nach selbstăndigen Unternehmen geordnet.

Die Konzentration des kommerziellen Erfolges im Tonträgermarkt kann mit Hilfe der Vergabe von Auszeichnungen abgebildet werden. Zunächst wird damit der an Musiker geknüpfte Verkaufserfolg dargestellt. Über das vertraglich mit dem Musiker verbundene Tonträgerunternehmen kann auch auf den Erfolg der Tonträgerhersteller mit der jeweiligen Veröffentlichung geschlossen werden. Dabei wird, wie bereits oben hergeleitet, von einer positiven Korrelation von Musiker- und Tonträgerunternehmenserfolg ausgegangen. Betrachtet man die Entwicklung der Auszeichnungen fur Singles und stellt sie in Beziehung zur Entwicklung der absolut verkauften Stückzahl (Tabelle 1), kann geschlossen werden, daß sich der Erfolg seit 1986 immer stärker auf einzelne Tonträgerveröffentlichungen konzentriert hat. Der Anstieg der Auszeichnungszahlen von 1986-1988 ist mit der Veränderung des Vergabemodus zu erklären. Dem weiteren Anstieg von 20 ausgezeichneten Singles 1992 bis zu 73 Singles in 1995 steht eine absolute Zunahme der abgesetzten Singles von 26,6 auf 44,1 Mio. Stück und eine Abnahme der jährlichen Neuerscheinungen von über 4.300 auf knapp 3.700 Stück gegenüber. Daraus kann gefolgert werden, daß sich der Erfolg einzelner Musiktitel in sehr hohen Absatzstückzahlen und damit auch unternehmerischen Erfolg der Tonträgerhersteller widerspiegelt. Die stärkere Konzentration der Verkaufserfolge auf einzelne Titel verteilt sich aber zugleich auf zunehmend mehr erfolgreich agierende Unternehmen.

${ }^{390}$ Von 1976 bis zum 1.7.1987 wurden für 500.000 verkaufter Tonträger goldene und für 1.000 .000 platine Schallplatten verliehen, insofern sind die Zahlen dieser nicht mit derjenigen späterer Jahre vergleichbar. Im US-amerikanischen Tonträgermarkt werden die äquivalenten Auszeichnungen für das Erreichen von Umsatzwertgrößen zu Händlerabgabepreisen (1 Mio US-S) vergeben. In Deutschland bestehen neben den goldenen und platinen Schallplatten für Single und Longplay noch Auszeichnungen für Kinder-Longplays, Musikvideos, der Jazz Award und Echo, der Deutsche Schallplattenpreis für die Musikrepertoireteile Pop und Klassik. 
Die Verteilung des Erfolgs von Veröffentlichungen von Musikern, gemessen an goldenen Schallplatten, wurde für den Zeitraum 1958 - 1989 für den US-amerikanischen Tonträgermarkt getestet. ${ }^{391}$ Ausgehend von den Untersuchungen des Versicherungsmathematikers Alfred Lot$\mathrm{ka}^{392}$ fanden Cox, Felton und Chung mit Daten der Recording Industry Association of Amerika (RIAA) heraus, daß sich die Verteilung der goldenen Schallplatten auf Musiker mit der folgenden Formel (= erweitertes Gesetz von Lotka) beschreiben läßt:

$a_{n}=\frac{a_{1}}{n^{c}}$ mit $a_{1}=$ Zahl der Musiker mit einer goldenen Schallplatte, $a_{n}=$ Zahl der Musiker mit $\mathrm{n}$ goldenen Schallplatten und $\boldsymbol{n}^{c}=$ Vergabe goldener Schallplatten hoch einer Konstanten $\mathrm{c}$.

Damit beschreiben Cox, Felton und Chung zwar das Muster des erfolgreichen Tonträgeroutputs, ${ }^{393}$ aber weitergehende Aussagen verbieten sich. Es kann nicht von der Verteilung erfolgreicher Musiktitel der Vergangenheit auf marktpolitische Zusammenhänge der Zukunft geschlossen werden, da das erweiterte Gesetz von Lotka nur angibt, wie sich die Zahl derjenigen Musiker, die eine Auszeichnung erhalten, zu der Zahl von Musikern verhält, die mehr als eine Auszeichnung erhalten. Nicht bekannt ist erstens die Gesamtzahl der Auszeichnungen in der Zukunft, von der man auf ein anteiliges Marktvolumen der ausgezeichneten Titel schließen könnte. Zweitens ist nicht bekannt, wer zu den erfolgreichen Musikern gehören wird und welche Musiker in den deutschen Markt neu eintreten. Drittens kann von der prinzipiellen Verteilung der Auszeichnungen auf bestimmte Musiker nicht geschlossen werden, in welchen Repertoiresegmenten diese Auszeichnungen vorkommen. Von daher ist eine empirische Überprüfung des erweiterten Gesetzes von Lotka nicht für Prognosen im Sinne von Voraussagen für Marktzusammenhänge zu gebrauchen. ${ }^{394}$

Abschließend zu den Marktergebnissen im Tonträgermarkt sollen zwei häufig vertretene, sich vermeintlich widersprechende Hypothesen untersucht werden. Erstens wird behauptet, daß die Konsumenten nicht in der Lage sind, eine wie auch immer geartete Qualität, gemessen z. B. an der Fähigkeit zu Singen, zu beurteilen. Zweitens wird gleichzeitig behauptet, daß der Tonträgermarkt ein Beispiel für einen Winner-Take-all-Market ist, in dem das Starphänomen im Sinne von Marshall ${ }^{395}$ und Rosen ${ }^{396}$ gilt: Ein kleiner Unterschied in der Fähigkeit, irgendetwas im musikalischen Bereich zu tun (z. B. zu singen), kann zu überproportionalen Unterschieden im Erfolg, gemessen an Tonträgerverkäufen führen. Um empirisch zu überprüfen, ob evtl. beide

391 Vgl. Cox, Raymond A. K., James M. Felton und Kee H. Chung, supra, S. 333-340 [Cox/Felton/Chung].

$392 \mathrm{Vgl}$. Lotka, Alfred J., The Frequency Distribution of Scientific Productivity, in: Journal of the Washington Academy of Sciences, Vol. 16 (1926), S. 317-323. Lotka's Law lautet: $a_{n}=\frac{a_{1}}{n^{2}}$, mit $n=1,2,3, \ldots$ Die Zahl der Wissenschaftler, die $\mathbf{n}$ Artikel veröffentlichen, ist $\mathbf{a}_{\mathbf{n}}$, die Zahl der Wissenschaftler, die nur einen Artikel veröffentlichen ist $a_{1}$.

${ }^{393}$ Dabei variieren die für den gesamten ausgezeichneten Output erzielten Ergebnisse geringfuigig, wenn man nur Longplays oder nur Singles betrachtet. Vgl. Cox/Felton/Chung, supra, S. 337.

394 Interessant zu untersuchen wäre jedoch, welcher Anteil am Gesamtumsatz des Tonträgermarktes durch Charttiteln erzielt wird. Dieses Unterfangen scheitert jedoch an der mangelnden Datenverfügbarkeit.

395 Vgl. Marshall, Alfred, Principles of Economics, 8th ed., New York 1947.

396 Vgl. Rosen, Sherwin, supra, S. 845-858. 
Aussagen gültig sind, wurde die Elastizität der Tonträgerverkäufe zur Qualität der Sangesleistung von Musikern gemessen. ${ }^{397}$ Im Ergebnis wurde festgestellt, daß die Konsumenten von Tonträgern sehr wohl Qualitätsunterschiede der Musik feststellen können, daß der Grad der Proportionalität zwischen der Musikqualität und Tonträgerkäufen aber signifikant geringer ist als in anderen Konsumgüterindustrien. ${ }^{398}$ Die empirische Untersuchung von Hamlen ergab keine Unterstützung für die Hypothese, daß der Tonträgermarkt ein Beispiel für das Starphänomen im Sinne von Marshall und Rosen ist. Dieses lag nach Ansicht des Verfassers aber an der mangelnden Datenverfügbarkeit und der zu geringen Qualitätsreagibilität der Konsumenten.

Die Aussagen der Qualitätsreagibilität und des Starphänomens widersprechen sich jedoch nach der beschriebenen empirischen Überprüfung nicht. Vielmehr durchlaufen Musiker und Musikgruppen, bevor sie ein größeres Publikum ansprechen können, einen Selektionsprozeß, in dem Musikmanager und Tonträgerhersteller u. a. auch qualitative Maßstäbe anlegen. ${ }^{399}$ Nach erfolgreicher Selektion sind die Gewinnerzielungsabsichten von Musikern und Tonträgerherstellern soweit angenähert, daß Unterschiede in tatsächlichen Erträgen verschiedener Musiker nicht allein auf ihre Qualitätsunterschiede zurückgeführt werden können, sondern auch auf unterschiedliche Fähigkeiten von Managern in den vermarktenden Tonträgerunternehmen. ${ }^{400}$ Ebenso entspricht es nicht dem Charakter des Wettbewerbs auf dem Tonträgermarkt, bei erfolgreichen Musikern, die seit Jahren im Markt tätig sind, ex post eine Qualitätsdifferenz zu Newcomern zu messen, sondern im Gegensatz dazu müssen sich Neueintretende durch eine neue (andere) Qualität etablieren. ${ }^{401}$

Die Marktergebnisse des Tonträgermarktes wurden anhand der absoluten Veröffentlichungszahlen, der Plazierung der Titel in den Charts im Zeitablauf und schließlich anhand der Verteilung von Verkaufsaufzeichnungen auf die Tonträgerhersteller dargestellt. Dabei zeigte sich, $\mathrm{da} ß$ unabhängig von der wachsenden $\mathrm{Zahl}$ jährlicher Neuerscheinungen nur ein geringer Teil von $10-20 \%$ der Titel die Rangtabelle erreicht. Ebenso - zumindestens mittelfristig unabhängig vom Chartdesign - ist die Relation von Neueintritten zu Chartplätzen pro Jahr annähernd konstant geblieben, die für den betrachteten Zeitraum unter 10\% liegt. Dieser als gering anzusehende Prozentsatz scheint im Gegensatz zu der Tatsache kurzer Produktlebenszyklen fur Single-Tonträger zu stehen, ist aber dadurch erklärbar, daß die Rezeptionsgewohnheiten der Tonträgerkonsumenten auf Wiedererkennungen basieren. Veränderungen des Marktergebnisses sind erkennbar, wenn man für den Zeitraum (1986-1995) die Zahl und die Verteilung von Verkaufsauszeichnungen (goldene Schallplatten) betrachtet. Sowohl die Zahl der goldenen

397 Vgl. Hamlen, William A., Superstardom in Popular Music: Empirical Evidence, in: The Review Of Economics and Statistics, Vol. 73 (1991), S. 729-733.

398 Vgl. Hamlen, William A., supra, S. 732.

399 Natürlich kann der Qualitătsmaßstab von Tonträgerherstellern nur subjektiv sein, aber er beruht auf ihren Erfahrungswerten über Vermarktungsmöglichkeiten.

${ }^{400}$ Diese Erklărung läßt auch eine Modifikation des ursprünglichen Modells von Rosen zu, die MacDonald vornimmt, indem er den dynamischen Charakter des Erfolgs modelliert. Vgl. MacDonald, Glenn M., The Economics of Rising Stars, in: American Economic Review, Vol. 78 (1988), S. 155-166.

401 Gleichwohl gilt, ,...there are few stars in the Industrie - the older, well-established performers - but as a Group they serve a large fraction of the audience and obtain an even larger share of the returns. The distribution of rewards is always positively skewed." MacDonald, Glenn M., supra. S. 166. 
Schallplatten als auch die summierten Verkaufszahlen der einzelnen erfolgreichen Tonträgertitel sind im Zeitablauf gestiegen. Daher ist zu konstatieren, daß die Tonträgerhersteller zunehmend in der Lage sind, den Erfolg ihrer Marketing- und Öffentlichkeitsarbeit auch logistisch in Verkaufszahlen umzusetzen. Gleichzeitig ist bei den Single-Produkten die Zahl der Unternehmen gestiegen, die Verkaufserfolge ausweislich goldener Schallplatten erlangt haben.

\subsubsection{Zusammenhänge zwischen Marktstruktur und -ergebnis}

Die Zusammenhänge zwischen Marktstruktur und Marktergebnis sollen auf den Stufen des Tonträgermarktes analysiert werden. In Abschnitt 4.1 sind als relevante Marktstufen Musikschaffende, Tonträgerhersteller, Handel und Konsumenten ausdifferenziert worden. Bei der Analyse der Marktstrukturfaktoren in Abschnitt 4.2 sind die Vertragsbeziehungen zwischen Musikschaffenden und Tonträgerherstellern betrachtet worden. Daher werden hier die Bezüge dieser Vertragsbeziehungen zum Marktergebnis zunächst für die Musikschaffenden und danach für die Tonträgerhersteller geschaffen, bevor auf die Zusammenhänge zwischen Handels- und Konsumentenstruktur und Ergebnis eingegangen wird.

Auszeichnungsfähige Verkaufszahlen erreichen die Musikschaffenden nur in Zusammenarbeit mit Tonträgerherstellern. Der Zusammenhang zwischen dem Markterfolg von Musikern und ihrer Stellung im Prozeß der Musikverwertung läßt sich durch das generelle Prinzip beschreiben, daß vom Erfolg der Musiker auch deren Kontrollmöglichkeiten über ihr Werk abhängen. Je erfolgreicher ein Musiker ist, gemessen an den oben aufgestellten Marktergebniskriterien, ${ }^{402}$ desto stärker ist seine Fähigkeit, seine Wünsche bei allen Verwertungen durchzusetzen. Denn die Konsumentenbindung bezieht sich im wesentlichen auf die Musiker. Für die Tonträgerhersteller ist daher bei Vertragsbindung eine Einschätzung des Verkaufspotentials des oder der Musiker entscheidend. Die Einschätzung basiert, sofern möglich, auf Verkaufserfahrungen der Vergangenheit. Liegen keine Erfahrungswerte vor, weil es sich bei den Musikern beispielweise um Newcomer handelt, beziehen sich die Überlegungen auf die Art des Vertragsverhältnisses, die Qualität des Künstlermanagements, die Art der zu produzierenden Tonträger ${ }^{403}$ und schließlich die Höhe der zu tätigenden Investitionen. ${ }^{404}$ Ebenso muß die Vertragsdauer und die künstlerische Leistungs- und Lebensfähigkeit der Musiker in Betracht gezogen werden. Dabei variiert die Bezahlung der Musiker, jeweils vom Händlerabgabepreis der Tonträger gerechnet, von $2,5 \%$ bei Backkatalogverwertungen über $6 \%$ für einen Newcomer-Musiker (mit Künstlervertrag) bis zu 15 oder $20 \%$ für einen Bandübernahme- oder Lizenzvertrag eines Stars. ${ }^{405}$ Die Aufgabe der Tonträgerhersteller zur Sicherung der Kontinuität des Ertragsflusses ist es daher,

${ }^{402}$ Interessanterweise beurteilen auch Tonträgerhersteller den Erfolg der bei ihnen vertraglich gebundenen Musiker nicht nur an den absoluten Verkaufszahlen, für deren Approximation die goldenen und platinen Schallplatten herangezogen worden sind, sondern auch an der Plazierung und Verweildauer in den Charts. Hierfür können als Erklärung externe Werbeeffekte dienen. An Charterfolge der Vergangenheit wird bei neuen Titeln der entsprechenden Musiker zur Verkaufsfordenung angeknüpft. Quelle: Gespräch mit einem Insider (Dirk Ewald, Intercord Tonträger GmbH) am 16.01.1998.

${ }^{403}$ Single- oder Longplay-Tontrăger, Verkauf im Vollpreissegment oder zum Budgetpreis, etc.

${ }^{404}$ Hierbei spielt die absolute Höhe und die Fälligkeit von Produktionskosten, Konzerttourunterstützung, Marketing, Tantiemen etc. eine Rolle (im voraus oder erst nach erfolgtem Verkauf von Tonträgern).

${ }^{405} \mathrm{Vgl}$. Hill, Leslie, supra, S. $34 \mathrm{f}$. 
Aufgabe der Tonträgerhersteller zur Sicherung der Kontinuität des Ertragsflusses ist es daher, ihr individuelles Portfolio von Musikern aus Newcomern, sich durchschnittlich verkaufenden Musikern und den Stars zusammenzustellen. Die hier gewählten Marktergebniskriterien können daher nur den Teil der Veröffentlichungspolitik abbilden, der sich auf Stars und gut verkaufende Musiker bezieht, und nicht denjenigen Teil der Produktpolitik der Tonträgerhersteller, der die Förderung von Talenten und damit potentiellen zukünftigen Verkaufserfolgen betrifft. Anfänglich unbekannte Musiker werden von den Tonträgerherstellern zu günstigen Konditionen verpflichtet. Das so produzierte Repertoire birgt im Erfolgsfall den größten Gewinn für Tonträgerhersteller. Doch im Mißerfolgsfall sind die Investitionen in die Musiker versunkene Kosten, so daß das Risiko hier größer ist als bei etablierten Musikern. Die Notwendigkeit der Risikostreuung mit Hilfe eines entsprechenden Musikerportefeuilles und die für die Marktdynamik nötigen finanziellen Mittel ${ }^{406}$ sind Erklärungsansätze für die Beherrschung des Marktes durch eine Gruppe von Unternehmen, die das Oligopol der Majors bilden.

Um den Zusammenhang zwischen der oligopolistischen Marktstruktur und den Marktergebnissen empirisch zu belegen, werden für die Jahre 1985-1997 die Konzentrationsraten CR und $\mathrm{CR}_{\mathbf{B}}$ auf der Basis der jährlichen Chartanteile für Longplay- und Singlecharts ermittelt. In Abschnitt 4.2.2.3 wurde der These von der Übertragbarkeit von Chart- zu Marktanteilen u. a. mangels veröffentlichter Marktanteile einzelner Unternehmen gefolgt. Die Problematik der Charts als Marktergebniskriterium wurde im vorangegangenen Abschnitt erläutert. Die Daten sind daher nur als Näherungswerte zu betrachten.

Tab. 12: Konzentrationsentwicklung 1985-1997, gemessen an Chartanteilen

\begin{tabular}{|l|l|l|l|l|l|l|l|l|l|l|l|l|l|}
\hline Jahr & 1985 & 1986 & 1987 & 1988 & 1989 & 1990 & 1991 & 1992 & 1993 & 1994 & 1995 & 1996 & 1997 \\
\hline $\begin{array}{l}\text { CR } \\
\text { Single }\end{array}$ & 70,4 & 70,1 & 67,1 & 76,1 & 70,0 & 64,5 & 75,2 & 66,0 & 63,6 & 75,3 & 73,1 & 75,0 & 68,5 \\
\hline $\begin{array}{l}\text { CR } \\
\text { Long- } \\
\text { play }\end{array}$ & 75,8 & 73,6 & 76,3 & 77,9 & 73,6 & 61,7 & 75,9 & 65,1 & 64,5 & 78,3 & 76,1 & 79,4 & 79,0 \\
\hline $\begin{array}{l}\text { CR } \\
\text { Single }\end{array}$ & 97,7 & 98,1 & 96,8 & 92,7 & 96,2 & 93,1 & 98,1 & 94,5 & 94,9 & 99,0 & 98,2 & 98,5 & 94,3 \\
\hline $\begin{array}{l}\text { CR } \\
\text { Long- } \\
\text { play }\end{array}$ & 99,1 & 96,5 & 96,9 & 98,1 & 97,3 & 96,3 & 96,8 & 95,4 & 93,1 & 97,9 & 95,6 & 97,9 & 97,7 \\
\hline
\end{tabular}

Quelle: eigene Berechnungen und Schulze, Ralf, op. cit., S. 296-301.

Die Anteile der führenden vier Unternehmen an den Musiktiteln in den Charts variierten im betrachteten Zeitraum zwischen $61 \%$ und $79 \%$, wobei festzustellen ist, daß die Konzentration in den Longplay-Charts - abgesehen von der Periode 1990-1992 - höher ist als in den SingleCharts. Als Gründe hierfür können u. a. angeführt werden, daß die Produktion einer Single

${ }^{406}$ Vgl. zu dem Finanzierungsproblem der Musikproduktion Steinel, Roland, op. cit., S. 189-207. 
Musikern zu kontrahieren, deren Repertoire noch nicht so umfangreich ist, weil sie erst am Anfang ihrer Karriere stehen. Denn die Verhandlungsstärke etablierter Musiker, der hohe Finanzbedarf zu ihrer Akquisition und der Kapitalbedarf der Musikproduktion ${ }^{\mathbf{4 0 7}}$ und -etablierung war als einzelwirtschaftiches Konzentrationsmotiv festgestellt worden. Diese Zusammenhänge zeigen sich auch an der steigenden Zahl der für Single-Veröffentlichungen ausgezeichneten Tonträgerhersteller (vgl. Tabelle 11). Bei der Betrachtung der führenden acht Unternehmen im Zeitraum von 1985-1997 wird quasi der gesamte Markt erfaßt, der sich in Single- und Longplay-Plazierungen niederschlägt. Unter den genannten Vorbehalten zeigt sich daher die Konzentration des Tonträgermarktes auch durch die mit den Charts gemessenen Anteile.

Die Analyse der Zusammenhänge zwischen Marktstruktur und -ergebnissen desjenigen Teils der Musikveröffentlichungen, die nicht bzw. nicht mehr in den Charts sind, knüpt an den Rechten an. Rechtsinhaber sind zumeist die Musikverlage. Die Majors sind Eigentümer der größten Musikverlage: EMI Music, Warner/Chappell Music, BMG/Ufa, Polygram Songs, MCA Music und Sony/ATV Music. ${ }^{408}$ Rechte zu besitzen ist die Vorausssetzung für eine Zweit- und Drittverwertung. Insofern ist während der Dauer der Leistungsschutzrechte (50 Jahre ${ }^{409}$ die Verwertbarkeit der musikalischen Inhalte interessant. Abgesehen von Ausnahmen, liegen die meisten Rechte bereits erfolgreich verwerteter Musik in den Händen der Majors, die allenfalls in Lizenz an andere Unternehmen vergeben werden. ${ }^{410}$ Die Konzentration der Rechte auf die Majors ist gegenwärtig Bestandteil der Integrationsstruktur der vollintegrierten Majors, die bereits in Abschnitt 4.2.2.5 dargelegt wurde. Die musikalischen Inhalte sind aber auch Gegenstand neuer Distributionswege und der Frage, wie Musik anderweitig vermarktet werden kann. Angesichts der technisch möglichen Entkopplung des musikalischen Inhalts von einem Trägermedium, z. B. bei der Verwertung in Netzen, sind sowohl Veränderungen der Integrationsgrade als auch Neueintritte in den Markt über einen vermehrten Einkauf von Rechten möglich. ${ }^{411}$

Die Untersuchung der realen Marktvolumensentwicklung hatte ergeben, daß sich der Markt für Tonträger in Deutschland in einer Stagnationsphase befindet. Den Stagnationstendenzen vorangegangen waren Strukturbrüche. ${ }^{412}$ So beeinflußte von 1978-1983 neben rezessiven Entwicklungen der steigende Absatz von Leerkassetten und das private Kopieren den Umsatz negativ. In den Jahren 1987-1989 entwickelte sich die Tonträgerkategorie CD zum Standard und veranlaßte die Tonträgerhersteller, bestehendes Repertoire von analogen auf digitale Tonträger zu übertragen, was sich in der steigenden Zahl der Veröffentlichungen niederschlug. Der relativ

${ }^{407}$ Die Produktionskosten der Erstellung eines Master-Tapes variieren von 10.000,- bis über 500.000,- DM und sind für die verschiedenen Unternehmensgrößen signifikant verschieden. Generell gilt, daß die Proctuktion durch Independents zu geringeren Kosten durchgeführt wird als durch Majors. Vgl. Alexander, Peter J, 1994, S. 91.

408 Diese Aufzăhlung ist nur beispielhaft und nicht vollstăndig, schließt aber die größten im deutschen Tontrăgermarkt tătigen Verlage aller Majors ein.

$409 \mathrm{Vgl}$. hierzu die Ausführungen in Abschnitt 2.1.3.

${ }^{410}$ Ein Beispiel für eine Ausnahme ist der Aufkauf der Beatles-Rechte durch Michael Jackson.

411 Auf diesen Zusammenhang wird im Rahmen von Kapitel 5 eingegangen werden.

${ }^{412} \mathrm{Vgl}$. Brodbeck, K.-H., Ansătze zur Theorie und Empirie des Musikmarktes, Studie der GrM, München 1991, unveröffentlichtes Manuskript, zitiert nach Steinel, Roland, op. cit., S. 88. 
teurere Träger CD verdrängte billigere Trägerkategorien. Die deutsche Vereinigung beeinflußte den Umsatz zusätzlich positiv. Die Preisentwicklung der CD ist seither in den 90er Jahren rückläufig, wobei der Preisindex für Bildungs-, Unterhaltungs- und Freizeitgüter hinter der Preisentwicklung für die allgemeine Lebenshaltung zurückbleibt. ${ }^{413} \mathrm{Nach}$ der CD führten neue Trägerformate hingegen nicht zu weiteren Strukturbrüchen; beispielsweise setzte sich die digitale Kassette (Digital Audio Tape) nicht im Markt durch, sondern wird lediglich im professionellen Bereich eingesetzt. Die nächsten Strukturbrüche sind erst bei der Akzeptanz unkörperlicher, d. h. trägerloser Verwertungswege zu erwarten. Dann wird eine neue Marktentwicklung eintreten, die auch zu einer Veränderung der Marktphase führt. ${ }^{414}$

Wesentliche Marktbarrieren im Tonträgermarkt sind der vertragliche Zugang zu den etablierten Musikern, anfänglich hoher Kapitalbedarf mit Vorfinanzierungscharakter und der Zugang zu den Absatzkanälen, der sich sowohl auf die Distribution als auch die medienbezogene Verkaufsförderung bezieht. Auswirkungen auf das Marktergebnis insgesamt haben diese strukturellen Barrieren insofern, als sie im Ergebnis nicht eintrittsverhindernd, sondern als endogene Mobilitätsbarrieren im Markt wirken, indem sie das Wachstum von einem Independent zu einem Major behindern. Die Barrieren wirken auf das Kontrahierungsverhalten etablierter Musiker zurück, die nahezu ausschließlich mit Majors in Vertragsbeziehungen stehen. Dabei läßt sich das Risiko der Tonträgerhersteller, das wesentlich vom Grad der Irreversibilität der Investitionen in die Musikveröffentlichung abhängt, eben gerade dadurch reduzieren, daß an frühere Erfolge der etablierten Musiker angeknüpft wird. Weiterhin versuchen Majors ihr Risiko damit zu minimieren, daß sie ihre Veröffentlichungen über verschiedene Repertoiresegmente streuen und in ihnen jeweils vielfältige Rechte erwerben. ${ }^{415}$ Demgegenüber liegt die Risikominimierungsstrategie der Independents darin, Spezialisierungsvorteile in einzelnen Reperoiresegmenten zu realisieren, auf die sie sich jeweils beschränken. Dies impliziert jedoch von vornherein beschränkte Potentiale für Marktanteilszuwächse. Ebenso stellen bei Veröffentlichungen Independents eher auf das mit geringeren Kosten zu produzierende Format der Single ab, wie aus den Marktergebnissen, insbesondere den Konzentrationsraten der Charts abzulesen war. Sie war im betrachteten Zeitraum für Longplays größer als für Singles. Zusätzlich kann festgestellt werden, daß bei den Majors durchschnittlich höhere Produktionskosten als bei den kleineren Unternehmen realisiert werden. ${ }^{416}$

${ }^{413} \mathrm{Vgl}$. die Abschnitte 4.2.2 und 4.2.2.6. Gleichwohl wird der Preisindex der Güter für Bildung, Unterhaltung und Freizeit durch schr unterschiedliche Preisentwicklungen gekennzeichnet. Wahrend die Preise für Tontrăger in der $90 \mathrm{er}$ Jahren nominal nur geringrugig gesunken sind bzw. annähernd konstant blieben, sind diejenigen für Hardware (Abspielgeräte) signifikant gesunken. Vgl. Mahlmann 1997, op. cit., S. 172.

${ }^{414}$ Das folgt unmittelbar daraus, daß die Produktvermarktung von Musik sich ändern wird. Vgl. Kapitel 5.

${ }^{415}$ Diese Aussagen lassen sich auch unmittelbar aus der Portfolio-Theorie ableiten. Vgl. etwa Hielscher, U. Investmentanalyse, München u.a. 1990, S. 40.

${ }^{416}$ Die Produktionskostenunterschiede sind allerdings nicht durch Qualitătsunterschiede zu erklären, sondern als möglicher Hinweis auf X-Ineffizienzen. „(...) One might assume that this larger market share lof the majors] results from greater expenditure at the production stage, i. e. quality effect.(...)Through the use of these tapes [of the independent firms], the major firms implicitly acknowledge that they are of a sonic quality sufficient for use in mass production. Thus a link between expenditures at the production stage and market share is tenuous." Alexander. Peter J, 1994, S. 91. 
Der Zugang zu den Distributionskanälen war als weitere Mobilitätsbarriere identifiziert worden. Hier bestehen die unterschiedlichen Integrationsgrade darin, daß die Majors im Gegensatz zu den Independents über eigene Vetriebskanäle verfügen. Bei Aufkäufen kleinerer Unternehmen waren auch deren Distributionsfazilitäten an die Majors gefallen, so daß schließlich viele Independents den Herstellungs- und Distributionsservice der Majors in Anspruch nehmen. ${ }^{417}$ Dadurch besteht für die Independents die Gefahr, die Kontrolle über ihre Musiker zu verlieren, z. B. durch Abwerben der Majors, oder gezwungen zu werden, für weitere Veröffentlichungen den Service derselben Majors in Anspruch zu nehmen. ${ }^{418}$ Die strukturellen Unterschiede zwischen der Oligopolgruppe der Majors und der Vielzahl der Independents zeigen sich daher auch dadurch in den Marktergebnissen, daß weit über $80 \%$ aller Charttitel von den Majors vertrieben werden. ${ }^{419}$

Die Zusammenhänge zwischen der Handels- und der Konsumentenstruktur und dem Ergebnis beschließen diesen Abschnitt. Auf der Handelsstufe steht der steigenden Zahl an jährlichen Neuerscheinungen von Tonträgern eine abnehmende Zahl an Verkaufsstellen gegenüber. Der Fachhandel mit der größten Sortimentsbreite erzielte 1995 nur noch $20 \%$ des Umsatzwertes. Die größten Umsatzsteigerungen in den 90er Jahren verzeichneten dagegen Elektromärkte und Filialunternehmen. Der Konzentrationsprozeß im Handel führte dazu, daß 1995 die 10 größten Händler $60 \%$ des Gesamtumsatzes mit Tonträgern tätigten. Einhergehend mit der Umsatzwertkonzentration erfolgte eine größere Beschränkung auf musikalisches Repertoire, das die Charts erreicht hatte. Dieses wiederum führte zu einer steigenden Zahl an Goldenen Schallplatten und damit einer stärkeren Konzentration der Nachfrage auf einzelne Titel. Damit sind die Charts als informationskostensparende Rangtabellen in ihrer Bedeutung für die Konsumenten gestiegen. Dieses Marktergebnis geht einher mit einer Abnahme der Konzentration auf der Nachfrageseite. Zwar ist die absolute Zahl der Konsumenten, die sog. Käuferreichweite, im betrachteten Zeitraum konstant geblieben, jedoch hat sich die relative Verteilung in den Konsumentengruppen zugunsten der Durchschnitts- und Extensivkäufer verschoben. Die Veränderung der alterspezifischen Bevölkerungsstruktur zeigt, daß insgesamt die Bevölkerungsgruppen mit unterproportionalen Käufen zunehmen. Deren geringerer Informationsgrad über Musik läßt auf eine weitere Zunahme der Bedeutung der Charts schließen. ${ }^{420}$

417 Vgl. Abschnitt 4.2.2.5.

${ }^{418}$ Vgl. Federal Trade Commission v. Warner Communications Inc., et al., in: 1984-1, Trade Cases $§ 66,025$, S. 68,543-68,544. Von Interesse ist die Zeugenaussagen in diesem Fall vor dem United States District Court, Central District of California: ${ }_{n}(\ldots)$ the independent labels must increasingly rely on the majors for various services like distribution, a dependency that permits the majors to obtain contractual options on the acts of independent labels." Greer 1984, zitiert nach Alexander, Peter J. 1994, S.92. Greer verweist auf die fehlenden Alternativen der Independents, um den Vetrieb durch die Majors zu vermeiden. Er rekuriert auf Schätzungen, wonach die Integrationskosten in die Distribution für die gesamte USA auf 100 Mio. US-\$ veranschlagt werden.

$419 \mathrm{Vgl}$. Tabelle 12 in diesem Abschnitt.

${ }^{420}$ Die Konzentration auf Chartprodukte mag kritisiert werden, z. B. von Wicke (1996), supra, S. 9-14. Die auditiven Rezeptionsgewohnheiten von Durchschnitts- und Extensivkäufern sind jedoch noch stärker auf das Radio und dadurch die Rangtabellen ausgerichtet als diejenige von Intensivkäufern, die sich mehr mit Musik beschäftigen 


\subsubsection{Zusammenhänge zwischen Marktverhalten und -ergebnis}

Für die Zusammenhänge zwischen Marktverhalten und -ergebnis wird wieder Bezug genommen auf die einzelnen Marktstufen des Tonträgermarktes, die in Abschnitt 4.1 ausdifferenziert worden sind. Bei der Analyse der Marktverhaltensfaktoren in Abschnitt 4.3 sind die Vertragsbeziehungen zwischen Musikschaffenden und Tonträgerherstellem betrachtet worden. Daher werden hier die Bezüge dieser Vertragsbeziehungen zum Marktergebnis für die Musikschaffenden und für die Tonträgerhersteller hergestellt.

In der Vertragsbeziehung zwischen Musikern (ausübenden Künstlem) und Tonträgerherstellern bestehen generelle Zielkonflikte. Die Musiker sind daran interessiert, ihre Musik zu veröffentlichen. Aus der Sicht von neuen Musikern wird nur durch Veröffentlichung ein Erfolg möglich, der notwendig ist für das Aushandeln neuer Verträge mit den Herstellern. Neuverhandlungen können wiederum zu günstigeren Konditionen in den Künstlerverträgen führen oder den Musikern überhaupt erst Investitionen in die eigene Erstellung von Masterbändern und damit den Abschluß von Bandübernahmeverträgen möglich machen. ${ }^{421}$ Aus der Sicht der Tonträgerhersteller steigt zwar die Wahrscheinlichkeit des Unternehmenserfolges mit der Zahl der Veröffentlichungen, aber ebenso steigen die Kosten. Ein positiver Zusammenhang zwischen der Höhe der reinen Produktionskosten und dem Ausmaß des Markterfolgs kann nicht nachgewiesen werden. ${ }^{422}$ Für die Tonträgerhersteller bestehen daher in kurz- und langfristiger Sichtweise unterschiedliche Anreize, denn für sie ist eine Verpflichtung neuer Musiker riskant und deren Veröffentlichungen stellen risikoreiche Investitionen dar. Der Erfolg neuer Musiker bei vertraglich günstigen Konditionen steigert zwar das Gewinnpotential der Tonträgerhersteller, ist aber für die Musiker Anknüpfungspunkt für Neuverhandlungen bzw. für die konkurrierenden Tonträgerhersteller für Abwerbeversuche. ${ }^{423}$ Kurzfristig ist es daher für Tonträgerhersteller sinnvoll, die anstehenden Veröffentlichungen nach den zu erwartenden Erträgen zu reihen. So kann es sowohl profitabel sein, die Stücke neuer Musiker zu veröffentlichen als auch Neuerscheinungen von etablierten Stars zeitlich zu strecken. Langfristig vonnöten ist aber die Gestaltung des Portefeuilles. Da die Veröffentlichungen der etablierten Stars ${ }^{424}$ den sichersten Gewinn versprechen, ist die Aufnahmefähigkeit der Tonträgerhersteller für neue Musiker beschränkt. Ihre Portfolio-Strategie wird darin bestehen, so viele Stars wie möglich und so wenig neue Musiker wie nötig unter Vertrag zu nehmen. ${ }^{425}$

${ }^{421}$ Bandübernahmeverurăge steigern für die Musiker den Einkommensanteil pro verkauftem Tontrăger und erleichtern ihnen spater eigene Verwertungen ihrer Rechte.

422 Beispiele für Musikproduktionen, die mit einem reinem Produktionsbudget von 250-1.000 US-\$ für das Masterband mehr als 1 Mio. verkaufter Exemplare erzielten, finden sich in Alexander, Peter, J., 1994, S. 97.

${ }^{423}$ Natürlich kann man argumentieren, daß ein erfolgreicher Verkauf des bestehenden Repertoires die Tontrăgerhersteller in die Lage versetzt, keine neuen Musiker verpflichten zu müssen. Aber die künstlerische Lebensfahigkeit von Musikern ist begrenzt und ihre Dauer schwierig vorherzusagen.

${ }^{424}$ Währenddessen die Anreize für etablierte Stars, noch neue Musik zu produzieren, mit zunehmenden Erfolgen der Vergangenheit abnehmen.

$425 \mathrm{Vgl}$. Black, Michael, und Douglas Greer, Concentration and Non-Price Competition in the Recording Industry, in: Review of Industrial Organization, Vol. 3 (1987), S. 16. 
Stellen wir die Zusammenhänge zwischen dem Verhalten der Tonträgerhersteller und dem Marktergebnis dar, so ergeben sich unmittelbare Zusammenhänge aus der internen Unternehmensstruktur von Majors und Independents im Hinblick auf die Vertragsverhältnisse. Es ergeben sich - für die Unternehmensgruppen unterschiedliche - Zusammenhänge zwischen der Produktpolitik, der Zahl der Veröffentlichungen ${ }^{426}$ und der Angebotsbreite. Bei nur geringer Bedeutung des Preiswettbewerbs auf dieser Marktstufe ergeben sich schließlich Zusammenhänge zwischen strategischen Barrieren und Marktergebnis.

Für die vollintegrierten Majors ergibt sich durch den hohen Fixkostenanteil, in Personal und Anlagen gebunden, im Gegensatz zu den Independents das Risiko der Auslastung. Auch aus diesen Motiven resultieren die Vertragsbeziehungen zwischen den vollintegrierten Majors und den Independents, die sich als Lizenzverträge, Sales- und Distributionverträge sowie Labelverträge oder - wenn die Bearbeitung bestehender Musik Ausgangspunkt neuer Tonträgerveröffentlichungen sein soll - als Sampling- und Remixverträge gestalten. Um einerseits die Größenkostenvorteile des Marketings, der physischen Herstellung und der Distribution nutzen zu können, andererseits auch den gleichen Zugang wie die verschiedenen Independents zu neu zu akquirierenden Musikern zu bekommen, haben die Majors ihre interne Organisationsstruktur umgestellt. Sie gliedern die Tätigkeit der Artist- und Repertoirebetreuung sowie der Überwachung der Masterbanderstellung aus. Dieses Outsourcing ist nur zu einem Teil auf die Kostenspareffekte zurückzuführen, zum größeren Teil aber auf die größere Glaubwürdigkeit der kleineren Einheiten (Label) den Musikern gegenüber, insbesondere wenn ihre Verbindung bzw. Abhängigkeit zum Major nicht bekannt ist. Daneben resultiert ein besserer Zugang zu neuen Musikern aus der Tatsache, daß kleinere Einheiten die lokale Musikentwicklung besser beobachten können und als Anknüpfungspunkt für die Vermarktung geeigneter sind.

Die Produktpolitik wurde nach Majors und Independents unterschieden. Produkte der Independents erreichen die für Charterfolge bzw. die für goldene oder platine Schallplatten nötigen Umsätze mit Hilfe der Logistik der Majors. ${ }^{427}$ Denn Verkaufserfolge, die durch Radio-Einsätze und Marketingmaßnahmen vorbereitet werden, bedürfen dennoch der Präsenz des Produktes im Handel selbst. Durch den kurzen Produktlebenszyklus ${ }^{428}$ und die große Konkurrenz wieder neu erscheinender Tonträgertitel müssen die Verkaufszahlen innerhalb kürzester Zeit erreicht werden. Bereits bewertet wurde die steigende Titelzahl als Erhöhung der Angebotsbreite und als stärkere Ausdifferenzierung des Marktes, da auch die Titelzahl in den einzelnen verschiedenen Repertoiresegmenten zugenommen hat. ${ }^{429}$ Möglicherweise ist der verstärkte Produktwett-

${ }^{426}$ Crain und Tollison untersuchen die Struktur der erfolgreichen Musiktitel in Bezug zu gesamtwirtschaftichen Größen. Vgl. Crain, Mark, W., und Robert D. Tollison, Economics and the architecture of popular music, in: Journal of Economic Behavior \& Organization, Vol. 32 (1997), S. 185-205.

${ }^{427}$ Vgl. Vogel, Harold L., op. cit., S. 149 f. Die entscheidende Rolle für den Erfolg der reinen Distributionsaufgabe liegt in der Făhigkeit, in kürzester Zeit zu erkennen, welche neue Musik sich gut verkauft, und die logistische Aufgabe zu bewăltigen, daß genau diese Musik immer im Handel präsent ist.

${ }^{428}$ Vgl. zu der Ermittlung von Produktlebenszyklen von Single- und Longplay-Tonträgern aus Charts Steinel, Roland, op. cit., S. 164-171.

${ }^{429}$ Verschiedentlich wird die Funktion der Tonträgerhersteller als GateKeeper des offentlichen Musikangebots gesehen. Diese Ansicht ist allerdings empirisch nicht belegbar. Vgl. Christianen, supra, S. 18; Lopes, supra, 
bewerb in Form einer zunehmenden Musikproduktion Folge der insgesamt gesunkenen Konzentration, insbesondere des kumulierten Marktanteils der Majors. ${ }^{430}$ Denn auch wenn unterstellt werden kann, daß die Produkte der Tonträgerhersteller nur beschränkt substituierbar sind, vermindert jede neue Veröffentlichung das Verkaufspotentiel für die bereits bestehenden Produkte. Daher kann gezeigt werden, ${ }^{431}$ daß eine zunehmende Konzentration bei den Tonträgerhersteller mit abnehmender Zahl an Veröffentlichungen und damit einer Reduktion des Nicht-Preis-Wettbewerbs im Tonträgermarkt einhergeht. ${ }^{432}$ Eine Kollusion der Oligopolgruppe der Majors mit Hilfe der Produktpolitik führt c. p. zu sinkenden Veröffentlichungszahlen und steigenden Gewinnen. ${ }^{43}$

Wesentlicher Preiswettbewerb findet seitens der Tonträgerhersteller nicht statt. Bespielte Tonträger sind beschränkt heterogene Güter. Die Preisvariationen von maximal $10 \%$ innerhalb der einzelnen Preiskategorien sind ein Indiz für gleichgerichtetes Preisverhalten. Eine Schätzung der Angebotskurven ergab eine größere Preiselastizität des Angebots für Independents als für Majors. ${ }^{434}$ Dieses Ergebnis geht konform mit den Erkenntnissen über die Produktpolitk der Independents (Abschnitt 4.3.2.2.2). Die drei bestehenden Preisklassen (full-, mid- und lowprice) haben die Aufgabe, die Produkte zu kategorisieren. Untersucht man das Marktergebnis nach den Anteilen der verschiedenen Preisklassen am Umsatz, erkennt man, daß der größte Teil des Umsatzes und die größte Stückzahl mit dem Vollpreissegment erzielt wird (Abschnitt 4.3.2.3.1). Im Vollpreissegment sind die Neuveröffentlichungen positioniert, die auf der Tonträgerkategorie CD erscheinen. Der Großteil des Gesamtumsatzes wird mit Neuveröffentlichungen getätigt. Die Schätzungen variieren zwischen 65 und $80 \% .{ }^{435}$ Für sie sind noch geringere als die o. g. Preisvariationen auf der Händlerabgabestufe zu registrieren. ${ }^{436}$ Neuveröffentlichungen treffen auf eine preisunelastische Nachfrage; insbesondere das Vorliegen externer Konsumeffekte (z. B. Fanverhalten) für diese Titel lassen darauf schließen. ${ }^{47}$ Die Hypothese, daß die Zahl der jährlichen Veröffentlichungen nur auf der Grundlage eines oligopolistischen Preiskartells möglich ist, läßt sich sowohl positiv als auch negativ interpretieren. Einerseits

S. 62 ff. Abgewandelt Wicke, Peter, 1991, op. cit., S. 70 ff., der von der GateKeeper-Funktion der Radiostationen im Verbund mit den Major-Tontrăgerherstellern spricht.

${ }^{430}$ Es kann modelltheoretisch gezeigt werden, daß die Anreize neuer Tonträgerunternehmen neue Musiker unter Vertrag zu nehmen größer sind als diejenigen etablierter. Vgl. Black, Michael, und Douglas Greer, supra, S. 17-27.

${ }^{431}$ Vgl, Black, Michael, und Douglas Greer, supra, S. 17-28.

${ }^{432}$ Selbst für den Fall, daB keine oligopolistische Interdependenz, sondern Cournot-Verhalten unterstellt wird, ist die Zahl der Veröffentlichungen höher als bei kollusivem Oligopolverhalten, welches den Majors erlaubt, die Kosten niedrig zu halten und das Veroffentlichungsverhalten zu koordinieren.

${ }^{433} \mathrm{Vgl}$. Alexander, Peter J., 1994, supra, S. 87-90.

${ }^{434}$ Diese Schătzung betraf den niederländischen Markt und ergab für Independents einen Wert von 0,98 und für Majors einen Wert von 1,13. Vgl. Christianen, supra, S. 41 f.

${ }^{435} \mathrm{Vgl}$. Thurow, Norbert, und Peter Zombik, supra, S. 202. Eine empirische Überprüfung, die auf einer allgemeinverbindlichen Definition des Begriffes Neuveröffentlichung (jede Veröffentlichung oder nur die Veröffentlichung vorher noch nicht verwerteter Musik) basieren müßte, ist mangels Datenverfügbarkeit nicht möglich.

${ }^{436}$ Das Preisverhalten wurde in Abschnitt 4.3.2.3 behandelt. Die 0. g. Aussage wird für den Zeitraum 1991/92 durch Verfahrensakten des BKartA belegt.

${ }^{437} \mathrm{DaB}$ keine vollkommen preisunelastische Nachfrage vorliegt, wird dadurch bewiesen, daß es möglich ist, zusătzliche Nachfrage damit zu attrahieren, daB die aktuellen CDs als Lockvogel im Handel angeboten werden, um mit anderen Produkten des Sortiments Gewinn zu machen. 
negativ als Ressourcenverschwendung, andererseits positiv als Vielfalt im Interesse der Auswahlmöglichkeiten der Konsumenten.

Die Abhängigkeit aller Tonträgerhersteller von der Präsentation ihrer Musik in den Radiostationen als den entscheidenden Medienträgern und Multiplikatoren ${ }^{438}$ wurde von den Majors als Marktbarriere erkannt und strategisch gegen Independents und Newcomer ausgenutzt:

"The record companies understood on some level that if radio airplay were not free, it would mean a major competitive advantage. The large companies had the money, [and their representatives] plied station program directors with cash and others. After 1978, records put out by small labels began to vanish from the Top 40 ainwaves. “ 439

Die für den US-amerikanischen Tonträgermarkt beschriebene Praktik der Schaffung von Medienpräsenz hat bislang keine deutsche Entsprechung gefunden. Gleichwohl sind andere Ansatzpunkte für eine ergebnisrelevante Zusammenarbeit der Majors i. S. einer parametrischen oligopolistischen Interdependenz zu konstatieren. Dazu gehören z. B. die Aktivitäten des durch die Majors getragenen Bundesverbandes der Phonographischen Wirtschaft und das kollektiv installierte, bezahlte und benutzte Marktforschungsinstrument Phononet ${ }^{40}$ zur Erhöhung der Markttransparenz. Ferner zeugen von der kollektiven Verfolgung der marktpolitischen Interessen der Majors gemeinsam in Auftrag gegebene und bezahlte Studien. ${ }^{41}$ Im oligopolistischen Tonträgermarkt kommen diese Investitionen der gesamten Oligopolgruppe zugute und nicht nur einzelnen Anbietern. Daher entsteht auch das Kalkül, kollektive Investitionen in Marktbarrieren zu tätigen, die als Summe der individuellen zusätzlichen Kosten mindestens dem zusätzlichen Grenzerlös der Oligopolgruppe insgesamt entsprechen.

Auf der Stufe des Tonträgerhandels ist als Folge des Preiswettbewerbs eine weitere Konzentration festzustellen. Die Stellung der Tonträgerhersteller zu diesem Konzentrationsproze $B$ ist ambivalent. Wegen der als gesichert geltenden positiven Korrelation zwischen Käuferreichweite und flächendeckender Versorgung mit Tonträgerverkaufsstellen (siehe Abschnitt 4.3.4.2) wurde eine Unterstützung des Facheinzelhandels durch die Hersteller postuliert. ${ }^{\mathbf{4 2}}$ Andererseits versuchen die Tonträgerhersteller, sich neue Verkaufsstellen zu erschließen. ${ }^{443}$ Ebenso lassen die jeweils individuellen Ausgestaltungen der Konditionen zwischen Tonträgerherstel-

${ }^{438}$ Wicke zitiert hier einen Manager der Tonträgerindustrie, nach dem es in Ermangelung von Erfolgschancen überhaupt keinen Sinn macht, Musik zu produzieren, die den Musikredakteuren der Radiostationen nicht gefallt. Vgl. Wicke, Peter, 1991, op. cit., S. 71.

439 Dannen, F., Hit Men: Power Brokers and Fast Money Inside the Music Business, New York 1990, S. 14 f.

440 Ziele der Einführung von Phononet waren a) schnellere Befriedigung von Kundenwünschen, b) logistische Vorteile durch das Warenwirtschaftssystem und c) genaue Erfassung der Verkaufsdaten für die Chartermittlung. Ebenso zahlt zu den kollektiven Markttransparenz-Dienstleistungen die Aufbereitung und Weiterverarbeitung der gewonnenen Daten durch MediaControl und GfK.

41 Dazu gehören u. a. die Nichtkăuferstudie 1995 und die Prognos-Studie Music and Demand 1996.

${ }^{442} \mathrm{Zu}$ diesem $\mathrm{Zweck}$ wurde eine sog. Clearingstelle für den Tontrăgermarkt gegründet, die den Fachhandel unterstützen soll.

${ }^{443}$ Diese sog. non-traditional outlets sind z. B. Drogeriemărkte und Tankstellen. 
lern und Handelsunternehmen ${ }^{444}$ erkennen, daß die Frage der Sortimentsstruktur und Sortimentspolitik (siehe Abschnitt 4.3.3.3) hinter den unternehmensspezifischen Absatzerfolgen der Vergangenheit zurückstehen. Die praktizierte Konditionenspreizung beinhaltet sowohl Gesamtumsatzboni, Skonti als auch Werbekostenzuschüsse und Rückgaberechte, die sich auf einen durchschnittlichen Preisnachlaß von ca. $13 \%$ auf den gelisteten Händlerabgabepreis in der Longplay-Tonträgerkategorie aufsummieren. ${ }^{4 / 5}$ Diese für größere Händler erzielbaren Nachlässe waren seitens der kleineren Tonträgerfachgeschäfte Anlaß für eine Beschwerde beim Bundeskartellamt, um die Konditionenpolitik der Tonträgerhersteller zu bemängeln. Die Untersuchungen des Kartellamtes ergaben zwar, daß seitens der Hersteller eine - wie bereits beschrieben - jährliche individuelle Verhandlung mit den Händlern stattfand, daß die gewährten Vergünstigungen aber Ausdruck des jeweiligen Leistungswettbewerbs seien, da sie sich an den jeweils in den Vorjahren erzielten Umsätzen mit Tonträgern orientierten. Die Versuche des Facheinzelhandels, sich gegenüber den Niedrig- bzw. Kampfpreisstrategien der Großformen des Einzelhandels mit Hilfe der Gerichte zur Wehr zu setzen, sind gescheitert. ${ }^{416}$

Das Nachfrageverhalten der Konsumenten wird einerseits durch das Fanverhalten geprägt. In ihm kommt die preisunelastische Nachfrage insbesondere der Intensivkäufer zum Ausdruck, die sich in einer hohen Zeitpräferenzrate äußert. Die starke Orientierung an Neuheiten ermöglicht es, aktuelle Tonträger als Lockvogel einzusetzen, um preiselastische Käufergruppen anzusprechen. Andererseits ist das Kaufverhalten der Durchschnitts- und Extensivkäufer von den Rangtabellen geprägt. Die Hersteller haben kein dauerhaftes Interesse daran, daß Tonträger Ausgleichsartikel sind. Eine weitergehende Spreizung der Konditionen wird durch den Zielkonflikt zwischen dem Preiswettbewerb der Handelsstufe und den Preisvorstellungen der Tonträgerhersteller wegen des Nachfrageverhaltens der Konsumenten (siehe Abschnitte 4.3.3.4 und 4.3.4) begrenzt.

\subsection{Zusammenfassung: Industrieökonomischer Ausblick}

Am Ende des industrieökonomischen Kapitels läßt sich der Tonträgermarkt als ein Bereich der Musikverwertung begreifen, der potentiell mit anderen Verwertungsformen zusammenwächst, zu anderen Verwertungsformen in enger Abhängigkeit steht und dessen Teilnehmer sich durch neue Verwertungswege ändern können, weil ein anderer Marktzugang durch die Benutzung von Netzen zur Musiklieferung möglich wird. Daher stellt sich die Frage, in welchen Kontext der Tonträgermarkt eingebunden ist. Eine erweiterte Sichtweise relativiert Zusammenhänge zwischen Marktverhalten und Marktergebnissen. Denn sie zeigt letztlich, daß mit der Vermarktung der Rechte an einem Musiktitel, wenn er erfolgreich ist, weitere Erlöspotentiale erschlossen werden, als lediglich aus seinem Verkauf mit Hilfe von Tonträgern. Daraus kann

\footnotetext{
444 Eine Vorstellung von der Größenordnung der Handelsspannen liefert der Insider Hill. Er beschreibt für den Tonträgermarkt Großbritanniens, daß EMI, RCA und Pye eine Handelsspanne von 36,33\% (ohne Umsatzsteuer) den Einzelhändlern auf Singles und Longplays offerieren. Andere Tonträgerhersteller wie CBS, WEA, Phonogram und Decca bieten eine Handelsspanne von 33,3\% auf Alben, räumen aber zusätzlich ein Retourenrocht von $5 \%$ ein. $\mathrm{Vgl}$, Hill, Leslie, supra $32 \mathrm{ff}$.

445 BKartA, Verfahrensakten.

${ }^{446} \mathrm{Vgl}$. Hitlisten-Platten, in: WuW/E BGH $2977 \mathrm{ff}$.
} 
gefolgert werden, daß alle - die Geld für den Einkauf von Musikrechten aufzubringen in der Lage sind - bestimmen, welche Musik vermarktet wird, und nicht mehr die Musikrezipienten allein. Daraus läßt sich weiter folgern, daß sich die Nachfragestruktur für Musik verändern wird. Sie wird sich in der Hauptsache nicht mehr allein auf die Tonträgerkonsumenten beziehen, sondern mit Hilfe des Musikrechteerwerbs wird das Zielpublikum der werbetreibenden Wirtschaft verstärkt Zielgruppe von Musik. Damit verlagert sich die Altersstruktur von den 10bis 29- Jährigen, die überproportional zum derzeitigen Musikkonsum beitragen, zu den 30- bis 50- Jährigen Konsumenten mit höherem Einkommen, die als Zielpublikum der werbetreibenden Wirtschaft bekannt sind. Hier kann die Betrachtung von Marktverhalten und -ergebnissen durchaus zu Prognosezwecken verwendet werden. Dabei sind Funktionszusammenhänge von Marktstruktur und -verhalten auch kennzeichnend dafür, daß die Marktakteure als Töchter multinationaler Unternehmen den Verwertungsinteressen der Konzernleitungen folgen. ${ }^{47}$

Die Verwertungsmöglichkeiten von Musik werden von verschiedenen Märkten unterschiedlich bewertet. Das führt dazu, daß ein Musiktitel für die Tonträgerhersteller ein Bündel von Rechten ist, das neben der Auswertung im Tonträgermarkt auch für Film, Fernsehen, Werbung etc. verwendet wird. Das Produktverständnis verändert sich und die Verwertung von Musik unterliegt dem Rendite- und Umsatzvergleich zu anderen Märkten. Das bedeutet natürlich, daß die Tonträgerhersteller sich nicht auf einzelne Trägermedien wie z. B. die CD konzentrieren, sondern die Rechte an Künstlern und ihrer Musik, auch der Backkataloge (d. h. komplette Verlagskataloge) erwerben werden und dafür die Verwertungsmöglichkeiten eröffnen müssen. Tonträgerhersteller werden mit ihrer Verwertungsfähigkeit, d. h. dem Know-how der Vermarktung von Musik bei den Musikern selbst zu werben haben. Am anderen Ende der Verwertungskette steht nicht mehr nur die Akzeptanz der potentiellen Tonträgerkonsumenten, sondern auch die Akzeptanz gegenüber Sponsoren und der werbetreibenden Wirtschaft etc. Das kommerzielle Potential auszuschöpfen, wird das Hauptinteresse der Tonträgerhersteller sein. Diese Entwicklung wird zudem beschleunigt durch den technologischen Wandel, der im Kernbereich des Tonträgermarktes eine unkörperliche Verbreitung von Musik über Netze möglich macht. Die Entkopplung des Produktes Musik von seinem Träger zeigt auf deutliche Weise, daß Zusammenhänge zwischen Verhalten und Ergebnis über den Tonträgermarkt hinausgehen. Nur die Major-Tonträgerhersteller sind in der Lage, weitergehende Verwertungsmöglichkeiten der Musik sowohl der werbetreibenden Wirtschaft als auch den Musikern und hier insbesondere den Stars anzubieten. Damit grenzt sich die Oligopolgruppe der Majors auch weiterhin ab von der Vielzahl kleinerer Independents, die nur Musik auf Tonträgern produzieren und diese auch nur teilweise selbst vermarkten können. Die Struktur des Tonträgermarktes wird in der Zukunft dann stabil bleiben, wenn die Verteilung der Rechte auf die Majors gleich bleibt und etablierte Musiker, die weltweit vermarktet werden möchten, nur die Möglichkeit haben, sich vertraglich an Majors zu binden. Eine genauere Untersuchung der Verwertungskette unkörperlicher Musikverwertung, Anreize und Eintrittsmöglichkeiten potentieller Newcomer und die Auswirkungen auf den Tonträgermarkt sind daher Gegenstand des abschlieBenden fünten Kapitels.

447 Dabei wird das Wissen um die Funktionszusammenhänge nur zur Gewinnmaximierung benutzt und nicht, um deterministisch bestimmte Marktergebnisse wettbewerbsbeschränkend zu erzielen. 


\section{Kapitel 5: Weiterentwicklungen zur unkörperlichen Musikverwertung}

Ausgehend von der industrieökonomischen Analyse des vorangegangenen vierten Kapitels sollen die neueren technischen Entwicklungen sowohl auf der einzelwirtschaftlichen Ebene der Unternehmen und ihrer Musikprodukte (5.1) als auch auf der Ebene des Marktes untersucht (5.2) und die sich daraus jeweils ergebenden Strukturen, das zu erwartende Unternehmensverhalten und die Marktprozesse analysiert werden. Die resultierenden Wettbewerbspotentiale werden auf den einzelnen Stufen des bisherigen Tonträgermarktes und für die Musikverwertungskette insgesamt betrachtet (5.3). Dabei werden die Entwicklungsszenarien die Möglichkeit des Zusammenwachsens von Unterhaltungsmärkten zeigen. Hieraus folgt eine Erweiterung des Kreises der potentiellen Wettbewerber, mit deren Markteintrittsfahigkeit sich die wettbewerbspolitische Analyse befaßt. $\mathrm{Zu}$ den analysierten Entwicklungsszenarien wird der urheberund ordnungsrechtliche Rahmen aufgezeigt. Der letzte Abschnitt (5.4) faßt die wesentlichen Implikationen des technischen Fortschritts der Musikverwertung zusammen.

\subsection{Neuere technische Entwicklungen der Musikverwertung}

Die Produkte des Tonträgermarktes wurden bisher charakterisiert als musikalische Inhalte, die mit Hilfe eines Trägermediums (Tonträger) gespeichert und handelbar gemacht worden sind. Die Digitalisierung der Aufzeichnung, Übertragung und Wiedergabe von Musik im Verbund mit der Digitalisierung der Informations- und Kommunikationstechnologie hat neue Möglichkeiten für Produkte und Vertriebswege geschaffen. Dabei führt die Verknüpfung verschiedener medialer Inhalte und Kommunikationswege zum Begriff Multimedia. ' Im folgenden wird unter Multimedia die Kombination von unabhängigen Informationen verstanden, die in Form von kontinuierlichen (Ton, Film) und diskreten Medien (Text, Grafik, Bild) kodiert sind. Multimedia ermöglicht die digitale Verarbeitung, Speicherung und Übertragung zeitabhängiger Informationen und eine - aus Sicht der Konsumenten - interagierende Nutzung. Zuerst ist im Hinblick auf die Musikverwertung die Erweiterung der digitalen Trägermedien um Zusatzinformationen (Notenpartituren, biographische Informationen zu den ausführenden Künstlern etc.) technisch realisiert worden. Da aber weiterhin ein physischer Träger nötig ist, damit die Produkte vom Hersteller zum Konsumenten gelangen, werden sie Omine-Multimedia-Produkte genannt. Der Konsument kann selbst über die Nutzung des zusätzlichen Informationsinhaltes entscheiden. Diese Produkte werden bereits auf dem Markt angeboten; sie werden im Abschnitt 5.1.1 behandelt. Bei der sog. Instore-Production werden dem Konsumenten aus einer im Handel aufgestellten Musikdatenbank Musikttitel angeboten, die er nach eigener Wahl zusammenstellen und dann auf einer herkömmlichen $C D$ speichern kann. Dadurch hat er selbst einen Einfluß auf den Inhalt des Produktes. Diese Angebote befinden sich in der Erprobungsphase und werden im Abschnitt 5.1.2 behandelt. ${ }^{2}$ Der Schritt zur sog. OnlineMusikverwertung ist technisch bereits entwickelt und wird in Abschnitt 5.1.3 dargestellt.

1 Der Begriff Multimedia wird bisher in der Literatur nicht einheitlich verwendet. Vgl. Greiffenberg, Horsh, Multimedia zwischen Rundfunkregulierung und wettbewerblicher Medienordnung, in: Wirtschaftsdienst, 76. Jg. (1996), S. 590-595.

$2 \mathrm{Zu}$ unterscheiden ist hier jedoch in a) die Benutzung von Musikdatenbanken zur reinen Information über Tonträgerangebote und in b) Musikdatenbanken, die das eigene Zusammenstellen von Tontrăgern ermögli- 


\subsubsection{Offline-Multimedia-Produkte}

Die Offline-Multimedia-Produkte basieren auf der CD-Technologie, die die verbreiteteste Tonträgerkategorie ist, und bieten zusätzliche Informationen zur Musik. Angeboten werden CD-ROM ${ }^{3}$ (read only memory) ${ }^{4}$ und als weitere Kategorien CD-Plus ${ }^{5}$ u. ä., die aber auf derselben Technologie basieren. Schließlich wurde 1997 die digital versatile disc (DVD) in den Markt eingeführt, die vor allem in Konkurrenz zu Musikvideos und Tonträgern mit Filmmusik tritt. $^{6}$ Der CD-ROM wird neben der Musik ein audio-visuelles Zusatzelement (Informationen über die Musiker, Texte, Spiele etc.) beigefügt. Der zusätzliche Nutzen für die Konsumenten hängt davon ab, ob sie die entsprechenden Inhalte präferieren, mit denen die technologischen Möglichkeiten gefüllt werden. Für die Anbieter erhöht sich im Vergleich zur herkömmlichen Audio-CD der Produktionsetat, je nachdem ob zusätzliche Rechte oder Know-how eingekauft werden müssen. ${ }^{7}$ Die Vertriebskosten sind mit den herkömmlichen Tonträgern identisch, da i. d. R. dieselben Vertriebskanäle für die CD-ROM genutzt werden. Für die weitere Marktdurchdringung der CD-ROM ist die Penetration der Haushalte mit CD-ROM-Laufwerken entscheidend. ${ }^{8}$ Es ist davon auszugehen, daß von den über 10 Millionen in Deutschland benutzten Personalcomputern (PC) diejenigen ein CD-ROM-Laufwerk besitzen, die seit 1994 neugekauft worden sind, da die multimediafähige Ausstattung des PC seither im Paket verkauft wird. Daraus resultiert rein rechnerisch eine technische Reichweite von ca. 3 Millionen potentiellen Nachfragern. ${ }^{9}$ Bei der Verbreitung der CD-ROM als Trägerformat differiert die technische von der tatsächlichen Reichweite. Zwar wird beim Kauf eines Computers das CD-ROM-Laufwerk quasi automatisch mitgekauft, jedoch ist dadurch keineswegs eine Nutzung des vorhandenen Laufwerks garantiert. Im privaten Bereich wird die CD-ROM-Nutzung bei PCs dennoch zum Standard. ${ }^{10}$

chen. Vgl. zu a) Heimbach, P., Multimedia im Musik-Marketing, in: Marketing mit Multimedia: Grundlagen, Anwendungen und Management einer neuen Technologie im Marketing, hrsg. von Silberer, Günter, Stuttgart 1995, S. 185-218, hier S. 199-208. Vgl. zu b) 0. V., Der digitale Weg zum Tontrăger, in: Musikwoche, 6. Jg. (1998), Nr. 10, S. 16.

3 Vgl. Bellinghausen, I., CD-ROM: Einstieg in das Multimediazeitalter, in: Media Perspektiven, o. Jg. (1995), S. 489-495.

4 Die Markteinführung der CD-ROM mit musikalischen Inhalten in den deutschen Markt erfolgte 1994. Es wurden allerdings sehr unterschiedliche Zusatzinhalte angeboten, woraus auch sehr starke Preisdifferenzen folgten. Vgl. Zombik, Peter, Tonträger im Markt der Zukunft, in: Media Perspektiven, o. Jg. (1995), S. 508.

5 Ebenfalls auf Technik einer CD-ROM basiert die 1998 erstmals von Polygram angebotene CD-pluscore, bei der zeitgleich zum Hören die Partitur gelesen werden kann. Vgl. o. V., Musikgenuß mit digitalen Notenblättern, in: Musikwoche, 6. Jg. (1998), Nr. 10, S. 28.

6 Die digitale versatile disc (DVD) wird hier nicht weiter behandelt. Aufgnund der Einigung einer Gruppe von Unternehmen (u. a. Philips, Sony, Warner und Toshiba) über dieses Trägermedium ist eine Marktetablierung zwar zu erwarten, die Inhalte werden sich aber im wesentlichen auf die Videoauswertung von Produkten der Filmindustrie (oder auch Spiele) beziehen und keinen originär musikalischen Inhalt haben.

7 Vgl. Neidhardt, H., und J. Schmalholz, CD-ROM Publishing, in: Deutscher Multimedia Kongress 1995, hrsg. von Glowalla, U., Berlin u. a. 1995, S. 251-258, die Beispiele für Produktionskosten einer CD-ROM bis zu 1 Mio. US-S nennen.

8 Vgl. Bellinghausen, I., supra, S. 491. Mittelfristig wird die Musikkassette u. a. durch die CD-ROM verdrängt.

9 Die Zahlen zur PC- und CD-ROM-Ausstattung basieren auf Angaben des Statistischen Bundesamtes, vgl. StBA 1997, op. cit., S. 524, und eigenen Berechnungen.

10 Zunehmender Vertrieb von Software auf CD-ROM unterstützt diese Entwicklung. 
Insgesamt ergibt sich für die Tonträgerhersteller mit der CD-ROM eine Verwertungsmöglichkeit für Musik mit einem zusätzlichen multimedialen Teil, für dessen Produktion Mehrkosten entstehen. Wegen der zusätzlichen Produktionskosten kann ein preisunelastisches Angebotsverhalten festgestellt werden. Dadurch wird bei Beibehaltung der traditionellen Tonträgervertriebswege des Handels eine weitere Zunahme der unterschiedlichen Tonträgerkategorien bewirkt. Der Verbreitungserfolg multimedialer nutzbarer Musik auf CD-ROM ist fraglich und hängt von der Nutzeneinschätzung des Zusatznutzens durch die Konsumenten bei - im Vergleich zur reinen Audio-CD - höheren Preisen ab. Werden dagegen mit einer CD-ROM anderweitig nicht zugängliche Daten und Informationen verbreitet, sind volkswirtschaftlich positive Effekte zu erwarten. ${ }^{11}$ Diese betreffen jedoch nicht den Bereich der Musikverwertung.

\subsubsection{Offline-Musikprodukte als Instore-Production}

Den Einstieg in den elektronischen Vertrieb von Musik stellen Musikdatenbanken dar. Diese können entweder direkt im Handel auf einem Server plaziert sein, oder es wird - im Sinne einer Client-Server-Lösung - im Handel online auf Musikdatenbanken der Tonträgerhersteller zugegriffen. Hierbei handelt es sich um eine elektronische Übertragung von Musik, die beim Empfänger, dem Tonträgerhändler, gespeichert wird. Nachfrager können sich in Form von Selbstbedienung aus den gespeicherten Titeln die jeweils gewünschten aussuchen, sie zu einer individuellen $\mathrm{CD}$ zusammenstellen und diese im Handel auf eine beschreibbare Compact-Disk (die CD-R) brennen lassen. ${ }^{12}$ Die Technik der sog. Instore-Production ist im US-amerikanischen Tonträgermarkt im Rahmen eines Pilotprojektes erprobt worden. ${ }^{13}$ Von Bedeutung für diese Arbeit sind urheberrechtliche Probleme dieses Produktangebots. Die Musiker als Urheber der Musiktitel haben das ausschließliche Recht, über die Zusammenstellung ihrer Musiktitel auf Tonträgern zu entscheiden. ${ }^{14}$ Zahlreiche Musiker wünschen aus Imagegründen nicht, mit Musikern anderer Stilrichtungen zusammen auf einem Tonträger vermarktet zu werden. Die Entscheidung darüber hätte beim Selbstzusammenstellen aus einer Datenbank aber jeder einzelne Konsument. Erlauben es die Musikurheber den Tonträgerherstellern nicht, die eigenen Musiktitel in freier Wahl durch den Konsumenten zusammenstellen zu lassen, muß die Einspeisung in

"Beispiele für gesamtwirtschaflich sinnvolle Anwendungen der CD-ROM sind Telefonverzeichnisse, Bibliotheks- und andere Kataloge, Lexika etc., die erhebliche Ressourcen von Material und Platz einsparen.

12 Inzwischen sind sowohl einmalig beschreibbare CD-Rohlinge als auch lösch- und wieder beschreibbare CDs, Re-writetable oder Recordable (CD-R) und Erasable (CD-E) erhaltlich.

13 Die Entwicklung des Gerätes für den US-amerikanischen Tonträgerhandel war eine Gemeinschaftsproduktion von IBM und Blockbuster. Vgl. o. V., Geplanter CD-Automat der Fachhandelskette Blockbuster und der IBM stoßt nicht auf große Gegenliebe, in: Musikmarkt, o. Jg., Nr. 11 (1993), S. 28. Für den deutschen Markt wurde 1998 ein Gerăt vorgestellt, daß ăhnliche Eigenschaften aufweist, bei dem der individuell zusammengestellte Tontrăger aber erst einen Tag spăter an den Nachfrager geschickt wird. Vgl. o. V., Der digitale Weg zum Tontrăger, supra, S. 16.

14 Das ergibt sich sowohl aus den Urheberpersönlichkeitsrechten der §§ 12-14 UrhG als auch aus den Verwertungsrechten der §§ 15-24 UrhG. Vgl. Eisenmann, Hartmut, Grundriß Gewerblicher Rechtsschutz und Urheberrecht, 3. Aufl., Heidelberg 1995, S. 11 ff. Denkbar ist eine beschränkte Rechtevergabe z. B. im Sinne bestimmter Kopplungsverbote unterschiedlicher Musiker. 
eine Musikdatenbank unterbleiben. ${ }^{\text {s }}$ Die Nachfrager sind dann nicht in der Lage, sich ihre Wunschtitel auf einem Tonträger zusammenzustellen.

Das Produkt "selbstzusammengestellter Tonträger" bietet einzelwirtschaftliche und gesamtwirtschaftiche Vorteile gegenüber dem herkömmlichen Vertrieb bereits vorbespielter Tonträger. Auf der Stufe der Tonträgerhersteller entfallen die Entscheidungen über die Wiederveröffentlichungen bereits verwerteter Musik und die jeweilige Auflagenhöhe, die sich insbesondere bei Nischen- und Spezialprodukten stellen. Ebenso ist es auf diesem Weg möglich, der zunehmend individualisierten Nachfrage ein individuelles Angebot zu bieten. Auf der Stufe des Tonträgerhandels entfallen bei dieser Art von ,just-in-time“-Produktion Lagerkosten, Retourenrisiko und -kosten sowie das Problem der Verfügbarkeit bzw. Vorratshaltung. Diese Vorteile lassen sich allerdings erst im Zeitablauf realisieren, wenn der physische Vertrieb sukzessive wegfältt. Gesamtwirtschaftlich ermöglichen die Kosteneinsparungen niedrigere Preise für Musik auf Tonträgern. $\mathrm{Ob}$ diese jedoch an die Konsumenten weitergegeben werden, hängt von der Marktform und Konzentration von Tonträgerherstellern und -händlern sowie der Preiselastizität der Nachfrage ab. Ein weiterer gesamtwirtschaftlicher Vorteil liegt darin, daß weniger Kapital bei der Musikproduktion gebunden werden muß und möglicherweise für mehr Musikveröffentlichungen der break-even-Punkt erreichbar ist. Das könnte c. p. zu einer größeren Zahl von für die Konsumenten verfügbaren Musik führen.

Den genannten Vorteilen stehen jedoch vorwiegend einzelwirtschaftliche Nachteile gegenüber. Da das Produkt „mit Musik bespielter Tonträger" nicht mehr direkt physisch greifbar ist, werden Impuls- und Spontankäufe der Nachfrager unterbleiben. ${ }^{16}$ Dafür können die Konsumenten gezielter die Musik kaufen, die ihren Präferenzen entspricht. Sie sind nicht mehr an die vorgegebenen Titelzusammenstellungen gebunden. Folge ist eine höhere Anforderung an die Kunden, ihre Präferenzen zu bekunden. Ebenso wird sich auch eine Änderung des auf Musikdatenbanken angebotenen Produktinhalts ergeben. Durch eine Zusammenstellung der Tonträger mit einzelnen Titeln wird die Produktpolitik der Tonträgerhersteller und Musiker nicht mehr darauf abzielen, ganze Alben (Longplays) zu veröffentlichen, sondern nur noch einzelne Musiktitel. Aus der Sicht der Tonträgerhersteller ist eine Abkehr vom Albenformat nachteilig zu bewerten. Daneben ist aber auch zu erwarten, daß das technische System der eigenen Tonträgerproduktion nicht alle Dimensionen eines Verkaufsgesprächs im Handel ersetzen kann und entsprechend die Funktionen des Handels nicht automatisch überflüssig werden. Wenn also die Handelsstufe bestehen bleibt, ist eine Geschäftsbeziehung zwischen Tonträgerhersteller und Handel und eine Aufteilung von Margen weiterhin zu erwarten. ${ }^{17}$ Die volkswirtschaftlichen Kostenersparnisse unterbleiben oder fallen geringer aus. Zudem treten für die Konsumenten immer noch die Wegkosten zum Handelsgeschäft auf. Daher kann dieses Angebot von offline-Produkten nur als ein Zwischenstadium zur Musikverwertung online verstanden werden.

is Ein faktischer Zustimmungszwang ist von der Vertragsverhandlungsposition der Musiker im Verhältnis zu den Tontrăgerherstellern abhăngig.

16 Dafür werden aber Kăufe von solchen Konsumenten vorgenommen, die das neue Produkt unbedingt ausprobieren wollen.

17 Z. B. ist für das Aufstellen der Musikdatenbank und des CD-Brenners im Handel eine Provision denkbar. 


\subsubsection{Online-Musikverwertung mit Hilfe von Netzen}

Die technischen Entwicklungen der Telekommunikation ermöglichen durch Vernetzung, Datenkomprimierung und Digitalisierung zusammengenommen einen Markt für die elektronische Verwertung von Musik. Hier interessieren insbesondere die Übertragungswege musikalischer Inhalte. Dies sind die neuen digitalen Distributionswege für Musik über schmal- und breitbandige Kabel-, Satelliten- und terrestrische Systeme an Medien, Händler und Endnachfrager. Dabei ist unter der Vernetzung nicht nur eine physische, $d$. h. kabelgebundene zu verstehen, sondern auch eine kabellose mit Hilfe von terrestrischer oder satellitenbasierter Übertragungstechnik.

Verbunden ist die netzgebundene Musikverwertung als ein Inhalt von Telekommunikationsdiensten mit dem Markt für Netzinfrastruktur. ${ }^{18}$ Denn alle Telekommunikationsdienste basieren auf der Netzinfrastruktur, die quasi als Vertriebsweg dient. Zu unterscheiden ist die Netzinfrastruktur nach Verteil- und Vermittlungsnetzen. In Verteilnetzen werden die musikalischen Informationen in eine Richtung an alle Netzwerkteilnehmer verteilt. Verteilnetze bieten Verwertungsmöglichkeiten von Musik, die entweder bereits genutzt werden oder sich in der Erprobungs- bzw. Planungsphase befinden. Verteilnetze sind die typischen Netzwerke für die Telekommunikationsgrund- bzw. Universaldienste (Fernsehen, Radio etc.). ${ }^{19}$ Als Verteilnetzanwendungen werden Multichanneldienste und digitales Radio (Digital Audio Broadcasting) besprochen (5.1.3.1).

Vermittlungsnetze ermöglichen mit einem Rückkanal bzw. durch Vermittlungsmöglichkeiten zwischen zwei oder mehr Teilnehmern eine interaktive Kommunikation und sind die technische Voraussetzung für alle Abfragedienste (On-Demand-Dienste). Abfragedienste werden als sog. Mehrwertdienste der Telekommunikation bezeichnet. Hierzu gehört innerhalb der Teleunterhaltung neben anderen Verwertungsinhalten auch die Musikverwertung online. ${ }^{20} \mathrm{Als}$ Vermittlungsnetzanwendungen werden Internetnutzungen und kommerzielle Online-Dienste, die ein Bündel von Inhalten - u. a. auch Musik - anbieten (5.1.3.2), behandelt. Eine Musikverwertung in diesen Diensten wurde lange Zeit unter dem Stichwort Music On Demand diskutiert. ${ }^{21}$ Der elektronische Musikabruf On Demand ist 1998 in den Markt eingeführt worden. ${ }^{22}$ Wir betrachten den elektronischen Vertrieb von Musik auf Abfrage (5.1.3.3) innerhalb eines OnlineDienstes. Voraussetzung dafür sind neue digitale Speicher- und Archivierungssysteme, die als

18 Vgl. Klod, Henning, Claus-Friedrich Laaser, Jens Oliver Lorz und Rainer Maurer, Wettbewerb und Regulierung in der Telekommunikation, Kieler Studien 272, hrsg. von Sicber, Horst, Tübingen 1995, S. 25 ff.

19 Auch die Grunddienste beziehen sich auf Musikverwertungen wie das Musikspartenfernsehen zeigt. Vgl. Frielingsdorf, Britta, und Sabine Haas, Fernsehen zum Musikhören, in: Media Perspektiven, o. Jg. (1995), S. 331-339.

20 Weitere Mehrwertdienste sind Teleinformation (Tageszeitung, Bibliothek), Telekauf (Warenangebot, Warenbestellung, Zahlungsverkehr), Leitungsvermittlungsdienste (Videokonferenzen und Telearbeitsplätze) und der Netzzugang zum Internet und zu ausländischen Online-Anbietern.

21 Vgl. Nestele, K., Technische Innovationen und ihre Auswirkungen, in: Handbuch der Musikwirtschaf, hrsg. von Moser, Rolf, und Andreas Scheuermann, 3. Aufl., Starnberg 1994, S. 69-75.

$22 \mathrm{Vgl}$. Riehm, U., und B. Wingert, Multimedia, Mythen, Chancen und Herausfordenungen, Arbeitsbericht Nr. 33, Büro für Technikfolgenabschătzung beim Deutschen Bundestag, Bonn 1995. 
Musikserver mit entsprechendem Musikrepertoire bestückt sind ${ }^{23}$ Hierzu werden verschiedene Organisationsmodelle diskutiert.

Die Abbildung 23 faßt die Möglichkeiten der netzgebundenen Musikverwertung zusammen.

\section{Abbildung 23: Technische Möglichkeiten der netzgebundenen Musikverwertung}

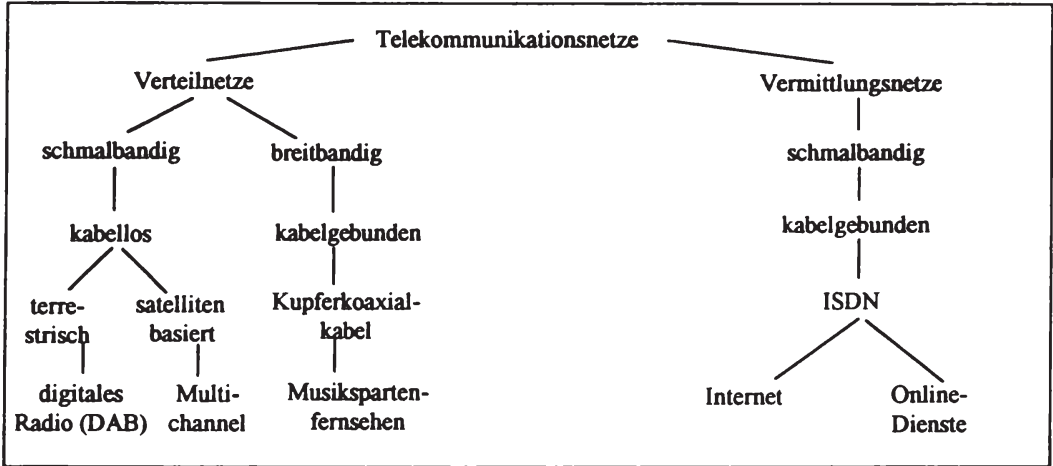

\subsubsection{Verteilnetzanwendungen: Multichannel-Dienste und digitales Radio}

Die EU-Kommission hat im Rahmen ihrer Forschungsinitiative Eureka die technische Normierung des Digital Audio Broadcasting (DAB) gefördert und 1994 abgeschlossen. Nachdem auf einer Konferenz 1995 Frequenzen nach einem europäischen Plan administrativ zugeteilt worden waren, wurden mehrere Pilotprojekte in Deutschland und anderen Ländern der EU durchgeführt. ${ }^{24}$ Neben öffentlich-rechtlichen Sendern bieten auch private Veranstalter digitales Radio u. a. via Satellit an, wofür sie Verschlüsselungstechniken verwenden und von den Konsumenten Abonnentengebühr verlangen. ${ }^{25}$ Diese Multichannel-Anbieter nutzen die durch die Digitalisierung ermöglichte Vervielfachung der Übertragungskapazitäten dazu, um auf mehreren Kanälen Musik ohne Unterbrechungen durch Werbung oder Wortbeiträge zu senden.

Hinsichtlich des Urheberschutzes der musikalischen Programminhalte im digitalen Radio und Fernsehen bestehen unterschiedliche Positionen. Die wirtschaftliche Erstauswertung von Musik ist die Festlegung auf Tonträger zum Zwecke des Verkaufs und die Live-Darbietung. Hierfür

23 Für den Aufwand, der mit der digitalen Aufbereitung und Einspeicherung der Musik verbunden ist, vgl. Hafner, Albrecht, Digitalisierung im Hörfunkarchiv des Südwestfunks, in: Wer zappelt im Netz, wer knüpft die Fåden?, hrsg. von Lange, Eckhard, Baden-Baden 1997, S. 212-221.

24 Die Standardsetzang durch die EU ist ein gutes Beispiel für deren Industriepolitik. Vgl. Breunig, Ch., Digitales Radio: Industriepolitik gibt den Ton an, in: Media Perspektiven, o. Jg. (1995), S. 462-475.

25 Hierzu gehören Astra Digital Radio (ADR) und Multi-Channel-Angebote von MC Europe und DMX, die als Übertragungswege jeweils Satellit und Kabel nutzen. Der Konsument kann einen Receiver zum Empfang gegen eine monatliche Gebühr mieten (conditional access). Dagegen wird DAB als potentielles Nachfolgesystem für UKW terrestrisch ausgestrahlt und ist frei empfangbar (free access). 
hat der Urheber ausschließliche Rechte. Sind Tonträger mit Zustimmung des Urhebers in Verkehr gebracht worden, so ist sein Verbreitungsrecht erschöpft ( 17 UrhG). Eine Zweitauswertung geschieht durch Sendung, öffentliche Wiedergabe oder private Vervielfältigung des Tonträgers. Hierfür haben Urheber, ausübende Künstler und Tonträgerhersteller lediglich einen Vergütungsanspruch. Nach Ansicht der Radiostationen ist die digitale Ausstrahlung von Musik eine unter das urheberrechtliche Senderecht ( $§ 20$ UrhG) fallende Zweitverwertung, ${ }^{26}$ die nicht verboten werden kann, sondern für die nur eine Vergütung aus den Werbe- bzw. Gebühreneinnahmen der Radiosender gezahlt werden muB ${ }^{27}$ Bei analogem Radiobetrieb vergüten die Radiostationen nach dem Senderecht entsprechend den gesendeten Minuten an die Verwertungsgesellschaft für musikalische Auffuihrungs- und mechanischen Vervielfältigungsrechte (GEMA) für die Ansprüche der Urheber und entsprechend der Zahl der zugelassenen Empfangsgeräte und prozentual aus den Werbeeinnahmen an die Verwertungsgesellschaft zur Verwertung von Leistungsschutzrechten (GVL) für die Tonträgerhersteller und ausübenden Künstler gem. $\S \S$ 76 Abs. 2 und 77 UrhG. ${ }^{28}$ Demgegenüber liegt das Besondere am digitalen Radio und Fernsehen darin, daß für Musikkonsumenten noch kein vergleichbar günstiger Zugangsweg zu Musik in digitaler Qualität besteht, wie er nun durch die digitale Sendung geschaffen wird. Mit Hilfe entsprechender Endgeräte und digitaler Aufzeichnungsmedien ${ }^{29}$ sind private Mitschnitte in CDQualität und damit eine Substitution des Tonträgerkaufs in gleicher Qualität möglich. Eine Titelankündigung, das Abspielen vollständiger Alben sowie eine automatische Titelkennung ermöglichen eine Professionalisierung der Kopiertätigkeit, die die Ertragsmöglichkeiten der Tonträgerhersteller reduziert. Neben die direkte Substitution des Tonträgerkaufs durch das Kopieren tritt ein indirekter Substitutionseffekt. Statt Musik auf Trägern oder trägerlos zu kaufen, hören die Konsumenten sie nur noch per Radio und im Fernsehen. Musik in digitaler Qualität wird ständig verfügbar und die zu erwartende Ausdifferenzierung des Musikrepertoireangebots in Radiospartensendern ermöglicht somit eine Abdeckung der gesamten Präferenzbreite. Auch durch das Musikspartenfernsehen ist ein Ersatz des Tonträgerkaufs durch Musikhören via Fernsehen möglich. Die auf der Zweitverwertungsbasis erzielbaren Umsätze nach dem urheberrechtlichen Senderecht betragen für die Tonträgerhersteller und ausübenden Musiker jedoch nur ein Bruchteil ${ }^{30}$ der durch Erstverwertung durch Tonträgerverkäufe realisierbaren Umsätze. Tabelle 13 gibt einen Überblick über die unterschiedlichen Erlöspotentiale, indem die Einnahmen der GEMA und der GVL dem Gesamtmarktvolumen des Tonträgermarktes für den Zeitraum 1986-1996 gegenübergestellt werden:

26 Die Drittverwertung besteht $\mathrm{u}$. a. in der offentlichen Wiedergabe und der privaten Vervielfaltigung gesendeter Tonträger.

27 Dabei variieren die Vergütungssätze zwischen offentlich-rechulichen und privaten Medienunternehmen. Insgesamt wurden durch die GEMA für Radio- und Fernsehverwertungen geschützter Musik 1994, 1995 und 1996 Vergütungen in Höhe von 286, 298 und 321 Mio. DM vereinnahmt. Vgl. Gema-Jahrbücher 1995/96, S. 49, 1996/97, S. 51, und 1997/98, S. 59.

28 Die offentlich-rechulichen Sendeanstalten vergüten aus dem Gebührenaufkommen und prozentual aus Werbeerlösen, die privaten Sendeanstalten vergüten prozentual aus Werbeerlösen.

29 Geeignet sind z. B. die beschreibbare CD-R und die digitale Kassette DAT.

${ }^{30}$ Ein weiterer Umsatzteil bei Zweitverwertung resultiert aus der öffentlichen Wiedergabe. Die Erträge für die Tonträgerhersteller aus offentlicher Wiedergabe sind noch geringer als aus dem Senderecht. Vgl. GEMAJahrbücher 1995/96, S. 49, 1996/67, S. 51, und 1997/98, S. 59. 
Tabelle 13 Einnahmen der Verwertungsgesellschaften u. Gesamtmarktvolumen 1986-96:

\begin{tabular}{|l|r|r|r|r|r|r|r|r|r|r|r|}
\hline $\begin{array}{l}\text { Umsätze } \\
\text { (in Mio. DM) }\end{array}$ & 1986 & 1987 & 1988 & 1989 & 1990 & 1991 & 1992 & 1993 & 1994 & 1995 & 1996 \\
\hline $\begin{array}{l}\text { Tonträger- } \\
\text { Gesamtmarkt }\end{array}$ & 2718 & 2977 & 3276 & 3685 & 4392 & 4867 & 5130 & 5644 & 5753 & 5850 & 5835 \\
\hline GVL-Vergütung & 106 & 90 & 107 & 114 & 122 & 133 & 152 & 156 & 163 & 186 & 209 \\
\hline GEMA-Vergütung & 587 & 628 & 645 & 718 & 811 & 1014 & 1138 & 1191 & 1262 & 1340 & 1371 \\
\hline
\end{tabular}

Quelle: GEMA-Jahrbücher 1995/96, S. 49, 1996/97, S. 51, und 1997/98, S. 59, sowie BPW 1997.

Der Tabelle ist die ökonomische Konsequenz der unterschiedlichen urheberrechtlichen Positionen zu entnehmen. Größere Erlöspotentiale sind durch den Verkauf von körperlichen Tonträgern oder einer unkörperlichen (z. B. elektronischen) Form der Erstverwertung von Musik zu erzielen als bei der Verbreitung durch Radio, Fernsehen oder öffentlicher Aufführung. Daher ergab sich das Interesse der Tonträgerhersteller an der Etablierung eines ausschließlichen elektronischen Verbreitungsrechts, daß auch die digitale Sendung auf Abruf erfaßt. Auf internationaler Ebene fand im Dezember 1996 zu diesen Fragen eine Konferenz der World Intellectual Property Rights Organisation (WIPO) statt. Auf ihr wurden zwei Verträge verabschiedet, das World Copyright Treaty (WCT) und das World Performances and Phonogram Treaty (WPPT). ${ }^{31}$ Im Ergebnis sichern diese Verträge den Urhebern, Tonträgerherstellern und ausübenden Künstlern ein ausschließliches Vervielfältigungs- und Verbreitungsrecht zu, das auch für die elektronische Übertragung auf Abruf gilt (vgl. Abschnitt 5.3.3.1). In den Verträgen wird die Speicherung von Musikstücken in Datenbanken und ihre Verfügbarmachung als „communication to the public" bezeichnet; den Urhebern und Tonträgerherstellern werden hierfür ausschließliche Rechte eingeräumt. Nach Ratifizierung dieses Abkommens ${ }^{32}$ ist eine Steuerung der Online Musikverwertung seitens der Tonträgerhersteller bzw. der Rechteinhaber möglich. ${ }^{33}$

Die wirtschaftichen Beziehungen zwischen der Erstverwertung von Musik durch Tonträger und einer Zweitverwertung in den Medien Radio und (Musik)Fernsehen haben sich durch die Digitalisierung nicht verändert. Bestehen bleiben die wechselseitigen Abhängigkeiten. Einerseits benötigen digitales Radio und Musikfernsehen die musikalischen Programminhalte. Andererseits verändert die Weiterentwicklung von Übertragungstechnik und Übertragungsqualität nicht den verkaufsfördernden Charakter der Musikpräsenz in den Medien, wenn der Sendecharakter beibehalten wird. ${ }^{34}$ Verändert sich das Medienangebot in Richtung elektronische Liefe-

31 Vgl. von Lewinski, Silke, und Jens Gaster, Die Diplomatische Konferenz der WTPO 1996 zum Urheberrecht und zu verwandten Schutzrechten, in: Zeitschrift für Urheber- und Medienrecht (ZUM), 41. Jg. (1997), S. $607-625$.

$32 \mathrm{Zu}$ einer Ratifizierung haben alle Justizminister der EU bereits positiv Stellung genommen. Vgl. Kreile, Johannes, in: GEMA-Jahruch 1997/98, Baden-Baden 1998, S. 39.

33 Vgl. Flechsig, Norbert, EU-Harmonisierung des Urheberrechts und der verwandten Schutzrechte in der Informationsgesellschaft, in: ZUM, 42. Jg. (1998), S. 139-154.

34 Die Medienprăsenz fördert den Diffusionsprozeß der Musik. Eigenständige Programmgestaltung durch die Konsumenten ersetzt jedoch den Musikkauf und ist wirtschaftlich nicht mehr als Sendung anzusehen. 
rung von Musik, kann die Verwertung auf Basis eines ausschließlichen Verbreitungsrechts bei der Vereinbarung angemessener Entgelte für die Rechteinhaber - Tonträgerhersteller und Musiker - auf dem Verhandlungsweg ertragsneutral ausgestaltet werden. Die Tonträgerhersteller können bei entsprechender Rechtseinräumung durch die Urheber stufenweise eine digitale Verwertungskette aufbauen, indem sie zuerst die Medien elektronisch beliefern (für Radio- und Fernsehverwertungen), danach den Handel und schließlich die Endverbraucher direkt. Auf der Stufe der Multi-Channel-Dienste kann den Rechteinhabern eine zusätzliche Einnahmequelle dadurch entstehen, daß sie auch von Nicht-Tonträgerkäufern einen Teil aus dem Aufkommen der Abonnentengebühr als Vergütung erhalten.

\subsubsection{Vermittlungsnetzanwendungen: Internet und Online-Dienste}

Die Existenz und verbreitete Verwendung von Internet und darauf basierenden Diensten ermöglicht Handlungsoptionen für Musiker, Tonträgerhersteller und Konsumenten, deren volkswirtschaftiche Effekte ebenfalls untersucht werden sollen. Dabei ist zwischen dem offenen System des Internet und dem geschlossenen System kommerzieller Online-DiensteAnbieter zu differenzieren. Die Musikvermarktung im Online-Bereich mit physischem Vertrieb ist als ein erster Schritt der online Musikverwertung mit Vermittlungsnetzen zu verstehen. Sie ermöglicht einzelwirtschaftich eine Steigerung der Kundenbindung und gesamtwirtschaftich eine Ersparnis der Wegekosten der Konsumenten. Abbildung 24 veranschaulicht die Möglichkeiten der Musikvermarktung in Online-Bereich mit physischem Vertrieb, die anschließend genauer betrachtet werden.

\section{Abbildung 24: Musikvermarktung im Online-Bereich mit physischem Vertrieb}

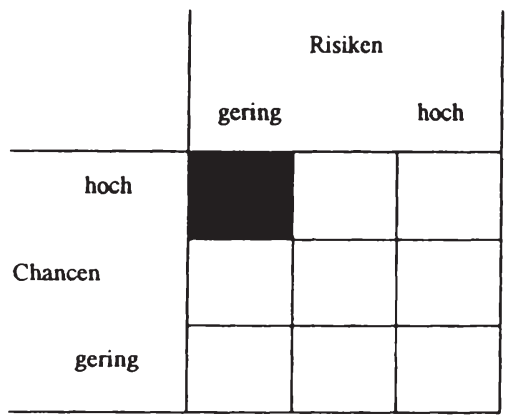

Voraussetzungen/Annahmen:

Online-Vermarktung nur als Marketing, Kommunikation zu den Konsumenten, gegebenenfalls direkte Bestellmöglichkeit der Kunden

Bewertung aus Sicht der Musik-Content-Provider:* Kundenbindung, Ertragszuwachs bei Realisierung der Handelsmargen, Betreuungskosten

Volkswirtschaftliche Bewertung: Ressourcenersparnis durch Wegfall von Wegekosten der Konsumenten, abhängig vom Bestellverhalten Verlust von Funktionen des TT-Handels

Quelle: In Anlehnung an Prognos (Hrsg.), Music And Demand, Basel 1996, S. 81.

*Musik-Content-Provider sind die Tonträgerhersteller. Vgl. Abschnitt 5.2.1.

Betrachten wir zunächst das Internet, das allen Nutzern, also auch Anbietern und Nachfragern von Waren und Dienstleistungen bei freiem Zugang zur Verfügung steht. Für Musiker und Tonträgerhersteller kann Internet als Plattform für Präsentationen, Marketing-, Informations- 
und Serviceaktivitäten dienen. ${ }^{35}$ Ferner ist via Electronic-mail eine direkte Kommunikation mit Konsumenten möglich. Internet kann auch als Verkaufsplattform dienen. Im Frühjahr 1998 waren alle größeren Tonträgerhersteller in Deutschland im Internet präsent. ${ }^{36}$ Sie aktualisierten ihre sog. Homepages zur Kundenbindung teilweise täglich. Als Dienstleister für den InternetZugang und die technische Realisierung der Präsenzen sind z. T. Service-Provider für Musiker und Tonträgerhersteller tätig. Damit ist für Musiker und Tonträgerhersteller die weltweite Präsenz und die Möglichkeit der Werbung zu vergleichsweise geringen Kosten möglich. ${ }^{37}$

Eine andere Qualität erhält die Internetpräsenz, wenn der Kontakt zu potentiellen Konsumenten in den direkten Vertrieb übergeht. Werden Bestellmöglichkeiten für Nachfrager angeboten, fällt zwar die Handelsmarge weg und die Tonträgerhersteller treten in Konkurrenzbeziehungen zum Versandhandel. Andererseits verursacht der eigene Vertrieb aber auch Kosten. ${ }^{38}$ Mit dem direkten Konsumentenkontakt ergeben sich allerdings Potentiale für die Marktbeobachtung und Marktforschung sowie Chancen zum Direktverkauf von Tonträgern auf dem Weg des Home-shopping ${ }^{39}$ und für die Erprobung weiterer Entwicklungsschritte zur elektronischen Musiklieferung. ${ }^{40}$ Für die Konsumenten ermöglichen die Informationsangebote des Internets eine höhere Markttransparenz und - bei Existenz von Bestellmöglichkeiten - eine Einsparung der Wegkosten. Dem steht ein Bedeutungsverlust von Tonträgerhandel, Clubs und herkömmlichem Versandhandel gegenüber, wenn ein signifikanter Anteil von Tonträgern via Internet vertrieben wird. Etabliert sich Internet als Vertriebskanal, senkt dies die Transaktionskosten ${ }^{41}$ und die Markteintrittsbarrieren für Newcomer, die nicht mehr auf die Distribution durch die Majors angewiesen sind. Ebenso können Musiker die von ihnen produzierte Musik auch direkt vertreiben. Daher kann sich eine Einsparung der Funktionen des Tonträgerhandels oder zusätzlich noch die Einsparung der physischen Distribution ergeben, was eine Kostensenkung und eine wesentliche Veränderung des Tonträgermarktes zur Folge hätte. ${ }^{42}$

Kommerzielle Online-Dienste bieten neben dem Zugang zum Internet sog. Mehrwertdienste an. Mehrwertdienste sind jene Telekommunikationsleistungen, die über das Angebot von Netzinfrastruktur hinausgehen und $u$. a. auch Teleunterhaltung mit Musik enthalten. Daneben sind

35 Vgl. Alpar, Paul, Kommerzielle Nutzung von Marketing, Produktion, Logistik und Querschnittsfunktionen durch das Internet und kommerzielle Online-Dienste, Berlin u. a. 1996.

${ }^{36}$ Ergebnis eigener Internet-Recherche.

37 Die Kosten von Werbung in Print-Medien, Audio-Medien oder audiovisuellen Medien sind auch in Relation zu den Kundenkontaktpotentialen wesentlich höher als diejenigen mit Hilfe des Internets.

38 Beispielsweise für zusătzliches Personal, das Errichten und Betreiben von Call-Centern, Versandkosten, Inkasso etc.

39 Der jetzige Anteil von Clubs und Versandhandel am Tonträgerabsatz (1996 betrug er 16,5\% vom Umsatzanteil) spricht dafür, daß das Produkt „Musik auf Tonträger“ prinzipiell für den Vertrieb via Internet geeignet ist. Vgl. Bundesverband der Phonographischen Wirtschaf, Jahrbuch 1997, S. 32 und Abschnitt 4.2.3.2.

40 Denkbar sind weitere Anwendungen wie ein Online-Gesamtkatalog aller Tonträgerhersteller oder auch kollusive Varianten wie eine gemeinsame Nutzeroberfläche aller Majors mit einer Weiterschaltungsmöglichkeit zu den jeweiligen Unternehmen. Hierbei sind dic Kooperations- und Wettbewerbsbereiche der Tonträgerhersteller unterschiedlich gestaltbar und werden durch kartellrechtliche Aspekte begrenzt.

4) Vgl. Beck, Hanno, und Aloys Prinz, Das globale Internet-Dorf regieren, in: Frankfurter Allgemeine Zeitung [FAZ], Nr. 56 vom 7.3.98, S. 15.

${ }^{42} \mathrm{Zu}$ den Auswirkungen der neuen Technologien auf Unternehmensstrategien und Wettbewerbspotentiale vgl weiter unten Abschnitte 5.2 und 5.3. 
Inhalt von Mehrwertdiensten Telekauf, Teleinformation sowie Leitungsvermittlungsdienste etc. Die Tonträgerhersteller besitzen als Gruppe den größten Anteil der Rechte an musikalischen Inhalten. Die Rechte sind Engpaßfaktor der Online-Musikverwertung. Die Tonträgerhersteller haben daher die strategische Option, sich vertraglich an einen Service-Provider zu binden, der wiederum die Netzinfrastruktur bereitstell ${ }^{43}$ sowie Rechte an anderen Inhalten erwirbt, um beispielsweise Teleunterhaltung und andere Mehrwertdienste anzubieten, oder selbst in diesen Bereich zu integrieren. Es ist für Produzenten von Inhalten wenig wahrscheinlich, daß sie sich jeweils ein eigenes Telekommunikationsnetz und einen eigenen Online-Dienst aufbauen, um ihre Produkte zu vertreiben. Denn beim Vertrieb der Mehrwertdienste bestehen starke horizontale Verbundvorteile, die einen Anreiz bilden, mehrere Mehrwertdienste über das gleiche Netz zu vertreiben. Neben horizontalen existieren vertikale Integrationsanreize. ${ }^{44}$ Letztere sind vorwiegend marktstrategisch bedingt und können in Gemeinschaftsunternehmen von Inhalteproduzenten, Kooperationen zwischen Service- und Content-Providern oder anderen vertraglichen Bindungen organisiert werden.

Nachfrageseitig ist es wenig wahrscheinlich, daß jeder Endabnehmer mit dem von ihm gewünschten Anbieter von Mehrwertdiensten kontrahiert und dazu die jeweils erforderlichen Übertragungstechnologien in Form von Endgeräten und Betriebssoftware erwirbt. Dagegen sprechen der Zeit- und Informationsaufwand sowie die hohen Anschaffungskosten für die Konsumenten. Daher werden unter Wettbewerbsbedingungen Dienstleister auftreten, die für die von den Konsumenten jeweils präferierten Mehrwertdienstebündel unter den lokalen Umständen die optimale Übertragungstechnologie nebst Softwarekomponenten als Paketlösung für die multimediafähigen PCs anbieten werden. ${ }^{45}$ Möglich sind dabei sowohl standardisierte als auch individuelle Lösungen. Diese Dienstleister werden die Rolle von Intermediären zwischen den Anbietern von Mehrwertdiensten und Netzinfrastrukturbetreibern einerseits und den Endnachfragern andererseits sein. Prinzipiell sind zwar Kooperationsverträge zwischen selbständig bleibenden Netzinfrastrukturanbietern, Mehrwertdiensteproduzenten und Online-Anbietern möglich, wegen der hohen Transaktionskosten und der strategischen Nachteile bei vertraglichen Lösungen sind vertikale Integrationen aber zu erwarten bzw. bereits realisiert. ${ }^{46}$ Insbesondere sind bei der Markteinführung von Mehrwertdiensten technische Standards nötig und Netzwerke zu etablieren. Diese erschweren dann nachfolgenden Unternehmen den Markteintritt. ${ }^{47}$

Vertikale Integration zwischen den Content- und den Service-Providern hat dann einen negativen Einfluß auf die Wettbewerbsintensität, wenn es keine ausreichende Zahl vertikal integrierter Unternehmen gibt und auf einer der Stufen eine Zusammenarbeit marktstarker oder marktbeherrschender Unternehmen erfolgt, so daß im Ergebnis das enge Oligopol des Tonträger-

43 Entweder mit Hilfe vertraglicher Bindung oder unternehmensintern durch Integration (z. B. bei der Telekom).

44 Vgl. Klodt, Henning, Claus-Friedrich Laaser, Jens Oliver Lorz und Rainer Maurer, op. cit., S. 64 f.

45 Der multimediafahige PC ist das für die online-Musikverwertung benötigte Endgerăt.

46 Gemeinsame Vertriebsgesellschaften existieren z. B. für AOL/Bertelsmann sowie für Burda, MatraHachette, Pearson und AT\&T

47 Zur Wirkung von indirekten Netzwerkeffekten und der Standardsetzung als Markteintrittsbarriere vgl. den Abschnitt 5.3.1 und Thum, Marcel, Netzwerkeffekte, Standardisienung und staatlicher Regulierungsbedarf, Tübingen 1995, S. $8 \mathrm{ff}$. und S. $146 \mathrm{ff}$. 
marktes auch bei elektronischer Musiklieferung fortbesteht. Negative Rückwirkungen auf den Wettbewerb unter den Online-Diensteanbietern können durch Bündelung des Angebots von stark nachgefragten Schlüsselmehrwertdiensten - wie z. B. Musik auf einen Online-Dienst entstehen. Die Kennzeichnung von Musik als einer Schlüsselfunktion trifft insbesondere für diejenigen Mehrwertdienste zu, die auf den Bereich der privaten Haushalte als Nachfrager abzielen. Diese Mehrwertdiensteanbieter werden überwiegend Unterhaltungsangebote von den Produzenten nachfragen. Für sie ist Musik ein Kernbestandteil, der die Attraktivität ihres Mehrwertdienstes signifikant erhöht. Denn auf der Stufe der Mehrwertdienste wäre es potentiellen Konkurrenten nicht möglich, ausreichende Nachfrage zum Markteintritt zu attrahieren, ohne ihr einen Zugang zu ähnlich attraktivem Musikangebot zu verschaffen. ${ }^{48}$ Auch wäre die Effektivität des bestehenden Wettbewerbs stark eingeschränkt, da es aktuellen Konkurrenten nicht möglich wäre, ohne dasselbe attraktive Musikangebot um die Kunden des integrierten Unternehmens zu werben. ${ }^{49}$ Möglicherweise kann ein integriertes Unternehmen als „Major für Musikinhalte" aufgrund der hohen Teilnehmerzahl seines Netzes dann auch überhöhte Preise für den Vertrieb von Mehrwertdiensten Dritter durchsetzen.

Einige der Tonträgerhersteller sind in der o. g. Weise integriert. Warner, Sony und Bertelsmann Music Group sind Töchter internationaler Medienunternehmen und haben daher Integrationspotentiale. Bertelsmann ist durch ein joint venture mit Compuserve und durch den Aufbau von AOL/Bertelsmann Online bereits in den Markt integriert, ${ }^{50}$ bietet aber noch keine Musik an. Mit ca. 250.000 Geschäftskunden (Compuserve) und 550.000 Privatkunden (AOL/Bertelsmann) hat Bertelsmann in Deutschland bei den Mehrwertdiensten bedeutende Unternehmensgrößen erreicht. ${ }^{51}$ Marktführer in Deutschland ist als Tochter des Netzbetreibers Telekom das Unternehmen T-Online mit ca. 1,9 Mio. Abonnenten. ${ }^{\$ 2}$ Weitere Anbieter sind Microsoft Network, Europe Online (Burda), Apple eWorld, Eunet, MAZ und einige kleinere Unternehmen. ${ }^{53}$ Die Konditionen der Mehrwertdiensteanbieter bestehen in einer monatlichen Grundgebühr und - bei Übertragung über die Telefonleitung - in den Verbindungskosten bis zum Einwahlknoten. Zusätzliche Kosten entstehen bei Nutzungen in Spitzenzeiten und bei bestimmten zusätzlichen Diensten (z. B. dem Abruf von Musik). Das oben beschriebene Szenario der vertikalen Integration könnte Realität werden, denn der Mehrwertdiensteanbieter TOnline hat bereits mit dem Bundesverband der Phonographischen Wirtschaft einen Rahmenvertrag über die Nutzung musikalischer Inhalte ausgehandelt und verhandelt $\mathrm{z}$. $\mathrm{Zt}$. mit den Major-

48 Die potentielle Konkurrenz betriff den Aufbau eines eigenen Online-Dienstes, welches dann in Konkurrenz zu demjenigen mit den Schlüsselmehrwertdiensten tritt.

49 Die aktuelle Konkurrenz im bestehenden Netz betriff den intramediären Wettbewerb.

so $\mathrm{Ob}$ es sich dabei um eine Vorwärtsintegration in die elektronische Verbreitung von Musik oder um eine Rückwărtsintegration in den Betrieb eines Online-Netzdienstes handelt, hängt vom gewählten Blickwinkel ab.

51 Die Abonenntenzahl bezieht sich auf eigene Firmenangaben vom Februar 1998.

52 Die Abonnentenzahl bezieht sich auf eigene Firmenangaben vom Februar 1998. Die Marktführerschaft beruht darauf, daB T-Online Nachfolger der seit ca. 15 Jahren in Deutschland etablierten Dienste Btx und DatexJ ist. Sollte sich der Online-Musikvertrieb etablieren, wird die Kontrahierung der musikalischen Content-Provider mit einem globalen Online-Diensteanbieter ein wahrscheinliches Szenario.

53 Diese Anbieter verfuggen bisher nur über geringe Abonnentenzahlen mit Stand vom Februar 1998. Microsoft und Apple bündeln ihr Angebot mit ihrer entsprechenden Software und Burda bezieht sich hauptsächlich auf Geschăftskunden als Nachfrager. 
Tonträgerherstellern direkt über die Rechte zur Online-Verwertung von Musik. ${ }^{54}$ Dabei haben die Netzbetreiber und T-Online die Investitionen in die Musikdatenbank bereits getätigt und in den Verhandlungen sogar angeboten, die Musiktitel für den Online-Handel digital aufzubereiten." Ob Bertelsmann mit einer Vereinbarung zugunsten von T-Online seiner Tochter AOL/Bertelsmann-Online selbst Konkurrenz macht, bleibt abzuwarten. Mit einer steigenden Verbreitung des Internet-Zugangs steigen Größe und Attraktivität des Netzwerkes und damit die Erfolgschancen der Online-Dienste. ${ }^{56}$ Damit entwickelt sich das technische Potential, um die Online-Musikverwertung als eigenständigen Vertriebskanal zu begreifen. Natürlich wird der Vertriebskanal in der Anfangsphase erst dadurch entstehen, daß das Musikangebot eines von vielen innerhalb der Mehrwertdienste ist. Das gebündelte Angebot soll hier einen Nutzen stiften, der die Nachfrage entsprechend stimuliert.

\subsubsection{Elektronischer Vertrieb von Musik als Teil von Online-Diensten}

Neben der bereits beschriebenen Digitalisierung von Punkt zu Multipunkt-Verteilsystemen, die beim digitalen Radio, Fernsehen und Multi-Channel-Angeboten verwendet werden, ist auch eine Digitalisierung der individualisierten Punkt zu Punkt-Übertragung möglich. Hierfür werden die digitalen Mobilfunknetze und die digitale Übertragung von Informationen durch das analoge Telefonnetz mittels eines Modem ${ }^{57}$ verwendet. Dieses Übertragungsprinzip liegt dem Internet und den kommerziellen Online-Diensten zugrunde. Durch die Sternstruktur des Netzes bei Punkt zu Punkt-Übertragungen steht ein Rückkanal zur Verfügung und eine Zwei-WegeKommunikation ist prinzipiell möglich. ${ }^{38}$ Zur Lieferung von Musik muß das Ausgangssignal der Audio-Daten codiert und datenreduziert bzw. komprimiert werden und kann dann ohne hörbare Qualitätsverluste über eine ISDN-Telefon-Leitung übertragen werden. ${ }^{59}$ Technische Voraussetzungen für den elektronischen Vertrieb sind spezielle Musikdatenbanken (Server), auf denen die Musikstücke digital abgelegt sind, und Übertragungswege und -kapazitäten (ISDN-Telefonanschluß). Weiterhin sind Kopiersperr- und Abrechnungstechniken ${ }^{60}$ nötig und bei den Konsumenten als entsprechende Endgeräteausstattung (Client) ein Multimedia-PC mit

s4 Vgl. Clausen, Sven O., Hits aus dem Computer, Konkurrenz für CD-Läden, in: Die Zeit, Nr. 7 vom 5.2.98, S. 32, und Telefoninterview mit Herm Böhm, Telekom, vom 13.3.98.

ss Nach Angaben von T-Online und Telekom vom Mărz 1998.

s6 Zu Jahresbeginn 1998 waren nach Angaben von Bertelsmann in Deutschland ca. 3.5 Mio. Personalcomputer in Privathaushalten und Unternehmen vernetzt.

57 Der Modulator/Demodulator wandelt analoge in digitale Signale um et vice versa.

58 Technische Probleme treten aber auf, da das Telefonnetz schmalbandig und die Übertragungskapazitát daher begrenzt ist.

s9 Vgl. Zhou, Minhua, Optimization of MPEG-2 video encoding, Aachen 1997, S. 9 ff. Die International Standard Organization (ISO) hat eine Expertengruppe (Moving Pictures Expert Group, MPEG) zur Erarbeitung von Codierungs-, Kompressions- und Reduktionsstandards im Video- und Audio-Bereich eingesetzt. In Deutschland erprobt die Telekom im Projekt Audio on Demand auf der Basis von MPEG 1 Layer 3 die Datenreduktion bzw. -kompression mit einer Übertragungsgeschwindigkeit von $128 \mathrm{~KB}$ pro Sekunde.

60 Die Kopiersperrtechnik soll bewirken, daß die Musikstücke nur einmal zum privaten Gebrauch kopiert werden können (vgl. die Darstellung des Serial Copyright Management System SCMS in Kap. 2) und nicht gewerblich weitervertrieben werden. Die Abrechnungstechnik soll auf dem Branchenstandard International Standard Record File ISRF basieren, der die Identifizierung des Urhebers und anderer Rechteinhaber ermöglicht. Zusátzlich kommt noch die Abrochnungstechnik des kommerziellen Online-Dienste-Anbieters hinzu. 
ISDN-Soundcard und MPEG 1 Layer 3-Karte, durch die die Musik in digitaler Qualität wiedergegeben wird, die entsprechende Software sowie der Zugang zu einem kommerziellen Online-Dienste-Anbieter (hier T-Online) erforderlich.

Sind die Realisierungsmöglichkeiten technisch gegeben, stellen sich Fragen im Hinblick auf die organisatorische und wirtschaftiche Umsetzung aus Sicht der Unternehmen und aus wettbewerbspolitischer Sicht. ${ }^{61}$ Die organisatorische Umsetzung betrifft die Ausgestaltung der Beziehungen zwischen den Tonträgerherstellern als den Rechtsinhabern, den Service-Providern und den Endnachfragern, die die Musik konsumieren. Sie wird im folgenden behandelt. Die wirtschaftliche Umsetzung bezieht sich auf die dadurch geschaffene Konkurrenzbeziehung der elektronischen Musikverbreitung zum physischen Tonträgerkauf, zum Radiohören und zu anderen Nutzungsarten von Musik. Sie wird im Abschnitt 5.2 behandelt. Abbildung 25 veranschaulicht den technischen Ablauf der elektronischen Musikbelieferung.

\section{Abbildung 25: Ablauf der elektronischen Musikbelieferung}

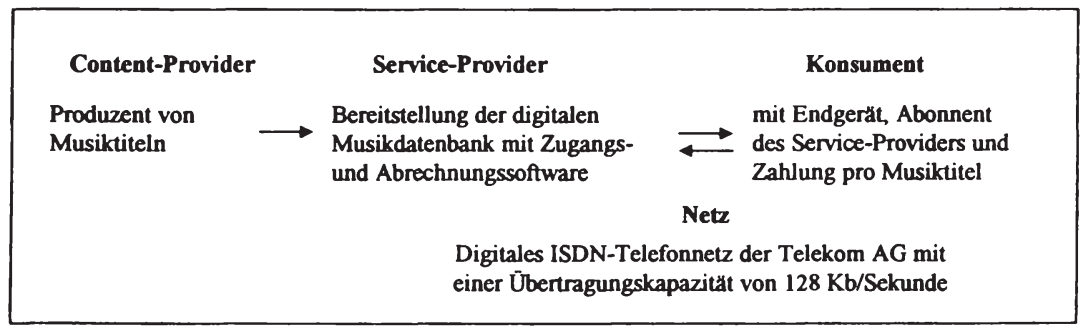

Bei der organisatorischen Umsetzung des elektronischen Musikvertriebs sind die Ebenen des Programmproduzenten, des Dienste-Anbieters, der Distributionsinfrastruktur (Netzbetreiber) und der Konsumentenplattform zu unterscheiden. Wir gehen im folgenden davon aus, daß die Entwicklung des elektronischen Musikvertriebs auf bestehenden Musikprogrammen der Majors, bestehenden Online-Diensteanbietern und auf dem bestehendem Distributionsweg des Telefonnetzes wegen seiner fast vollständigen technischen Reichweite bzgl. der privaten Haushalte aufbaut. Dieses Szenario ist wahrscheinlich, da die bestehende Infrastruktur genügend Investitionsanreize für Diensteanbieter und Spielraum für kommerzielle Musikverwertungen eröffnet und damit Ausgangsbasis für die Entwicklung des elektronischen Musikvertriebs ist. Hinzu kommt, daß die auf der Basis der bestehenden flächendeckenden Infrastruktur wachsende Anschlußdichte an Online-Diensteanbieter das Hardware-Software Problem löst. ${ }^{62}$ Die Lösung dieses Problems reduziert die einzelwirtschaftlichen Investitionsrisiken.

61 Dies ist Gegenstand von Abschnitt 5.3.2.

62 Dieses Problem besteht in der Überwindung der kritischen Masse. Vgl. Economides, N., und C. Himmelberg. Critical mass and network size with application to the US fax market, in: Discussion Paper EC-95-11, Stern School of Business, New York 1995, und Katz, M., und C. Shapiro, Product introduction with network externalities, in: Journal of Industrial Economics, Vol. 40 (1992), S. 55-84 [Katz/Shapiro 1992]. 
Für die Konsumenten ist die Attraktivität des Angebots für die Geschwindigkeit des Diffusionsprozesses ebenso entscheidend wie die Höhe der Kosten, die der einzelne aufwenden muß. Im oben beschriebenen Szenario bestehen die einmaligen Kosten in der Anschaffung des Modems und des multimediafähigen $\mathrm{PCs}^{63}$ und die laufenden Kosten in der Abonnenten- und Telefongebühr. Musikalische Inhalte können hier den Nutzen von Online-Mehrwertdiensten aus Konsumentensicht steigern. Damit aus Nachfragepotential Zahlungsbereitschaft erwächst, ist Voraussetzung, daß alle Dienste von einer einheitlichen Plattform (dem Multimedia-PC) konsumierbar sind. Ein solches common interface stellt Anforderungen an die Standardisierung der Angebotsformen und die Kompatibilität verschiedener Nutzungsarten. Die Nachfrage wird daher wegen der lock-in-Effekte solange zurückhaltend reagieren, bis sich die Integrationstendenzen der Multimedianutzung herauskristallisiert haben und die Gerätepreise signifikant sinken. $^{64}$

Die organisatorische Umsetzung des elektronischen Vertriebs bedarf zuerst eines Servers, der die Funktion der Musikdatenbank übernimmt. Diese Datenbank enthält die digitalen Musiktitel der Tonträgerhersteller. Denkbar ist sowohl eine zentrale Datenbank aller Hersteller als auch die jeweils eigene Datenbank jedes Unternehmens. Eine wettbewerbspolitische Unbedenklichkeit für eine zentrale Datenbank aller Tonträgerhersteller ist aus kartellrechtliche Sicht abhängig von ihrer Funktion (Phononet z. B. ist unkritisch). Die Unternehmen werden zudem aus strategischen Gründen keine zentralen Zugriffe auf ihre Produkte zulassen wollen. Der ServiceProvider fungiert als zweite Stufe der elektronischen Musikverwertung. Denkbar ist, daß die Tonträgerhersteller alle oder teilweise selbst als Service-Provider mit eigenen Abonnenten auftreten, oder daß sie Exklusivverträge mit je einem oder mehreren Service-Providern schließen. Ferner ist denkbar, daß sie Verträge mit Service-Providern schließen und diese die Inhalte gegen Entgelt auch an andere Service-Provider weitervermarkten, oder daß alle Tonträgerhersteller zusammen mit einem Service-Provider kontrahieren und daß dieser OnlineAlleinvermarktungs-berechtigt ist oder für die Tonträgerhersteller an andere Service-Provider weiterlizensiert. Aus den beschriebenen Organisationsmodellen der Online-Musikverwertung wird in Abbildung 26 ein denkbares dargestellt. ${ }^{65}$ Wettbewerbs- und Kooperationsanteile variieren, je nachdem, wo die jeweilige Musikdatenbank integriert ist und wie viele ServiceProvider am Vertrieb beteiligt sind

63 Vorausgesetzt ein TelefonanschluB (ISDN) ist vorhanden. Hierbei muß berücksichtigt werden, daB die Anschaffung von Modem und multimediafähigem PC keine alleinigen Kosten (stand alone costs) der elektronischen Musiknutzung darstellen, sondern daß diese Gerăte vielmehr für ein ganzes Bündel von elektronisch gelieferten Diensten Voraussetzung sind. Insofern könnte man bei bestehender PC-Ausstattung die Anschaffung von ISDN-Soundcard und MPEG 1 Layer 3-Karte als Zusatzkosten (incremental costs) der elektronischen Musiknutzung bezeichnen.

64 Insofern haben Content- und Service-Provider hinsichtlich der common-interface-Problematik dieselben Interessen. Im Bereich von Personalcomputern sind Preissenkungen innerhalb kurzer Zeit die Regel. Der multimediafähige PC ist heute bereits Standard bei Neuanschaffung eines Personalcomputers für private Haushalte.

65 Dieses Modell wurde ausgewählt, weil es zu Jahresbeginn 1998 die wahrscheinlichste Alternative darstellte 


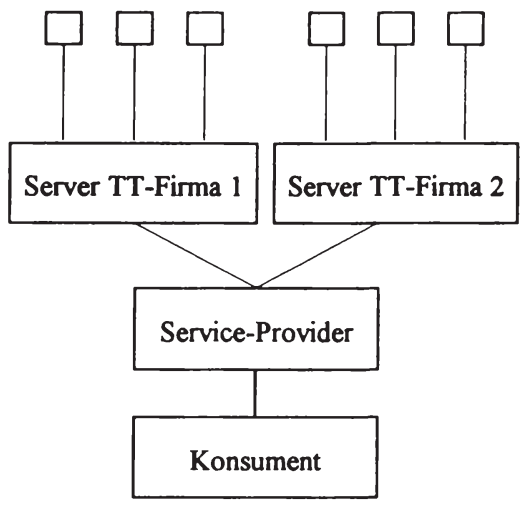

\section{Kooperationsstrategie}

Jedes Tontrăgenunternehmen hat seinen eigenen Server bzw. seine eigene Datenbank

Ein gemeinsamer Service-Provider koordiniert und vermarktet das Angebot der Tonträgerhersteller und hat einen eigenen Kunden/Abonnentenstamm

Der Kunde wird Abonnent beim gemeinsamen Service-Provider

Quelle: In Anlehnung an Prognos (1996), S. 75.

Aus Konsumentensicht ist ebenfalls denkbar, daß man nur als Kunde des Musik-OnlineDienstes Zugriff auf Musik hat, oder daß man unabhängig davon, bei welchem Online-Dienst man Kunde ist, gegen Entgelt weitergeleitet wird. Ebenso ist möglich, daß man Abonnent verschiedener Service-Provider werden muß, um verschiedene Musiktitel Online kaufen zu können. Für den Konsumenten ist zusätzlich von Bedeutung, ob er mit einem Abonnement das gesamte Musikrepertoire, das Online verfügbar ist, erhalten kann oder nicht, und ob das Abonnement auch andere Dienstleistungen anbietet, die für ihn von Nutzen sind. Aus Musikersicht sind ebenfalls unterschiedliche Konstellationen denkbar. Durch die Entkopplung des Produktes Musik von seinem Träger kann auch der Musiker (der z. B. bei einem Bandübernahmevertrag mit dem Tonträgerhersteller auch heute schon das Mastertape selbst erstellt) eine eigene Musikdatenbank betreiben und einem Service-Provider seine musikalischen Inhalte anbieten. ${ }^{66}$

Die organisatorischen Lösungen des elektronischen Musikvertriebs unterscheiden sich offensichtlich darin, wieviele Stufen zwischen der Musikdatenbank und dem Endverbraucher existieren und wieviele Marktteilnehmer daher an der Musik mitverdienen, sowie darin, auf welcher Stufe Wettbewerb und Kooperation jeweils herrscht. Zwischen den verschiedenen ServiceProvidern wird deswegen Wettbewerb bestehen, weil dieser Markt in der Expansionsphase ist und dringend Inhalte benötigt werden. Mit weiteren technischen Fortschritten in der Datenreduktion und -kompression wird die Entkopplung von Inhalten und Distributionsmöglichkeiten weiter zunehmen und damit wird auch der Wettbewerb intensiviert werden. Daher ist zu er-

66 Bei Etablierung eines Kopierschutz- und Abrechnungssystems im Internet könnte sich jeder Musiker auch ohne Service-Provider direkt an die Konsumenten wenden. 
warten, daß die Anbieter von Inhalten eine stärkere Position als die Service-Provider haben und Abhängigkeiten eher in dieser Richtung bestehen. ${ }^{67}$ Die Wettbewerbsintensität der Tonträgerhersteller beschränkte sich bisher auf Aktionsparameter der Produktpolitik, den musikalischen Inhalt, den Zeitpunkt der Veröffentlichung, die Wirksamkeit des Marketings, die effiziente Mehrfachverwertung und Aktionsparameter der Kommunikationspolitik. Nun wird mit der netzgebundenen Musikverwertung neben dem Preis und der Qualität noch ein weiterer Aktionsparameter im Wettbewerb ausfallen, wenn durch einen Service-Provider ein einheitlicher Zugang zu allen online verfügbaren Musikstücken geschaffen wird. Es findet dann kein Service-Wettbewerb mehr um die Verfügbarkeit der Produkte statt.

Abbildung $27 \mathrm{faßt}$ die in Abschnitt 5.1 beschriebenen technischen Weiterentwicklungen in ihren Auswirkungen auf die Musikvermarktung zusammen und zeigt den Übergang von der physischen zur nicht physischen Verwertung.

Abbildung 27: Künftiger Tonträgermarkt, Übergang von körperlicher zu unkörperlicher Musikverwertung

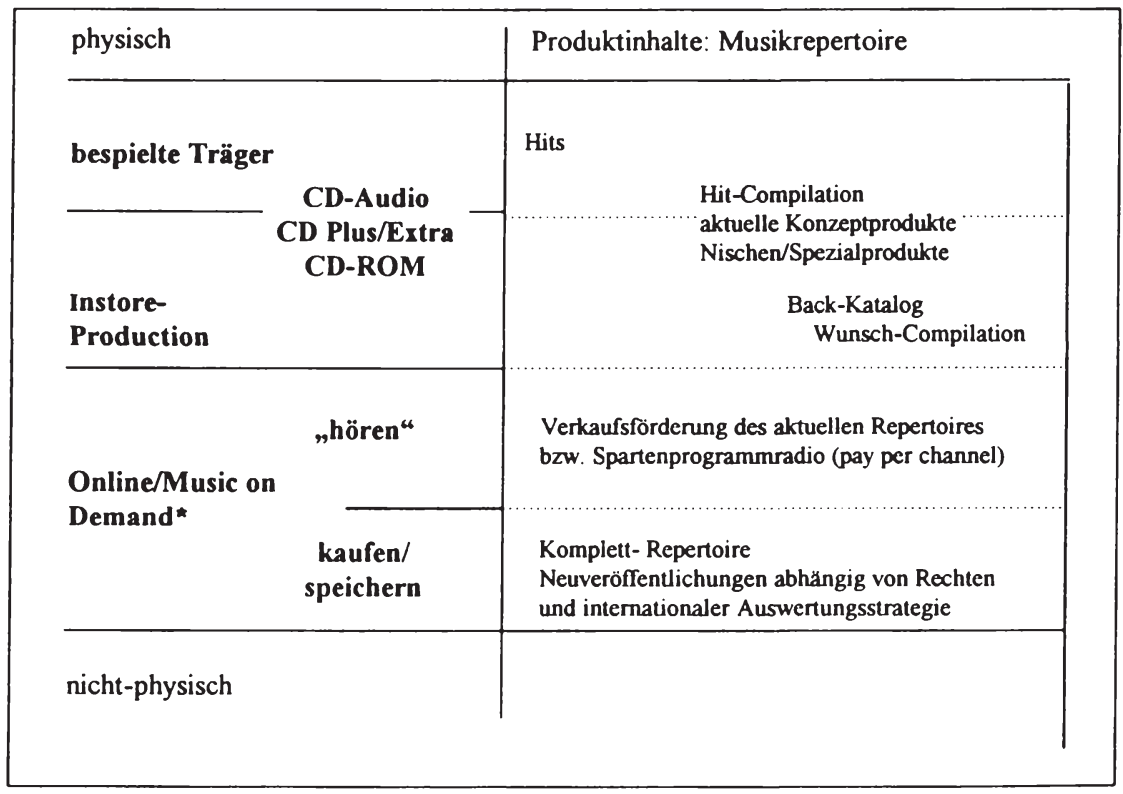

Quelle: In Anlehnung an Prognos, op. cit., S. 105. * Hören und kaufen/speichern kann gleichzeitig geschehen, da in Echtzeit in subjektiver CD-Qualität übertragen wird.

67 Das bedeutet, daß Markteintrittschancen weiterer Online-Dienste von ihren inhalulichen Angeboten abhängen. 


\subsection{Strategien, Unternehmensverhalten und Marktprozesse für Online- Musikverwertungen}

In diesem Abschnitt werden Strategien, Unternehmensverhalten und Marktprozesse der netzgebundenen Musikverwertung untersucht. Da für die multimedialen Offline-Tonträger gegenüber den bereits vorher analysierten herkömmlichen Tonträgern keine wesentlichen Änderungen entstehen, werden diese hier nicht weiter betrachtet. Denn die oben beschriebenen multimedialen Aufwertungen der Offline-Tonträger ergeben zwar neue Anforderungen für die Produktion des Angebots, so daß für die nicht musikalischen zusätzlichen Inhalte weitere Kosten entstehen, aber der Vertriebsweg und die Konkurrenzbeziehungen ändern sich prinzipiell nicht. Die elektronische Musikverwertung bedingt jedoch eine Veränderung der Verwertungskette von Musik. Daher werden im folgenden hierfür Strategien, Unternehmensverhalten und Marktprozesse als Entwicklungsszenarien untersucht. Hierbei wird von den Stufen des bisher bestehenden Tonträgermarktes (vgl. Abbildung 14 in Abschnitt 4.1.1) ausgegangen, beginnend mit den Musikern und Tonträgerherstellern (5.2.1), den Netzinfrastruktur- und Online-DiensteAnbieter (5.2.2) und schließlich den Nachfragern (5.2.3). Die Analyse der strategischen Verhaltensweisen der Unternehmen und der daraus resultierende dynamische Marktprozeß wird durch die Veränderungen der Verwertungskette netzgebundener Musikverwertung (5.2.4) zusammengefaßt.

\subsubsection{Musiker und Tonträgerhersteller als Content-Provider}

Für eine Online-Verwertung ist Musik als einer von mehreren Inhalten der OnlineUnterhaltungsdienste anzusehen. Musiker und Tonträgerhersteller können als Produzenten und Lieferanten von musikalischen Inhalten (sog. Content-Provider) verstanden werden. Bei der körperlichen Musikverwertung mit Hilfe von Tonträgern wurde ein polypolistisches Angebot von Musikern konstatiert, dem nachfrageseitig als Teiloligopsongruppe die Majors und eine Vielzahl von Independents gegenüberstanden. Daher sind bereits erzielte Verkaufserfolge Voraussetzung der Musiker für eine gute Verhandlungsposition mit den Tonträgerherstellern gewesen. Etablierte Musiker haben die Tonträgerverkaufszahlen in Bandübernahmeverträgen mit Konditionen umgesetzt, die ihren Marktwert wiederspiegeln. Newcomer unter den Musikern haben (wenn überhaupt) Künstlerverträge erhalten, die bisweilen einen Versorgungscharakter hatten. Die elektronische Musikvermarktung über Internet oder Online-Dienste eröffnet den Musikern nun ein Medium für Werbung und Öffentlichkeitsarbeit, das einen direkten Kontakt zu potentiellen Konsumenten ermöglicht. Im Sinne einer vertikalen Vorwärtsintegration in eine eigene Online-Vermarktung sind für die Musiker statt den Tonträgerherstellern eher Softwareunternehmen Ansprechpartner. Musiker könnten direkt, d. h. an den Tonträgerherstellern vorbei, mit den Online-Diensten kontrahieren ${ }^{68}$ und die digital in Form von Masterbändern vorliegende Musik in die Musikdatenbank des Online-Dienstes einspeisen. ${ }^{69} \mathrm{Zu}$ der technischen

${ }_{68}$ Dies gilt selbstverstăndlich nur, wenn die Online-Dienste bei der Programm- bzw. Inhalte-Beschaffung Einzelkontrakte mit Musikem abschließen. Wahrscheinlicher ist aus Transaktionskostengründen aber, daß die Online-Dienste eher zu Katalogkontrakten mit den Tontrăgerherstellern neigen werden.

69 Interessanterweise haben etablierte Musiker (David Bowie, Peter Gabricl und Rolling Stones) dies bereits getan. Sie haben dabei das offene Netz Internet genutzt, um Ausschnitte ihrer neuen Musikstücke zu pră- 
Abwicklung kommen die kaufmännischen Funktionen, die sie in diesem Fall i. S. eines makeor-buy-Kalküls selbst zu erledigen oder einzukaufen hätten. ${ }^{70}$ Die Online-Verwertung kann das Aushandeln besserer Konditionen oder den Einkauf nur einzelner Unternehmensfunktionen zu Pauschalpreisen ermöglichen.

Bei einer weiteren Zusammenarbeit mit Tonträgerherstellern ergeben sich für die Musiker als Urheber Handlungsoptionen aus der Tatsache, daß die digitale Online-Vermarktung über Netze eine neue Nutzungsform musikalischer Werke ist. Hierfür stehen die Rechte nicht automatisch den Tonträgerherstellern zur Verfügung, sondern sie müssen diesen explizit übertragen werden. ${ }^{71}$ Musiker können die Rechte zum Abruf von Musik den Tonträgerherstellern im gleichen Umfang zur Verfügung stellen, wie sie das bereits für die körperliche Verwertung getan haben. ${ }^{72} \mathrm{Da}$ es sich bei der oben diskutierten elektronischen Belieferung der privaten Haushalte von Online-Diensten um geschlossene Netze handelt, können die Musiker die Rechte für die unkörperliche Verwertung via Netz auch zeitlich und räumlich beschränken. Zudem können sie Vorgaben für die inhaltliche Gestaltung des Angebots treffen. Es kann beispielsweise nur aktuelles Repertoire oder auch bereits veröffentlichte Musik (Backkatalog) eingespeichert werden (vgl. Abb. 27). ${ }^{73}$ Die Musiker haben damit einen neuen Ansatz für Verhandlungen. Die zugrundezulegende wirtschaftliche Ausgangslage hat sich jedoch für sie durch die Möglichkeit der netzgebundenen Verwertung nicht wesentlich geändert. Denn aus der Sicht der Tonträgerhersteller wird der Beschaffungsmarkt gespalten bleiben. Die Qualitätsunsicherheit im Hinblick auf die erwartete Attraktivität der Musik bleibt bei etablierten Musikern geringer, weswegen deren Angebot auf große Nachfrage trifft. Dagegen besteht für unbekannte Musiker ein Käufermarkt, auf dem das große Angebot einer geringeren Nachfrage gegenübersteht. Die grundsätzlichen ökonomischen Besonderheiten der Vertragsverhandlungen für die Musikverwertung sind presales und package-deals. Presales kennzeichnen das bei Künstlerverträgen übliche Verfahren, die Rechte an den noch zu erstellenden Produkten im voraus zu erwerben. Packagedeals wird das bei Künstler- und Bandübernahmeverträgen übliche Verfahren genannt, die Rechte über eine Zeitspanne und das in dieser Zeit zu erstellende Produktbündel (i. d. R. mehrere Tonträgerveröffentlichungen) zu erwerben. Diese Vertragsbesonderheiten bleiben auch beim elektronischen Vertrieb von Musik bestehen.

Für die Tonträgerhersteller eröffnen sich analog zur körperlichen Verwertung Handlungsmöglichkeiten im Hinblick auf Produkt-, Preis und Distributionspolitik sowie Kontrahierungsverhalten mit den Online-Diensten. Im Zuge der Online-Musikverwertung werden Tonträgerhersteller zu Content-Providern, die mit den Online-Diensten zusammenarbeiten, um die Konsu-

sentieren. Hierbei handelte es sich nur um Werbung für physische Tonträger, nicht um Substitution durch Herunterladen vom Netz. Der Musiker Phil Collins hat sich zwischenzeitlich an einer Audio-SoftwareFirma beteiligt.

70 Diese Unternehmensfunktionen sind Marketing, physische Herstellung, Distribution und Inkasso.

7 Vgl. § 31 Abs. 4 UrhG und Abschnitt 5.3.3.1.

72 Vgl. Emst, Stefan, Urheberrechtliche Probleme bei der Veranstaltung von On-demand-Diensten, in: Gewerblicher Rechtsschutz und Urheberrecht (GRUR), 99. Jg. (1997), S. 592-597.

73 Hierfür wăre eine nachtrăgliche Übertragung der Verwertungsrechte für die Online-Verwertung nötig. 
menten zu erreichen. Aus der Sicht der Tonträgerhersteller ergänzen die Service-Provider den Handel, indem sie die Musik via Netz zu den privaten Haushalten liefern.

Die generelle Voraussetzung für eine Produktpolitik der Tonträgerhersteller zur OnlineVerwertung ist die Rechteeinräumung durch die Musiker. Im ersten Schritt werden sie daher alle neuen Verträge so ausgestalten, daß sie die digitale elektronische Verwertung einschließlich der Belieferung der privaten Haushalte über Netze ermöglichen. Der zweite Schritt wird darin bestehen, sich die Auswertungsrechte bereits bestehender Master-Tapes (des sog. BackKatalogs) einräumen zu lassen. Dabei müssen auch für die neuen Möglichkeiten der Musikzusammenstellung durch die Konsumenten bei der sog. Instore-Production die Rechte eingeholt werden. ${ }^{74}$ Dann kann das Programmangebot der Tonträgerhersteller nach Musikrepertoiregruppen gestaffelt werden, zu denen die einzelnen Musiker oder Musikgruppen zusammengestellt werden. Dabei bleibt der Input-Ressourcenwettbewerb um die vertragliche Exklusivbindung der etablierten Musiker zwischen den Herstellern bestehen. Diese bleiben auch bei unkörperlicher Verwertung die Markenzeichenträger und begründen die Präferenzbindung der Konsumenten ad personam.

Die Hersteller erlangen auch bei netzgebundener Musikverwertung durch die Bindung von etablierten Musikern einen Produktdifferenzierungsvorteil gegenüber ihren direkten Konkurrenten, wenn diese keine Stars an sich binden konnten. Insofern ändert der Online-Vertrieb den Beschaffungswettbewerb der musikalischen Content-Provider nicht. Die Produktpolitik hat schließlich auch die Aufgabe, die Etablierung des neuen Distributionsweges für Musik zu fördern. Daher ist zu erwarten, daß das aktuelle Repertoire, für das seitens der Konsumenten die größten Präferenzen bestehen, über diesen Kanal zugänglich gemacht wird.

Die Preispolitik der Tonträgerhersteller bezog sich auf den Händlerabgabepreis, durch den die Hersteller versuchten, für unterschiedliche Verwertungsstufen und Produktkategorien auf der Endverkaufsebene Preiskategorien zu definieren (vgl. Abschnitt 4.3.2.3). Insbesondere der Preiswettbewerb zwischen den Tonträgerhändlern hatte dafür gesorgt, daß auf der Endverkaufsebene unterschiedliche Preise festzustellen waren. Beim Wegfall der physischen Distribution und damit des Handels fällt ebenso dessen Marge und der Preiswettbewerb weg. Die Preisgestaltung wird sich $\mathrm{m}$. E. am Endverkaufspreis herkömmlicher Tonträger als Kalkulationsgrundlage orientieren. ${ }^{75} \mathrm{Ob}$ die Einsparung der Kosten von Distribution und Handel an die Konsumenten weitergegeben wird, hängt von der Marge des Online-Dienstes, dem Preisverhalten der Rechteinhaber und der Preiselastizität der Nachfrage für diese Art der Musikverwertung ab. Es wird zu erwarten sein, daß die Tonträgerhersteller versuchen werden, sich i. S. einer Erhöhung ihrer Produzentenrente die ersparte Handelsmarge als Ausgleich für Zusatzko-

74 Das betriff den Wunsch der Musiker, nicht zusammen mit bestimmten anderen Künstlern vermarktet zu werden (sog. Heino-Effekt).

75 Die Preisdifferenzierung der musikalischen Content-Provider orientiert sich idealerweise an der Nutzungsintensităt. So wird die via Netz abgerufene Musik billiger sein, wenn sie nur zum Hören angefordert wird, und teurer, wenn sie überspielt bzw. gespeichent wird. Vgl. Thurow, Norbert, Die digitale Verwertung von Musik aus der Sicht von Schallplattenproduzenten und ausübenden Künstlern, in: Becker, Jürgen, und Thomas Dreier (Hrsg.), Urheberrecht und digitale Technologie, Baden-Baden 1994, S. 77-84. 
sten anzueignen. Die Online-Dienste werden den Konsumenten neben der Abonnentengebühr die Übertragungskosten auferlegen und den Preis der Tonträgerhersteller bzw. Rechteinhaber weitergeben. ${ }^{76}$ Andererseits sind im Hinblick auf die Akzeptanz dieses neuen Distributionsweges keine höheren Preise als für die vergleichbare Musikmenge auf herkömmlichen Tonträgern zu erwarten. Ein volkswirtschaftlicher Ressourcengewinn bestünde dann zumindestens in den ersparten Wegkosten der Konsumenten.

Die Distributionspolitik der Tonträgerhersteller bezieht sich auf die technische Umsetzung der Online-Distribution und die Präsentation der Musikprodukte auf der Benutzeroberfläche der Konsumenten sowie auf das Kontrahierungsverhalten mit den Online-Diensten. Bei einer gemeinsamen Nutzeroberfläche für die Konsumenten bestünde die Schwierigkeit für die Herstellerfirmen darin, sich gegenüber den Produkten der direkten Konkurrenz etablieren zu können. Ermöglichte die technische Ausgestaltung der Präsentation hingegen für jede Herstellerfirma ihre eigene Präsentationsplattform, so wäre die Software (Browser) dafür mitentscheidend, wie gut die Markttransparenz für die Konsumenten ist und wessen Angebot leichter zu wählen ist. ${ }^{n}$ Dieses läge aber im Gestaltungsbereich der Online-Dienste. Zu den technischen Voraussetzungen für die Marktfähigkeit der netzgebundenen Musikverwertung gehören die Zugangskontroll- und Kopiersperrtechniken. Durch die Zugangskontrolle soll eine Ausschließbarkeit vom Konsum realisiert ${ }^{78}$ und durch die Kopiersperrtechniken sollen die erneute Verwertung gesteuert sowie weitere Verwertungen seitens der Konsumenten verhindert werden. Die $\mathrm{Zu}$ gangskontrolltechnik ist die Aufgabe der Online-Dienste, da diese ihren Mehrwertdienst nicht kostenlos, sondern als zu abonnierendes Programm vertreiben wollen. Die Aufgabe der Kopierspertechnik hingegen hat für die Tonträgerhersteller als Content-Provider strategische Bedeutung. Tonträgerhersteller wollen zwar einerseits die Endverbraucher in den privaten Haushalten elektronisch beliefern, andererseits wollen sie zur Refinanzierung ihrer Künstlerund Bandübernahmeverträge weitere Verwertungen, an deren Erlösen sie nicht teilhaben, verhindern. Insbesondere die Weiterverbreitung der heruntergeladenen Musiktitel mit Hilfe selbstgefertigter Kopien könnte zu Nachfrageausfällen bei Tonträgerkäufen führen. Deswegen ist der Online-Musikvertrieb von der Kopiersperrsoftware des Service-Providers abhängig. Diese Kopiersperrsoftware muß sich i. S. einer Kompatibilität an dem von der internationalen Tonträgerwirtschaft etablierte Serial Copy Management System (SCMS) orientieren, da dieses System auch für die bestehenden Abspielgeräte Standardcharakter hat (vgl. Abschnitt 2.2.1).

Mit einer zunehmenden Etablierung der Online-Musikbelieferung an die Haushalte könnten zwischen den Tonträgerherstellern Reichweitenasymmetrien entstehen, die angesichts der groBen Reaktionsverbundenheit im engen Oligopol des Tonträgermarktes schnelle Imitations-

76 Diese Informationen erhielt der Verfasser in einem Telefoninterview vom 13.3.98 mit Herm Böhm, zuständig bei der Telekom für das Projekt Music on Demand.

77 Beispielsweise hatte auf dem Markt für Flugbuchungen die Gestaltung der Benutzeroberfläche von Computerreservierungssystemen die Wirkung, da $B$ in den überwiegenden Fällen der erstgenannte Veranstalter und zu $90 \%$ die Flüge von der ersten Bildschirmseite gebucht wurden. Vgl. Weinhold, Marisa, Computerreservierungssysteme im Luftverkehr, Baden-Baden 1995, S. 94 ff.

${ }_{78}$ Beim Transport von Musik über Netze ergibt sich ebenso - in Abhängigkeit von der Kapazität der Netze und des Servers - eine Nichtrivalităt im Konsum. Diese konstituiert aber keinen öffentlichen Gutscharakter der Musik, sondern lediglich economies of scale bei ihrer Verbreitung durch den Online-Dienst. 
handlungen der Konkurrenten bei der Distributionsstrategie zur Folge hätten. Es steht zu erwarten, daß sich bei erfolgreicher Etablierung netzgebundener Musikverwertung alle Tonträgerhersteller dieses Distributionskanals bedienen. Da die Musiker, die nicht selbst als ContentProvider auftreten können oder wollen, vertraglich exklusiv an die musikalischen ContentProvider gebunden sind, können letztere eine zeitliche Verwertungskette aufbauen. Entspechend dem Grad der Nutzung, der durch die unterschiedliche Penetration von Endgeräten gegeben ist, können zuerst Veröffentlichungen im Netz und danach auf Tonträgern getätigt werden. Die Zeitabstände zwischen den Verwertungsstufen würden sich dann an den erwarteten Produktlebenszyklen orientieren.

\subsubsection{Netzinfrastruktur- und Online-Dienste Anbieter als Service-Provider}

Die Distributionsfunktionen übernehmen analog zu physischen Tonträgern bei der netzgebundenen Musikverwertung die Online-Dienste, die im folgenden als Service-Provider bezeichnet werden. Zentraler Aspekt für die Nachfrage der Service-Provider nach Musikinhalten der Tonträgerhersteller (Contents) ist deren erwartete Attraktivität. Jeder Service-Provider wird versuchen, seinen potentiellen Kunden ein breites Musikrepertoire anzubieten. Das ist das Ziel des Kontrahierungsverhaltens der Service- mit den Content-Providern. Maßgeblicher Faktor für die Attraktivität des musikalischen Programmangebots ist neben dem Bekanntheits- und Beliebtheitsgrad des Musikers auch die relative Neuheit der Musik.

Die konsumtive Nichtrivalität der musikalischen Inhalte erlaubt es den Service-Providern bei einer Ausschließbarkeit durch Zugangskontrollsysteme und Kopiersperrtechnik, ihren Abonnenten dieselben Inhalte gleichzeitig oder nacheinander zu verkaufen. Auf der Ebene der Programmdistribution liegen dadurch für den Service-Provider bedeutende Skaleneffekte vor, die nur durch die Kapazität der Übertragungs- und der Zugriffsmöglichkeit auf die Musikdatenbank begrenzt werden. Die Realisierung der Skaleneffekte durch eine Steigenung der Abonnentenzahlen ermöglicht zugleich die Refinanzierung der Programminhalte. Daher ergibt sich für den Serviceprovider eine ökonomische Verbundinterdependenz zwischen seinen Vertragsbeziehungen $\mathrm{zu}$ den Content-Providern und den Abonnenten. ${ }^{79}$ Je größer der Abonnentenstamm, desto stärker ist die Verhandlungsposition gegenüber den musikalischen InhalteAnbietern und je attraktiver die Programminhalte, desto wahrscheinlicher ist der Anstieg der Abonnentenzahl.

Für die Attraktivität des Musikprogramms sind neben dem Inhalt auch die konkurrierenden Zugangsmöglichkeiten der Konsumenten zur Musik und deren zeitliche Abfolge bedeutend. Die Musikindustrie als Programmanbieter (Content-Provider) wird wegen der noch vergleichsweise geringen Saturation der Online-Dienste ihre Musik nicht ausschließlich über das Netz anbieten. Von daher und wegen des Ziels, das Produkt möglichst schnell in die Charts zu bringen, wird es keinen zeitlich begrenzten Verwertungsvorsprung der Service-Provider vor

79 Zur Verbundinterdependenz zwischen Programmbeschaffung und Rezipientenmarkt für TV-Märkte vgl. Wirtz, Bernd W., Neue Medien, Unternehmensstrategien und Wettbewerb im Medienmarkt, Frankfurt u. a. 1994, S. 19. 
anderen Distributionskanälen von Musik geben. ${ }^{80}$ Damit verschafft sich der Service-Provider auch keinen first mover-advantage bei der intermediären Konkurrenz der Musikverwertung.

Um seine Stellung im Wettbewerb zu anderen Online-Diensten zu stärken, wird ein ServiceProvider eine Online-Alleinvertriebsstellung für musikalische Inhalte anstreben. Wenn Musik Online nur bei einem Service-Provider erhältlich ist, steigert das seine Attraktivität bei den potentiellen Konsumenten. Ist die Präferenz für Musik online so groß, daß sie nachfragebestimmend wird, kann sich Musik zu einem Schlüssel-Mehrwertdienst für Online-Anbieter entwikkeln. Eine solche Stellung ist allerdings nur mit Hilfe der bisherigen Major-Tonträgerhersteller zu erreichen. Dies bedeutet, daß von Online-Diensten, deren Zielgruppe private Haushalte sind, erwartet wird, daß Musik zu ihrem Programmangebot gehört. Hat ein Service-Provider eine Position als Schlüssel-Mehrwertdienste-Anbieter erlangt und die Programm-Input-Ressource Musik monopolisiert, kann er damit Wettbewerbsvorteile gegenüber seinen direkten Konkurrenten realisieren. Eine solche Alleinvertriebsstellung wird sich ggfs. nur auf den intramediären Wettbewerb gegenüber anderen Online-Diensten beziehen, nicht jedoch auf das verfügbare Musikangebot in den Medien insgesamt. Denn nur die mediale Präsenz von Musik schafft für sie selbst Nachfrage. Daher ist eine intermediäre Konkurrenz für den Diffusionserfolg von Musik unabdingbar

Im Zeitablauf ist zu erwarten, daß die physische Distribution nicht ersetzt, sondern ergänzt werden wird. Der Exklusivität des Online-Vertriebsweges stehen die anfänglichen Investitionen der Konsumenten entgegen, um Musik online kaufen zu können. Die Strategie des ersten in diesem Markt tätigen Service-Providers wird daher eine unentgeltliche Bereitstellung der Software sein, die die Zugriffsmöglichkeiten auf den Musikserver bieten ${ }^{81}$ Wegen der Verbundinterdependenz zwischen dem Programmbeschaffungsmarkt der Content-Provider und dem Erfolg auf dem Rezipientenmarkt der Abonnenten des Online-Dienstes werden die ContentProvider an den Erlöszuwächsen des Service-Providers teilhaben wollen. ${ }^{82}$ Der ContentProvider will eine möglichst breite Publikumsbasis und der Service-Provider eine möglichst hohe Abonnentenzahl erreichen. Insoweit sind die Verwertungsinteressen von Content- und Service-Provider identisch.

Electronic Delivery durch den Online-Dienst wird in der Verwertungskette der Musik zum Handel in Konkurrenz treten. Die beim herkömmlichen Vertrieb diskutierten Probleme der Sortimentsbreite und -dynamik stellen sich beim Online-Vertrieb nicht. Im Rahmen der verfügbaren Kapazität kann jegliches Repertoire, für das die elektronischen Verwertungsrechte vorliegen, in die Musikdatenbank eingespeist werden. Da die Konsumenten nur nach ihrem jeweiligen Bedarf abrufen, fallen keine Retouren an, unverkäufliche Musiktitel verursachen nur un-

${ }^{80}$ Sowohl der physische als auch der nicht physische Vertrieb verwenden eine demand pull-Strategie, die die Aufmerksamkeit nicht nur auf das Produkt, sondern ebenso auf den Vertriebsweg zieht.

81 Diese Strategie soll für eine schnelle Diffusion der Hardware bei den Konsumenten sorgen. Vergleichbar hierzu ist z. B. die Strategie der Quersubventionienung für Mobilfunkgeräte aus laufenden Vertragserlösen.

82 In der Praxis liegen unterschiedliche Geschăftspraktiken vor. Vgl. Alpar, op. cit., S. 255-283. Im Fall der musikalischen Content-Provider ist bekannt, da $\mathrm{B}$ sie eine Provision pro neu akquiriertem Abonnenten von T-Online verlangt haben. Vgl. Clausen, supra, S. 32 
erhebliche Lagerkosten auf dem Musikserver. Die Kundenbindung an die Service-Provider ist durch das Abonnement höher als diejenige der Tonträgerkäufer an ihr Handelsgeschäft. Zusätzlich liefert die Abonnentenverwaltung der Service-Provider die Daten, um Käuferprofile, Kaufverhalten und Marktentwicklungspotentiale für den Online-Vertrieb zu erforschen.

Für die Etablierung des Online-Dienstes als Vertriebskanal ist die Verbreitung der Netzinfrastruktur Voraussetzung. Dazu gehört die Ausstattung der privaten Haushalte mit ISDNTelefonanschlüssen und multimediafähigen PCs mit Modem. Die Etablierung des Vertriebskanals ist wiederum die Voraussetzung für die Diffusion der Musik auf diesem Kanal. Daher ist als Nachfrager nach den Rechten für Online-Musikvertrieb zunächst nur der mit dem Netzbetreiber (Telekom) verbundene Online-Dienst T-Online aufgetreten, der sowohl über andere Produkte, die an private Haushalte elektronisch distribuiert werden, als auch über den derzeit größten Abonnentenstamm in Deutschland verfügt.

Die Strategien zur Etablierung der elektronischen Belieferung privater Haushalte mit Musik auf Abruf im Rahmen des Mehrwertdiensteanbieters T-Online können bestehen in niedrigen Preisen zur Einführung (penetration pricing), der unentgeltlichen Bereitstellung der Software, der Ankündigung der neuen Dienstleistung elektronischer Musiklieferung auf Abruf (product preannouncements). Ferner sind mögliche Strategien eine Faktormonopolisierung durch den Abschluß langfristiger Verträge mit der Musikindustrie, um den Zugang potentieller und aktueller Konkurrenz zu diesen Inputfaktoren versperren zu können, und das Commitment gegenüber den eigenen Abonnenten, ein großes Softwareangebot bereitzustellen, verbunden mit irreversiblen Investitionen in das Software-Repertoire, die dieses Commitment glaubwürdig werden lassen. In der Startphase des Online-Musikvertriebs wird ein zusätzliches Commitment gegenüber den Content-Providern diese erst dazu bewegen, ihre Inhalte zu verbreiten. Diese Commitments hat die Telekom als Investitionen getätigt, indem sie den Aufbau eines Servers, der als digitale Musikdatenbank fungiert, als Vorleistung vor den Abschlüssen mit den einzelnen Tonträgerherstellern (Musikprogrammanbietern) betrieben hat. Ihre Strategie kann zwar in der expansiven Marktphase des Online-Mehrwertdienstemarktes nicht zur Marktbeherrschung durch T-Online führen, allerdings wird dadurch die Position der Marktführerschaft ausgebaut.

\subsubsection{Nachfrageakzeptanz, Konsumentenstruktur und Medienkonkurrenz}

Die Analyse der durch die elektronische Musikbelieferung induzierten Marktprozesse beinhaltet auch das Akzeptanzverhalten der Nachfrage. Es läßt sich unterteilen in die Kriterien Preis, Qualität, Service, Verfügbarkeit und Markttransparenz. Bestandteile des Preises und zugleich variable Kosten der Online-Musiknachfrage werden die Übertragungskosten und der Preis des Musiktitels selbst sein. Hinzu treten - unabhängig von der Menge der tatsächlich nachgefragten Musiktitel - die Abonnementkosten sowie die Kosten der Installierung des Systems. Ansatzpunkt für die Kalkulation der variablen Kosten (Übertragungskosten und Kosten für die Musiktitel) sind die vergleichbaren Preise für aktuelles Musikrepertoire auf $\mathrm{CD}^{83}$ Wegen der

83 Bei einer Übertragung auf der Basis der MPEG 1-Layer 3-Technik können bis zu $128 \mathrm{~KB} / \mathrm{S}$ übertragen werden. Bei einer Übertragung von 60 Minuten Musik werden - abhängig von der Tageszeit und den Tele- 
Übertragungskosten ist Musik online (noch) nicht billiger als im Tonträgerhandel ${ }^{84}$ Die Produktqualität kann aus Verbrauchersicht gemessen werden mit der Soundqualität, die bei der Übertragungstechnik möglich wird, mit der Attraktivität der verfügbaren Musiktitel, der Neuartigkeit des Zugangs zu der Musik und der ständigen Verfügbarkeit aufgrund des Netzanschlusses, sowie den Möglichkeiten der weiteren Speicherung. Die bisherigen ServiceKategorien der Verfügbarkeit und Beratung werden durch die netzgebundene Musikverwertung obsolet. Die Auslastung der Netzwerkkapazitäten als Service-limitierender Faktor ist nur bedingt durch die Anbieter steuerbar und zum größeren Teil vom Nachfrageverhalten abhängig. Eine neue Qualitätsdimension ist dann erreicht, wenn das gesamte Repertoire jederzeit abrufbar sein wird.

Die Ausgestaltung der Software ist entscheidend für den Grad an Markttransparenz. Wesentlich wird dabei die Ausgestaltung der Benutzeroberfläche sein, mit der sich der Konsument selbst den Überblick über die angebotenen Titel schaffen muß. Es ist aber davon auszugehen, $\mathrm{da} ß$ sie größer sein wird als diejenige des herkömmlichen Tonträgerhandels, da der Verbraucher keine Wegkosten o. ä. hat, um sich über das verfügbare Angebot und die jeweiligen Preise zu informieren. Ebenso werden die Verbundinterdependenz und die Ausstrahlungseffekte anderer Sortimentsteile wie beim herkömmlichen Handel im Online-Dienst nicht auf die Musiknachfrage wirken. Es ist bei den Mehrwertdiensten nicht vorstellbar, daß Musik die Funktion des Ausgleichsnehmers für andere Waren haben wird. Daher könnte mit der gesteigerten Markttransparenz möglicherweise ein rationaleres Kaufverhalten der Konsumenten einhergehen.

Auch wenn die zukünftige Konsumentenstruktur nicht bekannt sein kann, können wir Schlüsse anhand der Ausstattung der privaten Haushalte mit vernetzten PCs (ca. 3,5 Mio.) und der Altersstruktur der Abonnenten von Online-Diensten ziehen. Es ergibt sich eine weitgehende Kongruenz derjenigen Altersgruppen, die überproportional Tonträger kaufen, und derjenigen, die Online-Dienste abonnieren. ${ }^{85}$ Wie bereits in den Abschnitten 4.2.4.2 und 4.3.4.1 gezeigt, war dies die Altersgruppe der 10-35 jährigen. Das bedeutet zwar einerseits, daß wegen der Identität der Nutzergruppen ein Wechsel der Konsumenten von der Offline- zur OnlineMusiknutzung möglich ist, aber andererseits werden keine weiteren potentiellen Konsumentengruppen angesprochen und die Käuferreichweite nimmt durch die Verfügbarkeit von Musik im Netz nicht per se zu. ${ }^{86}$

fonübertragungstarifen - Kosten zwischen 4 und $10 \mathrm{DM}$ anfallen. Vgl. Gramatke, Wolf D., Musik auf dem Daten Highway, in: Handbuch der Musikwirtschaft, hrsg. von Moser, Rolf, und Andreas Scheuermann, 4. Aufl., Starnberg 1997, S. 56-66, hier S. 60; Telefoninterview mit Herrn Böhm, Deutsche Telekom AG, und eigene Berechnungen. Die Kosten für eine Stunde Internet-Nutzung ohne Music on Demand betragen bei TOnline ab dem 1.4.98 pro Stunde $3 \mathrm{DM}$. Vgl. o. V., Die Telekom will ihre Preise weiter senken, in: FAZ, Nr. 65 vom 18.3.98, S. 21.

84 Hierbei sind die Kosten leerer digitaler Kassetten oder leerer bespielbarer CDs noch nicht eingerechnet, mit denen die Konsumenten die Musik evtl. archivieren möchten.

85 Vgl. Gramatke, Wolf D., op. cit., S. 56.

$86 \mathrm{Vgl}$. hierzu auch die Aussagen der sog. Nichtkäufer-Studie. 
Die Heterogenität der Konsumentenpräferenzen bezieht sich nicht auf den Distributionskanal, sondern auf das Musikrepertoire. Daher verändern sich durch die Einführung des OnlineMusikvertriebs die bereits in Abschnitt 4.3.4.2 hergeleiteten Zusammenhänge zwischen Preisund Nutzungsverhalten nicht. Anders dagegen sind die Kommunikationsmöglichkeiten netzgebundener Verwertung. Sie stellen eine zusätzliche Plattform zur Diffusion neuer Musiktitel dar. Das persönliche Gespräch zur Übertragung der Kaufmotivation fallt weg. Ihm gegenüber tritt mit den Online-Mehrwertdiensten eine Nachfrageverbundenheit mit anderen medialen Inhalten. Der Grad der Austauschbarkeit der medialen Inhalte und ihrer Nutzung wird zu einem Bestimmungsfaktor der Nachfrage. Er wird c. p. zunehmen. Musik ist zwar das einzige reine Audio-Medium, konkurriert aber sowohl intramediär mit anderen Diensten von Online-ServiceProvidern als auch intermediär mit Radio und Musikfernsehen in der Nutzung um das Freizeitund Geldbudget der Konsumenten. Diese betrachten verschiedene Beschaffungskanäle von Musik unter dem Blickwinkel ihrer Kosten und der zeitlichen Verfügbarkeit. Gerade Konsumenten mit hoher Präferenz für die Musik eines bestimmten Musikers werden den Distributionskanal wählen, bei dem sie über neueste Musiktitel zuerst verfügen können. Eine zeitliche Erstverwertung über das Netz kann daher dessen installierte Basis und damit seine Reichweite als Musikvertriebskanal erhöhen. Dem steht in der Medienkonkurrenz das altersspezifische Nachfrageverhalten gegenüber. Dieses bedeutet, daß Online-Dienste als neue Medien tendenziell nicht von älteren Konsumenten angenommen werden und daher auch kein Musikvertrieb an sie möglich ist. Im Ergebnis werden sich die nachfrageseitigen Konzentrationstendenzen, die in Abschnitt 4.2.4 herausgearbeitet wurden, auch durch die Online-Musikverwertung nicht verringern. Das alterspezifische Nutzungsverhalten und das im jugendlichen Alter niedrige Budget sorgen dafür, daß zu bezweifeln ist, da $\$$ sich durch den veränderten Zugang zur Musik bei unverändertem Preis eine Erhöhung der Kaufintensität einstellt.

\subsubsection{Auswirkungen des netzgebundenen Vertriebs auf die Verwertungskette von Musik}

Strategien, Unternehmensverhalten und Marktprozesse des netzgebundenen Musikvertriebs lassen sich durch die Veränderungen in der Verwertungskette zusammenfassen. Bei der bisherigen Verwertung von Musik mit Hilfe von Tonträgern bestand die folgende Verwertungskette. 


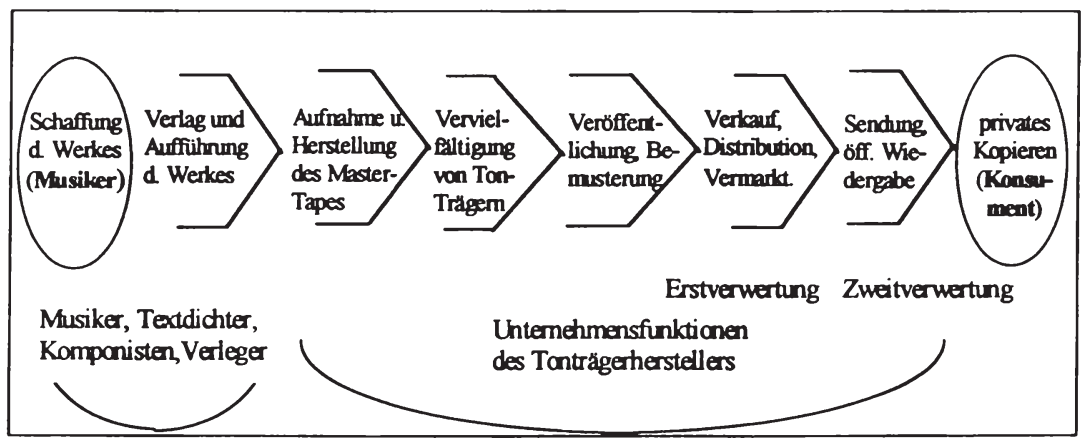

Wird nun die Online-Musikverwertung betrachtet, ergeben sich durch die Handlungsoptionen der am Verwertungsprozeß Beteiligten Veränderungen der Verwertungskette.

\section{Abbildung 29: Verwertungskette der Online-Musikverwertung}

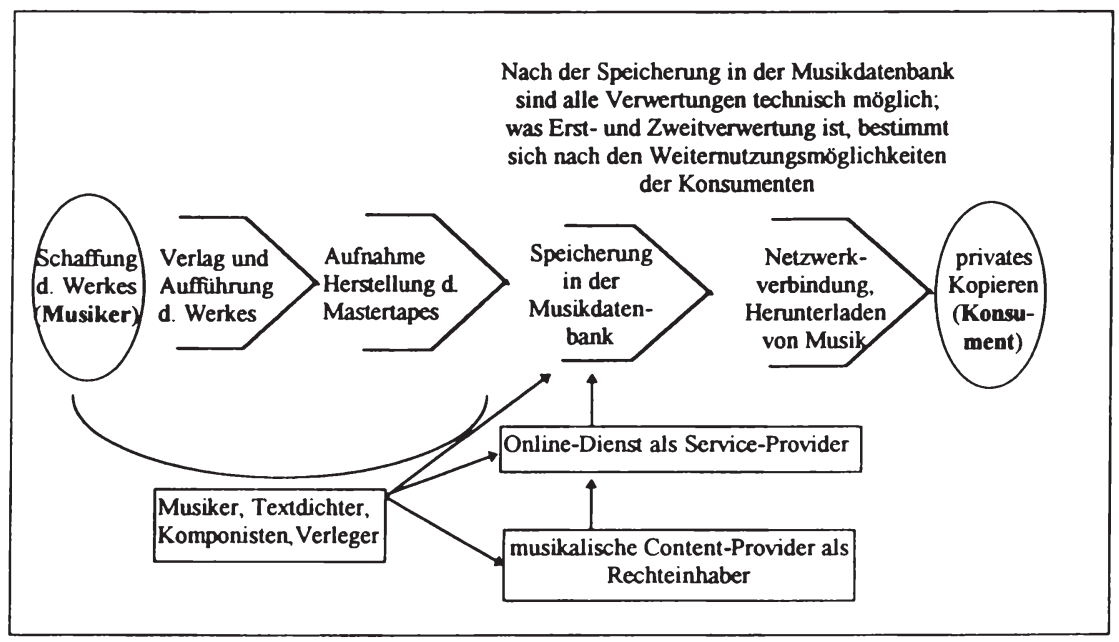

Festzustellen ist, daß die Verwertungskette durch die Online-Musikverwertung erheblich kürzer geworden ist. Die Zugriffsmöglichkeiten der Konsumenten haben sich ebenso erhöht wie die eigenen Vermarktungsmöglichkeiten der Musiker. Die Rolle der Online-Dienste kann auf die Übernahme der Handelsfunktion beschränkt bleiben, kann sich aber auch auf eine Übernahme der Vermarktung von Musik in Konkurrenz zu den Content-Providern ausweiten. 


\section{3 Ökonomische Implikationen, Wettbewerbspotentiale und Rechtsrahmen bei der On- line-Musikverwertung}

Wenn es sich aus der Sicht der früheren Tonträgerhersteller (im folgenden werden sie musikalische Content-Provider genannt) bei Electronic Delivery auch nur um einen weiteren Vertriebskanal handelt, impliziert die Online-Musikverwertung doch bestimmte ökonomische Besonderheiten, die im folgenden behandelt werden sollen (5.3.1). Ihre Auswirkungen auf die Wettbewerbspotentiale werden anschließend thematisiert (5.3.2), bevor die urheberrechtlichen Bestimmungen und Regulierungsansätze für eine kompetitive Marktentwicklung netzgebundener Musikverwertung (5.3.3) diskutiert werden.

\subsubsection{Netzwerkeffekte, Standardisierung und Lock-In-Effekte}

In der ökonomischen Literatur werden wechselseitige Abhängigkeiten zwischen Nutzern mit den Stichwort der Netzwerkeffekte gekennzeichnet, bei denen mit der zunehmenden Verbreitung der Nutzung eines Gutes ein unmittelbarer Vorteil für hinzukommende Nutzer erwächst. ${ }^{\mathbf{8 7}}$ Netzwerkeffekten liegen positive Externalitäten zugrunde, die durch jeden weiteren Kauf oder Nutzung entstehen. Es gilt:

$$
U_{i}(x, T)<U_{i}[(x+1), T]
$$

Dabei hängt der Nutzen eines einzelnen Individuums $U_{i}$ von der Technik $T$ und der Teilnehmerzahl $x$ ab und steigt mit zunehmender Teilnehmerzahl. Jeder weitere Teilnehmer des Telefonnetzes erhöht beispielsweise den Nutzen für die bereits angeschlossenen. ${ }^{88}$ Bei der individuellen Konsumentscheidung fließen nur die privaten, nicht aber die sozialen Nutzen in die individuelle Zahlungsbereitschaft ein. Daher kommt es gesamtwirtschaftlich i. d. R. zu einer Unterversorgung mit Netzgütern. Neben den direkten Netzwerkeffekten, bei denen der Vorteil den am Netz angeschlossenen Nutzern unmittelbar aus der Zunahme der Teilnehmerzahl erwächst, existieren auch indirekte Netzwerkeffekte, bei denen die wechselseitige Nutzenabhängigkeit ohne eine unmittelbare Verbindung zwischen den Konsumenten entsteht. ${ }^{89}$

Indirekte Netzwerkeffekte können auf direkten basieren. Ihre Ursachen liegen u. a. in komplementären Produkten und technologischen Unsicherheiten. ${ }^{90}$ Die Online-Verwertung von Musik ist ein Beispiel für indirekte Netzeffekte. Sie wird technisch auf dem ISDN-Telefonnetz basieren, dessen weitere Verbreitung der Netzbetreiber (Telekom) anstrebt. Als Teil der vom Onli-

87 Grundlegend ist Katz, Michael L., und Carl Shapiro, Network Externalities, Competition, and Compatibility, in: AER, Vol. 75 (1985), S. 424-440 [Katz/Shapiro 1985]. Vgl. auch Chou, Chien-fu, und Oz Shy, Network Effects without Network Externalities, in: International Journal of Industrial Organization, Vol. 8 (1990), S. 259-270.

88 Hier wird einmal davon abgesehen, daß bei Erreichen von Kapazitätsgrenzen eines Netzes auch negative Externalităten in Form von Wartezeiten auftreten. Dennoch sind Übernutzungen bei freiem Zugang zum Netz individuell bkonomisch rational. Eine Übernutzung z. B. des Internets ist erklärbar mit der Theorie der Allmendegüter.

$89 \mathrm{Vgl}$. Katz/Shapiro 1985, supra, S. 424-440.

90 Vgl. Thum, Marcel, op. cit., S. 8-12. 
ne-Dienst (T-Online) distribuierten Produkte ist die über das Netz abrufbare Musik komplementär zum Netz. Je mehr Abonnenten der Online-Dienst hat, desto eher können Investitionen in die Programmbeschaffung refinanziert werden. Das Musikangebot wird beispielsweise für die Konsumenten um so attraktiver sein, je größer das verfügbare Musikrepertoire ist. Es ergibt sich eine Verbundinterdependenz zwischen der Programmattraktivität und der Abonnentenzahl. Den signifikant hohen Fixkosten der Installierung des Systems seitens des ServiceProviders (Investitionen in die Musikdatenbank) stehen geringe Grenzkosten sowohl der Aufnahme zusätzlicher Musiktitel (von den Content-Providern) als auch zusätzlicher Konsumenten (Abonnenten) gegenüber. ${ }^{91}$ Gleichzeitig wächst mit der Zahl der potentiellen Nachfrager das verfügbare Angebot an komplementärer Musiksoftware, da es immer attraktiver wird, Musik im Netz anzubieten. ${ }^{92}$ Daher ist es offensichtlich, daß mit Hilfe der Attraktivität der komplementären musikalischen Inhalte die installierte Basis für das zugrundeliegende ISDN-Netzwerk vergrößert ${ }^{93}$ und das Hardware-Software-Problem ${ }^{94}$ des Online-Dienstes gelöst werden sollte.

Ein weiterer indirekter Netzwerkeffekt beim elektronischen Vertrieb von Musik liegt in der Unsicherheit der Konsumenten hinsichtlich des technischen Standards begründet. Das Endgerät zum Empfang und zum Hören der Musik kann als Komponente eines (Multimedia-) Systems verstanden werden, das bei privatem Gebrauch den Charakter eines langfristigen Konsumgutes hat. $\mathrm{Zu}$ diesem System wird auch in Zukunft Bedarf an Ersatzteilen oder weiteren komplementären Gütern zur Systemvervollständigung bestehen. Der indirekte Netzwerkeffekt bei der technischen Adoption dieses Systems besteht darin, daß jeder weitere Teilnehmer den erwarteten Wert der Technologie für alle anderen Nutzer erhöht und die Wahrscheinlichkeit der Kompatibilität zukünftiger technischer Entwicklungen steigert. ${ }^{95}$ Für den Konsumenten ist es wichtig, daß die von ihm selbst benutzte Technologie die weitere technische Entwicklung überlebt, da ansonsten seine Investitionen nutzlos und irreversibel geworden sind ${ }^{96}$ Die Unsicherheit der zukünftigen Abonnenten versucht der Netzbetreiber Telekom bei der elektronischen Musiklieferung dadurch zu verringern, daß er die Software kostenlos abgibt. ${ }^{97}$ Dadurch verspricht sich die Telekom eine Verbreiterung der installierten Basis sowohl des ISDN-

91 Die erfolgreiche Verbreitung des Online-Musikvertriebs wird nicht an den Endgeräten scheitern, da multimediafăhige PCs mit Soundcard als Common Interface für viele Produkte der Freizeitgüterindustrie nötig und daher zum Standard geworden sind. Die Probleme dieses Distributionsweges liegen in der Zugangskontrolle und den Kopiersperrtechniken.

92 Vgl. Katz/Shapiro 1992, supra, S. 55-84

$93 \mathrm{Vgl}$. Church, Jeffrey, und Neil Gandal, Integration, Complementary Products, and Variety, in: Journal of Economics \& Management Strategy, Vol. 1 (1992), S. 651-675.

94 Das Hardware-Software-Problem liegt darin, daB weder Abspielgerăte ohne entsprechende Softwareinhalte in den Markt eingeführt werden können noch umgekehrt. Meistens wird die Hardware durch die Software subventioniert, weil die Hardware eine längere (tochnische) Nutzungsdauer hat. Im Fall der Musiksoftware handelt es sich um eine begrenzte Lebensdauer durch psychische Obsoleszenz. (Zerstorning des Zusatznutzens).

95 Vgl. Church, Jeffrey, und Neil Gandal, Complementary Network Externalities, and Technological Adoption, in: International Journal of Industrial Organization, Vol. 11 (1993), S. 239-260.

$96 \mathrm{Vgl}$. Beggs, Alan, A Note on Switching Costs and Technology Choice, in: Journal of Industrial Economics, Vol. 37 (1989), S. 437-440.

97 Finanziert aus dem laufenden Netzbetrieb bzw. den Abonnentenerlösen. Quelle für diese Information ist ein Interview mit einem Insider. 
Netzanschlusses ${ }^{98}$ als auch des T-Online-Mehrwertdienstes und damit einen Wettbewerbsvorsprung. 99

Die angeführten indirekten Netzwerkeffekte sind auf der Nachfragerseite ${ }^{100}$ elektronischer Musikverwertung offensichtlich signifikant, da anzunehmen ist, daß die Zahl der Abonnenten positiv mit der Attraktivität des musikalischen Programms korreliert. Ebenso sind die indirekten Netzwerkeffekte für die Anbieter des Online-Dienstes relevant. In beiden Fällen besteht die Verbundinterdependenz zwischen Service- und Content-Provider-Markt. Wegen des Hardware-Software-Problems ist es furr die Service-Provider wichtig, schnell die kritische Masse von Abonnenten zu akquirieren, um die Skaleneffekte beim Programm realisieren zu können. ${ }^{101}$ Für die Hersteller des musikalischen Programms, die bisherigen Tonträgerhersteller, liegen keine Netzwerkeffekte vor, da es sich für sie bei der elektronischen Lieferung von Musik lediglich um einen neuen Vertriebskanal handelt. Die indirekten Netzeffekte wirken aber auf die Funktionsfähigkeit des Vertriebskanals zurück. Je stärker sich der Vertriebskanal etablieren wird und um so geringer der Anteil der körperlich distribuierten Tonträger in der Folge wird, desto eher werden der Netzbetreiber und der Online-Dienste-Anbieter in eine Gate-KeeperFunktion hineinwachsen, da der Zugang der Musikprogrammanbieter zu den Konsumenten von der Aufnahme der Programminhalte in den Online-Dienst abhängen wird.

Damit keine Monopolstellung eines Mehrwertdienste-Anbieters beim Zugang zu den OnlineKonsumenten erwächst, ist Wettbewerb auf diesem Markt nötig. Dieser ist grundsätzlich um so intensiver, je eher es durch eine Standardisierung der technischen Möglichkeiten zu einer Vergrößerung und Erschließung des Marktpotentials kommt. ${ }^{102}$ Die Standardisierung kann sich als endogener Marktprozeß der beteiligten Unternehmen vollziehen oder exogen durch eine Setzung erreicht werden. ${ }^{103}$ Eine Setzung von Standards erfordert kollektive Eingriffe in den Standardisierungsprozeß, die entweder von staatlichen Behörden, Standardisierungsorganisationen oder eigens eingesetzten Expertengruppen oder Komitees vorbereitet und durchgefüht werden. Dabei wächst die Notwendigkeit der Standardisierung mit der Stärke des Netzeffekts. ${ }^{104}$ Faktisch werden alle Standards in Online-Bereich durch die bestehende InternetTechnologie vorgegeben.

98 Die Verbreitung des ISDN-Anschlusses und eine evtl. Netzüberlastung sind technische Engpaßfaktoren.

99 Als installierte Basis bezeichnet man die GröBe eines Netzwerkes. Hier bezieht sich die installierte Basis sowohl auf die Zahl der Nutzer des ISDN-Netzes als auch die Abonnentenzahl des auf diesem Netz basierenden Online Dienstes T-Online.

${ }^{100}$ Ein weiterer, hier nicht weiter verfolgter indirekter Netzwerkeffekt entsteht durch Musikrepertoire, daB vom Nachfrager selbst erstellt wurde (z. B. durch Kopieren). Die Auswahl des zu kopierenden Repertoires ist um so großer, je mehr Konsumenten uber Repertoire eines kompatiblen Musiknutzungssystem verfugen. Ein Wechsel des Kompatibilitătsstandards zerstört die Kopiermoglichkeit bzw. Abspielmöglichkeit von Kopien.

${ }^{101}$ Der Begriff der kritischen Masse besteht - übertragen auf einen Online-Dienst - darin, daB erst mit Erreichen eines gewissen Abonnentenstammes die Möglichkeit besteht, aus den Abonnementseinnahmen eine Steigerung der Programmattraktivităt zu finanzieren, die wiederum ursăchlich für eine weitere Steigenung der Abonnentenzahlen ist.

102 Vgl. Church, Jeffrey, und Neil Gandal, Network Effects, Software Provision, and Standardization, in: Journal of Industrial Economics, Vol. 40 (1992), S. 85-103.

${ }^{103} \mathrm{Vgl}$. Besen, Stanley M., und Joseph Farrell, Choosing How to Compete: Strategies and Tactics in Standardization, in: Journal of Economic Perspectives, Vol. 8 (1994), S. 117-131.

$104 \mathrm{Vgl}$. Thum, Marcel, op. cit., S. 14 f. 
Im Fall der Online-Musikverwertung wird die von einer Expertengruppe der International Standard Organization (ISO) für die Datenkompression und -übertragung entwickelte MPEG 1-Layer 3-Technik als Hardware-Standard gesetzt sowie eine auf Winplayer basierende Software. ${ }^{105}$ Der Zweck einer Standardisierung ist die Schaffung von Kompatibilität. ${ }^{106}$ Die Wettbewerbswirkungen der Kompatibilitätsstandards sind ambivalent. ${ }^{107}$ Besonders bedeutsam sind die Kompatibilitätsstandards in unserem Fall wegen des zu erwartenden breiten Portfolios der Nutzung, welches sich ganz allgemein auf sämtliche multimedialen Unterhaltungsinhalte beziehen wird, die Online übertragbar sind. Da das bestehende digitale Netzwerk ein umfassendes Bündel von Dienstleistungen an Nutzer abgeben kann, ist die Online-Musikverwertung hier nur als eine kommerzielle Pionieranwendung der on Demand (auf Abruf)-Technik zu sehen. Deshalb muß die Standardisierung für die weitere Entwicklung von Nutzungsanwendungen Aufwärtskompatibilität garantieren. ${ }^{108}$ Dabei ist sowohl die Beteiligung der Internationalen Standardorganisation als auch eine Kooperation der involvierten Unternehmen rechtlich zulässig und ökonomisch sinnvoll. ${ }^{109}$ Bei den Online-Diensten besteht z. B. ein kompatibler Rückkanal im ISDN-Telefonnetz. Die Weiterentwicklung der Datenkompressions- und Datenreduktionstechnik ist von derjenigen der Codierungs- und Kopiersperrtechnik, die die wesentliche Voraussetzung für die Online-Musikverwertung darstellt, unabhängig. Ebenfalls bestehen keine direkten Abhängigkeiten zur Weiterentwicklung der Netzwerktechnik. Daraus folgt, daß für die einzelnen Technikkomponenten getrennte Standardisierungsprozesse ablaufen können. Deswegen spricht im Ergebnis vieles dafür, daß eine exklusive Bindung unkörperlicher Musikverwertung an ein Netz und einen Online-Dienst nicht per se langfristig bestehen bleiben muß.

Als lock-in-Effekt ${ }^{110}$ kann die dauerhafte Monopolstellung einer Netztechnologie bezeichnet werden. In der Entwicklung des Tonträgermarktes ist dieses Phänomen durch die Vormachtstellung jeweils einer Trägerkategorie aufgetreten. Haben Konsumenten über Jahre ein Repertoire der jeweils herrschenden Trägerkategorie gesammelt (zunächst LP, dann MC und CD), ${ }^{11}$ werden sie nicht ohne weiteres auf eine neue Technologie wechseln. Ihnen entstehen switching costs (Wechselkosten). Das Ausmaß des lock-in-Effekts ist für Nachfrager abhängig von der Höhe der switching costs von einer Trägertechnologie zur anderen und von der Größe der

${ }^{105}$ Quelle für diese Informationen sind Interviews mit Insidern.

106 Verschiedene Hardware ist dann kompatibel, wenn auf ihr dieselbe Software benutzt werden kann. Vgl. Katz/ Shapiro 1985, supra, S. 425. Eine Standardisierung schaff eine ex ante Kompatibilităt, wăhrend diese ex post nur durch Netzwerkbrücken oder Gateways bzw. Konverter hergestellt werden kann.

$107 \mathrm{Vgl}$. Monopolkommission, 9. Hauptgutachten, Wettbewerbspolitik oder Industriepolitik, Baden-Baden 1992, Tz. $149 \mathrm{ff}$.

108 Aufwărtskompatibilităt sichert die kompatible Einführung technischen Fortschritts in die bestchenden Standards. Inzwischen werden beispielsweise MPEG 3 und 4 Standards entwickelt.

109 Für den Fall der Standardisierung durch MSG Media Services vgl. Monopolkommission, 11. Hauptgutachten, Wettbewerbspolitik in Zeiten des Umbruchs, Baden-Baden 1996, Tz. 755.

$110 \mathrm{Vgl}$. Weizsácker, C. C. von, The Costs of Substitution, in: Econometrica, Vol. 52 (1984), S. 1085-1116. Aber bereits früher wurden lock-in-Effekte gesehen, jedoch nicht so bezeichnet. Vgl. beispielsweise Veblen, Thorstein, Imperial Germany and the Industrial Revolution, New York 1954, S. 129-132, der den Effekt an der Festlegung der Spurweite der Eisenbahnen demonstrient. Ein anderer Autor hat ihn anhand der Kernenergie beschrieben. Vgl. Cowan, $\mathrm{R}$, Nuclear power reactors: a study in technological lock-in, in: Journal of Economic History, Vol. 50 (1990), 541-567.

11 Bei der netzgebundenen Musikverwertung ist statt der Trägertechnologie die Investition in das Zugangskontrollgerăt (Set-top-box o. ă.) für den lock-in-Effekt verantwortlich. 
installierten Basis. ${ }^{112}$ Die installierte Basis ist hier die Zahl der Abonnenten. ${ }^{113}$ Die Ursachen für switching costs liegen in den Kosten für die Hardware und den Beschaffungskosten der komplementären Software. Früher bestand die Hardware in Abspielgeräten für die jeweiligen Musikträgerkategorien, beim netzgebundenen Musikabruf besteht sie im multimediafahigen PC mit entsprechender Software und dem Zugangskontrollgerät (set-top-box o. ä.). Mit dem Ende der Nutzung einer Technologie werden auch die Investitionen in diese obsolet. ${ }^{114}$ Inwiefern der lock-in-Effekt wettbewerbspolitisch relevant ist, hängt neben der Marktreife der Technologie von der Phase des Marktes ab, in dem sie eingesetzt werden soll. Die Markteinführung der elektronischen Belieferung der Haushalte mit Musik ist 1998 erfolgt. Vor dem Hintergrund der weiteren Expansion des Marktes für Online-Dienste dürfte damit der lock-in-Effekt momentan keine wesentliche Rolle spielen. ${ }^{11}$

\subsubsection{Auswirkungen auf die Wettbewerbspotentiale der netzgebundenen Musikverwertung}

Die Wettbewerbspotentiale der Musikverwertung werden zunächst durch die Möglichkeiten der Beteiligten am gerade entstehenden Online-Vertrieb von Musik diskutiert. Beteiligt sind Musiker, die musikalischen Content-Provider (Tonträgerhersteller und Musiker), die ServiceProvider und die Netzinfrastrukturbetreiber. Anschließend werden die Wettbewerbspotentiale der netzgebundenen Musikverwertung durch die Charakterisierung des marktnahen Bereichs analysiert.

Für die Musiker bestehen Wettbewerbspotentiale in der Vorwärtsintegration. Sie können ihre eigene Homepage gestalten sowie mit Hilfe von Kontrakten mit Service-Providern einen Direktvertrieb ihrer Musik via Netz anstreben. Der prinzipiellen Möglichkeit, daß sie damit zwei Wertschöpfungsstufen (Tonträgerhersteller und Handel) überspringen könnten, um damit einen größeren Teil des Erlöspotentials der Musikverwertung für sich zu realisieren, stehen technische und organisatorische Schwierigkeiten gegenüber. Für die Musiker als Urheber besteht ein Zielkonflikt zwischen der Verbreitung ihrer Musik und den nötigen Schutzmechanismen, ${ }^{116}$ um von dieser Verbreitung tatsächlich auch Erträge zu erhalten. Bei der netzgebun-

112 Vgl. Liebermann, Marvin B., und David B. Montgomery, First-Mover Advantages, in: Strategic Management Journal, Vol. 9 (1988), S. 41-58, hier S. 46. Ebenso können private Kopieraktivităten oder Tauschakte nur bei gleicher Technologie durchgefuhrt werden.

113 So stellte der Supreme Court of the United States in einer Entscheidung von Juni 1992 gegen Kodak fest: "If the cost of switching is high, consumers who already have purchased the equipment and are thus 'locked-in', will tolerate some level of service-price increases before changing equipment brands [or tochnology]. Under this scenario, a seller profitably could maintain supracompetitive prices in the aftermarket if the switching costs were high relative to the increase in service prices, and the number of locked-in consumers were high relative to the number of new purchasers." Vgl. Eastman Kodak Co., Petitioner v. Image Technical Services, Inc.,in: CCH 1992 - 1 Trade Cases $\$ 69,839$, S. 67,946-67,968.

114 Wenn man davon absieht, daß die angeschaffe Software weiter benutzt oder auch an Sammler veräußert werden kann.

115 Empirisch läBt sich die Expansion des Online-Dienste-Marktes mit folgenden Zahlen belegen: Mitte 1996 gab es in Deutschland 1,2 Mio. Abonnenten für Online-Dienste. Anfang 1998 waren es knapp 3 Mio. Quelle: Gramatke, Wolf D., op. cit., S. 57, und nach Unternehmensangaben.

116 Dieser Zielkonflikt besteht für Musiker in der Notwendigkeit, durch Verbreitung einen Bekanntheitsgrad zu erlangen. Hierfür wăre ein kostenloser und einfacher Zugang zur Musik von Vorteil. Andererseits wird mittelfristig ohne Ertrags- und Gewinnaussicht keine Musik produziert, daher kann Musik nicht nur ko- 
denen Musikverwertung via Internet ist die Zahlungsfunktion über das offene Netz zu regeln, ${ }^{117}$ und es sind durch Kopiersperrtechniken weitere Verwertungen der Musik zu verhindern, damit aus dem einseitigen Aneignen von Verfügungsmöglichkeiten durch das Herunterladen der Musik aus dem Netz (Transfer) eine gegenseitige Übertragung von Verfügungsrechten (Transaktion) wird. Dabei lassen sich für die Entwicklung von Kopiersperrschutz und die Durchführung von Zahlungsfunktionen Größenkostenvorteile realisieren. Hinzu kommt, daß Service-Provider aus Transaktionskostengründen nicht mit einzelnen Musikern kontrahieren, sondern ganze Musikkataloge online vertreiben werden. Ziel der Vorwärtsintegration ist eine Verbesserung des Wettbewerbsverhälnisses zu anderen Musikern. Dieses wird mit einer Integrationsstrategie in die Online-Präsenz nicht automatisch erreicht, da auch die Tonträgerhersteller eine Online-Vermarktung ihrer Vertragskünstler betreiben. Der Produktwettbewerb bleibt in gleichem Umfang bestehen. Daher ist mit einer Vielzahl von Integrationen der Musiker in den Online-Direktvertrieb nicht zu rechnen.

Für die Tonträgerhersteller als Content-Provider ist die netzgebundene Musikverwertung in erster Linie ein Distributionskanal. Sollte mittels Kopiersperr- und Abrechnungstechnik derselbe Grad an Ausschließbarkeit vom Konsum wie bei körperlichen Tonträgern hergestellt werden können, bietet sich dieser Distributionskanal zur Erstverwertung des musikalischen Repertoires an. Ohne physische Herstellungskosten der Vervielfältigungsstücke und mit erheblich geringeren Distributionskosten könnten dieselben Erlöspotentiale erreicht werden. Die Erlösanteile der Tonträgerhersteller, die heute $70 \%$ ihrer Umsätze mit körperlichen Tonträgern erzielen und $20 \%$ mit Lizenzen, würden sich sukzessive umkehren (vgl. Tabelle 15). Die netzgebundene Musikverwertung schafft jedoch dann keine darüber hinausgehenden Erlöspotentiale, wenn die Altersstruktur der Konsumenten, Käuferreichweiten und Kaufintensitäten nicht wesentlich von der bisherigen Zusammensetzung der Käufer herkömmlicher Tonträger abweichen. Der Unterschied des elektronischen Vertriebskanals liegt in einer stärkeren Kundenbindung durch ein Abonnement des Musikangebots. Ein potentieller Nachfrager, der einen OnlineDienst abonniert, kann auch dessen Möglichkeiten nutzen, wozu u. a. der Musikkauf zählt. ${ }^{118}$

Wegen ihrer Finanzkraft eröffnet sich für die Oligopolgruppe der Majors mit der technischen Realisierung der elektronischen Belieferung (electronic delivery, ED) der privaten Haushalte die Möglichkeit der Integration in die nachgelagerte Ebene. Die Voraussetzungen für Integrationsstrategien sind je nach der Ausrichtung der Konzerne unterschiedlich. So ist die Konzernmutter eines Majors (BMG) mit anderen Abteilungen des Konzerns selbst als Service-Provider tätig. ${ }^{119}$ Eine Vorwärtsintegration in den Markt für Online-Mehrwertdienste ist für die musikalischen Content-Provider aber nicht eo ipso lohnend. Ohne Integration könnten sie regelmäßige

stenlos abgegeben werden. Dieser Zusammenhang wird gesamtwirtschaflich als trade-off, bestehend aus „welfare loss due to underutilization versus welfare loss due to underproduction“ bezeichnet und wurde bereits ausfuihrlich in den Abschnitten 3.1.3 und 3.2.2 diskutiert.

11 'Um Zahlungsvorgänge im Internet-Handel auf eine sichere Grundlage zu stellen, bilden sich z. Zt. Unternehmenskooperationen. Vgl. o. V., IBM und GZS kooperieren, in: FAZ, Nr. 65 vom 18.3.98, S. 32, und o. V., Zahlsystem für Internet-Handel, in: FAZ, Nr. 68 vom 21.3.98, S. 29.

${ }^{118}$ Hierzu gehören z. B. auch Probekăufe von technikbegeisterten Konsumenten. Z. Zt. (Angaben auf der Popkomm. 98 im August 1998) betătigen sich nur $15 \%$ der registrienten Kăufer wiederkehrend.

119 Mit Compuserve und AOL/Bertelsmann-Online. 
Output-deals mit dem Service-Provider abschließen. Bei Output-deals des Service- mit einem Content-Provider wird die gesamte (rechtlich verfügbare) Musikproduktion eines Tonträgerherstellers in das Netz eingestellt und abrufbar gemacht. Output-deals regeln zeitlich vor der Produktion den Online-Vertrieb. Bei der Realisierung einer Integration müßte ein Tonträgerhersteller selbst zusätzliche Musikinhalte akquirieren, um ein vollständiges Programm anbieten zu können. Wegen der bestehenden Verbundinterdependenz zwischen dem Beschaffungsmarkt für Mehrwertdiensteanbieter und dessen Rezipientenmarkt, wäre eine vertikale Integration nur mit einer zusätzlichen und gleichzeitigen Diversifikation in die Verwertung weiterer Unterhaltungsinhalte möglich. Gleichwohl kann diese Strategie aus einer Gesamtkonzernsicht eines Medienkonzerns rational sein, wenn entsprechende Inhalte zur Verfügung stehen. Für diese Konzerne mit entsprechendem musikalischen Content-Provider als Tochter bestehen Integrationsvorteile in den Online-Dienstemarkt und damit den netzgebundenen Direktvertrieb von Musik. Darüber hinaus eröffnet der elektronische Vertrieb keine Möglichkeiten zur Vergabe von Unterlizenzen zur räumlich getrennten Verwertung. Denn die Netzinfrastruktur, auf der die Musiklieferung basiert, ist bisher auf den nationalen Markt beschränkt. ${ }^{120}$ Einer internationalen Online-Verwertbarkeit der Musik müßten daher zunächst Investitionen vorausgehen, die die Nutzungsmöglichkeit der Infrastruktur sicherstellen und zur Realisierung der technischen Reichweite beitragen müßten.

Die strategischen Vorteile der musikalischen Content-Provider gegenüber den vorgelagerten Musikern und den nachgelagerten Service-Providern liegen in ihren Fähigkeiten, für die jeweilige Musik Verwertungsmöglichkeiten zu schaffen. Bei den bisherigen Funktionsinhalten von Tonträgerherstellern kommen m. E. nur marktstrategische Gesichtspunkte für die Rechtfertigung von Integrationen in Betracht. Sie bestehen darin, daß die Majors den bisherigen physischen Vertrieb von Tonträgern im deutschen Markt kontrollieren. Das eröffnet ihnen Möglichkeiten zu wettbewerbsbeschränkenden Strategien (vgl. Abschnitte 4.2.2.6 und 4.3.2.4). Diese Möglichkeiten könnten sie bei einem unkörperlichen Vertrieb via Online-Diensten verlieren und in Vertragsabhängigkeit vom Service-Provider geraten. ${ }^{121}$

Die Wettbewerbspotentiale der Service-Provider lassen sich untersuchen gegenüber den vorgelagerten Content-Providern, den direkten Konkurrenten auf dem Markt für Mehrwertdienste und den nachgelagerten Rezipienten ihrer Mehrwertdienste. Ebenso sind die Anreize zu einer Rückwärtsintegration in den Content-Markt sowie die Stellung der Service-Provider zum Netzinfrastrukturbetreiber zu behandeln

Die Wettbewerbspotentiale gegenüber Content-Providern ergeben sich aus dem Umfang der Bezugsrechte für musikalischen Inhalt. Der Umfang bezieht sich auf die Zahl der bezogenen Musiktitel und die Zeitdauer des Liefervertrags für die elektronische Belieferung der privaten Haushalte. Der Titelumfang ist für die Attraktivität des elektronischen im Vergleich zu anderen Distributionswegen von Musik bei den Konsumenten entscheidend. Die Zeitdauer des konti-

${ }^{120}$ Denkbar ist die Lizenzübernahme von auslăndischem Repertoire zur inlăndischen Online-Verwertung.

${ }^{121}$ Diese Abhăngigkeit ergăbe sich natürlich nur, wenn ein Service-Provider sehr viele Abonnenten hătte und die Distribution körperlicher Tonträger zunehmend bedeutungslos werden würde. 
nuierlichen Flusses an aktuellem Musikrepertoire ist für die Stellung des netzgebundenen Musikvertriebs im intramodalen Wettbewerb des Musikverkaufs bedeutend. Diese wiederum ist die Voraussetzung für Wettbewerbspotentiale der Service- gegenüber den Content-Provider. Der Service-Provider T-Online wird daher eine möglichst lange Vertragszeit anstreben, um den netzgebundenen Vertriebskanal etablieren zu können. Langfristige Exklusivverträge zwischen allen musikalischen Content-Providern und nur einem Service-Betreiber (T-Online) würden auf eine Ressourcenmonopolisierung musikalischer Programminhalte mit der Folge diskriminierender Handlungsoptionen gegenüber Konkurrenten hinauslaufen. Für die musikalischen ContentProvider ist hinsichtlich der Vertragslänge für elektronischen Musikvertrieb die Etablierung dieses Distributionskanals gegenüber den Konsumenten bedeutsam. Darüber hinaus werden sie versuchen, sich nicht in Abhängigkeit von einem Online-Dienst zu begeben.

In einem Szenario der elektronischen Musikbelieferung bestehen Wettbewerbspotentiale unter den Service-Providern neben dem Preis im wesentlichen in ihren unterschiedlichen musikalischen Programminhalten, die sie den Rezipienten anbieten können. Daher können die Outputdeals mit den musikalischen Content-Providern als Abschreckungsstrategie (deterrency strategy) gegenüber anderen Online-Service-Providern dienen, um den Programminhalt Musik zu monopolisieren. Für die Service-Provider ist die Intensität des Wettbewerbs der Vertriebskanäle von Musik abhängig von der Abwärtskompatibilität der neuen netzgebundenen Technik zu der alten CD-Technologie. Als Netzwerkbrücke zwischen der Offline- und der OnlineVerwertung fungiert hier die CD-Technologie. Die bisher genutzten CD-Abspielgeräte sind weiter nutzbar, wenn die vom Netz via Computer herunterladbare Musik mittels eines an den Computer angeschlossenen CD-Brenners wieder auf einer Audio-CD gespeichert wird. ${ }^{122}$ Um genügend Nachfrage zu attrahieren, wird es nötig sein, mit Hilfe der Abwärtskompatibilität bei der netzgebundenen Musikverwertung Konsumenten vom herkömmlichen Tonträgerhandel zu gewinnen. Abwärtskompatibilität bedeutet, daß die älteren CD-Abspielgeräte auch die neuen CDs spielen können, deren Inhalt vom Netz heruntergeladen wurde. Die Einrichtung von kompatiblen Standards wird im Rahmen der Moving Pictures Expert Group (MPEG) erreicht. ${ }^{123}$ Positive Wettbewerbswirkungen dieser Standardisierung bestehen darin, daß Transaktionskosten gesenkt und economies of scale durch die Beschleunigung der Marktentwicklung und Beseitigung der Unsicherheit über den technologischen Weg eher realisiert werden können. Dadurch werden Voraussetzungen für ein zukünftiges Wachstum des Abonnentennetzes und damit Wettbewerbspotentiale bei den Service-Providern geschaffen, denn mit der Kompatibilität der Netzwerkübertragungs- und Endgeräteabspieltechnik werden positive indirekte Netzwerkexternalitäten internalisiert. Die Frage, wer sich die Internalisienungsrenten aneignet, wird sich im Bargainingprozeß zwischen Content- und Service-Providern entscheiden.

${ }^{122}$ Es ist technisch nicht erforderlich, die über das Netz transportierte Musik zuerst zu speichern, um sie hören zu können, wenn im Computer eine Soundcard vorhanden ist. Will man die Musik aber später auf CD brennen, muB sie zuerst gespeichert werden und das System des netzgebundenen Musikvertriebs abwärtskompatibel gestaltet sein. Durch die Entwicklung geeigneter Brenner-Software wăre die direkte Speicherung auf $\mathrm{CD}$ möglich.

123 Die Moving Pictures Expert Group ist eine von der Internationalen Standard Organisation eingesetzie Gruppe, die die Standards im Video- und Audiobereich koordiniert. Das kommt einer de jureStandardsetzung gleich. 
Der Erstanbieter von Service-Providing-Dienstleistungen für netzgebundene Musikverwertung kann first mover-Vorteile realisieren, weil er die Zugangstechnik zum Übertragungssystem sowie die Abonnentenverwaltungs- und Abrechnungstechnik gestalten kann. Diese Techniken könnten sich bei entsprechendem Erfolg des Übertragungssystems schon bald als Engpaßfaktoren (sog. bottleneck) dieses Distributionskanals herausstellen. Denn mit ihr hat der ServiceProvider eine proprietäre Zugangstechnologie, die gegenüber nachfolgenden Unternehmen als Markteintrittsbarriere wirkt. ${ }^{124}$ Zudem bewirkt ein Anwachsen der Abonnentenzahlen als Vergrößerung der installierten Basis eine Verbesserung der Verhandlungsposition von Servicegegenüber den musikalischen Content-Providern. ${ }^{125}$ Service-Provider verfügen wegen der Abonnentenverwaltung auch über Informationsvorsprünge hinsichtlich Konsumentenstruktur und -verhalten. Damit kann der first mover gegenüber seinen konkurrierenden Online-Diensten und sukzessive auch gegenüber den Content-Providern Marktmacht realisieren. Diese kann er zu Behinderungsstrategien nutzen. Denkbar sind Beschränkungen der Weiterleitung von Programminhalten konkurrierender Online-Dienste, ungünstigere Konditionen für nachfolgende Content-Anbieter, eine schlechte Positionierung der Konkurrenz bei elektronischen Navigationshilfen oder eine preisdiskriminierende Bereitstellung der Infrastruktur.

Wenn ein Service-Provider Marktmacht erlangt hat, kann er gegenüber den nachgelagerten Konsumenten verschiedene Varianten der Ausbeutungsstrategie durchfüren. Hat er beispielsweise den Konsumenten anfänglich die Sorftware zeitlich befristet kostenlos zur Verfügung gestellt, wenn sie über die nötigen Empfangsvoraussetzungen verfügen (ISDN-TelefonanschluB, Modem und Abonnentenstatus bei T-Online), kann er ihnen nach erfolgreicher Etablierung abverlangen, daß sie die Software kaufen sollen. Eine Ausbeutungsstrategie ist insbesondere dann erfolgreich, wenn ein Service-Provider das gesamte aktuelle Musikrepertoire als einziger exklusiv anbieten kann. Diese Strategie ist raising switching costs zu nennen, da sie den Konsumenten erschwert, auf das Angebot konkurrierender Service-Provider überzuwechseln. Weitere Möglichkeiten der Ausbeutung bestehen in gekoppelten Produktangeboten. ${ }^{126}$ Zudem kann versucht werden, mittels elektronischer Navigationshilfen oder entsprechender Gestaltung der Benutzeroberfläche das Konsumentenverhalten im Hinblick auf bestimmte Programminhalte $\mathrm{zu}$ beeinflussen. ${ }^{127}$

Nun soll der Anreiz des Service-Providers, in den musikalischen Content-Markt rückwärts zu integrieren, betrachtet werden. Der Service-Provider T-Online hatte zunächst idiosynkratische Investitionen $^{128}$ für das Projekt Music on Demand zu tätigen. Ein Integrationsanreiz könnte

124 Bestehen bleibt jedoch der intermodale Wettbewerb der Distributionswege von Musik.

${ }^{125}$ Die Content-Provider sind im Besitz der Eigentumsrechte an den musikalischen Inhalten und der ServiceProvider hat Eigentumsrechte an dem Zugangssystem zu den Online-Konsumenten. Die Verbesserung der Verhandlungsposition der Service-Provider besteht nur, wenn dessen Netz der Nachfrage ohne Engpaß gerecht werden kann.

${ }^{126}$ Beispielsweise freie Produkte im Rahmen des Grundangebots, die mit der Abo-Gebühr abgegolten sind, und zusătzliche Produkte (Musik), für die zusătzlich zu zahlen ist.

${ }^{127}$ Der Service-Provider kann so versuchen, gezielt den elektronischen Absatz der für ihn rentabelsten Produkte zu fordern.

${ }^{128}$ Eine Investition ist dann idiosynkratisch, wenn sie auf einen speziellen Transaktionszweck ausgerichtet und eine andere Verwendung nicht möglich ist. Zur Bedeutung idiosynkratischer Investitionen bei Rück- 
deshalb darin bestehen, die Amortisation der Investitionen durch eine Kontrolle über die Programminhalte zu betreiben. Da für die Diffusion der Musik aber weiterhin das Interesse der Öffentlichkeit erforderlich ist, müßten auch die weiteren Unternehmensfunktionen dieses Marktes, Marketing und Zugang zu musikrelevanten Medien, ausgeübt werden. ${ }^{129}$ Hierfür haben die Content-Provider (Tonträgerhersteller) nicht nur strategische, sondern auch horizontale Verbundvorteile und mengenmäßigen Größenkostenvorteile. Horizontale Verbundvorteile ergeben sich in der Vermarktung von mehreren Musikprodukten und der Aggregation der dafur nötigen Promotionaktivitäten. Größenkostenvorteile ergeben sich pekuniär aus Preisnachlässen bei der Werbung und Verkaufsförderung des Unternehmens und real aus Spezialisierungsvorteilen. Die Realisierung von economies of scale and scope ist für Service-Provider unterhalb einer gewissen Größe, gemessen in exklusiven Kontrakten zu etablierten Musikern, unmöglich. Zudem stehen die musikalischen Content-Provider in einem intensiven Beschaffungswettbewerb um die exklusive Bindung etablierter Musiker. ${ }^{130}$ Für den Service-Provider erweist es sich daher als günstiger, die musikalischen Inhalte auf dem Vertragsweg langfristig zu binden. Im Wettbewerb mit anderen Service-Providern wird die Gesamtprogrammattraktivität entscheidend sein. Daher wird die Akquirierung weiterer Programminhalte wichtig werden. Bei der Herstellung der unterschiedlichen Programminhalte bestehen aber keinerlei ökonomische Kostenvorteile, sondern lediglich beim Vertrieb. Deshalb besteht keine ökonomische Notwendigkeit für die Rückwärtsintegration.

Die Beziehungen zwischen Service-Providern und Netzwerkbetreibern spielt für das Wettbewerbspotential netzgebundener Musikverwertung nur eine indirekte Rolle, wenn es bei integriertem Netz- und Online-Betreiber zu Beschränkungen des Wettbewerbs auf der Stufe der Service-Provider kommt. Hat der integrierte Service-Provider in Kooperation mit dem Netzwerkbetreiber einen proprietären Zugang zur Musikdatenbank aufgebaut, kann er die marktbeherrschende Stellung von Netzbetreiber-Markt auf den Online-Dienste-Markt übertragen, falls sich die Musik als Schlüsselmehrwertdienst etabliert. Die strategischen Vorteile der vertikalen Integration des Online-Dienstes T-Online mit dem Netzbetreiber Telekom gegenüber anderen Unternehmen dieses Marktes könnten wiederum negative Auswirkungen auf die Vertragsbeziehungen zu den musikalischen Content-Providern haben, wenn die Bedeutung dieses Musikvertriebskanals zunimmt. ${ }^{131}$

wärsintegrationen vgl. Williamson, Oliver E., The Economic Institutions of Capitalism, New York u. a. 1985 , S. $118 \mathrm{f}$.

129 Für die Vermarktung von musikalischen Inhalten ist es realistisch, daß die musikalischen Content-Provider mittelfristig mit einem weltweit agierenden Service-Provider kontrahieren. Dies wird dann wahrscheinlich, wenn die urheberrechtliche und die netzwerktechnische Situation weltweit annăhernd einheitlich ist.

130 Dieser Beschaffungswettbewerb wurde in den Abschnitten 4.3.1 und 4.3.2 behandelt. Im Ergebnis wurde festgestellt, daB für etablierte Musiker hohe Summen erhielten, die teilweise über ihre Grenzproduktivităt hinaus gingen und nur durch spekulative Ertragserwartungen zu rechtfertigen waren.

131 Diese wettbewerbstheoretische Möglichkeit der Überwălzung von Marktmacht auf nachgelagerte Stufen ist in unserem Fall nicht zu erwarten, da sich der Markt für netzgebundene Musikverwertung erst im Aufbau und der Markt für Online-Mehrwertienste in der Expansionsphase befindet. 
$\mathrm{Zu}$ der elektronischen netzgebundenen Musikverwertung läßt sich ein marktnaher Bereich definieren. Zum marktnahen Bereich zählen Unternehmen, deren Markteintrittswahrscheinlichkeit erhöht ist. Hierzu können alle Unternehmen aus Branchen gerechnet werden, deren Tätigkeit Know-how in Inhalten, Vertrieb und Technik ${ }^{132}$ von Medien- und Kommunikationsmärkten verlangt. Hierzu gehört die Medien-Industrie im weiteren Sinne, die Hersteller von Unterhaltungselektronik, die Telekommunikationsindustrie sowie die datenverarbeitende Industrie. In diesem marktnahen Bereich besteht ein Strategiepotential zur Integration in die für die Musikverwertungen relevanten Marktprozesse. Dabei können die Einflußnahmen auf die OnlineMusikverwertungen sowohl durch direkte Unternehmensübernahmen als auch strategische Allianzen ${ }^{133}$ erfolgen. Wie aus der Zusammensetzung der Online-Mehrwertdienste ersichtlich, bestehen horizontale Verbundvorteile beim Vertrieb von Entertainment-Inhalten. ${ }^{134}$ Traditionelle Anbieter sind Fernsehsender, Zeitungs-, Buch- und Zeitschriftenverlage, Film- und Videoproduktion sowie weitere Informationsanbieter. $\mathrm{Zu}$ den Kompetenzen dieser Unternehmen gehört die Schaffung und Strukturierung von Inhalten, die bisher weitgehend getrennt in Medienmarken ${ }^{135}$ angeboten wurden. Die Funktion der Zusammenstellung von Inhalten zu Programmen entfallen künftig, wenn sich der Endverbraucher die Inhalte selbst zusammenstellt, die er über den Vertieb von Netzbetreibern und Service-Providern erhalten hat. Daher werden sich Medienunternehmen neue Vermarktungsmöglichkeiten für bestehende Inhalte insbesondere durch vertikale Diversifikation suchen. Hierzu arbeiten sie mit Software-Produzenten zur digitalen Aufbereitung ihrer Inhalte zusammen ${ }^{136}$ und könnten ein Interesse an der Ergänzung ihrer Inhalte durch Musik haben.

Für die Unterhaltungselektronikhersteller sind ihre Geräte Plattformen für neue Dienste, multimediafähige Personalcomputer das common-interface zum Konsumenten. Gelingt es ihnen, eine große Basis von multimediafähigen Endgeräten bei den Nachfragern zu installieren, wären sie in einem Engpaß-Bereich für elektronische Märkte präsent, woraus sich weitere Optionen ableiten lassen. ${ }^{137}$ Die horizontale Erweiterung ihrer Produktpalette ist nur eine mögliche Strategie. Hierzu gehen sie auch Kooperationen mit Computer-Hardwareherstellem ein. ${ }^{138}$ Im Online-Musikvertrieb ist die Entwicklung und Standardisierung der Kopiersperttechnik und ihre

${ }^{132}$ Dabei bedeutet in diesem Kontext Inhalt, über Mitarbeiter für die Entwicklung neuer Medien-Produkte zu verfügen oder die Rechte zur Verwertung von Musik 0 . a. zu besitzen. Vertrieb bedeutet Besitz und Verfugbarkeit von Übertragungskapazitatten (z. B. durch Netze) sowie die Erfahrung im Umgang mit den Endverbrauchern. Technik bedeutet die Entwicklung und Anwendung der Digitaltechnik und Mikroelektronik sowie die Produktion technischer Schnittstellen, d. h. Endgeräte für die Verbraucher. Ebenso schließt das die Entwicklung der Hardware (Musikdatenbank als Server, Endgerăte als Client) und der Software zur Steuerung und Gestaltung der Angebote ein.

${ }^{133} \mathrm{Vgl}$. Kiessling. Thomas, und G. Johnson, Strategic Alliances in Telecommunications and Media: An Economic Analysis of Recent European Commission Decisions, in: MacDonald, Stuart, G. Madden und M. Salomon (Ed.), Telecommunications and Socio-Economic Development, Elsevier 1998, S. 43-78.

134 Vgl. Klodt, Henning, Claus-Friedrich Laaser, Jens Oliver Lorz und Rainer Maurer, op. cit., S. 63.

${ }_{135}$ Medienmarkennamen sind etwa Spiegel, ARD, regionale Tageszeitungen, etc.

${ }^{136}$ Denkbar ist auch eine Neukombination verschiedener Inhalte, also z. B. Musik mit Spiel, Information, Werbung etc.

${ }^{137}$ Die Technologie der Endgerăte wird bzgl. der Standardisienung und der weiteren Kompatibilităt von Adapterlösungen möglicherweise ein „bottleneck“ darstellen, dessen Wirkung kartellrechtlich ăhnlich der essential facility zu beurteilen ist.

138 Die Kooperation von Philips und IBM zur Entwicklung von Set-Top-Boxen ist ein Beispiel hierfür. 
Integration in die Endgeräte eine ihrer Aufgaben. Daneben diversifizieren sie - wie bereits in Kapitel 4 ausgeführt - in Medienunternehmen, z. B. Philips und Sony in Tonträgerhersteller. Die Kontrolle über musikalische Inhalte für ein Angebot im Verbund mit ihren Endgeräten kann Motivation für Integration in den von uns betrachteten Markt sein.

Die Telekommunikationsindustrie sucht zwar in Kooperation mit Telekom-Unternehmen aus anderen Ländern eine Internationalisierungsstrategie umzusetzen, sie ist für die netzgebundene Musikverwertung aber zugleich Netzbetreiber (der digitalen Verteil- und Vermittlungsnetze) und Service-Provider der Online-Mehrwertdienste. Damit stellt sie die künttigen Vertriebskapazitäten und kann bei Marktbeherrschung in einem der beiden genannten Märkte entsprechende Kooperationen vorantreiben oder Ausbeutung vornehmen. Ebenso kann sie versuchen, durch vertikale Integration ihre marktstarke Stellung auf die nachgelagerte Stufe der netzgebundenen Musikverwertung zu übertragen.

Die datenverarbeitende Industrie, die mit der Digitalisierung und Mikroelektronik die Schlüsseltechnologien entwickelt hat, läßt sich in Hardware- und Software-Hersteller unterteilen. Die Hardware-Hersteller verfolgen eine horizontale Diversifikationsstrategie, für die sie bestehende PC-Systeme in neue Plattformen für die interaktive Mediennutzung weiterentwickeln. Hierbei werden als Zielgruppe in erster Linie private Haushalte angestrebt. Zugleich entwickeln sie die Speichertechnik weiter, um die Datenmengen einer Musikdatenbank im Rahmen der ClientServer-Architektur verfügbar zu halten. Die Software-Hersteller integrieren vertikal in den nachgelagerten Bereich des Vertriebs. Sie werden verstärkt mediale Inhalte nachfragen und versuchen, ihre Software-Kompetenzen als Service-Provider umzusetzen.

Die Analyse des marktnahen Bereichs hat gezeigt, daß sowohl angebotsseitig als auch nachfrageseitig erhebliche Kooperationspotentiale bei der netzgebundenen Verwertung von Musik bestehen. Die Verbreitung von Musik über Netze auf Abruf kann dabei als eine Pionieranwendung neuentstehender Medien- und Kommunikationsmärkte gesehen werden, für deren Erschließung die Unternehmen Kompetenzen in den drei Bereichen Inhalt, Technik und Vertrieb benötigen. Diese Kompetenzen erwerben sich Unternehmen der genannten Branchen durch Aufkauf von Musik-Content-Providern (als die man die früheren Tonträgerhersteller nun bezeichnen kann), Unternehmenskooperationen ${ }^{139}$ und strategische Allianzen. Das Szenario des marktnahen Bereichs hat gezeigt, daß zunehmende Internationalisierung und vertikale Branchenverflechtungen die Auflösung traditioneller Branchenstrukturen begünstigen. ${ }^{140}$ Rechtlich schwer greifbar sind die Auswirkungen möglicher vertikaler Verflechtungen auf Wettbewerbsstrukturen und Marktmacht. Mängel in der Umsetzung urheberrechtlicher Regelungen verhindern augenblicklich noch globale Lösungsansätze.

139 Denkbar ist natürlich auch die Bildung von kooperativen Gemeinschaftsunternehmen, in denen Kernkompetenzen aus medialen Inhalten, technischem Know-how und Vertriebserfahrung zusammengefaßt werden. Solche Unternehmen sind per se kooperative und nicht konzentrative Gemeinschaftsunternehmen, da sie in noch nicht bestehenden Märkten tătig werden. Trotzdem können daraus Wettbewerbsprobleme entstehen.

140 Vgl. Schrape, Klaus, Wolfgang Seufert, Hansjörg Haas, Daniel Hürst und Sabine Gafke, Künflige Entwicklung des Medien- und Kommunikationssektors in Deutschland, DIW Beiträge zur Strukturforschung. Heft 162, Berlin 1996, S. 61 . 
5.3.3 Urheberrechtliche Bestimmungen und Regulierungsansätze für netzgebundene Musik verwertung

Für die Darstellung des rechtlichen Ordnungsrahmens netzgebundener Musikverwertung sollen im folgenden die urheberrechtlichen Bestimmungen der netzgebundenen Musikverwertung (5.3.3.1) und die Regulierungsansätze für eine kompetitive Marktentwicklung netzgebundener Musikverwertung (5.3.3.2) behandelt werden.

\subsubsection{Urheberrechtliche Bestimmungen netzgebundener Musikverwertung}

Gegenüber der bisherigen Musikverwertung mit Tonträgern ist die netzgebundene Musikverwertung urheberrechtlich anders zu bewerten, weil das musikalische Eigentum nicht mehr an ein physisches Trägermedium, d. $h$. an den Tonträger als Ware gebunden ist, sondern online abrufbar gemacht wird. Bei der wirtschaftlichen Online-Musikverwertung auf Abruf (Musik oder Audio on Demand) handelt es sich um einen Dienst, bei dem jeder Netzteilnehmer (bzw. Abonnent) zu jedem Zeitpunkt auf den Musikkatalog zurückgreifen und sich den gewünschten Musiktitel herunterspielen lassen kann. ${ }^{141}$ Im folgenden werden zunächst die Bestimmungen des nationalen deutschen Urheberrechtes (de lege lata) gegenüber netzgebundener Musikverwertung untersucht. Dann werden die auf der diplomatischen Konferenz der World Intellectual Property Rights Organization (WIPO) vom Dezember 1996 beschlossenen internationalen Weiterentwicklungen und schließlich deren Umsetzung im Richtlinienentwurf der EUKommission vom Dezember 1997 (de lege ferenda) dargestellt.

Für die urheberrechtliche Einordnung sind die wirtschaftlichen Ziele von Musik on Demand unbeachtlich. ${ }^{142} \mathrm{Zu}$ unterscheiden ist zwischen der Speicherung der urheberrechtlich geschützten Musik auf den Server, der als Musikdatenbank fungiert, und dem Konsum durch das Abfragen der einzelnen Musiktitel mit Hilfe der Clients (Endgeräte). Das Speichern ist urheberrechtlich als Vervielfältigung nach $\S 16$ UrhG anzusehen. ${ }^{143}$ Denn es erfolgt mit der Maßgabe, die Musik so zu speichern, daß sie Dritten zugänglich wird. ${ }^{144}$ Hierfür ist erforderlich, daß die Musiker als Urheber den Tonträgerherstellern entsprechende Nutzungsrechte einräumen.

141 Vgl. Flechsig, Norbert P., Die Auswirkungen der digitalen Signalverarbeitung auf Anbieter von Rundfunk und Fernsehen, in: Becker, Jürgen, und Thomas Dreier (Hrsg.), Urheberrecht und digitale Technologie, Baden-Baden 1994, S. 27-44 [Becker/Dreier].

142 Insbesondere, ob die Konkurrenzbeziehung den CD-Kauf oder den CD-Vermietungsmarkt betriff, ist nachrangig. De lege lata bedarf die gewerbliche Vermietung von CDs seit dem 1.7.95 der Zustimmung durch die Rechtsinhaber. Dies ergibt sich aus der Umsetzung der Vermiet- und Verleihrechtsrichtlinie der EU in das deutsche UrhG. Damit wird dem Kontroll- und Partizipationsinteresse der Urheber Rechnung getragen. Vgl. Dreier, Thomas, Perspektiven einer Entwicklung des Urheberrechts, in: Becker/Dreier, op. cit., S. 123-153.

${ }_{143}$ Vgl. Ernst, Stefan, supra, S. 592-597.

$144 \mathrm{Vgl}$. Melchiar, Ferdinand, Die digitale Verwertung von Sprachwerken, in: Becker/Dreier, op. cit., S. 85-94; Gamm, Otto Friedrich Freiherr v., Urheber- und Urhebervertragsrechtliche Probleme des digitalen Fernsehens, in: ZUM, 38. Jg. (1994), S. 591-596, und Becker, Jürgen, Neue Übertragungstechniken und Urheberrechtsschutz, in: ZUM, 39. Jg. (1995), S. 231-249. 
Die urheberrechtliche Klassifizierung des Abrufens einzelner Musiktitel ist vom Konsumentenverhalten abhängig. Da es sich nicht um eine körperliche Verwertung handelt, kann eine Vervielfältigung de lege lata nicht vorliegen. Diese setzt voraus, daß das Musikwerk erneut körperlich festgelegt wird, so daß es den menschlichen Sinnen wiederholt wahrnehmbar gemacht werden kann. ${ }^{145}$ Damit ist im Umkehrschluß dann eine Vervielfältigung gegeben, wenn der Konsument eine weitere körperliche Verwertung vornimmt oder vorbereitet, beispielsweise durch eine Speicherung in seinem Endgerät oder durch eigene Herstellung körperlicher Tonträger mit dem online bezogenen musikalischen Inhalt. ${ }^{146}$ Diese Variante ist technisch für die Durchführung von Musik on demand nicht erforderlich, war aber i. S. einer Abwärtskompatibilität und damit einer Erhöhung der Akzeptanz weiter oben diskutiert worden. ${ }^{147}$ Will sich der Konsument sein eigenes Musikarchiv aufbauen, wird wegen der begrenzten Speicherkapazität seines Endgeräts (Festplatte o. ä.) eine getrennte Speicherung erforderlich, sei es auf externen Computerspeichern oder selbstzuerstellenden Tonträgern mit Hilfe des CD-Brennens. Dann ist der Tatbestand der Vervielfältigung in jedem Fall erfüllt. ${ }^{148}$ Hier gilt dann wieder die für körperliche Tonträger herrschende Regel, daß private Kopien i. S. des $\S 53$ Abs. 1 UrhG erlaubt sind bei angemessener Vergütung für die Rechtsinhaber nach $\S 54$ UrhG (Leerkassetten- und Geräteabgabe). ${ }^{149}$ In der Praxis wird dieses zu einer Weiterentwicklung des seriellen (SCMS) zu einem elektronischen Copyright Management System (ECMS) führen, das nur eine einmalige Kopie erlaubt. ${ }^{150}$

Der Verbreitungsbegriff des $\S 17$ UrhG erfaßt das Recht, Vervielfältigungsstücke in der Öffentlichkeit anzubieten oder in Verkehr zu bringen. Voraussetzung für die Subsumierung unter die urheberrechtliche Verbreitung ist die körperliche Weitergabe bzw. Überlassung von Vervielfältigungsstücken. Vermieten als entgeltliche und Verleihen als unentgeltliche Überlassung sind urheberrechtliche Unterbegriffe der Verbreitung. Die Weitergabe in unkörperlicher Form kann nicht als Verbreitung angesehen werden. ${ }^{151}$ Diese Rechtsinterpretation führt zu dem Kuriosum, daß seit der Umsetzung der EU-Richtlinie zum Vermiet- und Verleihrecht in das deutsche UrhG (1.7.95) die Vermietung von CDs von der Erschöpfung des Verbreitungsrechts ausgenommen ist, daher jede Vermietung körperlicher Tonträger der Zustimmung der Rechtsinhaber bedarf. Die unkörperliche Weiterleitung von Musiktiteln, die vom Server abge-

${ }^{145}$ Vgl. Nordemann, Wilhelm, Kai Vinck und Paul W. Hertin, Urheberrecht: Kommentar, 9. Aufl., Stuttgart 1998, § $16 \mathrm{Rdn}$. 1. Eine Vervielfaltigung erfordert rechulich zumindestens eine Beständigkeit der Festlegung, die eine neue Möglichkeit der Werknutzung ermöglicht. Diese wäre gegeben, wenn die Speicherung im Endgerăt des Clients einen wiederholten Abruf ermöglicht oder wenn der Konsument sich sogar seine eigene CD brennen könnte.

146 Das Kopieren des übertragenen Musikstückes auf CD-Rohlinge ist urheberrechtlich als Vervielfaltigung zu beurteilen, wăhrend die bloße Übertragung der Musik vom Server zum Client als offentliche Wiedergabe einzuordnen ist. Entscheidend furr diese Trennung ist, daß tochnisch das vorherige Kopieren auf CD zur Wiedergabe der Musik nicht erforderlich ist und vom Absender, dem Betreiber des Musikserver, nicht beabsichtigt wird.

${ }^{147}$ Für das erneute Hören ist die Speicherung erforderlich. Damit wäre eine Vervielfalltigung gegeben.

$148 \mathrm{Vgl}$. Becker, Jürgen, Die digitale Verwertung von Musikwerken aus der Sicht der Musikurheber, in: Bekker/Dreier, op. cit., S. 45-76.; hier S. 60 f.

149 Daher ist für CD-Rohlinge die entsprechende Abgabe bereits eingeführt worden.

150 Zum Serial Copyright Management System siehe Kapitel 2. Vgl. Flechsig, Norbert P., 1998, supra, S. $150 \mathrm{f}$.

151 Vgl. Ernst, Stefan, supra, S. 594. Im Gegensatz dazu Lewinski, Silke von, Die Umsetzung der Richtlinie zum Vermict- und Verleihrecht, in: ZUM, 39. Jg. (1995), S. 442-450. 
rufen worden sind, wäre dann jedoch frei, weil das Verbreitungsrecht nicht verletzt ist, obwohl jeder, dem unkörperlich Musik weitergeleitet worden ist, sie bei Existenz entsprechender Endgeräte körperlich verfügbar machen kann. Daher wird auch hier i. S. wirtschaftlicher Verwertungsinteressen der Musiker und Tonträgerhersteller ein Weiterleitungsschutz einzubauen sein, der einer Rechtsnormierung vorausgeht. ${ }^{152}$

Musik on Demand kann urheberrechtlich als unkörperliche Verwertung durch öffentliche Wiedergabe eingeordnet werden ( $§ 15$ Abs. 2 UrhG). In der Legaldefinition des Begriffes Öffentlichkeit ist der Personenkreis in $\S 15$ Abs. 3 als Vielzahl von Personen konkretisiert worden. Öffentlichkeit ist bei jeder einzelnen Nutzung (individuelles Herunterladen des Musiktitels) daher nicht gegeben. Aber die Auslegung bei küntigen zum Zeitpunkt der Gesetzesformulierung noch nicht absehbaren Verwertungsformen hat sich an den veränderten Gegebenheiten zu orientieren. ${ }^{153}$ Die Speicherung von Musik auf einem Server als Musikdatenbank geschieht zum Zweck des Abrufens durch die Konsumenten (Clients). Der wirtschaftliche Zweck ist damit das Erreichen einer möglichst breiten Öffentlichkeit von Abonnenten. Daher wird mit der Speicherung der Musiktitel in der Musikdatenbank i. S. der Zweckübertragungstheorie die öffentliche Wiedergabe angestrebt, die nach § 15 Abs. 2 UrhG nicht gleichzeitig erfolgen muß. Denn es stellt rechtlich keine Einschränkung der öffentlichen Wiedergabe dar, ob tatsächlich gleichzeitig oder nacheinander abgerufen wird, solange der Zweck mit dem Bestehen eines Abonnentenstammes, das diesen Dienst nutzt, verfolgt wird. ${ }^{154}$

Schließlich muß noch klargestellt werden, daß es sich bei On-Demand-Diensten nicht um eine urheberrechtliche Sendung i. S. des $§ 20$ UrhG handelt. Denn die mediale Verbindung zwischen Online-Dienst und Abonnent hat individual-kommunikativen Charakter durch das Abrufen und jeweilige Bezahlen der gewünschten Musiktitel. Diese Einschätzung ist nicht nur herrschende Meinung im Hinblick auf das deutsche Urheberrecht, ${ }^{15 s}$ sie hat auch Eingang gefunden in das WPPT der WIPO ${ }^{156}$ und den Richtlinienentwurf der EU-Kommission. ${ }^{157}$

152 Es darf bezweifelt werden, daß dieses Problem bisher juristisch erkannt worden ist. Ein Abonnent von Music on Demand, der sich aktuelle Musiktitel herunterlädt, eigene Datenkomprimierung betreibt und über Internet die Datensätze vertreibt, würde Music on demand sofort wirtschaftlich obsolet machen, wenn genügend Anwender über die Technik verfügen, um die eingespeicherte Musik zu nutzen.

${ }^{153}$ Für eine frühere Fortentwicklung der Auslegung von Rechtsbegriffen vgl. Weissthanner, Margot, Urheberrechtliche Probleme neuer Musik, München 1974, S. 2 f.

154 Die Unwirksamkeit der konkludenten Übertragung der Verwertungsrechte für neue Werknutzungsarten nach § 31 Abs. 4 UrhG und der Grundsatz der Zweckübertragung nach § 31 Abs. 5 UrhG bedingen, daB die Urheber für die Einspeisung ihrer Musik in Musikdatenbanken, auf die ein netzgebundener Zugriff möglich ist, zustimmen müssen. Der Schutzgedanke des § 31 Abs. 4 UrhG ist die Sicherung von Mehrerträgen, die aufgrund technischer Entwicklungen für den Urheber erreichbar werden. Der Schutzgedanke des $\S 31$ Abs. 5 UrhG ist das Bewahren des Urhebers vor unangemessenen wirtschaftlichen Folgen einer Pauschalvergabe von Nutzungsrechten.

iss Vgl. Ernst, Stefan, supra, S. 595; Dreier, Thomas, in: Becker/Dreier, op. cit., S. 123-136, und Schwarz, Mathias, Der urheberrechtliche Schutz audiovisueller Werke im Zeitalter der digitalen Medien, in: Bekker/Dreier, op. cit., S. 105-121.

156 Vgl. Lewinski, Silke v., und Jens L. Gaster, supra, S. 607-625.

157 Vgl. Flechsig, Norben P., supra, S. 139-154. 
Die diplomatische Konferenz hat im Dezember 1996 den WIPO Copyright Treaty (WCT) und den WIPO Performances and Phonogram Treaty (WPPT) beschlossen. ${ }^{158}$ Während der WCT die Rechte der Urheber betriff, regelt der WPPT die Leistungsschutzrechte von ausübenden Künstlern und Tonträgerherstellern. In den Verträgen sind Neuerungen hinsichtlich Vervielfätigungs-, Verbreitungs- und Vermietrecht enthalten. Es wurde ein sog. Agreed Statement zu Art. 9 Revidierte Berner Übereinkunf (RBÜ) aufgenommen, in dem sich die Mitgliedstaaten der Verträge verpflichten, das Vervielfältigungsrecht bei der Nutzung von Werken in digitaler Form einzuhalten. Hierfür ist de lege ferenda eine Änderung des Vervielfältigungsbegriffes nötig, so daß das in digitaler Form erfolgte Abspeichern eines geschützten Werkes in einem elektronischen Medium rechtlich als Vervielfätigung angesehen wird. ${ }^{159}$ Nach Art. 11 und 14 WPPT gilt dieses Vervielfältigungsrecht ausdrücklich auch für ausübende Künstler und Tonträgerhersteller. Damit können letztere die Einspeicherung in eine Musikdatenbank durch ein Ausschlußrecht steuern. ${ }^{160}$ Ebenso ist das Verbreitungsrecht für Urheber (Art. 6 WCT), ausübende Künstler (Art. 8 WPPT) und Tonträgerhersteller (Art. 12 WPPT) als ausschließliches Verbotsrecht ausgestaltet worden, die Verbreitung von Originalen oder Vervielfältigungsstükken zu gestatten oder zu untersagen. Dieses ist die erstmalige Anerkennung des Verbreitungsrechts in einem internationalem Übereinkommen zum Urheberrecht und Leistungsschutz. Da sich die Verbreitung aber nur auf eine tangible Form (z. B. Tonträger) bezieht, betriff diese Änderung die netzgebundene Musikverwertung nicht. Art. 13 WPPT verpflichtet die Vertragsstaaten zur Gewährung eines ausschließlichen Vermietrechts für Tonträgerhersteller, das bei kommerzieller Vermietung greift, weil die Vermietung ein urheberrechtlicher Unterbegriff der Verbreitung ist. Damit wird die gewerbliche Weiterverwertung von online heruntergeladener Musik durch eigenes Brennen von CDs ohne Erlaubnis der Tonträgerhersteller illegal.

Neu geregelt ist in Art. 8 WCT die ausschließliche Befugnis des Urheberrechtsinhabers im Rahmen des Rechts der öffentlichen Wiedergabe, netzgebundene Übermittlungen zuzulassen oder zu untersagen. Hierzu wurde der Begriff der öffentlichen Verfügbarmachung zum Zugang oder Abruf (making available right) definiert. Als öffentliche Verfugbarmachung gilt alles, was Angehörigen der Öffentlichkeit ermöglicht, das Werk an einem von ihnen selbst bestimmten Ort und Zeitpunkt abrufen zu können. Das Ausschließlichkeitsrecht gilt nunmehr auch für Abrufdienste und Online-Übertragungen. Das weiter oben diskutierte Problem des juristischen Begriffs der Öffentlichkeit wurde dadurch umgangen, daß der maßgebliche Rechtsakt bereits mit der Zugänglichmachung beginnt. Das spezielle „communication to the public“ ist für ausübende Künstler und Tonträgerhersteller als „making available right“ ein Ausschließlichkeitsrecht nach Art. 10 und 14 WPPT geworden, während für das allgemeine Wiedergaberecht (analog den $\S \S 19 \mathrm{ff}$. deutsches UrhG) in Art. 15 WPPT nur ein Vergütungsanspruch vorgesehen worden ist. Damit wird sowohl die Speicherung von Musiktiteln in Musikdatenbanken (i. S. des Vervielfältigungsrechts) als auch die netzgebundene Zugangsregelung beispielsweise für

$158 \mathrm{Vgl}$. Reinbothe, Jörg, Martin Prat und Silke v. Lewinski, The New Wipo Treaties, in: European Intellectual Property Review (EIPR), Vol. 19 (1997), S. 171-184.

$159 \mathrm{Vgl}$. Lewinski, Silke v., und Jens L. Gaster, supra, S. 615 f.

${ }^{160}$ Letztlich bleibt rechtlich umstritten, ob die vorübergehende Speicherung z. B. im Arbeitsspeicher (Random access memory, RAM) als Vervielfältigung anzusehen ist. Dies ist für die netzgebundene Musikverwertung wirtschaflich ohne Belang. 
Abonnenten (i. S. des making available right) von der Zustimmung durch die Urheber und die Tonträgerhersteller abhängig werden. Das bedeutet, daß durch die WCT und WPPT die netzgebundene Musikverwertung durch die Rechtsinhaber (Urheber, ausübende Künstler und Tonträgerhersteller) steuerbar geworden ist.

Nachdem zwischenzeitlich die EU-Kommission als follow up zum Grünbuch ${ }^{161}$ eine Mitteilung zur Harmonisierung ${ }^{162}$ veröffentlicht hatte, erschien am 10.12.97 der Richtlinienentwurf (RLE) der EU-Kommission zur Harmonisierung bestimmter Aspekte des Urheberrechts und verwandter Schutzrechte in der Informationsgesellschaft. ${ }^{163}$ Durch den RL-E sollen die Verträge der diplomatischen Konferenz der WIPO zum Schutz der Urheber, ausübenden Künstler und Tonträgerhersteller umgesetzt werden. Rechtsgrundlage der geplanten Richtlinie sind die Regeln für das Funktionieren eines gemeinsamen Binnenmarktes. ${ }^{164}$ Richtlinien sind an die Mitgliedstaaten gerichtete Rechtsakte, durch die diese entsprechend dem Inhalt zur Rechtssetzungstätigkeit verpflichtet werden. Sie sind als erste Stufe des zweistufigen Rechtsetzungsverfahrens nach Art. 249 Abs. 3 EGV im Hinblick auf die Ziele verbindlich, nicht jedoch hinsichtlich der Form und der Umsetzungsmittel. ${ }^{165}$

Der RL-E setzt in Art. 2 das im WPPT festgelegte Vervielfalltigungsrecht um. Er sieht vor, daß die Mitgliedstaaten der EU verpflichtet sind, ein ausschließliches Recht gegen Vervielfältigung zu gewähren, demzufolge die unmittelbare oder mittelbare, vorübergehende oder dauerhafte Vervielfältigung durch welche technischen Mittel auch immer und in jeder Form, in Gänze oder in Teilen von der Genehmigung der Rechtsinhaber abhängt. Der RL-E unterscheidet nicht hinsichtlich analoger und digitaler Vervielfältigung und umfaßt jegliche Art, ob online oder offline, und jegliche Form, ob materiell oder immateriell, ob dauerhaft oder vorübergehend. Die Urheber, ausübenden Künstler und Tonträgerhersteller sollen danach gegen unmittelbare und mittelbare Vervielfältigung, ${ }^{166}$ Verbreitung und öffentlichen Zugang zu ihren Tonträgern in jeder Weise und Form geschützt werden. Damit stellt der RL-E die online-Vervielfältigung der direkten mechanischen gleich.

Das bloße Angebot im Netz wird nicht zu einer mittelbaren Vervielfältigung, sondern es erfüllt den öffentlichen Zugang i. S. eines Unterfalls des umfassender ausgestalteten öffentlichen Wiedergaberechts. ${ }^{167}$ Die on-demand Nutzung wird als „communication to the public“ mit Ver-

${ }^{161} \mathrm{Vgl}$. EU-Kommission, Grünbuch uber Urheberrechte und verwandte Schutzrechte in der Informationsgesellschaft, KOM (95) 382 endg. vom 19.7.1995.

$162 \mathrm{Vgl}$. EU-Kommission, Initiativen zum Grïnbuch über Urheberrechte und verwandte Schutzrechte in der Informationsgesellschaf, Kom (96) 568 endg. vom 20.11.1996

$163 \mathrm{Vgl}$. EU-Kommission, Kom (97) 628 endg.

164 Art. 95 EGV und die Regeln über den freien Waren- und Dienstleistungsverkehr nach Art. 47 Abs. 2 EGV.

$165 \mathrm{Vgl}$. Bleckmann, Albert, Europarecht, 6. Aufl., Koln 1997, Rdnr. 379 ff. und 189 Abs. 3 EGV. So auch Art 11 Abs. 1 des Richtlinienentwurfs.

166 Die unmittelbare Vervielfaltigung meint die direkte mechanische Nachfertigung (MC oder DAT von CD), wăhrend man sich bei der mittelbaren Vervielfaltigung der online übermittelten Werkwiedergabe bedient (CD vom Netz).

${ }^{167} \mathrm{Vgl}$. Flechsig, Norbert P., supra, S. 142 f. 
botsrecht für Urheber und Tonträgerhersteller in Art. 3 RL-E spezifiziert. ${ }^{168}$ Die Urheber sind gemäß RL-E umfassender als die Tonträgerhersteller geschützt. Für sie schließt der Begriff "communication to the public" eine Vielzahl von Verbreitungsprozessen ein. ${ }^{169}$ Für die Tonträgerhersteller und ausübenden Künstler beschränkt sich das Verbotsrecht auf den online-Zugang On-Demand. Dieses Verbotsrecht bezieht sich auf den öffentlichen Zugang i. S. eines makingavailable-right. Die Kommission begründet dieses Leistungsschutzrecht mit den signifikanten wirtschaftlichen Herausforderungen durch diese neue Nutzungsform und dem bedeutenden Risiko der Piraterie. Ein über die on-demand-Nutzung hinausgehender Rechtsschutz, beispielsweise bei der Sendung, wird vom RL-E für die Tonträgerhersteller und ausübenden Künstler nicht vorgesehen. Bezüglich einer Sendung (analog § $20 \mathrm{dt}$. UrhG) können sich die Tonträgerhersteller nicht auf ein Verbotsrecht berufen. Es besteht nur ein Vergütungsanspruch (analog $\S 76$ Abs 2, 77 und $86 \mathrm{dt}$. UrhG). ${ }^{170}$ Daher ist de lege ferenda bei der Umsetzung der Richtlinie in nationales deutsches Recht, sofern sie unverändert gültig wird, zusätzlich zu dem originären Vervielfältigungs- und Verbreitungsrecht der Tonträgerhersteller i. S. von $\S 85$ UrhG ein öffentliches Zugangsrecht als ausschließliches Nutzungsrecht einzurichten. ${ }^{171}$

Schließlich sieht der RL-E vor, daß die Mitgliedstaaten angemessenen Rechtsschutz gegen die Verbreitung von Geräten oder das Anbieten von Leistungen gewähren, die geeignet sind, gewerbliche Umgehungszwecke zu ermöglichen. Dabei sind technologische Schutzeinrichtungen dann wirksam und ausreichend, wenn die vorgesehene und genehmigte Nutzung möglich ist und weitere Nutzungen, die die Verwertungsinteressen der Urheber- und Leistungsschutzberechtigten berühren, unterbunden werden. Zudem sollen insbesondere mit Hilfe des Electronic Copyright Management System (ECMS) Informationen über die Verwaltung von Rechten sowie den individuellen Nutzungsvorgang erfaßt werden und darauf aufbauend die Vergütungsansprüche durchgesetzt werden. ${ }^{17}$

Festgehalten werden kann, daß für die unkörperliche Musikverwertung die Rechte der Urheber ausgeweitet worden sind und für die Tonträgerhersteller erstmals auch bei on-demandDiensten ein Ausschließlichkeitsrecht eingeräumt wurde. Diese Regelungen sind de lege ferenda auch in nationales Urheberrecht umzusetzen. Damit ist eine Rechtsgrundlage sowohl für Musiksendungen in digitalem Radio als auch für netzgebundenes Abrufen einzelner Musiktitel von einer Musikdatenbank (Musik on demand) geschaffen. Der Rechtsrahmen beläßt den Urhebern und Tonträgerherstellern die Steuerungsmöglichkeiten über die wirtschaftliche Ver-

168 Art. 3 RL-E: „Communication to the public, including the right of making available of works or other subject matter."

169 Zusátzlich zu traditionellen Verbreitungstatbestănden mit körperlichen Vervielfältigungsstücken treten hier Übertragungen via Kabel oder kabellos. Alle Vorgănge bedürfen der Zustimmung der Urheber.

${ }^{170}$ Die generelle Haltung der Kommission besteht darin, daB sich das Senderecht nicht auf alle Arten von ondemand Angeboten beziehen soll, bei denen zum Zugang jeweils eine individuelle Leistungsabfrage erfolgen muß. Vgl. Flechsig, Norbert P., supra, S. 145.

171 Dieses Recht hat den Charakter eines teil-offentlichen Wiedergaberechts, da es nur die Nutzung auf Abfrage, nicht aber die Sendung, Aufführung etc. betriff.

172 Dieses Managementsystem wird die Tătigkeit von Verwertungsgesellschaften betreffen. Zu den technischen Grundlagen vgl. Bechthold, Stefan, Der Schutz des Anbieters von Information: Urheberrecht und Gewerblicher Rechtsschutz im Internet, in: ZUM, 41. Jg. (1997), S. 427-450, und ders., Multimedia und Urheberrecht: einige grundsătzliche Anmerkungen, in: GRUR, 100. Jg. (1998), S. 18-27. 
wertung der Musik entsprechend ihrem unternehmerischen Kalkül, etwa durch den Aufbau entsprechender Online-/Offline-Verwertungsketten.

\subsubsection{Regulierungsansätze für eine kompetitive netzgebundene Musikverwertung}

Die ordnungsrechtliche Erfassung des netzgebundenen Musikvertriebs im Rahmen von OnlineDiensten stand zunächst unter kompetenzrechtlicher Konkurrenz des Bundes und der Länder. Ein Rechtsgutachten ${ }^{173} \mathrm{kam}$ zu dem Ergebnis, daß Online-Dienste nicht als Rundfunk angesehen werden können ${ }^{174}$ und deswegen nicht in der generellen Zuständigkeit der Länder liegen. Das Angebot von Online-Diensten besteht wegen der o. g. horizontalen Verbundvorteile bei der Distribution der Dienste aus verschiedenen Elementen, insbesondere Mediendiensten und Telediensten. Mediendienste sind elektronische Informations- und Kommunikationsdienste, die an die Allgemeinheit gerichtet sind. Sie unterfallen damit der Regelungskompetenz der Länder, die mit Wirkung zum 1.8.1997 den Mediendienste-Staatsvertrag (MDStV) ${ }^{175}$ verabschiedet haben. Teledienste sind alle elektronischen Informations- und Kommunikationsdienste, die für eine individuelle Nutzung von Inhalten mittels Telekommunikation bestimmt sind. Sie fallen damit unter die Regelungskompetenz des Bundes, der ebenfalls zum 1.8.1997 das Informations- und Kommunikations-Dienstegesetz (IuKDG) ${ }^{176}$ erlassen hat. Diese Bestimmungen sollen die rechtlichen Rahmenbedingungen für die neuen Informations- und Kommunikationsdienste schaffen. ${ }^{17}$ Gleichwohl geht die Unterscheidung der Dienste in solche mit individueller Nutzung in der Zuständigkeit des Bundes und nach Programmdiensten für die Allgemeinheit in der Zuständigkeit der Länder fehl, da die technische Entwicklung die Unterscheidung zwischen Individual- und Massenkommunikation aufhebt. ${ }^{178}$

Zur Abgrenzung der Zuständigkeiten stehen daher in beiden Bestimmungen Regelbeispiele. In $\S 2$ Abs. 2 MDStV werden Teleshopping, Textdienste und On-demand-Dienste (AbrufDienste) genannt, in $\S 2$ Abs. 2 Teledienstgesetz (TDG, Bestandteil des IuKDG) werden Telebanking und Telespiele angeführt. In $\S 2$ Abs. $2 \mathrm{Nr}$. $4 \mathrm{MDStV}$ werden solche On-demandAngebote vom Geltungsbereich des MDStV ausgenommen, bei denen eine unmittelbare $\mathrm{Ge}$ genleistung des Nutzers durch Bezahlung des abgerufenen Inhalts erfolgt. ${ }^{179}$ Die Bezahlung wird als Indiz für Individualkommunikation angesehen. Ebenso gilt dies für alle InternetDienste, die nur gegen Bezahlung erfolgen, wozu regelmäßig auch der Online-Musikkauf zählt. ${ }^{180}$ Damit fallen die behandelten netzgebundenen Musikvertriebsformen, Internet und Mu-

${ }^{173}$ Bullinger, Martin, und Ernst-Joachim Mestmäcker, Multimediadienste: Struktur und staatliche Aufgaben nach deutschem und europaischem Recht, Gutachten im Auftrag des Ministeriums für Bildung, Wissenschaf, Forschung und Technologie, Bonn 1996.

174 Damit entfallt Art. 5 GG als móglicher Ansatzpunkt für Regulierungen.

175 Mediendienste-Staatsvertrag vom 1.8.1997.

176 Informations- und Komunikationsdienste-Gesetz (IuKDG) vom 22.7.1997, BGBI. I, S. 1870.

$177 \mathrm{Vgl}$. Engel-Flachsig, Stefan, Das Informations- und Kommunikationsdienstegesetz des Bundes und der Mediendienstestaatsvertrag der Bundesländer, in: ZUM, 41. Jg. (1997), S. 231-239.

${ }^{178} \mathrm{Vgl}$. Kröger, Detlef, und Flemming Moos, Regelungsansătze für Multimediadienste, in: ZUM, 41. Jg. (1997), S. 462-471 [Kröger/Moos].

179 Kröger/Moos, supra, S. 467.

${ }^{180}$ Dieses gilt jedoch nicht für unentgeltliche Client-Server-Anwendungen, die damit unter den MDStV fallen. Hierunter wăre das unentgeltliche Angebot von Musik zu Werbezwecken zu subsumieren. 
sik on Demand, unter die Gesetzgebungskompetenz des Bundes. Anzuwenden ist das IuKDG, dessen für Online-Musikverwertung wichtiger Teil das Teledienstegesetz (TDG) ist.

Im TDG ist ein freier Marktzutritt geregelt. Diensteanbieter und -nutzer haben freien Zugang zu Telediensten wie z. B. Musik on Demand. Als Diensteanbieter i. S. des § 3 Nr. 1 TDG gelten diejenigen, die eigene oder fremde Dienste zur Nutzung bereithalten oder den Zugang zur Nutzung verschaffen, mithin die Service-Provider. Dabei erfolgt die Zuordnung der Providertätigkeit nach MDStV oder IuKDG im Zusammenhang mit dem vermittelten Dienst. Die netzgebundene Musikverwertung als Unterhaltungsangebot mit Kaufcharakter ${ }^{181}$ unterliegt damit den weiteren Bestimmungen des IuKDG. ${ }^{182}$ Hinsichtlich der urheberrechtlichen Regelungen sind o. g. neuere Rechtsentwicklungen noch nicht berücksichtigt. ${ }^{183}$ Allerdings werden gemäß Art. 7 IuKDG weitere Änderungen des Urhebergesetzes auch für die Teledienste wirksam. Hierbei wird es aus Sicht der musikalischen Content-Provider zu Schutzverbesserungen kommen, wenn der WPPT und der RL-E in nationales Recht umgesetzt werden.

Das IuKDG enthält keine Bestimmungen über spezielle Wettbewerbsregeln. Lediglich Änderungen des Preisangabengesetzes und der Preisangabenverordnung sollen die Kosten- und Anbietertransparenz sicherstellen (Art. 8 und 9). Für die Konsumenten muß erkennbar sein, welche Musikstücke wie teuer sind und welche Zeit die Übertragung in Anspruch nehmen wird, so $\mathrm{da}$ für sie neben den Abonnement- und Musikstückkosten auch die Übertragungskosten kalkulierbar sind. ${ }^{184}$ Ferner müssen die Bestimmungen zum Datenschutz, beispielsweise Zugangskennungsschutz, auch technisch realisierbar sein.

Will man die mit den Regelungen bezweckte Ordnung der Wettbewerbsbeziehungen bei der netzgebundenen Musikverwertung untersuchen, sind die einzelnen Ebenen zu unterscheiden. ${ }^{185}$ Als wettbewerbspolitisch problematisch erweist sich die Ebene der Service-Provider (OnlineDienste). Zwar ist die Rolle der Anbieter von Online-Diensten prinzipiell mit derjenigen des Groß- und Einzelhandels und des Vertriebs bei physischen Tonträgern zu vergleichen. Aufgrund der Möglichkeiten zu vertikaler Integration des Angebots von Mehrwert-OnlineDiensten und Netzinfrastruktur kann es jedoch zu Rückwirkungen vom Markt der Online-

${ }^{181}$ Die Gesetzgeber (Bund und Lănder) haben ihre eigene Systematik durchbrochen, wenn sie die Unterhaltungsangebote in die Regelungskompetenz der Lănder legen, sie aber zugleich bei Kaufakten wieder dem Bund übertragen. Die Mehrzahl der bereits bestehenden oder zur Marktreife entwickelten Unterhaltungsangebote werden Kaufcharakter haben. Vgl. im Ergebnis auch Kröger/Moos, supra, S. 471, die deshalb den gesetzlichen Regelungen auch keine lange Lebensdauer voraussagen.

182 Neben datenschutzrechtlichen Bestimmungen, in denen u. a. geregelt ist, daß eine Weitergabe von Nutzungsdaten zum Zweck der Marktforschung nur anonym erfolgen darf, bestehen Bestimmungen für die Verantwortlichkeit bzgl. der transportierten Inhalte. Der Service-Provider ist demnach für eigene Inhalte voll verantwortlich. Vermittelt ein Anbieter lediglich den Zugang zur Nutzung fremder Angebote, besteht keine Verantwortlichkeit.

183 Das ergibt sich aus der laufenden Fortentwicklung dieses Rechtsgebietes. Mit dem IuKDG ist die Datenbankschutzrichtlinie der EU umgesetzt worden. Vgl. Richtlinie 96/9/EG des Europäischen Parlaments und des Rates vom 11. Mărz 1996 über den rechulichen Schutz von Datenbanken, in: ABI. EG Nr. L 77, S. 20.

184 Sollten sich langfristig Pauschalangebote ohne eine zeitabhängige Gebühr durchsetzen, erübrigt sich die Kalkulation der Übertragungskosten für die Konsumenten.

$185 \mathrm{Vgl}$. Klodt, Henning. Claus-Friedrich Laaser, Jens Oliver Lorz und Rainer Maurer, op. cit., S. $169 \mathrm{f}$. 
Dienste auf den Markt der Netzinfrastruktur kommen. Insbesondere der first mover T-Online hat die Client-Server-Architektur der on-demand-Musiknutzung aufgebaut und den Standard gesetzt. Nachfolgende Unternehmen werden es nicht nur schwerer haben, eigene konkurrenzfähige musikalische Abfragekataloge anbieten zu können, sie sind zudem bei der Nutzung der Infrastruktur des first mover auf diskriminierungsfreien Zugang bzw. die diskriminierungsfreie Weiterleitung von Konsumenten angewiesen. Sollte sich die netzgebundene Musikverwertung als Schlüsselmehrwertdienst erweisen, werden andere Online-Dienste ohne dieses Programmangebot Wettbewerbsnachteile haben. ${ }^{186}$ Für die Konsumenten ist es dann vorteilhaft, ihre Nachfrage auf den Online-Dienst mit Musikangebot (T-Online) zu konzentrieren. ${ }^{187}$ Wettbewerbspolitisch wäre die Einrichtung von Verbindungen (sog. links) von den Online-Diensten anderer Anbieter zur Musikdatenbank von T-Online zu begrüßen. Diese Regelung entspricht dem Prinzip des offenen Netzzugangs, der im Markt für Online-Dienste die diskriminierungsfreie, d. h. ohne zusätzliche Kosten durchzuführende Weiterleitung der Kunden eines OnlineDienstes auf die Angebote aller anderen Online-Dienste vorsieht. Angesichts der Tatsache, daß eine wettbewerbliche Mißbrauchsaufsicht im IuKDG nicht explizit geregelt ist, käme dieser Regelung große Bedeutung zu. Damit wäre nicht nur die Forderung nach dem Zulassen von Netzwettbewerb gestellt, sondern die wesentliche Voraussetzung für ihn geschaffen. Kommt es zu einer Aggregation von Nachfrage bei einem Online-Dienst wegen seiner Kumulation von interessanten Musikabfragemöglichkeiten, so ermöglicht ein offener Zugang zu diesem Angebot des Online-Dienstes sowohl intramodale als auch potentielle Konkurrenz auf den Märkten für Online-Dienste und Netzinfrastruktur. ${ }^{188}$ Dadurch ist für die Konsumenten nicht nur ein offener Zugang zum Gesamtangebot gegeben, sondern auch für andere Online-DiensteAnbieter die Möglichkeit, sich in einer eigenen Marktnische zu etablieren. ${ }^{189}$

Sowohl auf dem Markt für Online-Dienste als auch bei den Offline-Angeboten mit der CD als Trägermedium haben sich strategische Allianzen gebildet, die wettbewerbspolitische Beachtung verdienen. Einerseits erfordern zwar die Marktrisiken in einem zunehmend branchenübergreifenden globalisierten Wettbewerb eine Risikoaufteilung durch versärkte unternehmerische $\mathrm{Zu}$ sammenarbeit. Über die Vereinheitlichung von technischen Standards und die Aufteilung von Entwicklungskosten läßt sich zudem gegebenenfalls eine raschere Markteinführung erreichen. Zum anderen ist aber eine Kooperation dann bedenklich, wenn sie zwischen den wichtigsten

${ }^{186}$ Natürlich ist diese Sichtweise auf den nationalen Anbieter T-Online langfristig zu kurz gegriffen, da Service-Provider global agieren und Partner der musikalischen Content-Provider werden. Insofern ist die gegenwartige Situation geprăgt durch die aus der füheren Monopolstellung der Telekom resultierende Marktführerschaft von $\mathrm{T}$-Online und das sich erst entwickelnde globale Urheberrecht. Erst ein einheitlicher Rechtsrahmen in den wichtigsten Mărkten verbunden mit einer effektiven Rechtsdurchsetzung schaff die Voraussetzung globale Verwertungsverträge.

187 Abgesehen davon ist $\mathrm{T}$-Online als Tochtergesellschaft der Telekom mit dem marktbeherrschenden Netzbetreiber verbunden.

$18 \mathrm{Vgl}$. Klimisch, Annette, und Markus Lange, Zugang zu Netzen und anderen wesentlichen Einrichtungen als Bestandteil der kartellrechtlichen Mißbrauchsaufsicht, in: Wirtschaft und Wettbewerb, 48. Jg. (1998), S. 15-26.

189 Vgl. Klodt, Henning, Claus-Friedrich Laaser, Jens Oliver Lorz und Rainer Maurer, op. cit., S. 170. 
Konkurrenten auf einem Markt vereinbart wird. ${ }^{190}$ Wettbewerbspolitisch entscheidend ist hier die Offenhaltung des Marktzugangs für interessierte Unternehmen.

Auf der Ebene der musikalischen Content-Provider (Tonträgerhersteller) spielt das Phänomen der kollektiven (Gruppen-)Macht eine Rolle. War bei der körperlichen Musikverwertung mit Tonträgern festzustellen, daß es weder nennenswerten Preis- noch Qualitätswettbewerb gab, läßt auch die netzgebundene Musikverwertung das Entstehen von Preiswettbewerb nicht erwarten. Zwar ist die formale Handlungsfreiheit des Service-Providers T-Online gegenüber den musikalischen Content-Providern gegeben, aber diese haben über ihren Bundesverband in einem Rahmenvertrag die Beteiligung am Erlös durch zusätzliche Abonnenten erreicht, die durch das netzgebundene Musikangebot gewonnen werden, so daß die materiale Entschließungsfreiheit beeinträchtigt ist. Zudem beinhaltet die getroffene Preisregelung zwar keine Verpflichtung zu einheitlichen Preisen, läßt diese gegenüber den Musikkonsumenten jedoch erwarten.

Als Ergebnis der Wettbewerbsanalyse der netzgebundenen Musikverwertung und der Untersuchung der Regelungen des IuKDG als Ordnungsrahmen lassen sich mehrere Punkte anführen. So ist erstens zu konstatieren, daß für Online- und Abrufdienste gesonderte rundfunkspezifische Kontrollmechanismen neben den bereits bestehenden allgemeinen Gesetzen nicht erforderlich sind. Zweitens wird die Regelung eines offenen Netzzugangs dann benötigt, wenn der netzgebundene Musikvertrieb zu nennenswerten Beschränkungen des Wettbewerbs auf der Ebene der Online-Dienste führt. Drittens wird sich durch die unkörperliche Musikverwertung keine wesentliche Veränderung des Wettbewerbs zwischen den musikalischen ContentProvidern ergeben. Dieser wird - ähnlich wie bei der Tonträger-Vermarktung - auf den Produktwettbewerb und damit die Medienpräsenz und Medienkonkurrenz beschränkt bleiben. Daher wird viertens auch die Qualitätsverbesserung bei der Übertragungstechnik (Digitalisierung) von Radio und Fernsehen den intermediärer Konkurrenzcharakter in der Musiknutzung nicht grundlegend revolutionieren.

\subsection{Zusammenfassung}

An der Schwelle der körperlichen Offline- zur unkörperlichen Online-Musikverwertung sind in den vergangenen Jahren eine Reihe neuer Produkte in den Markt eingeführt bzw. zur Marktreife entwickelt worden. Es handelt sich einmal um Multimediatonträger, die im Musikbereich wenig Entwicklungspotential haben. Zweitens handelt es sich um selbstzusammenstellbare Tonträger (sog. Instore-Production), die Handelsfunktionen reduzieren, die der Konsument aber im Handel erhält. Diese Produkte haben Übergangscharakter und bewirken die Veränderung der Produktpolitik der Hersteller von Albenveröffentlichungen zur Veröffentlichung von einzelnen Musiktiteln. Die Musikverwertung mit Verteilnetzen durch digitales Radio und mit Vermittlungsnetzen auf der Basis des ISDN-Telefonnetzes und des multimediafahigen PCs als common interface ist möglich geworden auf der Basis von Veränderungen des Urheberrechts. Dies hat seitens der Urheber und Tonträgerhersteller zu Handlungsoptionen der Musikverwertung geführt. Nachdem digitales Radio und Multichanneldienste bestehen, ist auf der WI-

${ }^{190}$ Im Markt der musikalischen Content-Provider sind die Major-Tonträgerhersteller die wichtigsten Konkurrenten. 
PO-Konferenz im Dezember 1996 ein ausschließliches elektronisches Verbreitungsrecht als 'communication to the public' fur Urheber und ein ausschließliches 'making available-right' furr die Tonträgerhersteller eingeführt worden. Dadurch ist die netzgebundene Musikverwertung für die Rechteinhaber steuerbar geworden. Die Markteinführung einer eigenen elektronischen netzgebundenen Musikverwertung steht bevor. Ein wahrscheinliches Modell der organisatorischen Umsetzung wurde vorgestellt. Im Ergebnis wird neben dem Preis und der Qualität als weiterer Aktionsparameter im Wettbewerb der Service ausfallen, da Musiktitel online über einen Service-Provider stets verfügbar sind.

Im Zuge der netzgebundenen Musikverwertung werden Musiker und Tonträgerhersteller zu Content-Providern. Vertragsbesonderheiten wie pre-sales und package-deals bleiben auch beim elektronischen Vertrieb von Musik bestehen, dafür wird jedoch mit der Handelsstufe auch der Preiswettbewerb beim online-Vertrieb wegfallen. Die verbleibenden Funktionen der Handelsstufe übernehmen Online-Dienste, die als Service-Provider fungieren. Eine mögliche Preisdifferenzierung orientiert sich eher an der Nutzungsintensität, die variiert, je nachdem, ob die Musik nur einmal gehört wird oder durch Speichenung jederzeit wieder hörbar ist. Die technischen Voraussetzungen netzgebundener Musikverwertung sind Zugangskontroll- und Kopiersperrtechniken, die einen Ausschluß vom Konsum und die Steuerung der weiteren Verwertung bewirken sollen. Wegen der Verbundinterdependenz zur Nachfrage der Konsumenten nach Online-Diensten ist deren Nachfrage nach Musik abhängig von ihrer Attraktivität. Online-Dienste realisieren als Service-Provider beim Vertrieb ihrer Programminhalte Skaleneffekte bis zur maximalen Netzwerkkapazität. Daraus resultiert eine partielle Interessenidentität bzw. eine gegenseitige Instrumentalisierung zwischen Content- und Service-Providern. Für Content-Provider wird eine breite Publikumsbasis mit einer hohen Abonnentenzahl erreicht, die Ausgangspunkt für einen Diffusionserfolg der Musik ist. Der Service-Provider kann eine größere Kundenbindung als der Tonträgerhandel schaffen. Die gesteigerte Verfügbarkeit von Musik und die gegenüber der physischen Distribution höhere Markttransparenz kann zu einer größeren Nachfrageakzeptanz führen. Gleichwohl wird vermutet, daß das altersspezifische Nachfrageverhalten nach Musik online und offline nicht divergiert. Die Veränderungen der Verwertungskette von off- zu online-Musikverwertung wurden in den Abbildungen 28 und 29 zusammengefaßt. Festzustellen ist, daß die Verwertungskette durch die Online-Musikverwertung erheblich kürzer geworden ist. Die Zugriffsmöglichkeiten der Konsumenten haben sich ebenso erhöht wie die eigenen Vermarktungsmöglichkeiten der Musiker.

Der netzgebundene Musikvertrieb hat indirekte Netzwerkeffekte zur Folge, die im Hardware/Software-Problem und der Unsicherheit der Konsumenten über die weitere technische Entwicklung ihre Ursache haben. Durch Abwärtskompatibilität und kostenloses Bereitstellen der Zugangsgeräte wurden diese gelöst. Lock-in-Effekte sind wegen der geringen switching costs daher ebenfalls nicht von Bedeutung. Die technischen Möglichkeiten haben Auswirkungen auf die Wettbewerbspotentiale geschaffen, die zu einer Veränderung der Marktstruktur im Tonträgermarkt führen können. Musiker haben Möglichkeiten zur Vorwärtsintegration in einen eigenen Vertrieb. Hierzu fehlen ihnen jedoch die erfolgreiche Durchfürung der Marketingund Zahlungsfunktion. Die Content-Provider (Tonträgerhersteller) haben bei einer Vor- 
wärtsintegration das Problem der Programmbeschaffung für den Online-Dienste-Markt, was sie zu einer gleichzeitigen Diversifikation zwingen würde. Eine Vertragsabhängigkeit der Contentvon Service-Providern ist wegen der Expansionsphase des Online-Dienste-Marktes nicht zu erwarten. Service-Provider werden zur Steigerung der Attraktivität gegenüber ihren Konkurrenten eine Faktormonopolisierung und mit der Zugangskontroll- und Kopierspertechnik die Schaffung eines Engpaßfaktors versuchen. Hinsichtlich einer möglichen Rückwärtsintegration erweist es sich für Service-Provider wegen des intensiven Beschaffungswettbewerbs auf der Ebene der musikalischen Content-Provider als günstiger, die musikalischen Inhalte auf dem Vertragsweg langfristig zu binden. Als marktnaher Bereich mit erhöhtem Potential zu Markteintritten in die netzgebundene Musikverwertung wurde die Telekommunikations-, Unterhaltungselektronik-, datenverarbeitende und die Medienindustrie i. w. S. identifiziert. Dabei sind zur Umsetzung des Marktzutritts sowohl Übernahmen als auch Kooperationen möglich.

Die Verwertung von Musik mit Hilfe von Netzen hat auch urheber- und ordnungsrechtliche Aspekte. Durch das Speichern in einem multimediafähigem PC ist die Vervielfältigung i. S. von $\S 16$ UrhG gegeben. Eine Verbreitung gemäß $\S 17$ UrhG erfolgt nicht, da keine körperliche Weitergabe der gespeicherten Musik auf einem Träger vollzogen wird. Die netzgebundene Musikverwertung auf Abruf kann urheberrechtlich als unkörperliche Verwertung durch öffentliche Wiedergabe i. S. v. $§ 15$ Abs. 2 UrhG klassifiziert werden. Eine Sendung i. S. v. $§ 20$ UrhG liegt nicht vor. Im Rahmen der Konferenz der WIPO im Dezember 1996 wurde ein ausschließliches Vervielfältigungsrecht für Urheber in Art. 6 WCT, für ausübende Künstler in Art. 8 WPPT und für Tonträgerhersteller in Art. 12 WPPT eingeführt. Zusätzlich wurde ein ausschließliches Vermietrecht für Tonträgerhersteller gegenüber dem Herunterladen von Musik, Brennen auf einen Tonträger und anschließende Verbreitung geschaffen (Art. 13 WPPT). Für Urheber wurde das Recht der öffentlichen Wiedergabe als making available right etabliert, netzgebundene Übertragungen zuzulassen oder zu untersagen. Ausübende Künstler und Tonträgerhersteller haben nach Art. 10 und 14 WPPT ein ausschließliches Recht der öffentlichen Wiedergabe, welches als communication to the public definiert ist. Auf europäischer Ebene sind die Beschlüsse der WIPO-Konferenz erst in einem Richtlinienentwurf vom Dezember 1997 verarbeitet. Die Verabschiedung einer Richtlinie sowie die Umsetzung in nationales Recht (de lege ferenda) steht noch aus. Musik auf Abruf via Netz wird wegen der dafür nötigen Bezahlung als Individualkommunikation angesehen und fallt damit in die Regelungskompetenz des Bundes, der ein IuKDG erlassen hat. In ihm wird der offene Netzzugang sowie zur Markttransparenz nötige Veränderungen der Preisangabenverordnung geregelt. Bezüglich der Mißbrauchsaufsicht werden keine speziellen Regelungen getroffen, die Anwendung der Bestimmungen des GWB und die allgemeinen Bestimmungen des Wirtschaftsrechts bleiben davon unberührt.

Veränderungen der elektronischen Musikbelieferung betreffen auch Marktverhalten und Marktergebnis. Musik ist online prinzipiell mit weniger Ressourcen verbreitbar als dies bei physischer Verwertung möglich war. Dadurch kann sie auch für die Konsumenten leichter verfügbar werden. Das ändert aber letztlich nichts an der Tatsache, daß ein erfolgreicher Diffusionsprozeß die Voraussetzung fur Musikverwertung ist. Daher bleibt es auch bei elektronischer 
Musiklieferung zentrale Aufgabe musikverwertender Unternehmen, die Aufmerksamkeit der Konsumenten zu bewirken und sie für die Erstverwertung (Musikkauf) zu gewinnen. Die Rezeptionsgewohnheiten der bisher nicht für Musik erreichbaren Nachfrage (insbesondere ältere Menschen) schließt eine Erhöhung der Käuferreichweite bei Online-Musikverwertung aus. Die Entwicklung zur multimedialen Freizeitgestaltung erhöht die Konkurrenz im Hinblick auf das Zeit- und Geldbudget der Konsumenten, die bisher Musik kauften. Daher steht zu erwarten, $\mathrm{da}$ zwar die Intensivkäufer und -nutzer von Musik von der neueren technischen und auch marktlichen Entwicklung profitieren werden, aber für den Gesamtmarkt bei Konstanz der Konzentration und Funktionsprinzipien lediglich ein evolutionärer Wechsel der Vertriebskanäle von Musik festzustellen sein wird. 


\section{Schlußbemerkungen}

Ziel der Untersuchung der Ökonomie der Musikindustrie war es einleitend, Funktionsweise und Funktionsprinzipien der Musikverwertung in ihrer historischen Entwicklung, ihren rechtlichen Rahmenbedingungen und deren ökonomischen Anreizen herauszuarbeiten. In einem zweiten Schritt erfolgte eine industrieökonomische Analyse der Musikverwertung mit Tonträgern in der Bundesrepublik Deutschland anhand der Marktstruktur- und Marktverhaltensmerkmale in ihrem jeweiligen Zusammenhang mit den Marktergebnissen. In einem abschlieBenden dritten Schritt wurden die Veränderungen betrachtet, die sich aus der technischen Weiterentwicklung zu einer unkörperlichen netzgebundenen Verwertung ergeben.

Die Verwertung von Musik war anfänglich nur direkt auf dem Weg der konzertanten Auffuihrung von Musikern und dem Konsum der hörenden Rezipienten möglich. Durch die Fixierung der Musik auf Noten wurde sie zunächst wiederholbar, aber erst durch die Erfindung von Schallaufzeichnungs- und Wiedergabetechniken vollzog sich die Entkopplung des Musikspielens vom Musikhören. Damit war die Verbreitung der Musik nicht mehr allein abhängig von Konzerten, sondern auch vom Verkauf der Abspielgeräte und der zugehörigen Tonträger. Das Zusammenspiel von Wiedergabegerät (als Hardware) und Trägermedium (als Software) begann mit Edisons Phonographen und Walze, es folgte Berliners Grammophon mit der Schellackplatte, die später durch Vinyl ersetzt wurde. Ein weiterer technischer Schritt war die Erfindung der Magnettonbänder, die neben der Wiedergabe nun auch die Aufzeichnung von Musik durch die Konsumenten selbst ermöglichten. Als sich die Tonbänder in Form von kompakten Musikkassetten etablierten, wurde für viele Nachfrager die private Kopie das Substitut zum Kauf bespielter Tonträger. Eine weitere Steigerung sowohl der Tonträgerumsätze als auch der Wiedergabequalität wurde durch die digitale Compact Disk erreicht, die sich schon wenige Jahre nach der Markteinführung zu Beginn der achtziger Jahre zum Standardtonträger entwikkelte. Weit über $90 \%$ der körperlichen Musikverwertung wird gegenwärtig mit diesem Trägermedium bewerkstelligt.

Mit Hilfe von Tonträgern wurden 1997 in der Bundesrepublik Deutschland knapp 6 Milliarden DM Umsatz erwirtschaftet. ${ }^{1}$ Tonträger sind superiore Freizeitkonsumgüter, deren gesamter Nachfrageverlauf stark von der Entwicklung des privaten Verbrauchs und der Altersstruktur der Bevölkerung abhängt. Tonträgerhersteller fragen Musikkomposition und Musikgestaltung durch ausübende Künstler nach, mit denen das Produkt „mit Musik bespielter Tonträger" erst vermarktbar wird. Ebenso spielen Rundfunk- und Fernsehanstalten eine konstitutive Rolle für den Diffusionsprozeß der Musik. Mit Hilfe von Tonträgern hat nur diejenige Musik eine Chance auf Absatz, die auch über die Medien bekannt geworden ist. Gleichwohl hat die Medienpräsenz von Musik auch substitutiven Charakter, wenn der Musikkauf durch ständiges Radiohören oder Musikfernsehen ersetzt wird. Verdeutlicht werden die durchaus unterschiedlichen Verwertungsinteressen von Tonträgerherstellern und Radioanstalten durch den herrschenden Konflikt bei der Auslegung des Urheberrechts. Besteht weitgehend Einigkeit darüber, daß Musikstücke nach $\S 2$ Abs. 2 UrhG schutzwürdige Werke sind, für die die Musiker ausschließ-

I Vgl. Phono-Press 1998, S. 2 f. 
liche Rechte haben, die sie ebenfalls ausschließlich nach den $\S \S 15$ Abs. 1, 16 und 17 UrhG den Tonträgerherstellern zum Zwecke der Vervielfältigung und Verbreitung der Musik auf Tonträgern einräumen, so steht hinsichtlich des ausschließlichen Vervielfältigungs- und Verbreitungsrechts der Tonträgerhersteller das Senderecht von Programmveranstaltern wirtschaftlich entgegen. Dieses ermöglicht den Radio- und Fernsehanstalten, bereits erschienene Tonträger gegen Zahlung einer vergleichsweise geringen Vergütung zu senden. Das den Tonträgerherstellern konträre Interesse der Radiostationen zielt darauf ab, Musik als hauptsächlichen Programminhalt preisgünstig zur Verfügung gestellt zu bekommen. Im juristischen Sinn wird bei Ausstrahlung von Musik nach dem Senderecht eine angemessene Vergütung für Tonträgerhersteller und ausübende Musiker gezahlt, wobei der Streit, welche Vergütungshöhe angemessen ist, seit Einführung dieser Rechtsinstitution währt.

Auf europäischer Ebene wurde im Zuge der Harmonisierung des Urheberrechts mit der Vermiet- und Verleihrechtsrichtlinie für die Tonträgerhersteller ein ausschließliches Vermietrecht etabliert, nachdem wegen der abnutzungsfreien und digitalen Qualität der CD gewerbliche Vermietgeschäfte entstanden waren. Ein weiterer Harmonisierungsschritt war die Richtlinie zum Schutzumfang und zur Schutzdauer. Ungeachtet aller Harmonisierungsbestrebungen der EU-Kommission und der richterrechtlichen Ausdehnung des Diskriminierungsverbots auf das Urheberrecht durch den EuGH besteht jedoch weiterhin ein Vereinheitlichungsbedarf im Hinblick auf private Vervielfältigungen. Hier ist die Rechtslage in verschiedenen Mitgliedstaaten der Europäischen Union unterschiedlich und reicht von der Einstufung privaten Kopierens als vergütungsfreiem „fair use“ über Leerkassetten- und Geräteabgaben bis zu speziellen Verbrauchssteuern. Im Rahmen des Abkommens zur Gründung der World Trade Organisation (WTO) sind erstmalig Urheberrechtsfragen mit allgemeinen Handelsfragen verknüpft worden. Hierzu wurde spieltheoretisch nachgewiesen, daß eine Schutzversagung von Copyrightschutz für Länder selbst dann die dominante Strategie ist, wenn andere Länder einen entsprechenden Schutz gewährt haben, so daß erst mit der Kombination urheberrechtlicher und allgemeiner handelspolitischer Interessen auch auf internationaler Ebene die Einführung des Urheberrechtsschutzes in Entwicklungs- und Schwellenländern sowie Harmonisierungsschritte zu erwarten sind.

Hinsichtlich unterschiedlicher Copyrightschutzhöhen wurde abgeleitet, daß die ökonomische Aufgabe von Copyrights darin besteht, den trade-off zwischen dem „social welfare loss due to underproduction" und dem „social welfare loss due to underutilisation“ zu lösen. Wichtige Parameter für die Differenz zwischen optimaler Versorgung mit Musik auf Tonträgern und optimalen Anreizen für ihre Produktion sind die Existenz von Zweitmärkten, die Höhe der Ausschlußkosten und die administrativen Kosten des Copyrightsystems selbst. Für eine gegebene Schutzhöhe wurde wiederum spieltheoretisch hergeleitet, daß es für Tonträgerhersteller und Musikurheber ökonomisch rational ist, ihre Musiktitel auf Tonträger in demjenigen Land zuerst zu veröffentlichen, in dem der Copyrightschutz am größten ist. In real existierenden Tonträgermärkten verlagert sich das Problem hingegen von der Schaffung ausschließlicher Verwertungsrechte für Musik auf die Rechtsdurchsetzung seitens der Behörden jener Nationalstaaten, deren Tonträgermärkte zum größten Teil aus dem Handel mit Piraterieware beste- 
hen. Weiterer Forschungsbedarf besteht hier in der Ermittlung der Zusammenhänge zwischen einer Effektivität der bestehenden Urheberschutzabkommen, der Rechtsdurchsetzungsaktivität der Behörden und der Minimierung der Schädigungen der legalen Tonträgeranbieter.

Der Tonträgermarkt der Bundesrepublik Deutschland konnte sachlich abgegrenzt und in drei Marktstufen ausdifferenziert werden. In der ersten Marktstufe bieten Musiker entweder mittels Künstlerverträgen ihre musikalische Dienstleistung oder in Zusammenarbeit mit Masterproduzenten mittels eines Bandübernahmevertrags fertige Masterbänder den Tonträgerherstellern an. Die Tonträgerhersteller erwerben von den Musikurhebern (Texter und Komponisten) und Leistungsschutzberechtigten (ausübende Musiker) ausschließliche Nutzungsrechte zur Vervielfältigung und Verbreitung zum Zweck der Festlegung von Musik auf Tonträgern und ihrer anschließenden Vermarktung. In der zweiten Marktstufe bieten die Hersteller ihre Tonträger den verschiedenen Handelsformen bei indirektem Absatz an bzw. wählen den direkten Absatzweg. Der nachfragende Handel wiederum verkauft die Tonträger in der dritten Marktstufe an die Konsumenten.

Die Struktur des deutschen Tonträgermarktes ist - ebenso wie die Struktur aller weltweit wichtigen Tonträgermärkte - von zwei Anbietergruppen geprägt. Zwischen der Oligopolgruppe der Majors und der Randgruppe einer Vielzahl von Independents existieren signifikante Mobilitätsbarrieren im Markt. Sie liegen im Zugang zu den international vermarktbaren Musikern und den Absatzkanälen, die für eine hohe Diffusionsgeschwindigkeit angesichts der kurzen Produktlebenszyklen von Musik auf Tonträgern nötig sind. Ebenso können die Majors Vorteile durch Produktdifferenzierung und Risikoausgleich realisieren, die bei der Vermarktung von Musik deshalb von Bedeutung sind, weil die Nachfrage schnellen Präferenzänderungen unterliegt. Auf der Handelsstufe steht der Abnahme der absoluten Zahl von Outlets eine Zunahme der Handelskonzentration gegenüber. Die Käuferreichweite hingegen ist im betrachteten Zeitraum annähernd konstant geblieben. Im Hinblick auf die Alterstruktur der Tonträgerkäufer haben die Bevölkerungsgruppen mit überproportionalen Tonträgerkäufen abgenommen, während diejenigen mit unterproportionalen Käufen zugenommen haben.

Das Marktverhalten der Tonträgerhersteller ist gekennzeichnet vom Beschaffungswettbewerb um die bekannten Musiker, die bereits etabliert sind. Bekannte Musiker haben eine Funktion als Markenartikel, deren Musik mittels eines Präferenztransfers zwischen ihnen und den Konsumenten sichere Tonträgerabsätze ermöglicht. Aktionsparameter im Wettbewerb sowohl innerhalb der Gruppe der Majors als auch zwischen den Majors und Independents ist die Produktpolitik mit Hilfe der Neuveröffentlichung von Tonträgertiteln, die den Charakter eines Innovationswettbewerbs aufweist. Permanente Neuveröffentlichungen bei kurzen Produktlebenszyklen führen zu einem Innovationsdruck, wofür das Innovationspotential nicht ausreicht. Deswegen werden neben den echten Produktinnovationen Quasi-Innovationen durch Bearbeitung bereits erfolgreich veröffentlichter Musik und Pseudoinnovationen durch Neuauflage, Neuzusammenstellung und Covern der Musik praktiziert. Der Grund für den Erfolg dieser Musik liegt am Produkttransfer, d. h. an ihrem Wiedererkennungswert im Vergleich zu früheren Versionen. Die internationale Verwertung etablierter Musiker ist ebenso ein strategischer 
Vorteil für die Majors, die in allen weltweit wichtigen Tonträgermärkten präsent sind, wie der umfangreiche Backkatalog bereits veröffentlichter Musiktitel, für den sie Rechte zur Zweitund Drittverwertung haben. Weitere Aktionsparameter im Wettbewerb spielen im Tonträgermarkt nur eine untergeordnete Rolle. Insbesondere die Preispolitik der Oligopolgruppe ist weitgehend einheitlich. Die bestehenden Preisunterschiede haben eher die Funktion, Produktgruppen zu definieren und werden von den Majors gleichgerichtet eingesetzt. Strategische Barrieren zwischen Majors und Independents bestehen im Zugang zu den Medien, um für das Produkt „Musik auf Tonträgern" Nachfrage zu schaffen, und der Fähigkeit der Majors, flexibel und schnell auf Nachfrageschwankungen durch das Vorhalten eigener physischer Herstellungsund Distributionskapazitäten reagieren zu können.

Die Marktstufe des Tonträgerhandels ist durch starken Preiswettbewerb gekennzeichnet und hat nicht zuletzt durch die Hitlisten-Platten-Entscheidung des $\mathrm{BGH}^{2}$ eine Diskussion zu UnterEinstandspreis-Verkäufen im Rahmen der 6. Kartellnovelle ausgelöst. ${ }^{3}$ Der Preiswettbewerb des Tonträgerhandels ist Ausdruck der Handelskonzentration und der unterschiedlichen Bedeutung von Tonträgern im Sortiment der verschiedenen Handelsformen. In Großbetriebsformen des Einzelhandels erfüllen Tonträger nicht selten Ausgleichsnehmerfunktionen für andere Artikel. Die Nachfrage nach Tonträgern ist ebenfalls stark konzentriert. Das Kaufverhalten der Nachfrager, das in Intensiv-, Durchschnitts- und Extensivkäufer unterteilt wurde, reagiert unterschiedlich auf die untersuchten Einflußgrößen. Während Intensivkäufer elastischer auf ein großes Sortiment und niedrige Preise reagieren, sind Extensivkäufer reagibler hinsichtlich des Einkaufsortes. Die räumliche Verfügbarkeit und damit die Dichte des Händlernetzes, welches angesichts der zunehmenden Konzentration auf der Handelsstufe gerade ausgedünnt wird und nicht mehr flächendeckend ist, hat daher einen großen Einfluß auf die Käuferreichweite und die zukünftige Konsumentenstruktur.

Im Hinblick auf Marktergebnisse des Tonträgermarktes ist die einzelwirtschaftliche Datenlage unbefriedigend. Die Oligopolisten haben kein Interesse an der Veröffentlichung ihrer Marktanteilsdaten, die nur kumuliert bekannt gegeben werden. Die Stückgewinnrelation von Tonträgern in Abhängigkeit von der verkauften Stückzahl wird ebensowenig bekanntgegeben wie die Einzelheiten der Verträge mit den Musikern. Da letztlich nicht einmal die gesamte verkaufte Stückzahl eines Tonträgertitels veröffentlicht wird, mußten Ersatzgrößen für die Untersuchung des Marktergebnisses herangezogen werden. Als Ersatzgrößen fungierten die Zahl der jährlichen Neuveröffentlichungen, die wöchentlichen Ranglisten (Charts) und die Vergabe von Erfolgsauszeichnungen (goldene Schallplatten), die an den Verkauf bestimmter Stückzahlen geknüpft ist.

Die Zahl der jährlichen Neuerscheinungen ist seit 1985 gestiegen, und in der Folge ist die durchschnittliche Verkaufszahl pro Neuerscheinung zurückgegangen. Anhand der Charts wurde die Erfolgsverteilung der Musikproduktion auf Single-Tonträgern von 1985-1997 gemes-

Vgl. BGH, Hitlisten-Platten, WuW/E BGH, 2977 ff.

Vgl. Schmidt, Ingo, und Jürgen Wuttke, Leistungswettbewerb und unbillige Behinderung i. S. des § 26 Abs. 4 GWB, in: Betriebs-Berater, 53. Jg. (1998), S. 753-758. 
sen. Die Zahl der Musiktitel, die neu in die Chartplätze eintreten konnten, ist über den gesamten Zeitraum annähernd konstant geblieben sind. Jedoch ist die Zahl der Musiktitel und der Musiker mit solchen Hits, die die ersten zehn Plätze (Top Ten Hits) erreichten, von 1985-1993 rückläufig gewesen. Invers dazu hat die durchschnittlichen Verweildauer in den ersten zehn Ranglistenplätzen zugenommen. Ebenso nahm die Zahl der Nr. 1 Hits ab. Seit 1993 nimmt die Zahl der Musiktitel in den Top Ten und der Musiker mit solchen Titeln wieder zu, und infolgedessen verkürzten sich die durchschnittlichen Verweildauern in den Top Ten wieder. Diese zeitliche Bewegung in den Chartplätzen wird nachgezeichnet durch die durchschnittliche jährliche Verkaufszahl pro Neuerscheinung, die ebenfalls von 1985-1991 abnahm und seitdem wieder zunahm. Von der großen Zahl veröffentlichter Singles erreichte offenbar nur ein konstant kleiner Teil überhaupt den Erfolg des Charteintritts und auch Änderungen des Chartdesigns hatten mittelfristig keinen Einfluß auf die prozentualen Neueintritte. Das Marktverhalten der Produktpolitik hatte offenbar keinen wesentlich marktausweitenden, sondern eher einen marktanteilsverschiebenden Effekt. Die Zahl der mit goldenen Schallplatten ausgezeichneten Singles stieg von 1986-1995 ebenso an wie die Zahl der ausgezeichneten Musiker und Tonträgerhersteller. Der Erfolg einzelner Musiktitel spiegelte sich in hohen Verkaufszahlen wieder, zugleich verteilte er sich aber auf zunehmend mehr erfolgreich agierende Unternehmen. Dieses könnten erste Anzeichen einer dekonzentrativen Entwicklung sein.

Die oligopolistische Marktstruktur spiegelte sich auch in den Chartanteilen der Tonträgerunternehmen wieder, die für den Zeitraum 1985-1997 untersucht wurden. Die Konzentration der Chartanteile auf die größten Unternehmen (Majors) war bei den Longplay-Tonträgern höher als bei den Singles. Hieraus konnte die Erkenntnis abgeleitet werden, daß es für Independents einfacher ist, Erfolge auf dem Single- als auf dem Longplay-Markt zu erzielen. Ebenso unterstützte die Untersuchung der Chartanteile die Hypothese vom Ablauf des Beschaffungswettbewerbs, in dem Independents insbesondere bei der Neuverpflichtung unbekannter Musiker, die sich erst am Anfang ihrer Karriere befinden, bestehen können. Mit diesen Künstlern werden zunächst vorwiegend Singles eingespielt, deren Produktionskosten und Risiko unterhalb einer Longplay-Veröffentlichung liegen. Etablieren sich die Musiker, setzen sie ihre Laufbahn meistens bei den Majors fort, obwohl (oder gerade weil) deren Produktionskosten (und auch Produktionsbudgets) höher sind als diejenigen der Independents. Demgegenüber haben Majors Größenkostenvorteile im Marketing, bei der physischen Herstellung und der Distribution. Diese Vorteile versuchen sie im Zuge von Reformen ihrer Organisationstruktur mit der Flexibilität und Nähe zu den Musikern zu verbinden, die die Independents auszeichnet. Unterschiedliche vertikale Integrationsgrade von Independents und Majors haben auch zu Unternehmenskooperationen geführt, wobei ein Erfolg von Independents diese stets zum Objekt von Übernahmen machte.

Bei der Vermarktung der Rechte an einem erfolgreichen Musiktitel wurden weitere Erlöspotentiale erschlossen. Neben der werbetreibenden Industrie wurden durch die technische Weiterentwicklung auch die Online-Dienste zur Vermarktung von Musik interessant. Mit Hilfe eines Online-Dienstes und Netzbetreibers wurde die unkörperliche Musikverwertung via Netz technisch realisiert. Eine Reihe von Produkten wurde in den Markt eingefuhrt bzw. ist in der 
Einführungsphase. In Verteilnetzen bei digitalem Radio und in Vermittlungsnetzen auf der Basis des ISDN-Telefonnetzes und des multimediafahigen PCs als common interface ist Musik eine Pionieranwendung der Online-Unterhaltung. Veränderungen des Urheberrechts, die durch die WIPO-Konferenz vom Dezember 1996 beschlossen wurden und noch in europäisches und nationales Recht umzusetzen sind, betrafen die Einfuhrung eines ausschließlichen elektronischen (daher unkörperlichen) Verbreitungsrechts für Urheber als "communication to the public" und ein ausschließliches „making available-right" für die Tonträgerhersteller. Im Ergebnis ist die netzgebundene unkörperliche Musikverwertung für die Rechteinhaber steuerbar geworden. Tonträgerhersteller werden im vorgestellten Szenario der organisatorischen Umsetzung netzgebundener Musikverwertung zu musikalischen Content-Providern, die mit den ServiceProvidern kontrahieren. Service Provider fungieren als Online-Dienste und bewerkstelligen den elektronischen Musikvertrieb. Die technischen Voraussetzungen netzgebundener Musikverwertung sind Zugangskontroll- und Kopiersperrtechniken, die einen Ausschluß vom Konsum und die Steuerung der weiteren Verwertung zum Ziel haben. Die Verwertungskette von Musik hat sich dadurch verändert. Neben der Handlungsoption der Musiker, selbst im Netz anzubieten, ergeben sich Markteintrittspotentiale für Unternehmen der Telekommunikations-, Unterhaltungselektronik-, datenverarbeitenden Industrie und der Medienindustrie i. w. S. Dabei sind zur Umsetzung des Marktzutritts sowohl Kooperationen als auch Übernahmen von Tonträgerherstellern möglich.

Veränderungen der elektronischen Musikverwertung betreffen auch Marktverhalten und Marktergebnis. Die Verbreitung von Musik ist mit geringerem Ressourceneinsatz möglich. Den musikalischen Content-Providern wird die Entscheidung über Neuveröffentlichungen und Neuauflagen erleichtert, da nur noch die Kosten der ersten Einspielung und Speicherung für die Musikdatenbank, die als Server fungiert, anfallen. Retouren und Wegekosten entfallen und ebenso sukzessive die Funktionen des Tonträgerhandels. Ob damit die Eintrittsmöglichkeit in den Markt der Musikverwertung erleichtert wird, darf bezweifelt werden. Denn für die erfolgreiche Verwertung von Musik ist ein Diffusionsprozeß nötig, zu dem die Medien als Multiplikatoren unabdingbar gehören. Daher bleibt es auch bei elektronischer Musikverwertung die zentrale Aufgabe der musikalischen Content-Provider, die Aufmerksamkeit der Konsumenten zu erreichen und sie für den Musikkauf (mit oder ohne Träger) zu gewinnen. Die zentrale Unternehmensfunktion besteht auch bei einem evolutionären Wechsel der Vertriebskanäle vom Tonträgerhandel mit dem körperlichem Produkt zum unkörperlichen online-Vertrieb in der Schaffung von Publika für das Produkt „kaufbare Musik“. Die Möglichkeit des Abrufens einzelner Musiktitel erhöht für die Konsumenten deren Souveränität und vereinfacht die Befriedigung ihrer Präferenzen. Durch den Übergang von der körperlichen zur unkörperlichen Musikverbreitung werden sich jedoch die analysierten Funktionsprinzipien der Musikökonomie und die Konzentration dieses Marktes nicht maßgeblich verändern.

Mit dem in den Kapiteln 4 und 5 verwendeten Struktur-, Verhalten- und Ergebnis-Paradigma der industrieökonomischen Forschung konnten Zusammenhänge aufgezeigt werden, die für die Musikindustrie typisch und für ihre Existenz zwingend notwendig sind. Gleichwohl wurde deutlich, daß weder die Entwicklung der körperlichen noch diejenige der unkörperlichen $\mathrm{Mu}$ - 
sikverwertung deterministisch erklärbar sind durch Zusammenhänge von Marktstruktur, Marktergebnis und Marktverhalten. Vielmehr resultieren Eintritte in den Markt aus den Charakter des Gutes Musik und dem Wunsch nach eigenständiger Vermarktung. Weiterentwicklungen der technischen Möglichkeiten sind für die Musikverwertung exogen gegeben und verändern die Funktionszusammenhänge nicht.

Friedrich Nietzsche wird der Satz zugeschrieben, ohne Musik wäre das Leben ein Irrtum. Es wäre jedoch auch ein solcher Irrtum, wenn man die Wiederholungen, die als Charakteristikum der Musik von der Musikwissenschaft selbst anerkannt sind und die aus dem Motiv der Wiedererkennung die Produktpolitik der Musikverwerter i. S. eines ständigen Produkttransfers leiten, nicht auch auf die Weiterentwicklung der Musikverwertung selbst übertragen würde. Die Funktionsprinzipien bedingen eine Wiederholung der Abläufe, deren Konstellationen mit der Ökonomie der Musikindustrie erklärt werden können. 
Jürgen Kulle - 978-3-631-75477-1

Downloaded from PubFactory at 01/11/2019 04:31:24AM

via free access 


\section{Literaturverzeichnis:}

Abbot, Lawrence, Qualität und Wettbewerb, München 1958.

Alexander, P. J., Entry Barriers, Release Behavior, and Multiproduct Firms in the Music Recording Industry, in: Review of Industrial Organization, Vol. 9 (1994), S. 85-98.

Alpar, Paul, Kommerzielle Nutzung von Marketing, Produktion, Logistik und Querschnittsfunktionen durch das Internet und kommerzielle Online-Dienste, Berlin u. a. 1996.

Alpert, Leon, Estimating A Multi-Attribute Model for Different Music Styles, in: Journal of Cultural Economics, Vol. 7 (1983), S. 63-81.

Anderson, B., et. al., Hit Record Trends 1940-1977, in: Journal of Communication, o. Jg. (1980), S. 31-43.

Arthur, W. B., Competing Technologies, Increasing Returns, and Lock-in by Historical Events, in: Economic Journal, Vol. 99 (1989), S. 116-129.

Audretsch, David B., Divergent views in antitrust economics, in: Antitrust Bulletin, Vol. 33 (1988), S. $135 \mathrm{ff}$.

Bain, Joe S., Barriers to New Competition, Cambridge, Mass. 1956.

ders., Industrial Organisation, 2. Aufl., New York u. a. 1968.

ders., Relation of Profit Rate to Industry Concentration: American Manufacturing 1936-1940, in: Quarterly Journal of Economics, Vol. 65 (1951), S. 293-324

ders., Economies of Scale, Concentration and the Condition of Entry in Twenty Manufacturing Industries, in: American Economic Review, Vol. 44 (1954), S. 15-19.

ders., Price Leaders, Barometers and Kinks, in: Journal of Business, Vol. 33 (1960), S. 193203.

ders., Changes in Concentration in Manufacturing Industries in the United States 1954-1966: Trends and Relationships to Levels of 1954 Concentration, in: Review of Economics and Statistics, Vol. 52 (1970), S. 411-416.

Bain, Joe S., und P. David Qualls, Industrial Organization: A Treatise, Greenwich, London 1987. 
Baker, Alan, A Modell of Competition and Monopoly in the Record Music Industry, in: Journal of Cultural Economics, Vol. 15 (1991), S. 29-54.

Baumol, William J., Income and Substitution Effects of the Linder Theorem, in: Quarterly Journal of Economics, Vol. 87 (1973), S. 629-633.

Baumol, William J., und William G. Bowen, Performing Arts: The Economic Dilemma, 2. Aufl., New York 1978.

Bechtold, Stefan, Der Schutz des Anbieters von Information: Urheberrecht und Gewerblicher Rechtsschutz im Internet, in: Zeitschrift für Urheber- und Medienrecht (ZUM), 41. Jg. (1997), S. 427-450.

ders., Multimedia und Urheberrecht: einige grundsätzliche Anmerkungen, in: Gewerblicher Rechtsschutz und Urheberrecht (GRUR), 100. Jg. (1998), S. 18-27

Beck, Hanno, und Aloys Prinz, Das globale Internet-Dorf regieren, in: Frankfurter Allgemeine Zeitung, Nr. 56 vom 7.3.98, S. 15

Becker, Jochen, Marketing-Konzeption, 5. Aufl., München 1993

Becker, Jürgen, Die digitale Verwertung von Musikwerken aus der Sicht der Musikurheber, in: Becker, Jürgen, und Thomas Dreier (Hrsg.), Urheberrecht und digitale Technologie, Baden-Baden 1994, S. 45-76.

ders., Neue Übertragungstechniken und Urheberrechtsschutz, in: Zeitschrift für Urheber- und Medienrecht (ZUM), 39. Jg. (1995), S. 231-249.

Beggs, Alan, A Note on Switching Costs and Technology Choice, in: Journal of Industrial Economics, Vol. 37 (1989), S. 437-440.

Beier, K.-F., Die Bedeutung des Patentsystems für den technischen, wirtschaftichen und sozialen Fortschritt, in: Gewerblicher Rechtsschutz und Urheberrecht/Internationaler Teil (GRUR/I), Vol. 81 (1979), S. 227-237.

Behnke, Horst, Ein Erklärungsansatz für unterschiedliche Veränderungen in der Standortstruktur von Geschäften innerhalb verschiedener Städte bei gleichen Veränderungen in den Rahmenbedingungen, in: Beiträge zur Standortforschung, hrsg. von Behnke, Horst, u. a., Berlin 1994, S. 59-73.

Belinfante, Alexander, und Richard L. Johnson, Competition, Pricing and Concentration in the U. S. Recorded Music Industry, in: Journal of Cultural Economics, Vol. 6 (1982),

S. 11-24. 
Bellinghausen, I., CD-ROM: Einstieg in das Multimediazeitalter, in: Media Perspektiven, o. Jg., (1995), S. 489-495.

Beseler, Hans Friedrich, Die Harmonisierung des Urheberrechts aus europäischer Sicht, in: Zeitschrift für Urheber- und Medienrecht, $39 \mathrm{Jg}$. (1995), S. 437-441.

Besen, Stanley M., und Joseph Farrell, Choosing How to Compete: Strategies and Tactics in Standardization, in: Journal of Economic Perspectives, Vol. 8 (1994), S. 117-131.

Besen, Stanley M., und Leo J. Raskind, An Introduction to the Law and Economics of Intellectual Property, in: Journal of Economic Perspektives, Vol. 5 (1991), S. 3-27.

Besen, Stanley M., und Sheila Nataraj Kirby, Private Copying, Appropriability, and Optimal Copying Royalities, in: Journal of Law and Economics, Vol. 32 (1989), S. 255-280.

Bezold, N., Marktanalyse Tonträger, Nürnberg 1985.

Black, M., und D. Greer, Concentration and Non-Price Competition in the Recording Industry, in: Review of Industrial Organization, Vol. 3 (1987), S. 13-37.

Bleckmann, Albert, Europarecht, 6. Aufl., Köln u. a. 1997.

Bork, Robert H., Antitrust and the Theory of Concentrated Markets, in: Industrial Concentration and the Market System: Legal, Economic, Social and Political Perspektives, hrsg. von Fox, Eleanor M., und James T. Halverson, American Bar Association 1979, S. 81 ff.

Bortloff, Nils, Der Tonträgerpiraterieschutz im Immaterialgüterrecht, Baden-Baden 1995.

Braun, Thorsten, Das Diskriminierungsverbot des Art. 7 Abs. 1 EWGV und das internationale Urheber- und Leistungsschutzrecht, in: Internationale Privatrechtspraxis, $14 \mathrm{Jg}$. (1994), S. 263-266.

Breunig, Ch., Digitales Radio: Industriepolitik gibt den Ton an, in: Media Perspektiven, o. Jg. (1995), S. 462-475.

Brodbeck, Karl-Heinz, Ansätze zur Theorie und Empirie des Musikmarktes, München 1991.

Brodbeck, Karl-Heinz, und Marlies Hummel, Musikwirtschaft, Ifo - Studien zu Kultur und Wirtschaft Bd. 5, München 1991.

Brozen, Yale, The Concentration-Collusion Doctrine, in: Antitrust Law Journal, Vol. 46 (1977), S. $827 \mathrm{ff}$. 
Bullinger, Martin, und Emst-Joachim Mestmäcker, Multimediadienste: Struktur und staatliche Aufgaben nach deutschem und europäischem Recht, Gutachten im Auftrag des Ministeriums für Bildung, Wissenschaft, Forschung und Technologie, Bonn 1996.

Bundesbank, deutsche, Monatsberichte September 1996 und April 1998, Frankfurt a. M. 1996 und 1998.

Bundeskartellamt, Tätigkeitsberichte, diverse Jahrgänge als Bundestagsdrucksache.

Bundesverband der Phonographischen Wirtschaft, Jahrbuch 1994, 1995, 1996 und 1997, Starnberg 1994, 1995, 1996 und 1997.

ders., Phono-Press 1998, Hamburg 1998

Bundesverband der Phonographischen Wirtschaft (BPW) u. a., Der Markt für CD, MC und Schallplatten, Hamburg 1995.

Burke, Andrew E., The Demand for Vinyl L.P.s 1975-1988, in: Journal of Cultural Economics, Vol. 18 (1994), S. 41-64.

ders., An Economic Analysis of Enterprise in the Music Industry, Oxford 1994.

ders., How Effective Are International Copyright Conventions in the Music Industry?, in: Journal of Cultural Economics, Vol. 20 (1996), S. 51-66.

ders., The Dynamics of Product Differentiation in the British Record Industry, in: Journal of Cultural Economics, Vol. 20 (1996), S. 145-164.

Burnett, Robert, Concentration and Diversity in the International Phonogram Industrie, Gothenburg (Schweden) 1990.

Caves, Richard, American Industry: Structure, Conduct, Performance, 6. Aufl., Englewood Cliffs, N. J. 1986.

Caves, Richard E., und Michael E. Porter, From Entry Barriers to Mobility Barriers, in: Quarterly Journal of Economics, Vol. 91 (1977), S. 241-261.

Chamberlin, Edward H., The Product as an Economic Variable, in: Towards a More General Theory of Value, 2nd printing, New York 1966, S. 105-137.

Chou, Chien-fu, und Oz Shy, Network Effects without Network Externalities, in: International Journal of Industrial Organization, Vol. 8 (1990), S. 259-270. 
Christianen, Michael, The Dutch music industry, paper presented at the 8th International Congress on Cultural Economics in Witten/Germany, 24.-27.8.1994, Witten, S. 1-42.

Church, Jeffrey, und Neil Gandal, Integration, Complementary Products, and Variety, in: Journal of Economics \& Management Strategy, Vol. 1 (1992), S. 651-675.

dies., Network Effects, Software Provision, and Standardization, in: Journal of Industrial Economics, Vol. 40 (1992), S. 85-103.

dies., Complementary Network Externalities and Technological Adoption, in: International Journal of Industrial Organization, Vol. 11 (1993), S. 239-260.

Clausen, Sven O., Hits aus dem Computer, Konkurrenz für CD-Läden, in: Die Zeit, Nr. 7 vom 5.2.1998, S. 32.

Coase, Ronald, Payola in radio and television broadcasting, Journal of Law and Economics, Vol. 22 (1979), S. 269-328.

Colonna, Carl M., Patricia M. Kearns und John E. Anderson, Electronically Produced Music and its Economic Effects on the Performing Musician and Music Industry, in: Journal of Cultural Economics, Vol. 17 (1993), S. 69-75.

Conen, Michael, Tonträgermarketing, Wiesbaden 1995.

Copyright Act der USA [17 U.S.A. C Sec. 101-810].

Cowan, Robin, Nuclear power reactors: a study in technological lock-in, in: Journal of Economic History, Vol. 50 (1990), S. 541-567.

Cowan, Robin, William Cowan und Peter Swann, A model of demand with interactions among consumers, in: International Journal of Industrial Organization, Vol. 15 (1997),

S. 711-732.

Cox, Raymond A., James M. Felton und Kee H. Chung, The Concentration of Commercial Success in Popular Music: An Analysis of the Distribution of Gold Records, in: Journal of Cultural Economics, Vol. 19 (1995), S. 333-340.

Crain, Mark W., und Robert D. Tollison, Economics and the architecture of popular music, in: Journal of Economic Behavior \& Organization, Vol. 32 (1997), S. 185-205.

Dannen, F., Hit Men: Power Brokers and Fast Money Inside the Music Business, New York 1990 
Davies, Gillian, The Private Copying of Sound and Audio-Visual Recordings: A Study Requested by the Commission of the European Communities, Brüssel 1993.

Davies, Gillian, und Hans Hugo von Rauscher auf Weeg, Das Recht der Hersteller von Tonträgern, München 1983.

De Alessi, Louis, Property Rights, Transaction Costs, and X-Efficiency: An Essay in Economic Theory, in: American Economic Review, Vol. 73 (1983), S. 64-81.

Deboer, L., Is Rock 'n 'Roll a Symptom of Baumol's Disease, in: Journal of Cultural Economics, Vol. 9 (1985), S. 48-59.

Demsetz, Harold, Joint Supply and Price Discrimination, in: The Journal of Law and Economics, Vol. 16 (1973), S. 389-405.

ders., Reply to Professor Thompson, in: The Journal of Law and Economics, Vol. 16 (1973), S. 413-415.

ders., The Private Production of Public Goods, in: The Journal of Law and Economics, Vol. 13 (1970), S. 293-306.

ders., Industry Structure, Market Rivalry, and Public Policy, in: Journal of Law and Economics, Vol. 16 (1973), S. $1 \mathrm{ff}$.

Denzau, Arthur, Microeconomic Analysis, Boston Ma., 1992.

De Sanctis, Valerio, La Conventione Internazionale per la protezione degli artisti interpreti o esecutori, dei produttori di fonogrammi e degli organismi di radiodiffusione, Rom 1963.

Diederichs, Frank A., Budgetlinie und Special Products, in: Handbuch der Musikwirtschaft, hrsg. von Moser, Rolf, und Andreas Scheuermann, 4. Aufl., Starnberg 1997, S. 227-240.

Dieselhorst, Jochen, Die Harmonisierung der Leerkassetten- und Geräteabgabe, in: Gewerblicher Rechtsschutz und Urheberrecht, internationaler Teil (GRUR/I), Vol. 96 (1994), S. 788-798.

Dietz, Adolf, Das Urheberrecht in der Europäischen Gemeinschaft, Baden-Baden 1978.

ders., Das primäre Urhebervertragsrecht in der Bundesrepublik Deutschland und in den anderen Mitgliedstaaten der Europäischen Gemeinschaft, München 1984.

ders., Das Urheberrecht in Spanien und Portugal, Baden-Baden 1990. 
Dixit, Avinash K., und Joseph E. Stiglitz, Monopolistic Competition and Optimum Product Diversity, in: American Economic Review (AER), Vol 67 (1977), S. 297-308.

Dorfman, R., und P. O. Steiner, Optimal Advertising and Optimal Quality, in: American Economic Review, Vol. 44 (1954), S. 826-836.

Dreier, Thomas, Perspektiven einer Entwicklung des Urheberrechts, in: Becker, Jürgen, und Thomas Dreier (Hrsg.), Urheberrecht und digitale Technologie, Baden-Baden 1994, S. 123 153.

Drexl, Josef, Entwicklungsmöglichkeiten des Urheberrechts im Rahmen des GATT, München 1990.

Economides, N., und C. Himmelberg, Critical mass and network size with application to the US fax market, Discussion Paper EC-95-11, Stern School of Business, New York 1995.

Eisenmann, Hartmut, Grundriß Gewerblicher Rechtsschutz und Urheberrecht, 3. Aufl., Heidelberg 1995.

Elste, Martin, Kleines Tonträgerlexikon: Von der Walze zur Compact Disc, Kassel 1989.

ElBer, Stefan, Innovationswettbewerb: Determinanten und Unternehmensverhalten, Frankfurt a. M. u. a. 1993.

Emmerich, Volker, Kartellrecht, 7. Aufl., München 1994.

Endres, Alfred, Second Hand Markets and the Private Supply of Excludable Public Goods, in: Public Finance, Vol. 35 (1980), S. 227-238.

Engel-Flachsig, Stefan, Das Informations- und Kommunikationsdienstegesetz des Bundes und der Mediendienstestaatsvertrag der Bundesländer, in: Zeitschrift für Urheber- und Medienrecht (ZUM), 41. Jg. (1997), S. 231-239.

Ernst, Stefan, Urheberrechtliche Probleme bei der Veranstaltung von On-demand-Diensten, in: Gewerblicher Rechtsschutz und Urheberrecht (GRUR), 99. Jg. (1997), S. 592-597.

EU-Kommission, Grünbuch über Urheberrecht und die technologische Herausforderung, KOM (88) 172 endg.

dies., Initiativen zum Grünbuch, KOM (90) 584 endg. 
dies., Vorschlag für eine Richtlinie des Rates zur Harmonisierung der Schutzdauer des Urheberrechts und bestimmter verwandter Schutzrechte, KOM (92) 33 endg. - Syn 395, in: ABI. Nr. C 92, S. 6 ff.

dies., Richtlinie 92/100/EWG des Rates vom 19.11.1992 zum Vermiet- und Verleihrecht sowie zu bestimmten dem Urheberrecht verwandten Schutzrechten im Bereich des geistigen Eigentums, in: ABI. EG Nr. L 346, S. $61 \mathrm{ff}$.

dies., Richtlinie 93/98 des Rates zur Harmonisierung der Schutzdauer des Urheberrechts und bestimmter verwandter Schutzrechte, in: ABl. Nr. L 290, S. 9 ff.

dies., Grünbuch über Urheberrecht und verwandte Schutzrechte in der Informationsgesellschaft vom 19.7.1995, KOM (95) 382 endg.

dies., Richtlinie 96/9 des Rates vom 11. März 1996 über den rechtlichen Schutz von Datenbanken, in: ABI. EG Nr. L 77, S. $20 \mathrm{ff}$.

dies., Initiativen zum Grünbuch über Urheberrecht und verwandte Schutzrechte in der Informationsgesellschaft vom 20.11.96, KOM (96) 568 endg.

dies., Richtlinienentwurf der EU-Kommission zur Harmonisierung bestimmter Aspekte des Urheberrechts und verwandter Schutzrechte in der Informationsgesellschaft vom 10.12.1997, KOM (97) 628 endg.

Fessler, Hans Ulrich, DCC: Die digitale Compact Cassette, in: Stereoplay, September 1992, S. 9-10.

Fiebiger, Hilde, Ausgaben für Freizeitgüter in ausgewählten privaten Haushalten im früheren Bundesgebiet und sowie den neuen Ländern und Berlin-Ost, in: Wirtschaft und Statistik, Heft 2/1993.

Fishbein, M., S. E. Middlestradt, und M. Kapp, Home Taping: A Consumer Survey, New York 1982.

Flechsig, Norbert, EU-Harmonisierung des Urheberrechts und der verwandten Schutzrechte in der Informationsgesellschaft, in: Zeitschrift für Urheber- und Medienrecht (ZUM), 42. Jg. (1998), S. 139-154.

ders., Die Auswirkungen der digitalen Signalverarbeitung auf Anbieter von Rundfunk und Fernsehen, in: Becker, Jürgen, und Thomas Dreier (Hrsg.), Urheberrecht und digitale Technologie, Baden-Baden 1994, S. 27-44.

Frank, Björn, Zur Ökonomie der Filmindustrie, Hamburg 1993. 
Frank, Robert H., und Philip J. Cook, The Winner-Take-All Society, New York u. a. 1995.

Franz, Eckhard, Der Werkbegriff der Berner Übereinkunft zum Schutz von Werken der Literatur und Kunst, Baden-Baden 1993.

Frey, Bruno S., The Economics of Music Festivals, in: Journal of Cultural Economics, Vol. 18 (1994), S. 29-39.

Frielingsdorf, Britta, und Sabine Hås, Fernsehen zum Musikhören, in: Media Perspektiven, o. Jg. (1995), S. 331-339.

Fromm, Friedrich Karl, und Wilhelm Nordemann, Urheberrecht: Kommentar, 7. Aufl., Stuttgart u. a. 1988.

Gamm, Otto Friedrich Freiherr von, Urheber- und Urhebervertragsrechtliche Probleme des digitalen Fernsehens, in: Zeitschrift furr Urheber- und Medienrecht (ZUM), 38. Jg. (1994), S. 591-596.

Gesellschaft für musikalische Aufrührungs- und mechanische Vervielfältigungsrechte (GEMA), Jahrbücher 1995/96, 1996/97 und 1997/98, Baden-Baden 1996, 1997 und 1998.

Gilbert, Rolf, und Andreas Scheuermann, Künstler-, Produzenten-, Bandübernahmeverträge, in: Handbuch der Musikwirtschaft, hrsg. von Moser, Rolf, und Andreas Scheuermann, 4. Aufl., Starnberg 1997, S. 1018-1039.

Gramatke, Wolf D., Musik auf dem Daten Highway, in: Handbuch der Musikwirtschaft, hrsg. von Moser, Rolf, und Andreas Scheuermann, 4. Aufl., Starnberg 1997, S. 56-66.

Granovetter, M., Threshold models of collective behavior, in: American Journal of Sociology, Vol 83 (1978), S. 1420-1443.

Greiffenberg, Horst, Multimedia zwischen Rundfunkregulierung und wettbewerblicher Medienordnung, in: Wirtschaftsdienst, 76. Jg. (1996), S. 590-595.

Gross, Ulrich, Die digitale Schallplatte: Compact Disc, 12. Tonmeistertagung, München 1981

Große, Günter, Von der Edisonwalze zur Stereoplatte, Berlin 1989.

Gutenberg, Erich, Grundlagen der Betriebswirtschaftslehre, Band 2, 17. Aufl., Berlin u. a. 1984.

Haas, Walter, Das Jahrhundert der Schallplatte, Bielefeld 1977. 
Häfner, Albrecht, Digitalisienung im Hörfunkarchiv des Südwestfunks, in: Wer zappelt im Netz, wer knüpft die Fäden?, hrsg. von Lange, Eckhard, Baden-Baden 1997, S. 212-221.

Hamlen, William A., Superstardom in Popular Music: Empirical Evidence, in: The Review of Economics and Statistics, Vol. 73 (1991), S. 729-733.

Hayek, Friedrich August v., Die Verwertung des Wissens in der Gesellschaft, in: Hayek, F. A. v., Individualismus und Wirtschaftliche Ordnung, Erlenbach-Zürich 1952, S. 103 ff.

ders., Die Irttümer des Konstruktivismus, Tübingen 1975.

ders., Recht, Gesetz und Wirtschaftsfreiheit, in: Freiburger Studien: Gesammelte Aufsätze von F. A. v. Hayek, Tübingen 1969, S. $47 \mathrm{ff}$.

Heckhausen, H., Motivation und Handeln, 2. Aufl., Berlin u. a. 1989.

Heimbach, Petja, Multimedia im Musik-Marketing, in: Marketing mit Multimedia: Grundlagen, Anwendungen und Management einer neuen Technologie im Marketing, hrsg. von Silberer, Günter, Stuttgart 1995, S. 185-218.

Herdzina, Klaus, Konzept und Voraussetzungen des funktionsfähigen Wettbewerbs, Köln 1970.

ders., zur historischen Entwicklung der Wettbewerbstheorie, in: Wettbewerbstheorie, hrsg. von Herdzina, Klaus, Köln 1975, S. 15 ff.

Heuss, Ernst, Allgemeine Markttheorie, Tübingen und Zürich 1965.

Hielscher, U., Investmentanalyse, München u. a. 1990.

Hill, Leslie F., An Insight into the Finances of the Record Industry, in: The Three Banks Review, Nr. 118 (1978), S. 28-45.

Hörschgen, Hans, Jürgen Kirsch, Günter Käßer-Pawelka und Jürgen Krenz, MarketingStrategien: Konzepte zur Strategienbildung im Marketing, 2. Aufl., Ludwigsburg, Berlin 1993.

Hoppmann, Erich, Das Konzept der optimalen Wettbewerbsintensität, in: Jahrbücher für Nationalökonomie und Statistik, Bd. 179 (1966), S. $286 \mathrm{ff}$.

ders., Wettbewerb als Norm der Wettbewerbspolitik, in: ORDO, Bd. 18 (1967), S. $77 \mathrm{ff}$.

Hoskins, Colin, und Rolf Mirus, Reasons for the US dominance in the international trade in television programmes, in: Media, Culture and Society, Vol. 10 (1988), S. 499-515. 
Hubmann, Heinrich, und Manfred Rehbinder, Urheber- und Verlagsrecht, 7. Aufl., München 1991.

Hughes, Justin, The Philosophy of Intellectual Property, in: Georgetown Law Journal, Vol. 77 (1988), S. 287-366.

Hummel, Marlies, Die volkswirtschaftliche Bedeutung des Urheberrechts (Gutachten im Auftrag des Bundesministers der Justiz), Schriftenreihe des IFO-Instituts für Wirtschaftsforschung Nr. 125, Berlin u. a. 1989.

Hurt, Robert M., und Robert M. Schuchman, The Economic Rationale of Copyright, in: American Economic Review, Vol. 56 (1966), S. 421-432.

Immenga, Ulrich, und Ernst-Joachim Mestmäcker, Gesetz gegen Wettbewerbsbeschränkungen: Kommentar, 2. Aufl., München 1992.

Institut für Psychologie und Sozialforschung (IPS), Nichtkäuferstudie, Kiel 1996.

International Federation of Phonographic Industry (IFPI), The Recording Industry in Numbers 1994 und 1995, London 1995 und 1996.

Jehoram, Cohen, Kritische Überlegungen zur wirtschaftlichen Bedeutung des Urheberrechts, in: Gewerblicher Rechtsschutz und Urheberrecht, Internationaler Teil (GRUR/I), Vol. 91 (1989), S. 23-29.

Jetzkus, Frank-Werner, Rackjobbing, in: Handbuch der Musikwirtschaft, hrsg. von Moser, Rolf, und Andreas Scheuermann, 4. Aufl., Starnberg 1997, S. 279-287.

Jörger, Thomas M., Das Plagiat in der Popularmusik, Baden-Baden 1992.

Jungk, Klaus, Musik im technischen Zeitalter: Von der Edison-Walze zur Bildplatte, Berlin 1971 .

Kaas, K. P., Diffusion und Marketing, Stuttgart 1973.

Kantzenbach, Erhard, Die Funktionsfähigkeit des Wettbewerbs, 2. Aufl., Göttingen 1967.

ders., Das Konzept der optimalen Wettbewerbsintensität, in: Jahrbücher für Nationalökonomie und Statistik, Bd. 181 (1967), S. 193 ff.

Kantzenbach, Erhard, Elke Kottmann und Reinald Krüger, Kollektive Marktbeherrschung: Neue Industrieökonomik und Erfahrungen aus der Europäischen Fusionskontrolle, BadenBaden 1996. 
Katz, Michael L., und Carl Shapiro, Network Externalities, Competition and Compatibility, in: American Economic Review, Vol. 75 (1985), S. 424-440.

dies., Product introduction with network externalities, in: Journal of Industrial Economics, Vol. 40 (1992), S. 55-84.

Katzenberger, Paul, TRIPs und das Urheberrecht, in: Gewerblicher Rechtsschutz und Urheberrecht, Internationaler Teil (GRUR/I), Vol. 97 (1995), S. 447-468.

Kaufer, Erich, Konzentration und Fusionskontrolle, Tübingen 1977.

Késenne, Stefan, Can A Basic Income Cure Baumol's Disease, in: Journal of Cultural Economics, Vol. 18 (1994), S. 93-100.

Kiessling, Thomas, und G. Johnson, Strategic Alliances in Telecommunications and Media: An Economic Analysis of Recent European Commission Decisions, in: MacDonald, Stuart, G. Madden und M. Salomon (Ed.), Telecommunications and Socio-Economic Development, Elsevier 1998, S. 43-78.

Kirschner, Ulrich, Die Erfassung der Nachfragemacht von Handelsunternehmen: Eine Analyse der ökonomischen Beurteilungskriterien und der wettbewerbsrechtlichen Instrumente im Bereich der Verhaltenskontrolle, Hohenheimer Volkswirtschaftliche Schriften Bd. 8, Frankfurt am Main u. a. 1988.

Kirzner, Israel M., Wettbewerb und Unternehmertum, Tübingen 1978, S. 3 ff.

ders., On the Method of Austrian Economics, in: The Foundations of Modern Austrian Economics, hrsg. von Dolan, Edwin G., Kansas City 1976, S. 40 ff.

ders., Die Krise aus „österreichischer“ Sicht, in: Die Krise in der Wirtschaftstheorie, hrsg. von Bell, David, und Irving Kristol, Berlin u. a. 1984, S. $148 \mathrm{ff}$.

Klimisch, Annette, und Markus Lange, Zugang zu Netzen und anderen wesentlichen Einrichtungen als Bestandteil der kartellrechtlichen Mißbrauchsaufsicht, in: Wirtschaft und Wettbewerb, 48. Jg. (1998), S. 15-26.

Klodt, Henning, Claus-Friedrich Laaser, Jens Oliver Lorz und Rainer Maurer, Wettbewerb und Regulierung in der Telekommunikation, Kieler Studien 272, hrsg. von Siebert, Horst, Tübingen 1995.

Klose, Werner, und Horst Lietzberg, Budgetlinie, in: Handbuch der Musikwirtschaft, hrsg. von Moser, Rolf, und Andreas Scheuermann, 3. Aufl., Starnberg 1994, S. 128-135. 
Koboldt, Christian, Property Rights und Urheberschutz, in: Ökonomische Analyse der rechtlichen Organisation von Innovationen, hrsg. von Ott, Claus, und Hans-Bernd Schäfer, Tübingen 1994, S. 69-114.

Kolbe, Clemens, Eintrittsbarrieren und die Eintrittsfähigkeit potentieller Konkurrenten, Göttingen 1991.

Kornmeier, Udo, „Sales- and Distribution“-Verträge, in: Handbuch der Musikwirtschaft, hrsg. von Moser, Rolf, und Andreas Scheuermann, 4. Aufl., Starnberg 1997, S. 1107-1125.

Koutsoyiannis, A., Modern Microeconomics, 2. Aufl., London 1981 (Reprint).

Kreile, Reinhold, Einnahme und Verteilung der gesetzlichen Geräte- und Leerkassettenvergütung für private Vervielfältigung in Deutschland, in: Gewerblicher Rechtsschutz und Urheberrecht, Internationaler Teil (GRUR/I), Vol. 94 (1992), S. 24-36.

ders., Rede des Vorstands der GEMA, in: GEMA Jahrbuch 1995/96, Baden-Baden 1996, S. 37-46.

ders., Stellungnahme zum Geschäftsbericht, in: GEMA-Jahrbuch 1997/98, Baden-Baden 1998, S. 39.

Kreile, Reinhold, und Jürgen Becker, Neuordnung des Urheberrechts in der Europäischen Union, in: Gewerblicher Rechtsschutz und Urheberrecht, Internationaler Teil (GRUR/), Vol. 96 (1994), S. 901-911.

dies., Multimedia und die Praxis der Lizenzierung von Urheberrechten, in: Gewerblicher Rechtsschutz und Urheberrecht, Internationaler Teil (GRUR/I), Vol. 98 (1996), S. 677-692.

Kroeber-Riel, W., Konsumentenverhalten, 6. Aufl., München 1996.

Kröger, Detlef, Die Anwendung des Diskriminierungsverbots auf das Urheberrecht und verwandte Schutzrechte, zugleich Urteilsanmerkung zu Phil Collins u. a., in: Europäische Zeitschrift für Wirtschaftsrecht (EuZW), $6 \mathrm{Jg}$. (1994), S. 85-87.

Kröger, Detlef, und Flemming Moos, Regelungsansätze für Multimediadienste, in: Zeitschrift für Urheber- und Medienrecht (ZUM), 41. Jg. (1997), S. 462-471.

Kruse, Jörn, Präferenztransfer und Kontrollwettbewerb in regulierten Unternehmen, in: Jahrbuch für Sozialwissenschaft, Bd. 33 (1982), S. 367-394. 
ders., vertikale Integration als Wettbewerbsproblem, in: Wettbewerbspolitik im Spannungsfeld nationaler und internationaler Kartellrechtsordnungen, hrsg. von Kruse, Jörn, Kurt Stockmann und Lothar Vollmer, Festschrift für Ingo Schmidt, Baden-Baden 1997, S. 247-270.

Kuhnke, Klaus, Manfred Miller, und Peter Schulze, Geschichte der Pop-Musik, Bd. 1, 2. Aufl., Bremen 1976.

Lademann, Rainer, Nachfragemacht von Handelsunternehmen: Analyse der Begriffs-, Erklärungs- und Rechtstatsachenprobleme, Göttingen 1986.

Landes, William M., und Richard A. Posner, An Economic Analysis of Copyright Law, in: Journal of Legal Studies, Vol. 18 (1989), S. 325-363.

Leadbeater, T., The Music Market, London 1994.

Leibfritz, W., W. Niehaus und R. Parsche, Der Beitrag des Steuersystems zur Reform der Alterssichenung, Ifo-Studien zur Finanzpolitik Bd. 48, München 1990.

Lencher, Uwe, und Bodo Bochnig, Vertriebsstrukturen und Situation des Handels, in: Handbuch der Musikwirtschaft, hrsg. von Moser, Rolf, und Andreas Scheuermann, 4. Aufl., Starnberg 1997, S. 241-244.

Lewinski, Silke von, Der EG-Richtlinienvorschlag zur Harmonisierung der Schutzdauer im Urheber- und Leistungsschutzrecht, in: Gewerblicher Rechtsschutz und Urheberrecht, Internationaler Teil (GRUR/I), Vol. 94 (1992), S. 724-733.

dies., Vermieten, Verleihen, verwandte Schutzrechte, in: Gewerblicher Rechtsschutz und Urheberrecht, Internationaler Teil (GRUR/I), Vol. 93 (1991), S. 104-111.

dies., Die Umsetzung der Richtlinie zum Vermiet- und Verleihrecht, in: Zeitschrift für Urheber- und Medienrecht (ZUM), $39 \mathrm{Jg}$. (1995), S. 442-450.

Lewinski, Silke von, und Jens Gaster, Die Diplomatische Konferenz der WIPO 1996 zum Urheberrecht und zu verwandten Schutzrechten, in: Zeitschrift für Urheber- und Medienrecht (ZUM), 41. Jg. (1997), S. 607-625.

Liebermann, Marvin B., und David B. Montgomery, First Mover Advantages, in: Strategic Management Journal, Vol. 9 (1988), S. 41-58.

Linder, S., The Harried Leisure Class, New York 1970.

Lopes, Paul D., Innovation and Diversity in the Popular Music Industry, in: American Sociological Review, Vol. 57 (1992), S. 56-71. 
Lotka, Alfred J., The Frequency Distribution of Scientific Productivity, in: Journal of the Washington Academy of Sciences, Vol. 16 (1926), S. 317-323.

Ludwig, Hans-Werner, Schallplatte/Tonband, in: Kritische Stichwörter zur Medienwissenschaft, hrsg. von Faulstich, Werner, München 1979, S. 277-313.

MacDonald, Glenn M., The Economics of Rising Stars, in: American Economic Review, Vol. 78 (1988), S. 155-166.

Macqueen, Hector L., und Alan Peacock, Implementing Performing Rights, in: Journal of Cultural Economics, Vol. 19 (1995), S. 157-175.

Mahlmann, Carl, Die Elastizität der Nachfrage im Tonträgerhandel (Unveröffentlichte Studie der EMI), Köln 1986.

ders., Carl, Strukturen des deutschen Tonträgermarktes, in: Handbuch der Musikwirtschaft, hrsg. von Moser, Rolf, und Andreas Scheuermann, 4. Aufl., Starnberg 1997, S. 161-184.

Markham, Jesse W., The Nature and Significance of Price-Leadership, in: American Economic Review, Vol. 41 (1951), S. 891-905.

Marshall, Alfred, Principles of Economics, 8th ed., New York 1947.

Mason, E. S., Economic Concentration and the Monopoly Problem, Cambridge, Mass. 1959.

Melchiar, Ferdinand, Die digitale Verwertung von Sprachwerken, in: Becker, Jürgen, und Thomas Dreier (Hrsg.), Urheberrecht und digitale Technologie, Baden-Baden 1994,

S. 85-94.

Menge, John A., Style Change As A Market Weapon, in: Quarterly Journal of Economics, Vol. 76 (1962), S. 632-647.

Merx, Stefan, Bis an die Schmerzgrenze, in: Die ZEIT, Nr. 43 vom 21. Oktober 1994, S. 32.

Mestmäcker, Emst-Joachim, Der Schutz der ausübenden Künstler und das EWGDiskriminierungsverbot, in: Gewerblicher Rechtsschutz und Urheberrecht, Internationaler Teil (GRUR/), Vol. 95 (1993), S. 532-536.

Möschel, Wernhard, Neue Medien und Geistiges Eigentum: Papier zum Deutsch-Japanischen Symposium, Tübingen 1996.

Monopolies and Merger Commission, The Supply of Recorded Music, London 1994. 
Monopolkommission, 9. Hauptgutachten, Wettbewerbspolitik oder Industriepolitik, BadenBaden 1992.

dies., 11. Hauptgutachten, Wettbewerbspolitik in Zeiten des Umbruches, Baden-Baden 1996.

Moritz, Carl-Heinz, Marktpolitische Probleme der Konsumgüterwerbung, Berlin 1977.

Movsessian, Vera, und Fedor Seifert, Einführung in das Urheberrecht der Musik, 3. Aufl., Wilhelmshaven 1995.

Müller-Hagedorn, L., Handelsmarketing, 2. Aufl., Stuttgart u. a. 1993.

Münker, Reiner, Urheberrechtliche Zustimmungserfordernisse beim Digital Sampling, Frankfurt a. M. 1995.

Musgrave, Richard A., Peggy B. Musgrave und Lore Kullmer, Die öffentlichen Finanzen in Theorie und Praxis, Bd. 1, 6. Aufl., Tübingen 1994.

National Heritage Committee of the House of Commons (NHC), Bericht des NHC vom Mai 1993, London 1993.

Neidhardt, H., und J. Schmalholz, CD-ROM Publishing, in: Deutscher Multimedia Kongreß 1995, hrsg. von Glowalla, U., Berlin u. a. 1995, S. 251-258.

Nestele, K., Technische Innovationen und ihre Auswirkungen, in: Handbuch der Musikwirtschaft, hrsg. von Moser, Rolf, und Andreas Scheuermann, 3. Aufl., Starnberg 1994, S. 69-75.

Nick, Wolfgang, Musikdiebstahl, Hamburg 1979.

Nieschlag, Robert, Erwin Dichtl und Hans Hörschgen, Marketing, 18. Aufl., Berlin 1997.

Nordemann, Wilhelm, Kai Vinck, und Paul Hertin, Internationales Urheberrecht und Leistungsschutzrecht der deutschsprachigen Länder unter Berücksichtigung auch der Staaten der Europäischen Gemeinschaft: Kommentar, Düsseldorf 1977.

dies., Urheberrecht: Kommentar, 9. Aufl., Stuttgart 1998.

Novos, Ian E., und Michael Waldman, The Effects of Increased Copyright Protection: An Analytic Approach, in: Journal of Political Economy, Vol. 92 (1984), S. 236-246.

Oakland, W. H., Public Goods, Perfect Competition and Underproduktion, in: Journal of Political Economy, Vol. 82 (1974), S. 927-939. 
Oberender, Peter (hrsg.), Marktstruktur und Wettbewerb in der Bundesrepublik Deutschland, München 1984.

Oberparleitner, Karl, Funktionen und Risiken des Warenhandels, 2. Aufl., Wien 1955.

O'Hare, Michael, Copyright and the Protection of Economic Rights, in: Journal of Cultural Economics, Vol. 6 (1982), S. 33-48.

ders., When Is Monopoly Efficient?, in: Journal of Policy Analysis and Management, Vol. 4 (1985), S. 407-418.

Ordover, J. A., und R. D. Willig, An Economic Definition of Predatory Product Innovation, in: Salop, S. C. (Hrsg.), Strategy, Predation and Antitrust Analysis, Washington, D. C. 1981, S. $45-99$.

o. V., Record Sales in 1947, in: Fortune Magazine, o. Jg. (1951), S. 97-100.

o. V., Geplanter CD-Automat der Fachhandelskette Blockbuster und der IBM stößt nicht auf große Gegenliebe, in: Musikmarkt, o. Jg., Nr. 11 (1993), S. 28.

o. V., Praxistest: „Kopierschutz-Knacker“, in: Stereoplay 1993, S. 44-46.

o. V., Mitgliedschaft in internationalen Urheberrechtsabkommen, in: Gewerblicher Rechtsschutz und Urheberrecht/Internationaler Teil (GRUR/I), Vol. 99 (1997), S. 446-448.

o. V., Branchenhandbuch des Musikmarktes, Starnberg 1997.

o. V., Der digitale Weg zum Tonträger, in: Musikwoche, 6. Jg. (1998), Nr. 10, S. 16.

o. V., Musikgenuß mit digitalen Notenblättern, in: Musikwoche, 6. Jg. (1998), Nr. 10, S. 28

o. V., Die Telekom will ihre Preise weiter senken, in: Frankfurter Allgemeine Zeitung, Nr. 65 vom 18.3.98, S. 21 .

o. V., IBM und GZS kooperieren, in: Frankfurter Allgemeine Zeitung, Nr. 65 vom 18.3.98, S. 32 .

o. V., Zahlsystem für Internet-Handel, in: Frankfurter Allgemeine Zeitung, Nr. 68 vom 21.3.98, S. 29

Paprotka, Reinhard, Paroli, in: Stereo Nr.8 (1992), S. 14-15 
Peacock, Alan, The Cost Disease: Analytical and Policy Aspects, in: Special Supplement to the Journal of Cultural Economics o. Jg. (1985), S. 51-58.

ders., The Economic Value of Musical Composition, in: Beiträge zu einer Theorie der Sozialpolitik, Berlin S. 11-27.

Petersen, Richard A., und David G. Berger, Cycles in Symbolic Production: The Case of Popular Music, in: American Sociological Review, Vol. 40 (1975), S. 158-173.

Pethig, Rüdiger, Copyrights and Copyright Costs: A new Price-Theoretic Approach, in: Journal of Institutional and Theoretical Economics (JTE/ZgS), Vol. 144 (1988), S. 462-495.

Phillips, Almarin, Structure, Conduct and Performance: and Performance, Conduct and Structure, in: Industrial Organization and Economic Development, in Honor of E. S. Mason, hrsg. von Markham, Jesse W., und Gustav F. Papanek, New York u. a. 1970, S. 26-37.

Porter, Michael E., Wettbewerbsstrategie: Methoden zur Analyse von Branchen und Konkurrenten, 6. Aufl., Frankfurt 1990.

ders., Michael E., Interbrand Choice, Strategy, and Bilateral Market Power, Cambridge, Mass. und London 1976.

Posner, Richard A., Economic Analysis of Law, 2. Aufl., Boston 1977.

ders., The Chicago School of Antitrust Analysis, in: University of Pennsylvania Law Review, Vol. 127 (1989), S. 929.

Prognos AG, Music And Demand, Strategiestudie im Auftrag der Unternehmen BMG, EMI, MCA, Ploygram, Sony Music und Warner Music, Basel 1996.

Prosi, Gerhard, Die ökonomische Theorie des Buches, Düsseldorf 1971.

Reichardt, Robert, Die Schallplatte als kulturelles und ökonomisches Phänomen, Zürich 1962.

Reinbothe, Jörg, Martin Prat, und Silke von Lewinski, The New WIPO Treaties, in: European Intellectual Property Review (EIPR), Vol. 19 (1997), S. 171-184.

Reiners, Bernd, Differenzlizenzen und Parallelimporte, in: Handbuch der Musikwirtschaft, hrsg. von Moser, Rolf, und Andreas Scheuermann, 3. Aufl., Starnberg 1994, S. 543-561.

Riehm, U., und B. Wingert, Multimedia, Mythen, Chancen und Herausfordenungen, Arbeitsbericht Nr. 33, Büro für Technikfolgenabschätzung beim Deutschen Bundestag, Bonn 1995. 
Riess, Curt, Knaurs Weltgeschichte der Schallplatte, Zürich 1966.

Rochlitz, Burkhard, Vermietung von Tonträgern, in: Handbuch der Musikwirtschaft, hrsg. von Moser, Rolf, und Andreas Scheuermann, 3. Aufl., Starnberg 1994, S. 535-542.

Rogers, Everett, Diffusion of Innovations, 4th edition, New York 1995.

Rohlfs, Jeffrey, A Theory of Interdependent Demand for a Communications Service, in: Bell Journal of Economics and Management Science, Vol. 5 (1974), S. 16-37.

Rosen, Sherwin, The Economics of Superstars, in: American Economic Review, Vol. 71 (1981), S. 845-858.

Rothenbuhler, Eric W., und John W. Dimmick, Popular Music: Concentration and Diversity in the Industry 1974-1980, in: Journal of Communication, O. Jg. (1982), S. 143-149.

Salop, S. C., Measuring Ease of Entry, in: The Antitrust Bulletin, Vol. 31 (1986), S. 551-570.

Schack, Haimo, Urheber- und Urhebervertragsrecht, Tübingen 1997.

Schaefer, Martin, Tonträgerpiraterie, in: Handbuch der Musikwirtschaft, hrsg. von Moser, Rolf, und Andreas Scheuermann, 3. Aufl., Starnberg 1994, S. 518-533.

Schaefer, Martin, und Manfred Körfer, Tonträgerpiraterie: Eine Leitfaden für die Praxis, Starnberg 1995.

Scherer, Frederic M., und David Ross, Industrial Market Structure and Economic Performance, 3. Aufl., Dallas u. a. 1990.

Schmalensee, Richard, Entry Deterrence in the Ready-to-Eat Breakfast Cereal Industry, in: Bell Journal of Economics, Vol. 9 (1978), S. 305-327.

Schmidt, Christoph, Organisation der Majors, in: Handbuch der Musikwirtschaft, hrsg. von Moser, Rolf, und Andreas Scheuermann, 4. Aufl., Starnberg 1997, S. 185-200.

Schmidt, Ingo, Wettbewerbspolitik und Kartellrecht, 5. Aufl., Stuttgart 1996.

ders., Handelskonzentration, Nachfragemacht und 6. GWB-Novelle, in: Wirtschaft und Wettbewerb, 47. Jg. (1997), S. 101-120.

ders., Hauptprobleme der 6. Kartellnovelle, in: Wirtschaftsdienst, 77. Jg. (1997), S. 637-646. 
Schmidt, Ingo, und Jürgen Wuttke, Leistungswettbewerb und unbillige Behinderung i. S. des $\S 26$ Abs. 4 GWB, in: Betriebs-Berater, 53. Jg. (1998), S. 753-758.

Schrape, Klaus, Wolfgang Seufert, Hansjörg Hås, Daniel Hürst und Sabine Gafke, Künftige Entwicklung des Medien- und Kommunikationssektors in Deutschland, DIW Beiträge zur Strukturforschung, Heft 162, Berlin 1996.

Schricker, Gerhard, Urheberrecht: Kommentar, München 1987.

Schulze, Ralf, Die Musikwirtschaft: Marktstrukturen und Wettbewerbsstrategien der Deutschen Musikindustrie, Hamburg 1996.

Schumann, Jochen, Grundzüge der mikroökonomischen Theorie, 6. Aufl., Berlin u. a. 1992.

Schwarz, Mathias, Der urheberrechtliche Schutz audiovisueller Werke im Zeitalter der digitalen Medien, in: Becker, Jürgen, und Thomas Dreier (Hrsg.), Urheberrecht und digitale Technologie, Baden-Baden 1994, S. 105-121.

Scitovsky, Tibor, Can Changing Consumer's Tastes Save Resources?, in: Journal of Cultural Economics, Vol. 1 (1977), S. 1-12.

Shemel, Sydney, und M. William Krasilovsky, This Business of Music, 6th ed., New York 1990.

Sikorski, Axel, Musikwirtschaft und neue Musik, Frankfurt u. a. 1997.

Sosnick, Stephen H., A Critique of Concepts of Workable Competition, in: Quarterly Journal of Economics, Vol. 72 (1958), S. $391 \mathrm{ff}$.

Stackelberg, Heinrich von, Marktform und Gleichgewicht, Wien, Berlin 1934.

Statistisches Bundesamt, Fachserie 1, Bevölkerung und Gebiet, Jahrgänge 1981 - 1997.

dasselbe, Fachserie 15, Ausgaben für den privaten Verbrauch, Jahrgänge 1985 - 1997.

dasselbe, Statistisches Jahrbuch für die Bundesrepublik Deutschland 1996 und 1997, Stuttgart 1996 und 1997.

Steinel, Roland, Zur Lage und Problematik der Musikwirtschaft, München 1992.

Steinhausen, Hans Werner von, Hundert Jahre Tonträger, in: Streitobjekt Schallplatte, hrsg. von der Deutschen Phono Akademie e.V., Hamburg, Wiesbaden 1978, S. 149-158.

Stigler, George J., The Organization of Industry, Homewood, Ill. 1968. 
Stolberg, Christian, und Wolfgang Orthmayr, Vom Schallplattenladen zum Multimediakaufhaus, in: Handbuch der Musikwirtschaft, hrsg. von Moser, Rolf, und Andreas Scheuermann, 4. Aufl., Starnberg 1997, S. 245-255.

Thompson, Earl A., The Perfectly Competitive Production of Collective Goods, in: The Review of Economics and Statistics, Vol. 50 (1968), S. 1-12.

ders., The Perfectly Competitive Production of Collective Goods, in: The Review of Economics and Statistics, Vol. 51 (1969), S. 479-482.

ders., The Private Production of Public Goods: A Comment, in: The Journal of Law and Economics, Vol. 16 (1973), S. 407-412.

Thum, Marcel, Netzwerkeffekte, Standardisierung und staatlicher Regulierungsbedarf, Tübingen 1995.

Thurow, Norbert, Die digitale Verwertung von Musik aus der Sicht von Schallplattenproduzenten und ausübenden Künstlern, in: Becker, Jürgen, und Thomas Dreier (Hrsg.), Urheberrecht und digitale Technologie, Baden-Baden 1994, S. 77-84.

Thurow, Norbert, und Peter Zombik, Phonographische Wirtschaft, in: Rauhe, Hermann, und Christine Remmer, Kulturmanagement: Theorie und Praxis einer professionellen Kunst, Berlin u. a. 1994, S. 197-210.

Todt, Horst, Wettbewerb durch Standortwahl in der Fläche, in: Beiträge zur Standortforschung, hrsg. v. Behnke, Horst, u. a., Berlin 1994, S. 75-92.

Tolksdorf, Michael, Stand und Entwicklungstendenzen der Wettbewerbstheorie, in: Wirtschaft und Wettbewerb, 30. Jg. (1980), S. 785 ff.

Ullmann, Eike, Die europäische Union und das nationale Wettbewerbs- und Urheberrecht, in: Juristenzeitung, 19 Jg. (1994), S. 928-937.

Veblen, Thorstein, The Theory of the leisure class: an economic study of institutions, London 1924.

ders., Imperial Germany and the Industrial Revolution, New York 1954.

Vereinte Nationen, Vollversammlung, Art. 27 Abs. 2 der Erklärung vom 10.12.1948

Vogel, Harold L., Entertainment Industries Economics, Cambridge 1986. 
Vogel, Martin, Die Umsetzung der Richtlinie zur Harmonisierung der Schutzdauer der Urheberrechte und bestimmter verwandter Schutzrechte, in: Zeitschrift fur Urheber- und Medienrecht (ZUM), $39 \mathrm{Jg}$. (1995), S.451-458.

Vormehr, Ulrich, Independents, in: Handbuch der Musikwirtschaft, hrsg. von Moser, Rolf, und Andreas Scheuermann, 4. Aufl., Starnberg 1997, S. 201-212.

Wagner-Silva Tarouca, Beatrice, Der Urheberschutz der ausübenden Künstler und der Tonträgerproduzenten in den USA, München 1983.

Webers, Johannes, Tonstudiotechnik, 6. Aufl., Poing bei München 1994.

Weinhold, Marisa, Computerreservierungssysteme im Luftverkehr, Baden-Baden 1995.

Weissthanner, Margot, Urheberrechtliche Probleme neuer Musik, München 1974.

Weizsäcker, C. C. v., A Welfare Analysis of Barriers to Entry, in: Bell Journal of Economics and Management, Vol. 11 (1980), S. 399-420.

ders., The Costs of Substitution, in: Econometrica, Vol. 52 (1984), S. 1085-1116.

Wicke, Peter, Die Charts im Musikgeschäft, in: Musik und Unterricht, o. Jg. (1996), S. 9-14.

ders., Bigger Than Life: Rock und Pop in den USA, Leipzig 1991.

Wiese, Harald, Marktschaffung: Das Startproblem bei Netzeffekt-Gütern, in: Marketing ZFP, 13. Jg. (1991), S. 43-51.

Williamson, Oliver E., Selling Expense As A Barrier To Entry, in: Quarterly Journal of Economics, Vol. 77 (1963), S. 112-128.

ders., Markets and Hierarchies: Analysis and Antitrust Implications, New York 1983 (Reprint).

ders., The Economic Institutions of Capitalism, New York u. a., 1985.

Williamson, P. J., Oligopolistic dominance and EC merger policy, in: European Economy, Nr. 57 (1994), S. 150-167.

Wirtz, Bernd W., Neue Medien, Unternehmensstrategien und Wettbewerb im Medienmarkt, Frankfurt u. a. 1994.

Zeppenfeld, Werner, Tonträger in der Bundesrepublik Deutschland: Anatomie eines medialen Massenmarktes, Bochum 1978. 
Zhou, Minhua, Optimization of MPEG-2 Video Encoding, Aachen 1997.

Zimmermann, Joern H., Sampling- und Remixverträge, in: Handbuch der Musikwirtschaft, hrsg. von Moser, Rolf, und Andreas Scheuermann, 4. Aufl., Starnberg 1997, S. 1085-1106.

Zombik, Peter, Die Schallplatte: Kulturträger und Wirtschaftsfaktor, in: Media Perspektiven, o. Jg. (1987), S. 437-448.

ders., Einführung in den Tonträgermarkt, in: Zentrum für Kulturforschung (Hrsg.): Kulturstatistik in den 90er Jahren: Aus der Tätigkeit des Arbeitskreises Kulturstatistik, Berichte zur Kulturstatistik III, Bonn 1991, S. 65-75.

ders., Tonträger im Markt der Zukunft, in: Media Perspektiven, o. Jg. (1995), S. 496-511.

ders., Die Bedeutung der Charts für die Musikwirtschaft, in: Handbuch der Musikwirtschaft, hrsg. von Moser, Rolf, und Andreas Scheuermann, 4. Aufl., Starnberg 1997, S. 138-146.

ders., Die offiziellen deutschen Charts, in: Handbuch der Musikwirtschaft, hrsg. von Moser, Rolf, und Andreas Scheuermann, 4. Aufl., Starnberg 1997, S. 147-158.

\section{Verzeichnis der zitierten Fälle:}

Entscheidungen des Bundeskartellamtes und deutscher Gerichte erster Instanz:

Selex-Tania, in: WuW/E BKartA $2191 \mathrm{ff}$. und OLG $3737 \mathrm{ff}$.

\section{Entscheidungen des BGH:}

Kabelfernsehen in Abschattungsgebieten (Aktz: : IZR 161/81), in: BGHZ, Bd. 79, S. 350-362.

Hitlisten-Platten, in: WuW/E BGH $2977 \mathrm{ff}$.

Entscheidungen der EU-Kommission:

ZPÜ v. 01.02.1971, in: ABI. EG Nr. L 34, S. 13-16.

GEMA v. 02.06.1971, in: ABI. EG Nr. L 134, S. 15-29.

Miller International Schallplatten GmbH v. 01.12.1976, in: ABI. EG Nr. L 357, S. 40-43

GVL v. 29.10.1981, in: ABI. EG Nr. L 370, S. 49-59.

GEMA-Satzung v. 04.12.1982, in: ABI. EG Nr. L 94, S. 12-20.

Thorn EMI/Virgin Music v. 27.04.1992, in: WuW/E EV 1836-1844

\section{Entscheidungen des EuGH:}

Grammophon v. 28.06.1971 (Rechtssache 78/70), in: Sammlung der Rechtsprechung des Gerichthofes [EuGH Slg.], 17. Jg. (1971), S. 487-514. 
BRT I v. 30.01.1974 (Rechtssache 127/73), in: EuGH Slg., 20. Jg. (1974), S. 51-79.

EMI Records - CBS Schallplatten v. 15.06.1976 (Rechtssache 96/75), in: EuGH Slg., 22. Jg. (1976), S. 913-954.

Miller International Schallplatten GmbH v. 01.02.1978 (Rechtssache 19/77), in: EuGH Slg., 24. Jg. (1978), S. 131-164.

SACEM v. 25.10. 1979 (Rechtssache 22/79), in: EuGH Slg., 25. Jg. (1979), S. 3275-3298.

Musik-Vertrieb Membran - GEMA v. 20.01.1981 (verbundene Rechtssachen 55 und 57/80), in: EuGH Slg., 27. Jg. (1981), S. 147-180.

SACEM v. 09.04.1987 (Rechtssache 402/85), in: EuGH Slg., 33. Jg. (1987), S. 1747-1771.

EMI Electrola v. 24.01. 1989 (Rechtssache 341/87), in: EuGH Slg., 35. Jg. (1989), S. 79-98.

Ministère Public/Tournier v. 13.07 .1989 (Rechtssache 395/87), in: EuGH Slg., 35. Jg. (1989), S. 2521-2581.

\section{Sonstige Entscheidungen:}

Eastman Kodal Co., Petitioner v. Image Technical Services, Inc., in: CCH 1992 - 1 Trade Cases $\S 69,839$, S. 67,946-67,968.

Federal Trade Commission v. Warner Communications Inc., et. al., in: CCH 1984 - Trade Cases $\S 66,025$, S. 68,543-68,544. 


\section{HOHENHEIMER VOLKSWIRTSCHAFTLICHE SCHRIFTEN}

Band 1 Walter Deffaa: Anonymisierte Befragungen mit zufallsverschlüsselten Antworten. Die Randomized-Response-Technik (RRT). Methodische Grundlagen, Modelle und Anwendungen. 1982.

Band 2 Thomas Michael Baum: Staatsverschuldung und Stabilisierungspolitik in der Demokratie. Zur neoinstitutionalistischen Kritik der keynesianischen Fiskalpolitik. 1982.

Band 3 Klaus Schröter: Die wettbewerbspolitische Behandlung der leitungsgebundenen Energiewirtschaft. Dargestellt am Beispiel der Fernwärmewirtschaft der Bundesrepublik Deutschland. 1986.

Band 4 Hugo Mann: Theorie und Politik der Steuerreform in der Demokratie. 1987.

Band 5 Max Christoph Wewel: Intervallarithmetische Dependenzanalyse in der Ökonometrie. Ein konjekturaler Ansatz. 1987.

Band 6 Heinrich Pascher: Die U.S.-amerikanische Deregulation Policy im Luftverkehrs- und Bankenbereich. 1987.

Band 7 Harald Lob: Die Entwicklung der französischen Wettbewerbspolitik bis zur Verordnung Nr. 86-1243 vom 01. Dezember 1986. Eine exemplarische Untersuchung der Erfassung der Behinderungsstrategie auf der Grundlage des Konzepts eines wirksamen Wettbewerbs. 1988.

Band 8 Ulrich Kirschner: Die Erfassung der Nachfragemacht von Handelsunternehmen. Eine Analyse der ökonomischen Beurteilungskriterien und der wettbewerbsrechtlichen Instrumente im Bereich der Verhaltenskontrolle.1988.

Band 9 Friedhelm Herb: Marktwirtschaftliche Innovationspolitik. 1988.

Band 10 Claus Schnabel: Zur ökonomischen Analyse der Gewerkschaften in der Bundesrepublik Deutschland. Theoretische und empirische Untersuchungen von Mitgliederentwicklung, Verhalten und Einfluß auf wirtschaftliche Größen. 1989.

Band 11 Jan B. Rittaler: Industrial Concentration and the Chicago School of Antitrust Analysis. A Critical Evaluation on the Basis of Effective Competition. 1989.

Band 12 Thomas Märtz: Interessengruppen und Gruppeninteressen in der Demokratie. Zur Theorie des Rent-Seeking. 1990.

Band 13 Andreas Maurer: Statistische Verfahren zur Ermittlung von oligopolistischen Strukturen. 1990.

Band 14 Peter Mendler: Zur ökonomischen und politisch-institutionellen Analyse öffentlicher Kredithilfen. 1992.

Band 15 Heinrich J. Engelke: Die Interpretation der Rundfunkfreiheit des Grundgesetzes: Eine Analyse aus ökonomischer Sicht. 1992.

Band 16 Thomas Fischer: Staat, Recht und Verfassung im Denken von Walter Eucken. Zu den staats- und rechtstheoretischen Grundlagen einer wirtschaftsordnungspolitischen Konzeption. 1993.

Band 17 Stefan Elßer: Innovationswettbewerb. Determinanten und Unternehmensverhalten. 1993.

Band 18 Reinhard Scharf: Regionalpolitik und regionale Entwicklungspotentiale. Eine kritische Analyse. 1993.

Band 19 Karin Beckmann: Probleme der Regionalpolitik im Zuge der Vollendung des Europäischen Binnenmarktes. Eine ökonomische Analyse. 1995. 
Band 20 Bernd Nolte: Engpaßfaktoren der Innovation und Innovationsinfrastruktur. Eine theoretische und empirische Analyse für ländliche Wirtschaftsräume in Baden-Württemberg. 1996.

Band 21 Klaus-Rainer Brintzinger: Die Nationalökonomie an den Universitäten Freiburg, Heidelberg und Tübingen 1918 - 1945. Eine institutionenhistorische, vergleichende Studie der wirtschaftswissenschaftlichen Fakultäten und Abteilungen südwestdeutscher Universitäten. 1996.

Band 22 Steffen Binder: Die Idee der Konsumentensouveränität in der Wettbewerbstheorie. Teleokratische vs. nomokratische Auffassung. 1996.

Band 23 Alexander Burger: Deregulierungspotentiale in der Gesetzlichen Rentenversicherung. Reformnotwendigkeiten versus Reformmöglichkeiten. 1996.

Band 24 Burkhard Scherer: Regionale Entwicklungspolitik. Konzeption einer dezentralisierten und integrierten Regionalpolitik. 1997.

Band 25 Frauke Wolf: Lorenzkurvendisparität. Neuere Entwicklungen, Erweiterungen und Anwendungen. 1997.

Band 26 Hans Pitlik: Politische Ökonomie des Föderalismus. Föderative Kompetenzverteilung im Lichte der konstitutionellen Ökonomik. 1997.

Band 27 Stephan Seiter: Der Beitrag Nicholas Kaldors zur Neuen Wachstumstheorie. Eine vergleichende Studie vor dem Hintergrund der Debatte über den Verdoorn-Zusammenhang. 1997.

Band 28 André Schmidt: Ordnungspolitische Perspektiven der europäischen Integration im Spannungsfeld von Wettbewerbs- und Industriepolitik. 1998.

Band 29 Bernd Blessin: Innovations- und Umweltmanagement in kleinen und mittleren Unternehmen. Eine theoretische und empirische Analyse. 1998.

Band 30 Oliver Letzgus: Die Ökonomie internationalen Umweltschutzes. 1999.

Band 31 Claudia Hafner: Systemwettbewerb versus Harmonisierung in Europa. Am Beispiel des Arbeitsmarktes. 1999.

Band 32 Jürgen Kulle: Ökonomie der Musikindustrie. Eine Analyse der körperlichen und unkörperlichen Musikverwertung mit Hilfe von Tonträgern und Netzen. 1998. 